\title{
Synthesis of polycyclic aromatics having unusual molecular architectures via cascade cyclization reactions of enyne -allenes
}

\author{
Yu-Hsuan Wang \\ West Virginia University
}

Follow this and additional works at: https://researchrepository.wvu.edu/etd

\footnotetext{
Recommended Citation

Wang, Yu-Hsuan, "Synthesis of polycyclic aromatics having unusual molecular architectures via cascade cyclization reactions of enyne -allenes" (2008). Graduate Theses, Dissertations, and Problem Reports. 4430.

https://researchrepository.wvu.edu/etd/4430

This Dissertation is protected by copyright and/or related rights. It has been brought to you by the The Research Repository @ WVU with permission from the rights-holder(s). You are free to use this Dissertation in any way that is permitted by the copyright and related rights legislation that applies to your use. For other uses you must obtain permission from the rights-holder(s) directly, unless additional rights are indicated by a Creative Commons license in the record and/ or on the work itself. This Dissertation has been accepted for inclusion in WVU Graduate Theses, Dissertations, and Problem Reports collection by an authorized administrator of The Research Repository @ WVU. For more information, please contact researchrepository@mail.wvu.edu.
} 
Synthesis of Polycyclic Aromatics Having Unusual Molecular

Architectures via Cascade Cyclization Reactions of Enyne-Allenes

\author{
YU-HSUAN WANG \\ Dissertation submitted to the \\ Eberly College of Arts and Sciences \\ at West Virginia University \\ in partial fulfillment of the requirements \\ for the degree of
}
Doctor of Philosophy
In
Organic Chemistry

\author{
Kung K. Wang, Ph.D., Chair \\ Peter M. Gannett, Ph.D. \\ George A. O'Doherty, Ph.D. \\ Jeffrey L. Petersen, Ph.D. \\ John H. Penn, Ph.D. \\ C. Eugene Bennett Department of Chemistry \\ Morgantown, West Virginia
}

2008

Keyword: Schmittel Cyclization, Enyne-Allenes, Biradical, Buckybowls

Copyright 2008 Yu-Hsuan Wang 


\section{ABSTRACT \\ Synthesis of Polycyclic Aromatics Having Unusual Molecular Architectures via Cascade Cyclization Reactions of Enyne-Allenes}

\section{YU-HSUAN WANG}

The $\mathrm{C}^{2}-\mathrm{C}^{6}$ Schmittel cyclization reaction of the benzannulated enyne-allenes provides an efficient synthetic pathway for the construction of a variety of polycyclic aromatics. By starting from truxenone, the cascade cyclization reactions furnished several unusual and congested polycyclic compounds. The in situ generated enyne-allenes are key intermediates in these cyclization reactions.

A new synthetic approach to 2,2'-disubstituted 1,1'-binaphthyls and related compounds was also successfully developed by using the benzannulated enediynes as precursors. These 1,1'-binaphthyls derivatives can serve as potential BINOL type ligands. The assembly of the enediynyl precursors from three separate aromatic fragments allows the possibility of placing a variety of functional groups at various positions of the 1,1'-binaphthyl system.

A 12-step non-pyrolytic synthetic pathway employing the Schmittel cyclization reactions has been developed, leading to a bowl-shaped polycyclic aromatic hydrocarbon (PAH) having a 54-carbon framework of the surface of $\mathrm{C}_{60}$. Incorporating of $\mathrm{sp}^{3}$-carbons on the 54-carbon framework facilitates the connection of carbon atoms intramolecularly. 


\section{Dedicated to}

My parents, brother, Leo, and sisters 


\section{ACKNOWLEDGMENTS}

Firstly, I would like to express sincere appreciation to my advisor, Dr. Kung K. Wang, for his continuous support and encouragement during the past five years. His great patience and knowledge in chemistry guided me to solve so many problems. I was so pleased and lucky to have associated with this outstanding teacher and chemist. The way of his teaching not only benefits me academically but also led me to have a logical thinking when seeing through a problem. His enthusiasm and optimism are always my driving force to keep forward.

My special thanks go to Dr. Jeffery Petersen for his significant work in X-ray crystal structure analysis. His work really helped me in identification of product structure which made my research keep forward. Also, Dr. Novruz.Akhmedov is greatly appreciated for his assistance in NMR studies of lots of my products. In addition, I would like to thank the rest of my research committee members, Dr. George A. O’Doherty, Dr. Peter M. Gannett, and Dr. John Penn for their valuable suggestions and discussion on my dissertation.

My appreciation is also extended to the former and present group members, Dr. Hua Yang, Dr. Yonghong Yang, Dr. Weixiang Dai, Dr. Yanzhong Zhang, Ruoxin Zhang, Daehwan Kim and many other people for helping and accompanying me to go through my graduate student life.

Most importantly, I want to thank my family: my grandpa (Kuei Wang), my parents (Edward Wang and Debra Cheng), my sisters (Susan and Maria), my brother (Leo) and my boyfriend (Al Lee) for their unconditional support and encouragement; Especially Leo, without his accompanying and strong backup whenever I was in ups and downs, I definitely cannot achieve it today. Furthermore, the financial support of department of chemistry at West Virginia University and the National Science Foundation are gratefully acknowledged. 


\section{TABLE OF CONTENTS}

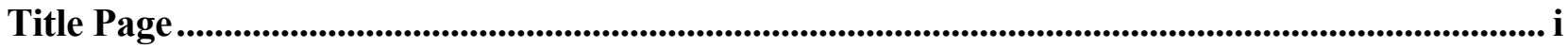

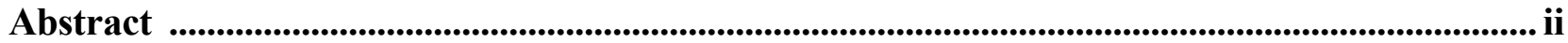

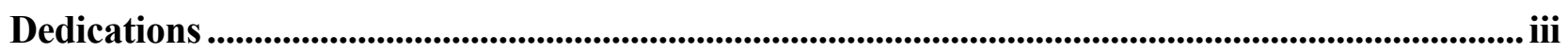

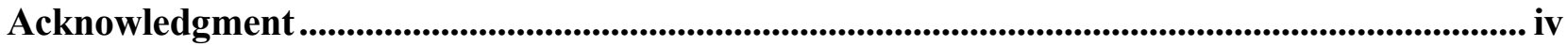

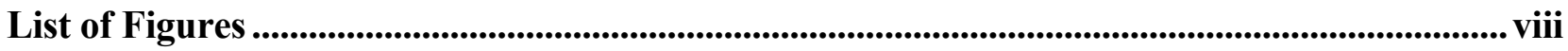

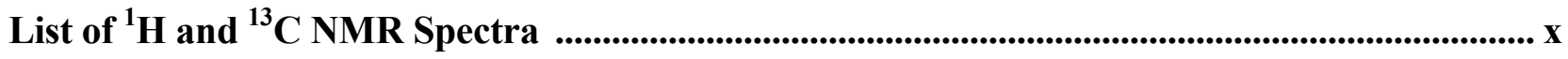

\section{CHAPTER I}

\section{Construction of Unusual and Congested Polycyclic Structures via}

Benzannulated Enediynyl Alcohols

Derived from Truxenone

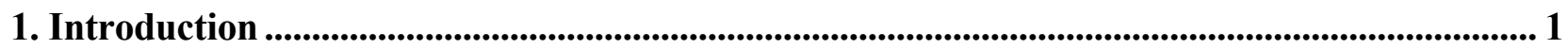

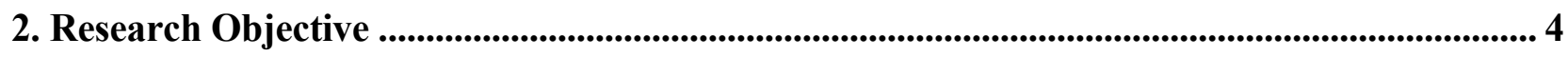

3. Literature Survey of the Synthesis of $C_{3}$ Symmetric Polycyclic Aromatics ................................. 5

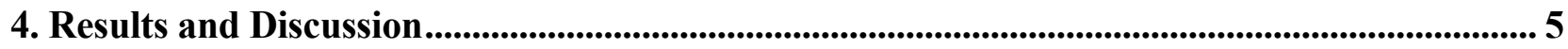

4.1 Unusual Cascade Cyclization of Mono-propargylic Alcohol 24 ............................................ 5

4.2 NMR Studies and Complete Signal Assignment of Compound 28..................................... 8

4.3 Unusual Transformation of 28 in $\mathrm{CDCl}_{3}$ to Other Unknown Compounds ...................... 11

4.4 Unusual Cascade Cyclization of Di-propargylic Alcohol 30 ........................................... 13 
4.5 Unusual Cascade Cyclization of Propargylic Triol 20 ............................................................... 14

4.6 Other Attempts to Synthesize Polycyclic Aromatic Compounds .......................................... 16

5. Conclusions .............................................................................................................................................................. 17

\title{
CHAPTER II
}

\author{
Synthesis of 5-(2-Methoxy-1-naphthyl)- and \\ 5-[2-(Methoxymethyl)-1-naphthyl]-11H-benzo[b]fluorene \\ as $2,2^{\prime}$-Disubstituted $1,1^{\prime}$-Binaphthyls
}

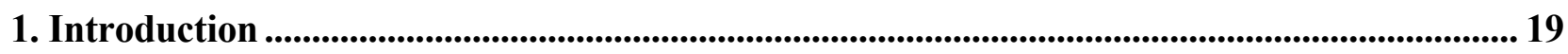

2. Research Objective ........................................................................................................................................... 21

3. Literature Survey of BINOL Derivatives and Synthesis of Bidentate Fluorenyl Complex .. 21

3.1. Literature Survey of BINOL Derivatives ..................................................................................... 21

3.2. Literature Survey of Synthesis of Bidentate Fluorenyl Complex........................................ 22

4. Results and Discussion...................................................................................................................... 23

4.1. Synthesis of 1-Arylnaphthyl Derivatives.............................................................................. 23

4.2. Synthesis of $2,2^{\prime}$-Disubstituted 1,1'-Binaphthyls..................................................................... 25

4.2.1 Preparation of Benzannulated Enediyne 80................................................................... 25

4.2.2 Synthesis of $1,1^{\prime}$-Binaphthyls $86 \mathrm{a}$ and $86 \mathrm{~b}$................................................................ 26

4.2.3 Preparation of Precursor Acetylene 90............................................................................. 27

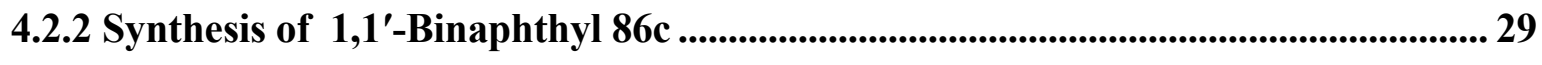

4.3. NMR Studies of 1-Arylnaphthyl Derivatives and 1,1'-Binaphthyls .................................. 29

4.4. Resolution of $1,1^{\prime}$-Binaphthyl 86b................................................................................................ 31 


\section{CHAPTER III}

Synthesis of a Novel Bowl-Shaped Polycyclic Aromatic Hydrocarbon Having a 54-Carbon Framework Represented on the Surface of $C_{60}$

1. Introduction .34

2. Research Objective .36

3. Literature Survey of Synthesis of Buckybowls, Coordination Chemistry of Buckybowls and Fluorenyl Ligands and Molecular Tweezers......................................................................................38

3.1. Synthesis of Buckybowls ..........................................................................................................38

3.1.1 Flash Vacuum Pyrolysis (FVP)..................................................................................................38

3.1.2 Non-pyrolytic Pathway ................................................................................................................40

3.2. Coordination Chemistry of Buckybowls and Fluorenyl Ligands......................................43

3.3. Molecular Tweezers....................................................................................................4

4. Results and Discussion......................................................................................................................................46

4.1. Preparation of Precursor Diketone 150 ......................................................................................46

4.2. Condensation of Diketone 150...........................................................................................................47

4.3. Schmittel Cyclization of 152 and Furan-ring Opening ............................................................48

4.4. Alternative Route Toward Diol 157................................................................................................49

4.5. Revised Synthetic Pathway Toward $I_{2}$-Diketone 154 .............................................................49

4.6. NMR Studies of $\mathrm{I}_{2}$-Diketone 154 .............................................................................................52 
4.7. Intramolecular Cyclization of $I_{2}$-Diketone (154).....................................................................54

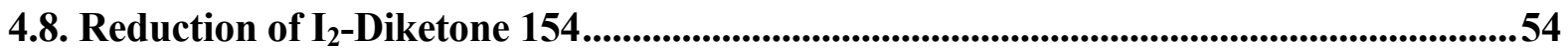

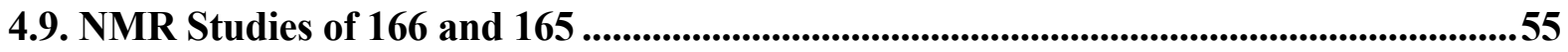

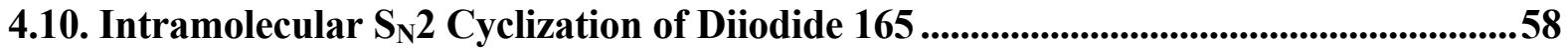

4.11. NMR Studies of Buckybowl 167 ...................................................................................58

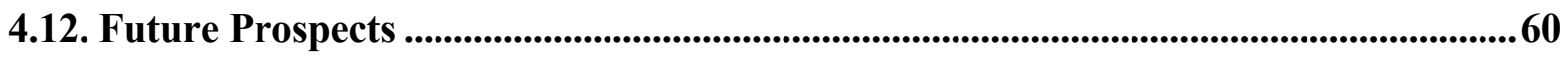

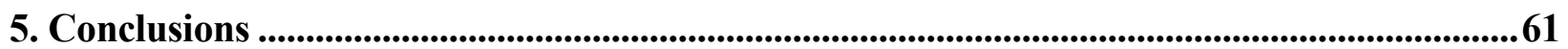

\section{CHAPTER IV}

\section{Experimental Section}

Instrumentation, Materials and Manipulation ..............................................................................62

References $\quad$......................................................................................................................................................................95

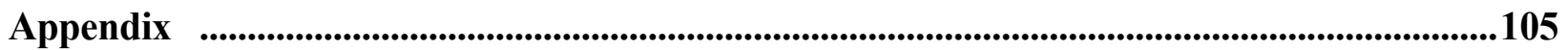

Approval of Examining Committee

\section{List of Figures}

Figure 1. Some examples of $C_{3}$ symmetric polycyclic aromatics .......................................................5

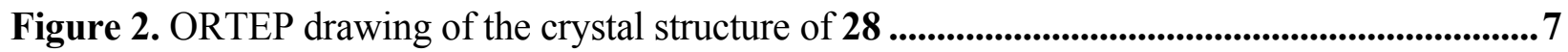

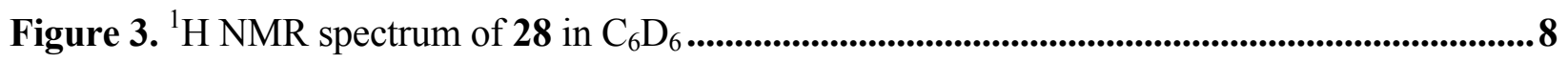

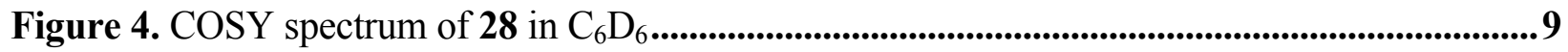

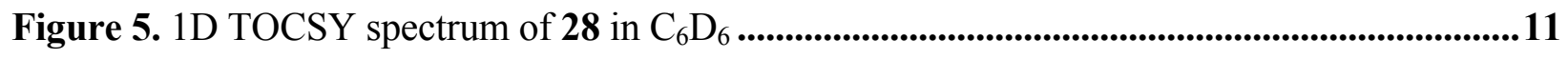

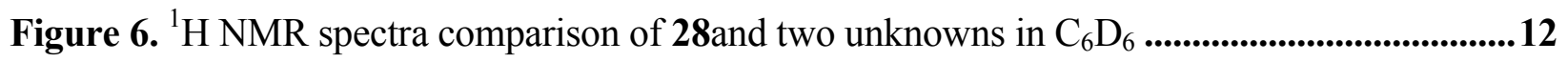

Figure 7. ORTEP drawing of the crystal structure of $\mathbf{3 1}$ with atom labeling ...................................14 
Figure 8. ORTEP drawing of the crystal structures of $\mathbf{3 4}$ with atom labeling ...................................15

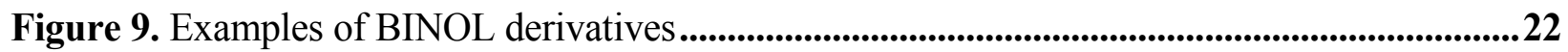

Figure 10. Examples of novel bidetate metallocene titanium complexes ...........................................22

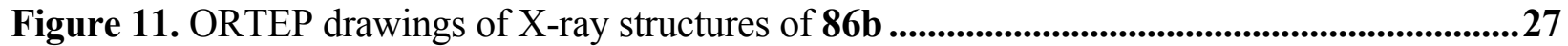

Figure 12. AB patterns of 73a,b, 86a,b,c shown on the ${ }^{1} \mathrm{H}$ NMR spectra .....................................30

Figure 13. ${ }^{1}$ H-NMR spectrum of partially separated $(1 S)$-camphanates 99 .........................................32

Figure 14. Representative examples of buckybowls ...........................................................................................334

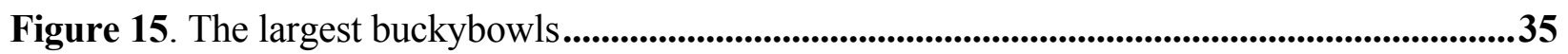

Figure 16. A buckybowls containing $\mathrm{sp}^{3}$-carbons ....................................................................................337

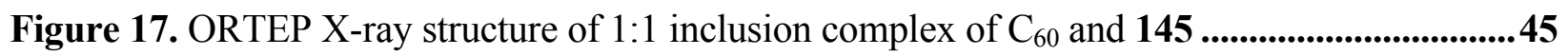

Figure 18. ORTEP drawing of the crystal structure of $\mathrm{C}_{56} \mathrm{H}_{36} \mathrm{I}_{2} \mathrm{O}_{2}(\mathbf{1 5 4})$.......................................51

Figure 19. ORTEP drawing of the crystal structure of $[2+2]$ cycloadduct $162 \ldots . . . . . . . . . . . . . . . . . . . . . . . .52$

Figure 20. Temperature-dependent ${ }^{1} \mathrm{H}$ spectra of $\mathbf{1 5 4}$ in $\mathrm{CDCl}_{3}$.........................................................52

Figure 21. Temperature-dependent ${ }^{1} \mathrm{H}$ spectra of $\mathrm{H} 7$ and $\mathrm{H} 10$.................................................53

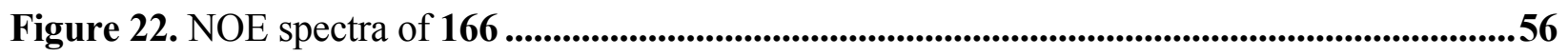

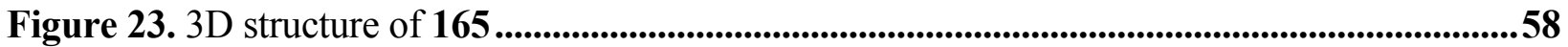

Figure 24. 3D structure of chiral buckybow1 167 ..............................................................................59

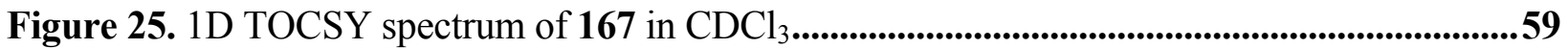

Figure 26. ORTEP drawing of the crystal structure of benzannulated enediynyl cis-diol $\mathbf{3 0}$.......106

Figure 27. ORTEP drawing of the crystal structure of ketone $\mathbf{3 1}$ with two independent molecules per unit cell .107

Figure 28. Perspective view of molecular structure of alcohol $\mathbf{3 4}$ with the atom labeling scheme .108 
Figure 29. Perspective view of molecular structure of $\mathrm{C}_{40} \mathrm{H}_{28} \mathrm{O}_{2} \mathrm{I}_{2}(\mathbf{1 5 9})$. The thermal ellipsoids are scaled to enclose $30 \%$ probability 109

Figure 30. Perspective view of molecular structure of molecule 1 of $\mathbf{1 6 2}$ with the atom labeling scheme. The thermal ellipsoids are scaled to enclose $30 \%$ probability. .110

Figure 31. Perspective view of molecular structure of molecule 2 of 162 with the atom labeling scheme. The thermal ellipsoids are scaled to enclose $30 \%$ probability. .110

Figure 32. Perspective view of molecular structure of alcohol 163 with the atom labeling scheme

\section{List of ${ }^{1} \mathrm{H}$ and ${ }^{13} \mathrm{C}$ NMR Spectra}

${ }^{1} \mathrm{H}$ NMR Spectrum of Benzannulated Enediynyl Alcohol 24

${ }^{1} \mathrm{H}$ and ${ }^{13} \mathrm{C}$ NMR Spectra of Diketone 28.

Chemical Shifts and Coupling Constants in 28.

gNMR-Simulated ${ }^{1} \mathrm{H}$ NMR Spectra of 28 in $\mathrm{C}_{6} \mathrm{D}_{6}$

${ }^{1} \mathrm{H}$ and ${ }^{13} \mathrm{C}$ NMR Chemical Shifts of 28 in $\mathrm{C}_{6} \mathrm{D}_{6}$

gCOSY Spectrum of 28 in $\mathrm{C}_{6} \mathrm{D}_{6}$

1D TOCSY Spectrum of $\mathbf{2 8}$ in $\mathrm{C}_{6} \mathrm{D}_{6}$

2D TOCSY Spectrum of 28 in $\mathrm{C}_{6} \mathrm{D}_{6}$

gHMBC Spectrum of $\mathbf{2 8}$ in $\mathrm{C}_{6} \mathrm{D}_{6}$

gHSQC-TOCSY Spectrum of $\mathbf{2 8}$ in $\mathrm{C}_{6} \mathrm{D}_{6}$

${ }^{1} \mathrm{H}$ and ${ }^{13} \mathrm{C}$ NMR Spectra of Benzannulated Enediynyl cis-Diol 30 
${ }^{1} \mathrm{H}$ and ${ }^{13} \mathrm{C}$ NMR Spectra of Benzannulated Enediynyl trans-Diol 30

${ }^{1} \mathrm{H}$ and ${ }^{13} \mathrm{C}$ NMR Spectra of Ketone 31

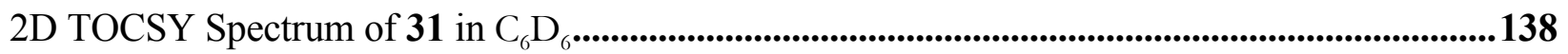

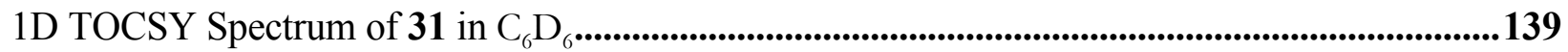

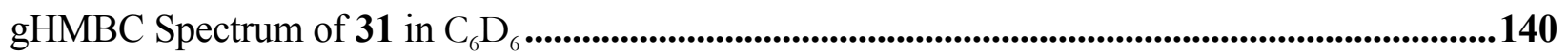

${ }^{1} \mathrm{H}$ and ${ }^{13} \mathrm{C}$ NMR Spectra of Benzannulated Enediynyl anti-Triol 20.......................................... 141-142

${ }^{1} \mathrm{H}$ and ${ }^{13} \mathrm{C}$ NMR Spectra of Benzannulated Enediynyl syn-Triol 20 .......................................... 143-144

${ }^{1} \mathrm{H}$ and ${ }^{13} \mathrm{C}$ NMR Spectra of Alcohol 34 ......................................................................................... 145-146

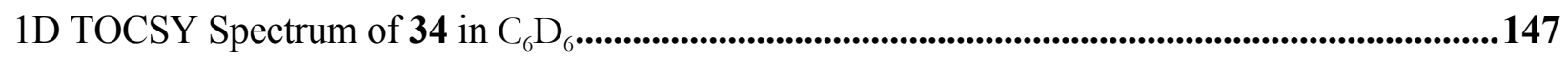

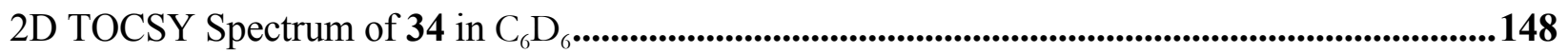

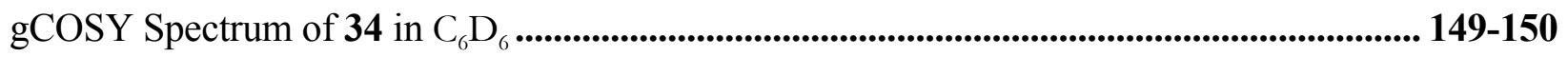

${ }^{1} \mathrm{H}$ and ${ }^{13} \mathrm{C}$ NMR Spectra of Trimethyl[[2-[(2-methoxyphenyl)ethynyl]phenyl]ethynyl]silane (66) n.

${ }^{1} \mathrm{H}$ and ${ }^{13} \mathrm{C}$ NMR Spectra of Benzannulated Enediyne 67a......................................................... 153-154

${ }^{1} \mathrm{H}$ and ${ }^{13} \mathrm{C}$ NMR Spectra of $\alpha$-[[2-[(2-Methoxyphenyl)ethynyl]phenyl]ethynyl]- $\alpha-(1,1-$ dimethylethyl)benzenemethanol (68a) 155-156

${ }^{1} \mathrm{H}$ and ${ }^{13} \mathrm{C}$ NMR Spectra of Benzannulated Enediyne 69a 157-158

${ }^{1} \mathrm{H}$ and ${ }^{13} \mathrm{C}$ NMR Spectra of 5-(2-Methoxyphenyl)-10-(1,1-dimethylethyl)-11H-benzo[b]fluorene (73a) 159-160

${ }^{1} \mathrm{H}$ and ${ }^{13} \mathrm{C}$ NMR Spectra of Trimethyl[[2-[[2-(methoxymethyl)phenyl]ethynyl]phenyl] ethynyl]silane $\mathbf{( 6 6 b )}$ 
${ }^{1} \mathrm{H}$ and ${ }^{13} \mathrm{C}$ NMR Spectra of of Benzannulated Enediyne 67b 163-164

${ }^{1} \mathrm{H}$ and ${ }^{13} \mathrm{C}$ NMR Spectra of $\alpha$-[[2-[[2-(Methoxymethyl)phenyl]ethynyl]phenyl]ethynyl]- $\alpha-(1,1-$ dimethylethyl)benzenemethanol (68b) $165-166$

${ }^{1} \mathrm{H}$ and ${ }^{13} \mathrm{C}$ NMR Spectra of Benzannulated Enediyne 69b. $167-168$

${ }^{1} \mathrm{H}$ and ${ }^{13} \mathrm{C}$ NMR Spectra of 5-[2-(Methoxymethyl)phenyl]-10-(1,1-dimethylethyl)-11Hbenzo[b]fluorene (73b) 169-170

${ }^{1} \mathrm{H}$ and ${ }^{13} \mathrm{C}$ NMR Spectra of 1-Iodo-2-(4,4-dimethyl-3-phenyl-1-pentynyl)benzene (83) ... 171-172

${ }^{1} \mathrm{H}$ and ${ }^{13} \mathrm{C}$ NMR Spectra of Benzannulated Enediyne 85 . 173-174

${ }^{1} \mathrm{H}$ and ${ }^{13} \mathrm{C}$ NMR Spectra of 10-(1,1-Dimethylethyl)-5-(1-naphthyl)-11H-benzo[b]fluorene (86a) 175-177

${ }^{1} \mathrm{H}$ and ${ }^{13} \mathrm{C}$ NMR Spectra of 1-Ethynyl-2-methoxynaphthalene (76) 178-179

${ }^{1} \mathrm{H}$ and ${ }^{13} \mathrm{C}$ NMR Spectra of Benzannulated Enediyne 80 $180-181$

${ }^{1} \mathrm{H} \quad$ and $\quad{ }^{13} \mathrm{C} \quad \mathrm{NMR} \quad$ Spectra of $\quad$ 5-(2-Methoxy-1-naphthyl)-10-(1,1-dimethylethyl)-11Hbenzo[b]fluorene (86b) $182-184$

${ }^{1} \mathrm{H}$ and ${ }^{13} \mathrm{C}$ NMR Spectra of Benzannulated Enediyne 96 $185-186$

${ }^{1} \mathrm{H}$ and ${ }^{13} \mathrm{C}$ NMR Spectra of Benzannulated Enediyne 97 $187-188$

${ }^{1} \mathrm{H}$ and ${ }^{13} \mathrm{C}$ NMR Spectra of 1-Iodo-2-(methoxymethyl)naphthalene (93).............................. 189-190

${ }^{1} \mathrm{H}$ and ${ }^{13} \mathrm{C}$ NMR Spectra of Benzannulated Enediyne 98. 191-192

${ }^{1} \mathrm{H}$ and ${ }^{13} \mathrm{C}$ NMR Spectra of 5-[2-(Methoxymethyl)-1-naphthyl]-10-(1,1-dimethylethyl)-11Hbenzo[b]fluorene (86c)

${ }^{1} \mathrm{H}$ and ${ }^{13} \mathrm{C}$ NMR Spectra of $1,1^{\prime}$-Binaphthyl 62 . 195-196

${ }^{1} \mathrm{H}$ NMR Spectra of (1S)-Camphanates of 62 (99) .197

${ }^{1} \mathrm{H}$ and Spectrum of Diketone 149 198 
${ }^{1} \mathrm{H}$ and ${ }^{13} \mathrm{C}$ NMR Spectra of Diiodide 155

${ }^{1} \mathrm{H}$ and ${ }^{13} \mathrm{C}$ NMR Spectra of Diiodide 159 ................................................................................ 201-202

${ }^{1} \mathrm{H}$ and ${ }^{13} \mathrm{C}$ NMR Spectra of Alcohol 160 ............................................................................ 203-204

${ }^{1} \mathrm{H}$ and ${ }^{13} \mathrm{C}$ NMR Spectra of Diketone 154............................................................................... 205-207

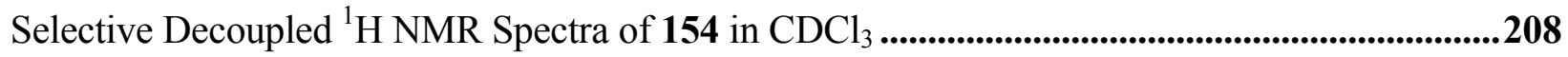

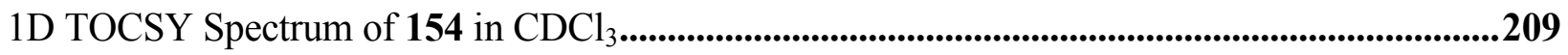

${ }^{1} \mathrm{H}$ and ${ }^{13} \mathrm{C}$ NMR Spectra of Spiro-162 ................................................................................210-211

COSY Spectrum of 162 in $\mathrm{CDCl}_{3}$.................................................................................... 212-214

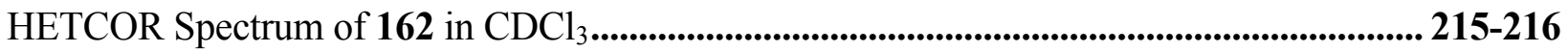

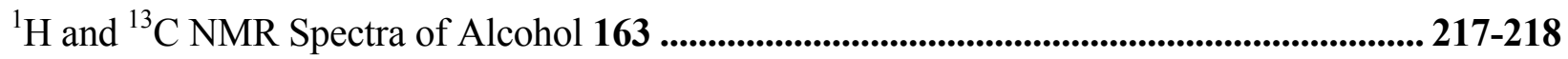

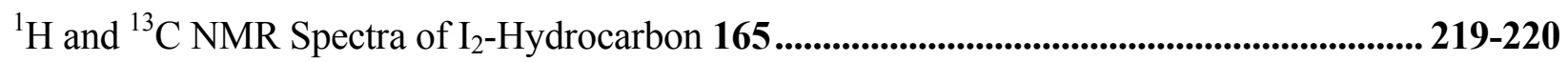

${ }^{1} \mathrm{H}$ and ${ }^{13} \mathrm{C}$ NMR Spectra of Ketone 166......................................................................................... 221-222

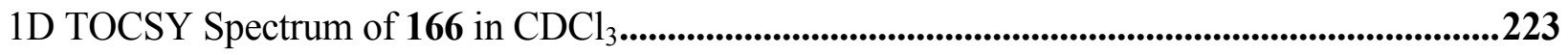

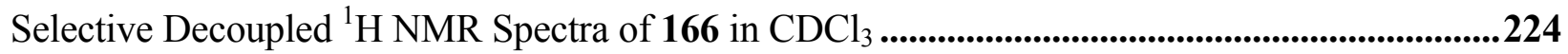

COSY Spectrum of 166 in $\mathrm{CDCl}_{3}$...............................................................................................................225

NOESY Spectrum of 166 in $\mathrm{CDCl}_{3}$.........................................................................................................226

1D NOE Spectra of 166 in $\mathrm{CDCl}_{3}$...................................................................................................... 227-228

Chemical Shifts and Coupling Constants in 167........................................................................................229

gNMR-Simulated ${ }^{1} \mathrm{H}$ NMR Spectra of $\mathbf{1 6 7}$ in $\mathrm{CDCl}_{3}$...........................................................................230

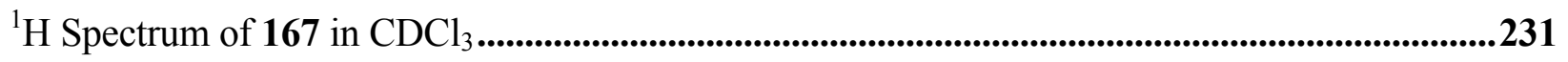

1D NOE Spectra of 167 in $\mathrm{CDCl}_{3}$.................................................................................................. 232-233

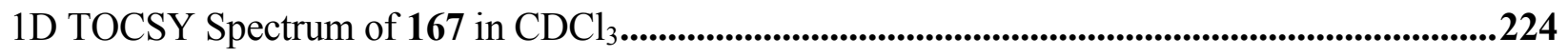

COSY Spectrum of 167 in $\mathrm{CDCl}_{3}$....................................................................................................... 235-237 
NOESY Spectrum of 167 in $\mathrm{CDCl}_{3}$

238-240 


\section{CHAPTER I}

\section{Construction of Unusual and Congested Polycyclic Structures via Benzannulated Enediynyl Alcohols \\ Derived from Truxenone}

\section{Introduction}

The cyclization reactions of enyne-allenes via biradical intermediates have been extensively investigated for the past decades. Under thermal conditions, (Z)-1,2,4-heptatrien6-yne (enyne-allenes) 1 could undergo two different cyclization pathways (Scheme 1): one is to involve the bond formation between the $\mathrm{C} 2$ and the $\mathrm{C} 7$ carbon atoms leading to a,3-didehydrotoluene biradicals $\mathbf{2}^{1}$ (Myers-Saito cyclization); the other is to proceed through $\mathrm{C}^{2}-\mathrm{C}^{6}$ pathway affording the five-membered fulvene biradicals 3 (Schmittel cyclization). ${ }^{2}$ In general, the regioselectivity of enyne-allenes is determined by the alkynyl terminus $\mathrm{R}$ group. The Myers-Saito cyclization reaction is preferred when $\mathrm{R}$ is hydrogen or a sterically non-demanding alkyl group. On the other hand, when R group is an aryl group or sterically demanding substituent, such as t-butyl or TMS, the Schmittel cyclization pathway is favored.

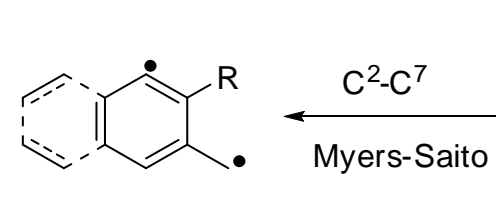

2

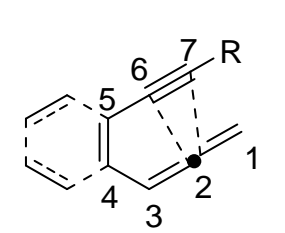

1

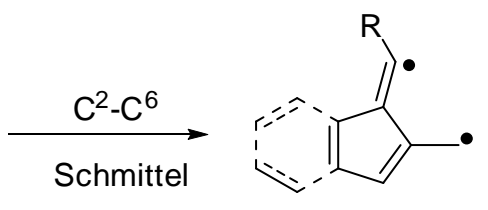

3

Scheme 1. Cyclization reactions of enyne-allenes.

The current research on the thermal biradical cyclization of enyne-allenes is not only focused on the synthesis of simple model compounds with potential antitumor and antibiotic activities mimicing the naturally occurring enediyne antitumor antibiotics, but also on using 
them for the construction of polycyclic ring systems. ${ }^{3}$ In particular, the Schmittel cyclization reaction has played an important role in the synthesis of carbocyclic ${ }^{4}$ and heterocyclic ${ }^{5,6}$ ring systems, beacuse the biradical intermediate may undergo a rapid radical-radical coupling reaction leading to the formal Diels-Alder adducts that provide easy access to polycyclic aromatic systems.

Benzannulated enediynyl alcohols, readily prepared from condensation between ketones and benzannulated enediynes and other related procedures, are excellent precursors of the reactive benzannulated enyne-allenes..$^{2 a, b, d, 7}$ Dr. Hongbin Li of our research group recently reported an efficient pathway to produce chlorinated benzoenyne-allene $\mathbf{8}$ in situ via a $\mathrm{S}_{\mathrm{N}} \mathrm{i}$ reaction promoted by thionyl chloride with benzannulated enediynyl propargylic alcohol $\mathbf{6}$ (Scheme 2). ${ }^{7 \mathrm{a}}$

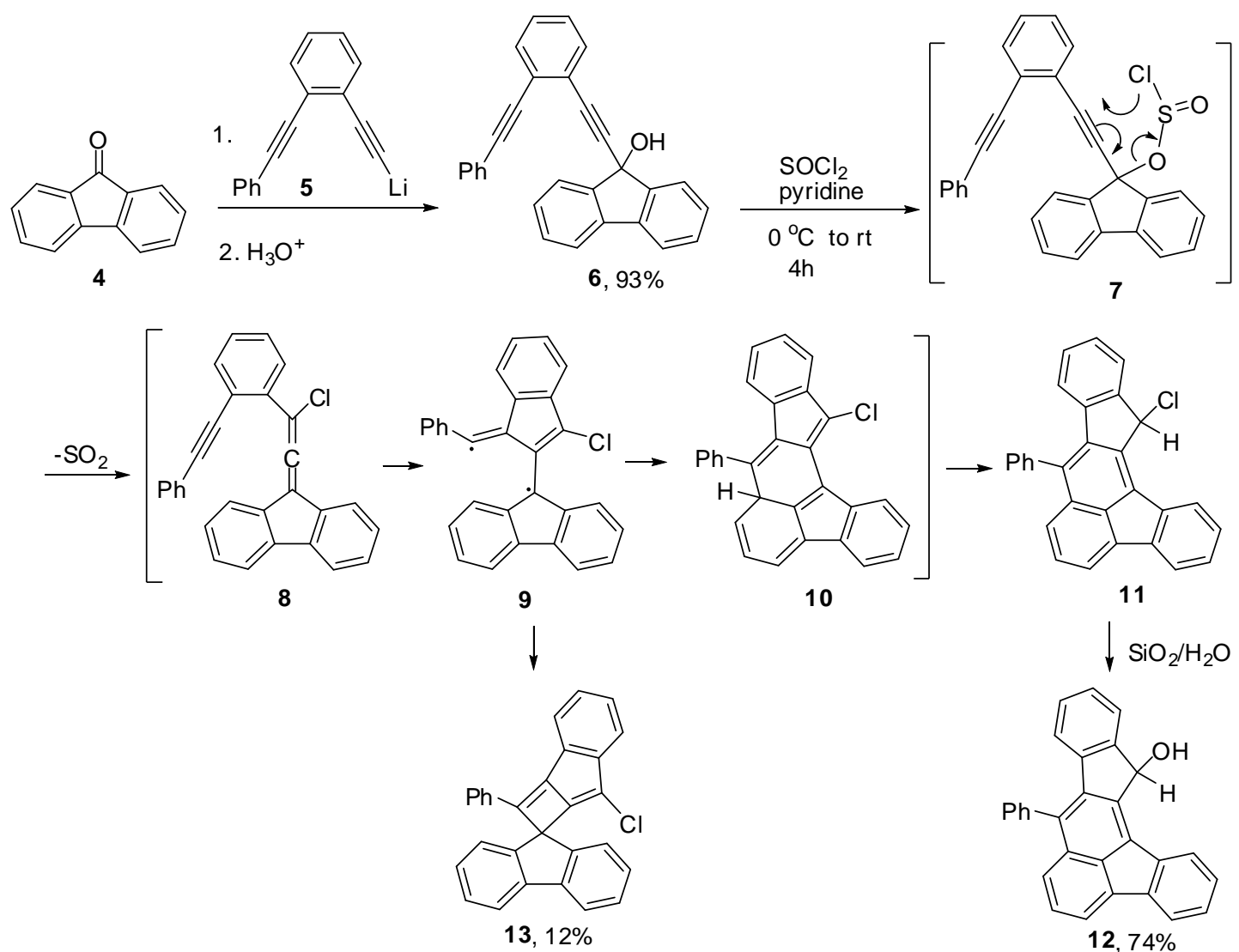

Scheme 2. Schmittel cyclization of chlorinated benzoenyne-allene. 
Benzannulated enediynyl alcohol $\mathbf{6}$ can be readily prepared from condensation between 9-fluorenone (4) and lithium acetylide 5. A subsequent Schmittel $C^{2}-C^{6}$ cyclization then generated the biradical 9, which underwent an intramolecular radical-radical coupling to give the formal Diels-Alder adduct 10. Tautomerization followed by hydrolysis then afforded $\mathbf{1 2}$ and a minor $[2+2]$ adduct 13 . The cascade cyclization reactions of the benzannulated enyne-allenes provide new pathways to a variety of highly unusual and congested polycyclic compounds. ${ }^{8}$

In particular, Dr. Yonghong Yang of our research group previously reported an unusual synthesis of involving condensation between diketone $\mathbf{1 3}$ and the lithium acetylide 5, prepared from treatment of 1-ethynyl-2-(phenylethynyl)benzene as a benzannulated enediyne with n-butyllithium to produce diol $\mathbf{1 4}$, which on exposure to thionyl chloride furnished polycyclic products 15 to 18 (Scheme 3). ${ }^{8 a}$<smiles>CCCc1c(CCC)c2c(=O)c3ccccc3c2c2c1c(=O)c1ccccc12</smiles>

13

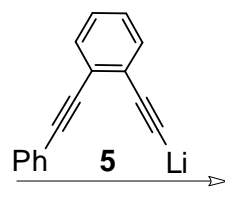

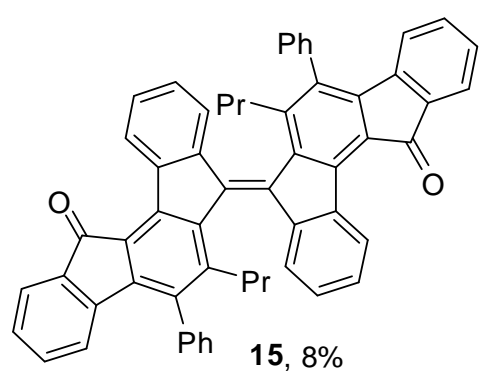

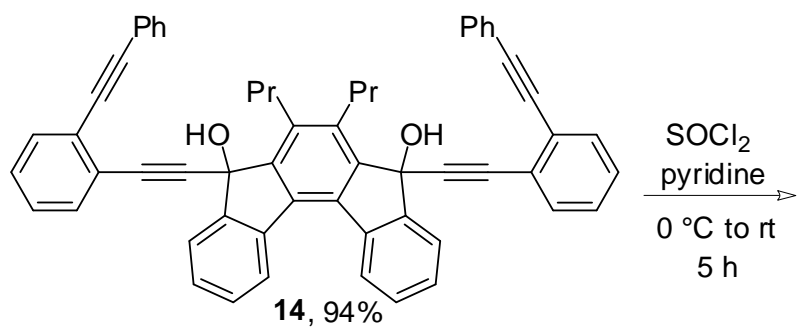

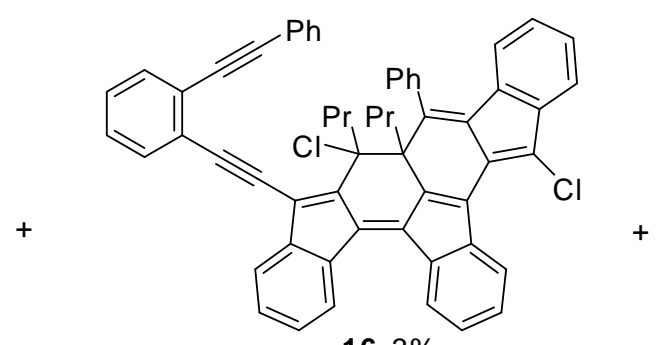

$16,3 \%$

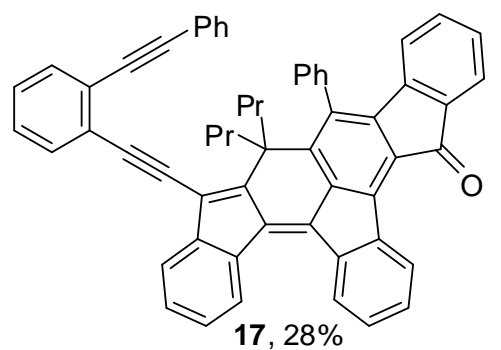

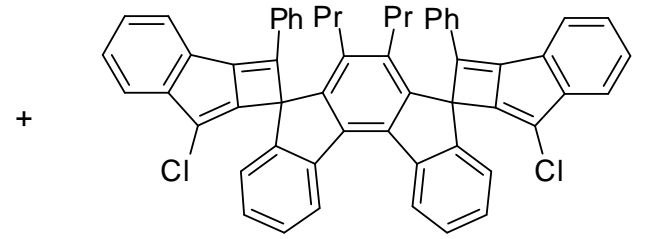

18, $30 \%$

Scheme 3. Unusual cascade $C^{2}-C^{6}$ cyclization of chlorinated benzoenyne-allenes. 
It is worth noting that in producing the twisted 1,1'-dipropyl-9,9'-bifluorenylidene 15, a rare and unusual process involving the cleavage of the central benzene ring of $\mathbf{1 4}$ occurred. However, the loss of the resonance energy is more than compensated for with the eventual formation of two new benzene rings in 15 .

\section{Research Objective}

Based on our previous discovery of the formation of chlorinated benzannulated enyne-allenes via a $\mathrm{S}_{\mathrm{N}} \mathrm{i}$ ' reaction promoted by thionyl chloride and subsequent $\mathrm{C}^{2}-\mathrm{C}^{6}$ cyclization, we were interested in further exploring the use of molecules having three benzannulated enyne-allene units for the synthesis of polycyclic aromatic compounds. The readily available truxenone (19) ${ }^{9}$ bearing three keto groups provides excellent opportunities for further expanding the use of benzannulated enediynyl alcohols for the synthesis of polycyclic compounds possessing interesting and unusual architectures. We envisioned the use of benzannulated enediynyl alcohol $\mathbf{2 0}$ as a potential precursor of the $C_{3}$ molecular propeller $\mathbf{2 1}$, if the reaction would proceed through the normal Schmittel cyclization pathway. However, this reaction unexpectedly led to the formation of highly congested polycyclic structures.

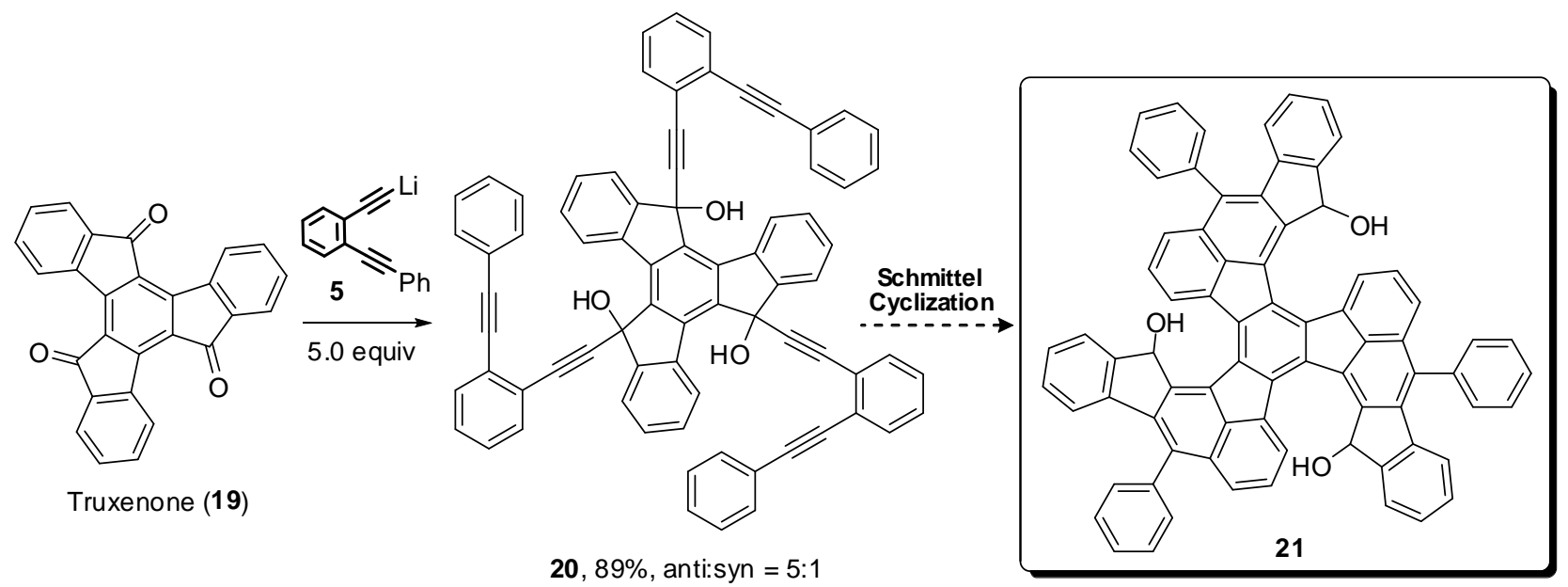

Scheme 4. Triol 20 as potential precursor of $C_{3}$ molecular propeller 21. 


\section{Literature Survey of the Synthesis of $C_{3}$ Symmetric Polycyclic Aromatics}

In 2004, Echavarren et al. reported a synthesis of a $C_{3}$ symmetrical "crushed fullerene derivatives” by intramolecular palladium-catalyzed arylation reactions. ${ }^{10} \mathrm{~A}$ versatile method from truxene derivatives can lead to the synthesis of large $\mathrm{C}_{48}$ polyaromatics 22 , as well as of $\mathrm{C}_{60}$ polycyclic aromatics 23a, b, and c. The synthesis of $\mathrm{C}_{60} \mathrm{H}_{30}$ (23a) by Echavarren et al. is the most efficient reported to date and proceeds in just three steps from truxene in 33\% overall yield. In 2001, Scott et al. also reported a synthesis of 23a by employing $\mathrm{TiCl}_{4}$-catalyzed trimerization of $5 H$-benzo[ $f]$ acephenanthrylen-4-one. ${ }^{11 a}$ His approach was later applied for the preparation of chlorinated derivatives of $\mathbf{2 3}$ in 11 steps from 1-bromo-4-chlorobenzene, which furnished $\mathrm{C}_{60}$ in $0.1-1.0 \%$ yield upon flash vacuum pyrolysis at $1100{ }^{\circ} \mathrm{C} .{ }^{11 \mathrm{~b}}$

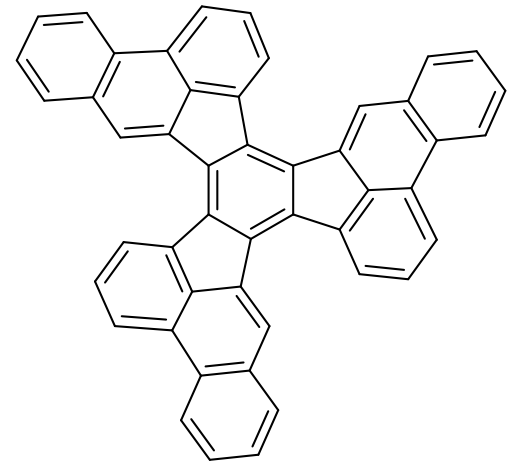

22, $\mathrm{R}=\mathrm{H}, \mathrm{OMe}$

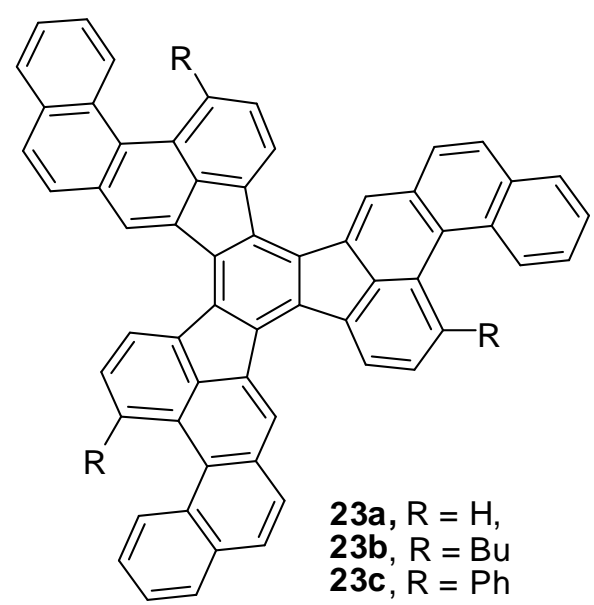

Figure 1. Some examples of $C_{3}$ symmetric polycyclic aromatics.

\section{Results and Discussion}

\subsection{Unusual Cascade Cyclization of Mono-propargylic Alcohol 24}

Condensation between truxenone (19) and 0.90 equiv. of lithium acetylide 5 furnished the benzannulated enediynyl propargylic alcohol $\mathbf{2 4}$, which on exposure to thionyl chloride was smoothly converted to the polycyclic product $\mathbf{2 8}$ (Scheme 5). The structure of $\mathbf{2 8}$ was established by X-ray structure analysis (Figure 2). The formation of the product $\mathbf{2 8}$ was unexpected. 
Presumably, the initially formed chlorosulfite 25 underwent an $\mathrm{S}_{\mathrm{N}} \mathrm{i}^{\prime}$ reaction ${ }^{12}$ to give the benzannulated enyne-allene 26. ${ }^{7 a, 8 j}$ A subsequent Schmittel cyclization reaction ${ }^{2 c, 5}$ to generate biradical 27 followed by an intramolecular radical-radical coupling reaction via 27a then produced 28 in a single cascade sequence. It is worth noting that the radical-radical coupling step involved the more congested central benzene ring to form the new quaternary carbon center in 28 instead of involving the neighboring less hindered benzene ring on the periphery as depicted in $\mathbf{2 7 b}$.

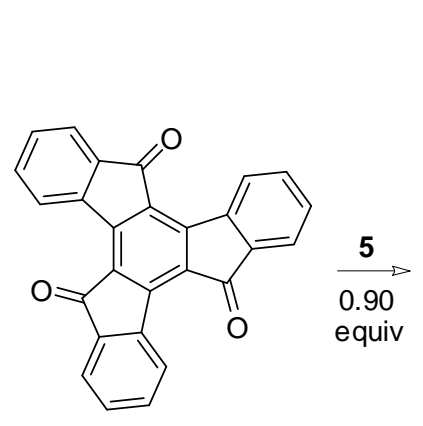

19

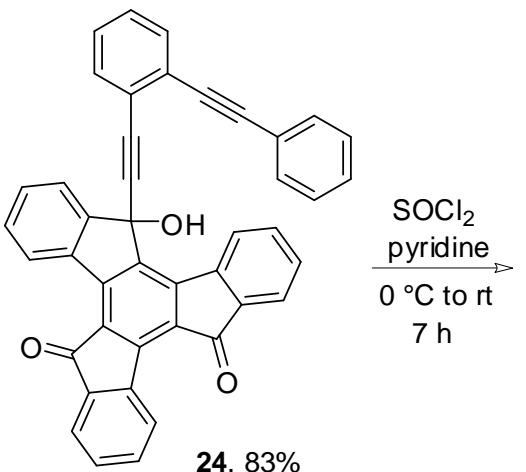

24, $83 \%$

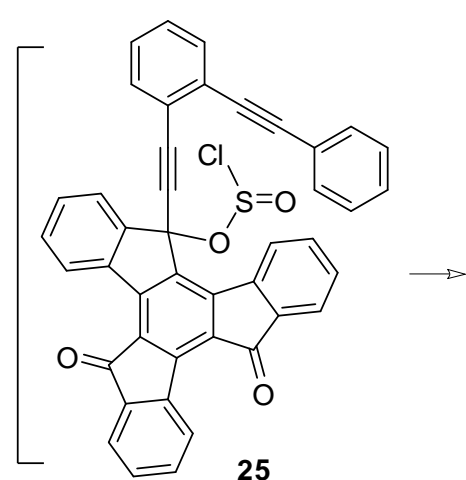

25
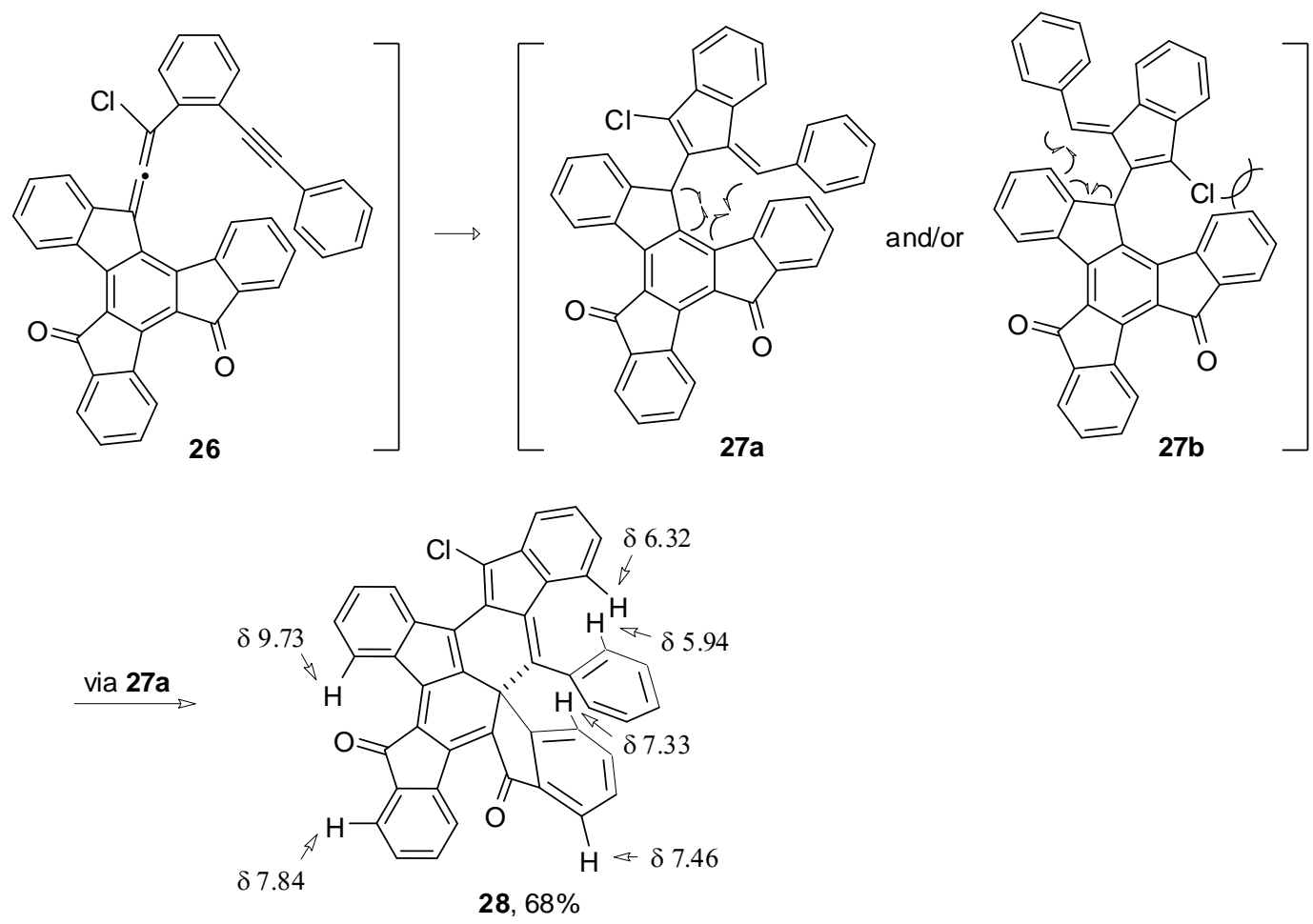

Scheme 5. Preparation of polycyclic diketone 28. 
Molecular modeling suggests that the pathway involving the attack of the peripheral benzene ring via 27b suffers from the emergence of nonbonded steric interactions between the chloro substituent and one of the other two peripheral benzene rings. ${ }^{7 a, 8 a}$ This observation is reminiscent of what was observed previously for $\mathbf{1 4}$ in which the preferential attack of the central benzene ring led to 15,16 , and 17 . The aromaticity of the central benzene ring in 26 is disrupted in producing $\mathbf{2 8}$. However, trading two $\pi$ bonds in $\mathbf{2 6}$ for two $\sigma$ bonds in $\mathbf{2 8}$ is more than sufficient to compensate for the loss of aromaticity.

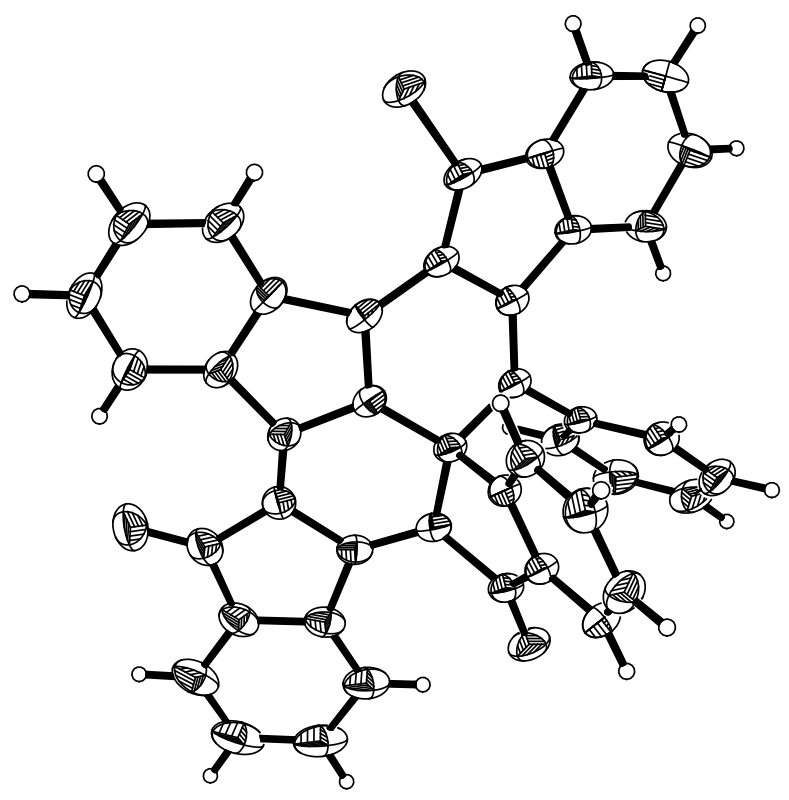

Figure 2. ORTEP drawing of the crystal structure of $\mathbf{2 8 .}$

It is worth noting that with the loss of the aromaticity of the central benzene ring in $\mathbf{1 9}$ the resultant structure of $\mathbf{2 8}$ contains a twisted enone system having four conjugated carbon-carbon double bonds and one keto group at its longest linear extension along with one cross-conjugated carbon-carbon double bond and one cross-conjugated keto group. In addition, the structure could also be regarded as bearing two connected benzofulvene moieties. Furthermore, the original 
central benzene ring in 19 is transformed to a reactive 5-methylene-1,3-cyclohexadiene moiety. ${ }^{14}$ The newly formed chlorofluorenyl group also contains an acid-sensitive 3-methylene1,4-cyclohexadiene substructure. ${ }^{15}$

\subsection{NMR Studies and Complete Signal Assignment of Compound 28}

The X-ray structure of $\mathbf{2 8}$ indicates that the phenyl substituent is in a sterically congested environment, which could cause a relatively slow rate of rotation. In addition, the phenyl substituent is oriented roughly perpendicular to the newly formed chlorofluorenyl moiety, placing one of the ortho hydrogens in the magnetic shielding region of the neighboring indanone group. Indeed, the ${ }^{1} \mathrm{H}$ NMR spectrum of 28 in $\mathrm{C}_{6} \mathrm{D}_{6}$ using the $1 \mathrm{D} / 2 \mathrm{D}$ TOCSY and COSY techniques revealed five distinct signals at $\delta 5.94$ (ortho), 6.89 (meta), 7.15 (ortho), 7.17 (para), and 7.24 (meta) for the five hydrogens on the phenyl substituent, indicating a slow rate of rotation on the NMR time scale (Figure 3).

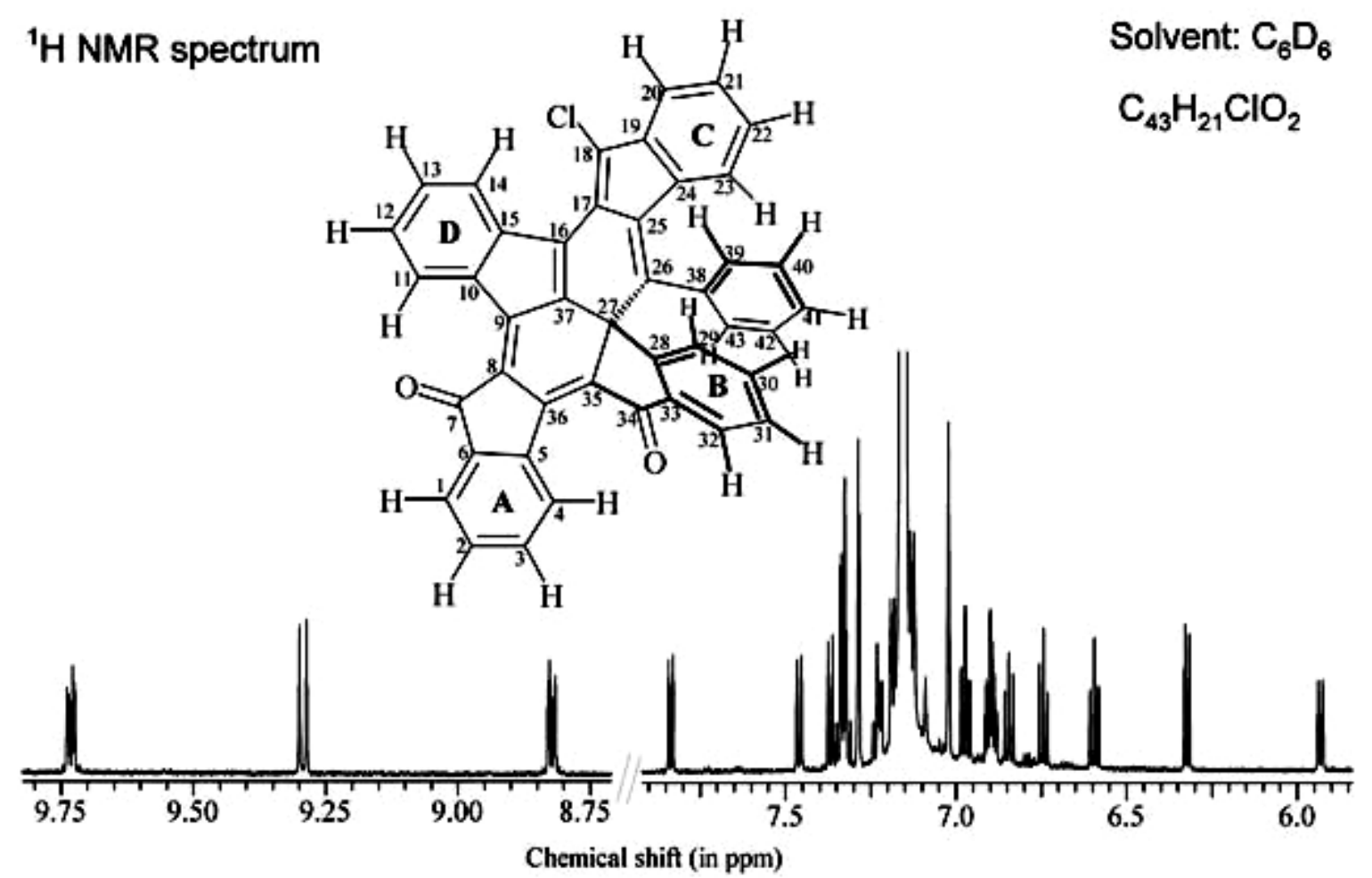

Figure 3. ${ }^{1} \mathrm{H}$ NMR spectrum of 28 in $\mathrm{C}_{6} \mathrm{D}_{6}$. 
In addition, the DEPT spectrum exhibited 21 signals for the 21 proton-bearing carbons, including five signals from the phenyl substituent and 16 signals from the rest of the molecule. The magnetic shielding was observed for one of the ortho hydrogens, which gave a significantly upfield shift signal at $\delta 5.94$ indicated in Scheme 5. Even at $80{ }^{\circ} \mathrm{C}$, this signal remained virtually unchanged and without significant line broadening. The perpendicular orientation of the phenyl substituent relative to the newly formed chlorofluorenyl moiety is also responsible for upfield shifting the proton signal of the neighboring hydrogen atom on the chlorofluorenyl moiety to $\delta$ $6.32(\mathrm{H} 23){ }^{7 a, 8 j}$ In the contour plot of the COSY spectrum (Figure 4), this signal was also used to locate the remaining three hydrogens on the same benzene ring at $\delta 6.60$ (ortho), 6.90 (meta), and 7.37 (para).

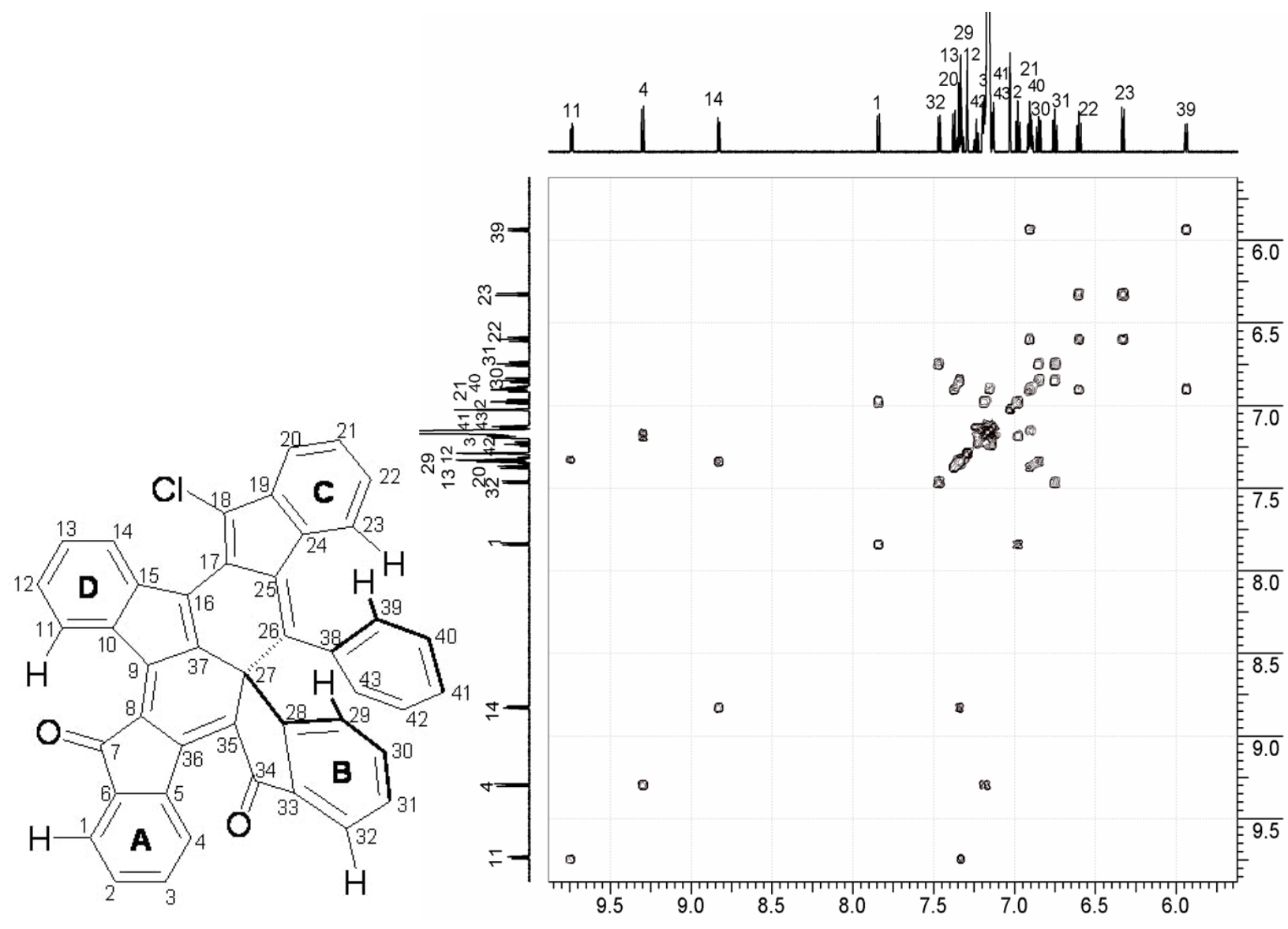

Figure 4. COSY spectrum of 28 in $\mathrm{C}_{6} \mathrm{D}_{6}$. 
A complete assignment of the ${ }^{1} \mathrm{H}$ NMR chemical shifts to the remaining hydrogens of $\mathbf{2 8}$ and the ${ }^{13} \mathrm{C}$ NMR chemical shifts to the 43 carbons were made by an analysis strategy based on the application of several gradient selected two-dimensional experiments, such as gHSQC, gHMBC, and gHSQC-TOCSY. Again, the proton connectivities were identified from the COSY and 1D/2D TOCSY spectra. The gHSQC correlations were used to confirm the proton bearing carbons, and the gHMBC cross peaks were used to define the locations of the quaternary carbons. The gHMBC correlation with the quaternary $\mathrm{sp}^{3}$ carbon resonance at $\delta 57.6$ allowed the assignment of the proton signal at $\delta 7.33$ to the hydrogen three bonds away, which in turn allowed the assignment of the remaining three hydrogens on the same benzene ring at $\delta 6.84$ (ortho), 6.75 (meta), and 7.46 (para) based on 2D TOCSY and COSY correlations.

Using the gHMBC technique, the proton signal at $\delta 7.46$ was used to locate the ${ }^{13} \mathrm{C}$ chemical shift of the neighboring carbonyl carbon at $\delta$ 187.7. Similarly, the chemical shift of the hydrogen three bonds away from the other carbonyl carbon at $\delta 190.3$ was identified at $\delta 7.84$, which in turn allowed the assignment of the remaining three hydrogens on the same benzene ring at $\delta 6.97$ (ortho), 7.19 (meta), and 9.29 (para). The most downfield proton signal at $\delta 9.73$ was assigned to the hydrogen on the remaining benzene ring closest to the carbonyl carbon with a chemical shift at $\delta$ 190.3. The last three proton signals at $\delta 7.32$ (ortho), 7.34 (meta), and 8.82 (para) were then assigned by COSY. The 1D TOCSY spectra (Figure 5) show all the spin-spin coupling network of hydrogens shown individually on the phenyl group, ring A, B, C and D. 


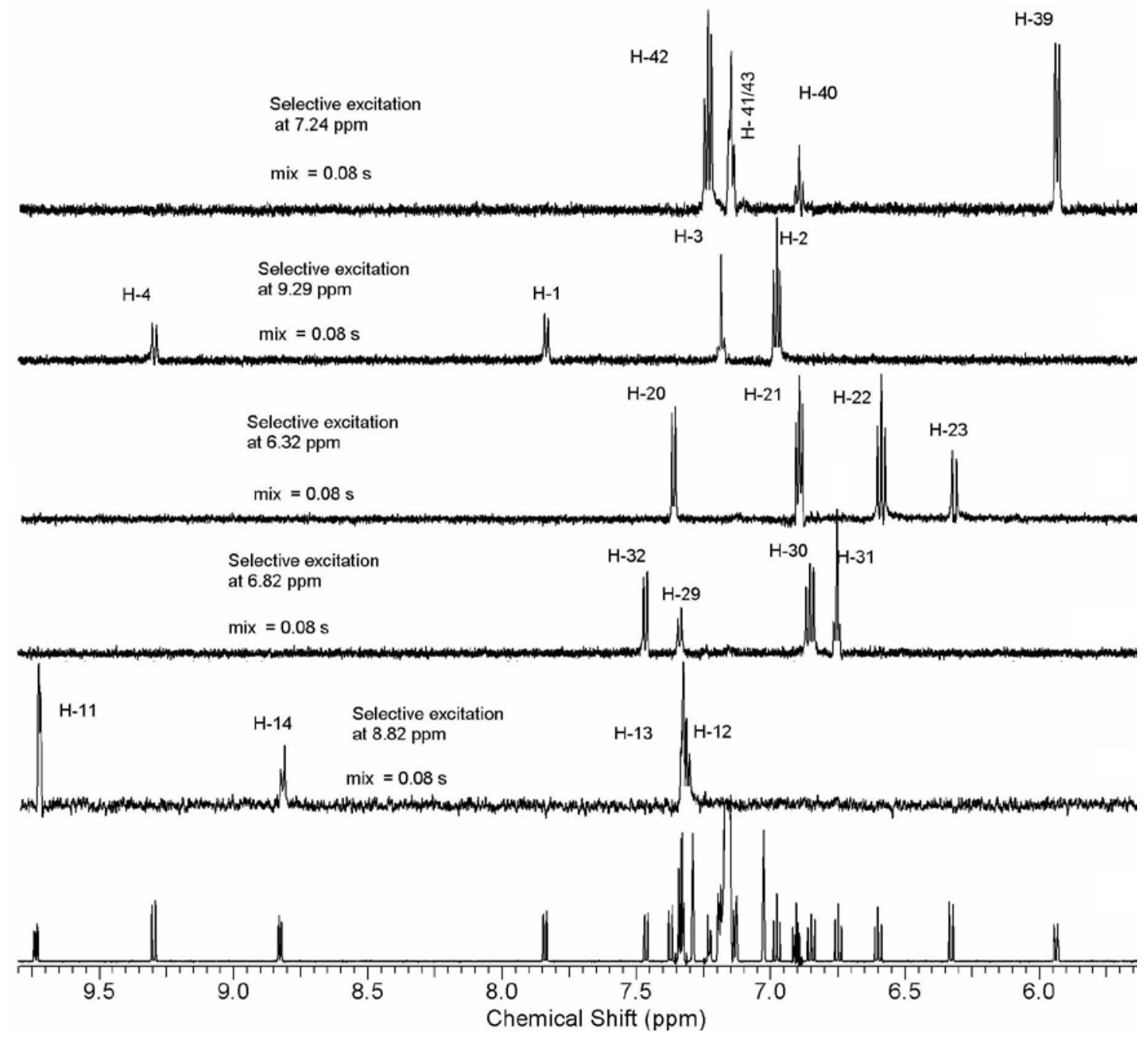

Figure 5. 1D TOCSY spectra of 28 in $\mathrm{C}_{6} \mathrm{D}_{6}$.

\subsection{Unusual Transformation of 28 in $\mathrm{CDCl}_{3}$ to Other Unknown Compounds}

It was observed that the polycyclic compound $\mathbf{2 8}$ gradually and cleanly transformed to an unknown compound II in $\mathrm{CDCl}_{3}$, which on further studying in air led to another unknown compound III. Compounds II and III exhibit a very different proton NMR spectrum with the two most upfield shift signals appearing at $\delta 5.28(1 \mathrm{H}, \mathrm{d}, J=7.8 \mathrm{~Hz})$ for compound II and $5.33(1 \mathrm{H}$, d, $J=7.8 \mathrm{~Hz}$ ) for compound III (Figure 6). The structures of these two new compounds have not been elucidated. However, NMR studies of unknown II showed that there are still 21 hydrogens, 
two keto groups and four ring substructures. One possible structure of compound III is depicted as 29 (Scheme 6). Further investigation is needed to determine its structures.

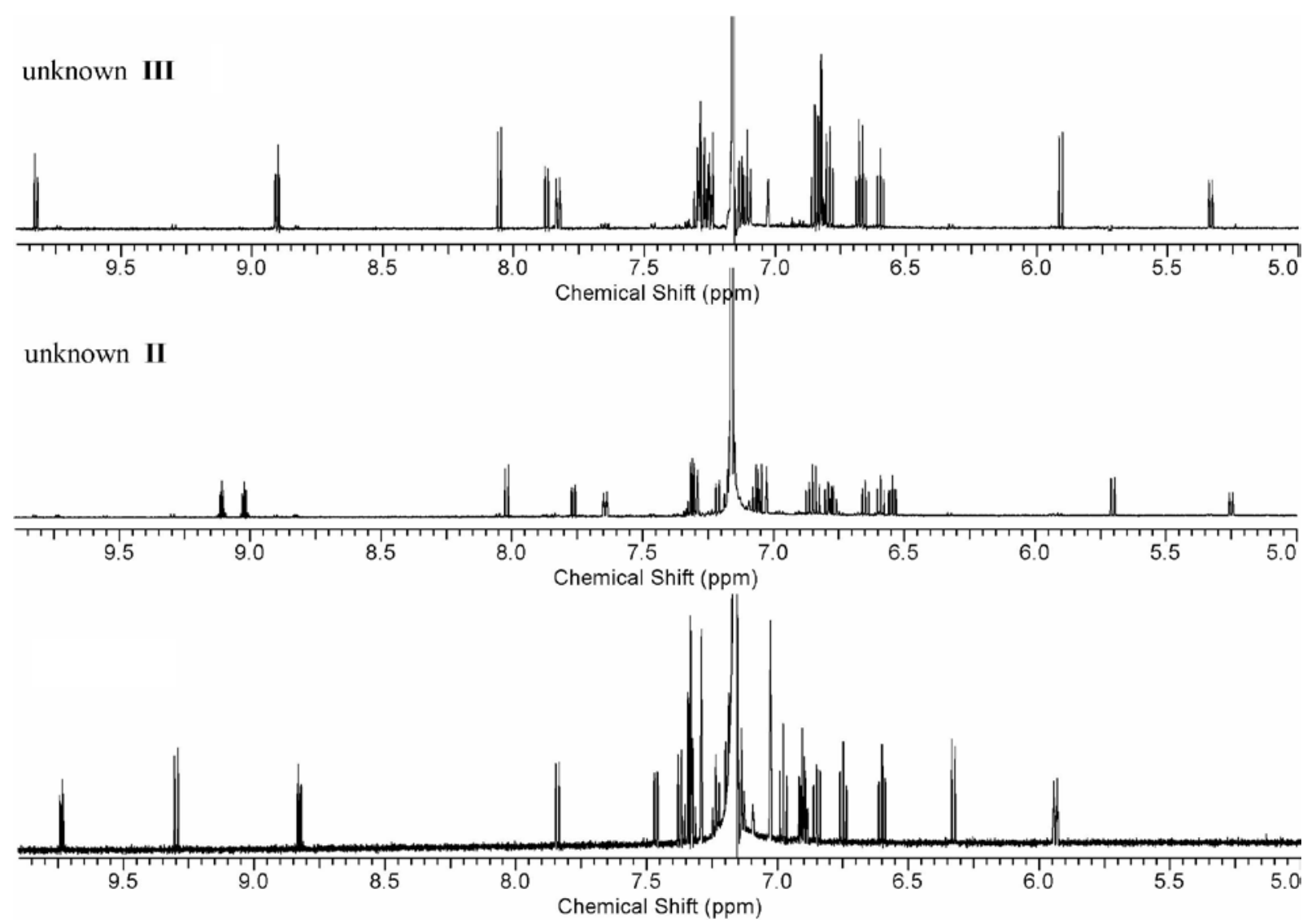

Figure 6. ${ }^{1} \mathrm{H}$ NMR spectra comparison of compound 28 and two unknowns in $\mathrm{C}_{6} \mathrm{D}_{6}$.

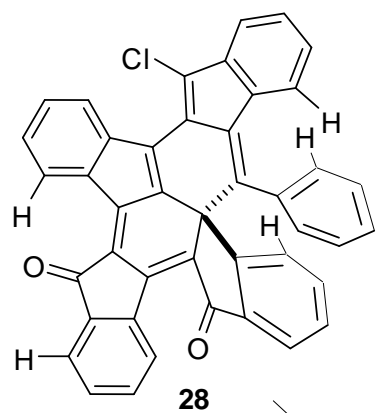

$\mathrm{CDCl}_{3}$

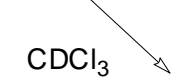

Unknown II

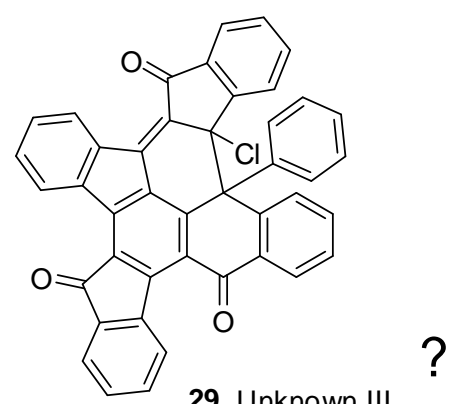

Exposed to the Air

Scheme 6. Proposed transformation of polycyclic diketone $\mathbf{2 8 .}$ 


\subsection{Unusual Cascade Cyclization of Di-propargylic Alcohol 30}

Treatment of truxenone with 2.5 equiv of 5 allowed the isolation of the cis diol 30 in $76 \%$ yield along with the corresponding trans diol in 13\% yield (Scheme 7). The structure of the cis diol was established by X-ray structure analysis. On exposure of a mixture of the cis and trans isomers of diol $\mathbf{3 0}$ to thionyl chloride, the product $\mathbf{3 1}$ bearing two quaternary carbon centers was produced. In addition, the two chlorinated fluorenyl moieties are trans to each other with respect to the central six-membered ring. The structure of $\mathbf{3 1}$ was established by X-ray structure analysis (Figure 7). Apparently, the second cascade cyclization reaction also involved a carbon-carbon double bond of the central six-membered ring. In addition, the second radical-radical coupling reaction occurred from the direction trans to the first chlorinated fluorenyl unit. As observed in 28, several ${ }^{1} \mathrm{H}$ NMR signals of $\mathbf{3 1}$ in $\mathrm{C}_{6} \mathrm{D}_{6}$ showed significant upfield shifts with the most upfield signal appearing at $\delta 5.62$.

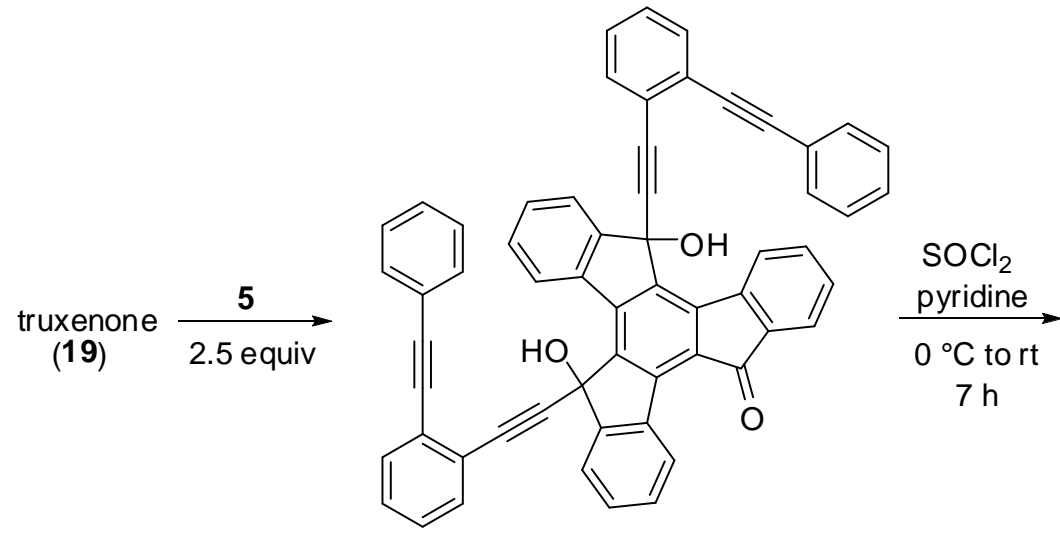

30, $89 \%$, cis:trans $=6: 1$

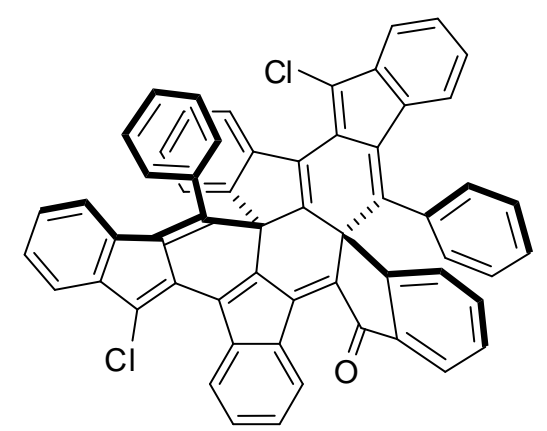

31, $55 \%$

Scheme 7. Preparation of congested polycyclic ketone 31. 


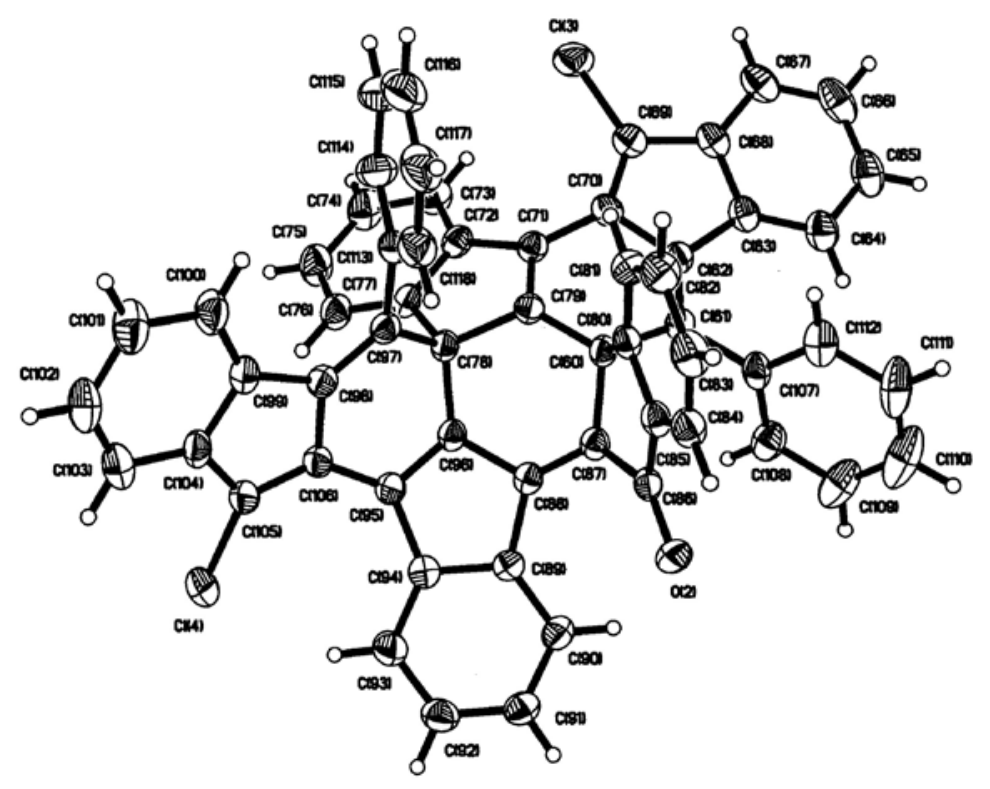

Figure 7. ORTEP drawing of the crystal structure of $\mathbf{3 1}$ with atom labeling.

\subsection{Unusual Cascade Cyclization of Propargylic Triol 20}

When truxenone was treated with 5.0 equiv of $\mathbf{5}$, triol 20 was obtained as a mixture of the anti and syn isomers (5:1) in 89\% combined yield (Scheme 4). On exposure of a mixture of the anti and syn isomers of $\mathbf{2 0}$ to thionyl chloride, the product $\mathbf{3 4}$ was produced in $48 \%$ yield (Scheme 8). The structure of $\mathbf{3 4}$ was established by X-ray structure analysis (Figure 8). Clearly, the third benzannulated enediynyl alcohol unit did not undergo the anticipated cascade cyclization reaction. Instead, the third chlorosulfite 32 underwent an $\mathrm{S}_{\mathrm{N}} \mathrm{i}^{\prime}$ reaction involving the remaining carbon-carbon double bond of the central six-membered ring might have occurred to give 33, which on hydrolytic workup then furnished 34. The attempt to synthesize highly congested compound 35 by heating the reaction to higher temperature at $80{ }^{\circ} \mathrm{C}$ was unsuccessful. The ${ }^{1} \mathrm{H}$ NMR spectrum of the crude reaction mixture showed very complicated broad peaks in the aromatic region, indicating that the starting material decomposed or polymerized. Apparently, the severe steric congestion of central six-membered ring prevented the cascade cyclization reaction from attacking the third carbon-carbon double bond of the central benzene ring. 

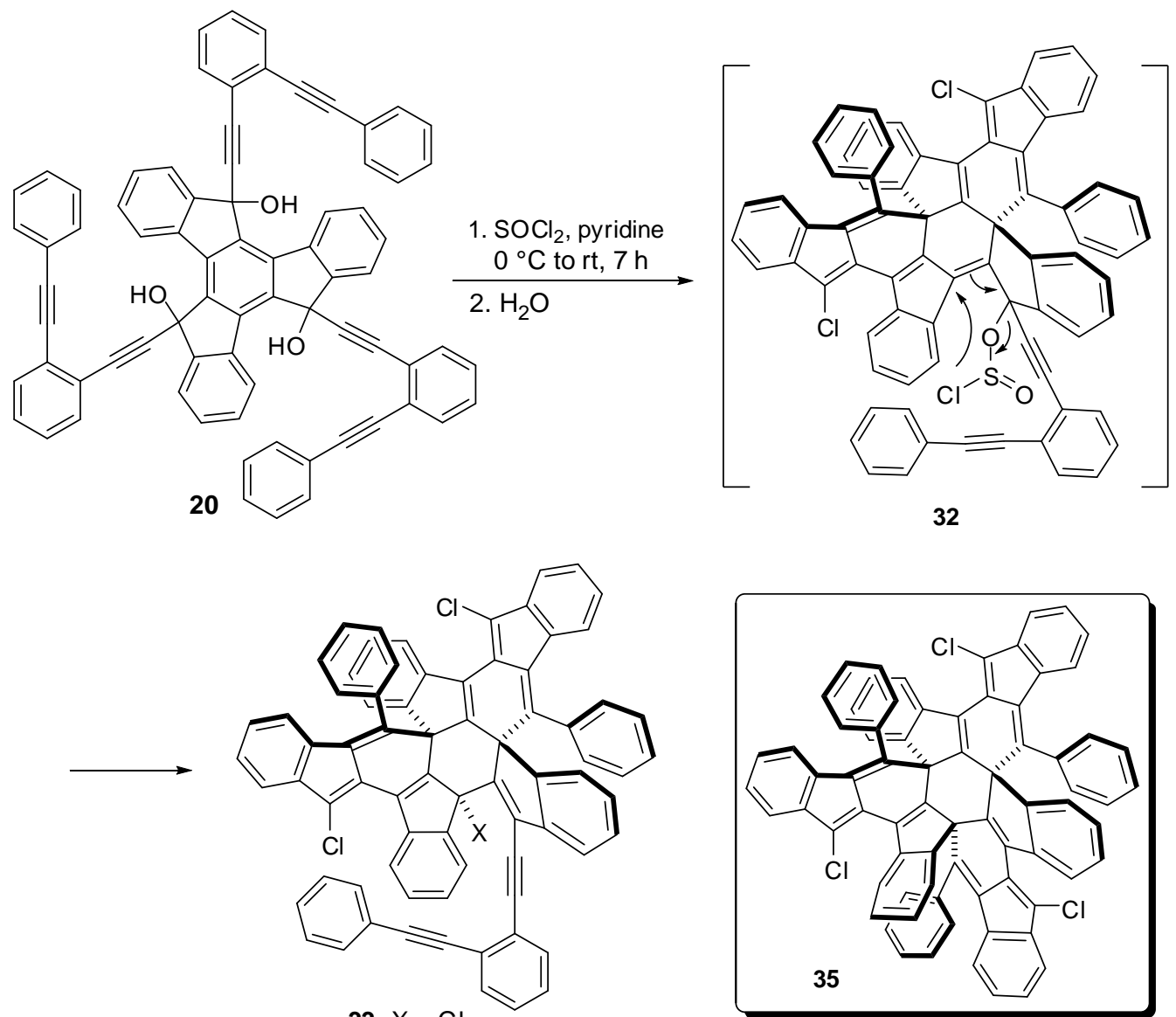

33, $\mathrm{X}=\mathrm{C}$

34, $\mathrm{X}=\mathrm{OH}, 48 \%$

Scheme 8. Preparation of polycyclic compound 34.

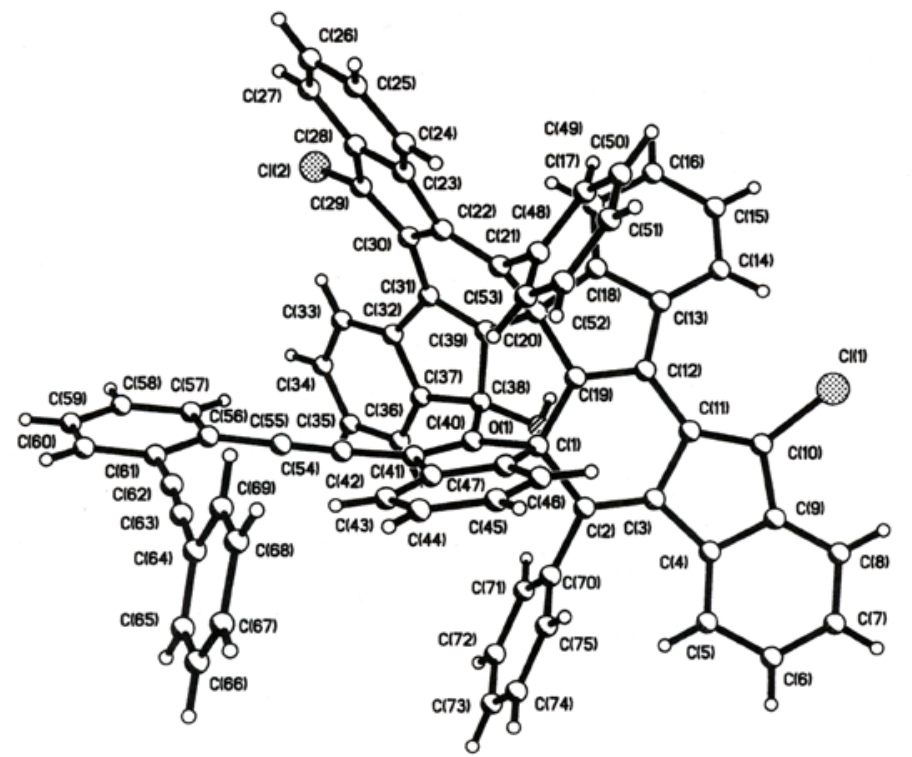

Figure 8. ORTEP drawing of the crystal structure of $\mathbf{3 4}$ with atom labeling. 


\subsection{Other Attempts to Synthesize Polycyclic Aromatic Compounds}

Dr. Yonghong Yang developed a new synthetic pathway to generate the benzannulated enyne-allenes in situ from crude propargylic acetate promoted by $\mathrm{Pd}\left(\mathrm{PPh}_{3}\right)_{4}, 2$-propanol and $\mathrm{SmI}_{2} \cdot \mathrm{THF}$, and then followed by cascade radical cyclization leading to the polycyclic hydrocarbon 37 in a single operation with $34 \%$ yield in two steps. ${ }^{16}$ Scheme 9 outlines a study to generate the benzannulated enyne-allenes in situ without a chloro-substituent. Reduction of the hydroxyl group was carried out by treatment with triethylsilane in the presence of $\mathrm{BF}_{3} \cdot \mathrm{OEt}_{2}$ to afford hydrocarbon 36. ${ }^{9 a}$ A prototropic rearrangement of $\mathbf{3 6}$ promoted by triethylamine to form benzannulated enyne-allene in situ followed by a cascade Schmittel cyclization and tautomerization led to the corresponding polycyclic aromatic hydrocarbons 37 in a single operation. ${ }^{17}$ However, the reduction by using trifluoroacetic acid in the presence of triethylsilane developed by Dr. Hongbin Li of our group failed in this case. Also, an attempt to promote cascade cyclization reactions of $\mathbf{3 6}$ with potassium tert-butoxide under refluxing toluene at 110 ${ }^{\circ} \mathrm{C}$ also was unsuccessful.

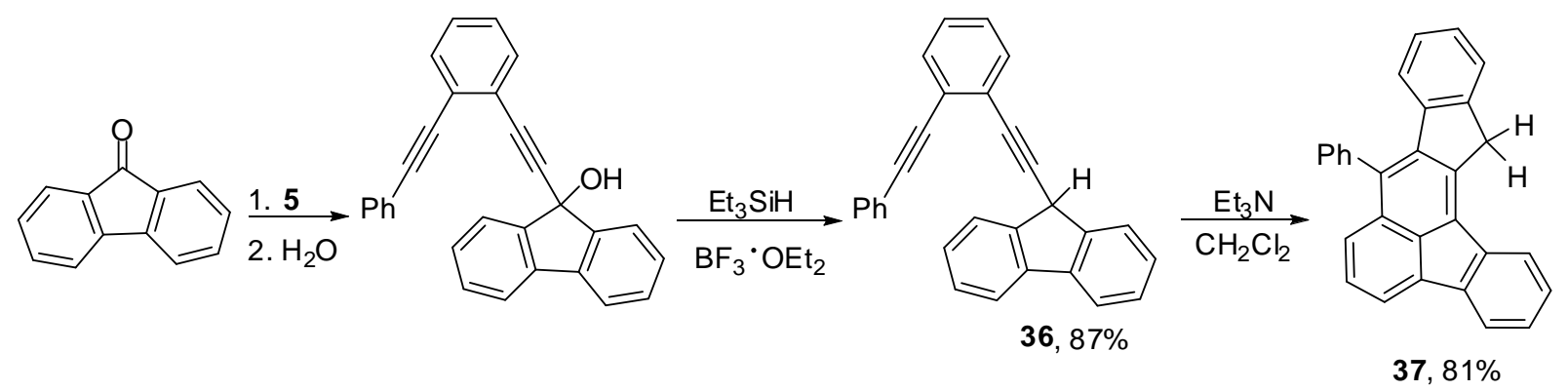

Scheme 9. A new synthetic pathway to polycyclic hydrocarbon 37.

Scheme 10 outlines the attempts to synthesize polycyclic aromatic hydrocarbon 39 via cascade radical cyclization of the molecule having three units of benzannulated enyne-allenes without a chloro substituent. Treatment of triol 20 with triethylsilane in the presence of $\mathrm{BF}_{3} \cdot \mathrm{OEt}_{2}$ afforded the hexacetylenic hydrocarbon 38. On exposure to triethylamine, the reaction mixture 
immediately became reddish in color. The ${ }^{1} \mathrm{H}$ NMR spectra of the crude and also the product after silica gel column chromatography showed very broad and complicated peaks in the aromatic region, indicating that the starting material decomposed or polymerized.

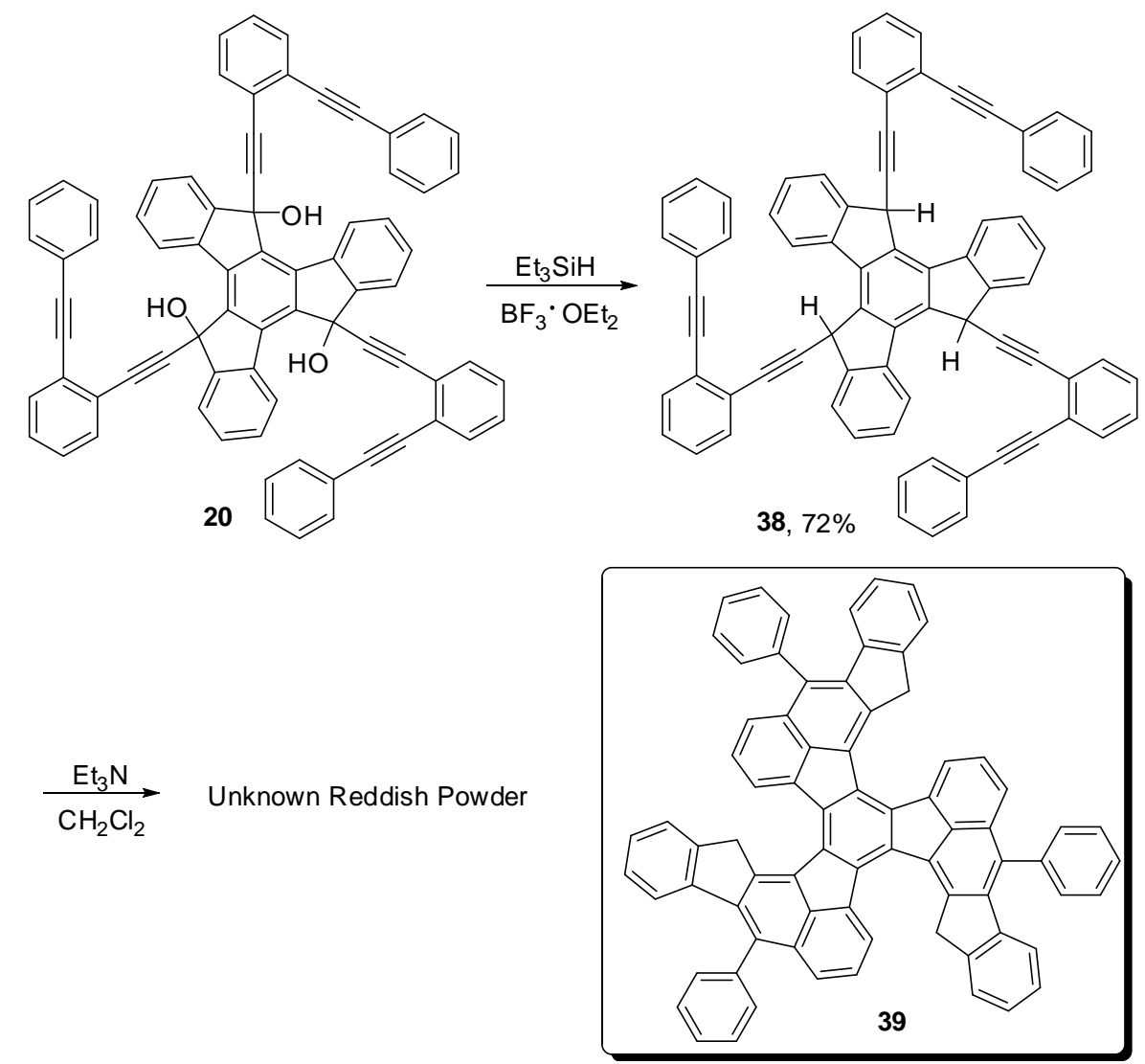

Scheme 10. Attempt to synthesize 39 via a new synthetic pathway.

\section{Conclusions}

Benzannulated enediynyl alcohols 24, 30, and 20, derived from condensations of truxenone and the lithium acetylide $\mathbf{5}$, were readily converted to the polycyclic compounds $\mathbf{2 8}$, 31, and 34 by thionyl chloride-promoted cascade cyclization reactions. The aromaticity of the central benzene ring of truxenone is disrupted in all three of the resultant products. Transformation of two $\pi$ bonds to two $\sigma$ bonds in each of the cascade cyclization sequence provides the necessary driving force for the construction of these unusual and congested 
polycyclic structures. Other attempts to prepare polycyclic aromatic compounds 21, 35, and 39 via different synthetic pathways were unsuccessful. 


\section{CHAPTER II}

\section{Synthesis of 5-(2-Methoxy-1-naphthyl)- and \\ 5-[2-(Methoxymethyl)-1-naphthyl]-11H-benzo[b]fluorene \\ as $2,2^{\prime}$-Disubstituted 1,1'-Binaphthyls}

\section{Introduction}

We recently reported an efficient synthesis of 5-phenyl-11H-benzo[b]fluorene $\mathbf{4 6}$ in a single cascade sequence by treatment of the benzannulated enediyne 42 having a phenyl substituent attached directly at one of the alkynyl termini with potassium $t$-butoxide in refluxing toluene for six hours (Scheme 11).$^{7 a}$ The benzannulated enediyne $\mathbf{4 2}$ was prepared from the condensation between lithium acetylide 5 and 2,2-dimethylpropiophenone (40) to furnish the corresponding propargylic alcohol $\mathbf{4 1}$, followed by reduction with triethylsilane in the presence of trifluoroacetic acid.

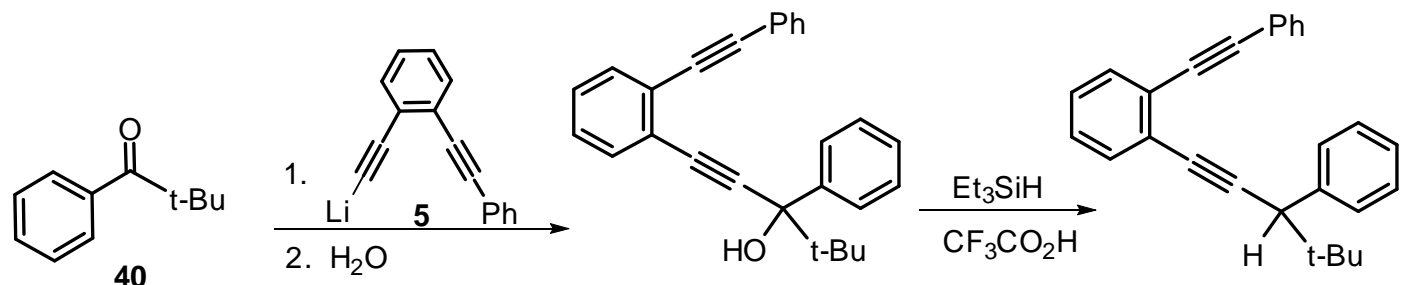

40

41, $94 \%$

42, $96 \%$
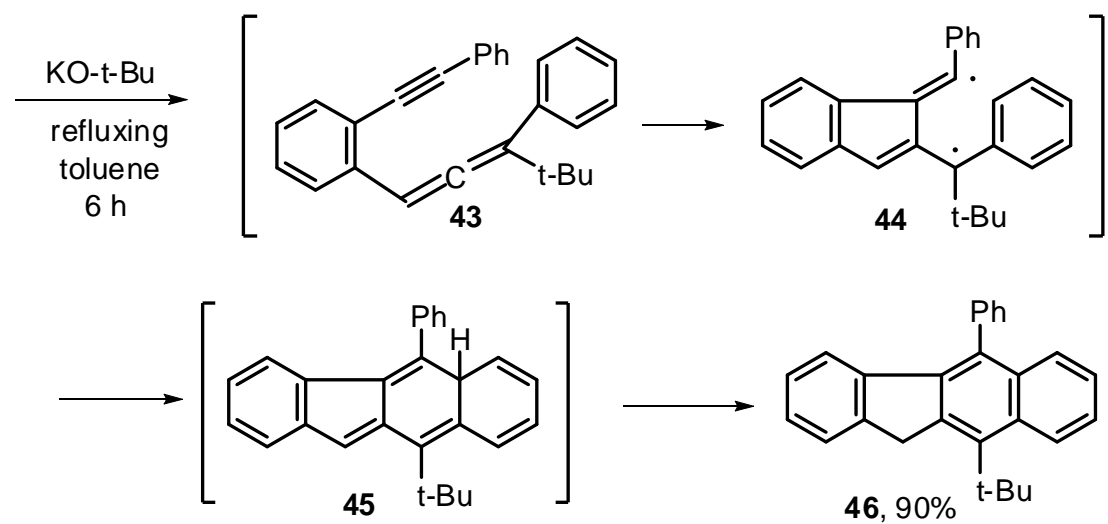

Scheme 11. Synthesis of $11 H$-benzo[b]fluorene $\mathbf{4 6}$ via Schmittel cyclization. 
Presumably, an initial 1,3-prototropic rearrangement of $\mathbf{4 2}$ afforded the benzannulated enyne-allene $\mathbf{4 3}$ in situ, followed by a Schmittel cyclization reaction to generate benzofulvene biradical 44. A subsequent intramolecular radical-radical coupling then gave the formal Diels-Alder adduct $\mathbf{4 5}$, which in turn undergoes a second prototropic rearrangement to regain aromaticity leading to $11 H$-benzo[b]fluorene $\mathbf{4 6}$ in $90 \%$ yield.

The reaction is not sensitive to the steric requirement of the substituent at the alkynyl terminus. We also reported that the benzannulated enediyne $\mathbf{4 7}$ having a sterically demanding 2,6-dibromophenyl substituent was also smoothly converted to 4 8. $^{8 \mathrm{c}}$ With the benzannulated enediyne 49 having a 1,1'-binaphthyl substituent, a 1:1 mixture of the syn and the anti atropisomers of $\mathbf{5 0}$ was likewise obtained. ${ }^{8 f}$
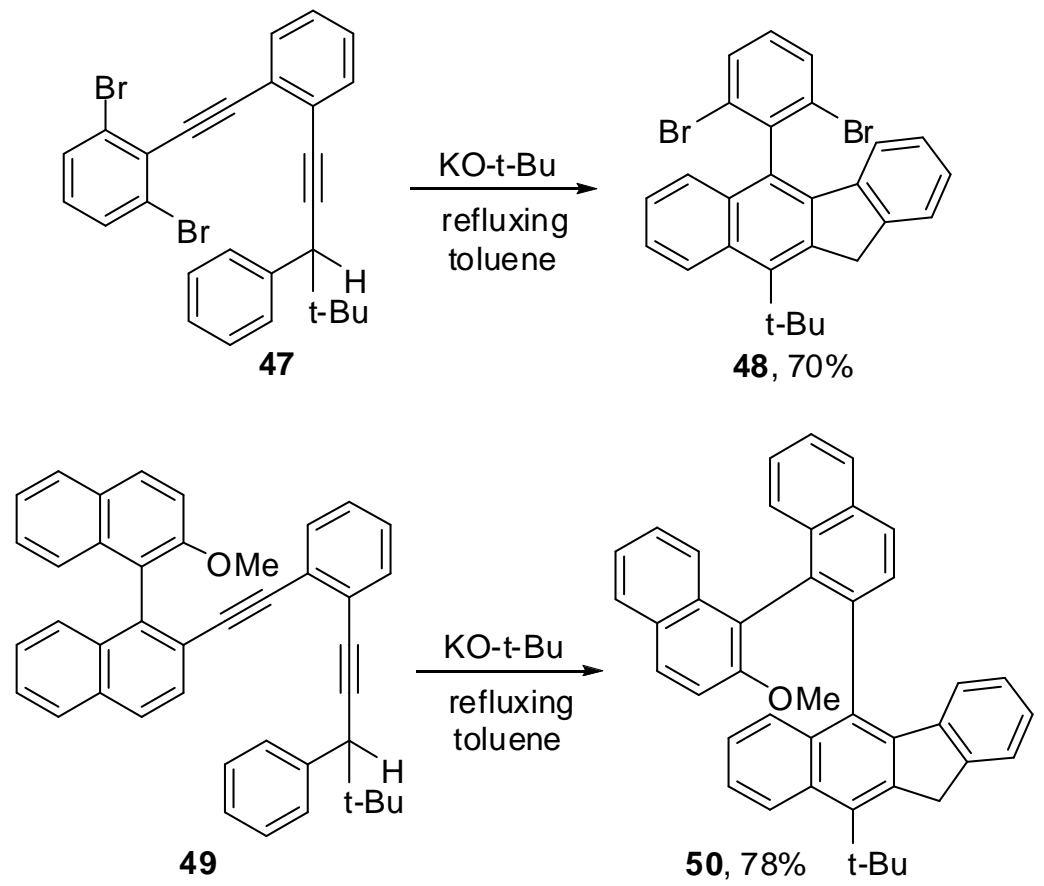

Scheme 12. Syntheses of $11 H$-benzo[b]fluorene derivatives.

It is interesting to note that the newly formed benzo[b]fluorenyl moiety in $\mathbf{4 6}$ and $\mathbf{4 8}$ could also be regarded as a 1-arylnaphthyl derivative with three additional substituents at the 2 , 3 , and 4 positions. We now have successfully extended the cascade sequence to the synthesis of 
other sterically congested analogues with an ortho-methoxyl or an ortho-methoxymethyl group on the phenyl substituent. In addition, by placing a 2-methoxy-1-naphthyl or a 2-(methoxymethyl)-1-naphthyl group at one of the alkynyl termini, the resulting naphthyl-substituted benzo[b]fluorenes could be regarded as 2,2'-disubstituted 1,1'-binaphthyls with two additional substituents at the 3 and 4 positions.

\section{Research Objective}

The versatility of 1,1'-binaphthyl-2,2'-diol (BINOL, 51) and BINOL derivatives as chiral reagents in asymmetric synthesis has stimulated the development of new synthetic methods for 2,2'-disubstituted 1,1'-binaphthyls. ${ }^{18}$ In 1979, the potential of BINOL as a ligand for metal-mediated catalysis was first recognized by Noyori et al. ${ }^{19 \mathrm{~b}}$ in the reduction of aromatic ketones and aldehydes. However, BINOL has its limitation and does not always give satisfactory results in asymmetric catalysis. As a result, there has been an intensive interest in designing and synthesizing novel modified BINOL ligands. The optimization of a given asymmetric transformation process depends on both steric and electronic properties of the chiral ligand therefore a strategic placement of substituents onto the framework of a BINOL derivative may lead to improvement of catalysis. The great majority of the reported methods involved coupling of two properly substituted 1-naphthyl derivatives. Construction of a new 1-naphthyl ring as an essential step toward $1,1^{\prime}$-binaphthyls is rare. ${ }^{19}$ Herein, we employed the Schmittel cyclization to construct the core structure of 1,1'-binaphthyls in a single operation as shown in Scheme 12.

\section{Literature Survey of BINOL derivatives and Synthesis of Bidentate Fluorenyl Complex}

\subsection{Literature Survey of the BINOL derivatives}

BINOL derivatives can be generally categorized into two main types: one is $C_{2}$-symmetrical homo bi-dentate ligand such as BINAP (52), ${ }^{20} \operatorname{BINAM~(53),~}{ }^{21}$ and 2,2'-bis(2-indenyl)binaphthyl (54); ${ }^{22}$ The other is non- $C_{2}$-symmetrical hetero bi-dentate ligand 
including NOBIN (55), ${ }^{23}$ MOP (56), ${ }^{24}$ and MAP $(57) .{ }^{25}$ Both of these BINOL derivatives have been widely investigated and used in the development of asymmetric catalysis (Figure 9). ${ }^{18 \mathrm{~h}}$<smiles>Oc1ccc2ccccc2c1-c1c(O)ccc2ccccc12</smiles>

BINOL, 51<smiles>Pc1cccc(-c2c(-c3ccccc3)ccc3ccccc23)c1-c1ccccc1</smiles>

BINAP, 52<smiles>Nc1ccc2ccccc2c1-c1c(N)ccc2ccccc12</smiles>

BINAM, 53<smiles>C1=C(c2ccc3ccccc3c2C2=Cc3ccccc3C2)c2ccccc2C1</smiles>

54<smiles>Nc1ccc2ccccc2c1-c1c(O)ccc2ccccc12</smiles>

NOBIN, 55<smiles>COc1ccc2ccccc2c1-c1c(P)ccc2ccccc12</smiles>

MOP, 56<smiles>Cc1ccc2ccccc2c1-c1c(P)ccc2ccccc12</smiles>

MAP, 57

Figure 9. Examples of BINOL derivatives.

Considering the rotational barrier around the carbon-carbon single bond connecting the two $\mathrm{C} 1$ carbons of these 2,2'-disubstituted binaphthyls, the type of non-symmetrical 1,1'-binaphthyls can provide higher rotation barrier since the lack of $C_{2}$ symmetry. ${ }^{26}$ This feature further gives stability to the chiral configuration even at high temperature which allows these molecules to be more attractive for synthetic applications and asymmetric catalysis.

\subsection{Literature Survey of Synthesis of Bidentate Fluorenyl Complexes}

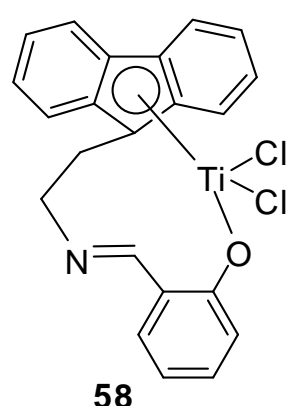

58

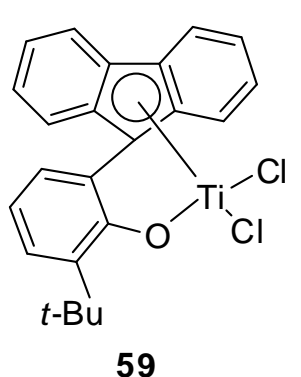

59

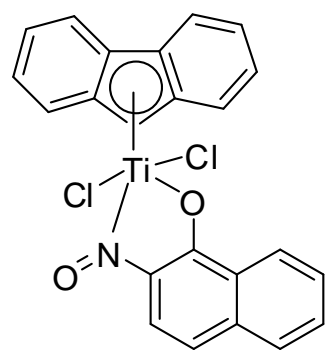

60

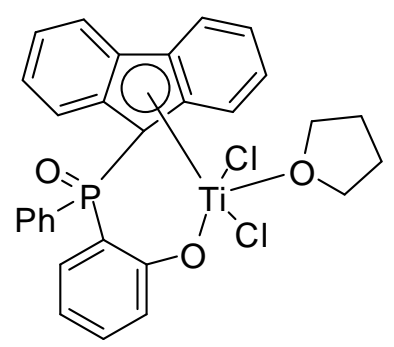

61

Figure 10. Examples of novel bidetate metallocene titanium complexes. 
In 1996, Kashiwamura et al. reported the synthesis of novel bidentate fluorene complex 58 and employed this kind of complex to catalyze the polymerization of propylene. ${ }^{27}$ Several other novel phenoxy side chain-containing metallocene titanium complexes (59-61) have also been synthesized and used for various olefin polymerizations (Figure 10). ${ }^{28}$ We envisioned the possibility of producing metallocene complexes 63 from 62, which could be readily prepared by employing the Schmittel cyclization reaction (Scheme 13).

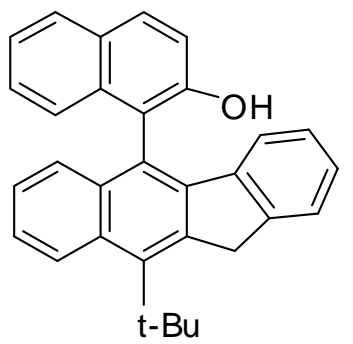

62
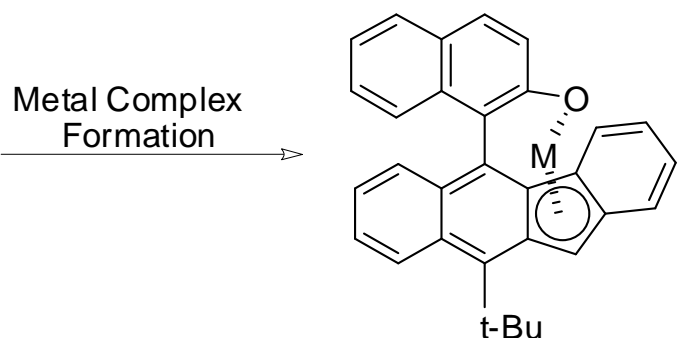

63

Scheme 13. Anticipated formation of metallocene complex.

\section{Results and Discussion}

\subsection{Synthesis of 1-Arylnaphthyl Derivatives}

The Sonogashira reaction between 1-ethynyl-2-methoxybenzene (64a) and aryl iodide 65 produced 66a, which was desilylated to give 67a (Scheme 14). Condensation between 67a and pivalophenone (40) then furnished the benzannulated enediynyl alcohol 68a. Subsequent reduction with triethylsilane in the presence of trifluoroacetic acid afforded the benzannulated enediyne 69a. Similarly, the benzannulated enediyne 69b was synthesized from 1-ethynyl2-(methoxymethyl)benzene (64b). Upon exposure to potassium $t$-butoxide in refluxing toluene for five hours, 69a was transformed to 5-(2-methoxyphenyl)-11H-benzo[b]fluorene 73a along with a small amount (ca. 2\%) of 74a in a single operation (Scheme 15). 


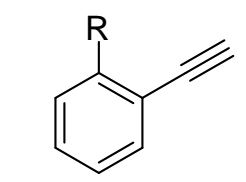

64a: $\mathrm{R}=\mathrm{OMe}$ 64b: $\mathrm{R}=\mathrm{CH}_{2} \mathrm{OMe}$
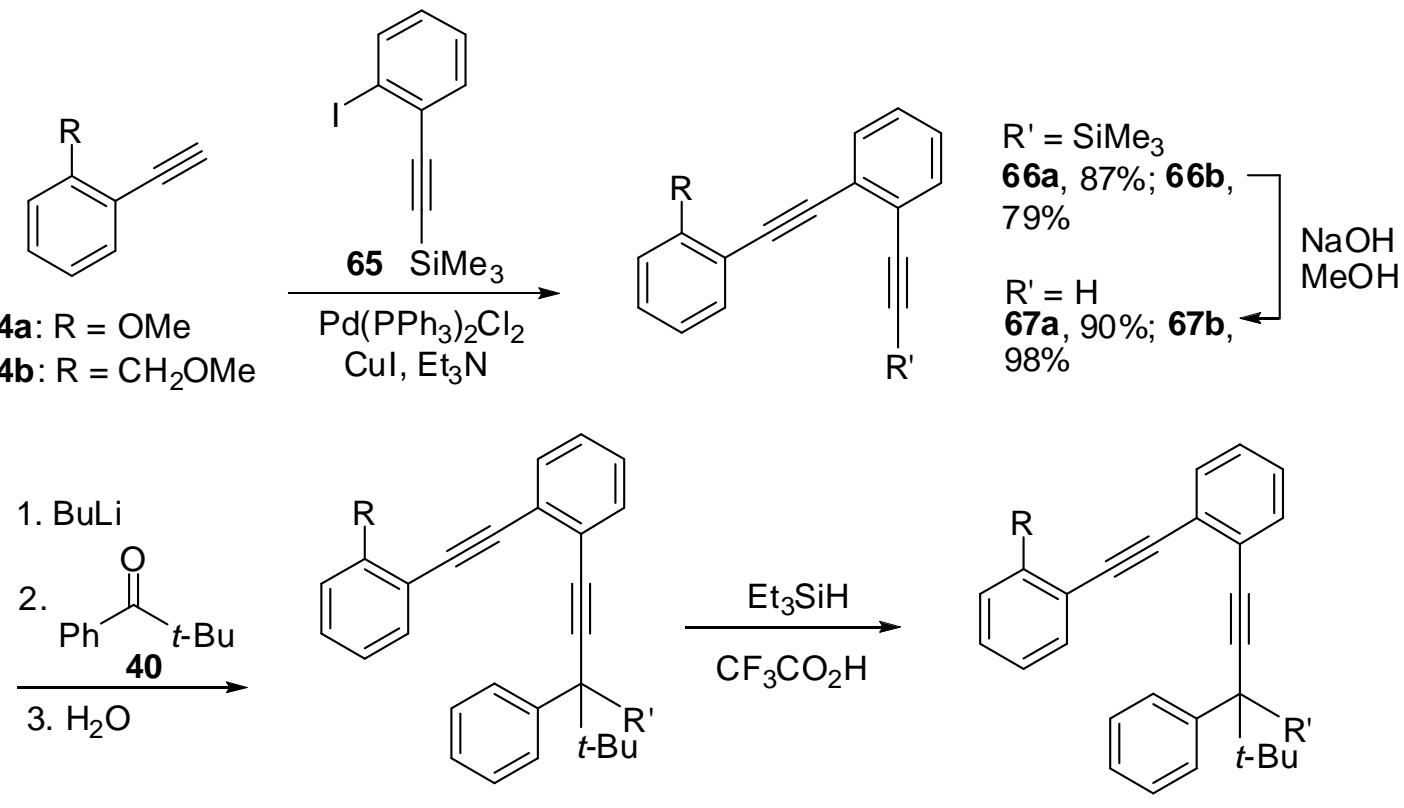

$\mathrm{R}^{\prime}=\mathrm{OH}$

68a, 99\%; 68b, 96\%

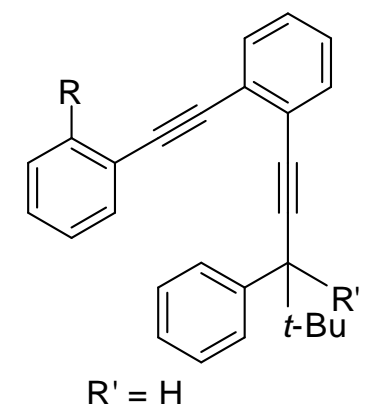

69a, 93\%; 69b, 90\%

Scheme 14. Prepararion of benzannulated enediyne 69.

Presumably, the cascade sequence involved an initial 1,3-prototropic rearrangement to form the corresponding benzannulated enyne-allene 70a. A Schmittel cyclization reaction ${ }^{2,13 b}$ to generate biradical 71a for an intramolecular radical-radical coupling to afford 72a followed by a second prototropic rearrangement to regain aromaticity then furnished 73a as proposed previously. An intramolecular [2 +2$]$ cycloaddition reaction of 70a or a direct radical-radical coupling of 71a could account for the formation of $74 a^{7 a}$ By starting from $\mathbf{6 9 b}$, 5-[2-(methoxymethyl)phenyl]-11H-benzo[b]fluorene 73b and the $[2+2]$ cycloaddition adduct $\mathbf{7 4 b}$ in a 5:1 ratio were produced. The presence of the carbon-carbon double bonds in $\mathbf{7 4 b}$ allows easy removal of $\mathbf{7 4 b}$ by treatment of the resulting mixture with $\mathrm{BH}_{3} \cdot \mathrm{THF}$ followed by silica gel column chromatography. The presence of a benzofluorenyl moiety and a methoxyl or a methoxymethyl group in 73a and 73b could allow them to serve as hetero-bidentate ligands for complex formation with transition metals. ${ }^{29}$ 


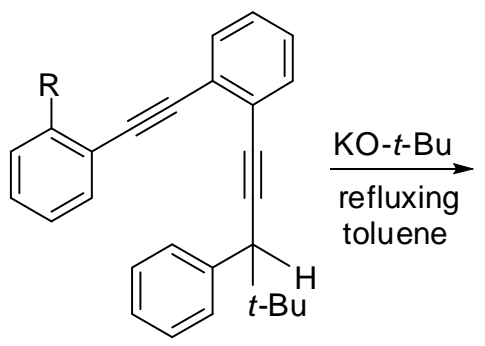

69
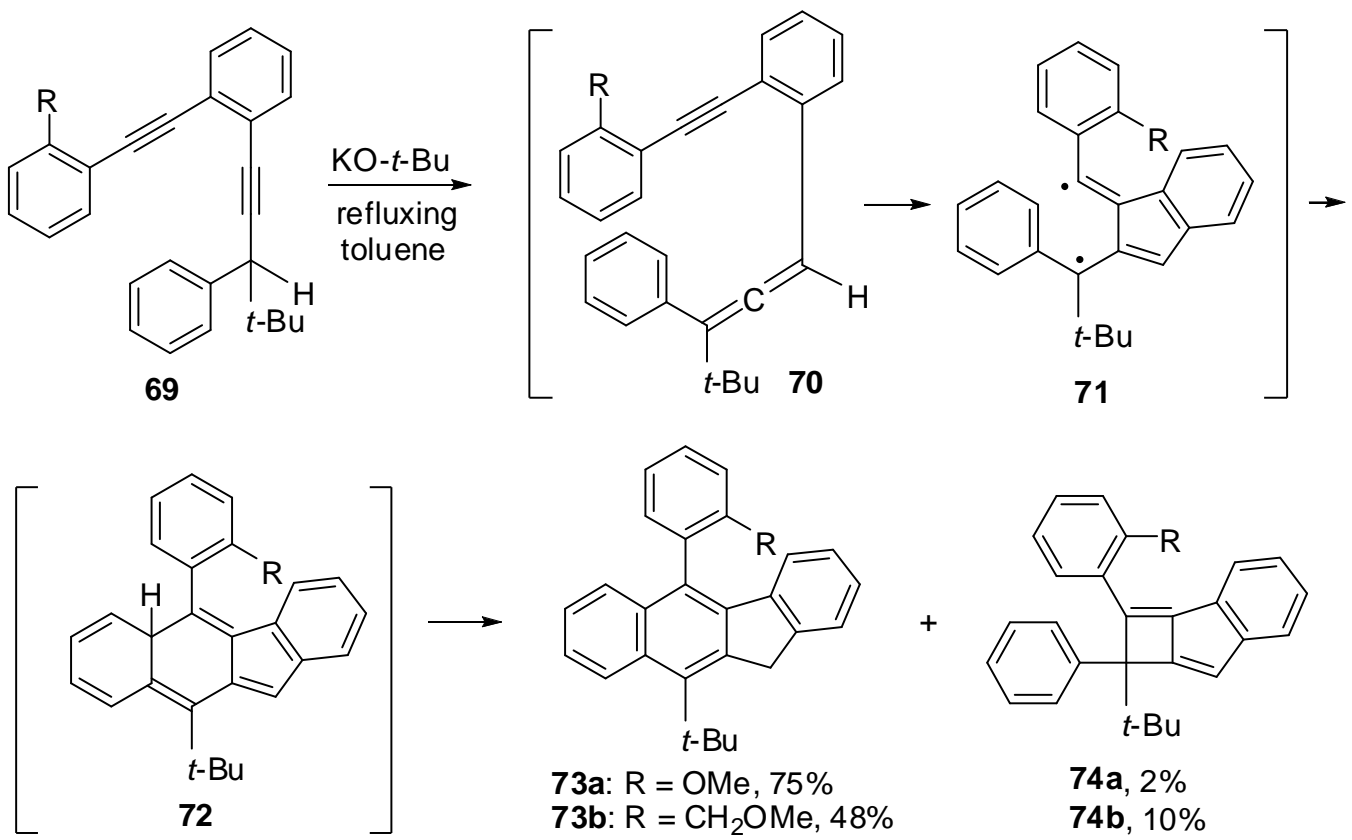

$74 a, 2 \%$

74b, $10 \%$

Scheme 15. Synthesis of 1-arylnaphthyl derivative 73.

\subsection{Synthesis of 2,2'-Disubstituted 1,1'-Binaphthyls}

\subsubsection{Preparation of Benzannulated Enediyne 80}

We also investigated the possibility of using the benzannulated enediynes bearing a 1-naphthyl, a 2-methoxy-1-naphthyl, or a 2-(methoxymethyl)-1-naphthyl substituent at one of the alkynyl termini for the cascade cyclization reaction. Treatment of 2-methoxy-1naphthaldehyde (75) with dimethyl(1-diazo-2-oxopropyl)phosphonate and $\mathrm{K}_{2} \mathrm{CO}_{3}$ gave acetylene 76 (Scheme 16). The Sonogashira reaction between 76 and aryl iodide 65 furnished 77. Subsequent desilylation and condensation gave the benzannulated enediynyl alcohol $\mathbf{7 9}$. However, reduction by using triethylsilane in either trifluoroacetic acid or $\mathrm{BF}_{3} \cdot \mathrm{OEt}_{2}$ were unsuccessful to afford the desired benzannulated enediyne 80. Therefore, the synthetic pathway was slightly modified by first preparing the fragment of reduced aryl iodide $\mathbf{8 3}$ followed by coupling with acetylene $\mathbf{7 6}$ (Scheme 17). The benzannulated enediyne 80 was successfully obtained. 
<smiles>COc1ccc2ccccc2c1C=O</smiles>

75

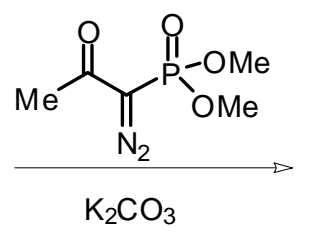<smiles>C#Cc1c(OC)ccc2ccccc12</smiles>

$76,53 \%$

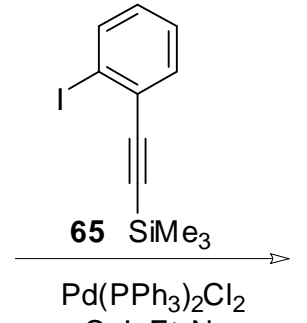

Cul, $\mathrm{Et}_{3} \mathrm{~N}$

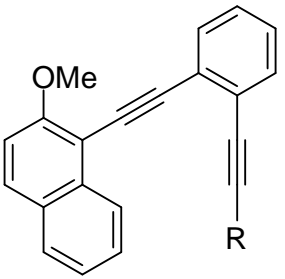

77: $\left.\mathrm{R}=\mathrm{Me}_{3} \mathrm{Si}, 60 \%\right] \mathrm{NaOH}$

1. BuLi
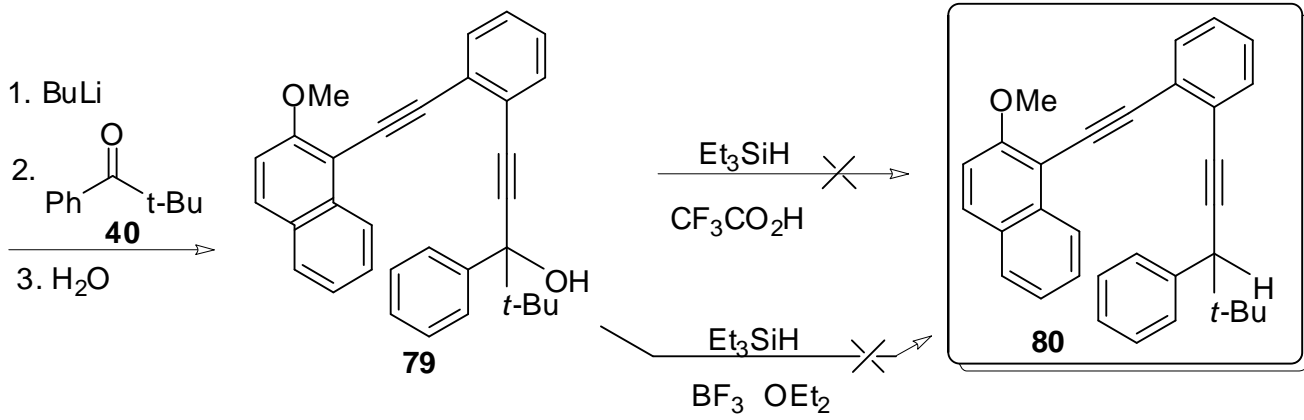

Scheme 16. Attempted synthetic pathway to benzannulated enediyne $\mathbf{8 0}$.

\subsubsection{Synthesis of $1,1^{\prime}$-Binaphthyls $86 a$ and $86 b$}<smiles>C#Cc1ccccc1I</smiles>

1. LDA $\underset{\text { 3. } \mathrm{H}_{2} \mathrm{O}}{\longrightarrow}$

81<smiles>[R]C(C#Cc1ccccc1I)(c1ccccc1)c1ccccc1</smiles>

82: $\mathrm{R}^{\prime}=\mathrm{OH}$

83. $R^{\prime}=H, 86 \%$ (2 steps)<smiles>[R]c1ccc2ccccc2c1C#C</smiles>

84: $\mathrm{R}=\mathrm{H} \quad$ 76: $\mathrm{R}=\mathrm{OMe}$

$\mathrm{Pd}\left(\mathrm{PPh}_{3}\right)_{2} \mathrm{Cl}_{2}$ or $\mathrm{Pd}\left(\mathrm{PPh}_{3}\right)_{4}$ $\mathrm{Cul}, \mathrm{Et}_{3} \mathrm{~N}$<smiles>[R]c1ccc2ccccc2c1C#Cc1ccccc1C#CC(CC(C)(C)C)c1ccccc1</smiles>

85: $\mathrm{R}=\mathrm{H}, 92 \%$

80: $R=O M e, 94 \%$

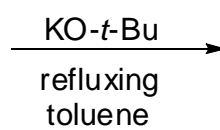

toluene

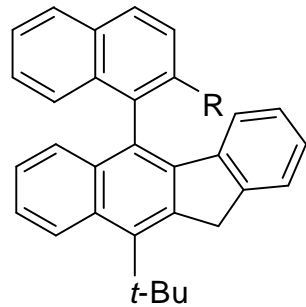

86a: $\mathrm{R}=\mathrm{H}, 69 \%$

86b: $\mathrm{R}=\mathrm{OMe}, 89 \%$

Scheme 17. Revised synthetic route toward 1,1'-binaphthyls $\mathbf{8 6 a}$ and $\mathbf{8 6 b}$. 
The benzannulated enediynes bearing a 1-naphthyl group 85 was also synthesized by using the same synthetic sequence as shown in Scheme 17. It was gratifying to observe that on treatment with potassium t-butoxide, benzannulated enediynes $\mathbf{8 5}$ and $\mathbf{8 0}$ were smoothly converted to 1,1'-binaphthyls $\mathbf{8 6 a}$ and $\mathbf{8 6 \mathbf { b }}$, respectively. The structure of $\mathbf{8 6 \mathbf { b }}$ was established by X-ray structure analysis (Figure 11).
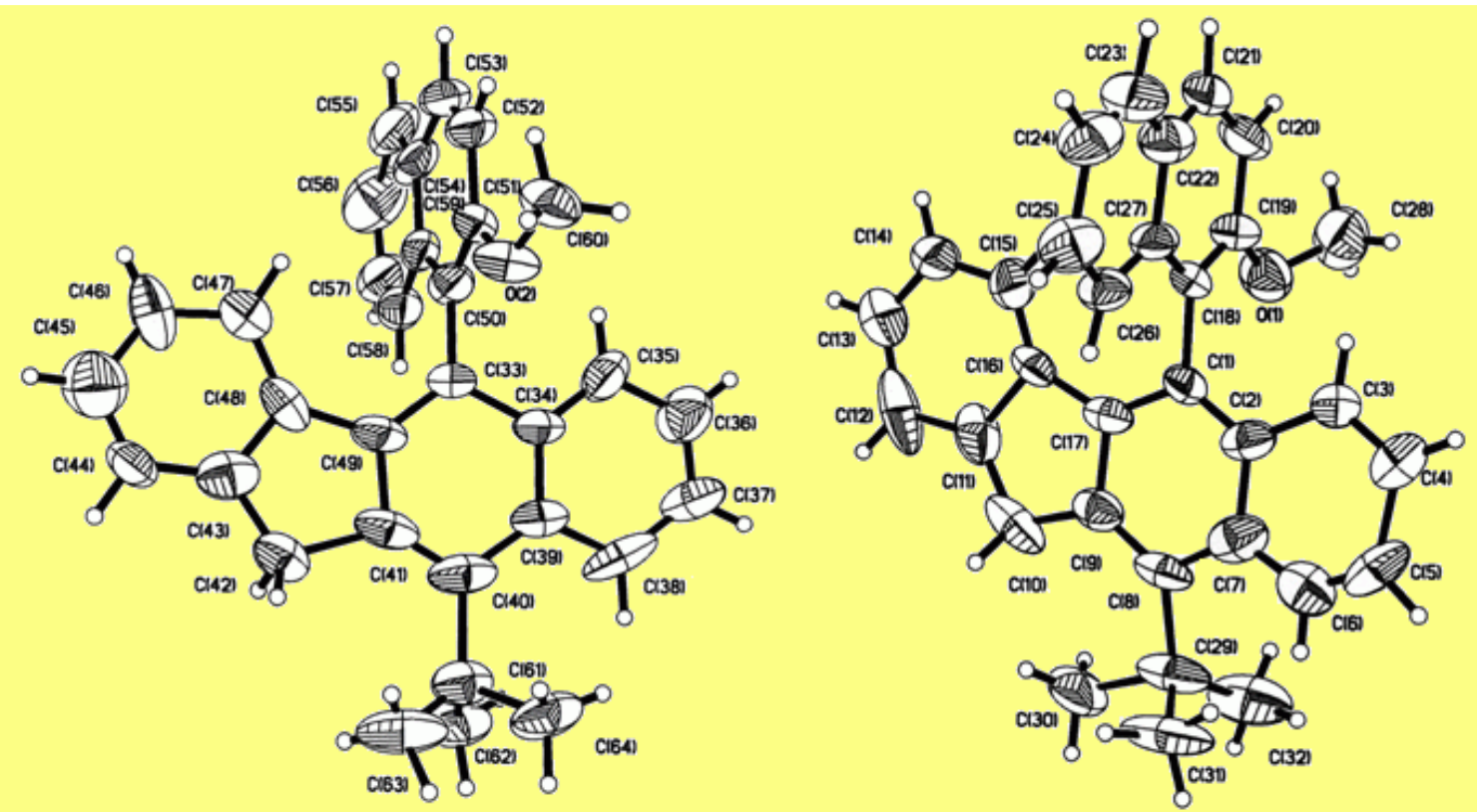

Figure 11. ORTEP Drawings for two molecules in the asymmetric unit of $\mathbf{8 6 \mathbf { b }}$.

\subsubsection{Preparation of Precursor Acetylene 90}

Scheme 18 outlines the synthetic pathway toward the precursor acetylene $\mathbf{9 0}$ bearing a 2-methoxymethyl substituent. The Sonogashira reaction between 1-bromo-naphthalidehyde (87) and trimethylsilylyacetylene furnished 88, which was reduced with $\mathrm{NaBH}_{4}$ to generate the corresponding primary alcohol 89. However, methylation of alcohol $\mathbf{8 9}$ to give the desired acetylene precursor $\mathbf{9 0}$ was unsuccessful. Alternatively, the Sonogashira reaction between $\mathbf{8 9}$ and aryl iodide 65 furnished 91 . Nevertheless, attempts to methylate 91 were unsuccessful. A revised synthetic pathway was made by starting with the methylation of (1-bromonaphthalen-2-yl) 
methanol to give bromide 92, which was converted to the corresponding iodide 93 (Scheme 19). A subsequent Sonogashira reaction with TMS-acetylene led to a 1:1 ratio mixture of the desired product 94 and unexpected byproduct 95, which are inseparable by silica gel chromatography.

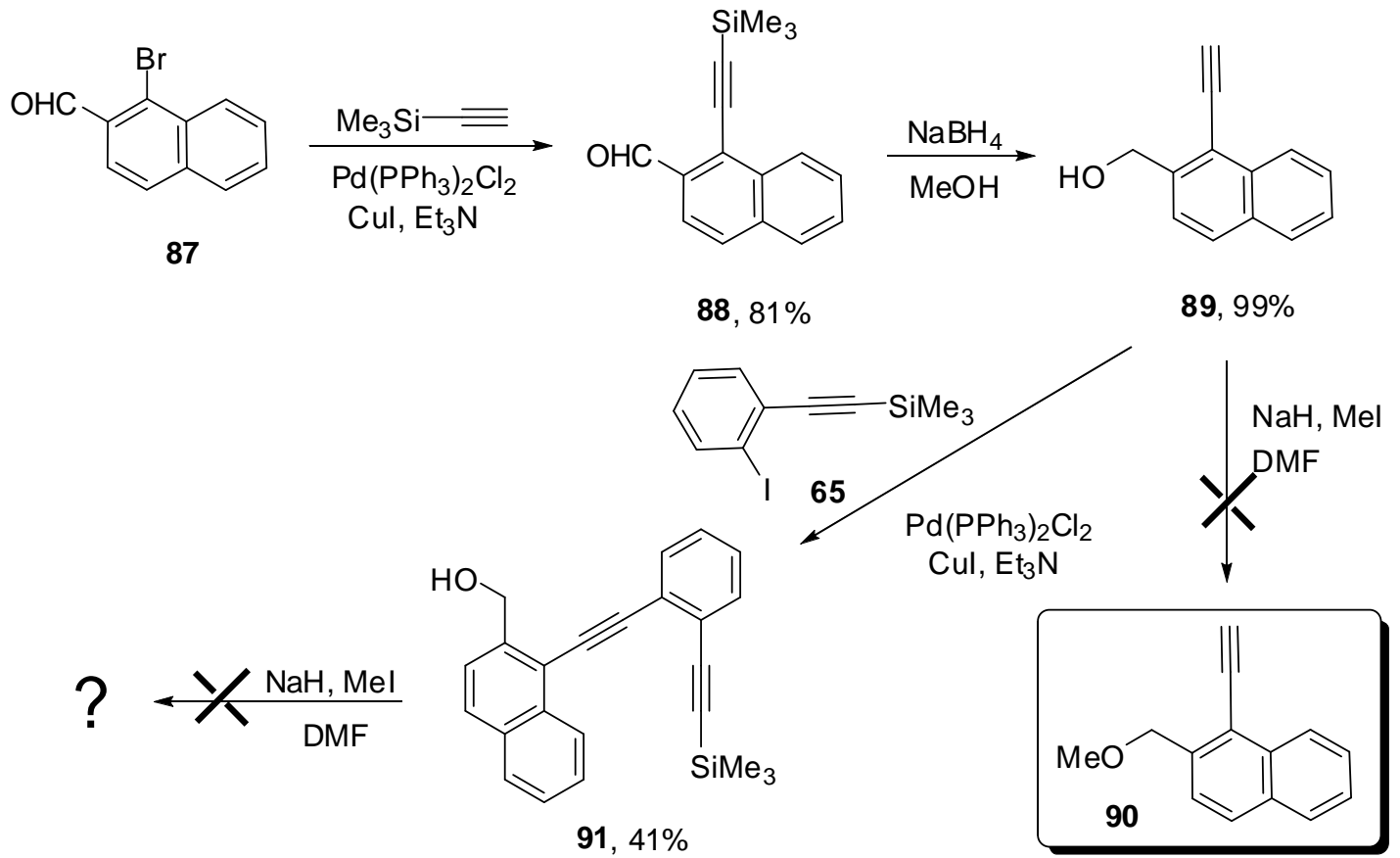

Scheme 18. Attempted synthetic pathway to acetylene $\mathbf{9 0 .}$
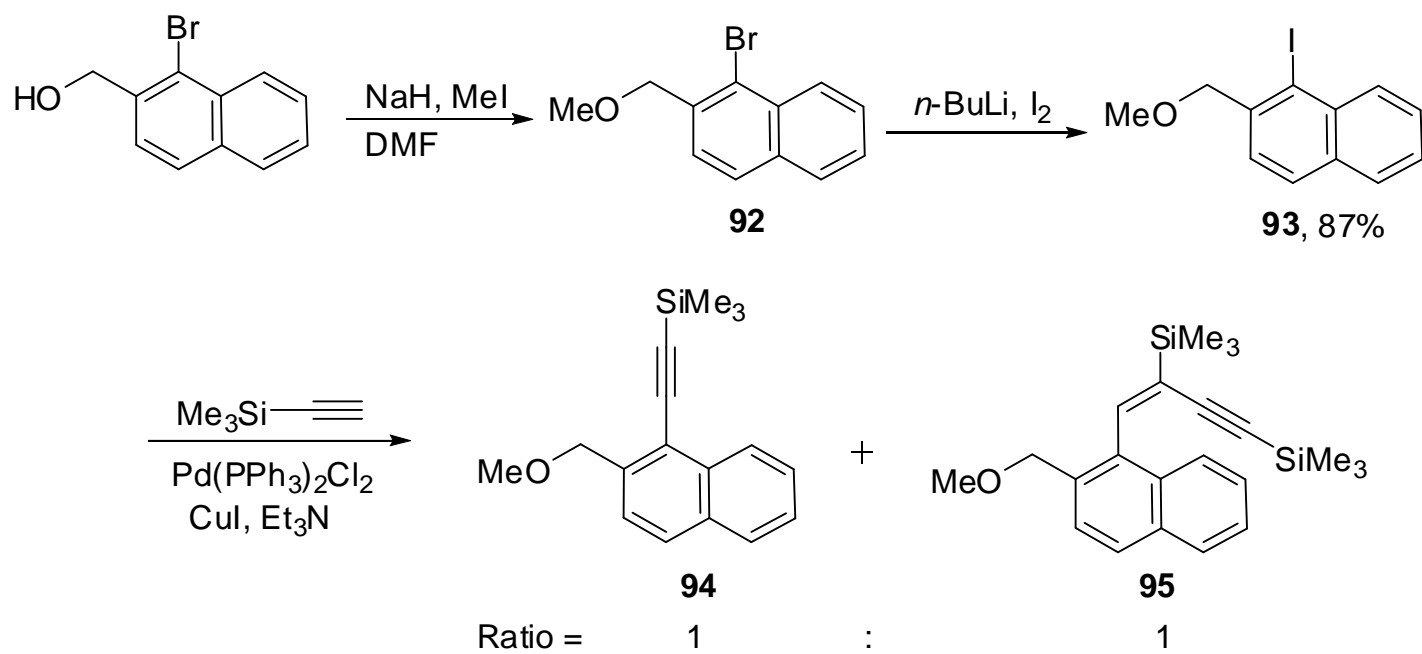

Scheme 19. Attempted synthetic pathway to TMS-acetylene 94. 


\subsubsection{Synthesis of 1,1'-Binaphthyl 86c}
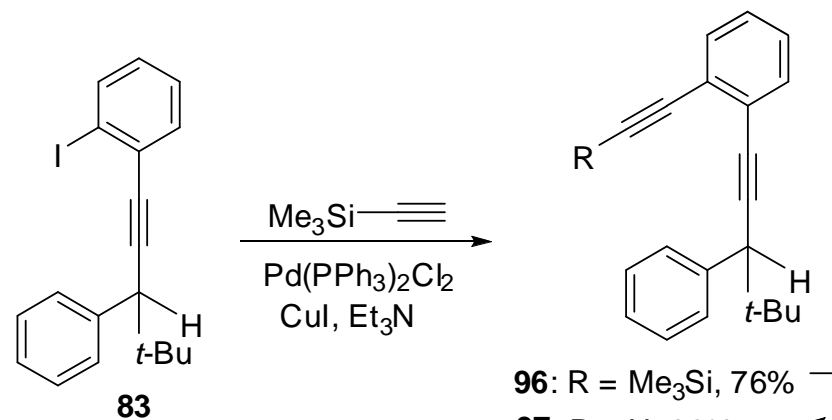

$\left.\begin{array}{l}\text { 96: } \mathrm{R}=\mathrm{Me}_{3} \mathrm{Si}, 76 \% \\ \text { 97: } \mathrm{R}=\mathrm{H}, 99 \%\end{array}\right\} \begin{aligned} & \mathrm{NaOH} \\ & \mathrm{MeOH}\end{aligned}$

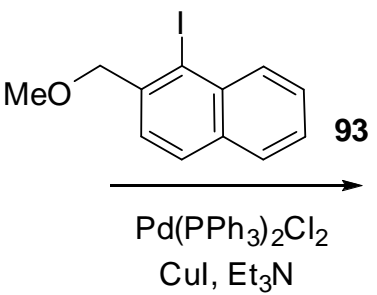

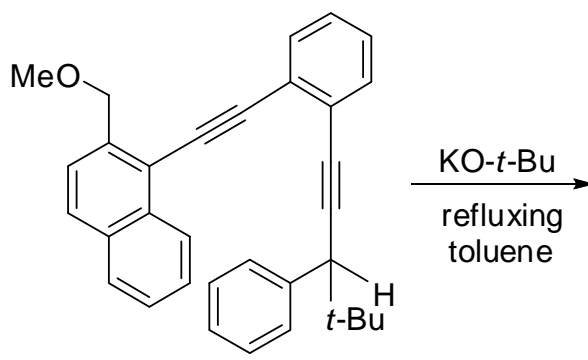

98, $71 \%$

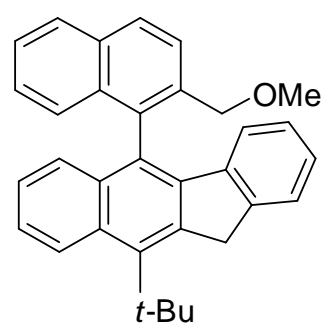

86c, $72 \%$

Scheme 20. Revised synthetic route toward 1,1'-binaphthyl 86c.

Again, with previously prepared iodide $\mathbf{8 3}$ in hand, the synthetic route was revised to conduct the Sonogashira reaction first with TMS-acetylene, followed by desilylation to give $\mathbf{9 7}$ (Scheme 20). The Sonogashira reaction between $\mathbf{9 7}$ and iodide $\mathbf{9 3}$ then afforded benzannulated enediyne 98, which on exposure to the potassium t-butoxide in refluxing toluene was successfully converted to $1,1^{\prime}$-binaphthyl 86c. It is worth noting that the synthetic sequences outlined in Schemes 17 and 20 represent new routes to 2,2'-disubstituted 1,1'-binaphthyls with the benzofluorenyl moiety newly constructed along the reaction pathways serving as one of the naphthyl groups.

\subsection{NMR Studies of 1-Arylnaphthyl Derivatives and 1,1'-Binaphthyls}

The ${ }^{1} \mathrm{H}$ NMR spectrum of $73 \mathbf{a}$ in $\mathrm{C}_{6} \mathrm{D}_{6}$ recorded on a $600 \mathrm{MHz}$ NMR spectrometer exhibited a set of AB quartet signals at $\delta 4.21(J=21.0 \mathrm{~Hz})$ and $4.13(\mathrm{~J}=21.0 \mathrm{~Hz})$, attributable to the methylene hydrogens on the five-membered ring (Figure 12). The AB quartet signals from 
the methylene hydrogens were also observed in other similar $11 H$-benzo[b]fluorenyl structures. ${ }^{7 \mathrm{a}}$ 8d,e,g The $A B$ pattern remained unchanged at $70{ }^{\circ} \mathrm{C}$, suggesting a relatively slow rotation, on the NMR time scale, around the carbon-carbon single bond connecting the 2-methoxyphenyl substituent to the C5 of the benzofluorenyl moiety.
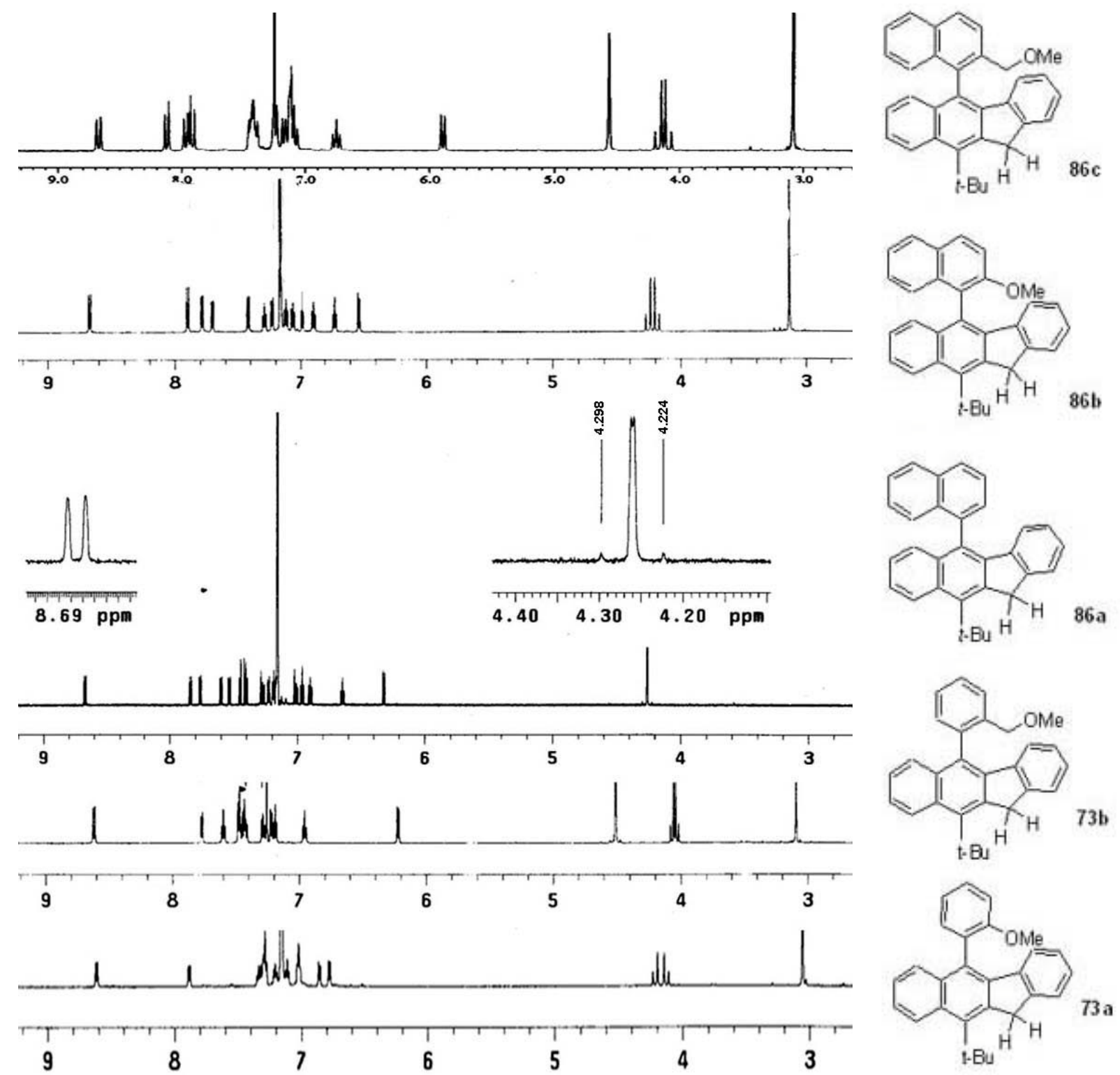

Figure 12. AB patterns of 73a,b, and $\mathbf{8 6 a}, \mathbf{b}, \mathbf{c}$ shown on the ${ }^{1} \mathrm{H}$ NMR spectra.

The rotational barrier is calculated to be at least $16.7 \mathrm{kcal} / \mathrm{mol}$ at $70{ }^{\circ} \mathrm{C}$ on the basis of the lack of coalescence of signals at this temperature. This lowest possible rotational barrier is 
significantly higher than that of 1-phenylnaphthalene, which was calculated by MM2' to be 12.4 $\mathrm{kcal} / \mathrm{mol} .{ }^{30}$ Similarly, the ${ }^{1} \mathrm{H}$ NMR spectrum of $73 \mathbf{b}$ taken in $\mathrm{CDCl}_{3}$ showed a clear set of $\mathrm{AB}$ quartet signals at $\delta 4.07(J=13.8 \mathrm{~Hz})$ and $4.04(J=13.8 \mathrm{~Hz})$, attributable to the methylene hydrogens on the carbon attached with the methoxyl group. The signals of the methylene hydrogens on the five-membered ring could barely be discerned as $A B$ quartets with the two inner signals overlapped at $\delta 4.51$ and two small outer signals appeared at $\delta 4.55$ and 4.47.

The rotational barrier of the parent 1,1'-binaphthyl in dimethylformamide was determined to be $23.5 \mathrm{kcal} / \mathrm{mol}$ at $50{ }^{\circ} \mathrm{C}$, corresponding to a half-life of 14.5 minutes for racemization. ${ }^{31}$ Because of the structure of $\mathbf{8 6 a}$ could be regarded as a 2,3,4-trisubstituted 1,1'-binaphthyl, the rate of rotation can be expected to be even slower. Again, in $\mathrm{C}_{6} \mathrm{D}_{6}$ recorded on a $600 \mathrm{MHz} \mathrm{NMR}$ spectrometer, the signals of the methylene hydrogens on the five-membered ring could be discerned as AB quartets at $\delta 4.27(J=21 \mathrm{~Hz})$ and $4.25(J=21 \mathrm{~Hz})$.

The rotational barrier of BINOL as a member of the 2,2'-disubstituted 1,1'-binaphthyls was determined to be $37.2 \mathrm{kcal} / \mathrm{mol}$ at $195{ }^{\circ} \mathrm{C}$ in naphthalene, corresponding to a half-life of 4.5 hours for racemization. ${ }^{31 b}$ The high stability of the configuration even at such an elevated temperature allows BINOL to be used in a variety of synthetic applications. The configurational stability of $\mathbf{8 6 \mathbf { b }}$ and $\mathbf{8 6 \mathbf { c }}$, which could be regarded as $2,2^{\prime}$-disubstituted $1,1^{\prime}$-binaphthyls with two additional substituents at the 3 and 4 positions, could also be expected to be high. The AB quartet signals were observed for the methylene hydrogens on the five-membered ring of $\mathbf{8 6 \mathbf { b }}$ and on the carbon bearing the methoxyl group of $\mathbf{8 6 c}$.

\subsection{Resolution of 1,1'-Binaphthyl 86b}

Treatment of $\mathbf{8 6} \mathbf{b}$ with boron tribromide converted the methoxyl group to the hydroxyl group, providing a handle for resolution of 62 with (1S)-(-)-camphanoyl chloride (Scheme 21). ${ }^{32}$ It was possible to achieve partial separation of a small fraction of the two diastereomeric 
(1S)-camphanates with a 5:1 ratio by silica gel column chromatography shown on the ${ }^{1} \mathrm{H}$ NMR spectrum (Figure 13). From ${ }^{1} \mathrm{H}$ NMR spectrum, there are clear sets of AB quartets indicating the two methylene hydrogens on the five-membered ring with the ratio of 5:1. Attempts to separate the resulting diastereomers by using (1S)-(+)-10-camphorsulfonyl chloride or Mosher's reagent were unsuccessful.<smiles>COc1ccc2ccccc2c1-c1c2c(c(C(C)(C)C)c3ccccc13)Cc1ccccc1-2</smiles>

86b
$\stackrel{\mathrm{BBr}_{3}}{\longrightarrow}$<smiles>CC(C)(C)c1c2c(c(-c3c(O)ccc4ccccc34)c3ccccc13)Cc1ccccc1-2</smiles>

$62,76 \%$

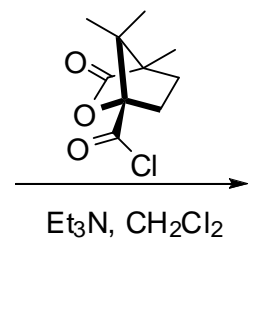

Scheme 21. Resolution of 1,1'-binaphthyl $86 \mathbf{b}$.

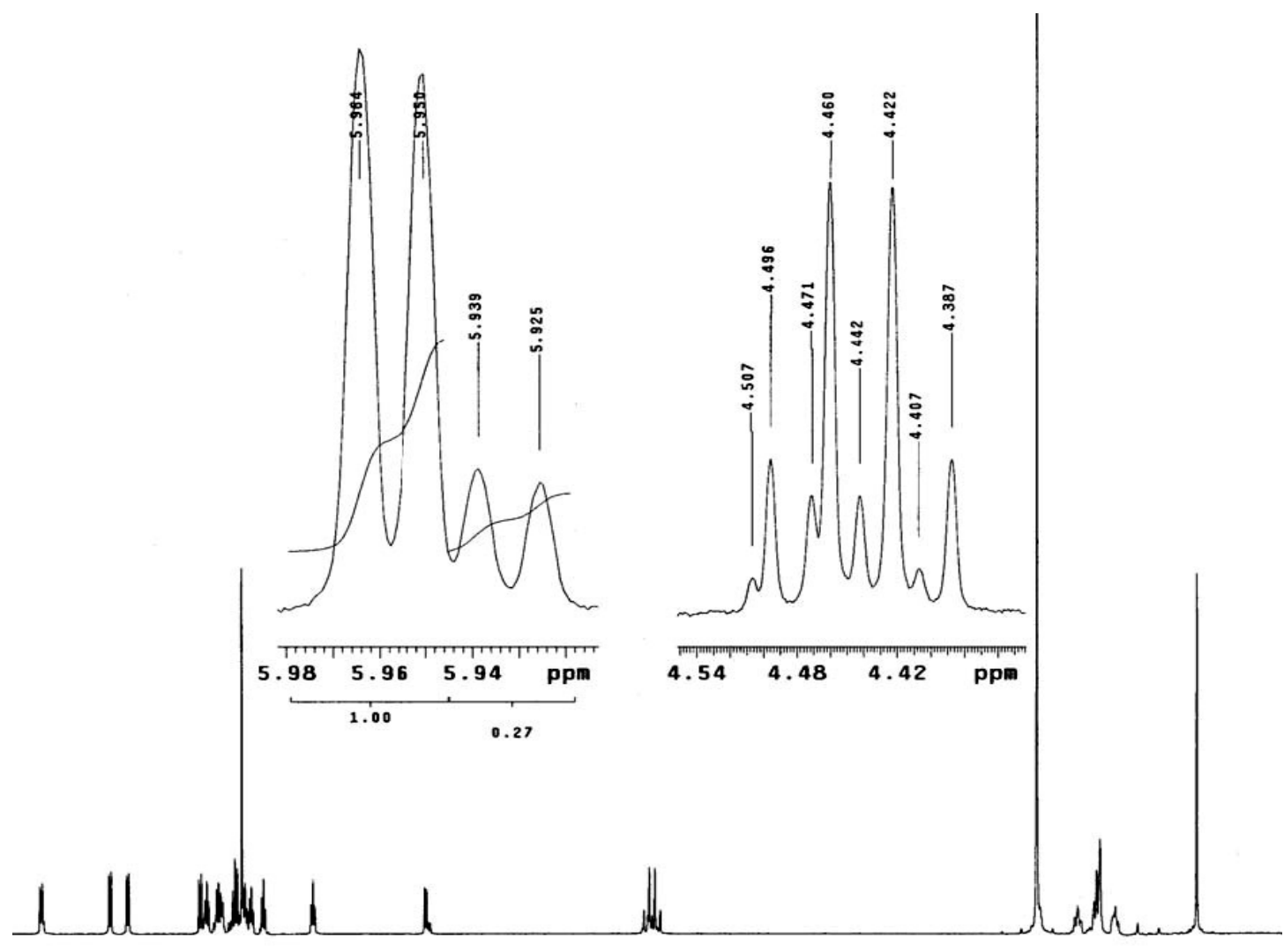

Figure 13. ${ }^{1} \mathrm{H}-\mathrm{NMR}$ spectrum of partially separated (1S)-camphanates 99. 
The resolution was optimized by Cui Hu of our group by converting the methylene hydrogens to the corresponding primary alcohol to afford a 1:1 ratio mixture of the syn and anti isomers 100 (Scheme 22). Treatment of syn-diol 100 with (1S)-(+)-10-camphorsulfonyl chloride gave syn 100-camphorsulfonate 101, which can be separated by silica gel chromatography and found to be of high diastereomeric purity ( $>99 \%$ de) in its ${ }^{1} \mathrm{H}$ NMR spectrum.<smiles>CC(C)(C)c1c2c(c(-c3c(O)ccc4ccccc34)c3ccccc13)-c1ccccc1C2</smiles><smiles>CC(C)(C)c1c2c(c(-c3c(O)ccc4ccccc34)c3ccccc13)-c1ccccc1C2CO</smiles>

100 syn $\underset{\text { 2. } \text { pDA }}{\stackrel{\text { paraformaldehyde }}{\longrightarrow}}$

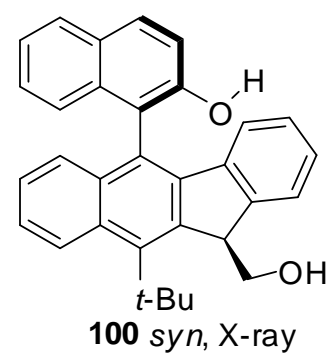

ratio $=$
100 syn, X-ray

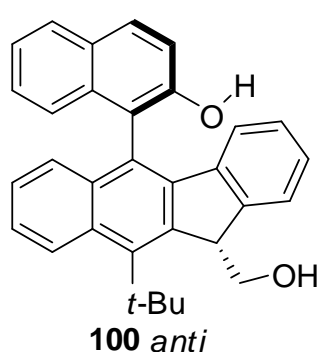

1
(1S)-(+)-10-Camphorsulfonyl chloride 4-DMAP, $\mathrm{CH}_{2} \mathrm{Cl}_{2}$

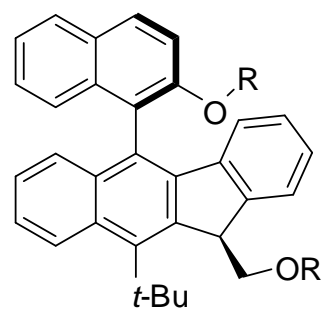

$101,95 \%,>99 \%$ de

Scheme 22. Optimized synthetic route for the resolution of 62.

\section{Conclusions}

In conclusion, the use of benzannulated enediynes as precursors of 2,2'-disubstituted 1,1'-binaphthyls represents a new synthetic approach to these sterically hindered molecules. The assembly of the enediynyl precursors from three separate aromatic fragments allows the possibility of placing a variety of functional groups at various positions of the $1,1^{\prime}$-binaphthyl system. Transformation of the methoxyl group in $\mathbf{8 6 \mathbf { b }}$ to a hydroxyl group provides a handle for resolution with optically active reagents. 


\section{CHAPTER III}

\section{Synthesis of a Novel Bowl-Shaped Polycyclic Aromatic Hydrocarbon Having a 54-Carbon Framework Represented on the Surface of $\mathbf{C}_{60}$}

\section{Introduction}

The discovery and continuous investigation of buckminsterfullerene $\left(\mathrm{C}_{60}\right),{ }^{33}$ also called “buckyball”, has aroused considerable interest in bowl-shaped polycyclic aromatic hydrocarbons (PAHs) and stimulated the development of new synthetic designs for their preparation over the last two decades. In 1996, Kroto, Curl, and Smalley, were awarded the Nobel Prize in chemistry by discovering the first closed geodesic polyarene $\mathrm{C}_{60} .{ }^{34}$ Open geodesic bowl-shaped PAHs, referred to as "buckybowls" or "fullerene fragments", comprise five- and six-membered rings, which can be mapped onto the surface of $\mathrm{C}_{60}$. Several examples of these curved hydrocarbons, such as corannulene $102\left(\mathrm{C}_{20} \mathrm{H}_{10}\right),{ }^{35}$ sumanene $103\left(\mathrm{C}_{21} \mathrm{H}_{12}\right),{ }^{36}$ hemibuckminsterfullerene 104 $\left(\mathrm{C}_{30} \mathrm{H}_{12}\right),{ }^{37}$ circumtrindene $105\left(\mathrm{C}_{36} \mathrm{H}_{12}\right)^{38}$ and indeno[bc]-circumtrindene $\left(\mathrm{C}_{42} \mathrm{H}_{14}\right)^{39}$ have been accessed and characterized by either conventional organic techniques ${ }^{40}$ or using efficient flash vacuum pyrolysis (FVP) ${ }^{41}$ (Figure 14). PAHs 105 and 106 which represent 60 and $70 \%$ of the $\mathrm{C}_{60}$ are the largest fullerene fragments synthesized up until 2006.

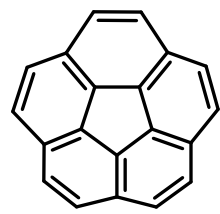

Corannulene $\mathrm{C}_{20} \mathrm{H}_{10}(102)$

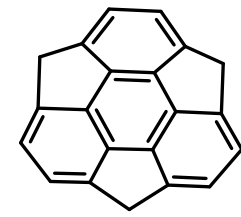

$\mathrm{C}_{21} \mathrm{H}_{12}(103)$

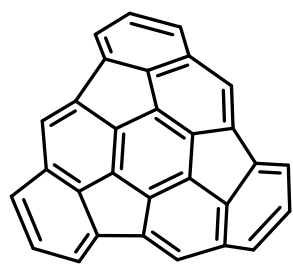

$\mathrm{C}_{30} \mathrm{H}_{12}$ (104)

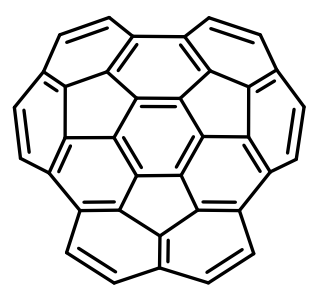

$\mathrm{C}_{36} \mathrm{H}_{12}(105)$

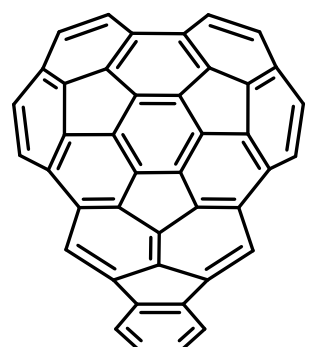

$\mathrm{C}_{42} \mathrm{H}_{14}$ (106)

Figure 14. Representative examples of buckybowls. 
In 2007, Scott et al. reported the syntheses of indenocorannulenes 107 and 108, the largest curved subunits of $C_{60}$ with curvatures surpassing that of $C_{60}$ (Figure 15). This achievement demonstrates unequivocally that rational synthetic method toward bowl-shaped PAHs by exclusively solution chemical methods is accessible and high-temperature vacuum pyrolysis method is no longer necessary. ${ }^{42}$
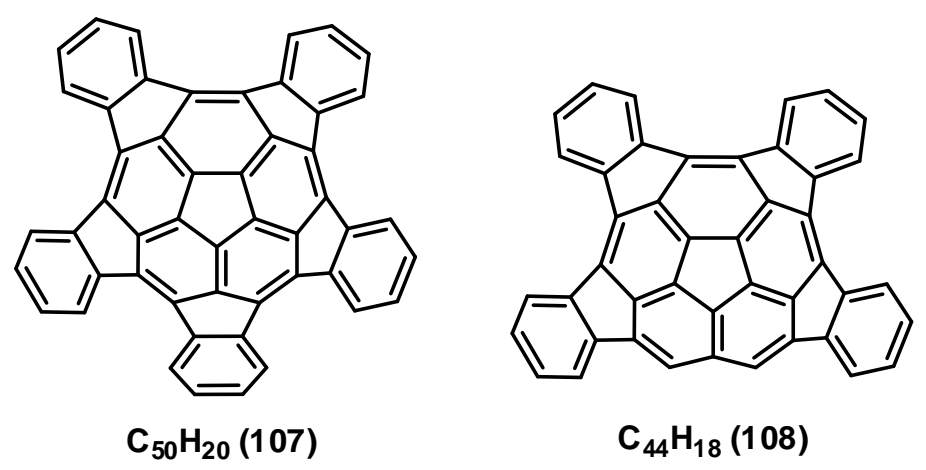

Figure 15. The largest buckybowls.

These bowl-shaped PAHs can serve as potential precursors of buckyball and related carbon cages. The most intriguing property of buckybowls is its electron-holding capability, which could further facilitate the invention of plastic batteries. ${ }^{43}$ For example, corannulene has the ability to accommodate up to four electrons to form a tetraanions. In addition, the outside (convex or exo) and the inside (concave or endo) unsaturated carbon surfaces could exhibit different physical and chemical properties. The more readily accessible concave surface of buckybowls provide opportunity for metal binding to mimic the endohedral chemistry of the spherical cluster. ${ }^{44}$ Also, they have rim or edge carbon atoms capped by hydrogen atoms for coordination, allowing buckybowls to possess multi-site coordination possibilities and preferences for metal binding. These appealing features of buckybowls could open new routes toward synthesis of fullerenes or nanotube inclusion complexes, ${ }^{45}$ which are of great interest for future applications such as drug delivery, ${ }^{46}$ molecular container, medical imaging, ${ }^{47}$ sieving 
systems and catalysis. ${ }^{48}$

Because buckybowls hold many promising potentials for applications in a variety of areas, it has attracted the attention of many researchers in trying to develop new synthetic pathways toward these bowl-shaped polycyclic hydrocarbons. The first synthesis of corannulene, the smallest subunit of buckybowl on the surface of $\mathrm{C}_{60}$, was reported by Barth and Lawton in 1966. ${ }^{35 a}$ Their 16-step synthesis was a remarkable achievement which demonstrated the feasibility of synthesizing such bowl-shaped PAHs by non-pyrolytic pathways. ${ }^{35 b}$ Twenty five years later in 1991, the flash vacuum pyrolysis (FVP) ${ }^{35 g}$ as a new strategy for the synthesis of corannulene was reported. The process required only three steps for the synthesis of corannulene and provided a more direct access toward many other bowl-shaped PAH targets that were previously considered difficult to prepare by other methods. However, under the high-temperature (1000 ${ }^{\circ} \mathrm{C}$ or higher) conditions, the buckybowl precursors with more delicate structures may not survive. As a consequence, recent efforts have turned toward the development of practical, non-pyrolytic and milder synthetic methods for the construction of buckybowls in order to realize the full potential of this emerging new field.

\section{Research Objective}

As a part of our continuing efforts toward the synthesis of polycyclic hydrocarbons via Schmittel cyclization reaction of enyne-allenes, we envisioned that this biradical cascade reaction pathway could lead to a variety of polycyclic aromatics as potential buckybowl precursors. Dr. Yonghong Yang of our research group reported the use of thionyl chloride to promote Schmittel cyclization of diol $\mathbf{1 4}$ having two benzannulated enyne-allene units. ${ }^{8 a}$ It was assumed that the Schmittel cyclization reaction of $\mathbf{1 4}$ would give the desired polycyclic hydrocarbon 109, which has a 52-carbon framework represented on the surface of $\mathrm{C}_{60}$ (Scheme 23) and may eventually lead to the formation of a bowl-shaped polycyclic aromatic hydrocarbon. 
Unexpectedly, the cleavage of the central benzene ring occurred during the cyclization sequence to give the highly twisted 1,1'-dialkyl-9,9'-bifluorenylidene 15.

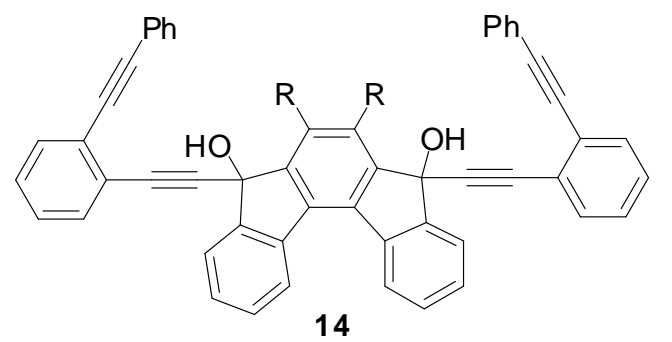

14

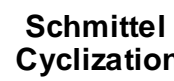

Cyclization

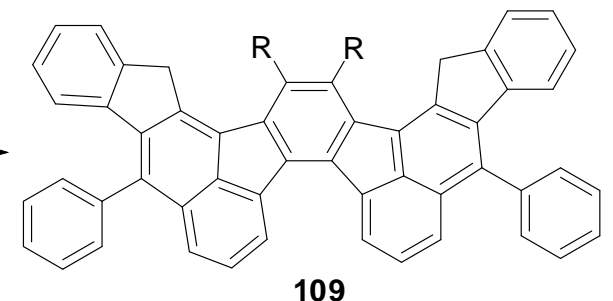

109
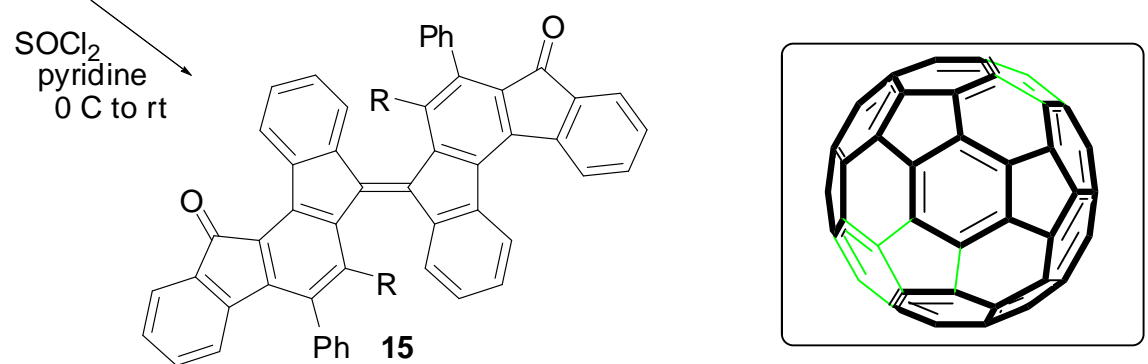

mapping 109 onto $\mathrm{C}_{60}$

Scheme 23. Schmittel cyclization of diol 14.

We envisioned an alternative approach to buckybowls by incorporating $\mathrm{sp}^{3}$-hybridized carbons in the precursors (Figure 16). There are several potential advantages of such an approach. The presence of $\mathrm{sp}^{3}$-hybridized carbons could greatly relieve the strain of buckybowl structures. They would also allow the intramolecular carbon-carbon formation more feasible. These $\mathrm{sp}^{3}$-hybridized carbons could permit attaching additional functional groups onto the carbon frameworks of buckybowls.

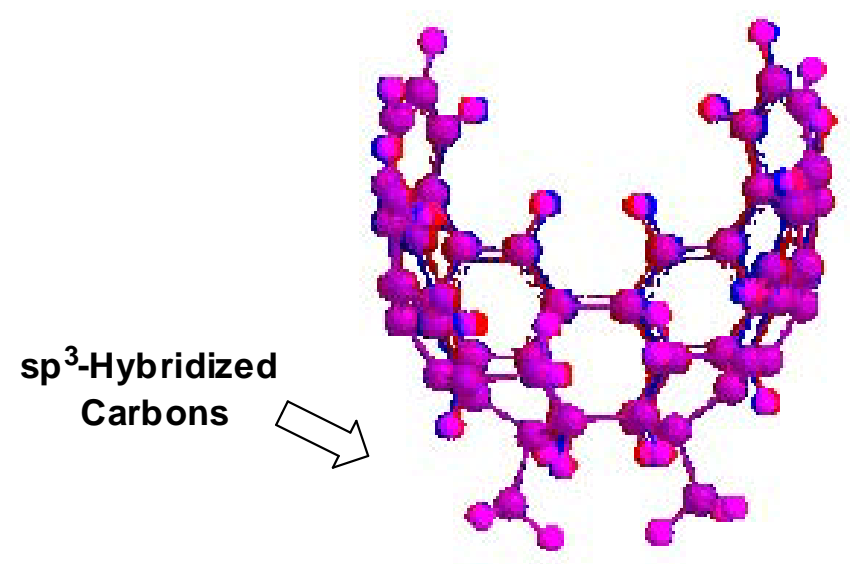

Figure 16. A buckybowl containing $\mathrm{sp}^{3}$-carbons. 


\section{Literature Survey of Synthesis of Buckybowls, Coordination Chemistry of Buckybowls and Fluorenyl Ligands and Molecular Tweezers}

\subsection{Synthesis of Buckybowls}

The synthesis of fullerene $\mathrm{C}_{60}$ by rational or controlled means has been a challenge for organic chemists since 1985 . The considerable attention given to $\mathrm{C}_{60}$ has led to renewed interest in the bowl-shaped polycyclic aromatic hydrocarbons. The first synthesis of the smallest buckybowl, corannulene, was achieved by Barth and Lawton in 1966 by using classic functional group transformations and catalytic dehydration. ${ }^{35 a, b}$ Twenty five years later, a new synthesis of corannulene by flash vacuum pyrolysis (FVP) was reported by Scott et al. ${ }^{35 \mathrm{~g}}$ in 1991 . To date, over two dozen buckybowls have been prepared and developed by either FVP or non-pyrolytic pathway.

\subsubsection{Flash Vacuum Pyrolysis (FVP)}

In 1991, Scott et al. first reported the strategy of employing flat PAHs under thermal condition for $\mathrm{C}-\mathrm{C}$ bond formation at the rim to form curved buckybowls (Scheme 24). Presumably, by proceeding via carbene 111, the starting 110 was converted to corannulene 102 in $10 \%$ yield. The low yield was due to polymerization of diyne $\mathbf{1 1 0}$ under the harsh thermal reaction condition. ${ }^{35 \mathrm{~g}}$

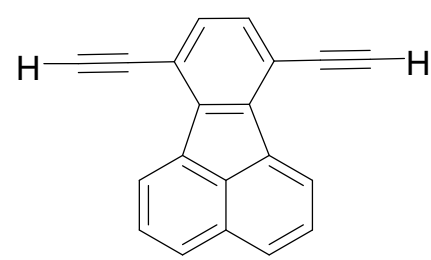

110

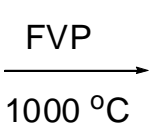

$00^{\circ} \mathrm{C}$

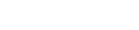

(1)

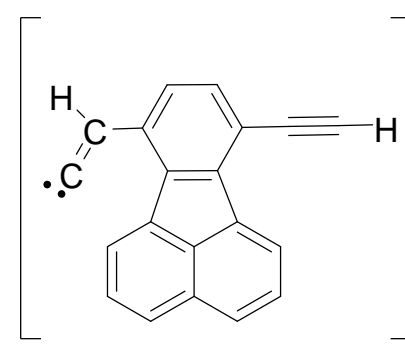

111

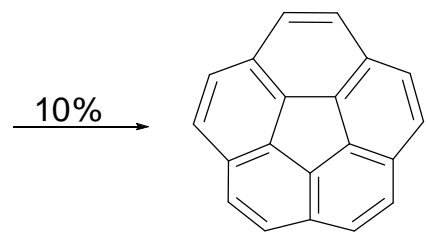

102

Scheme 24. The first FVP synthesis of corannulene. 
By using FVP, various precursors 112-117 were converted to corannulene (Scheme 25). The precursors $1 \mathbf{1 1}^{35 \mathrm{c}}, \mathbf{1 1 4}^{35 \mathrm{j}}$, and $\mathbf{1 1 5}^{35 \mathrm{e}}$ could be regarded as "masked acetylene (110)", which were less prone to polymerization and provide better yields. The key to the success of these strategies is to start with a precursor containing a properly fused central five-membered ring for FVP.

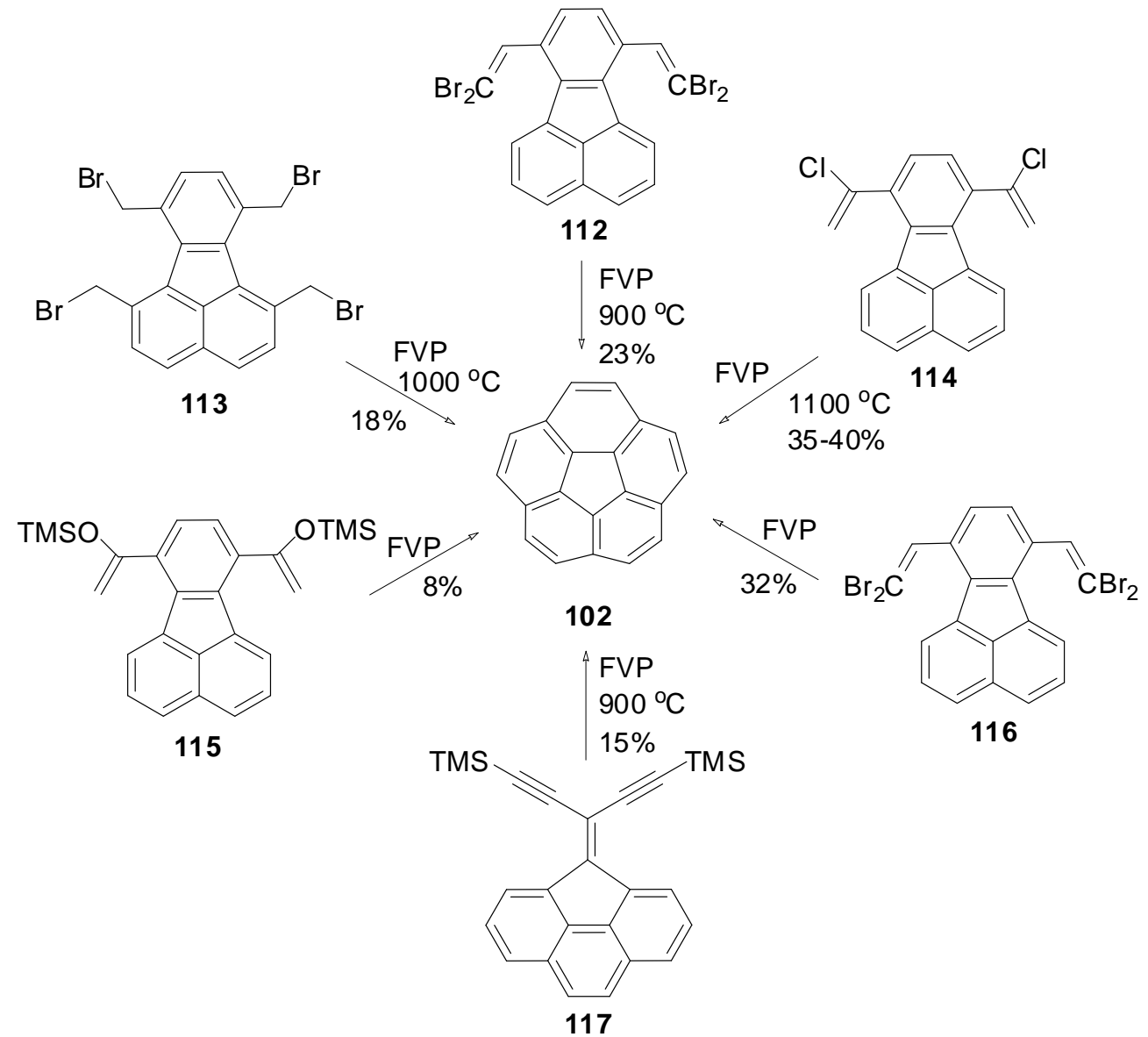

Scheme 25. Various syntheses toward corannulene via FVP.

Some larger fullerene fragments, such as $\mathbf{1 0 5}$ and 106, were obtained by using the FVP method (Scheme 26). The commercially available decacyclene 118a underwent a triple cyclodehydrogenation under FVP at $1200-1300{ }^{\circ} \mathrm{C}$ to give circumtrindene 105 in low yield along with a comparable quantity of byproduct $119 .{ }^{38 a, 40}$ The synthesis of circumtrindene was dramatically improved by starting with precursor trichlrodecacyclene 118b under lower temperature for FVP. ${ }^{39 \mathrm{c}}$ In addition, the open geodesic PAHs can be expanded to contain $70 \%$ of 
$\mathrm{C}_{60}$ by FVP of a 2-bromophenyl-substituted bowl 120, which can be prepared from monobromination of $\mathbf{1 0 5}$ followed by Suzuki-Miyaura coupling to yield an unseparable small amount of 106 together with a large amount of $\mathbf{1 0 5} .^{40}$

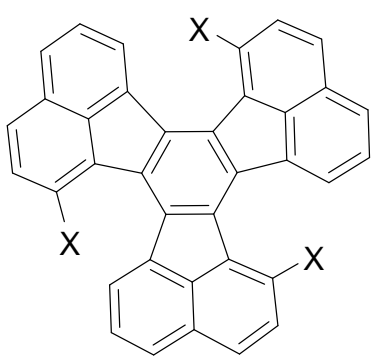

118a: $X=\mathrm{H}$

118b: $\mathrm{X}=\mathrm{Cl}$

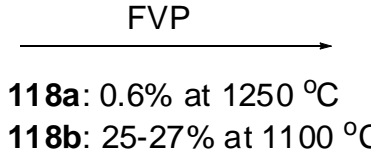

118b: $25-27 \%$ at $1100{ }^{\circ} \mathrm{C}$

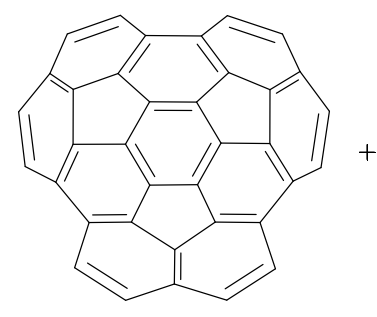

$\mathrm{C}_{36} \mathrm{H}_{12}$ (105)

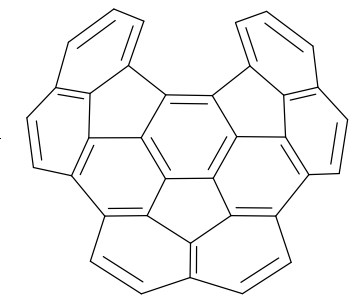

119
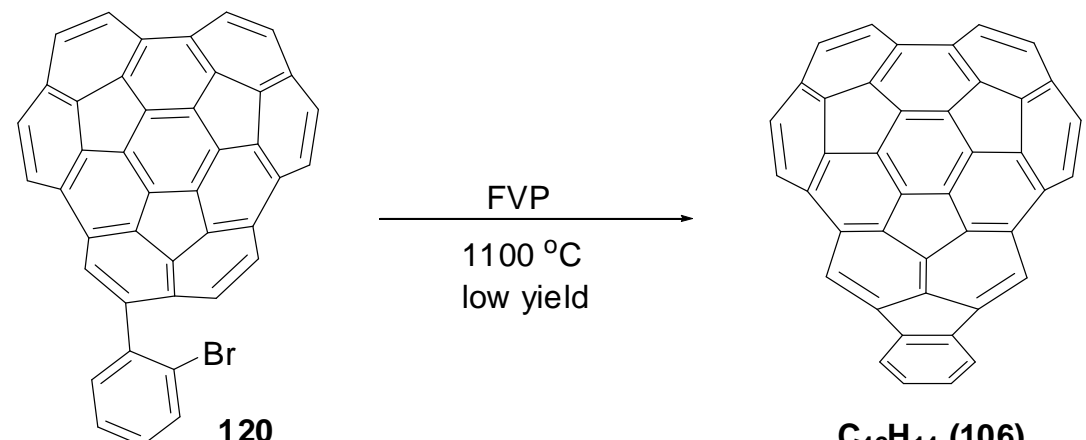

$\mathrm{C}_{42} \mathrm{H}_{14}(106)$

Scheme 26. Syntheses of larger buckybowls 105 and 106.

The experimental results have shown that the FVP method is a useful and efficient synthetic tool for the construction of buckybowls in moderate to low yields. However, the limitations of the method include low yield, many byproducts, difficulty to scale up, lack of functional group tolerance, and not applicable to nonvolatile systems. ${ }^{49}$

\subsubsection{Non-pyrolytic Pathways}

In 1996, Siegel et al. reported the first non-pyrolytic synthesis of corannulene derivatives by employing the McMurry-type reductive coupling of 122 with $\mathrm{TiCl}_{3} / \mathrm{LiAlH}_{4}$ or $\mathrm{VCl}_{3} / \mathrm{LiAlH}_{4}$ followed by DDQ dehydrogenation to give dimethylcorannulene 123. (Scheme 27). ${ }^{40 a}$ Later on, this methodology was utilized for preparation of several more complex corannulene derivatives by the Siegel and Rabideau's groups. ${ }^{40 \mathrm{~b}-\mathrm{d}}$ 


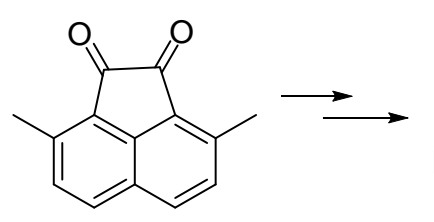

121

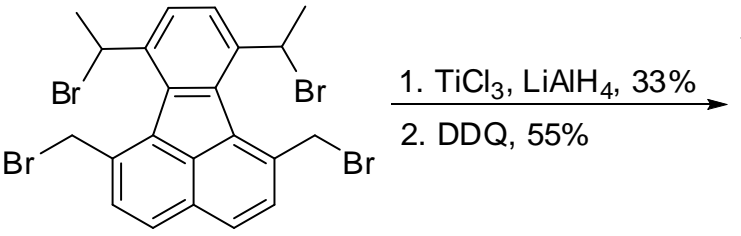

122

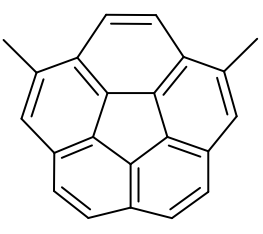

123

Scheme 27. Siegel’s non-pyrolytic approach to dimethylcorannulene 123.

In 2000, Rabideau et al. reported a new non-pyrolytic synthesis of corannulene and its derivatives in a convenient and inexpensive way by simply refluxing $\mathbf{1 2 4}$ under a mild condition in the presence of a small amount of $\mathrm{NaOH}$ in aqueous dioxane (Scheme 28). ${ }^{40 \mathrm{~g}, 50}$

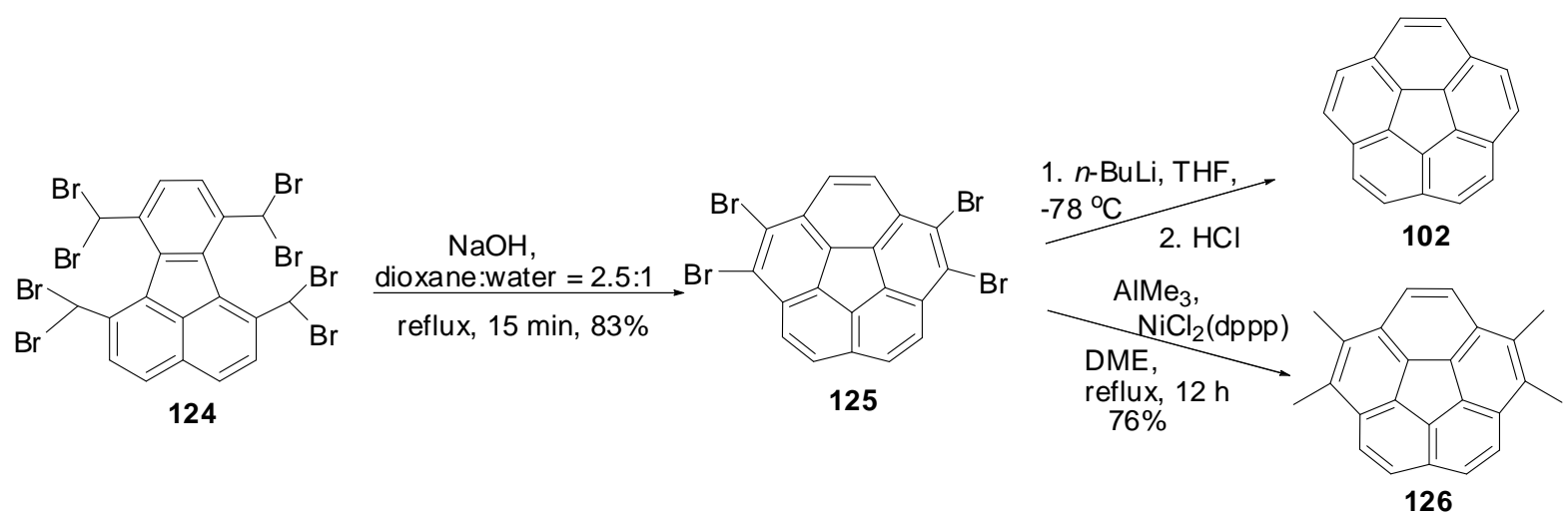

Scheme 28. Rabideau’s approach toward corannulene derivatives 125 and $\mathbf{1 2 6 .}$

Scott et al. also reported a three-step synthesis of dibenzo[a,g]corannulene by employing palladium-catalyzed intramolecular arylation reaction (Scheme 29). ${ }^{40 \mathrm{e}}$ At $150{ }^{\circ} \mathrm{C}$ dibromide 129 was converted to the bowl-shaped PAH 130 in 60\% yield using a suitable palladium catalyst and DBU in DMF for 3 days.<smiles>O=C1C(=O)c2cccc3cccc1c23</smiles>

127

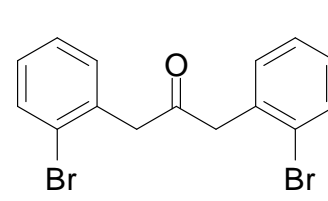

128

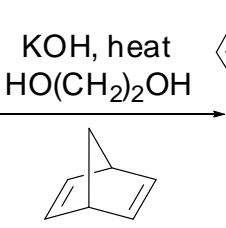

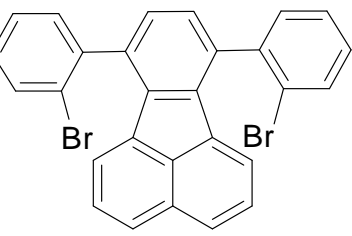

129

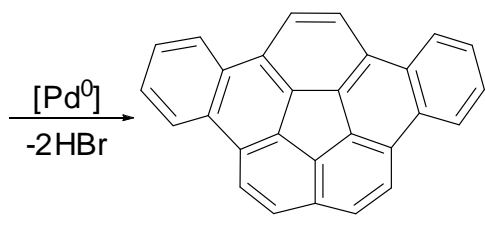

130

Scheme 29. Scott's non-pyrolytic approach to dibenzocorannulene $\mathbf{1 3 0 .}$ 
In 2007, Scott et al. reported the synthesis of the largest fullerene fragment $\left(\mathbf{1 0 7}, \mathrm{C}_{50} \mathrm{H}_{20}\right)$ of $\mathrm{C}_{60}$ via a non-pyrolytic pathway involving a five-fold Suzuki-Miyaura coupling of chlorinated corannulene $\mathbf{1 3 2}$ with 2-chlorophenylboronic acid $\mathbf{1 3 1}$ under the condition reported by Nolan et $a l^{51}$ to give 133 (Scheme 30 ). ${ }^{42}$ By microwave heating, the subsequent palladium-catalyzed intramolecular arylation reactions of $\mathbf{1 3 3}$ furnished pentaindenocorannulene $\mathbf{1 0 7 .}$

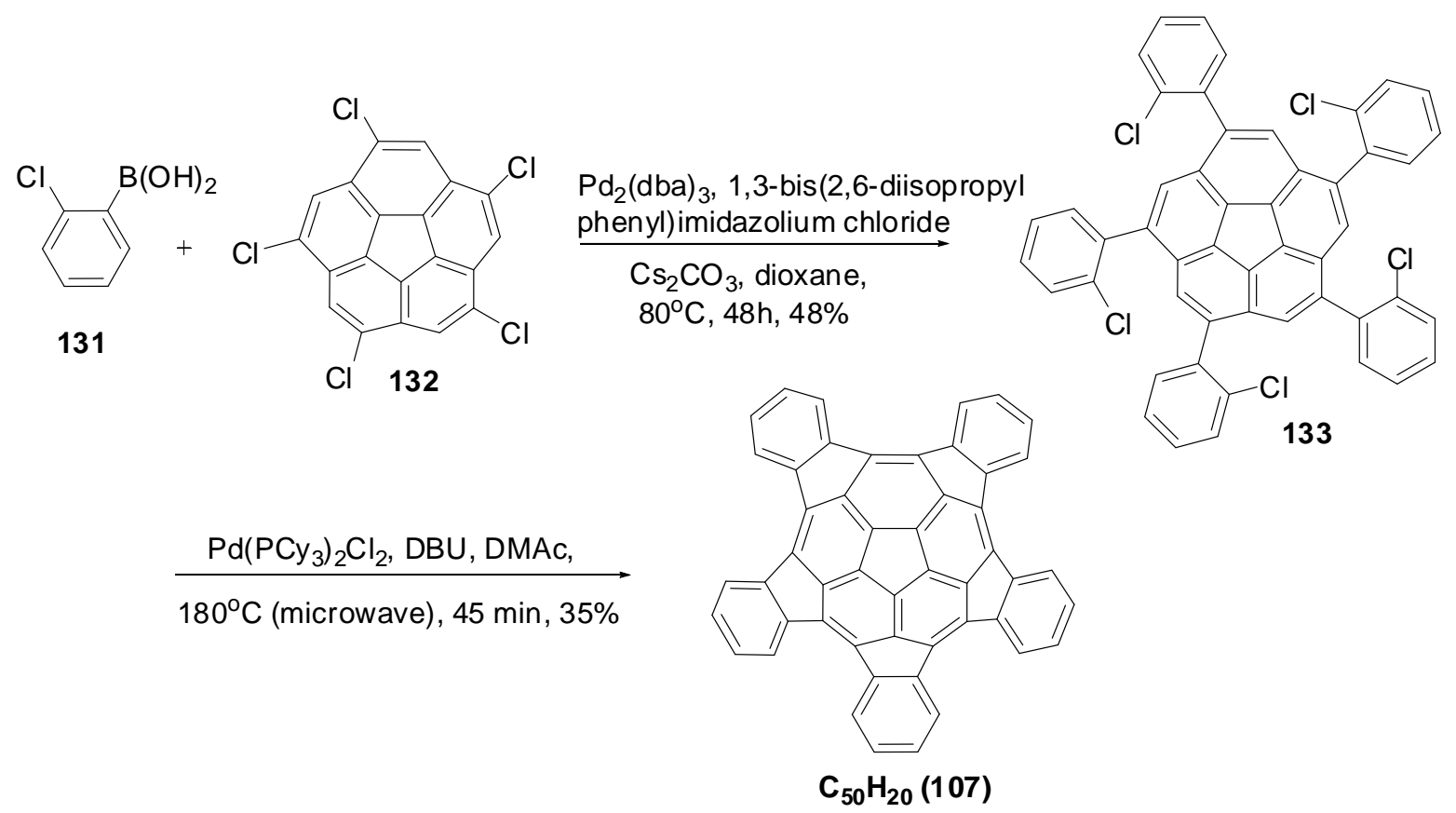

Scheme 30. Scott's non-pyrolytic route to the largest bowckybowl 107.

Most recently, Sakurai et al. reported the first asymmetric synthesis of a chiral buckybowl, (C)-(M)-8,13,18-trimethylsumanene (138), by a non-pyrolytic synthetic pathway (Scheme 31). ${ }^{52}$ The synthetic strategy involved the use of $\mathrm{sp}^{3}$ chiral halonorborene 134, which underwent cyclotrimerization to give syn-benzocyclotrimer 135. A subsequent conversion of carbonyl groups to the methyl olefins was accomplished by cross-coupling with MeMgI of the corresponding alkenyl phosphates to afford 136. Then tandem ring-opening/closing olefin metathesis with a Grubbs catalyst successfully afforded the bowled-shaped structure 137, which 
is chiral. The final key aromatization step was carried out at a low temperature to give chiral buckybowl (C)-138.

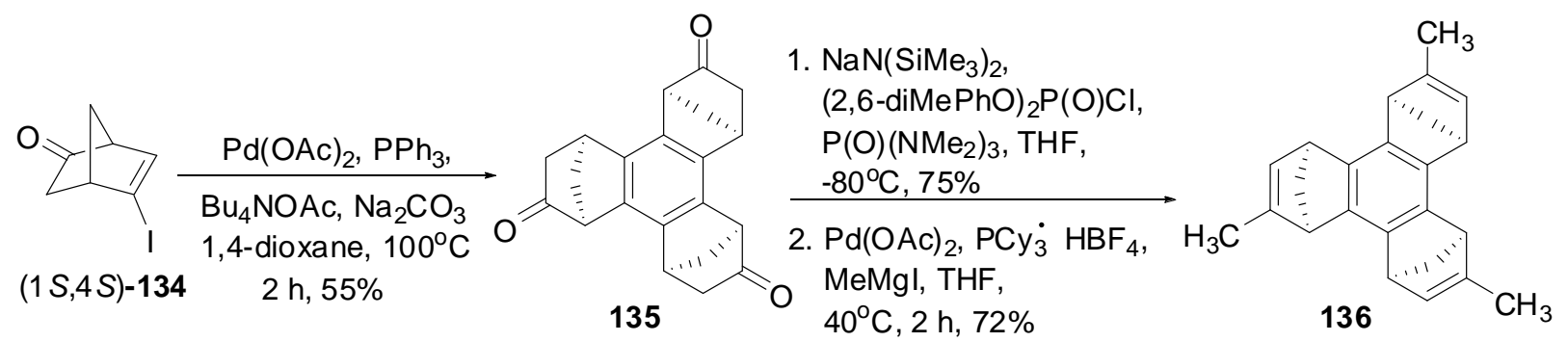

1. Grubbs $1^{\text {st }}$ generation cat. $\mathrm{CH}_{2} \mathrm{Cl}_{2}$, ethylene, $40^{\circ} \mathrm{C}, 4 \mathrm{~h}$

2. Grubbs $2^{\text {nd }}$ generation cat. $\mathrm{CH}_{2} \mathrm{Cl}_{2}, 40^{\circ} \mathrm{C}, 12 \mathrm{~h}$

(24\% two steps)

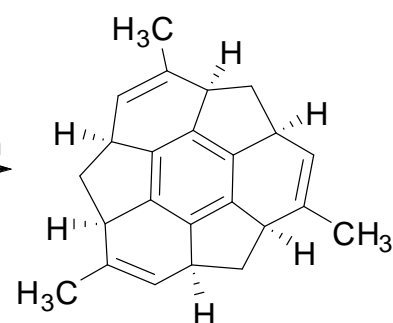

137

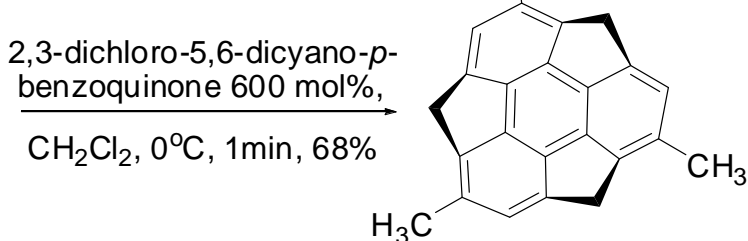

(C) -138

Scheme 31. Sakurai’s asymmetric synthesis of chiral buckybowl 138.

\subsection{Coordination Chemistry of Buckybowls and Fluorenyl Ligands}

Buckybowls with two distinct concave and convex surfaces have attracted substantial attention for the investigation of transition-metal complexes of bowl-shaped polycyclic aromatic hydrocarbons in recent years. ${ }^{53,54}$ Unlike the characterized transition-metal fullerene complexes where $\mathrm{C}_{60}$ serves as an electron-deficient polyalkene and the metal atom is attached in an $\eta^{2}$-fashion to the fused carbon-carbon bond of two six-membered rings, buckybowls having a readily accessible internal surface can give rise to $\pi$ systems with different coordination fashions $\left(\eta^{2} \rightarrow \eta^{6}\right)$ for transition-metal complexes.

In the studies of transition-metal coordination with the smallest buckybowl, corannulene, there are three major types of corannulene complexes observed: one is $\eta^{2}$-coordinated; the other is $\eta^{6}$-coordinated metal; ${ }^{54}$ another is where the metal $\sigma$-bonded to the rim carbon atom. The first $\eta^{6}$-coordinated transition metal complex of corannulene, $\left[\mathrm{Cp} * \mathrm{Ru}\left(\eta^{6}-\mathrm{C}_{20} \mathrm{H}_{10}\right)\right]\left(\mathrm{O}_{3} \mathrm{SCF}_{3}\right)$ was 
reported by Seiders et al. in $1997 .^{55}$ Since then, many research groups have reported the synthesis of various $\eta^{6}$-coordinated transition metal complexes, such as $\left[(\mathrm{Cp} * \mathrm{Ru})_{2}\left(\mu_{2}-\eta^{6}: \eta^{6}\right.\right.$ $\left.\left.-\mathrm{C}_{20} \mathrm{H}_{10}\right)\right][\mathrm{X}]_{2}\left(\mathrm{X}=\mathrm{BF}_{4}{ }^{-}, \mathrm{PF}_{6}{ }^{-}\right.$, or $\mathrm{SbF}_{6}{ }^{-56}$ and $\left[\mathrm{Cp} * \operatorname{Ir}\left(\eta^{6}-\mathrm{C}_{20} \mathrm{H}_{10}\right)\right]\left[\mathrm{BF}_{4}\right]_{2}{ }^{57}$ The $\eta^{2}$-coordinated corannulene complexes, such as $\left[\mathrm{Rh}_{2}\left(\mathrm{O}_{2} \mathrm{CCF}_{3}\right)_{4}\right] \cdot\left(\mathrm{C}_{20} \mathrm{H}_{10}\right)$ and $\mathrm{Ru}_{2}\left(\mathrm{O}_{2} \mathrm{CCF}_{3}\right)_{2}(\mathrm{CO})_{4} \bullet\left(\eta^{2}-\mathrm{C}_{20} \mathrm{H}_{10}\right)_{2}$, were prepared and characterized by X-ray structural analyses. ${ }^{58}$ In addition, there are several examples of complexes where a hydrogen of corannulene was replaced by a metal, such as $\left(\eta^{1}-\mathrm{C}_{20} \mathrm{H}_{9}\right) \mathrm{Ni}\left(\mathrm{PEt}_{3}\right)_{2} \mathrm{Br}^{59}$

In addition to the $\pi$-system coordinated corannulene complexes, an interesting was reported by Chin et al. showed that a partially hydrogenated corannulene $\mathbf{1 3 9}^{43 \mathrm{~d}}$ can function as a curved fluorenyl anion analogue with unique curvature as a ligand (Scheme 32). ${ }^{60 a}$ By employing Crabtree's catalyst under 1 atm of hydrogen, $\mathbf{1 3 9}$ was hydrogenated to octahydrocorannulene 140, which was deprotonated with $n$-BuLi followed by treatment with $\mathrm{CpZrCl}_{3}$ to afford complex 141. It is worth noting that the $\mathrm{Zr}-\mathrm{C}$ bond length ranges from 2.46 to $2.60 \AA$, which is about the same as other zirconium fluorenyl complexes. ${ }^{60 b-d}$ Also, the bond angle of $\mathrm{C}_{20} \mathrm{H}_{17}(\mathrm{C})-\mathrm{Zr}-\mathrm{Cp}(\mathrm{C})$ is $128.8^{\circ}$, which is also similar to other reported fluorenyl Cp complexes $\left(129.8-131.2^{\circ}\right)$.

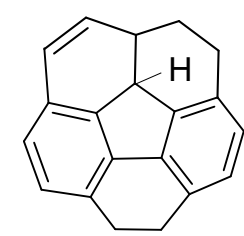

139

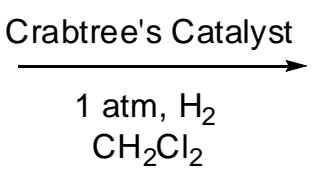

$\mathrm{CH}_{2} \mathrm{Cl}_{2}$

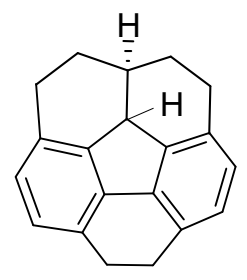

140 $\stackrel{\text { 1. } n-\mathrm{BuLi}, \mathrm{Et}_{2} \mathrm{O}}{\underset{\mathrm{CpZrCl}}{2}}$

$47 \%$

Scheme 32. Chin’s zirconium complex 141 containing a fluorenyl ligand.

\subsection{Molecular Tweezers}

Buckybowls having an open curved $\pi$ interior cavity can be ideal candidates to serve for molecular receptors such as molecular tweezers, ${ }^{61}$ also referred to as "molecular clips" to bind 
the guest molecules by non-covalent bonding including hydrogen bonding, metal coordination, and $\pi-\pi$ interactions. ${ }^{62}$ In 2007, Sygula et al. reported the synthesis of a $\mathrm{C}_{60} \mathrm{H}_{24}$ molecular tweezer 145 possessing double concave corannulene subunits, which can catch a $\mathrm{C}_{60}$ to form a concave-convex $\pi-\pi$ interaction complex in a 1:1 inclusion (Scheme 33). ${ }^{63}$ The complexation was also confirmed by X-ray structural analysis. The study is an excellent example of rich supramolecular chemistry ${ }^{64}$ of buckybowls and related materials (Figure 17).
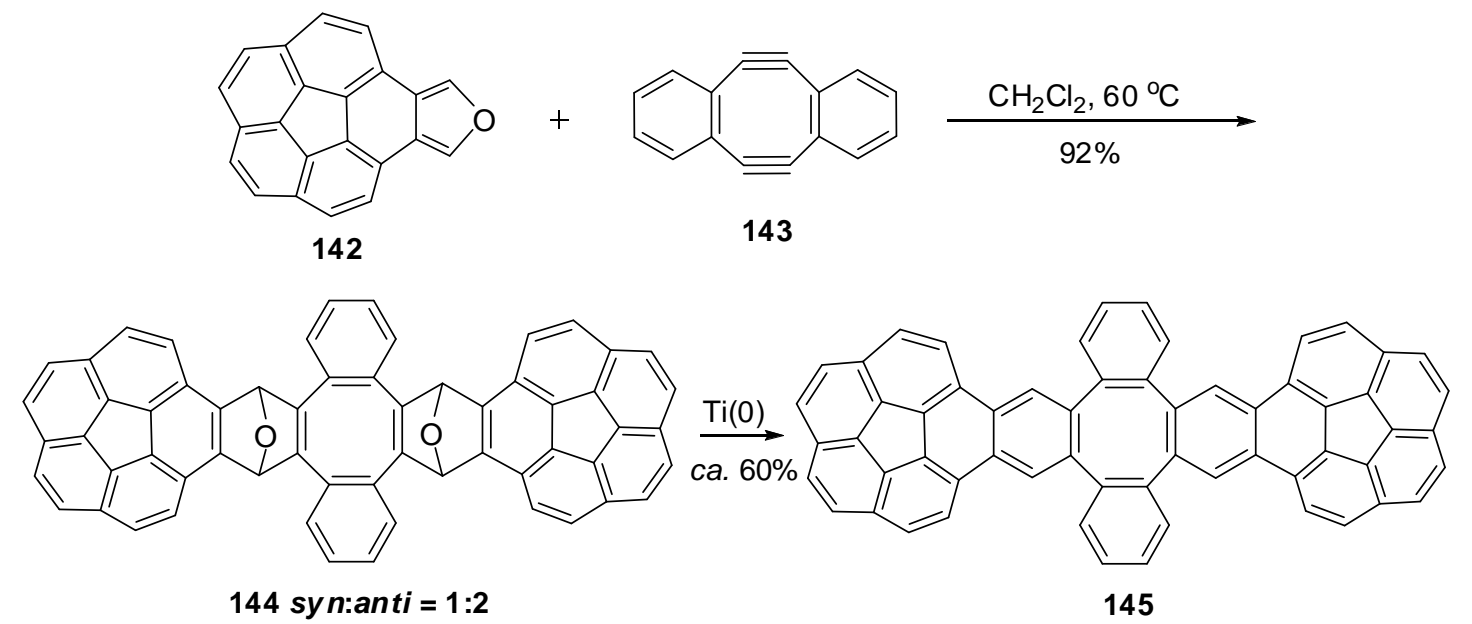

Scheme 33. The synthesis of double concave hydrocarbon buckycatcher 145.

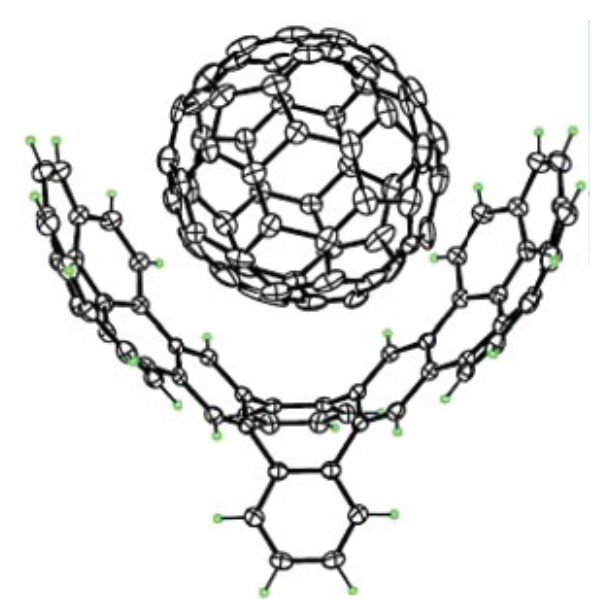

(Sygula et al. J. Am. Chem. Soc. 2007, 129, 3842-3843)

Figure 17. ORTEP X-ray structure of 1:1 inclusion complex of $C_{60}$ and $\mathbf{1 4 5 .}$ 


\section{Results and Discussion}

\subsection{Preparation of Precursor Diketone 150}

Dr. Hua Yang of our group initiated a research project involving the development of new synthetic pathways toward bowl-shaped polycyclic aromatic hydrocarbon with a 54-carbon framework represented on the surface of $\mathrm{C}_{60} \cdot{ }^{65}$ Herein, a continuing investigation with optimized yields and alternative pathways is reported leading to a buckybowl having a 54-carbon framework of $\mathrm{C}_{60}$. The synthetic sequence starts with 2,5-dicarbomethoxy-3,4diphenylcyclopentadienone (146), ${ }^{66}$ which underwent a Diels-Alder reaction with 2,5-dihydrofuran to furnish the endo-cycloadduct 147 as the major product in 95\% yield (Scheme 34). The structure of 147 was elucidated by X-ray structure analysis. A subsequent decarbonylation of 147 was achieved with excellent yield to give 148 by stirring in a mixture of methylene chloride/ethanol/water at $50{ }^{\circ} \mathrm{C}$ for 1 day.

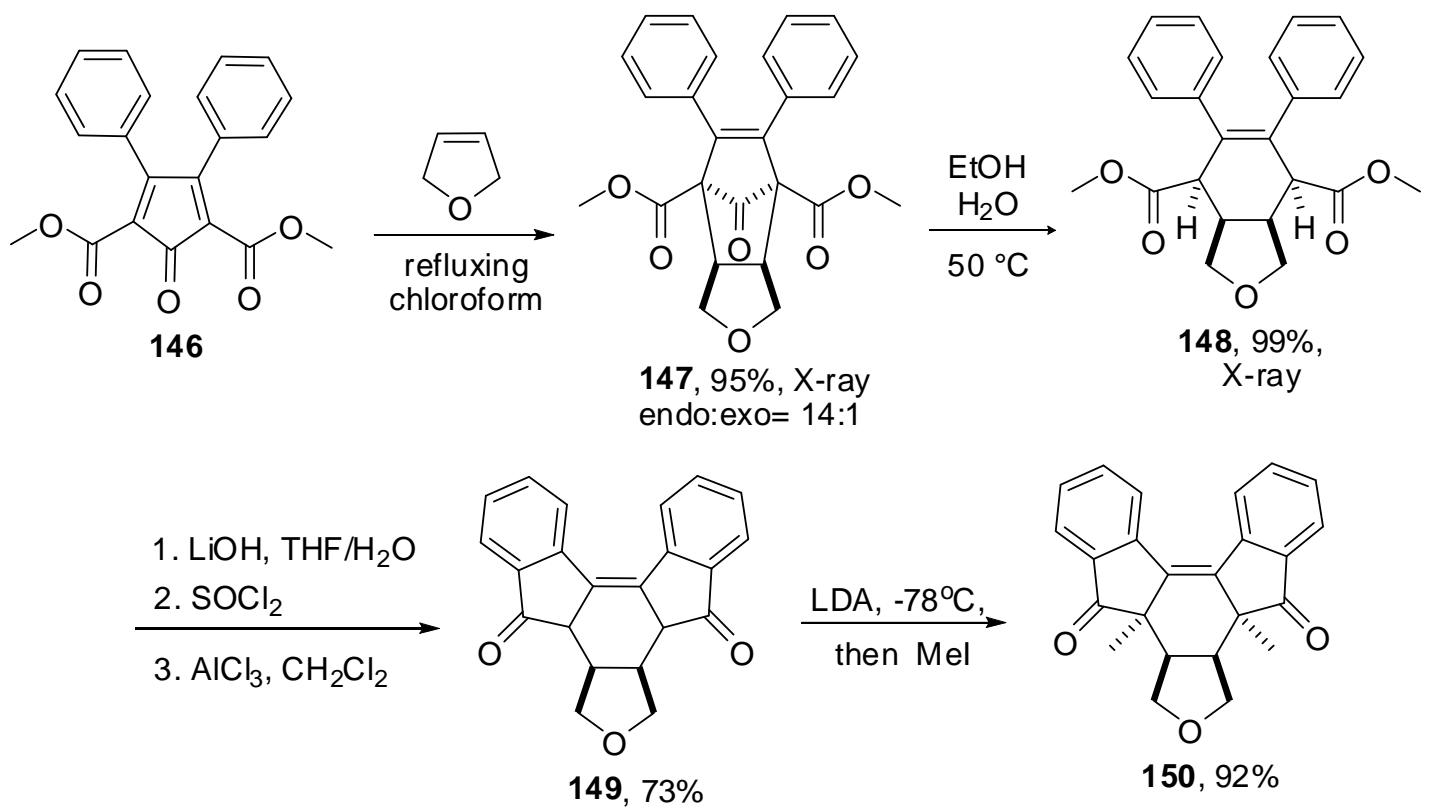

Scheme 34. Preparation of precursor diketone $\mathbf{1 5 0 .}$ 
As far as we know, this type of water-catalyzed decarbonylation has never been reported before. The structure of $\mathbf{1 4 8}$ was also established by X-ray structure analysis. ${ }^{65}$ The X-ray structure shows that the four hydrogens on the cyclohexenyl ring are cis to one another.

Hydrolysis of diester 148 by treatment with an excess of aqueous LiOH solution in refluxing THF for $18 \mathrm{~h}$ followed by acidification with $1 \mathrm{M} \mathrm{HCl}$ afforded the corresponding diacid. The crude diacid was treated with thionyl chloride under reflux to yield the corresponding diacid chloride, which underwent two Friedel-Crafts reactions to give 149 in $73 \%$ overall yield in three steps. The following double methylation of 149 by LDA and iodomethane led to the desired precursor diketone $\mathbf{1 5 0}$ in $92 \%$ yield.

\subsection{Condensation of Diketone 150}<smiles>CC1(C)C2=C(c3ccccc3)[C@](C)(C(=O)c3ccccc32)[C@@H]2COCC21</smiles>

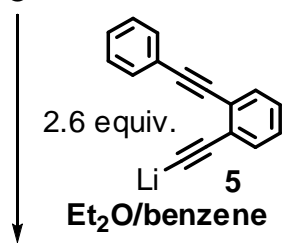

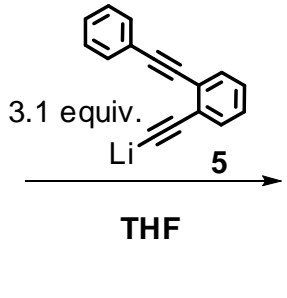
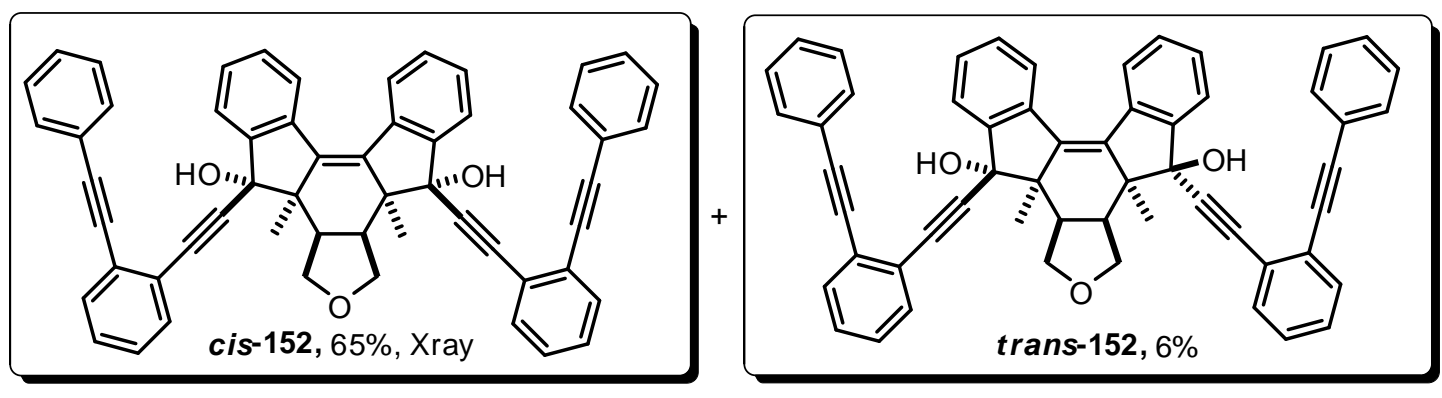

$+151,18 \%$

Scheme 35. Condensation of diketone 150 and acetylide 5.

Condensation between diketone $\mathbf{1 5 0}$ and 3.1 equiv of lithium acetylide $\mathbf{5}$ in THF produced the benzannulated enediynyl propargylic alcohol 151 in 91\% yield (Scheme 35). 
Interestingly, when solvent was changed to a combination of diethyl ether and benzene, both carbonyl groups can be converted to propargylic alcohol to give a mixture of cis/trans isomers 152 in 10:1 ratio as well as a $\mathbf{1 5 1 .}$

\subsection{Schmittel Cyclization of 152 and Furan-ring Opening}

Dr. Yang reported that a $C^{2}-C^{6}$ Schmittel cyclization of diol 152 promoted by thionyl chloride followed by silica gel chromatography led to diketone $\mathbf{1 5 3}$ in $57 \%$ yield. ${ }^{65}$ The structure of $\mathbf{1 5 3}$ was established by X-ray structure analysis (Scheme 36). Unfortunately, all the attempts toward the opening of furan ring ${ }^{67}$ under a variety of reaction conditions, such as heating in TMSI, diiodosilane (DIS), cleavage with transition metals, and photo irradiation were all unsuccessful. Interestingly, treatment of $\mathbf{1 5 3}$ with DIS, the two carbonyl groups in $\mathbf{1 5 3}$ were completely reduced to the methylene groups which were confirmed by ${ }^{1} \mathrm{H}$ NMR spectrum from previous synthetic work. ${ }^{65}$ From the X-ray structure of 153, it was clear that the central cyclohexenyl group with four $\mathrm{sp}^{3}$-hybridized carbons causes the furan ring to fold inside, preventing ring opening by trimethylsilyl iodide.
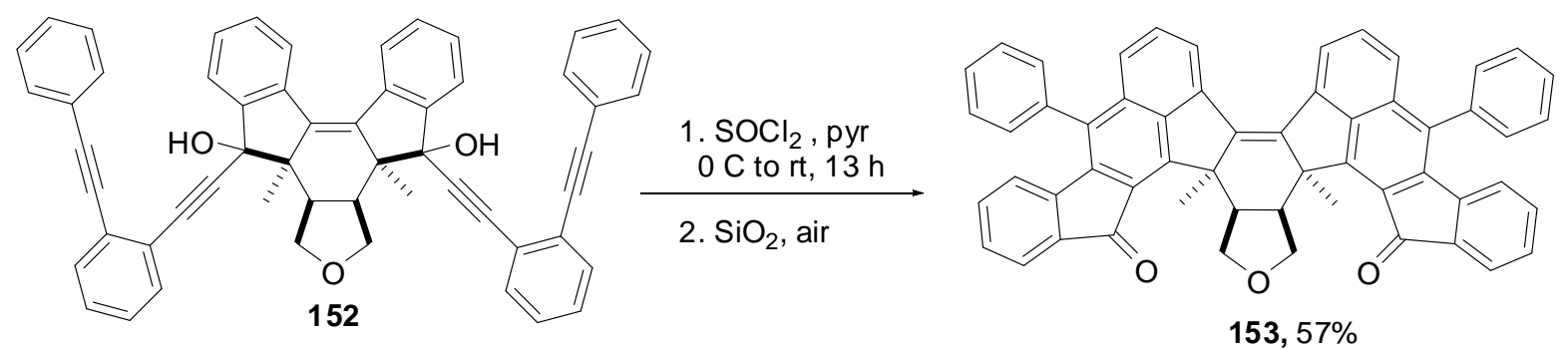

1. TMSI, heat or 2. $\mathrm{MoCl}_{5}$

or 3. $\mathrm{Re}_{2} \mathrm{O}_{7}$, TFAA, benzoic acid; or 4. Photo irradiation with $\mathrm{I}_{2}$, propylene oxide

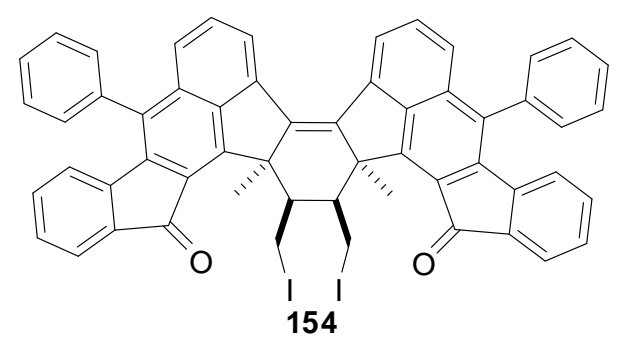

Scheme 36. Attempts toward the furan ring opening of 153. 


\subsection{Alternative Route Toward Diol 157}

Since all the attempts toward furan ring opening failed, we revised the synthetic route by opening the furan ring at an early synthetic stage. Conversion of 150 to diiodide 155 was achieved in 86\% yield (Scheme 37). Unfortunately, the following condensation between 155 and lithium acetylide $\mathbf{5}$ only led to the mono-propargylic alcohol $\mathbf{1 5 6}$ even in the solvent combination of ether and benzene or other condition such as cerium acetylide. The expected diol $\mathbf{1 5 7}$ was not observed. Examining the 3D structural modeling of $\mathbf{1 5 6}$ showed that the steric interactions between two iodide substitutes causes one iodide to sit in the axial position while the other in the equatorial position. The one in the axial position completely blocked the neighboring carbonyl group from being attacked by the acetylide 5 .

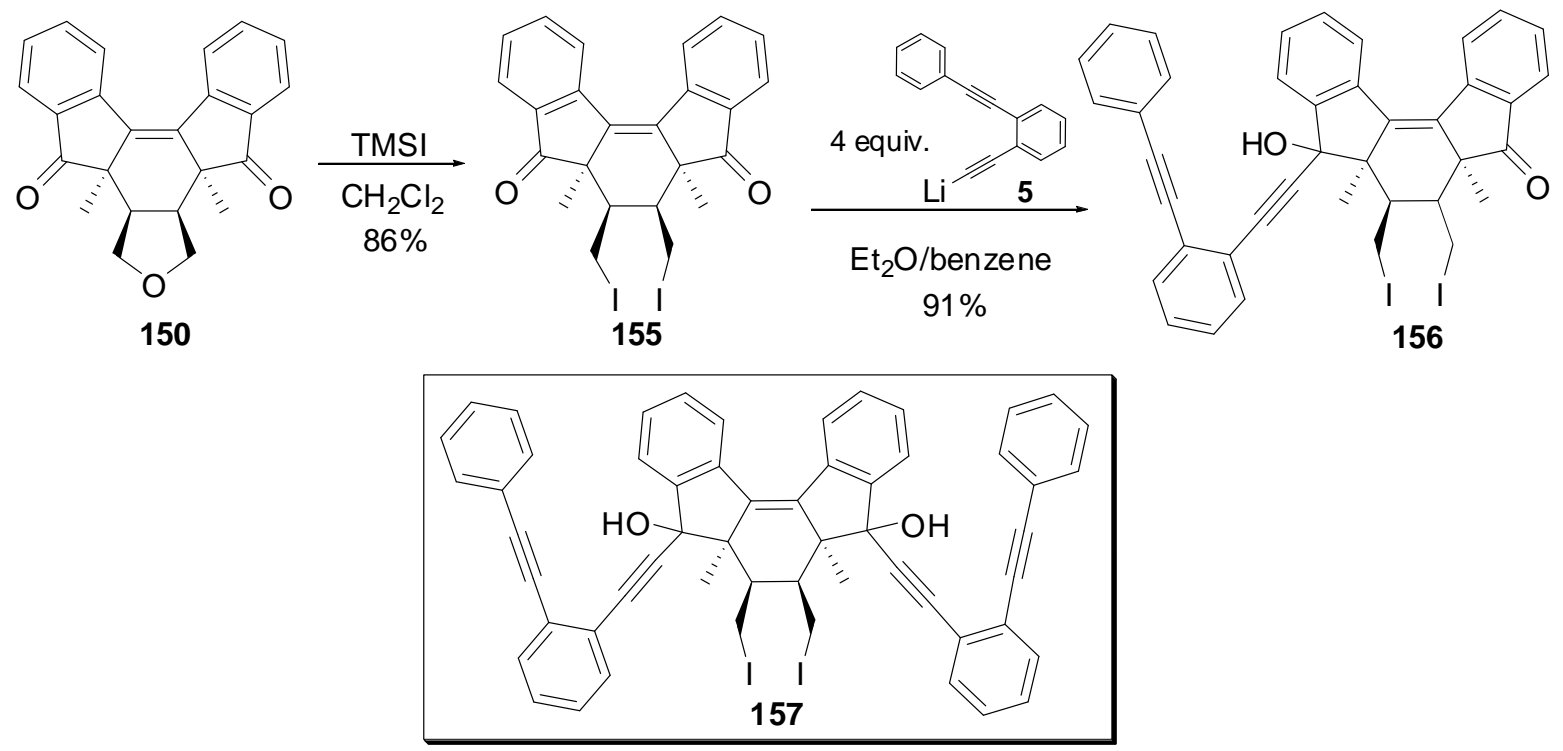

Scheme 37. Attempted synthetic route toward diol 157.

\subsection{Revised Synthetic Pathway Toward $I_{2}$-Diketone 154}

As an alternative synthetic pathway, we envisioned that by employing a stepwise cyclization of one side of propargylic alcohol followed by a second condensation and cyclization could lead to 154. A Schmittel cyclization of mono-propargylic alcohol 151 promoted by thionyl chloride followed by silica gel chromatography produced diketone 158 (Scheme 38). The furan 
ring of 158 was successfully opened by stirring with TMSI at room temperature to afford diiodide 159 in 85\% yield.
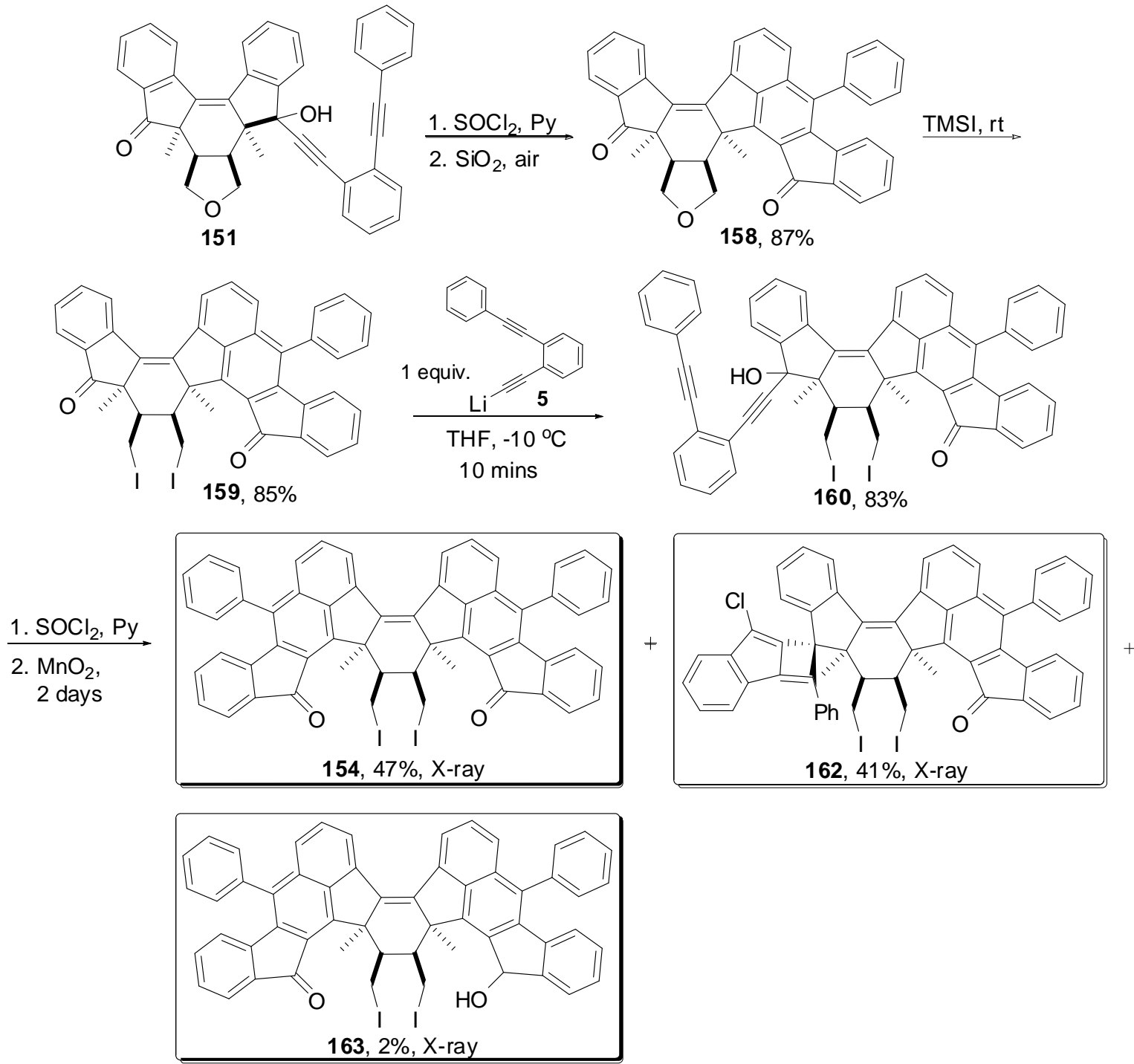

Scheme 38. Revised synthetic pathway toward $I_{2}$-diketone 154.

We envisioned that the two carbonyl groups in 159 have different steric environments, which could allow selective condensation with lithium acetylide 5. Fortunately, a regio-selective condensation was successfully achieved by a treatment with 1 equiv of lithium acetylide stirring at $-10{ }^{\circ} \mathrm{C}$ for 10 minutes to give the desired propargylic alcohol $\mathbf{1 6 0}$ in $83 \%$ yield. The structure of 160 was confirmed by ${ }^{13} \mathrm{C}$ NMR spectrum with the carbonyl carbon signal at $\delta 203$ belonging 
to the fluorenyl keto group disappears while the carbonyl carbon signal at $\delta 193$ of the benzofluorenyl group still remains.

On exposure to thionyl chloride followed by oxidation with $\mathrm{MnO}_{2}$ for two days, propargylic alcohol 160 was converted to three products, including the desired $\mathrm{I}_{2}$-diketone 154, spiro [2 + 2] adduct 162, and a trace amount of mono-alcohol 163. Alcohol 163 can be further oxidized to the desired diketone 154 by $\mathrm{MnO}_{2}$. The structures of these three products were established by X-ray structure analyses. The X-ray crystal structure of $\mathbf{1 5 4}$ reveals that the one of the iodomethyl substitutes is in the axial position while the other is in the equatorial position (Figure 18).

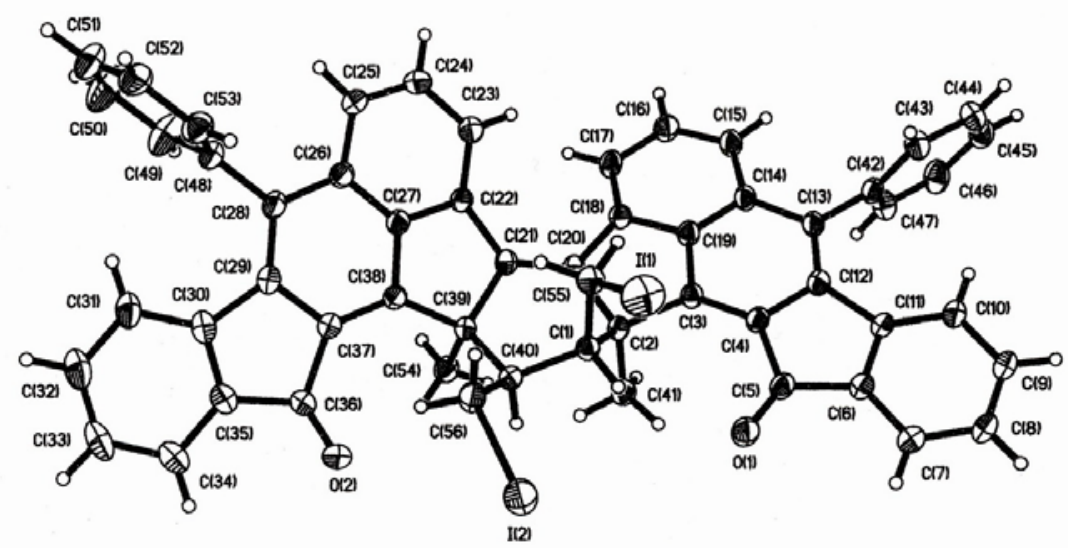

Figure 18. ORTEP drawing of the crystal structure of $\mathrm{C}_{56} \mathrm{H}_{36} \mathrm{I}_{2} \mathrm{O}_{2}$ (154).

The formation of [2 + 2] cycloadduct 162 was unexpected with the steric hindered phenyl group on the same side of the sterically hindered $-\mathrm{CH}_{2} \mathrm{I}$ group as shown by the $\mathrm{X}$-ray structure analysis (Figure 19). However, the preference of the [2 + 2] cycloadduct might be minimized by introducing a highly steric hindered substituent, such as 2,6-dibromophenyl group, on the terminus alkynes in $\mathbf{1 6 0}$ to further optimize this cyclization step. Also, by introducing bromosubstituents on the phenyl rings, it would be possible to further form carbon-carbon bonds by intramolecular Heck reactions to connect the peripheral two phenyl groups to form curved 
buckybasket with a deeper pocket. This type of intramolecular Heck reaction has been investigated and reported by Daehwan Kim of our group. ${ }^{8 c}$

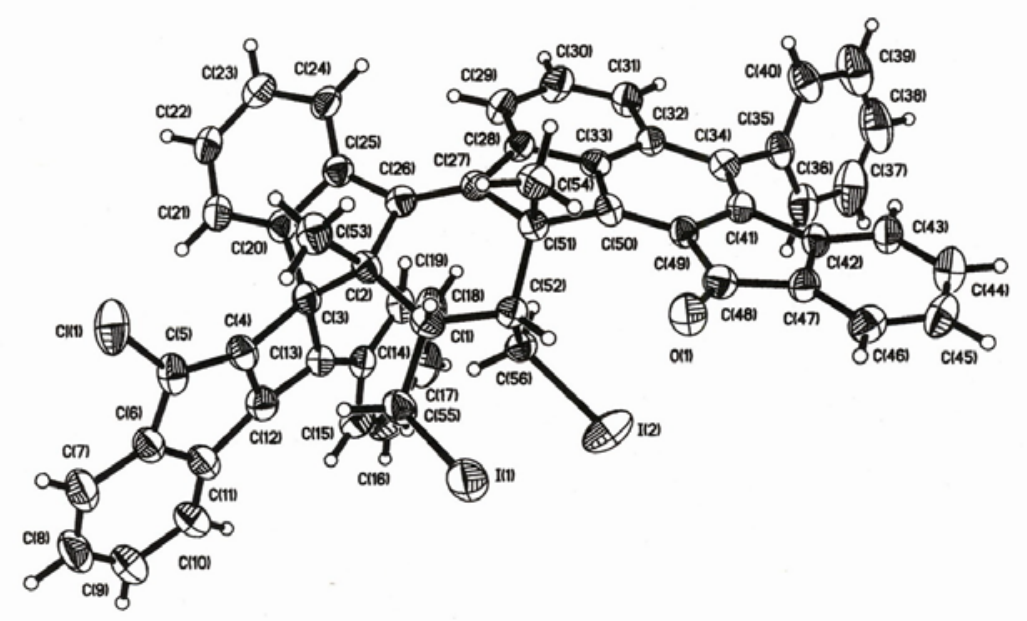

Figure 19. ORTEP drawing of the crystal structure of [2+2] cycloadduct 162.

\subsection{NMR Studies of $I_{2}$-Diketone 154}

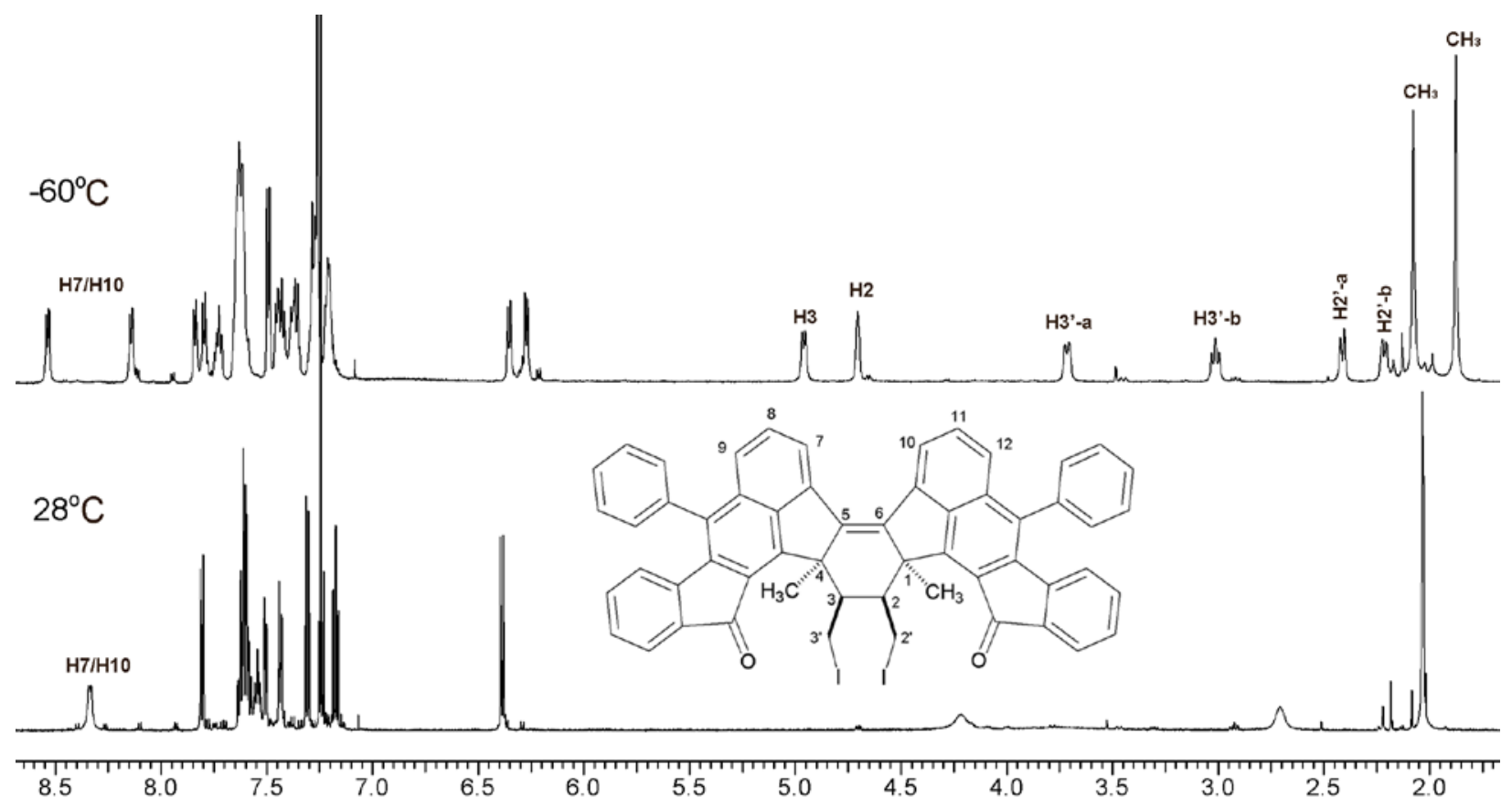

Figure 20. Temperature-dependent ${ }^{1} \mathrm{H}$ spectra of 154 in $\mathrm{CDCl}_{3}$.

The X-ray structure of $\mathbf{1 5 4}$ indicates that the two iodomethyl substituents are in sterically hindered environments. Indeed, the ${ }^{1} \mathrm{H}$ NMR spectrum of 154 recorded on a $600 \mathrm{MHz}$ 
spectrometer at room temperature exhibits several sets of broadened signals at $\delta 8.36,4.23,3.89$, 2.72 attributable to a rapid conformational exchange on the NMR time scale. The temperature-dependent ${ }^{1} \mathrm{H}$ NMR spectra show that at $-60{ }^{\circ} \mathrm{C}$, all the broad peaks turn to sharp distinct peaks with well defined splitting patterns (Figure 20). A complete assignment of the aliphatic ${ }^{1} \mathrm{H}$ NMR chemical shifts was made by using selective decoupling and 1D TOCSY techniques. The line sharpening was observed for all the aliphatic protons as the temperature is lowered from $28{ }^{\circ} \mathrm{C}$ to $-60^{\circ} \mathrm{C}$, which is explained by the slow conformational exchange on the NMR time scale. Six different aliphatic signals at $\delta 4.96(\mathrm{H} 3), 4.71(\mathrm{H} 2), 3.72\left(\mathrm{H} 3{ }^{\prime}-\mathrm{a}\right), 3.02$ (H3'-b), 2.42 (H2'-a), 2.22 (H2'-b) were observed due to unsymmetrical nature of the structure with one iodomethyl substituent in the equatorial while the other sits in the axial position.

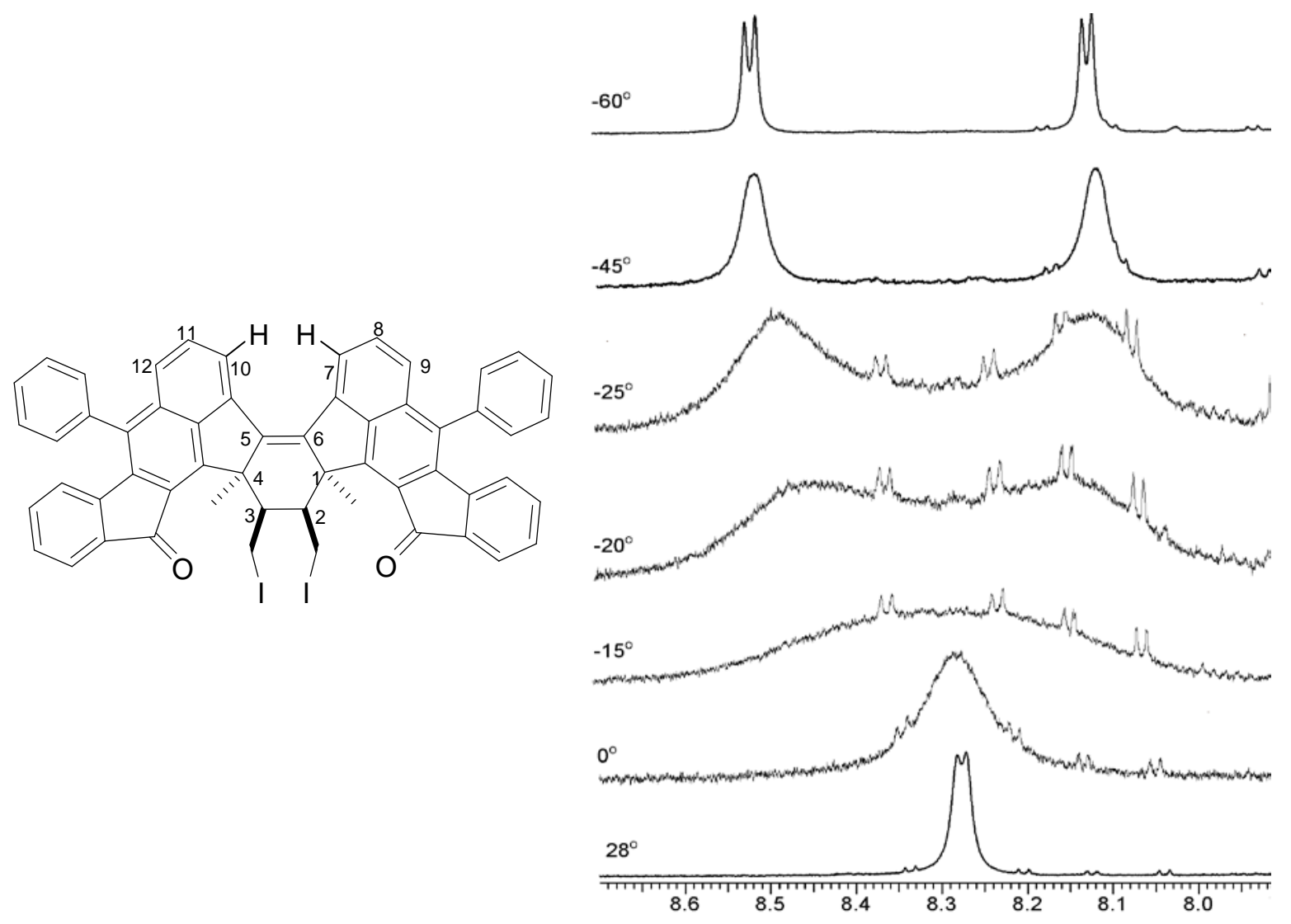

Figure 20. Temperature-dependent ${ }^{1} \mathrm{H}$ spectra of $\mathrm{H} 7$ and $\mathrm{H} 10$. 
In addition, the most downfield aliphatic signal at $\delta 4.96$ was assigned to be the axial hydrogen of the central cyclohexenyl ring with an equatorial iodomethyl substituent. Figure 21 also shows the coalescence of two aromatic peaks (H7/H10) in temperature-dependent ${ }^{1} \mathrm{H}$ NMR studies. The energy barrier of conformational exchange $\Delta \mathrm{G}^{\ddagger}$ was calculated at the coalescence temperature of $-15^{\circ} \mathrm{C}$ to be $11.8 \mathrm{kcal} / \mathrm{mol}$.

\subsection{Intramolecular Cyclization of $I_{2}$-Diketone (154)}

Scheme 39 outlines the attempts to synthesize the bowl-shaped diol 164 by employing intramolecular Barbier-type cyclizations ${ }^{68}$ of the $\mathrm{I}_{2}$-diketone 154. However, the ${ }^{1} \mathrm{H}$ NMR spectrum of the isolated compound showed only broad and complicated peaks in the aromatic region, which indicate that the starting material decomposed or polymerized. Also, attempts to treat 154 with $t-\mathrm{BuLi}^{69}$ under a nitrogen atmosphere at $-78{ }^{\circ} \mathrm{C}$ were unsuccessful in giving the desired product. Instead, simple reduction of the two carbonyl groups to hydroxyl groups was observed.
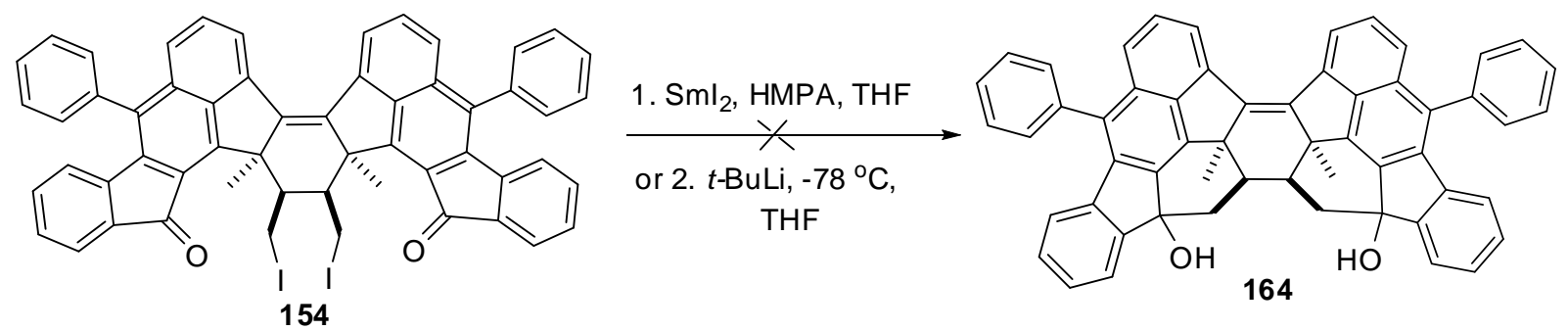

Scheme 39. Attempts toward the synthesis of buckybowl 164.

\subsection{Reduction of $\mathrm{I}_{2}$-Diketone 154}

Surprisingly, reduction of diketone $\mathbf{1 5 4}$ by treatment with freshly prepared diiodosilane (DIS) ${ }^{70}$ at $40{ }^{\circ} \mathrm{C}$ for two days produced 165 in $76 \%$ yield and a trace amount of mono-reduced byproduct 166 (Scheme 40). It is interesting to note that the central carbon-carbon double bond in 154 was also reduced, giving rise to two additional $\mathrm{sp}^{3}$-hybridized carbons in $\mathbf{1 6 5}$. The 
presence of these two additional $\mathrm{sp}^{3}$-hybridized carbons appears to shorten the distance between the carbon on the five-membered ring and the neighboring iodomethyl substituent.

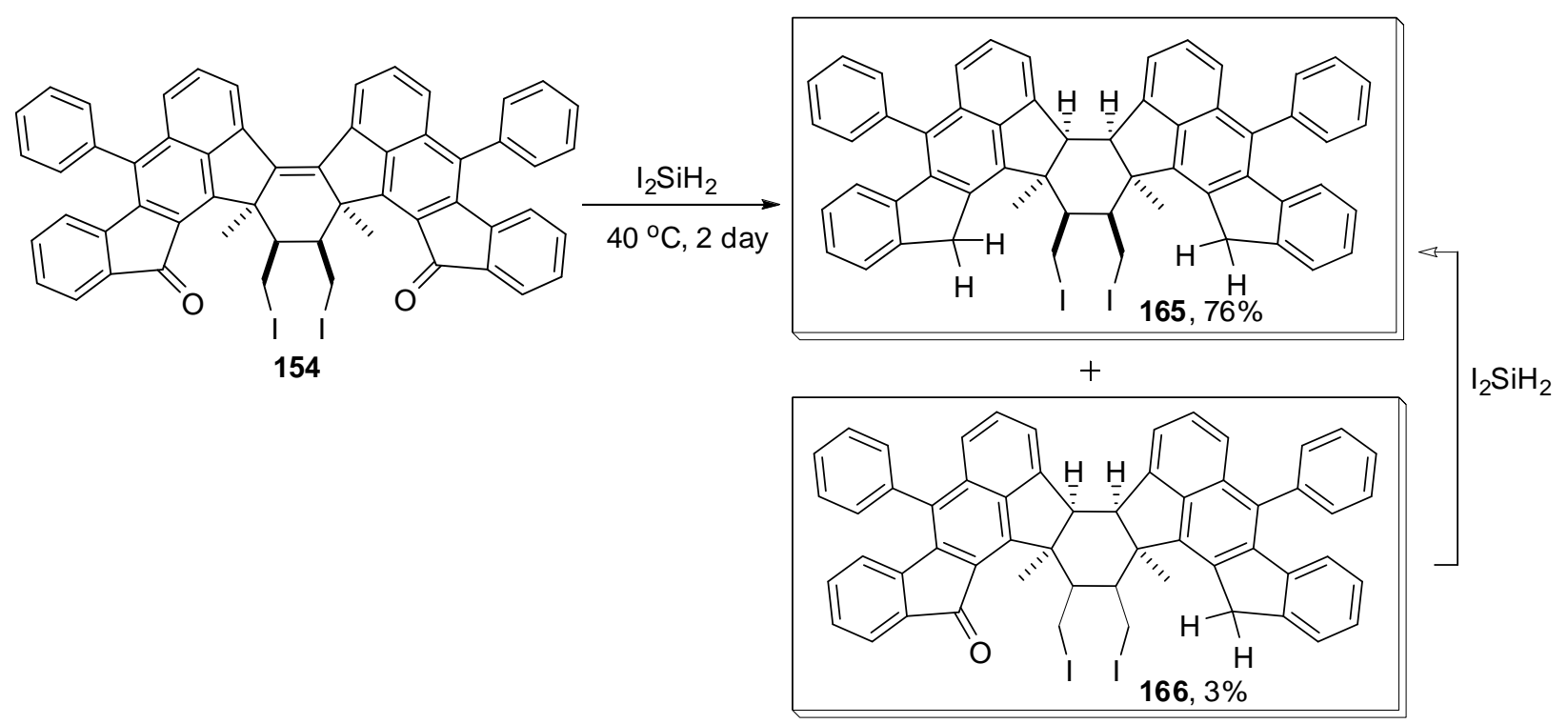

Scheme 40. Preparation of $\mathrm{I}_{2}$-hydrocarbon 165.

Monoketone 166 can be converted to $\mathbf{1 6 5}$ by stirring with DIS for a longer time. The stereochemistry of $\mathbf{1 6 5}$ and $\mathbf{1 6 6}$ were characterized and confirmed by NMR studies. Presumably, the double bond on the central six-membered ring was initially protonated by a trace amount of HI present in the freshly prepared DIS, followed by hydride attack to afford the cis-hydrogenated compound.

\subsection{NMR Studies of 166 and 165}

The ${ }^{1} \mathrm{H}$ NMR spectrum of $\mathbf{1 6 6}$ exhibits a set of AB quartet at $\delta 4.52 / 4.12$ with a large geminal coupling constant of $22 \mathrm{~Hz}$, indicating the formation of methylene groups of the fluorenyl groups. The selective decoupled ${ }^{1} \mathrm{H}$ NMR spectra of $\mathbf{1 6 6}$ allowed the assignment of the entire coupling network between the geminal or vicinal hydrogens on the two $-\mathrm{CH}_{2} \mathrm{I}$ substituents. A complete assignment of the entire aliphatic hydrogen chemical shifts was made by using 1D/2D TOCSY, 1D/2D NOESY and COSY. The very upfield shift aromatic signal at $\delta 4.97$ was 
assigned to $\mathrm{H7}$ on the basis of the observation that when it was irradiated, the aromatic signal at $\delta 6.73$ as a triplet becomes a doublet. It is worth noting that there is a dramatic chemical upfield shift of $\mathrm{H7}$ from $\delta 8.36$ of diketone $\mathbf{1 5 4}$ to $\delta 4.97$ of the reduced compound $\mathbf{1 6 6}$. Such an upfield aromatic shift was attributed to a flexible central boat-conformation of the central six-membered ring of 166, causing the two benzofluorenyl groups to orient roughly perpendicular to each other, thus placing $\mathrm{H} 7$ in the magnetic shielding region of the other benzofluorenyl group. Again, in the contour plot of the COSY spectrum, the $\mathrm{H} 7$ signal at $\delta 4.97$ was also used to locate the remaining two hydrogens on the same aromatic ring (ring A) at $\delta 6.85$ and 6.73 .

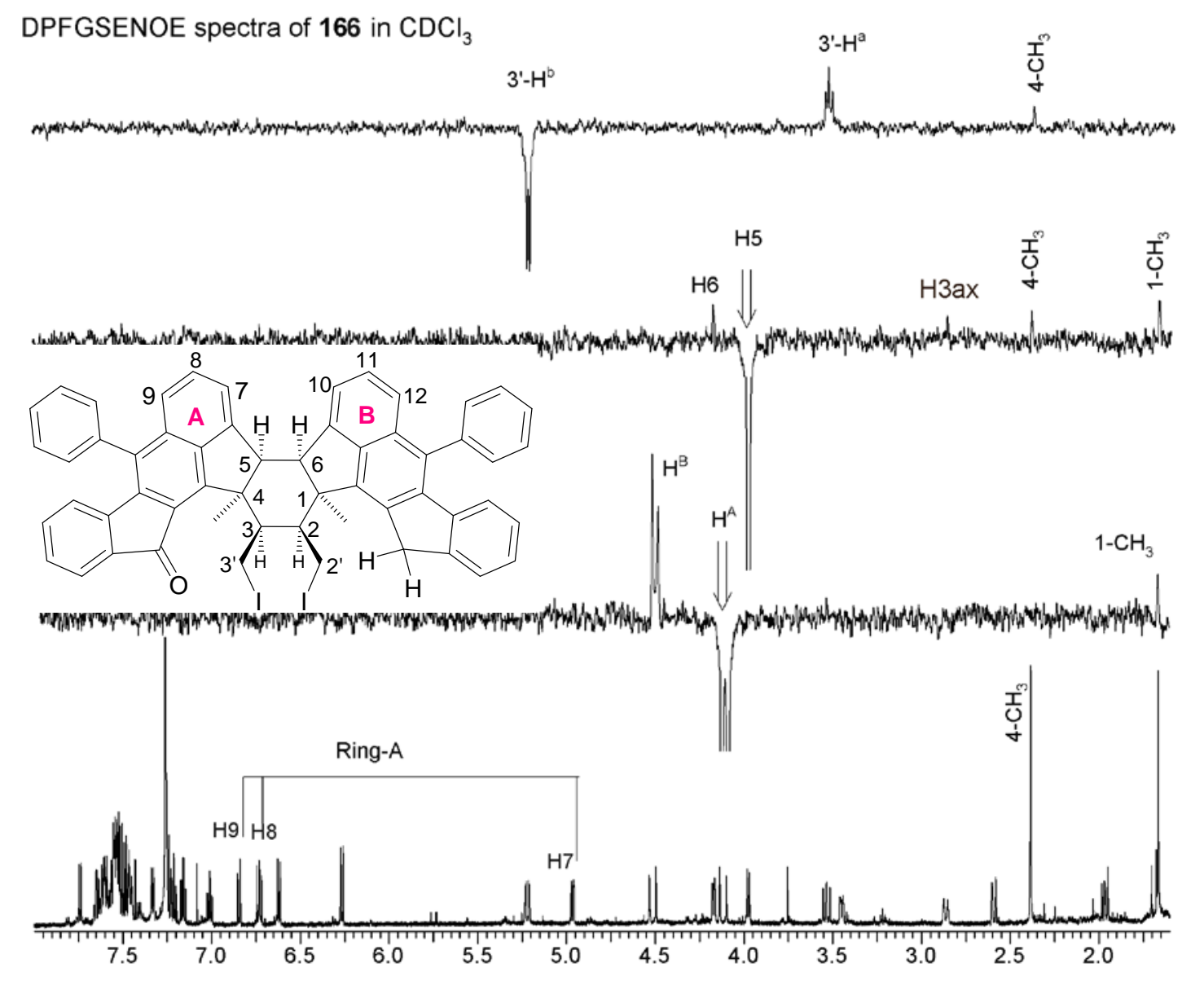

Figure 22. NOE spectra of 166.

In addition, the NOE spectra (Figure 22) allowed the assignment of the methyl group signal at $\delta 1.67$ to be on the same side of the methylene hydrogens on the five-membered ring by 
irradiating one of the $\mathrm{AB}$ pattern methylene hydrogen signals at $\delta 4.12$. The stereochemistry of $\mathrm{H} 5$ and $\mathrm{H} 6$ is also identified to be cis to each other from NOE spectra. The irradiation of H5 at $\delta$ 3.98 gave a cis NOE enhancement on the signal at $\delta 4.17$ which was assigned to H6. The H5 signal at $\delta 3.98$ is also used to locate the two methyl groups and confirm that $\mathrm{H} 3(\delta 2.87)$ is situated in the axial position. In other words, the $-\mathrm{CH}_{2} \mathrm{I}$ group neighboring the keto group is in the equatorial position where as the other $-\mathrm{CH}_{2} \mathrm{I}$ group is in the axial position. Moreover, the $1 \mathrm{D}$ TOCSY spectra allowed the connection of the spin-spin coupling network of hydrogens on ring A and the connection to $\mathrm{H} 5$ and $\mathrm{H} 6$ by longer mixing time that the signals at $\delta 4.97$ (doublet), $\delta$ 6.73 (triplet), $\delta 6.85$ (doublet) constitute one spin system (Ring A protons: H7, H8 and H9).

It is worth noting that the 3D structural modeling of 165 (Figure 23) reveals unsymmetrical structure with the central six-membered ring having a boat conformation. The ${ }^{1} \mathrm{H}$ NMR spectrum of $\mathbf{1 6 5}$ showed two sets of $\mathrm{AB}$ quartet at $\delta 4.48 / 4.12$ and $\delta 4.43 / 4.34$ with a large geminal coupling constant of $22 \mathrm{~Hz}$, indicating that both keto groups in $\mathbf{1 5 4}$ were successfully converted to methylene hydrogens on the five-membered rings.

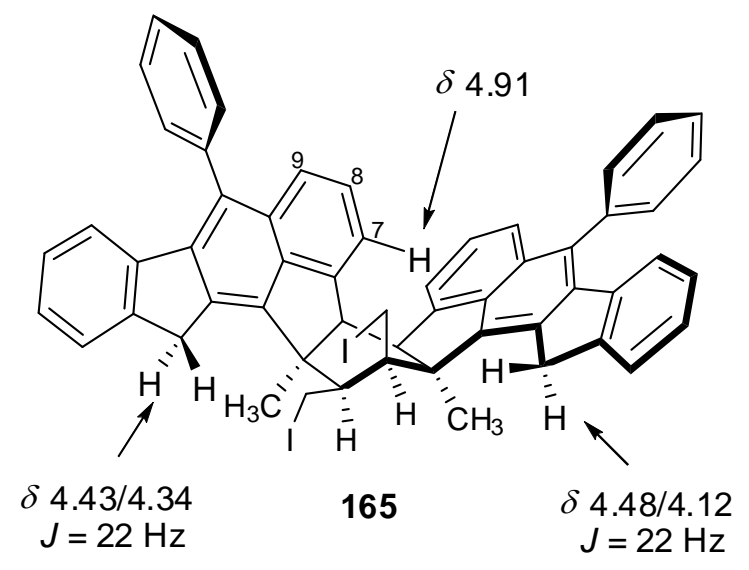

Figure 23. 3D structure of $\mathbf{1 6 5 .}$

The remaining aliphatic peaks are completely assigned by 1D/2D TOCSY, COSY and 1D NOESY techniques. Similar to the mono-reduced compound 166, there is also an extremely 
upfield shift of aromatic signal at $\delta 4.91$, indicating that $\mathrm{H} 7$ is situated inside the magnetic shielding region of the other benzofluorenyl group.

\subsection{Intramolecular $S_{\mathrm{N}} 2$ Cyclization of Diiodide 165}

The final step employing a classical intramolecular $S_{N} 2$ reationn of diiodide 165 under a very mild condition of sodium hydride in the presence of a catalytic amount of $t$-butyl alcohol at room temperature was successful in producing buckybowl 167 (Scheme 41). The presence of the two additional $\mathrm{sp}^{3}$-hybridized carbons on the six-membered ring of $\mathbf{1 6 7}$ is key to the success of the intramolecular $S_{N} 2$ reactions. The methylene hydrogens of the fluorenyl system now are relatively close to the iodomethyl substituents to facilitate the intramolecular $\mathrm{S}_{\mathrm{N}} 2$ reaction. The stereochemistry of $\mathbf{1 6 7}$ was characterized and confirmed by NMR studies.

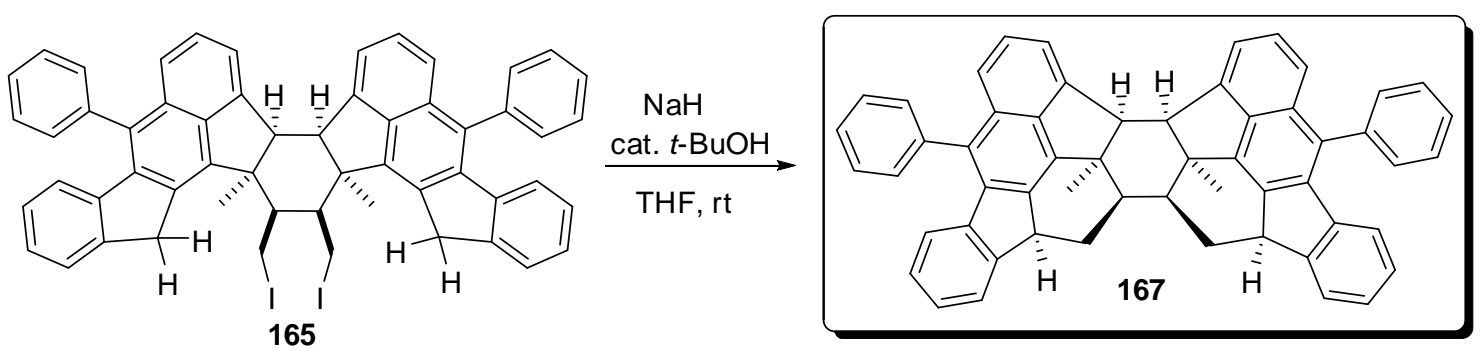

Scheme 41. Synthesis of chiral buckybowl 167.

\subsection{NMR Studies of Buckybowl 167}

The 3D molecular modeling of buckybowl 167 calculated by MM2 was shown in Figure 24. Interestingly, the structure of $\mathbf{1 6 7}$ is unsymmetrical due to the presence of a very flexible central six-membered ring with a boat-conformation, which twists the two benzofluorene groups to orient roughly perpendicular to each other. As a result, the ${ }^{1} \mathrm{H}$ NMR spectrum of 167 in $\mathrm{CDCl}_{3}$ revealed two extremely upfield shift aliphatic signals at $\delta-3.40$ and 0.28 . A complete assignment of entire aliphatic hydrogen was made by using 1D/2D TOCSY, COSY and 1D NOESY techniques. 

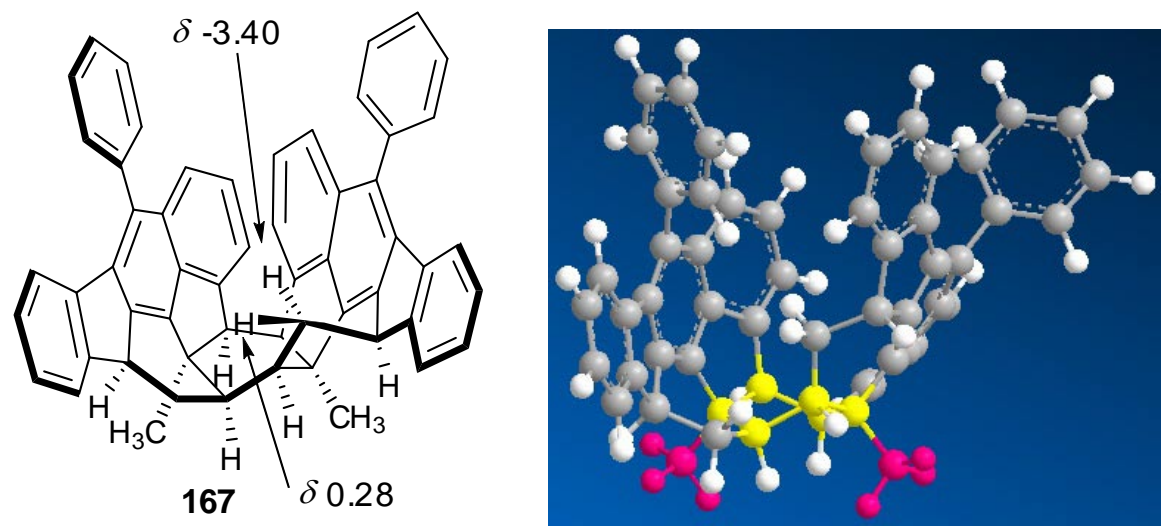

(Red atoms:

$\mathrm{CH}_{3}$ groups;

yellow bond:

the central

cyclohexanyl

group)

Figure 24. 3D structure of chiral buckybowl 167.

In addition, the 1D TOCSY spectra (Figure 25) reveals the spin-spin coupling network of hydrogens shown on one of the benzofluorenyl groups, H11, H12 and H13 as well as further connection to $\mathrm{H} 8$ and $\mathrm{H} 9$ on the central cyclohexyl ring. In addition, a very upfield shift of aromatic hydrogen $\mathrm{H} 11$ was found at $\delta 3.89$, indicating that the two benzofluorenyl groups are oriented perpendicular to each other.

1D TOCSY spectrum of 167 in $\mathrm{CDCl}_{3}$

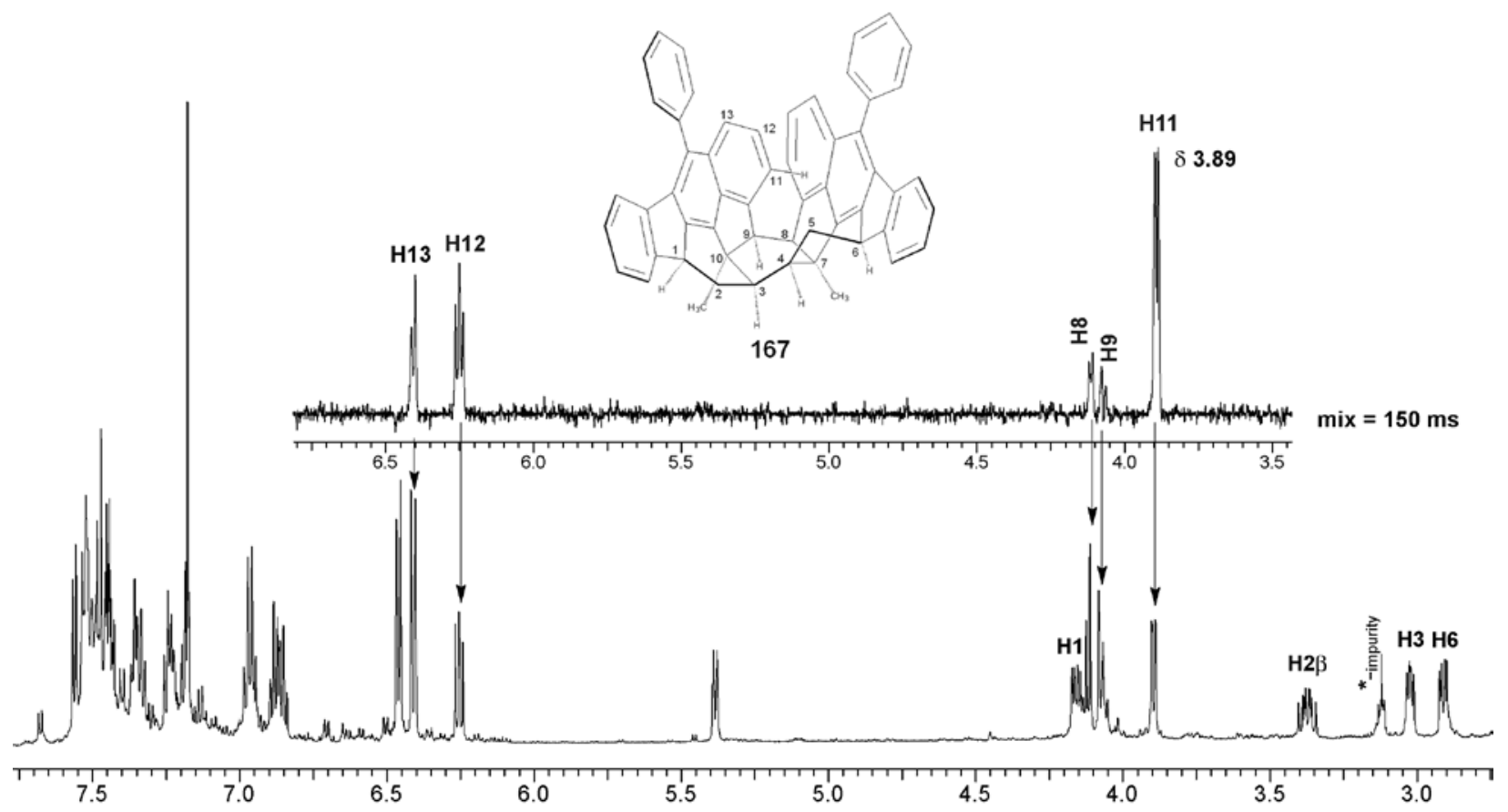

Figure 25. 1D TOCSY spectrum of 167 in $\mathrm{CDCl}_{3}$. 


\subsection{Future Prospects}

This buckybowl 167 can serve as a potential bidentate chiral ligand having two fluorenyl moieties. The acidic hydrogens on the benzofluorenyl groups can be deprotonated and the resulting dianion could form metal-complexes with transition-metals (Scheme 42).
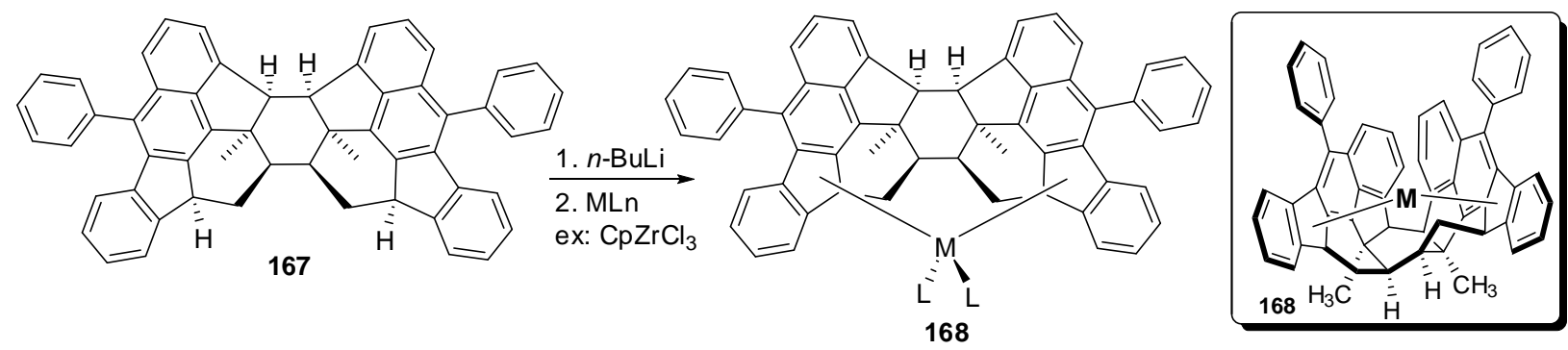

Scheme 42. Proposed further application of $\mathbf{1 6 7}$ in coordination chemistry.

It is worth noting that hydrocarbon 167 possesses a 54-carbon framework represented on the surface of $\mathrm{C}_{60}$. Moreover, it could undergo further transformations for the construction of buckybaskets 169 and 170 (Scheme 43).

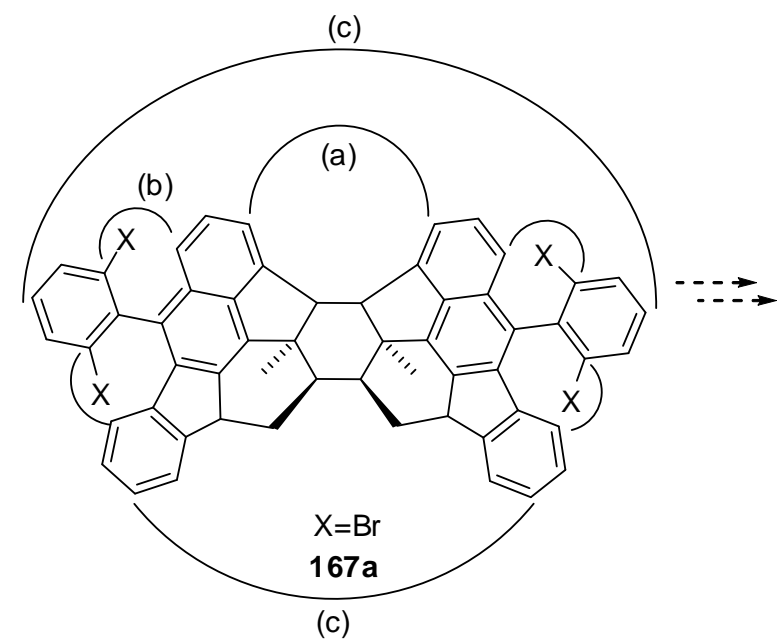

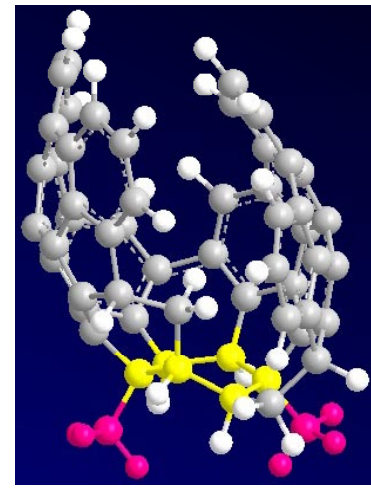

169

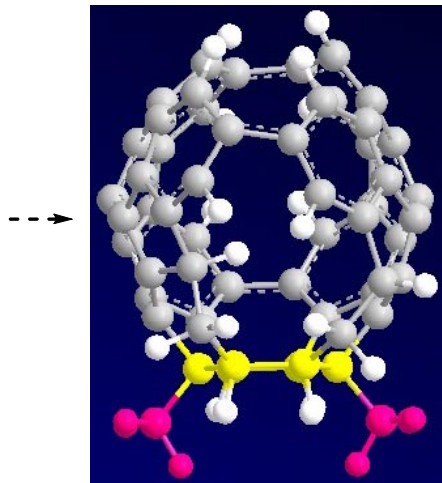

170

Scheme 43. Proposed further application of 167a.

Presumably, a brominated 167, such as 167a, could be converted to bowl-shaped hydrocarbon 169 by initially using Müllen’s method ${ }^{71}$ to connect the two benzene ring indicated as a connection followed by intramolecular Heck coupling reactions to connect the two 
dibromophenyl substituents with the benzofluorenyl groups indicated as b connection. Buckybasket 169 may ultimately lead to a novel buckybasket 170 having a hole via c connection. ${ }^{72}$ These promising PAHs, 169 and 170, unlike other buckybowls, are less strained surface and more accessible for further applications in nanotechnology. In addition, the $\mathrm{sp}^{3}$-hybridized carbons on the surface could be functionalized to undergo further chemical transformations.

\section{Conclusions}

A unique, non-pyrolytic synthetic pathway employing Schmittel cyclization reactions has been developed to synthesize chiral bowl-shaped polycyclic aromatic hydrocarbon (PAH). Introduction of $\mathrm{sp}^{3}$-hybridized carbons facilitates the cyclization step. Buckybowl 167 having a 54-carbon framework mapped onto the surface of $\mathrm{C}_{60}$ can serve as a potential precursor for a novel buckybasket. In addition, the structure of $\mathbf{1 6 7}$ could find applications in supramolecular chemistry and allow the study of endohedral chemistry. 


\section{CHAPTER IV \\ Experimental Section}

\section{General Experimental Methods}

All reactions were conducted in oven-dried $\left(120^{\circ} \mathrm{C}\right)$ glassware under a nitrogen atmosphere. Diethyl ether and tetrahydrofuran (THF) were distilled from benzophenone ketyl prior to use. Methylene chloride, benzene and toluene were distilled over calcium hydride $\left(\mathrm{CaH}_{2}\right)$ prior to use. Silica gel for flash column chromatography was purchased from chemical supplies. Melting points were uncorrected. ${ }^{1} \mathrm{H}(270 \mathrm{MHz}, 600 \mathrm{MHz})$ and ${ }^{13} \mathrm{C}(67.9 \mathrm{MHz}, 150 \mathrm{MHz}) \mathrm{NMR}$ spectra were recorded in $\mathrm{CDCl}_{3}$ using $\mathrm{CHCl}_{3}\left({ }^{1} \mathrm{H} \delta\right.$ 7.26) and $\mathrm{CDCl}_{3}\left({ }^{13} \mathrm{C} \delta 77.0\right)$ as internal standards unless otherwise indicated. IR spectra were taken on Perkin-Elmer LX10-8704 Spectrum One FT-IR spectrometer. Mass spectra and high resolution mass spectra were obtained on Hewlett Packard 5970B GC/MSD instrument at 70 eV, VG 7070 by DEI, VG-ZAB by FAB and DE-STR by MALDI. 3D structural modeling was obtained on computations using the MM2 force field provided by CambridgeSoft Corporation.

\section{Experimental Section of Chapter I}

1-Ethynyl-2-(phenylethynyl)benzene was prepared according to the reported procedure. ${ }^{8 \mathrm{i}}$ Truxenone (19), 1.6 M solution of $n$-butyllithium in hexanes, and thionyl chloride were purchased from chemical suppliers and were used as received.

Benzannulated Enediynyl Alcohol 24. To 0.049 g $\quad(0.243 \quad \mathrm{mmol})$ of 1-ethynyl-2-(phenylethynyl) benzene in $5 \mathrm{~mL}$ of THF under a nitrogen atmosphere at $0{ }^{\circ} \mathrm{C}$ was added $0.15 \mathrm{~mL}$ of a $1.6 \mathrm{M}$ solution of $n$-butyllithium $(0.24 \mathrm{mmol})$ in hexanes. After $30 \mathrm{~min}$ of stirring, a solution of $0.102 \mathrm{~g}$ of truxenone $(\mathbf{1 9}, 0.266 \mathrm{mmol})$ in $10 \mathrm{~mL}$ of THF was introduced via cannula, and the reaction mixture was allowed to warm to room temperature. After an 
additional $18 \mathrm{~h}, 15 \mathrm{~mL}$ of water was introduced, and the reaction mixture was extracted with methylene chloride. The combined organic extracts were washed with brine and water, dried over sodium sulfate, and concentrated. The residue was purified by flash chromatography (silica gel/methylene chloride) to afford $0.129 \mathrm{~g}(0.220 \mathrm{mmol}, 83 \%)$ of 24 as a pale yellow solid: ${ }^{1} \mathrm{H}$ NMR $\left(\mathrm{CDCl}_{3}, 600 \mathrm{MHz}\right) \delta 9.18-9.17(1 \mathrm{H}, \mathrm{m}), 9.03(1 \mathrm{H}, \mathrm{d}, J=7.2 \mathrm{~Hz}), 8.82(1 \mathrm{H}, \mathrm{d}, J=7.8$ Hz), 7.93-7.92 (1 H, m), $7.64(2 \mathrm{H}, \mathrm{d}, J=6.6 \mathrm{~Hz}), 7.56-7.52(2 \mathrm{H}, \mathrm{m}), 7.44-7.41(3 \mathrm{H}, \mathrm{m})$, 7.37-7.32 (3 H, m), 7.24-7.15 (7 H, m), 3.35 (I H, br); MS m/z $569\left(\mathrm{M}^{+}-\mathrm{OH}\right)$; HRMS calcd for $\mathrm{C}_{43} \mathrm{H}_{21} \mathrm{O}_{2}\left(\mathrm{M}^{+}-\mathrm{OH}\right)$ 569.1542, found 569.1543.

Diketone 28. To a solution of $0.102 \mathrm{~g}(0.174 \mathrm{mmol})$ of $24 \mathrm{in} 10 \mathrm{~mL}$ of THF under a nitrogen atmosphere at $0{ }^{\circ} \mathrm{C}$ was added slowly via cannula a solution of $0.1 \mathrm{~mL}(1.4 \mathrm{mmol})$ of thionyl chloride and $0.16 \mathrm{~mL}$ (2.0 mmol) of pyridine in $5 \mathrm{~mL}$ of THF. The reaction mixture then was allowed to warm to room temperature. After $7 \mathrm{~h}, 10 \mathrm{~mL}$ of water was introduced, and the organic layer was separated. The aqueous layer was back extracted with diethyl ether. The combined organic layers were washed with brine and water, dried over sodium sulfate, and concentrated. The residue was purified by flash chromatography (silica gel/50\% methylene chloride in hexanes) to afford $0.071 \mathrm{~g}(0.118 \mathrm{mmol}, 68 \%)$ of $\mathbf{2 8}$ as a green solid: IR 1701, $1434 \mathrm{~cm}^{-1} ;{ }^{1} \mathrm{H}$ $\left(\mathrm{C}_{6} \mathrm{D}_{6}, 600 \mathrm{MHz}\right) \delta 9.73(1 \mathrm{H}, \mathrm{ddd}, J=7.4,1.2,0.7 \mathrm{~Hz}), 9.29(1 \mathrm{H}, \mathrm{dt}, J=7.9,0.9 \mathrm{~Hz}), 8.82(1$ H, ddd, $J=7.6,1.1,0.7 \mathrm{~Hz}), 7.84(1 \mathrm{H}$, ddd, $J=7.5,1.2,0.7 \mathrm{~Hz}), 7.46(1 \mathrm{H}$, ddd, $J=7.5,1.2$, $0.7 \mathrm{~Hz}), 7.37(1 \mathrm{H}, \mathrm{ddd}, J=7.5,1.1,1.0 \mathrm{~Hz}), 7.34(1 \mathrm{H}, \mathrm{td}, J=7.6,1.2 \mathrm{~Hz}), 7.33(1 \mathrm{H}, \mathrm{ddd}, J=$ 7.9, 1.1, $0.7 \mathrm{~Hz}), 7.32$ (1 H, ddd, $J=7.6,7.4,1.1 \mathrm{~Hz}), 7.24(1 \mathrm{H}, \mathrm{td}, J=7.5,1.2 \mathrm{~Hz}), 7.19(1 \mathrm{H}$, ddd, $J=7.9,7.3,1.2 \mathrm{~Hz}), 7.17(1 \mathrm{H}, \mathrm{m}), 7.15(1 \mathrm{H}, \mathrm{m}), 6.97(1 \mathrm{H}, \mathrm{td}, J=7.4,1.0 \mathrm{~Hz}), 6.90(1 \mathrm{H}$, td, $J=7.5,0.9 \mathrm{~Hz}), 6.89(1 \mathrm{H}, \mathrm{m}), 6.84(1 \mathrm{H}, \mathrm{ddd}, J=7.9,7.3,1.2 \mathrm{~Hz}), 6.75(1 \mathrm{H}, \mathrm{td}, J=7.7,1.1$ Hz), $6.60(1 \mathrm{H}, \mathrm{td}, J=7.5,1.1 \mathrm{~Hz}), 6.32(1 \mathrm{H}, \mathrm{dt}, J=7.6,0.9 \mathrm{~Hz}), 5.94(1 \mathrm{H}, \mathrm{dt}, J=7.2,1.2 \mathrm{~Hz})$; ${ }^{1} \mathrm{H}\left(\mathrm{CDCl}_{3}, 600 \mathrm{MHz}\right) \delta 9.22(1 \mathrm{H}, \mathrm{d}, J=7.2 \mathrm{~Hz}), 8.99(1 \mathrm{H}, \mathrm{d}, J=7.8 \mathrm{~Hz}), 8.69(1 \mathrm{H}, \mathrm{d}, J=7.8$ 
Hz), $7.93(1 \mathrm{H}, \mathrm{d}, J=7.8 \mathrm{~Hz}), 7.72(1 \mathrm{H}, \mathrm{t}, J=7.8 \mathrm{~Hz}), 7.59(1 \mathrm{H}, \mathrm{t}, J=7.2 \mathrm{~Hz}), 7.53-7.47(7 \mathrm{H}$, m), $7.44(1 \mathrm{H}, \mathrm{t}, J=7.2 \mathrm{~Hz}), 7.30(1 \mathrm{H}, \mathrm{t}, J=7.8 \mathrm{~Hz}), 7.25-7.22(2 \mathrm{H}, \mathrm{m}), 7.18-7.16(1 \mathrm{H}, \mathrm{m})$, $6.88(1 \mathrm{H}, \mathrm{t}, J=7.8 \mathrm{~Hz}), 6.16(1 \mathrm{H}, \mathrm{d}, J=7.8 \mathrm{~Hz}), 5.88(1 \mathrm{H}, \mathrm{d}, J=6.6 \mathrm{~Hz}) ;{ }^{13} \mathrm{C}\left(\mathrm{C}_{6} \mathrm{D}_{6}, 150\right.$ MHz) $\delta 190.3,187.7,150.0,147.5,145.1,142.6,142.2,142.0,141.6,140.1,139.7,137.9,135.7$, $135.4,134.88,134.79,134.36,134.28,133.9,133.3,131.33,131.24,131.20,130.22,130.11$, $129.63,129.59,129.3,129.15,129.11,128.8,128.56,128.37,128.15,127.91,127.83,124.5$, 123.5, 123.02, 122.96, 122.8, 120.0, 57.6; ${ }^{13} \mathrm{C}\left(\mathrm{CDCl}_{3}, 150 \mathrm{MHz}\right) \delta$ 190.6, 188.1, 149.7, 146.9, 145.3, 142.0, 141.8, 141.6, 140.8, 139.5, 139.1, 138.1, 135.2, 135.0, 134.9, 134.4, 133.9, 133.1, $132.9,131.6,131.4,131.1,129.9,129.7,129.10,129.07,128.97,128.8,128.54,128.52,128.47$, $128.3,128.1,127.83,127.77,124.3,123.5,122.93,122.87,122.5,119.8,57.3$; HRMS calcd for $\mathrm{C}_{43} \mathrm{H}_{21} \mathrm{ClO}_{2}\left(\mathrm{M}^{+}\right)$604.1230, found 604.1231. Recrystallization of $\mathbf{2 8}$ from a mixture of methylene chloride and 2-propanol produced a single crystal suitable for X-ray structure analysis.

In $\mathrm{CDCl}_{3}, \mathbf{2 8}$ gradually and cleanly transformed to a new compound exhibiting a very different proton NMR spectrum with the two most upfield shift signals appearing at $\delta 5.28(1 \mathrm{H}$, d, $J=7.8 \mathrm{~Hz})$ and $5.60(1 \mathrm{H}, \mathrm{d}, J=8.4 \mathrm{~Hz})$. The structure of the new compound has not been elucidated.

Diol 30. To $0.155 \mathrm{~g}(0.767 \mathrm{mmol})$ of 1-ethynyl-2-(phenylethynyl)benzene in $10 \mathrm{~mL}$ of THF under a nitrogen atmosphere at $0{ }^{\circ} \mathrm{C}$ was added $0.461 \mathrm{~mL}$ of a $2.0 \mathrm{M}$ solution of LDA (0.921 $\mathrm{mmol})$ in THF. After $30 \mathrm{~min}$ of stirring, a solution of $0.118 \mathrm{~g}$ of truxenone $(\mathbf{1 9}, 0.307 \mathrm{mmol})$ in $20 \mathrm{~mL}$ of THF was introduced via cannula, and the reaction mixture was allowed to warm to room temperature. After an additional $18 \mathrm{~h}, 30 \mathrm{~mL}$ of a saturated aqueous ammonium chloride solution was introduced, and the reaction mixture was extracted with diethyl ether. The combined organic extracts were washed with brine and water, dried over sodium sulfate, and concentrated. The residue was purified by flash chromatography (silica gel/5 to $20 \%$ ethyl 
acetate in methylene chloride) to afford $0.184 \mathrm{~g}$ of the cis-diol $30(0.234 \mathrm{mmol}, 76 \%)$ as a bright yellow solid and $0.031 \mathrm{~g}$ of the trans-diol $30(0.040 \mathrm{mmol}, 13 \%)$ as a pale yellow solid. cis-30: IR 3400, 1689, $1605 \mathrm{~cm}^{-1} ;{ }^{1} \mathrm{H}\left(\mathrm{CDCl}_{3}, 600 \mathrm{MHz}\right) \delta 8.93-8.90(2 \mathrm{H}, \mathrm{m}), 8.65(1 \mathrm{H}, \mathrm{d}, J=7.8$ Hz), $7.89(1 \mathrm{H}, \mathrm{d}, J=7.2 \mathrm{~Hz}), 7.81(1 \mathrm{H}, \mathrm{d}, J=7.8 \mathrm{~Hz}), 7.43-7.34(5 \mathrm{H}, \mathrm{m}), 7.33-7.24(7 \mathrm{H}, \mathrm{m})$, 7.22-7.13 (8 H, m), 7.11-7.06 (4 H, m), $7.02(1 \mathrm{H}, \mathrm{t}, J=7.5 \mathrm{~Hz}), 3.36(1 \mathrm{H}, \mathrm{s}), 2.64(1 \mathrm{H}, \mathrm{s}) ;{ }^{13} \mathrm{C}$ $\left(\mathrm{CDCl}_{3}, 150 \mathrm{MHz}\right) \delta 193.9,149.1,148.7,142.5,142.1,141.8,141.4,141.0,140.2,136.5,135.5$, $134.9,134.3,132.2,132.1,131.7,131.4,130.6,130.3,130.1,129.7,129.2,128.3,128.24$, $128.21,128.20,128.1,127.7,127.3,127.0,126.2,126.1,124.62,124.58,124.0,123.9,123.8$, $122.9,122.7,93.5,93.4,91.2,91.0,87.8,87.6,83.0,82.9,74,8,74.6 ; \mathrm{MS} m / z 771\left(\mathrm{M}^{+}-\mathrm{OH}\right)$ 754; HRMS calcd for $\mathrm{C}_{59} \mathrm{H}_{32} \mathrm{O}_{3} \mathrm{Na}\left(\mathrm{MNa}^{+}\right)$811.2249, found 811.2245. Recrystallization of cis-30 from a mixture of methylene chloride and 2-propanol produced a single crystal suitable for X-ray structure analysis. trans-30: IR 3529, 3398, 1686, $1603 \mathrm{~cm}^{-1} ;{ }^{1} \mathrm{H}\left(\mathrm{CDCl}_{3}, 600 \mathrm{MHz}\right) \delta 8.88(1 \mathrm{H}$, d, $J=7.8 \mathrm{~Hz}), 8.68(1 \mathrm{H}, \mathrm{d}, J=7.8 \mathrm{~Hz}), 8.58(1 \mathrm{H}, \mathrm{d}, J=7.8 \mathrm{~Hz}), 7.87(1 \mathrm{H}, \mathrm{d}, J=7.2 \mathrm{~Hz}), 7.77$ $(1 \mathrm{H}, \mathrm{d}, J=7.2 \mathrm{~Hz}), 7.40(1 \mathrm{H}, \mathrm{td}, J=7.2,1.2 \mathrm{~Hz}), 7.38(1 \mathrm{H}, \mathrm{d}, J=7.8 \mathrm{~Hz}), 7.34(1 \mathrm{H}, \mathrm{d}, J=$ $7.8 \mathrm{~Hz}), 7.31(1 \mathrm{H}, \mathrm{td}, J=7.8,1.2 \mathrm{~Hz}), 7.28-7.24(4 \mathrm{H}, \mathrm{m}), 7.22(2 \mathrm{H}, \mathrm{d}, J=7.8 \mathrm{~Hz}), 7.20-7.13$ $(8 \mathrm{H}, \mathrm{m}), 7.12-7.04(6 \mathrm{H}, \mathrm{m}), 6.86(1 \mathrm{H}, \mathrm{d}, J=7.2 \mathrm{~Hz}), 3.73(1 \mathrm{H}, \mathrm{s}), 2.66(1 \mathrm{H}, \mathrm{s}) ;{ }^{13} \mathrm{C}\left(\mathrm{CDCl}_{3}\right.$, $150 \mathrm{MHz}) \delta 194.4,149.1,148.7,142.6,141.8,141.2,141.0,140.2,136.3,135.4,134.6,134.3$, $132.2,132.1,131.7,131.6,131.4,130.5,130.3,130.0,129.5,129.1,128.23,128.19,128.15$, 128.12, 128.10, 127.9, 127.6, 127.1, 126.7, 126.1, 126.0, 124.7, 124.6, 124.0, 123.9, 123.8, $122.9,122.6,93.4,93.3,91.3,91.0,87.7,87.5,82.8,82.5,74,8,74.5 ; \mathrm{MS} m / z 771\left(\mathrm{M}^{+}-\mathrm{OH}\right)$, 754; HRMS calcd for $\mathrm{C}_{59} \mathrm{H}_{32} \mathrm{O}_{3} \mathrm{Na}\left(\mathrm{MNa}^{+}\right)$811.2249, found 811.2251.

Ketone 31. To a solution of $0.097 \mathrm{~g}(0.123 \mathrm{mmol})$ of a mixture of the cis and trans isomers of diol 30 in $8 \mathrm{~mL}$ of diethyl ether under a nitrogen atmosphere at $0{ }^{\circ} \mathrm{C}$ was added slowly via cannula a solution of $0.09 \mathrm{~mL}(1.2 \mathrm{mmol})$ of thionyl chloride and $0.14 \mathrm{~mL}(1.7 \mathrm{mmol})$ of 
pyridine in $7 \mathrm{~mL}$ of diethyl ether. The reaction mixture was then allowed to warm to room temperature. After $7 \mathrm{~h}, 15 \mathrm{~mL}$ of water was introduced, and the organic layer was separated. The aqueous layer was back extracted with methylene chloride. The combined organic layers were washed with brine and water, dried over sodium sulfate, and concentrated. The residue was purified by flash chromatography (silica gel/50\% methylene chloride in hexanes) to afford 0.056 $\mathrm{g}(0.068 \mathrm{mmol}, 55 \%)$ of 31 as a red solid and ca. $0.004 \mathrm{~g}$ of an unidentified green solid. $31:{ }^{1} \mathrm{H}$ $\left(\mathrm{C}_{6} \mathrm{D}_{6}, 600 \mathrm{MHz}\right) \delta 8.73-8.71(1 \mathrm{H}, \mathrm{m}), 8.68-8.66(1 \mathrm{H}, \mathrm{m}), 8.62(1 \mathrm{H}, \mathrm{d}, J=7.8 \mathrm{~Hz}), 7.83(1 \mathrm{H}$, d, $J=7.8 \mathrm{~Hz}), 7.45(1 \mathrm{H}, \mathrm{d}, J=7.8 \mathrm{~Hz}), 7.43(1 \mathrm{H}, \mathrm{d}, J=7.8 \mathrm{~Hz}), 7.31(1 \mathrm{H}, \mathrm{d}, J=7.8 \mathrm{~Hz}), 7.27$ $(1 \mathrm{H}, \mathrm{d}, J=7.2 \mathrm{~Hz}), 7.25-7.23(2 \mathrm{H}, \mathrm{m}), 7.19-7.13(2 \mathrm{H}, \mathrm{m}), 7.10(1 \mathrm{H}, \mathrm{d}, J=6.6 \mathrm{~Hz}), 7.06(1$ H, t, $J=7.2 \mathrm{~Hz}), 7.03-7.01(1 \mathrm{H}, \mathrm{m}), 6.98(1 \mathrm{H}, \mathrm{t}, J=7.8 \mathrm{~Hz}), 6.91(1 \mathrm{H}, \mathrm{t}, J=7.5 \mathrm{~Hz}), 6.85(1$ H, t, $J=7.8 \mathrm{~Hz}), 6.81(1 \mathrm{H}, \mathrm{t}, J=7.5 \mathrm{~Hz}), 6.76(1 \mathrm{H}, \mathrm{t}, J=7.2 \mathrm{~Hz}), 6.74(1 \mathrm{H}, \mathrm{t}, J=7.2 \mathrm{~Hz})$, $6.68(1 \mathrm{H}, \mathrm{t}, J=7.8 \mathrm{~Hz}), 6.66(1 \mathrm{H}, \mathrm{t}, J=7.8 \mathrm{~Hz}), 6.59(1 \mathrm{H}, \mathrm{t}, J=7.8 \mathrm{~Hz}), 6.49(1 \mathrm{H}, \mathrm{t}, J=7.8$ Hz), $6.25(1 \mathrm{H}, \mathrm{d}, J=7.8 \mathrm{~Hz}), 6.23(1 \mathrm{H}, \mathrm{d}, J=7.8 \mathrm{~Hz}), 6.15(1 \mathrm{H}, \mathrm{d}, J=7.8 \mathrm{~Hz}), 6.07(1 \mathrm{H}, \mathrm{d}, J$ $=7.8 \mathrm{~Hz}), 5.62(1 \mathrm{H}, \mathrm{d}, J=7.8 \mathrm{~Hz}) ;{ }^{13} \mathrm{C}\left(\mathrm{C}_{6} \mathrm{D}_{6}, 150 \mathrm{MHz}\right) \delta 185.1,151.4,149.5,147.1,146.74$, $146.57,145.1,143.7,142.84,142.65,142.52,142.1,141.6,139.9,138.6,137.2,136.4,135.6$, $134.7,134.5,134.2,133.3,131.9,131.7,131.3,130.4,130.2,129.6,128.90,128.77,128.6$, $127.5,126.9,125.8,125.4,125.1,124.4,124.1,123.2,122.7,122.4,119.9,119.5,64.8,58.2$; HRMS calcd for $\mathrm{C}_{59} \mathrm{H}_{31} \mathrm{Cl}_{2} \mathrm{O}\left(\mathrm{MH}^{+}\right)$825.1752, found 825.1755. Recrystallization of 31 from a mixture of methylene chloride and hexanes produced a single crystal suitable for X-ray structure analysis.

In $\mathrm{CDCl}_{3}, \mathbf{3 1}$ gradually and cleanly transformed to the unidentified green solid, which exhibited the two most upfield shift signals at $\delta 5.56(1 \mathrm{H}, \mathrm{d}, J=7.8 \mathrm{~Hz})$ and $6.00(1 \mathrm{H}, \mathrm{d}, J=$ $7.8 \mathrm{~Hz})$. 
Triol 20. To $0.158 \mathrm{~g}(0.782 \mathrm{mmol})$ of 1-ethynyl-2-(phenylethynyl)benzene in $5 \mathrm{~mL}$ of THF under a nitrogen atmosphere at $0{ }^{\circ} \mathrm{C}$ was added $0.49 \mathrm{~mL}$ of a $1.6 \mathrm{M}$ solution of $n$-butyllithium $(0.78 \mathrm{mmol})$ in hexanes. After $30 \mathrm{~min}$ of stirring, a solution of $0.060 \mathrm{~g}$ of truxenone $(\mathbf{1 9}, 0.156$ mmol) in $10 \mathrm{~mL}$ of THF was introduced via cannula, and the reaction mixture was allowed to warm to room temperature. After an additional $18 \mathrm{~h}, 15 \mathrm{~mL}$ of water was introduced, and the reaction mixture was extracted with diethyl ether. The combined organic extracts were washed with brine and water, dried over sodium sulfate, and concentrated. The residue was purified by flash chromatography (methylene chloride followed by $20 \%$ diethyl ether in methylene chloride) to afford $0.114 \mathrm{~g}$ of the anti isomer of $20(0.115 \mathrm{mmol}, 74 \%)$ as a pale yellow solid and $0.024 \mathrm{~g}$ of the syn isomer of $\mathbf{2 0}(0.023 \mathrm{mmol}, 15 \%)$ as a brown solid. anti-20: IR 3538, 1606, $1494 \mathrm{~cm}^{-1}$; ${ }^{1} \mathrm{H}\left(\mathrm{CDCl}_{3}, 600 \mathrm{MHz}\right) \delta 8.95(1 \mathrm{H}, \mathrm{d}, J=7.8 \mathrm{~Hz}), 8.94(1 \mathrm{H}, \mathrm{d}, J=7.8 \mathrm{~Hz}), 8.88(1 \mathrm{H}, \mathrm{d}, J=7.8$ Hz), $7.88(2 \mathrm{H}, \mathrm{t}, J=7.8 \mathrm{~Hz}), 7.84(1 \mathrm{H}, \mathrm{d}, J=7.2 \mathrm{~Hz}), 7.45-7.36(8 \mathrm{H}, \mathrm{m}), 7.32-7.27(6 \mathrm{H}, \mathrm{m})$, 7.23-7.16 (15 H, m), 7.12-7.08 (3 H, m), $7.01(1 \mathrm{H}, \mathrm{t}, J=7.2 \mathrm{~Hz}), 2.59(1 \mathrm{H}, \mathrm{s}), 2.44(1 \mathrm{H}, \mathrm{s})$, $2.00(1 \mathrm{H}, \mathrm{s}) ;{ }^{13} \mathrm{C}\left(\mathrm{CDCl}_{3}, 150 \mathrm{MHz}\right) \delta 148.50,148.46,148.37,140.15,140.11,140.08,138.74$, $138.66,138.61,136.3,136.1,136.0,132.2,131.74,131.72,131.68,131.65,131.5,129.7,129.56$ $129.53,129.4,128.27,128.22,128.18,127.76,127.75,127.73,127.2,127.1,127.0,126.1$ $126.00,125.96,124.8,124.72,124.70,124.2,124.02,124.00,123.10,123.06,122.9,93.29$, $93.23,93.15,91.55,91.52,91.48,87.90,87.88,87.79,82.9,82.7,82.4,75.24,75.20,75.19$; MS m/z $973\left(\mathrm{M}^{+}-\mathrm{OH}\right), 771$; HRMS calcd for $\mathrm{C}_{75} \mathrm{H}_{42} \mathrm{O}_{3} \mathrm{Na}\left(\mathrm{MNa}^{+}\right)$1013.3032, found 1013.3031. syn-20: IR 3529, 1600, $1494 \mathrm{~cm}^{-1}$; ${ }^{1} \mathrm{H}\left(\mathrm{CDCl}_{3}, 600 \mathrm{MHz}\right) \delta 8.88(3 \mathrm{H}, \mathrm{d}, J=7.2 \mathrm{~Hz}), 7.81(3 \mathrm{H}$, d, $J=7.8 \mathrm{~Hz}), 7.39-7.35(6 \mathrm{H}, \mathrm{m}), 7.29-7.27(6 \mathrm{H}, \mathrm{m}), 7.20(3 \mathrm{H}, \mathrm{td}, J=7.2,1.2 \mathrm{~Hz}), 7.17-7.14$ (6 H, m), 7.13-7.10 (6 H, m), 7.09-7.06 (3 H, m), 7.03 (3 H, td, J = 7.8, 1.2 Hz), 2.74 (3 H, s); ${ }^{13} \mathrm{C}\left(\mathrm{CDCl}_{3}, 150 \mathrm{MHz}\right) \delta 148.4,140.1,138.5,136.1,132.3,131.64,131.61,129.6,129.3,128.19$, 
$128.13,128.08,127.6,126.9,126.0,124.6,124.0,122.9,93.5,91.3,87.9,82.9,75.0 ; \mathrm{MS} \mathrm{m} / \mathrm{z}$ $973\left(\mathrm{M}^{+}-\mathrm{OH}\right)$; HRMS calcd for $\mathrm{C}_{75} \mathrm{H}_{42} \mathrm{O}_{3} \mathrm{Na}\left(\mathrm{MNa}^{+}\right)$1013.3032, found 1013.3036.

Alcohol 34. To a solution of $0.089 \mathrm{~g}(0.090 \mathrm{mmol})$ of the anti and syn isomers of 20 in $10 \mathrm{~mL}$ of diethyl ether under a nitrogen atmosphere at $0{ }^{\circ} \mathrm{C}$ was added slowly via cannula a solution of $0.07 \mathrm{~mL}(0.9 \mathrm{mmol})$ of thionyl chloride and $0.11 \mathrm{~mL}(1.4 \mathrm{mmol})$ of pyridine in $5 \mathrm{~mL}$ of diethyl ether. The reaction mixture then was allowed to warm to room temperature. After $7 \mathrm{~h}, 15 \mathrm{~mL}$ of water was introduced, and the organic layer was separated. The aqueous layer was back extracted with methylene chloride. The combined organic layers were washed with brine and water, dried over sodium sulfate, and concentrated. The residue was purified by flash chromatography (silica gel $/ 40 \%$ methylene chloride in hexanes) to afford $0.044 \mathrm{~g}(0.043 \mathrm{mmol}, 48 \%)$ of 34 as a bright yellow solid: IR 1643, $1600 \mathrm{~cm}^{-1} ;{ }^{1} \mathrm{H}\left(\mathrm{C}_{6} \mathrm{D}_{6}, 600 \mathrm{MHz}\right) \delta 8.88(1 \mathrm{H}, \mathrm{d}, J=7.8 \mathrm{~Hz}), 8.85(1 \mathrm{H}, \mathrm{d}$, $J=7.8 \mathrm{~Hz}), 7.99(1 \mathrm{H}, \mathrm{d}, J=7.2 \mathrm{~Hz}), 7.77(1 \mathrm{H}, \mathrm{d}, J=7.2 \mathrm{~Hz}), 7.57(1 \mathrm{H}, \mathrm{d}, J=7.2 \mathrm{~Hz})$, 7.48-7.46 (2 H, t, $J=6.3 \mathrm{~Hz}), 7.42(1 \mathrm{H}, \mathrm{t}, J=7.5 \mathrm{~Hz}), 7.34(1 \mathrm{H}, \mathrm{d}, J=7.8 \mathrm{~Hz}), 7.31(1 \mathrm{H}, \mathrm{t}, J$ = 7.2 Hz), 7.27-7.21 (6 H, m), 7.03-6.84 (10 H, m), 6.76-6.69 (3 H, m), 6.66-6.61 (3 H, m), $6.53(1 \mathrm{H}, \mathrm{t}, J=7.5 \mathrm{~Hz}), 6.45(1 \mathrm{H}, \mathrm{d}, J=7.8 \mathrm{~Hz}), 6.34(1 \mathrm{H}, \mathrm{d}, J=7.8 \mathrm{~Hz}), 6.27(1 \mathrm{H}, \mathrm{d}, J=7.8$ Hz), $6.14(1 \mathrm{H}, \mathrm{d}, J=7.8 \mathrm{~Hz}), 6.01(1 \mathrm{H}, \mathrm{d}, J=7.8 \mathrm{~Hz}), 5.83(1 \mathrm{H}, \mathrm{d}, J=7.8 \mathrm{~Hz}), 1.07(1 \mathrm{H}, \mathrm{s})$; ${ }^{13} \mathrm{C}\left(\mathrm{C}_{6} \mathrm{D}_{6}, 150 \mathrm{MHz}\right) \delta 152.2,151.6,148.7,148.3,147.9,147.0,146.25,146.18,144.3,142.4$, $142.2,141.7,141.4,139.0,136.7,136.42,136.36,134.2,133.9,133.8,133.3,132.2,132.1$, $131.1,130.82,130.79,129.8,129.4,127.4,127.2,127.1,126.9,126.7,126.5,126.1,126.0$ $125.8,125.7,125.4,125.0,124.6,124.48,124.43,123.6,122.9,122.6,122.0,121.6,119.7$, 119.4, 100.2, 93.7, 89.1, 86.1, 85.4. (The ${ }^{13} \mathrm{C}$ NMR signals of the two $\mathrm{sp}^{3}$-hybridized quaternary carbons without a hydroxyl substituent are too weak to be discerned.); MS m/z $1009\left(\mathrm{M}^{+}-\mathrm{OH}\right)$; HRMS calcd for $\mathrm{C}_{75} \mathrm{H}_{40} \mathrm{Cl}_{2} \mathrm{ONa}\left(\mathrm{MNa}^{+}\right)$1049.2354, found 1049.2361. Recrystallization of 34 
from a mixture of methylene chloride and 2-propanol produced a single crystal suitable for X-ray structure analysis.

\section{Experimental Section of Chapter II}

1-Ethynyl-2-methoxybenzene (64a), pivalophenone (40), n-butyllithium (1.6 M) in hexanes, 1-bromo-2-[(trimethylsilyl)ethynyl]benzene, triethylsilane, trifluoroacetic acid, potassium t-butoxide $(1.0 \mathrm{M})$ in 2-methyl-2-propanol, lithium diisopropylamide (LDA, $2.0 \mathrm{M})$ in heptane/THF/ethylbenzene, $\mathrm{Pd}\left(\mathrm{PPh}_{3}\right)_{2} \mathrm{Cl}_{2}$, $\mathrm{Pd}\left(\mathrm{PPh}_{3}\right)_{4}$, copper(I) iodide, triethylamine, $1.0 \mathrm{M}$ $\mathrm{BH}_{3} \cdot$ THF solution in THF, 1-ethynylnaphthalene (84), 2-methoxy-1-naphthaldehyde, 1-bromo-2-(methoxymethyl)naphthalene, (trimethylsilyl)acetylene, boron tribromide, and (1S)-(-)-camphanoyl chloride were purchased from chemical suppliers and were used as

received. 1-Iodo-2-[(trimethylsilyl)ethynyl]benzene (65) was prepared by treatment of 1-bromo-2-[(trimethylsilyl)ethynyl]benzene in THF with $n$-butyllithium at $-78{ }^{\circ} \mathrm{C}$ followed by iodine. ${ }^{8 \mathrm{f}}$ 1-Ethynyl-2-iodo-benzene (81) was prepared in quantitative yield by desilylation of $\mathbf{6 5}$ with sodium hydroxide in methanol. 1-Ethynyl-2-(methoxymethyl)benzene (64b) ${ }^{12}$ and dimethyl (1-diazo-2-oxopropyl)phosphonate ${ }^{13}$ were prepared according to the reported procedures.

Trimethyl[[2-[(2-methoxyphenyl)ethynyl]phenyl]ethynyl]silane (66a). To a mixture of 0.318 g of 65 (1.059 mmol), $\mathrm{Pd}\left(\mathrm{PPh}_{3}\right)_{2} \mathrm{Cl}_{2}(0.027 \mathrm{~g}, 0.039 \mathrm{mmol})$, and copper(I) iodide $(0.008 \mathrm{~g}, 0.04$ mmol) in $15 \mathrm{~mL}$ of triethylamine was added via cannula a solution of $0.103 \mathrm{~g}$ of $64 \mathrm{a}(0.780$ mmol) in $5 \mathrm{~mL}$ of triethylamine. After $5 \mathrm{~h}$ of stirring at $70{ }^{\circ} \mathrm{C}, 20 \mathrm{~mL}$ of a saturated ammonium chloride solution and $20 \mathrm{~mL}$ of diethyl ether were added. The organic layer was separated, and the aqueous layer was back extracted with diethyl ether. The combined organic layers were washed with brine and water, dried over sodium sulfate, and concentrated. Purification of the residue by flash column chromatography (silica gel $/ 30 \%$ methylene chloride in hexanes) 
afforded $0.206 \mathrm{~g}$ of $\mathbf{6 6 a}(0.677 \mathrm{mmol}, 87 \%)$ as a colorless liquid: ${ }^{1} \mathrm{H}\left(\mathrm{CDCl}_{3}, 270 \mathrm{MHz}\right) \delta$ 7.59-7.47 (3 H, m), 7.35-7.20 (3 H, m), $6.94(1 \mathrm{H}, \mathrm{t}, J=7.7 \mathrm{~Hz}), 6.91(1 \mathrm{H}, \mathrm{d}, J=7.7 \mathrm{~Hz}), 3.91$ (3 H, s), $0.26(9 \mathrm{H}, \mathrm{s}) ;{ }^{13} \mathrm{C}\left(\mathrm{CDCl}_{3}, 67.9 \mathrm{MHz}\right) \delta 159.9,133.9,132.2,131.9,129.9,128.1,127.6$, $126.4,125.4,120.4,112.5,110.7,103.6,98.4,92.0,89.9,55.8,-0.1$.

Benzannulated Enediyne 67a. To $0.201 \mathrm{~g}$ ( $0.660 \mathrm{mmol})$ of 66a in $10 \mathrm{~mL}$ of diethyl ether were added $4 \mathrm{~mL}$ of a $10 \%$ sodium hydroxide solution and $10 \mathrm{~mL}$ of methanol. After $30 \mathrm{~min}$ of stirring at room temperature, $20 \mathrm{~mL}$ of water and $20 \mathrm{~mL}$ of diethyl ether were added. The organic layer was separated, and the aqueous layer was back extracted with diethyl ether. The combined organic layers were washed with brine and water, dried over sodium sulfate, and concentrated. Purification of the residue by flash column chromatography (silica gel $/ 30 \%$ methylene chloride in hexanes) afforded $0.137 \mathrm{~g}$ of $\mathbf{6 7 a}(0.591 \mathrm{mmol}, 90 \%)$ as a yellow liquid: IR 3286, 2114, 1496, $1247 \mathrm{~cm}^{-1}$; ${ }^{1} \mathrm{H}\left(\mathrm{CDCl}_{3}, 270 \mathrm{MHz}\right) \delta 7.60-7.51(3 \mathrm{H}, \mathrm{m}), 7.36-7.23(3 \mathrm{H}$, m), $6.95(1 \mathrm{H}, \mathrm{t}, J=7.6 \mathrm{~Hz}), 6.90(1 \mathrm{H}, \mathrm{d}, J=8.2 \mathrm{~Hz}), 3.91(3 \mathrm{H}, \mathrm{s}), 3.37(1 \mathrm{H}, \mathrm{s}) ;{ }^{13} \mathrm{C}\left(\mathrm{CDCl}_{3}\right.$, 67.9 MHz) $\delta 160.0,133.8,132.5,131.8,130.0,128.4,127.7,126.6,124.4,120.4,112.3,110.7$, 91.8, 90.0, 82.3, 81.0, 55.8. MS m/z $232\left(\mathrm{M}^{+}\right)$; HRMS calcd for $\mathrm{C}_{17} \mathrm{H}_{12} \mathrm{O}\left(\mathrm{M}^{+}\right)$232.0888, found 232.0883 .

\section{$\alpha$-[[2-[(2-Methoxyphenyl)ethynyl]phenyl]ethynyl]- $\alpha$-(1,1-dimethylethyl)benzenemethanol}

(68a). To $0.065 \mathrm{~g}(0.28 \mathrm{mmol})$ of $\mathbf{6 7 a}$ in $5 \mathrm{~mL}$ of anhydrous diethyl ether under a nitrogen atmosphere at $0{ }^{\circ} \mathrm{C}$ was added $0.18 \mathrm{~mL}$ of a $1.6 \mathrm{M}$ solution of $n$-butyllithium $(0.28 \mathrm{mmol})$ in hexanes. After $30 \mathrm{~min}$ of stirring, a solution of $0.064 \mathrm{~g}$ of $\mathbf{4 0}(0.39 \mathrm{mmol})$ in $10 \mathrm{~mL}$ of THF was introduced via cannula, and the reaction mixture was allowed to warm to room temperature. After an additional $3 \mathrm{~h}, 15 \mathrm{~mL}$ of water was introduced, and the reaction mixture was extracted with diethyl ether. The combined organic extracts were washed with brine and water, dried over sodium sulfate, and concentrated. The residue was purified by flash column chromatography 
(silica gel $/ 15 \%$ diethyl ether in hexanes) to provide $0.109 \mathrm{~g}(0.276 \mathrm{mmol}, 99 \%)$ of $\mathbf{6 8 a}$ as a light yellow liquid: ${ }^{1} \mathrm{H}\left(\mathrm{CDCl}_{3}, 270 \mathrm{MHz}\right) \delta 7.78-7.71(2 \mathrm{H}, \mathrm{m}), 7.61-7.57(1 \mathrm{H}, \mathrm{m}), 7.53-7.49(1 \mathrm{H}$, m), 7.41 (1 H, dd, $J=7.9,1.7 \mathrm{~Hz}), 7.35-7.20(6 \mathrm{H}, \mathrm{m}), 6.94-6.87(2 \mathrm{H}, \mathrm{m}), 3.84(3 \mathrm{H}, \mathrm{s}), 2.67(1$ H, s), 1.07 (9 H, s); ${ }^{13} \mathrm{C}\left(\mathrm{CDCl}_{3}, 67.9 \mathrm{MHz}\right) \delta 159.9,142.1,133.7,132.2,131.9,129.9,127.9$, 127.8, 127.2, 126.9, 126.1, 125.1, 120.5, 112.4, 110.9, 96.2, 92.1, 89.5, 84.6, 79.4, 55.9, 39.7, 25.5 .

Benzannulated Enediyne 69a. To a mixture of 68a $(0.109 \mathrm{~g}, 0.276 \mathrm{mmol})$ and triethylsilane (0.048 g, $0.41 \mathrm{mmol})$ in $10 \mathrm{~mL}$ of methylene chloride was added trifluoroacetic acid $(0.126 \mathrm{~g}$, $1.11 \mathrm{mmol}$ ). After $1 \mathrm{~h}$ of stirring at room temperature, $0.11 \mathrm{~g}$ of sodium carbonate (4.6 mmol) was added followed by $10 \mathrm{~mL}$ of water and $10 \mathrm{~mL}$ of diethyl ether. The organic layer was separated, dried over sodium sulfate, and concentrated. Purification of the residue by flash column chromatography (silica gel/25\% methylene chloride in hexanes) provided $0.097 \mathrm{~g}(0.256$ mmol, 93\%) of 69a as a light yellow liquid: ${ }^{1} \mathrm{H}\left(\mathrm{CDCl}_{3}, 270 \mathrm{MHz}\right) \delta 7.61-7.55(1 \mathrm{H}, \mathrm{m})$, 7.48-7.16 (10 H, m), 6.92-6.85 (2 H, m), $3.87(3 \mathrm{H}, \mathrm{s}), 3.69(1 \mathrm{H}, \mathrm{s}), 1.04(9 \mathrm{H}, \mathrm{s}) ;{ }^{13} \mathrm{C}\left(\mathrm{CDCl}_{3}\right.$, 67.9 MHz) $\delta 160.0,139.2,133.7,132.2,132.0,129.8,129.7,127.7,127.5,127.2,126.5,126.3$, $125.9,120.3,112.5,110.5,95.5,92.4,89.1,82.6,55.7,50.6,35.5,27.7$.

5-(2-Methoxyphenyl)-10-(1,1-dimethylethyl)-11H-benzo[b]fluorene (73a) To $0.097 \mathrm{~g}$ of 69a $(0.256 \mathrm{mmol})$ in $10 \mathrm{~mL}$ of anhydrous toluene under a nitrogen atmosphere was added $0.33 \mathrm{~mL}$ of a $1.0 \mathrm{M}$ solution of potassium $t$-butoxide $(0.33 \mathrm{mmol})$ in 2-methyl-2-propanol. The reaction mixture was then heated to reflux for $5 \mathrm{~h}$. After the reaction mixture was allowed to cool to room temperature, $10 \mathrm{~mL}$ of water and $20 \mathrm{~mL}$ of methylene chloride were introduced, and the organic layer was separated, dried over sodium sulfate, and concentrated. The residue was purified by flash column chromatography (silica gel $/ 20 \%$ methylene chloride in hexanes) to provide $0.073 \mathrm{~g}$ of 73a (0.192 mmol, 75\%) as a light yellow liquid and $0.002 \mathrm{~g}$ of 74a $(0.005 \mathrm{mmol}, 2 \%)$. 73a: IR 
1330, 811, $739 \mathrm{~cm}^{-1} ;{ }^{1} \mathrm{H}\left(\mathrm{C}_{6} \mathrm{D}_{6}, 600 \mathrm{MHz}\right) \delta 8.62(1 \mathrm{H}, \mathrm{d}, J=9.0 \mathrm{~Hz}), 7.89(1 \mathrm{H}, \mathrm{d}, J=8.4 \mathrm{~Hz})$, 7.35-7.27 (4 H, m), 7.22 (1 H, t, $J=7.2 \mathrm{~Hz}), 7.11(1 \mathrm{H}, \mathrm{t}, J=7.2 \mathrm{~Hz}), 7.04-7.02(2 \mathrm{H}, \mathrm{m}), 6.86$ $(1 \mathrm{H}, \mathrm{d}, J=7.8 \mathrm{~Hz}), 6.78(1 \mathrm{H}, \mathrm{d}, J=8.4 \mathrm{~Hz}), 4.21(1 \mathrm{H}, \mathrm{d}, J=21.0 \mathrm{~Hz}), 4.13(1 \mathrm{H}, \mathrm{d}, J=21.0$ $\mathrm{Hz}), 3.06(3 \mathrm{H}, \mathrm{s}), 1.71(9 \mathrm{H}, \mathrm{s}) ;{ }^{13} \mathrm{C}\left(\mathrm{CDCl}_{3}, 67.9 \mathrm{MHz}\right) \delta 157.7,144.2,140.7,140.5,138.4$, $137.7,134.4,131.8,131.5,129.6,129.3,128.3,128.0,127.2,126.7,126.3,124.0,123.8,123.2$, 123.1, 121.5, 111.6, 55.8, 40.2, 38.8, 34.4; MS m/z $378\left(\mathrm{M}^{+}\right), 363,349,321$; HRMS calcd for $\mathrm{C}_{28} \mathrm{H}_{26} \mathrm{O}$ 378.1984, found 378.1971. The ${ }^{1} \mathrm{H}$ NMR signals attributable to 74a (ca. 2\%) were observed at $\delta\left(\mathrm{CDCl}_{3}\right) 6.25(1 \mathrm{H}, \mathrm{s}), 3.86(3 \mathrm{H}, \mathrm{s})$, and $1.23(9 \mathrm{H}, \mathrm{s})$.

Trimethyl[[2-[[2-(methoxymethyl)phenyl]ethynyl]phenyl]ethynyl]silane (66b). The same procedure was repeated as described for 66a except that $0.445 \mathrm{~g}$ of 65 (1.482 mmol), $\operatorname{Pd}\left(\mathrm{PPh}_{3}\right)_{2} \mathrm{Cl}_{2}(0.040 \mathrm{~g}, 0.056 \mathrm{mmol})$, and copper(I) iodide $(0.015 \mathrm{~g}, 0.080 \mathrm{mmol})$ in $10 \mathrm{~mL}$ of triethylamine were treated with a solution of $0.167 \mathrm{~g}$ of $\mathbf{6 4 b}(1.140 \mathrm{mmol})$ in $5 \mathrm{~mL}$ of triethylamine to afford $0.287 \mathrm{~g}$ of $\mathbf{6 6 b}(0.900 \mathrm{mmol}, 79 \%)$ as a colorless liquid: IR 2959, 2156, 1490, 1473, $1250 \mathrm{~cm}^{-1} ;{ }^{1} \mathrm{H}\left(\mathrm{CDCl}_{3}, 600 \mathrm{MHz}\right) \delta 7.31(1 \mathrm{H}, \mathrm{d}, J=7.2 \mathrm{~Hz}), 7.28-7.23(2 \mathrm{H}, \mathrm{m})$, $7.11(1 \mathrm{H}, \mathrm{t}, J=7.2 \mathrm{~Hz}), 7.06-7.00(4 \mathrm{H}, \mathrm{m}), 4.52(2 \mathrm{H}, \mathrm{s}), 3.22(3 \mathrm{H}, \mathrm{s}), 0.01(9 \mathrm{H}, \mathrm{s}) ;{ }^{13} \mathrm{C}$ $\left(\mathrm{CDCl}_{3}, 150 \mathrm{MHz}\right) \delta 140.0,132.6,132.3,131.9,128.7,128.2,127.9,127.4,127.2,125.9,125.4$, $121.8,103.6,98.6,92.5,90.9,72.6,58.5,-0.04$.

Benzannulated Enediyne 67b. The same procedure was repeated as described for 67a except that a solution of $0.255 \mathrm{~g}(0.800 \mathrm{mmol}) \mathbf{6 6} \mathrm{b}$ in $15 \mathrm{~mL}$ of diethyl ether was treated with $6 \mathrm{~mL}$ of a $10 \%$ sodium hydroxide solution and $15 \mathrm{~mL}$ of methanol to afford $0.193 \mathrm{~g}$ of $\mathbf{6 7 b}(0.785 \mathrm{mmol}$, 98\%) as a yellow liquid: ${ }^{1} \mathrm{H}\left(\mathrm{CDCl}_{3}, 600 \mathrm{MHz}\right) \delta 7.56(1 \mathrm{H}, \mathrm{dd}, J=7.8,1.2 \mathrm{~Hz}), 7.55-7.53(2 \mathrm{H}$, m), $7.50(1 \mathrm{H}, \mathrm{d}, J=8.4 \mathrm{~Hz}), 7.36(1 \mathrm{H}, \mathrm{td}, J=7.7,1.2 \mathrm{~Hz}), 7.33(1 \mathrm{H}, \mathrm{td}, J=7.8,1.2 \mathrm{~Hz})$, 7.30-7.26 (2 H, m), $4.80(2 \mathrm{H}, \mathrm{s}), 3.47(3 \mathrm{H}, \mathrm{s}), 3.37(1 \mathrm{H}, \mathrm{s}) ; 13 \mathrm{C}(\mathrm{CDCl} 3,150 \mathrm{MHz}) \delta 140.3$, $132.7,132.2,131.9,128.8,128.6,128.0,127.21,127.18,126.3,124.3,121.5,92.2,91.0,82.5$, 
81.1, 72.6, 58.5. MS m/z $341\left(\mathrm{MNa}^{+}\right)$, 267; HRMS calcd for $\mathrm{C}_{21} \mathrm{H}_{22} \mathrm{OSi}\left(\mathrm{MNa}^{+}\right)$341.1332, found 341.1334.

$\alpha-[[2-[[2-(M e t h o x y m e t h y l) p h e n y l]$ ethynyl]phenyl]ethynyl]-a-(1,1-dimethylethyl)benzeneme thanol (68b). The same procedure was repeated as described for 68a except that $0.165 \mathrm{~g}$ (1.015 mmol) of 40 was treated with the lithium acetylide derived from $0.178 \mathrm{~g}(0.725 \mathrm{mmol})$ of $\mathbf{6 7 b}$ and $0.45 \mathrm{~mL}$ of a $1.6 \mathrm{M}$ solution of $n$-butyllithium $(0.72 \mathrm{mmol})$ in hexanes to afford $0.284 \mathrm{~g}$ (0.696 mmol, 96\%) of $\mathbf{6 8 b}$ as a light yellow liquid: IR 3410, 2961, 1490, $758 \mathrm{~cm}^{-1} ;{ }^{1} \mathrm{H}(\mathrm{CDCl} 3$, $270 \mathrm{MHz}) \delta$ 7.74-7.69 (2 H, m), 7.57-7.53 (2 H, m), 7.46-7.21 (7 H, m), $4.67(1 \mathrm{H}, \mathrm{d}, J=12.6$ $\mathrm{Hz}), 4.40(1 \mathrm{H}, \mathrm{d}, J=12.4 \mathrm{~Hz}), 3.31(3 \mathrm{H}, \mathrm{s}), 1.68(1 \mathrm{H}, \mathrm{s}$, broad $), 1.07(9 \mathrm{H}, \mathrm{s}) ;{ }^{13} \mathrm{C}\left(\mathrm{CDCl}_{3}, 67.9\right.$ MHz) $\delta 142.4,139.4,132.4,132.2,128.5,128.2,128.07,128.02,127.8,127.5,127.2,127.0$, 125.6, 125.3, 122.3, 96.8, 92.6, 90.8, 84.4, 79.3, 72.5, 57.7, 39.7, 25.6. MS m/z 431 ( $\left.\mathrm{MNa}^{+}\right), 359$; HRMS calcd for $\mathrm{C}_{29} \mathrm{H}_{28} \mathrm{O}_{2}\left(\mathrm{MNa}^{+}\right)$431.1982, found 431.1983 .

Benzannulated Enediyne 69b. The same procedure was repeated as described for 69a except that $0.163 \mathrm{~g}$ of $\mathbf{6 8 b}(0.400 \mathrm{mmol})$ and $0.070 \mathrm{~g}$ of triethylsilane $(0.601 \mathrm{mmol})$ was treated with $0.182 \mathrm{~g}$ of trifluoroacetic acid $(1.602 \mathrm{mmol})$ to afford $0.141 \mathrm{~g}(0.360 \mathrm{mmol}, 90 \%)$ of $\mathbf{6 9 b}$ as a light yellow liquid: ${ }^{1} \mathrm{H}\left(\mathrm{CDCl}_{3}, 600 \mathrm{MHz}\right) \delta 7.54-7.52(1 \mathrm{H}, \mathrm{m}), 7.50-7.48(1 \mathrm{H}, \mathrm{m}), 7.47(1 \mathrm{H}$, d, $J=7.2 \mathrm{~Hz}), 7.41-7.38(3 \mathrm{H}, \mathrm{m}), 7.34(1 \mathrm{H}, \mathrm{t}, J=7.8 \mathrm{~Hz}), 7.29-7.27(2 \mathrm{H}, \mathrm{m}), 7.21(1 \mathrm{H}, \mathrm{t}, J$ =7.8 Hz), 7.19-7.17 (3 H, m), $4.70(1 \mathrm{H}, \mathrm{d}, J=12.6 \mathrm{~Hz}), 4.63(1 \mathrm{H}, \mathrm{d}, J=13.2 \mathrm{~Hz}), 3.69(1 \mathrm{H}, \mathrm{s})$, $3.41(3 \mathrm{H}, \mathrm{s}), 1.03(9 \mathrm{H}, \mathrm{s}) ;{ }^{13} \mathrm{C}\left(\mathrm{CDCl}_{3}, 150 \mathrm{MHz}\right) \delta 140.2,139.1,132.3,132.11,132.05,129.7$, 128.5, 128.0, 127.6, 127.4, 127.2, 127.1, 126.7, 126.3, 125.5, 121.7, 95.7, 93.0, 90.3, 82.5, 72.5, $58.5,50.6,35.5,27.7$.

5-[2-(Methoxymethyl)phenyl]-10-(1,1-dimethylethyl)-11H-benzo[b]fluorene (73b). The same procedure was repeated as described for 73a except that $0.119 \mathrm{~g}$ of $\mathbf{6 9 b}(0.303 \mathrm{mmol})$ was treated with $0.39 \mathrm{~mL}$ of a $1.0 \mathrm{M}$ solution of potassium $t$-butoxide $(0.39 \mathrm{mmol})$ in 
2-methyl-2-propanol to afford $0.075 \mathrm{~g}$ of a mixture of $\mathbf{7 3 b}$ and $\mathbf{7 4 b}$ in a 5:1 ratio as a light yellow liquid. The mixture was then dissolved in $8 \mathrm{~mL}$ of THF and treated with $1 \mathrm{~mL}$ of a $1.0 \mathrm{M}$ $\mathrm{BH}_{3} \cdot \mathrm{THF}$ solution under a nitrogen atmosphere. After $5 \mathrm{~h}$ of stirring at room temperature, $10 \mathrm{~mL}$ of water and $10 \mathrm{~mL}$ of diethyl ether were added. The organic layer was separated, and the aqueous layer was back extracted with diethyl ether. The combined organic layers were washed with brine and water, dried over sodium sulfate, and concentrated. Purification of the residue by flash column chromatography (silica gel/30\% methylene chloride in hexanes) afforded $0.057 \mathrm{~g}$ of 73b (0.145 mmol, 48\%) as a colorless liquid: IR 2923, 1088, 764, $732 \mathrm{~cm}^{-1} ;{ }^{1} \mathrm{H}\left(\mathrm{CDCl}_{3}, 600\right.$ MHz) $\delta 8.62(1 \mathrm{H}, \mathrm{d}, J=9.6 \mathrm{~Hz}), 7.77(1 \mathrm{H}, \mathrm{d}, J=7.8 \mathrm{~Hz}), 7.60(1 \mathrm{H}, \mathrm{t}, J=7.8 \mathrm{~Hz}), 7.49-7.41$ (4 H, m), $7.29(1 \mathrm{H}, \mathrm{t}, J=7.2 \mathrm{~Hz}), 7.22(1 \mathrm{H}, \mathrm{d}, J=7.8 \mathrm{~Hz}), 7.19(1 \mathrm{H}, \mathrm{t}, J=7.2 \mathrm{~Hz}), 6.96(1 \mathrm{H}, \mathrm{t}$, $J=7.8 \mathrm{~Hz}), 6.22(1 \mathrm{H}, \mathrm{d}, J=7.8 \mathrm{~Hz}), 4.522(1 \mathrm{H}, \mathrm{d}, J=21 \mathrm{~Hz}), 4.504(1 \mathrm{H}, \mathrm{d}, J=21 \mathrm{~Hz}), 4.07$ $(1 \mathrm{H}, \mathrm{d}, J=13.8 \mathrm{~Hz}), 4.04(1 \mathrm{H}, \mathrm{d}, J=13.8 \mathrm{~Hz}), 3.10(3 \mathrm{H}, \mathrm{s}), 1.93(9 \mathrm{H}, \mathrm{s}) ;{ }^{13} \mathrm{C}\left(\mathrm{CDCl}_{3}, 67.9\right.$ MHz) $\delta 144.1,141.2,140.1,138.3,137.9,137.5,137.4,134.1,131.4,130.7,130.3,128.2,128.0$, 127.0, 126.5, 124.3, 123.9, 123.4, 123.1, 71.7, 58.3, 40.2, 38.9, 34.4; MS m/z $392\left(\mathrm{M}^{+}\right), 377,343$; HRMS calcd for $\mathrm{C}_{29} \mathrm{H}_{28} \mathrm{O}$ 392.2140, found 392.2135. The ${ }^{1} \mathrm{H}$ NMR signals attributable to 74b (ca. 10\%) before treatment with $\mathrm{BH}_{3} \cdot \mathrm{THF}$ were observed at $\delta\left(\mathrm{CDCl}_{3}\right) 6.36(1 \mathrm{H}, \mathrm{s}), 4.31(1 \mathrm{H}, \mathrm{d}$, $J=13.2 \mathrm{~Hz}), 3.83(1 \mathrm{H}, \mathrm{d}, J=13.2 \mathrm{~Hz}), 2.9(3 \mathrm{H}, \mathrm{s})$, and $1.21(9 \mathrm{H}, \mathrm{s})$.

1-Iodo-2-(4,4-dimethyl-3-phenyl-1-pentynyl)benzene (83). To $1.032 \mathrm{~g}(4.528 \mathrm{mmol})$ of 81 in $10 \mathrm{~mL}$ THF under a nitrogen atmosphere at $0{ }^{\circ} \mathrm{C}$ was added $3.77 \mathrm{~mL}$ of a $2.0 \mathrm{M}$ solution of LDA (7.55 mmol) in THF. After $30 \mathrm{~min}$ of stirring, a solution of $0.616 \mathrm{~g}$ of $\mathbf{4 0}(3.774 \mathrm{mmol})$ in $10 \mathrm{~mL}$ of THF was introduced via cannula, and the reaction mixture was allowed to warm to room temperature. After an additional $3 \mathrm{~h}, 20 \mathrm{~mL}$ of water was introduced, and the reaction mixture was extracted with diethyl ether. The combined organic extracts were washed with brine and water, dried over sodium sulfate, and concentrated. The residue was purified by flash 
chromatography (silica gel/10\% diethyl ether in hexanes) to afford $1.476 \mathrm{~g}$ of crude $\mathbf{8 2}$ as a light yellow liquid. The crude product of $\mathbf{8 2}$ without further purification was treated with $0.810 \mathrm{~g}$ of triethylsilane $(6.983 \mathrm{mmol})$ and $2.1 \mathrm{~g}$ of trifluoroacetic acid $(18.4 \mathrm{mmol})$ to afford $1.382 \mathrm{~g} \mathrm{(3.699}$ mmol, $86 \%$ for 2 steps) of 83 as a colorless liquid: IR 2966, $1463 \mathrm{~cm}^{-1} ;{ }^{1} \mathrm{H}\left(\mathrm{CDCl}_{3}, 270 \mathrm{MHz}\right) \delta$ $7.83(1 \mathrm{H}, \mathrm{dd}, J=7.9,1.2 \mathrm{~Hz}), 7.47-7.41(3 \mathrm{H}, \mathrm{m}), 7.36-7.23(4 \mathrm{H}, \mathrm{m}), 6.96(1 \mathrm{H}, \mathrm{td}, J=7.7,1.7$ Hz), $3.69(1 \mathrm{H}, \mathrm{s}), 1.09(9 \mathrm{H}, \mathrm{s}) ;{ }^{13} \mathrm{C}\left(\mathrm{CDCl}_{3}, 67.9 \mathrm{MHz}\right) \delta 138.9,138.6,132.9,130.5,129.9$, 128.8, 127.6, 126.7, 100.5, 95.5, 85.5, 50.6, 35.7, 27.9. HRMS calcd for $\mathrm{C}_{19} \mathrm{H}_{19} \mathrm{I}\left(\mathrm{MH}^{+}\right)$ 374.0604, found 375.0610 .

Benzannulated Enediyne 85. To a mixture of $0.193 \mathrm{~g}$ of $83(0.516 \mathrm{mmol}), \mathrm{Pd}\left(\mathrm{PPh}_{3}\right)_{2} \mathrm{Cl}_{2}(0.018$ g, $0.026 \mathrm{mmol})$, and copper(I) iodide $(0.010 \mathrm{~g}, 0.053 \mathrm{mmol})$ in $10 \mathrm{~mL}$ of triethylamine was added via cannula a solution of $0.102 \mathrm{~g}$ of $\mathbf{8 4}(0.670 \mathrm{mmol})$ in $3 \mathrm{~mL}$ of triethylamine. After $12 \mathrm{~h}$ of stirring at $60{ }^{\circ} \mathrm{C}, 15 \mathrm{~mL}$ of a saturated ammonium chloride solution and $15 \mathrm{~mL}$ of diethyl ether were added. The organic layer was separated, and the aqueous layer was back extracted with diethyl ether. The combined organic layers were washed with brine and water, dried over sodium sulfate, and concentrated. Purification of the residue by flash column chromatography (silica gel $/ 5 \%$ methylene chloride in hexanes) afforded $0.189 \mathrm{~g}$ of $85(0.475 \mathrm{mmol}, 92 \%)$ as a light yellow liquid: IR 2227, 1481, $758 \mathrm{~cm}^{-1} ;{ }^{1} \mathrm{H}\left(\mathrm{CDCl}_{3}, 270 \mathrm{MHz}\right) \delta 8.53-8.46(1 \mathrm{H}, \mathrm{m})$, 7.90-7.82 (2 H, m), 7.68-7.62 (2 H, m), 7.56-7.48 (3 H, m), 7.44-7.38 (3 H, m), 7.34-7.30 (2 $\mathrm{H}, \mathrm{m}), 7.16-7.12(3 \mathrm{H}, \mathrm{m}) 3.71(1 \mathrm{H}, \mathrm{s}), 1.01(9 \mathrm{H}, \mathrm{s}) ;{ }^{13} \mathrm{C}\left(\mathrm{CDCl}_{3}, 67.9 \mathrm{MHz}\right) \delta 138.9,133.2$, $133.1,132.3,132.1,130.4,129.7,128.7,128.1,128.0,127.5,127.4,126.7,126.6,126.4,126.3$, 125.6, 125.2, 120.9, 95.8, 93.4, 90.9, 82.6, 50.6, 35.5, 27.7. MS m/z $399\left(\mathrm{MH}^{+}\right)$, 359, 279; HRMS calcd for $\mathrm{C}_{31} \mathrm{H}_{26}\left(\mathrm{MH}^{+}\right)$399.2107, found 399.2109.

10-(1,1-Dimethylethyl)-5-(1-naphthyl)-11H-benzo[b]fluorene (86a). To 0.189 g of 85 (0.475 mmol) in $10 \mathrm{~mL}$ of anhydrous toluene under a nitrogen atmosphere was added $0.50 \mathrm{~mL}$ of a 1.0 
M solution of potassium t-butoxide $(0.50 \mathrm{mmol})$ in 2-methyl-2-propanol. The reaction mixture was then heated to reflux for $6 \mathrm{~h}$. After the reaction mixture was allowed to cool to room temperature, $10 \mathrm{~mL}$ of water and $40 \mathrm{~mL}$ of methylene chloride were introduced, and the organic layer was separated, dried over sodium sulfate, and concentrated. The residue was purified by flash column chromatography (silica gel $/ 5 \%$ methylene chloride in hexanes) to provide $0.131 \mathrm{~g}$ of 86a $(0.328 \mathrm{mmol}, 69 \%)$ as a bright yellow liquid: IR $1191,1015 \mathrm{~cm}^{-1} ;{ }^{1} \mathrm{H}\left(\mathrm{C}_{6} \mathrm{D}_{6}, 600 \mathrm{MHz}\right) \delta$ $8.68(1 \mathrm{H}, \mathrm{d}, J=9.0 \mathrm{~Hz}), 7.84(1 \mathrm{H}, \mathrm{d}, J=7.8 \mathrm{~Hz}), 7.76(1 \mathrm{H}, \mathrm{d}, J=8.4 \mathrm{~Hz}), 7.60(1 \mathrm{H}, \mathrm{dd}, J=$ 8.4, $1.2 \mathrm{~Hz}), 7.54(1 \mathrm{H}, \mathrm{d}, J=8.4 \mathrm{~Hz}), 7.45(1 \mathrm{H}, \mathrm{dd}, J=6.6,1.2 \mathrm{~Hz}), 7.41(1 \mathrm{H}, \mathrm{dd}, J=8.1,6.9$ Hz), 7.27 (1 H, ddd, $J$ = 9.0, 6.6, $1.2 \mathrm{~Hz}), 7.23(1 \mathrm{H}, \mathrm{d}, J=7.2 \mathrm{~Hz}), 7.19(1 \mathrm{H}, \mathrm{ddd}, J=8.4,6.6$, $1.2 \mathrm{~Hz}), 7.01$ (1 H, ddd, $J=8.4,6.6,1.2 \mathrm{~Hz}), 6.96(1 \mathrm{H}, \mathrm{td}, J=7.2,1.2 \mathrm{~Hz}), 6.90(1 \mathrm{H}$, ddd, $J=$ 8.4, 6.6, $1.2 \mathrm{~Hz}), 6.65(1 \mathrm{H}, \mathrm{t}, J=7.2 \mathrm{~Hz}), 6.32(1 \mathrm{H}, \mathrm{d}, J=7.8 \mathrm{~Hz}), 4.27(1 \mathrm{H}, \mathrm{d}, J=21 \mathrm{~Hz})$, $4.25(1 \mathrm{H}, \mathrm{d}, J=21 \mathrm{~Hz}), 1.81(9 \mathrm{H}, \mathrm{s}) ;{ }^{1} \mathrm{H}\left(\mathrm{CDCl}_{3}, 270 \mathrm{MHz}\right) \delta 8.66(1 \mathrm{H}, \mathrm{d}, J=8.7 \mathrm{~Hz}), 8.07(1$ H, d, $J=8.4 \mathrm{~Hz}), 8.00(1 \mathrm{H}, \mathrm{d}, J=8.4 \mathrm{~Hz}), 7.68(1 \mathrm{H}, \mathrm{t}, J=7.7 \mathrm{~Hz}), 7.52-7.15(10 \mathrm{H}, \mathrm{m}), 7.11$ (1 H, td, $J=7.4,1.0 \mathrm{~Hz}), 6.75(1 \mathrm{H}, \mathrm{t}, J=7.4 \mathrm{~Hz}), 5.89(1 \mathrm{H}, \mathrm{d}, J=8.2 \mathrm{~Hz}), 4.56(2 \mathrm{H}, \mathrm{s}), 1.96$ $(9 \mathrm{H}, \mathrm{s}) ;{ }^{13} \mathrm{C}\left(\mathrm{CDCl}_{3}, 67.9 \mathrm{MHz}\right) \delta 144.2,141.2,139.9,139.1,137.6,137.4,134.9,133.8,132.8$, $131.4,130.8,128.16,128.03,127.97,127.88,127.7,126.7,126.3,126.2,124.2,123.8,123.5$, 123.4, 40.2, 38.9, 34.4; MS m/z $398\left(\mathrm{M}^{+}\right)$, 383, 341; HRMS calcd for $\mathrm{C}_{31} \mathrm{H}_{26}$ 398.2035, found 398.2028.

1-Ethynyl-2-methoxynaphthalene (76). To a solution of $1.05 \mathrm{~g}(5.64 \mathrm{mmol})$ of 2methoxy-1-naphthaldehyde and $2.80 \mathrm{~g}$ of potassium carbonate in $20 \mathrm{~mL}$ of anhydrous methanol was added $1.37 \mathrm{~g}$ (7.15 mmol) of dimethyl (1-diazo-2-oxopropyl)phosphonate, and the reaction mixture was stirred at room temperature for 6 days. The reaction mixture was then diluted with diethyl ether, washed with a 5\% aqueous sodium bicarbonate solution, dried over sodium sulfate, and concentrated. Purification of the residue by flash column chromatography (silica gel $/ 25 \%$ 
methylene chloride in hexanes) afforded $0.545 \mathrm{~g}$ of $76(3.00 \mathrm{mmol}, 53 \%)$ as a white solid: IR 3260, 1274, 1083, $809 \mathrm{~cm}^{-1} ;{ }^{1} \mathrm{H}\left(\mathrm{CDCl}_{3}, 270 \mathrm{MHz}\right) \delta 8.27(1 \mathrm{H}, \mathrm{d}, J=8.4 \mathrm{~Hz}), 7.86(1 \mathrm{H}, \mathrm{d}, J=$ $8.9 \mathrm{~Hz}), 7.79(1 \mathrm{H}, \mathrm{d}, J=8.2 \mathrm{~Hz}), 7.56(1 \mathrm{H}, \mathrm{ddd}, J=8.2,6.9,1.2 \mathrm{~Hz}), 7.39(1 \mathrm{H}, \mathrm{ddd}, J=8.2$, 6.9, $1.2 \mathrm{~Hz}), 7.27(1 \mathrm{H}, \mathrm{d}, J=9.2 \mathrm{~Hz}), 4.05(3 \mathrm{H}, \mathrm{s}), 3.76(1 \mathrm{H}, \mathrm{s}) ;{ }^{13} \mathrm{C}\left(\mathrm{CDCl}_{3}, 150 \mathrm{MHz}\right) \delta$ $159.8,134.8,130.7,128.4,128.1,127.6,125.1,124.3,112.5,105.0,86.5,78.2,56.6$; HRMS calcd for $\mathrm{C}_{13} \mathrm{H}_{11} \mathrm{O}\left(\mathrm{MH}^{+}\right)$183.0810, found 183.0804.

Benzannulated Enediyne 80. To a mixture of $0.307 \mathrm{~g}$ of $83(0.822 \mathrm{mmol}), \mathrm{Pd}\left(\mathrm{PPh}_{3}\right)_{4}(0.040 \mathrm{~g}$, $0.035 \mathrm{mmol})$, and copper(I) iodide $(0.015 \mathrm{~g}, 0.080 \mathrm{mmol})$ in $10 \mathrm{~mL}$ of toluene was added via cannula a solution of $0.150 \mathrm{~g}$ of $\mathbf{7 6}(0.824 \mathrm{mmol})$ in $5 \mathrm{~mL}$ of triethylamine. After $12 \mathrm{~h}$ of stirring at $120{ }^{\circ} \mathrm{C}, 15 \mathrm{~mL}$ of a saturated ammonium chloride solution and $15 \mathrm{~mL}$ of diethyl ether were added. The organic layer was separated, and the aqueous layer was back extracted with diethyl ether. The combined organic layers were washed with brine and water, dried over sodium sulfate, and concentrated. Purification of the residue by flash column chromatography (silica gel $/ 30 \%$ methylene chloride in hexanes) afforded $0.331 \mathrm{~g}$ of $80(0.773 \mathrm{mmol}, 94 \%)$ as a colorless liquid: IR: 2207, 1271, $1078 \mathrm{~cm}^{-1}$; ${ }^{1} \mathrm{H}\left(\mathrm{CDCl}_{3}, 270 \mathrm{MHz}\right) \delta 8.43-8.39(1 \mathrm{H}, \mathrm{m}), 7.85(1 \mathrm{H}, \mathrm{d}, J=9.2$ Hz), 7.82-7.77 (1 H, m), 7.70-7.65 (1 H, m), 7.56-7.52 (1 H, m), 7.43-7.25 (7 H, m), 7.10-7.00 $(3 \mathrm{H}, \mathrm{m}), 4.00(3 \mathrm{H}, \mathrm{s}), 3.66(1 \mathrm{H}, \mathrm{s}), 0.95(9 \mathrm{H}, \mathrm{s}) ;{ }^{13} \mathrm{C}\left(\mathrm{CDCl}_{3}, 67.9 \mathrm{MHz}\right) \delta 158.9,139.0,134.5$, $132.3,130.2,129.7,128.4,127.9,127.8,127.3,127.2,126.4,126.3,126.0,125.7,124.1,112.6$, 106.5, 97.8, 95.5, 87.3, 82.6, 56.6, 50.5, 35.5, 27.7; HRMS calcd for $\mathrm{C}_{32} \mathrm{H}_{29} \mathrm{O}\left(\mathrm{MH}^{+}\right)$429.2218, found 429.2217 .

5-(2-Methoxy-1-naphthyl)-10-(1,1-dimethylethyl)-11H-benzo[b]fluorene (86b). The same procedure was repeated as described for $\mathbf{8 6 a}$ except that $0.295 \mathrm{~g}$ of $\mathbf{8 0}(0.689 \mathrm{mmol})$ was treated with $0.77 \mathrm{~mL}$ of a $1.0 \mathrm{M}$ solution of potassium $t$-butoxide $(0.77 \mathrm{mmol})$ in 2-methyl-2-propanol to afford $0.263 \mathrm{~g}$ of $\mathbf{8 6 b}(0.614 \mathrm{mmol}, 89 \%)$ as a light yellow liquid: IR 1267, 1250, $766 \mathrm{~cm}^{-1} ;{ }^{1} \mathrm{H}$ 
$\left(\mathrm{CDCl}_{3}, 600 \mathrm{MHz}\right) \delta 8.66(1 \mathrm{H}, \mathrm{d}, J=9.0 \mathrm{~Hz}), 8.11(1 \mathrm{H}, \mathrm{d}, J=9.6 \mathrm{~Hz}), 7.92(1 \mathrm{H}, \mathrm{d}, J=8.4$ Hz), $7.53(1 \mathrm{H}, \mathrm{d}, J=9.0 \mathrm{~Hz}), 7.44(1 \mathrm{H}, \mathrm{d}, J=7.2 \mathrm{~Hz}), 7.40(1 \mathrm{H}, \mathrm{ddd}, J=8.4,6.6,1.8 \mathrm{~Hz})$, $7.35(1 \mathrm{H}, \mathrm{d}, J=9.0 \mathrm{~Hz}), 7.31(1 \mathrm{H}, \mathrm{td}, J=6.6,1.2 \mathrm{~Hz}), 7.18(1 \mathrm{H}, \mathrm{t}, J=7.8 \mathrm{~Hz}), 7.13-7.05(3 \mathrm{H}$, m), $6.77(1 \mathrm{H}, \mathrm{t}, J=7.8 \mathrm{~Hz}), 6.08$ (1 H, d, $J=7.8 \mathrm{~Hz}), 4.55(2 \mathrm{H}, \mathrm{s}), 3.68(3 \mathrm{H}, \mathrm{s}), 1.97(9 \mathrm{H}, \mathrm{s})$; ${ }^{1} \mathrm{H}\left(\mathrm{C}_{6} \mathrm{D}_{6}, 600 \mathrm{MHz}\right) \delta 8.67(1 \mathrm{H}, \mathrm{d}, J=9.0 \mathrm{~Hz}), 7.90(1 \mathrm{H}, \mathrm{d}, J=9.6 \mathrm{~Hz}), 7.79(1 \mathrm{H}, \mathrm{d}, J=8.4$ Hz), $7.70(1 \mathrm{H}, \mathrm{d}, J=8.4 \mathrm{~Hz}), 7.42(1 \mathrm{H}, \mathrm{d}, J=8.4 \mathrm{~Hz}), 7.29(1 \mathrm{H}, \mathrm{t}, J=7.8 \mathrm{~Hz}), 7.23(1 \mathrm{H}, \mathrm{d}, J$ $=7.2 \mathrm{~Hz}), 7.17(1 \mathrm{H}, \mathrm{d}, J=6.6 \mathrm{~Hz}), 7.12(1 \mathrm{H}, \mathrm{t}, J=7.5 \mathrm{~Hz}), 7.06(1 \mathrm{H}, \mathrm{t}, J=7.5 \mathrm{~Hz}), 6.98(1 \mathrm{H}$, t, $J=7.2 \mathrm{~Hz}), 6.89(1 \mathrm{H}, \mathrm{t}, J=7.8 \mathrm{~Hz}), 6.72(1 \mathrm{H}, \mathrm{t}, J=7.5 \mathrm{~Hz}), 6.53(1 \mathrm{H}, \mathrm{d}, J=7.8 \mathrm{~Hz}), 4.25$ $(1 \mathrm{H}, \mathrm{d}, J=21.6 \mathrm{~Hz}), 4.19(1 \mathrm{H}, \mathrm{d}, J=21.6 \mathrm{~Hz}), 3.13(3 \mathrm{H}, \mathrm{s}), 1.77(9 \mathrm{H}, \mathrm{s}) ;{ }^{13} \mathrm{C}\left(\mathrm{CDCl}_{3}, 150\right.$ MHz) $\delta 154.8,144.2,141.0,140.3,139.3,137.9,134.7,133.9,131.8,129.8,129.5,128.1,127.8$, 127.2, 127.0, 126.7, 126.6, 126.4, 125.2, 124.1, 123.9, 123.7, 123.3, 122.8, 122.2, 114.4, 56.9, 40.3, 38.9, 34.5; MS m/z $428\left(\mathrm{M}^{+}\right), 413,400,371$; HRMS calcd for $\mathrm{C}_{32} \mathrm{H}_{28} \mathrm{O}$ 428.2140, found 428.2126. Recrystallization from a mixture of isopropyl alcohol and methylene chloride produced a crystal for X-ray structure analysis. Although the week diffracting crystal limited the amount of observed data, the analysis of these data supports the structural assignment of $\mathbf{8 6} \mathbf{b}$.

Benzannulated Enediyne 96. The same procedure was repeated as described for 66a except that $0.200 \mathrm{~g}$ of 83 (0.535 mmol), $\mathrm{Pd}\left(\mathrm{PPh}_{3}\right)_{2} \mathrm{Cl}_{2}$ (0.016 g, $\left.0.023 \mathrm{mmol}\right)$, and copper(I) iodide (0.015 g, $0.080 \mathrm{mmol}$ ) in $10 \mathrm{~mL}$ of triethylamine was treated with a solution of $0.263 \mathrm{~g}$ of (trimethylsilyl)acetylene (2.675 mmol) in $5 \mathrm{~mL}$ of triethylamine to afford $0.140 \mathrm{~g}$ of 96 (0.407 mmol, $76 \%)$ as a colorless liquid: ${ }^{1} \mathrm{H}\left(\mathrm{CDCl}_{3}, 270 \mathrm{MHz}\right) \delta 7.50-7.39(4 \mathrm{H}, \mathrm{m}), 7.35-7.20(5 \mathrm{H}$, m), 3.69 (1 H, s), 1.09 (9 H, s), 0.24 (9 H, s); ${ }^{13} \mathrm{C}\left(\mathrm{CDCl}_{3}, 67.9 \mathrm{MHz}\right) \delta 139.1,132.8,132.2$, $129.8,128.0,127.6,127.2,126.6,126.4,125.3,104.0,98.0,95.5,82.3,50.6,35.5,27.9,-0.1$.

Benzannulated Enediyne 97. The same procedure was repeated as described for 67 a except that a solution of $0.140 \mathrm{~g}(0.407 \mathrm{mmol})$ of $\mathbf{9 6}$ in $20 \mathrm{~mL}$ of diethyl ether was treated with $8 \mathrm{~mL}$ of a 
$10 \%$ sodium hydroxide solution and $20 \mathrm{~mL}$ of methanol to afford $0.110 \mathrm{~g}$ of $97(0.403 \mathrm{mmol}$, 99\%) as a light yellow liquid: ${ }^{1} \mathrm{H}\left(\mathrm{CDCl}_{3}, 270 \mathrm{MHz}\right) \delta 7.55-7.44(4 \mathrm{H}, \mathrm{m}), 7.38-7.22(5 \mathrm{H}, \mathrm{m})$, $3.72(1 \mathrm{H}, \mathrm{s}), 3.31(1 \mathrm{H}, \mathrm{s}), 1.11(9 \mathrm{H}, \mathrm{s}) ;{ }^{13} \mathrm{C}\left(\mathrm{CDCl}_{3}, 67.9 \mathrm{MHz}\right) \delta 139.1,132.5,132.0,129.8$, $128.4,127.5,127.3,127.1,126.7,124.4,95.7,82.8,82.0,80.7,50.5,35.5,27.8$.

1-Iodo-2-(methoxymethyl)naphthalene (93). To a solution of $0.500 \mathrm{~g}$ of 1-bromo-2(methoxymethyl)naphthalene $(1.99 \mathrm{mmol})$ in $10 \mathrm{~mL}$ of $\mathrm{THF}$ at $-78{ }^{\circ} \mathrm{C}$ was added dropwise 1.8 $\mathrm{mL}$ of a $1.6 \mathrm{M}$ solution of $n$-butyllithium $(3.06 \mathrm{mmol})$ in hexanes. After $1 \mathrm{~h}$ of stirring at $-78^{\circ} \mathrm{C}$, a solution of $1.02 \mathrm{~g}$ of iodine $(4.02 \mathrm{mmol})$ in $10 \mathrm{~mL}$ of THF was added dropwise via cannula. The reaction mixture then was allowed to warm to room temperature before $20 \mathrm{~mL}$ of a $5 \%$ sodium thiosulfate solution was introduced. The organic layer was separated, and the aqueous layer was back extracted with diethyl ether. The combined organic layers were washed with brine and water, dried over sodium sulfate, and concentrated. Purification of the residue by flash column chromatography (silica gel/30\% methylene chloride in hexanes) afforded $0.516 \mathrm{~g}$ of $\mathbf{9 3}$ (1.73 mmol, 87\%) as a pale yellow liquid: IR 2922, 1500, 1113, $814 \mathrm{~cm}^{-1} ;{ }^{1} \mathrm{H}\left(\mathrm{CDCl}_{3}, 270 \mathrm{MHz}\right)$ $\delta 8.26(1 \mathrm{H}, \mathrm{d}, J=7.7 \mathrm{~Hz}), 7.83(1 \mathrm{H}, \mathrm{d}, J=8.4 \mathrm{~Hz}), 7.78(1 \mathrm{H}, \mathrm{dd}, J=7.9,1.5 \mathrm{~Hz}), 7.61-7.48$ (3 H, m), $4.74(2 \mathrm{H}, \mathrm{s}), 3.53(3 \mathrm{H}, \mathrm{s}) ;{ }^{13} \mathrm{C}\left(\mathrm{CDCl}_{3}, 67.9 \mathrm{MHz}\right) \delta 139.8,134.6,133.6,132.2,128.7$, 128.3, 127.7, 126.4, 125.8, 103.1, 79.8, 58.6. MS m/z $267\left(\mathrm{M}^{+}-\mathrm{OMe}\right)$; HRMS calcd for $\mathrm{C}_{12} \mathrm{H}_{11} \mathrm{IO}\left(\mathrm{MH}^{+}\right)$298.9927, found 298.9930.

Benzannulated Enediyne 98. The same procedure was repeated as described for $\mathbf{8 5}$ except that a solution of $0.242 \mathrm{~g}$ of $93(0.812 \mathrm{mmol}), \mathrm{Pd}\left(\mathrm{PPh}_{3}\right)_{2} \mathrm{Cl}_{2}(0.030 \mathrm{~g}, 0.043 \mathrm{mmol})$, and copper(I) iodide ( $0.015 \mathrm{~g}, 0.080 \mathrm{mmol})$ in $6 \mathrm{~mL}$ of triethylamine was treated with a solution of $0.265 \mathrm{~g}$ of $97(0.974 \mathrm{mmol})$ in $2 \mathrm{~mL}$ of triethylamine to afford $0.255 \mathrm{~g}$ of $98(0.577 \mathrm{mmol}, 71 \%)$ as a colorless liquid: ${ }^{1} \mathrm{H}\left(\mathrm{CDCl}_{3}, 270 \mathrm{MHz}\right) \delta 8.51(1 \mathrm{H}, \mathrm{d}, J=7.7 \mathrm{~Hz}), 7.88-7.83(2 \mathrm{H}, \mathrm{m})$, 7.67-7.57 (3 H, m), 7.53-7.42 (2 H, m), 7.38-7.32 (4 H, m), 7.12-7.05 (3 H, m), $4.92(1 \mathrm{H}, \mathrm{d}, J$ 
$=13.1 \mathrm{~Hz}), 4.83(1 \mathrm{H}, \mathrm{d}, J=12.9 \mathrm{~Hz}), 3.69(2 \mathrm{H}, \mathrm{s}), 3.41(3 \mathrm{H}, \mathrm{s}), 0.97(9 \mathrm{H}, \mathrm{s}) ;{ }^{13} \mathrm{C}\left(\mathrm{CDCl}_{3}\right.$, 67.9 MHz) $\delta 139.1,138.9,133.2,132.5,132.1,129.6,128.7,128.1,128.0,127.4,126.8,126.6$, $126.3,126.2,125.5,125.0,119.0,98.3,96.0,88.4,82.7,72.8,58.3,50.5,35.5,27.7$.

5-[2-(Methoxymethyl)-1-naphthyl]-10-(1,1-dimethylethyl)-11H-benzo[b]fluorene (86c). The same procedure was repeated as described for 86a except that $0.142 \mathrm{~g}$ of $\mathbf{9 8}(0.321 \mathrm{mmol})$ was treated with $0.48 \mathrm{~mL}$ of a $1.0 \mathrm{M}$ solution of potassium $t$-butoxide $(0.48 \mathrm{mmol})$ in 2-methyl-2-propanol to afford $0.102 \mathrm{~g}$ of $\mathbf{8 6 c}(0.231 \mathrm{mmol}, 72 \%)$ as a light yellow liquid: IR 2943, 1273, 1248, $774 \mathrm{~cm}^{-1} ;{ }^{1} \mathrm{H}\left(\mathrm{CDCl}_{3}, 270 \mathrm{MHz}\right) \delta 8.67(1 \mathrm{H}, \mathrm{d}, J=8.9 \mathrm{~Hz}), 8.12(1 \mathrm{H}, \mathrm{d}, J=$ 8.7 Hz), $7.97(1 \mathrm{H}, \mathrm{d}, J=8.2 \mathrm{~Hz}), 7.91(1 \mathrm{H}, \mathrm{d}, J=8.6 \mathrm{~Hz}), 7.47-7.39(3 \mathrm{H}, \mathrm{m}), 7.28-7.08(5 \mathrm{H}$, m), $6.75(1 \mathrm{H}, \mathrm{t}, J=7.7 \mathrm{~Hz}), 5.89(1 \mathrm{H}, \mathrm{d}, J=7.9 \mathrm{~Hz}), 4.56(2 \mathrm{H}, \mathrm{s}), 4.16(1 \mathrm{H}, \mathrm{d}, J=13.4 \mathrm{~Hz})$, $4.10(1 \mathrm{H}, \mathrm{d}, J=13.3 \mathrm{~Hz}), 3.09(3 \mathrm{H}, \mathrm{s}), 1.98(9 \mathrm{H}, \mathrm{s}) ;{ }^{13} \mathrm{C}\left(\mathrm{CDCl}_{3}, 67.9 \mathrm{MHz}\right) \delta 144.1,141.5$, 139.7, 139.2, 137.7, 135.3, 134.3, 134.0, 133.2, 132.7, 131.6, 128.4, 128.1, 127.9, 126.95, 126.91, 126.6, 126.4, 126.0, 125.9, 124.9, 124.5, 123.8, 123.6, 122.9, 71.9, 58.4, 40.3, 39.0, 34.5; MS m/z $442\left(\mathrm{M}^{+}\right), 427,395$; HRMS calcd for $\mathrm{C}_{33} \mathrm{H}_{30} \mathrm{O} 442.2297$, found 442.2283 .

1,1'-Binaphthyl 62. To a solution of $\mathbf{8 6 b}(0.234 \mathrm{~g}, 0.546 \mathrm{mmol})$ in $10 \mathrm{~mL}$ of methylene chloride was added dropwise $0.5 \mathrm{~mL}$ of boron tribromide at $0{ }^{\circ} \mathrm{C}$. The reaction mixture was stirred at $0{ }^{\circ} \mathrm{C}$ for $2 \mathrm{~h}$ before $10 \mathrm{~mL}$ of water and $20 \mathrm{~mL}$ of methylene chloride were introduced. The organic layer was separated, dried over sodium sulfate, and concentrated. The residue was purified by flash column chromatography (silica gel $/ 50 \%$ methylene chloride in hexanes) to provide $0.172 \mathrm{~g}$ (0.42 mmol, $76 \%$ ) of 62 as a pale yellow solid: ${ }^{1} \mathrm{H}\left(\mathrm{CDCl}_{3}, 270 \mathrm{MHz}\right) \delta 8.69(1 \mathrm{H}, \mathrm{d}, J=8.9 \mathrm{~Hz})$, $8.03(1 \mathrm{H}, \mathrm{d}, J=8.9 \mathrm{~Hz}), 7.92(1 \mathrm{H}, \mathrm{d}, J=7.9 \mathrm{~Hz}), 7.47(1 \mathrm{H}, \mathrm{d}, J=7.4 \mathrm{~Hz}), 7.48-7.12(8 \mathrm{H}, \mathrm{m})$, $7.05(1 \mathrm{H}, \mathrm{d}, J=8.4 \mathrm{~Hz}), 6.83(1 \mathrm{H}, \mathrm{t}, J=7.4 \mathrm{~Hz}), 6.21(1 \mathrm{H}, \mathrm{d}, J=7.9 \mathrm{~Hz}), 4.89(1 \mathrm{H}, \mathrm{br} \mathrm{s})$, $4.59(1 \mathrm{H}, \mathrm{d}, J=21 \mathrm{~Hz}), 4.54(1 \mathrm{H}, \mathrm{d}, J=21 \mathrm{~Hz}), 1.97(9 \mathrm{H}, \mathrm{s}) ;{ }^{13} \mathrm{C}\left(\mathrm{CDCl}_{3}, 67.9 \mathrm{MHz}\right) \delta 151.1$, 144.2, 142.8, 141.1, 139.3, 138.2, 134.6, 133.5, 132.0, 130.1, 129.3, 128.3, 128.1, 127.5, 126.8, 
126.6, 125.1, 124.8, 124.1, 123.9, 123.6, 123.0, 117.6, 117.5, 40.3, 39.1, 34.4; HRMS calcd for $\mathrm{C}_{31} \mathrm{H}_{26} \mathrm{ONa}\left(\mathrm{MNa}^{+}\right)$437.1881, found 437.1877.

(1S)-Camphanates of 62 (99). To a solution of $0.039 \mathrm{~g}$ of $62(0.095 \mathrm{mmol})$ and $0.2 \mathrm{~mL}$ of triethylamine $(0.4 \mathrm{mmol})$ in $3 \mathrm{~mL}$ of anhydrous methylene chloride at room temperature under a nitrogen atmosphere was added $0.062 \mathrm{~g}$ of $(1 S)-(-)$-camphanoyl chloride $(0.29 \mathrm{mmol})$. The mixture was stirred for $12 \mathrm{~h}$ and then quenched with a saturated sodium bicarbonate solution. After $5 \mathrm{~mL}$ of methylene chloride was added, the organic layer was separated, and the aqueous layer was back extracted with methylene chloride. The combined organic extracts were washed with brine and water, dried over sodium sulfate, and concentrated. The residue was purified by flash column chromatography (silica gel/20\% ethyl acetate in hexanes). A small fraction of the eluent contained partially separated (1S)-camphanates in a 5:1 ratio. The solvent of this fraction was evaporated to afford a white solid: ${ }^{1} \mathrm{H}\left(\mathrm{CDCl}_{3}, 600 \mathrm{MHz}\right) \delta 8.54(1 \mathrm{H}, \mathrm{d}, J=9.0 \mathrm{~Hz}), 8.08(1$ H, d, $J=9.0 \mathrm{~Hz}), 7.96(1 \mathrm{H}, \mathrm{d}, J=8.4 \mathrm{~Hz}), 7.48(1 \mathrm{H}, \mathrm{dd}, J=9.0,1.8 \mathrm{~Hz}), 7.43(1 \mathrm{H}, \mathrm{t}, J=7.2$ Hz), 7.39-7.32 (2 H, m), 7.29-7.16 (4 H, m), $7.13(1 \mathrm{H}, \mathrm{t}, J=7.2 \mathrm{~Hz}), 7.05(1 \mathrm{H}, \mathrm{t}, J=7.8 \mathrm{~Hz})$, $5.96(1 \mathrm{H}, \mathrm{d}, J=8.4 \mathrm{~Hz}), 4.47(1 \mathrm{H}, \mathrm{d}, J=21.6 \mathrm{~Hz}), 4.41(1 \mathrm{H}, \mathrm{d}, J=21.0 \mathrm{~Hz}), 1.87(9 \mathrm{H}, \mathrm{s})$, 1.63-1.57 (1 H, m), 1.50-1.45 (2 H, m), 1.38-1.32 (1 H, m), $0.80(3 \mathrm{H}, \mathrm{s}), 0.07$ (3 H, s), 0.00 (3 H, s). A minor set of the ${ }^{1} \mathrm{H}$ NMR signals at $\delta 5.93(1 \mathrm{H}, \mathrm{d}, J=8.4 \mathrm{~Hz}), 4.48(1 \mathrm{H}, \mathrm{d}, J=21.6$ $\mathrm{Hz}), 4.43(1 \mathrm{H}, \mathrm{d}, J=21.0 \mathrm{~Hz}), 0.02(3 \mathrm{H}, \mathrm{s})$, and $0.01(3 \mathrm{H}, \mathrm{s})$ attributable to the other camphanate diastereomer were also observed. MS m/z $594\left(\mathrm{MH}^{+}\right), 381$; HRMS calcd for $\mathrm{C}_{41} \mathrm{H}_{38} \mathrm{O}_{4}\left(\mathrm{MH}^{+}\right)$595.2843, found 595.2848.

\section{Experimental Section of Chapter III}

1-Ethynyl-2-(phenylethynyl)benzene was prepared according to the reported procedure. ${ }^{8 \mathrm{i}}$ 2,5-Dihydrofuran, anhydrous aluminum trichloride, lithium diisopropylamide (LDA, $2.0 \mathrm{M}$ ) in 
heptane/THF/ethylbenzene, iodomethane, tri-n-butyltinhydride, AIBN, iodotrimethylsilane, phenylsilane, sodium hydride (60\% dispersion in mineral oil), 1.6 M solution of $n$-butyllithium in hexanes, and thionyl chloride were purchased from chemical suppliers and were used as received. 2,5-Dicarbomethoxy-3,4-diphenylcyclopentadienone was prepared according to the reported procedures. ${ }^{66}$ Diiodosilane was also prepared from the iodine and phenylsilane according to the reported procedure. ${ }^{70}$

Diels-Alder Adduct 147. A mixture of $0.682 \mathrm{~g}(1.96 \mathrm{mmol})$ of 2,5-dicarbomethoxy-3,4diphenylcyclopentadienone and $0.4 \mathrm{~mL}(5.30 \mathrm{mmol})$ of 2, 5-dihydrofuran in $20 \mathrm{~mL}$ of chloroform was heated under reflux for $15 \mathrm{~h}$. The solvent was removed in vacuo. The residue was purified by recrystallization from methylene chloride and hexanes to afford $0.729 \mathrm{~g}$ of $\mathbf{1 4 7}$ (1.74 mmol, 95\%) as white solid: endo-147: IR (neat) 2953, 1780, 1732, 1248, $700 \mathrm{~cm}^{-1} ;{ }^{1} \mathrm{H}$ $\left(\mathrm{CDCl}_{3}, 600 \mathrm{MHz}\right) \delta 7.22-7.16(6 \mathrm{H}, \mathrm{m}), 7.20-7.09(4 \mathrm{H}, \mathrm{m}), 4.12(2 \mathrm{H}, \mathrm{dd}, J=9.7,1.7 \mathrm{~Hz})$, 3.94-3.88 (2 H, m), $3.68(6 \mathrm{H}, \mathrm{s}), 3.52-3.50(2 \mathrm{H}, \mathrm{m}) ;{ }^{13} \mathrm{C}\left(\mathrm{CDCl}_{3}, 150 \mathrm{MHz}\right) \delta$ 188.4, 167.7, 136.5, 133.9, 128.8, 128.4, 128.0, 70.1, 67.5, 52.4, 43.5. Recrystallization of endo-147 from methylene chloride/hexanes produced a crystal suitable for X-ray structure analysis. exo-147: ${ }^{1} \mathrm{H}$ (CDCl $3,600 \mathrm{MHz}) \delta$ 7.23-7.17 (6 H, m), 7.08-7.04 (4 H, m), 4.16-4.09 (2 H, m), 3.87-3.80 (2 $\mathrm{H}, \mathrm{m}), 3.60(6 \mathrm{H}, \mathrm{s}), 3.28-3.24(2 \mathrm{H}, \mathrm{m}){ }^{65}$

Diester 148. To $2.30 \mathrm{~g}(5.50 \mathrm{mmol})$ of $\mathbf{1 4 7}$ in $5 \mathrm{~mL}$ methylene chloride, $20 \mathrm{~mL}$ ethanol was added $10 \mathrm{~mL}$ water. The reaction mixture was heated at $50{ }^{\circ} \mathrm{C}$ for $24 \mathrm{hr}$. The solvent was removed in vacuo. The residue was purified by flash column chromatography (silica gel/20\% ethyl acetate in hexanes) to provide $2.14 \mathrm{~g}$ (5.45 mmol, 99\%) of $\mathbf{1 4 8}$ as a white solid. mp 205-207 ${ }^{\circ} \mathrm{C} ;{ }^{1} \mathrm{H}\left(\mathrm{CDCl}_{3}, 600 \mathrm{MHz}\right) \delta 7.11-7.00(6 \mathrm{H}, \mathrm{m}), 6.93-6.89(4 \mathrm{H}, \mathrm{m}), 4.33-4.26(2 \mathrm{H}$, m), 3.93-3.87 (2 H, m), 3.74-3.72 (2 H, m), 3.33 (6 H, s), 3.13-2.99 (2 H, m). Recrystallization of $\mathbf{1 4 8}$ from methylene chloride/ethanol produced a crystal suitable for X-ray structure analysis. 
Diketone 149. To a solution of $1.24 \mathrm{~g}$ of $148(3.16 \mathrm{mmol})$ in $51 \mathrm{~mL}$ of THF was added aqueous lithium hydroxide $(38 \mathrm{~mL}, 1.0 \mathrm{M})$. The resulting solution was refluxed at $65^{\circ} \mathrm{C}$ for $18 \mathrm{~h}$ and then concentrated under pressure. The residue was diluted with water $(50 \mathrm{~mL})$ and extracted with diethyl ether $(3 \times 10 \mathrm{~mL})$. The diethyl ether extracts were discarded. The aqueous solution was acidified with $1 \mathrm{M}$ hydrochloric acid to $\mathrm{pH}$ around 4 . The white precipitate was filtered and dried. The crude product was used for next step without any further purification and characterization. A mixture of $1.13 \mathrm{~g}(3.10 \mathrm{mmol})$ of solid acid and $8.5 \mathrm{~mL}$ of thionyl chloride were refluxed at $70{ }^{\circ} \mathrm{C}$ for $18 \mathrm{~h}$. Then thionyl chloride was removed in vacuo and pumped to extremely dry for two days. To a residue dissolved in $100 \mathrm{~mL}$ of anhydrous methylene chloride at $0{ }^{\circ} \mathrm{C}$ under a nitrogen atmosphere was added $1.42 \mathrm{~g}$ of anhydrous aluminum chloride (10.6 mmol) slowly over a period of 15 minutes. After $2 \mathrm{~h}$ at $0{ }^{\circ} \mathrm{C}$, the reaction mixture was allowed to warm to room temperature. After additional $7 \mathrm{~h}$ at room temperature, the reaction mixture was cooled to $0{ }^{\circ} \mathrm{C}$ and $15 \mathrm{~mL}$ of saturated ammonium chloride solution was introduced slowly and the organic layer was separated. The aqueous layer was back extracted with ether. The combined organic layers were washed with brine, water, dried over sodium sulfate, and concentrated. The residue was purified by flash column chromatography (silica gel/ethyl acetate:methylene chloride:hexanes $=1: 5: 5)$ to provide $0.757 \mathrm{~g}(2.31 \mathrm{mmol}, 73 \%)$ of $\mathbf{1 4 9}$ as a pale yellow liquid: IR (neat) 2875, 1716, 1265, $732 \mathrm{~cm}^{-1} ;{ }^{1} \mathrm{H}\left(\mathrm{CDCl}_{3}, 600 \mathrm{MHz}\right) \delta 8.37$ (2 H, d, $\left.J=7.8 \mathrm{~Hz}\right), 7.92(2$ H, d, $J=7.2 \mathrm{~Hz}), 7.79(2 \mathrm{H}, \mathrm{t}, J=7.2 \mathrm{~Hz}), 7.55(2 \mathrm{H}, \mathrm{t}, J=7.8 \mathrm{~Hz}), 4.32-4.30(2 \mathrm{H}, \mathrm{m})$, 4.06-4.04 (2 H, m), 3.21-3.19 (2 H, m), 2.56-2.53 (2 H, m); ${ }^{13} \mathrm{C}\left(\mathrm{CDCl}_{3}, 150 \mathrm{MHz}\right) \delta 203.2$, $145.5,138.0,135.3,132.5,129.7,124.8,124.6,73.1,53.4,42.0 . \mathrm{MS} m / z 329\left(\mathrm{MH}^{+}\right), 307$; HRMS calcd for $\mathrm{C}_{22} \mathrm{H}_{16} \mathrm{O}_{3}\left(\mathrm{MH}^{+}\right)$329.1178, found 329.1173.

Diketone 150. To $0.206 \mathrm{~g}$ ( $0.627 \mathrm{mmol})$ of $\mathbf{1 4 9}$ in $15 \mathrm{~mL}$ of anhydrous THF under a nitrogen atmosphere at $-78{ }^{\circ} \mathrm{C}$ was added $0.7 \mathrm{~mL}$ of a $2 \mathrm{M}$ solution of lithium diisopropylamide (1.40 
$\mathrm{mmol}$ ) in THF/n-heptane. After $30 \mathrm{~min}$ of stirring, $0.2 \mathrm{~mL}$ of iodomethane was added. After an additional $18 \mathrm{~h}, 20 \mathrm{~mL}$ of saturated ammonium chloride solution was introduced, and the reaction mixture was extracted with diethyl ether. The combined organic extracts were washed with brine and water, dried over sodium sulfate, and concentrated. The residue was purified by flash column chromatography (silica gel/ethyl acetate:methylene chloride:hexanes $=1: 5: 5$ ) to provide $0.212 \mathrm{~g}$ (0.596 mmol, $95 \%$ ) of $\mathbf{1 5 0}$ as a pale yellow solid : mp $152-154{ }^{\circ} \mathrm{C} ;{ }^{1} \mathrm{H}\left(\mathrm{CDCl}_{3}\right.$, $600 \mathrm{MHz}) \delta 8.43(2 \mathrm{H}, \mathrm{d}, J=7.8 \mathrm{~Hz}), 7.88(2 \mathrm{H}, \mathrm{d}, J=7.8 \mathrm{~Hz}), 7.74(2 \mathrm{H}, \mathrm{td}, J=8.4,1.2 \mathrm{~Hz})$, $7.54(2 \mathrm{H}, \mathrm{t}, J=7.8 \mathrm{~Hz}), 4.10-4.07(2 \mathrm{H}, \mathrm{m}), 3.11-3.06(2 \mathrm{H}, \mathrm{m}), 2.77-2.71(2 \mathrm{H}, \mathrm{m}), 1.63(6 \mathrm{H}$, s); ${ }^{13} \mathrm{C} \delta 206.0,146.9,136.9,135.6,134.9,129.9,125.3,124.8,72.3,54.0,45.4,27.8$. MS m/z $356\left(\mathrm{M}^{+}\right)$, 288; HRMS calcd for $\mathrm{C}_{24} \mathrm{H}_{20} \mathrm{O}_{3} 356.1412$, found 356.1413 .

Alcohol 151. To $0.452 \mathrm{~g}$ (2.24 mmol) of 5 in $15 \mathrm{~mL}$ of anhydrous THF under a nitrogen atmosphere at $0{ }^{\circ} \mathrm{C}$ was added $1.4 \mathrm{~mL}$ of a $1.6 \mathrm{M}$ solution of $n$-butyllithium $(2.2 \mathrm{mmol})$ in hexanes. After $30 \mathrm{~min}$ of stirring, a solution of $0.319 \mathrm{~g}$ of $\mathbf{1 5 0}(0.896 \mathrm{mmol})$ in $20 \mathrm{~mL}$ of THF was introduced via cannula. The reaction mixture was then allowed to warm up to room temperature. After an additional $18 \mathrm{~h}, 30 \mathrm{~mL}$ of water was introduced, and the reaction mixture was extracted with diethyl ether. The combined organic extracts were washed with brine and water, dried over sodium sulfate, and concentrated. The residue was purified by flash column chromatography (silica gel/ethyl acetate:methylene chloride:hexanes $=1: 10: 10$ ) to provide 0.465 g $(0.833 \mathrm{mmol}, 93 \%)$ of 151 as a yellow liquid: ${ }^{1} \mathrm{H}\left(\mathrm{CDCl}_{3}, 600 \mathrm{MHz}\right) \delta 8.53(1 \mathrm{H}, \mathrm{d}, J=8.4$ Hz), $8.00(1 \mathrm{H}, \mathrm{d}, J=7.8 \mathrm{~Hz}), 7.82(2 \mathrm{H}, \mathrm{d}, J=7.2 \mathrm{~Hz}), 7.61(1 \mathrm{H}, \mathrm{t}, J=7.2 \mathrm{~Hz}), 7.60-7.57(2$ H, m), 7.44 (2 H, t, $J=7.8 \mathrm{~Hz}), 7.44(2 \mathrm{H}, \mathrm{d}, J=6.6 \mathrm{~Hz}), 7.36-7.27(6 \mathrm{H}, \mathrm{m}), 6.28(1 \mathrm{H}, \mathrm{s}), 5.24$ $(1 \mathrm{H}, \mathrm{d}, J=9.6 \mathrm{~Hz}), 3.88(1 \mathrm{H}, \mathrm{t}, J=7.2 \mathrm{~Hz}), 3.82(1 \mathrm{H}, \mathrm{q}, J=7.2 \mathrm{~Hz}), 3.13-3.10(1 \mathrm{H}, \mathrm{m})$, 3.05-3.00 (1 H, m), $2.08(1 \mathrm{H}, \mathrm{t}, J=5.4 \mathrm{~Hz}), 1.46(3 \mathrm{H}, \mathrm{s}), 1.44(3 \mathrm{H}, \mathrm{s}) ;{ }^{13} \mathrm{C}\left(\mathrm{CDCl}_{3}, 150 \mathrm{MHz}\right)$ $\delta$ 206.7, 148.3, 146.8, 141.0, 138.1, 135.4, 134.2, 132.6, 132.2, 132.1, 131.7, 129.2, 129.1, 128.5, 
$128.4,128.3,128.0,127.9,126.6,125.9,124.9,124.4,124.2,124.0,122.9,93.1,88.2,86.9,80.7$, 77.5, 77.2, 77.0, 76.5, 70.9, 68.6, 60.0, 49.8, 47.0, 45.3, 31.9, 26.1. MS m/z $581\left(\mathrm{MNa}^{+}\right), 541$; HRMS calcd for $\mathrm{C}_{40} \mathrm{H}_{30} \mathrm{O}_{3}\left(\mathrm{MNa}^{+}\right)$581.2087, found 556.2086.

cis-152, trans-152. To $0.152 \mathrm{~g}(0.752 \mathrm{mmol})$ of 5 in $10 \mathrm{~mL}$ of anhydrous diethyl ether under a nitrogen atmosphere at $0{ }^{\circ} \mathrm{C}$ was added $0.48 \mathrm{~mL}$ of a $1.6 \mathrm{M}$ solution of $n$-butyllithium (0.77 $\mathrm{mmol})$ in hexanes. After $30 \mathrm{~min}$ of stirring, a solution of $0.102 \mathrm{~g}$ of $\mathbf{1 5 0}(0.286 \mathrm{mmol})$ in $5 \mathrm{~mL}$ of diethyl ether was introduced via cannula, and $20 \mathrm{~mL}$ of anhydrous benzene was added to the mixture. After an additional $10 \mathrm{~h}, 30 \mathrm{~mL}$ of water was introduced, and the reaction mixture was extracted with diethyl ether. The combined organic extracts were washed with brine and water, dried over sodium sulfate, and concentrated. The residue was purified by flash column chromatography (silica gel/ethyl acetate:methylene chloride:hexanes $=1: 4: 4$ ) to provide $0.142 \mathrm{~g}$ $(0.187 \mathrm{mmol}, 65 \%)$ of cis-152 as a pale yellow solid, $0.013 \mathrm{~g}$ of trans-152 $(0.0171 \mathrm{mmol}, 6 \%)$ as a yellow solid and $0.029 \mathrm{~g}$ of $151(0.0520 \mathrm{mmol}, 18 \%)$ as yellow liquid. cis-152: ${ }^{1} \mathrm{H}\left(\mathrm{CDCl}_{3}, 600\right.$ MHz) $\delta 8.05(2 \mathrm{H}, \mathrm{d}, J=7.2 \mathrm{~Hz}), 7.52(2 \mathrm{H}, \mathrm{dd}, J=7.2,1.2 \mathrm{~Hz}), 7.40-7.37(6 \mathrm{H}, \mathrm{m}), 7.33-7.26$ (6 H, m), 7.20 (2 H, td, $J=7.2,1.2 \mathrm{~Hz}$ ), 7.16 (2 H, td, $J=7.2,1.2 \mathrm{~Hz}), 7.11(2 \mathrm{H}, \mathrm{td}, J=7.2,1.2$ Hz), 7.00 (2 H, td, $J=7.8,1.2$ Hz), 4.45 (4 H, d, $J=6.0 \mathrm{~Hz}$ ), 2.96-2.92 (2 H, m), 2.89 (2 H, s), 1.41 (6 H, s); ${ }^{13} \mathrm{C}\left(\mathrm{CDCl}_{3}, 150 \mathrm{MHz}\right) \delta 148.1,137.2,136.6,132.0,131.72,131.65,128.8,128.3$, 128.2, 127.99, 127.95, 127.8, 125.7, 124.8, 124.5, 123.3, 123.1, 94.8, 92.9, 87.9, 87.5, 79.6, 68.8, 57.6, 48.2, 27.9. MS m/z $783\left(\mathrm{MNa}^{+}\right)$; HRMS calcd for $\mathrm{C}_{56} \mathrm{H}_{40} \mathrm{O}_{3} 760.2977$, found 783.2832 $\left(\mathrm{MNa}^{+}\right)$. Recrystallization of cis-152 from methylene chloride/ethanol produced a crystal suitable for X-ray structure analysis. trans-152: ${ }^{1} \mathrm{H}\left(\mathrm{CDCl}_{3}, 600 \mathrm{MHz}\right) \delta 8.22(1 \mathrm{H}, \mathrm{d}, J=7.0 \mathrm{~Hz}), 8.05(1$ H, d, $J=7.7 \mathrm{~Hz}), 7.81(1 \mathrm{H}, \mathrm{d}, J=6.7 \mathrm{~Hz}), 7.64-7.54(3 \mathrm{H}, \mathrm{m}), 7.51-7.41(6 \mathrm{H}, \mathrm{m}), 7.39-7.17$ (14 H, m), $6.73(1 \mathrm{H}, \mathrm{s}), 5.15(1 \mathrm{H}, \mathrm{d}, J=9.7 \mathrm{~Hz}), 4.65(1 \mathrm{H}, \mathrm{t}, J=8.7 \mathrm{~Hz}), 3.88-3.81(1 \mathrm{H}, \mathrm{m})$, 3.72-3.67 (1 H, m), 3.05-2.94 (1 H, m), 2.78-2.74 (2 H, m), $1.47(3 \mathrm{H}, \mathrm{s}), 1.46(3 \mathrm{H}, \mathrm{s}) ;{ }^{13} \mathrm{C}$ 
$\left(\mathrm{CDCl}_{3}, 150 \mathrm{MHz}\right) \delta 148.0,146.9,138.3,138.0,137.3,136.7,132.3,132.1,131.9,131.73$, $131.70,131.6,129.3,128.9,128.47,128.42,128.36,128.31,126.25,128.2,128.0,127.8,125.9$, $125.2,124.6,124.3,124.1,123.7,123.0,122.8,95.3,94.1,93.2,93.1,88.2,87.8,87.4,86.2$, $80.5,79.2,69.5,69.4,58.0,56.4,49.8,47.1,32.6,26.1$.

Diketone 153. To $152(0.142 \mathrm{~g}, 0.187 \mathrm{mmol})$ in $10 \mathrm{~mL}$ of THF at $0{ }^{\circ} \mathrm{C}$ was added via cannula a solution of thionyl chloride $(0.1 \mathrm{~mL}, 1.4 \mathrm{mmol})$ and anhydrous pyridine $(0.16 \mathrm{~mL})$ in $5 \mathrm{~mL}$ of THF. The reaction mixture then was allowed to warm to room temperature. After an additional $12 \mathrm{~h}, 10 \mathrm{~mL}$ of water was introduced, and the reaction mixture was extracted with $30 \mathrm{~mL}$ of diethyl ether. The combined organic extracts were washed with water, dried over magnesium sulfate, and concentrated. Flash column chromatography (silica gel/ethyl acetate:methylene chloride:hexanes $=1: 5: 5)$ provided $0.080 \mathrm{~g}$ of $153(0.106 \mathrm{mmol}, 57 \%)$ as a yellow solid: IR (neat) 2947, 1719, 1366, 1216, $900 \mathrm{~cm}^{-1}$; ${ }^{1} \mathrm{H}\left(\mathrm{CDCl}_{3}, 600 \mathrm{MHz}\right) \delta 8.45(2 \mathrm{H}, \mathrm{d}, J=7.2 \mathrm{~Hz}), 7.75$ (2 H, d, $J=7.8 \mathrm{~Hz}), 7.63-7.58(8 \mathrm{H}, \mathrm{m}), 7.48-7.46(4 \mathrm{H}, \mathrm{m}), 7.32(2 \mathrm{H}, \mathrm{d}, J=8.4 \mathrm{~Hz}), 7.24(2$ H, d, $J=7.8 \mathrm{~Hz}), 7.18$ (2 H, t, $J=7.8 \mathrm{~Hz}), 6.42(2 \mathrm{H}, \mathrm{d}, J=7.2 \mathrm{~Hz}), 4.37-4.32(2 \mathrm{H}, \mathrm{m}), 3.90(2$ $\mathrm{H}, \mathrm{t}, J=8.4 \mathrm{~Hz}), 2.87-2.84(2 \mathrm{H}, \mathrm{m}), 2.06(6 \mathrm{H}, \mathrm{s}) ;{ }^{13} \mathrm{C}\left(\mathrm{CDCl}_{3}, 150 \mathrm{MHz}\right) \delta 192.6,151.2,145.1$, $142.8,141.5,137.94,137.88,136.9,136.3,135.0,134.4,131.9,131.0,129.8,129.7,129.3$, 128.7, 128.3 125.1, 124.6, 123.9, 123.8, 121.9, 73.6, 52.3, 46.4, 29.5; MS m/z $756\left(\mathrm{M}^{+}\right)$; HRMS calcd for $\mathrm{C}_{56} \mathrm{H}_{36} \mathrm{O}_{3}$ 756.2664, found 756.2655. Recrystallization of $\mathbf{1 5 3}$ from methylene chloride/hexanes produced a crystal suitable for X-ray structure analysis.

Diiodide 155. To $0.420 \mathrm{~g}$ (1.18 mmol) of $\mathbf{1 5 0} \mathrm{in} 10 \mathrm{~mL}$ of anhydrous methylene chloride under a nitrogen atmosphere at rt was added $0.8 \mathrm{~mL}$ of trimethylsilyl iodide. After $18 \mathrm{~h}$ of stirring, the reaction mixture was concentrated to remove TMSI and methylene chloride. The residue was purified by flash column chromatography (silica gel/ethyl acetate:methylene chloride:hexanes = 1:50:50) to provide $0.599 \mathrm{~g}(1.01 \mathrm{mmol}, 86 \%)$ of $\mathbf{1 5 5}$ as a pale yellow solid, ${ }^{1} \mathrm{H}\left(\mathrm{CDCl}_{3}, 270\right.$ 
MHz) $\delta 8.30(2 \mathrm{H}, \mathrm{d}, J=7.9 \mathrm{~Hz}), 7.89(2 \mathrm{H}, \mathrm{d}, J=7.6 \mathrm{~Hz}), 7.75(2 \mathrm{H}, \mathrm{t}, J=7.6 \mathrm{~Hz}), 7.54(2 \mathrm{H}, \mathrm{t}$, $J=7.4 \mathrm{~Hz}), 3.08$ (6 H, br), $1.55(3 \mathrm{H}, \mathrm{s}), 1.49(3 \mathrm{H}, \mathrm{s}) ;{ }^{13} \mathrm{C}\left(\mathrm{CDCl}_{3}, 67.9 \mathrm{MHz}\right) \delta$ 204.0, 146.1, 135.7, 134.8, 129.8, 125.6, 124.9, 56.7, 47.3 (br), 28.0 (br). MS m/z $594\left(\mathrm{MH}^{+}\right)$, 467; HRMS calcd for $\mathrm{C}_{24} \mathrm{H}_{20} \mathrm{I}_{2} \mathrm{O}_{2}\left(\mathrm{MH}^{+}\right)$594.9631, found 594.9623 .

Alcohol 156. To $0.464 \mathrm{~g}$ ( $2.30 \mathrm{mmol})$ of 5 in $10 \mathrm{~mL}$ of anhydrous diethyl ether under a nitrogen atmosphere at $0{ }^{\circ} \mathrm{C}$ was added $1.4 \mathrm{~mL}$ of a $1.6 \mathrm{M}$ solution of $n$-butyllithium $(2.3 \mathrm{mmol})$ in hexanes. After $30 \mathrm{~min}$ of stirring, a solution of $0.440 \mathrm{~g}$ of $\mathbf{1 5 5}(0.741 \mathrm{mmol})$ in $20 \mathrm{~mL}$ of diethyl ether was introduced via cannula, and $30 \mathrm{~mL}$ of anhydrous benzene was added to the mixture. After an additional $18 \mathrm{~h}, 30 \mathrm{~mL}$ of water was introduced, and the reaction mixture was extracted with diethyl ether. The combined organic extracts were washed with brine and water, dried over sodium sulfate, and concentrated. The residue was purified by flash column chromatography (silica gel/ethyl acetate:methylene chloride:hexanes $=2: 50: 50)$ to provide $0.537 \mathrm{~g}(0.674 \mathrm{mmol}$, $65 \%)$ of 156 as a pale yellow solid: ${ }^{1} \mathrm{H}\left(\mathrm{CDCl}_{3}, 600 \mathrm{MHz}\right) \delta 8.27(1 \mathrm{H}, \mathrm{d}, J=7.8 \mathrm{~Hz}), 7.87(1 \mathrm{H}$, d, $J=7.2 \mathrm{~Hz}), 7.82(1 \mathrm{H}, \mathrm{dd}, J=7.8,0.6 \mathrm{~Hz}), 7.47-7.45(2 \mathrm{H}, \mathrm{m}), 7.43-7.41(2 \mathrm{H}, \mathrm{m})$, 7.40-7.39 (1 H, m), 7.36-7.31 (3 H, m), 7.28-7.22 (2 H, m) 7.20-7.12 (4 H, m), 7.06 (1 H, t, $J$ $=7.8 \mathrm{~Hz}), 4.33(1 \mathrm{H}, \mathrm{dd}, J=10.2,3.6 \mathrm{~Hz}), 4.21(1 \mathrm{H}, \mathrm{t}, J=4.8 \mathrm{~Hz}), 3.76(1 \mathrm{H}, \mathrm{dd}, J=11.4$, $4.8 \mathrm{~Hz}), 3.27$ (1 H, q, $J=4.8 \mathrm{~Hz}), 2.70(1 \mathrm{H}, \mathrm{dt}, J=12,4.2 \mathrm{~Hz}), 2.33(1 \mathrm{H}, \mathrm{dd}, J=11.4,4.8 \mathrm{~Hz})$, $2.03(1 \mathrm{H}, \mathrm{s}, \mathrm{br}), 1.28(3 \mathrm{H}, \mathrm{s}), 1.22(3 \mathrm{H}, \mathrm{s})$.

Ketone 158. To 151 (0.382 g, $0.685 \mathrm{mmol})$ in $10 \mathrm{~mL}$ of THF at $0{ }^{\circ} \mathrm{C}$ was added via cannula a solution of thionyl chloride $(0.30 \mathrm{~mL}, 4.1 \mathrm{mmol})$ and anhydrous pyridine $(0.55 \mathrm{~mL})$ in $10 \mathrm{~mL}$ of THF. The reaction mixture then was allowed to warm to room temperature. After an additional $10 \mathrm{~h}, 10 \mathrm{~mL}$ of water was introduced, and the reaction mixture was extracted with $20 \mathrm{~mL}$ of diethyl ether. The combined organic extracts were washed with water, dried over magnesium sulfate, and concentrated. The residue was then purified by flash column chromatography (silica 
gel/ethyl acetate:methylene chloride:Hexanes $=1: 5: 5)$ provided $0.331 \mathrm{~g}$ of $\mathbf{1 5 8}(0.596 \mathrm{mmol}$, 87\%) as a yellow solid: mp $268{ }^{\circ} \mathrm{C}$ turned black without melting; ${ }^{1} \mathrm{H}\left(\mathrm{CDCl}_{3}, 600 \mathrm{MHz}\right) \delta 8.42$ $(1 \mathrm{H}, \mathrm{d}, J=7.2 \mathrm{~Hz}), 7.90(1 \mathrm{H}, \mathrm{d}, J=7.2 \mathrm{~Hz}), 7.81(1 \mathrm{H}, \mathrm{t}, J=7.8 \mathrm{~Hz}), 7.73(1 \mathrm{H}, \mathrm{d}, J=7.2 \mathrm{~Hz})$, 7.64-7.58 (3 H, m), $7.53(1 \mathrm{H}, \mathrm{t}, J=7.8 \mathrm{~Hz}), 7.52(1 \mathrm{H}, \mathrm{td}, J=7.2,1.8 \mathrm{~Hz}), 7.45(2 \mathrm{H}, \mathrm{t}, J=7.8$ Hz), $7.32(1 \mathrm{H}, \mathrm{dd}, J=7.8,1.2 \mathrm{~Hz}), 7.25(1 \mathrm{H}, \mathrm{t}, J=6.6 \mathrm{~Hz}), 7.19(1 \mathrm{H}, \mathrm{t}, J=7.8 \mathrm{~Hz}), 6.41(1 \mathrm{H}$, d, $J=7.8 \mathrm{~Hz}), 4.18(1 \mathrm{H}, \mathrm{t}, J=8.4 \mathrm{~Hz}), 4.15(1 \mathrm{H}, \mathrm{t}, J=8.4 \mathrm{~Hz}), 3.86(1 \mathrm{H}, \mathrm{t}, J=8.4 \mathrm{~Hz}), 3.17$ $(1 \mathrm{H}, \mathrm{q}, J=9.6 \mathrm{~Hz}), 2.77(1 \mathrm{H}, \mathrm{t}, J=9.6 \mathrm{~Hz}), 2.73(1 \mathrm{H}, \mathrm{t}, J=7.8 \mathrm{~Hz}), 1.96(3 \mathrm{H}, \mathrm{s}), 1.75(3 \mathrm{H}$, s); ${ }^{13} \mathrm{C}\left(\mathrm{CDCl}_{3}, 150 \mathrm{MHz}\right) \delta 206.5,192.9,150.0,148.5,145.1,143.1,140.4,138.1,137.8,136.7$, $136.6,136.3,135.5,135.1,134.48,134.44,132.0,131.2,129.8,129.7,129.4,129.31,129.25$, 128.7, 128.4, 126.6, 125.6, 124.8, 124.7, 123.94, 123.87, 120.2, 73.3, 72.7, 55.6, 52.0, 46.9, 44.9, 29.5, 28.0. MS m/z $556\left(\mathrm{M}^{+}\right)$, 487; HRMS calcd for $\mathrm{C}_{40} \mathrm{H}_{28} \mathrm{O}_{3}$ 556.2038, found 556.2051. Recrystallization of $\mathbf{1 5 8}$ from methylene chloride/ethanol produced a crystal suitable for X-ray structure analysis.

Diiodide 159. To $0.331 \mathrm{~g}(0.595 \mathrm{mmol})$ of $\mathbf{1 5 8} \mathrm{in} 10 \mathrm{~mL}$ of anhydrous methylene chloride under a nitrogen atmosphere at room temperature was added $1.0 \mathrm{~mL}$ of trimethylsilyl iodide. After $18 \mathrm{~h}$ of stirring, the reaction mixture was concentrated to remove TMSI and methylene chloride. The residue was purified by flash column chromatography (silica gel/ethyl acetate:methylene chloride:hexanes $=1: 50: 50)$ to provide $0.402 \mathrm{~g}(0.506 \mathrm{mmol}, 85 \%)$ of $\mathbf{1 5 9}$ as a bright yellow solid, mp $215{ }^{\circ} \mathrm{C}$ turned black without melting; IR 2927, 1719, 1701, $1612 \mathrm{~cm}^{-1} ;{ }^{1} \mathrm{H}\left(\mathrm{CDCl}_{3}, 600\right.$ MHz) $\delta 8.28(1 \mathrm{H}, \mathrm{d}, J=7.8 \mathrm{~Hz}), 8.26(1 \mathrm{H}, \mathrm{d}, J=7.8 \mathrm{~Hz}), 7.83(1 \mathrm{H}, \mathrm{d}, J=7.2 \mathrm{~Hz}), 7.81(1 \mathrm{H}$, d, $J=7.2 \mathrm{~Hz}), 7.77(1 \mathrm{H}, \mathrm{t}, J=7.2 \mathrm{~Hz}), 7.64-7.59(3 \mathrm{H}, \mathrm{m}), 7.54(1 \mathrm{H}, \mathrm{t}, J=7.8 \mathrm{~Hz}), 7.50(1 \mathrm{H}$, t, $J=7.8 \mathrm{~Hz}), 7.48-7.45(3 \mathrm{H}, \mathrm{m}), 7.34(1 \mathrm{H}, \mathrm{d}, J=8.4 \mathrm{~Hz}), 7.24(1 \mathrm{H}, \mathrm{t}, J=7.2 \mathrm{~Hz}), 7.18(1 \mathrm{H}$, t, $J=7.2 \mathrm{~Hz}), 6.41(1 \mathrm{H}, \mathrm{d}, J=7.8 \mathrm{~Hz}), 4.76(1 \mathrm{H}, \mathrm{dd}, J=10.8,3.6 \mathrm{~Hz}), 4.53-4.51(1 \mathrm{H}, \mathrm{m})$, $3.84(1 \mathrm{H}, \mathrm{t}, J=11.4 \mathrm{~Hz}), 3.23(1 \mathrm{H}, \mathrm{dt}, J=12.0,3.6 \mathrm{~Hz}), 2.55(2 \mathrm{H}, \mathrm{d}, J=3.6 \mathrm{~Hz}), 1.76(3 \mathrm{H}$, 
s), $1.67(3 \mathrm{H}, \mathrm{s}) ;{ }^{13} \mathrm{C}\left(\mathrm{CDCl}_{3}, 150 \mathrm{MHz}\right) \delta 203.5,192.8,148.2,146.5,145.0,140.7,140.4,138.7$, $138.4,138.0,136.8,136.4,135.7,135.0,134.4,134.0,132.3,131.2,129.9,129.7,129.32$ $129.29,129.2,128.8,128.4,126.5,126.2,125.7,124.6,124.3,123.9,121.0,56.0,55.3,49.4$, 43.4, 30.9, 25.0, 8.4, -0.9. MS m/z $795\left(\mathrm{MH}^{+}\right), 638$; HRMS calcd for $\mathrm{C}_{40} \mathrm{H}_{28} \mathrm{I}_{2} \mathrm{O}_{2}\left(\mathrm{MH}^{+}\right)$ 795.0257, found 795.0264. Recrystallization of $\mathbf{1 5 9}$ from methylene chloride/hexanes produced a crystal suitable for X-ray structure analysis.

Alcohol 160. To a solution of $0.477 \mathrm{~g}$ of $5(0.601 \mathrm{mmol})$ in $20 \mathrm{~mL}$ of anhydrous THF under a nitrogen atmosphere at $-10{ }^{\circ} \mathrm{C}$ was added $0.1 \mathrm{M}$ lthium acetylide/THF solution $6.1 \mathrm{~mL}$ via a syringe. The $0.1 \mathrm{M}$ lithium acetylide solution was prepared from $0.329 \mathrm{~g}(1.63 \mathrm{mmol})$ of $\mathbf{1 5 9}$ in $15 \mathrm{~mL}$ THF under a nitrogen atmosphere at $0{ }^{\circ} \mathrm{C}$ and $1.0 \mathrm{~mL}$ of a $1.6 \mathrm{M}$ solution of n-butyllithium (1.6 mmol) in hexanes. After $10 \mathrm{~min}$ of stirring, $20 \mathrm{~mL}$ of water was introduced, and the reaction mixture was extracted with diethyl ether. The combined organic extracts were washed with brine and water, dried over sodium sulfate, and concentrated. The residue was purified by flash column chromatography (silica gel/ethyl acetate:methylene chloride:hexanes = 1:50:50) to provide $0.503 \mathrm{~g}(0.505 \mathrm{mmol}, 84 \%)$ of $\mathbf{1 6 0}$ as a yellow solid: $\mathrm{mp} 175{ }^{\circ} \mathrm{C}$ turned dask without meling; IR 2340, 1702, $1613 \mathrm{~cm}^{-1} ;{ }^{1} \mathrm{H}\left(\mathrm{CDCl}_{3}, 600 \mathrm{MHz}\right) \delta 8.24(1 \mathrm{H}, \mathrm{d}, J=7.2 \mathrm{~Hz})$, $8.04(1 \mathrm{H}, \mathrm{d}, J=7.8 \mathrm{~Hz}), 7.81(2 \mathrm{H}, \mathrm{d}, J=6.6 \mathrm{~Hz}), 7.63-7.56(3 \mathrm{H}, \mathrm{m}), 7.53(1 \mathrm{H}, \mathrm{d}, J=7.8 \mathrm{~Hz})$, 7.49-7.39 (6 H, m), 7.36 (1 H, t, $J=7.8 \mathrm{~Hz}), 7.29-7.20(4 \mathrm{H}, \mathrm{m}) 7.16(1 \mathrm{H}, \mathrm{td}, J=7.8,1.2 \mathrm{~Hz})$, $7.13(1 \mathrm{H}, \mathrm{td}, J=7.2,1.2 \mathrm{~Hz}), 6.40(1 \mathrm{H}, \mathrm{d}, J=7.8 \mathrm{~Hz}), 4.53-4.49(2 \mathrm{H}, \mathrm{m}), 4.33(1 \mathrm{H}, \mathrm{t}, J=$ 11.4 Hz), 3.96 (1 H, td, $J$ = 11.4, 4.2 Hz), 3.11 (1 H, td, $J=11.4,4.2 \mathrm{~Hz}), 2.40(1 \mathrm{H}, \mathrm{dd}, J=11.4$, $4.8 \mathrm{~Hz}), 2.92$ (1 H, br), $1.80(3 \mathrm{H}, \mathrm{s}), 1.43(3 \mathrm{H}, \mathrm{s}) ;{ }^{13} \mathrm{C}\left(\mathrm{CDCl}_{3}, 150 \mathrm{MHz}\right) \delta 193.1,148.8,148.5$, 145.1, 141.0, 140.0, 139.2, 138.3, 137.7, 137.1, 136.6, 135.0, 134.1, 132.1, 132.0, 131.9, 131.8, $131.1,130.0,129.2,129.18,128.7,128.6,128.56,128.4,128.3,127.9,127.8,127.1,126.0$ $125.9,125.0,124.3,123.8,123.6,123.0,122.8,119.3,96.0,93.3,89.2,87.7,78.7,62.7,54.9$, 
50.5, 44.3, 27.4, 24.8, 5.1, 0.7. MS m/z $996\left(\mathrm{M}^{+}\right)$, 868; HRMS calcd for $\mathrm{C}_{56} \mathrm{H}_{38} \mathrm{I}_{2} \mathrm{O}_{2}\left(\mathrm{M}^{+}\right)$ 996.0961, found 996.0935.

Diketone 154, Spiro-162, Alcohol 163. To $160(0.303 \mathrm{~g}, 0.304 \mathrm{mmol})$ in $10 \mathrm{~mL}$ of THF at $0{ }^{\circ} \mathrm{C}$ was added via cannula a solution of thionyl chloride $(0.25 \mathrm{~mL}, 3.4 \mathrm{mmol})$ and anhydrous pyridine $(0.45 \mathrm{~mL})$ in $10 \mathrm{~mL}$ of THF. The reaction mixture then was allowed to warm to room temperature. After an additional $18 \mathrm{~h}, 20 \mathrm{~mL}$ of water was introduced, and the reaction mixture was extracted with $20 \mathrm{~mL}$ of diethyl ether. The combined organic extracts were washed with water, dried over magnesium sulfate, and concentrated. The crude product was directly for next oxidation step without any further purification. To a solution of crude solid product in $20 \mathrm{~mL}$ toluene was added $0.060 \mathrm{~g}$ of $\mathrm{MnO}_{2}$ at room temperature. After 2 days of stirring, $\mathrm{MnO}_{2}$ was filtered out followed by evaporation to remove toluene. The residue was then purified by flash column chromatography (silica gel/50\% methylene chloride in hexanes) to afford $0.143 \mathrm{~g}$ of $\mathbf{1 5 4}$ (0.144 mmol, $47 \%$ ) as a orange-yellow solid, (silica gel/30\% methylene chloride in hexanes) $0.126 \mathrm{~g}$ of $162(0.125 \mathrm{mmol}, 41 \%)$ as a bright yellow solid and (silica gel/ethyl acetate:methylene chloride:hexanes $=1: 50: 50) 0.006 \mathrm{~g}$ of $163(0.006 \mathrm{mmol}, 2 \%)$ as a yellow solid: 154: mp $247^{\circ} \mathrm{C}$ turned black without melting; IR 3058, 2121, 1698, $1602 \mathrm{~cm}^{-1} ;{ }^{1} \mathrm{H}\left(\mathrm{CDCl}_{3}\right.$, $600 \mathrm{MHz}$, room temperature) $\delta 8.36(2 \mathrm{H}, \mathrm{br}), 7.83(2 \mathrm{H}, \mathrm{d}, J=7.2 \mathrm{~Hz}), 7.64-7.59$ (6 H, m), 7.56 $(2 \mathrm{H}, \mathrm{t}, J=7.8 \mathrm{~Hz}), 7.52(2 \mathrm{H}, \mathrm{d}, J=7.2 \mathrm{~Hz}), 7.45(2 \mathrm{H}, \mathrm{t}, J=6.6 \mathrm{~Hz}), 7.33(2 \mathrm{H}, \mathrm{d}, J=8.4 \mathrm{~Hz})$, 7.26 (2 H, td, $J=7.2,0.6 \mathrm{~Hz}$ ), 7.19 (2 H, td, $J=7.8,1.2 \mathrm{~Hz}), 6.41(2 \mathrm{H}, \mathrm{d}, J=7.8 \mathrm{~Hz}), 4.23(2$ H, br), 3.80 (2 H, br), $2.72(2 \mathrm{H}, \mathrm{br}), 2.05(6 \mathrm{H}, \mathrm{s}) ;{ }^{1} \mathrm{H}\left(\mathrm{CDCl}_{3}, 600 \mathrm{MHz}\right.$, at $\left.-60{ }^{\circ} \mathrm{C}\right) \delta 8.53(1 \mathrm{H}$, d, $J=7.2 \mathrm{~Hz}), 8.14(1 \mathrm{H}, \mathrm{d}, J=7.2 \mathrm{~Hz}), 7.83(2 \mathrm{H}, \mathrm{d}, J=7.2 \mathrm{~Hz}), 7.80(2 \mathrm{H}, \mathrm{d}, J=7.2 \mathrm{~Hz}), 7.73$ (1 H, t, $J=6.6 \mathrm{~Hz}), 7.63-7.62$ (4 H, m), 7.49 (2 H, d, $J=7.8 \mathrm{~Hz}), 7.46-7.42$ (2 H, m), 7.39-7.35 (2 H, m), 7.28-7.27 (2 H, m), 7.22-7.19 (2 H, m), 6.25 (1 H, d, $J=7.8 \mathrm{~Hz}), 6.27(1 \mathrm{H}, \mathrm{d}, J=7.8$ Hz), $4.96(1 \mathrm{H}, \mathrm{d}, J=7.2 \mathrm{~Hz}), 4.71(1 \mathrm{H}, \mathrm{s}, \mathrm{br}), 3.72(1 \mathrm{H}, \mathrm{d}, J=12 \mathrm{~Hz}), 3.02(1 \mathrm{H}, \mathrm{t}, J=11.4$ 
Hz), $2.42(1 \mathrm{H}, \mathrm{d}, J=11.4 \mathrm{~Hz}), 2.22(1 \mathrm{H}, \mathrm{s}, \mathrm{br}), 2.08(3 \mathrm{H}, \mathrm{s}), 1.88(3 \mathrm{H}, \mathrm{s}) ;{ }^{13} \mathrm{C}\left(\mathrm{CDCl}_{3}, 150\right.$ $\mathrm{MHz}$, room temperature) $\delta 193.3,149.2,144.9,140.9,138.3,138.2,136.8,136.4,135.1,134.5$, $132.4,131.0,129.9,129.7,129.34,129.30,128.8,128.4,126.8,125.3,124.4,123.9,121.1(\mathrm{br})$ 56.4 (br), 49.1 (br), 4.6 (br). MS m/z 1017 ( $\left.\mathrm{MNa}^{+}\right)$, 995; HRMS calcd for $\mathrm{C}_{56} \mathrm{H}_{36} \mathrm{I}_{2} \mathrm{O}_{2}\left(\mathrm{MNa}^{+}\right)$ 1017.0703, found 1017.0698. Recrystallization of $\mathbf{1 5 4}$ from methylene chloride/hexanes/ethyl acetate produced a crystal suitable for X-ray structure analysis.162: mp $225{ }^{\circ} \mathrm{C}$ turned dark without melting; IR 3058, 2967, 2325, 1703, $1614 \mathrm{~cm}^{-1} ;{ }^{1} \mathrm{H}\left(\mathrm{CDCl}_{3}, 600 \mathrm{MHz}\right) \delta 8.48(1 \mathrm{H}, \mathrm{d}, J$ $=7.8 \mathrm{~Hz}), 8.20(1 \mathrm{H}, \mathrm{d}, J=7.2 \mathrm{~Hz}), 7.76(1 \mathrm{H}, \mathrm{d}, J=6.6 \mathrm{~Hz}), 7.73(1 \mathrm{H}, \mathrm{d}, J=7.8 \mathrm{~Hz})$, 7.65-7.58 (3 H, m), 7.57-7.53 (3 H, m), 7.51-7.48 (3 H, m), 7.35 (1 H, d, $J=7.8 \mathrm{~Hz}), 7.52$ (2 H, d, $J=7.2 \mathrm{~Hz}$ ), 7.45 (2 H, t, $J=6.6 \mathrm{~Hz}), 7.33(2 \mathrm{H}, \mathrm{d}, J=8.4 \mathrm{~Hz}), 7.32-7.29(2 \mathrm{H}, \mathrm{m}), 7.20$ (1 H, td, $J=7.2,0.6 \mathrm{~Hz}), 7.15(1 \mathrm{H}, \mathrm{td}, J=7.8,1.2 \mathrm{~Hz}), 7.12(1 \mathrm{H}, \mathrm{d}, J=7.8 \mathrm{~Hz}), 7.04(1 \mathrm{H}, \mathrm{t}, J=$ $7.2 \mathrm{~Hz}), 6.93$ (1 H, br), 6.40 (1 H, d, $J=7.8 \mathrm{~Hz}), 4.36-4.34(1 \mathrm{H}, \mathrm{m}), 4.05(1 \mathrm{H}, \mathrm{dd}, J=10.2,3$ Hz), $3.62(1 \mathrm{H}, \mathrm{t}, J=11.4 \mathrm{~Hz}), 3.19(1 \mathrm{H}, \mathrm{dt}, J=13.2,3.6 \mathrm{~Hz}), 2.40(1 \mathrm{H}, \mathrm{dd}, J=11.4,3 \mathrm{~Hz})$, $1.83(3 \mathrm{H}, \mathrm{s}), 1.78(3 \mathrm{H}, \mathrm{s}), 1.65(1 \mathrm{H}, \mathrm{dd}, J=11.4,5.4 \mathrm{~Hz}) ;{ }^{13} \mathrm{C}\left(\mathrm{CDCl}_{3}, 150 \mathrm{MHz}\right) \delta 193.0$, $152.7,148.8,148.3,148.1,147.0,145.1,142.5,141.2,140.5,140.1,138.6,137.8,137.3,137.1$, $136.6,135.2,134.1,133.2,132.1,131.2,130.2,130.1,129.8,129.7,129.4,129.24,129.22$, $128.8,128.79,128.6,128.3,127.8,127.3,126.4,125,5,125.1,125.0,124.2,123.9,123.8,120.6$, 118.1, 112.7, 74.9, 57.3, 54.5, 51.9, 43.7, 32.0, 25.1, 6.7, 0.2. MS m/z $1014\left(\mathrm{M}^{+}\right), 637$; HRMS calcd for $\mathrm{C}_{56} \mathrm{H}_{37} \mathrm{ClI}_{2} \mathrm{O}\left(\mathrm{MH}^{+}\right)$1015.0695, found 1015.0686. Recrystallization of 162 from methylene chloride/hexanes produced a crystal suitable for X-ray structure analysis. 163: ${ }^{1} \mathrm{H}$ $\left(\mathrm{CDCl}_{3}, 600 \mathrm{MHz}\right) \delta 8.54(1 \mathrm{H}, \mathrm{d}, J=7.8 \mathrm{~Hz}), 8.18(1 \mathrm{H}, \mathrm{d}, J=7.2 \mathrm{~Hz}), 7.81(1 \mathrm{H}, \mathrm{d}, J=7.2$ Hz), $7.75(1 \mathrm{H}, \mathrm{d}, J=7.2 \mathrm{~Hz}), 7.65-7.58(6 \mathrm{H}, \mathrm{m}), 7.52(1 \mathrm{H}, \mathrm{d}, J=7.8 \mathrm{~Hz}), 7.49(1 \mathrm{H}, \mathrm{d}, J=7.2$ Hz), 7.46 (1 H, d, $J=7.2 \mathrm{~Hz}), 7.44-7.41(3 \mathrm{H}, \mathrm{m}), 7.30$ (1 H, t, $J=7.2 \mathrm{~Hz}), 7.27-7.25$ (2 H, m) $7.19(1 \mathrm{H}, \mathrm{t}, J=7.8 \mathrm{~Hz}), 7.08(1 \mathrm{H}, \mathrm{d}, J=7.8 \mathrm{~Hz}), 6.53(1 \mathrm{H}, \mathrm{s}, \mathrm{br}), 6.50(1 \mathrm{H}, \mathrm{d}, J=7.8 \mathrm{~Hz})$, 
6.37 (1 H, d, $J=7.2$ Hz), 4.96 (2 H, s, br), 4.14-4.11 (1 H, m), 3.85 (1 H, s, br), 3.17-3.13 (1 H, m) 2.95, (1 H, s, br), $2.33(1 \mathrm{H}, \mathrm{m}, \mathrm{br}), 2.14(3 \mathrm{H}, \mathrm{s}), 2.01(1 \mathrm{H}, \mathrm{m}, \mathrm{br}), 2.03(3 \mathrm{H}, \mathrm{s}) ;{ }^{13} \mathrm{C}\left(\mathrm{CDCl}_{3}\right.$, $150 \mathrm{MHz}) \delta 193.9,148.8,146.6,145.8,144.8,140.0,139.8,138.5,138.2,138.1,137.9,137.6$, $136.9,136.2,135.6,135.4,134.6,132.7,132.3,131.7,131.3,130.2,129.9,129.8,129.7,129.4$ $129.3,129.2,129.17,128.9,128.7,128.4,128.2,128.0,127.8,127.3,125.2,125.0,124.5,124.4$ 123.9, 123.8, 122.6 (br), 118.3 (br), 74.3, 58.5, 55.1, 52.8 (br), 47.9 (br), 8.0 (br), 3.5 (br). MS m/z $1019\left(\mathrm{MNa}^{+}\right)$, 979; HRMS calcd for $\mathrm{C}_{56} \mathrm{H}_{36} \mathrm{I}_{2} \mathrm{O}_{2}\left(\mathrm{MNa}^{+}\right)$1019.0859, found 1019.0889. Recrystallization of $\mathbf{1 6 3}$ from methylene chloride/hexanes/ethyl acetate produced a crystal suitable for X-ray structure analysis.

$\mathbf{I}_{2}$-Hydrocarbon 165, Ketone 166. To $154(0.038 \mathrm{~g}, 0.038 \mathrm{mmol})$ in $8 \mathrm{~mL}$ of chloroform was added $0.5 \mathrm{~mL}$ freshly prepared $1.0 \mathrm{M}$ diiodosilane ${ }^{70}$ at $40{ }^{\circ} \mathrm{C}$ under a nitrogen gas atmosphere. After 2 days of stirring, the reaction mixture was quenched with $2 \mathrm{~mL} 20 \%$ aqueous $\mathrm{NaHCO}_{3}$. The aqueous layer was separated and back extracted twice with methylene chloride, and the combined organic layers were dried over sodium sulfate and concentrated. The residue was then purified by flash column chromatography (silica gel $/ 30 \%$ methylene chloride in hexanes) to afford $0.028 \mathrm{~g}$ of $165(0.028 \mathrm{mmol}, 76 \%)$ as a white solid and (silica gel/50\% methylene chloride in hexanes) $0.001 \mathrm{~g} 166$ (0.001 mmol, $3 \%)$ as a pale yellow solid. 165: ${ }^{1} \mathrm{H}\left(\mathrm{CDCl}_{3}, 600\right.$ MHz) $\delta 7.66(1 \mathrm{H}, \mathrm{dt}, J=7.2,1.2 \mathrm{~Hz}), 7.63-7.41(12 \mathrm{H}, \mathrm{m}), 7.36(1 \mathrm{H}, \mathrm{d}, J=7.2 \mathrm{~Hz}), 7.28-7.24$ (2 H, m), $7.21(1 \mathrm{H}, \mathrm{dt}, J=7.2,0.6 \mathrm{~Hz}), 7.03(1 \mathrm{H}, \mathrm{t}, J=7.8 \mathrm{~Hz}), 7.01(1 \mathrm{H}, \mathrm{t}, J=7.8 \mathrm{~Hz}), 6.95$ (1 H, d, $J=8.4 \mathrm{~Hz}), 7.65-6.62(2 \mathrm{H}, \mathrm{m}), 6.52(1 \mathrm{H}, \mathrm{d}, J=7.8 \mathrm{~Hz}), 4.91(1 \mathrm{H}, \mathrm{d}, J=7.8 \mathrm{~Hz}), 4.67$ $(1 \mathrm{H}, \mathrm{dd}, J=9.6,3.0 \mathrm{~Hz}), 4.48(1 \mathrm{H}, \mathrm{d}, J=22.2 \mathrm{~Hz}), 4.43(1 \mathrm{H}, \mathrm{d}, J=21.0 \mathrm{~Hz}), 4.34(1 \mathrm{H}, \mathrm{d}, J=$ $21.6 \mathrm{~Hz}), 4.23(1 \mathrm{H}, \mathrm{d}, J=6.6 \mathrm{~Hz}), 4.12(1 \mathrm{H}, \mathrm{d}, J=22.2 \mathrm{~Hz}), 3.97(1 \mathrm{H}, \mathrm{d}, J=6.6 \mathrm{~Hz}), 3.70(1$ H, dd, $J=12.0,3.6 \mathrm{~Hz}), 3.44(1 \mathrm{H}, \mathrm{d}, J=9.0 \mathrm{~Hz}), 2.81(1 \mathrm{H}, \mathrm{d}, J=12.0 \mathrm{~Hz}), 2.61(1 \mathrm{H}, \mathrm{d}, J=$ $11.4 \mathrm{~Hz}), 2.16(3 \mathrm{H}, \mathrm{s}), 2.12(1 \mathrm{H}, \mathrm{dd}, J=11.7,9.0 \mathrm{~Hz}), 1.67(3 \mathrm{H}, \mathrm{s}) ;{ }^{13} \mathrm{C}\left(\mathrm{CDCl}_{3}, 150 \mathrm{MHz}\right) \delta$ 
144.0, 143.9, 143.5, 142.8, 141.1, 141.0, 140.9, 140.1, 139.7, 138.6, 138.3, 138.1, 137.5, 135.9, 135.0, 132.3, 131.4, 131.3, 130.6, 130.3, 130.2, 129.7, 129.1, 129.08, 129.06, 128.9, 127.8, 127.7, $127.5,127.2,126.7,126.5,125.0,124.6,123.8,123.7,123.0,122.1,120.2,120.2,58.3,53.9$, 53.0, 52.0, 51.9, 46.1, 26.8, 35.3, 30.3, 26.8, 11.6, 0.8. MS m/z $968\left(\mathrm{M}^{+}\right)$, 876; HRMS calcd for $\mathrm{C}_{56} \mathrm{H}_{42} \mathrm{I}_{2}\left(\mathrm{MH}^{+}\right)$969.1449, found 969.1499. 166: ${ }^{1} \mathrm{H}\left(\mathrm{CDCl}_{3}, 600 \mathrm{MHz}\right) \delta 7.74(1 \mathrm{H}, \mathrm{d}, J=7.2$ Hz), 7.66-7.45 (13 H, m), 7.34 (1 H, d, $J=6.6 \mathrm{~Hz}), 7.24-7.20(2 \mathrm{H}, \mathrm{m}) 7.16(1 \mathrm{H}, \mathrm{t}, J=7.8 \mathrm{~Hz})$, $7.01(1 \mathrm{H}, \mathrm{t}, J=8.4 \mathrm{~Hz}), 6.85(1 \mathrm{H}, \mathrm{d}, J=7.8 \mathrm{~Hz}), 6.73(1 \mathrm{H}, \mathrm{t}, J=7.8 \mathrm{~Hz}), 6.62(1 \mathrm{H}, \mathrm{d}, J=8.4$ Hz), $6.27(1 \mathrm{H}, \mathrm{d}, J=7.8 \mathrm{~Hz}), 5.22(1 \mathrm{H}, \mathrm{dd}, J=10.2,3 \mathrm{~Hz}), 4.97(1 \mathrm{H}, \mathrm{d}, J=7.2 \mathrm{~Hz}), 4.52(1 \mathrm{H}$, d, $J=21.6 \mathrm{~Hz}), 4.17(1 \mathrm{H}, \mathrm{d}, J=7.2 \mathrm{~Hz}), 4.12(1 \mathrm{H}, \mathrm{d}, J=21.6 \mathrm{~Hz}), 3.98(1 \mathrm{H}, \mathrm{d}, J=6.0 \mathrm{~Hz})$, 3.54 (1 H, dd, $J=18,10.2 \mathrm{~Hz}), 3.45(1 \mathrm{H}, \mathrm{d}, J=9 \mathrm{~Hz}), 2.87(1 \mathrm{H}, \mathrm{d}, J=12 \mathrm{~Hz}), 2.59(1 \mathrm{H}, \mathrm{d}, J=$ $12 \mathrm{~Hz}), 2.39$ (3 H, s), 1.97 (1 H, dd, $J=11.1,8.4 \mathrm{~Hz}), 1.67(3 \mathrm{H}, \mathrm{s}) ;{ }^{13} \mathrm{C}\left(\mathrm{CDCl}_{3}, 150 \mathrm{MHz}\right) \delta$ 193.5, 149.6, 147.2, 144.4, 144.1, 143.6, 141.1, 139.5, 138.5, 138.1, 137.4, 136.8, 136.2, 135.1, 134.7, 134.3, 133.3, 131.4, 131.3, 131.0, 130.2, 129.8, 129.4, 129.3, 129.2, 129.1, 129.0, 128.7, $128.3,127.8,127.5,127.2,126.5,125.0,124.2,123.9,123.7,123.1,123.0,121.8,120.2,58.5$, 53.7, 53.3, 53.1, 51.6, 45.8, 35.3, 30.1, 26.7, 10.3, 0.5. MS m/z $982\left(\mathrm{M}^{+}\right)$, 855; HRMS calcd for $\mathrm{C}_{56} \mathrm{H}_{40} \mathrm{I}_{2} \mathrm{O}\left(\mathrm{MH}^{+}\right)$983.1241, found 983.1223.

Hydrocarbon 167. To a solution of $\mathrm{NaH}(0.002 \mathrm{~g}, 0.063 \mathrm{mmol})$ and catalytic amount of $t-\mathrm{BuOH}$ in $8 \mathrm{~mL}$ of anhydrous THF was added $165\left(0.010 \mathrm{~g}\right.$, mmol) via cannula at $-78{ }^{\circ} \mathrm{C}$ under a nitrogen gas atmosphere. Degas the reaction mixture for three times followed by warming up to the room temperature. After $18 \mathrm{~h}$ of stirring, the reaction mixture was quenched with aqueous $\mathrm{NH}_{4} \mathrm{Cl}$ solution under nitrogen gas. The aqueous layer was separated and back extracted twice with methylene chloride, and the combined organic layers were dried over sodium sulfate and concentrated. The residue was then purified by flash column chromatography (silica gel/20\% methylene chloride in hexanes) to afford 167. ${ }^{1} \mathrm{H}\left(\mathrm{CDCl}_{3}, 600 \mathrm{MHz}\right) \delta 7.64(1 \mathrm{H}, \mathrm{d}, J=6.6 \mathrm{~Hz})$, 
7.63-7.51 (10 H, m), 7.45-7.40 (3 H, m), 7.34-7.29 (3 H, m), 7.27-7.25 (2 H, m), 7.07-7.03 (2 H, m), $6.97(1 \mathrm{H}, \mathrm{dt}, J=7.2,1.2 \mathrm{~Hz}), 6.94(1 \mathrm{H}, \mathrm{dt}, J=7.82,1.8 \mathrm{~Hz}), 6.54(2 \mathrm{H}, \mathrm{d}, J=7.2 \mathrm{~Hz})$, $6.48(1 \mathrm{H}, \mathrm{d}, J=8.4 \mathrm{~Hz}), 6.34(1 \mathrm{H}, \mathrm{t}, J=7.8 \mathrm{~Hz}), 5.47(1 \mathrm{H}, \mathrm{d}, J=7.2 \mathrm{~Hz}), 4.24(1 \mathrm{H}, \mathrm{dd}, J=$ 12.0, $5.4 \mathrm{~Hz}), 4.20(1 \mathrm{H}, \mathrm{d}, J=7.8 \mathrm{~Hz}), 4.16(1 \mathrm{H}, \mathrm{d}, J=7.8 \mathrm{~Hz}), 3.98(1 \mathrm{H}, \mathrm{dd}, J=7.2,1.2 \mathrm{~Hz})$, $3.46(1 \mathrm{H}, \mathrm{dt}, J=14.7,8.4 \mathrm{~Hz}), 3.11(1 \mathrm{H}, \mathrm{dd}, J=7.8,5.4 \mathrm{~Hz}), 2.99(1 \mathrm{H}, \mathrm{dd}, J=10.8,4.2 \mathrm{~Hz})$, $1.90(1 \mathrm{H}, \mathrm{dt}, J=13.2,4.5 \mathrm{~Hz}), 1.76(1 \mathrm{H}, \mathrm{dd}, J=14.7,0.01 \mathrm{~Hz}), 1.79(3 \mathrm{H}, \mathrm{s}), 1.57(3 \mathrm{H}, \mathrm{s})$, 0.29 (1 H, dt, $J=12.0,4.2 \mathrm{~Hz}),-3.32(1 \mathrm{H}, \mathrm{ddd}, J=13.2,12.7,11.2, \mathrm{~Hz}) ; \mathrm{MS} m / z 712\left(\mathrm{M}^{+}\right)$, 711; HRMS calcd for $\mathrm{C}_{56} \mathrm{H}_{40}\left(\mathrm{M}^{+}\right)$712.31300, found 712.30795. 


\section{References}

1. (a) Myers, A. G.; Kuo, E. Y.; Finney, N. S. J. Am. Chem. Soc. 1989, 111, 8057-8059. (b) Myers, A. G.; Dragovich, P. S. J. Am. Chem. Soc. 1989, 111, 9130-9132. (c) Myers, A. G.; Dragovich, P. S.; Kuo, E. Y. J. Am. Chem. Soc. 1992, 114, 9369-9386. (d) Nagata, R.; Yamanaka, H.; Okazaki, E.; Saito, I. Tetrahedron Lett. 1989, 30, 4995-4998. (e) Nagata, R.; Yamanaka, H.; Murahashi, E.; Saito, I. Tetrahedron Lett. 1990, 31, 2907-2910.

2. (a) Schmittel, M.; Strittmatter, M.; Kiau, S. Tetrahedron Lett. 1995, 36, 4975-4978. (b) Schmittel, M.; Strittmatter, M.; Vollmann, K.; Kiau, S. Tetrahedron Lett. 1996, 37, 999-1002. (c) Schmittel, M.; Strittmatter, M.; Kiau, S. Angew. Chem. Int. Ed. Engl. 1996, 35, 1843-1845. (d) Schmittel, M.; Kiau, S.; Siebert, T.; Strittmatter, M. Tetrahedron Lett. 1996, 37, 7691-7694. (e) Schmittel, M.; Steffen, J.-P.; Mayward, M.; Engels, B.; Helten, H.; Musch, P. J. Chem. Soc. Perkin Trans. 2 2001, 1331-1339.

3. Schmittel, M.; Keller, M.; Kiau, S.; Strittmatter, M. Chem. Eur. J. 1997, 3, 807-816.

4. (a) de Frutos, Ó.; Echavarren, A. M. Tetrahedron Lett. 1997, 38, 7941-7942. (b) Wang, K. K.; Zhang, H. R.; Petersen, J. L. J. Org. Chem. 1999, 64, 1650-1656.

5. (a) Shi, C.; Wang, K. K. J. Org. Chem. 1998, 63, 3517-3520. (b) Shi, C.; Zhang, Q.; Wang, K. K. J. Org. Chem. 1999, 64, 925-932. (c) Schmittel, M.; Steffen, J. P.; Wencesla-Angel, M. A.; Engels, B.; Lennartz, C.; Hanrath, M. Angew. Chem. Int. Ed. Engl. 1998, 37, 1562-1564. (d) Schmittel, M.; Steffen, J. P.; Engels, B.; Lennartz, C.; Hanrath, M. Angew. Chem. Int. Ed. Engl. 1998, 37, 2371-2373.

6. (a) Schmittel, M.; Rodríguez, D.; Steffen, J. P. Angew. Chem. Int. Ed. Engl. 2000, 39, 2152-2155. (b) Li, H.; Petersen, J. L.; Wang, K. K. J. Org. Chem. 2003, 68, 5512-5518.

7. (a) Li, H.; Zhang, H.-R.; Petersen, J. L.; Wang, K. K. J. Org. Chem. 2001, 66, 6662-6668.

(b) Wang, K. K. In Modern Allene Chemistry; Krause, N., Hashmi, A. S. K., Eds.; 
Wiley-VCH: Weinheim, Germany, 2004; Vol. 2, pp 1091-1126.

8. (a) Yang, Y.; Petersen, J. L.; Wang, K. K. J. Org. Chem. 2003, 68, 5832-5837. (b) Zhang, Y.; Petersen, J. L.; Wang, K. K. Org. Lett. 2007, 9, 1025-1028. (c) Kim, D.; Petersen, J. L.; Wang, K. K. Org. Lett. 2006, 8, 2313-2316. (d) Yang, Y.; Dai, W.; Zhang, Y.; Petersen, J. L.; Wang, K. K. Tetrahedron 2006, 62, 4364-4371. (e) Yang, H.; Petersen, J. L.; Wang, K. K. Tetrahedron 2006, 62, 1231-1238. (f) Yang, H.; Petersen, J. L.; Wang, K. K. Tetrahedron 2006, 62, 8133-8141. (g) Han, X.; Zhang, Y.; Petersen, J. L.; Wang, K. K. J. Org. Chem. 2005, 70, 2406-2408. (h) Dai, W.; Petersen, J. L.; Wang, K. K. Org. Lett. 2004, 6, 4355-4357. (i) Yang, Y.; Petersen, J. L.; Wang, K. K. J. Org. Chem. 2003, 68, 8545-8549. (i) Li, H.; Petersen, J. L.; Wang, K. K. J. Org. Chem. 2001, 66, 7804-7810. (j) Zhang, H.-R.; Petersen, J. L.; Wang, K. K. J. Org. Chem. 1999, 64, 7996-7999.

9. (a) Dehmlow, E. V.; Kelle, T. Synth. Commun. 1997, 27, 2021-2031. (b) Gómez-Lor, B.; de Frutos, Ó.; Ceballos, P. A.; Granier, T.; Echavarren, A. M. Eur. J. Org. Chem. 2001, $2107-2114$.

10. Gómez-Lor, B.; González-Cantalapiedra, E.; Ruiz, M.; de Frutos, Ó.; Cárdenas, D. J.; Granier, T.; Echavarren, A. M. Chem. Eur. J. 2004, 10, 2601-2608

11. (a) Boorum, M. M.; Vasilév, Y. V.; Drewello, T.; Scott, L. T. Science 2001, 294, 828-831.

(b) Scott, L. T.; Boorum, M. M.; McMahon, B. J.; Hagen, S.; Mack, J.; Balnk, J.; Wegner, H. ; de Meijere, A. Science 2002, 295, 1500-1503.

12. Jacobs, T. L.; Fenton, D. M. J. Org. Chem. 1965, 30, 1808-1812.

13. (a) Schmittel, M.; Maywald, M. Chem. Commun. 2001, 155-156. (c) Schmittel, M.; Vavilala, C. J. Org. Chem. 2005, 70, 4865-4868.

14. Dytnerski, D.; Ranganayakulu, K.; Singh, B. P.; Sorensen, T. S. J. Org. Chem. 1983, 48, 309-315. 
15. Lukáč, J.; Heimgartner, H. Helv. Chim. Acta 1985, 68, 335-370.

16. Tabuchi, T.; Inanaga, J.; Yamaguchi, M. Tetrahedron Lett. 1986, 27, 5237-5240

17. Phyllis D. Landor 2.1 hydrocarbon 47

18. (a) Brunel, J. M. Chem. Rev. 2005, 105, 857-897. (b) Noyori, R.; Tomino, I.; Tanimoto, Y. J. Am. Chem. Soc. 1979, 101, 3129-3131. (c) Noyori, R.; Tomino, I.; Nishizawa, M. J. Am. Chem. Soc. 1979, 101, 5843-5844. (d) Nishizawa, M.; Noyori, R. Tetrahedron Lett. 1980, 21, 2821-2824. (e) Noyori, R. Chem. Soc. Rev. 1989, 18, 187-208. (f) Chen, Y.; Yekta, S.; Yudin, A. Chem. Rev. 2003, 103, 3155-3211. (g) Pu, L. Chem. Rev. 1998, 98, 2405-2494. (h) Kočovský, P.; Vyskočil, Š.; Smrčina, M. Chem. Rev. 2003, 103, 3213-3245. (i) Berthod, M.; Mignani, G.; Woodward, G.; Lemaire, M. Chem. Rev. 2005, 105, 1801-1836.

19. (a) Einhorn, C.; Einhorn, J.; Marcadal-Abbadi, C.; Pierre, J.-L. J. Org. Chem. 1999, 64, 4542-4546. (b) Dufková, L.; Kotora, M.; Císařová, I. Eur. J. Org. Chem. 2005, 2491-2499.

20. (a) Miyashita, A.; Yasuda, A.; Takaya, H.; Toriumi, K.; Ito, T.; Souchi, T.; Noyori, R. J. Am. Chem. Soc. 1980, 102, 7932-7934. (b) Noyori, R.; Takaya, H. Acc. Chem. Res. 1990, 23, 345-350. (c) Noyori, R. Angew. Chem. Int. Ed. 2002, 41, 2008-2022.

21. Rosini, C.; Franzini, L.; Raffaelli, A.; Salvadori, P. Synthesis 1992, 503-517.

22. Ellis, W. W.; Hollis, T. K.; Odenkirk, W.; Whelan, J.; Ostrander, R.; Rheingold, A. L.; Bosnich, B. Organometallics 1993, 12, 4391-4401.

23. (a) Smrčina, M; Lorenc, M.; Hanuš, V.; Kočovský, P. Synlett, 1991, 231-232. (b) Smrčina, M.; Lorenc, M.; Hanuš, V.; Sedmera, P.; Kočovský, P. J. Org. Chem. 1992, 57, 1917-1920. (c) Smrčina, M; Poláková, J.; Vyskočil, Š.; Kočovský, P. J. Org. Chem. 1993, 58, 4534-4538. (d) Smrčina, M; Vyskočil, Š.; Máca, B.; Polášek, M.; Claxton, T. A.; Abbott, A. P.; Kočovský, P. J. Org. Chem. 1994, 59, 2156-2163. (e) Vyskočil, Š.; Jaracz, S.; Smrčina, M; Štícha, M.; Hanuš, V.; Polášek, M.; Kočovský, P. J. Org. Chem. 1998, 63, 7727-7737. 
24. (a) Uozumi, Y.; Hayashi, T. J. Am. Chem. Soc. 1991, 113, 9887-9888. (b) Uozumi, Y.; Tanahashi, A.; Lee, S.-Y.; Hayashi, T. J. Org. Chem. 1993, 58, 1945-1948. (c) Hayashi, T. Acc. Chem. Res. 2000, 33, 354-362.

25. Vyskočil, Š.; Smrčina, M.; Hanuš, V.; Polášek, M.; Kočovský, P. J. Org. Chem. 1998, 63, 7738-7748.

26. (a) Meca, L.; Řeha, D.; Havlas, Z. J. Org. Chem. 2003, 68, 5677-5680. (b) Hall, D. M.; Turner, E. E. J. Chem. Soc. 1955, 1242-1251

27. Kashiwamura, T. Jpn. KoKai Tokkyo Koho JP 08239413, 1996.

28. (a) Yi, J.; Jing, Z.; Hong, X.; Zhang, W.; Huang, X. Faming Zhuanli Shengqing Gongkai Shuomingshu CN 1468857, 2004. (b) Mu, Y.; Zhang, Y.; Lu, C.; Wang, J.; Xu, J.; Zhang, Y.; Qiao, L. Faming Zhuanli Shengqing Gongkai Shuomingshu CN 1431232, 2003. (c) Katayama, H.; Imai, A.; Hanaoka, H.; Kawamura, N.; Miyashita, A. PCT Int. Appl. WO 9708179, 1997.

29. Alt, H. G.; Köppl, A. Chem. Rev. 2000, 100, 1205-1221.

30. (a) Tszuki, S.; Tanabe, K.; Nagawa, Y.; Nakanishi, H. J. Mol. Struct. 1990, 216, 279-295.

(b) Nori-shargh, D.; Asadzadeh, S.; Ghanizadeh, F.-R.; Deyhimi, F.; Amini, M. M.; Jameh-Bozorghi, S. J. Mol. Struct.: THEOCHEM 2005, 717, 41-51.

31. (a) Cooke, A. S.; Harris, M. M. J. Chem. Soc. 1963, 2365-2373. (b) Meca, L.; Řeha, D.; Havlas, Z. J. Org. Chem. 2003, 68, 5677-5680. (b) Meca, L.; Řeha, D.; Havlas, Z. J. Org. Chem. 2003, 68, 5677-5680.

32. Thongpanchang, T.; Paruch, K.; Katz, T. J.; Rheingold, A. L.; Lam, K.-C.; Liable-Sands, L. J. Org. Chem. 2000, 65, 1850-1856.

33. (a) Kroto, H. W.; Heath, J. R.; O’Breien, S. C.; Curl, R. F.; Smalley, R. E. Nature 1985, 318, 162 (b) Heath, J. R.; O’Breien, S. C.; Curl, R. F.; Kroto, H. W.; Smalley, R. E. Comments 
Condens. Mater. Phys. 1987, 13, 119 (c) Kroto, H. W. Nature 1987, 329, 529 (d) Kraetschmer, W.; Lamb, L. D.; Fostiropoulos, K.; Huffman, D. R. Nature 1990, 347, 354. (e) Kroto, H. Pure Appl. Chem. 1990, 62, 407. (f) Hirsch, A.; Brettreich, M. Fullerenes; Wiley-VCH: New York, NY, 2005.

34. (a) Curl, R. F. Angew. Chem., Int. Ed. Engl. 1997, 36, 2566-2576. (b) Kroto, R. Angew. Chem., Int. Ed. Engl. 1997, 36, 1578-1539. (c) Smalley, R. E. Angew. Chem., Int. Ed. Engl. 1997, 36, 1594-1603.

35. (a) Barth, W. E.; Lawton, R. G. J. Am. Chem. Soc. 1966, 88, 380. (b) Lawton, R. G.; Barth, W. E. J. Am. Chem. Soc. 1971, 93, 1730. (c) Scott, L. T.; Hashemi, M. M.; Bratcher, M. S. J. Am. Chem. Soc. 1992, 114, 1920. (d) Borchardt, A.; Fuchicello, A.; Kilway, K. V.; Baldridge, K. K.; Siegel, J. S. J. Am. Chem. Soc. 1992, 114, 1921. (e) Liu, C. Z.; Rabideau, P. W. Tetrahedron Lett. 1996, 37, 34373440. (f) Zimmermann, G.; Nuechter, U.; Hagen, S.; Nuechter, M. Tetrahedron Lett. 1994, 35, 4747. (g) Scott, L. T.; Hashemi, M. M.; Meyer, D. T.; Warren, H. B. J. Am. Chem. Soc. 1991, 113, 7082. (h) Mehta, G.; Panda, G. Tetrahedron Lett. 1997, 38, 2145. (i) Sygula, A.; Rabideau, P. W. J. Am. Chem. Soc. 1999, 121, 7804. (j) Scott, L. T.; Cheng, P.-C; Hashemi, M. M. ; Bratcher, M. S.; Meyer, D.T.; Warren, H. B. J. Am. Chem. Soc. 1997, 119, 10963.

36. Sakurai, H.; Daiko, T.; Hirao, T. Science 2003, 301, 1878.

37. (a) Rabideau, P. W.; Abdourazak, A. H.; Folsom, H. E.; Marcinow, Z.; Sygula, A.; Sygula, R. J. Am. Chem. Soc. 1994, 116, 7891-7892. (b) Geneste, F.; Moradpour, A.; Dive, G.; Peeters, D.; Malthête, J.; Sadoc, J. -F. J. Org. Chem. 2002, 67, 605-607. (c) Clayton, M. D.; Marcinow, Z.; Rabideau, P. W. J. Org. Chem. 1996, 61, 6052. (d) Abdourazak, A. H.; Marcinow, Z.; Sygula, A.; Sygula, R.; Rabideau, P. W. J. Am. Chem. Soc. 1995, 117, 6410-6411. (e) Sygula, A.; Rabideau, P. W. J. Am. Chem. Soc. 1998, 120, 12666. (e) Hagen, 
S.; Bratcher, M. S.; Erickson, M. S.; Zimmermann, G.; Scott, L. T. Angew. Chem., Int. Ed. Engl. 1997, 36, 406-408. (f)Mehta, G.; Panda, G.; Srirama Sarma, P. V. V. Tetrahedron Lett. 1998, 39, 5835-5836.

38. (a) Scott, L. T.; Bratcher, M. S.; Hagen, S. J. Am. Chem. Soc. 1996, 118, 8743-8744. (b) Forkey, D. M.; Attar, S.; Noll, B. C.; Koerner, R.; Olmstead, M. M.; Balch, A. L. J. Am. Chem. Soc. 1997, 119, 5766-5767. (c) Ansems, R. B. M.; Scott, L. T. J. Am. Chem. Soc. 2000, 122, 2719-2724.

39. Ansems, R. B. M. Ph. D. Dissertation, Boston College, Chestnut Hill, MA, 2004.

40. (a) Seiders, T. J.; Baldridge, K. K.; Siegel, J. S. J. Am. Chem. Soc. 1996, 118, 2754-2755. (b) Sygula, A.; Rabideau, P. W. J. Am. Chem. Soc. 1998, 120, 12666. (c) Rabideau, P. W.; Sygula, A. J. Am. Chem. Soc. 1999, 121, 7800. (d) Seiders, T. J.; Elliott, E. L.; Grube, G. H.; Siegel, J. S. J. Am. Chem. Soc. 1999, 121, 7804. (e) Reisch, H. A.; Bratcher, M. S.; Scott, L. T. Org. Lett. 2000, 2, 1427-1430. (f) Wang, L.; Shevlin, P. B. Org. Lett. 2000, 2, 3703. (g) Sygula, A.; Xu, G.; Marcinow, Z.; Rabideau, P. W. Tetrahedron 2001, 57, 3637. (h) Seiders, J. T.; Baldridge, K. K.; Siegel, J. S. Tetrahedron 2001, 57, 3737.

41. For reviews, see: (a) Rabideau, P. W.; Sygula, A. Acc. Chem. Res. 1996, 29, 235-242. (b) Scott, L. T. Pure Appl. Chem. 1996, 68, 291-300. (c) Mehta, G.; Rao, H. S. P. Tetrahedron 1998, 54, 13325-13370. (d) Scott, L. T.; Bronstein, H. E.; Preda, D. V.; Ansems, R. B. M.; Bratcher, M. S.; Hagen, S. Pure Appl. Chem. 1999, 71, 209-219. (e) Mehta, G.; Srirama Sarma, P. V. V. Chem. Commun. 2000, 19. (f) Scott, L. T. Angew. Chem., Int. Ed. 2004, 43, 4994-5007. (g) Tsefrikas, V. M.; Scott, L. T. Chem. Rev. 2006, 106, 4868-4884.

42. Jackson, E. A.; Steinberg, B. D.; Bancu, M.; Wakamiya, A.; Scott, L. T. J. Am. Chem. Soc. 2007, 129, 484-485.

43. (a) Ayalon, A.; Rabinovitz, M.; Cheng, P.-C.; Scott, L. T. Angew. Chem., Int. Ed. 1992, 31, 
1636. (b) Weitz, A.; Shabtai, E.; Rabinovitz, M.; Bratcher, M. S.; McComas, C. C.; Best, M. D.; Scott, L. T. Chem. Eur. J. 1998, 4, 234. (c) Baumgarten, M.; Gherghel, L.; Wagner, M.; Weitz, A.; Rabinovitz, M.; Cheng, P. -C.; Scott, L. T. J. Am. Chem. Soc. 1995, 117, 6254. (d) Rabideau, P. W.; Marcinow, Z.; Sygula, R.; Sygula, A. Tetrahedron Lett 1993, 34, 6351. (f) Aprahamian, I.; Preda, D. V.; Bancu, M.; Belanger, A. P.; Sheradsky, T.; Scott, L. T.; Rabinovitz, M. J. Org. Chem 2006, 71, 291-298.

44. (a) Diederich, F.; Rubin, Y. Angew. Chem., Int. Ed. Engl. 1992, 31, 1101-1123. (b) McElvany, S. W.; Ross, M. M.; Goroff, N. S.; Diederich, F. Science 1993, 259, 1594-1596. (c) Narahari, G. H.; Jemmis, E. D.; Mehta, G.; Shah, S. R. J. Chem. Soc., Perkin Trans. 2 1993, 1867-1871. (d) Seiders, T.; J.; Baldridge, K. K.; O’Conner, J. M.; Seigel, J. S. J. Am. Chem. Soc. 1997, 119, 4781. (e) Shaltout, R. M.; Sygula, R.; Sygula, A.; Fronczek, F. R.; Stanley, G. G.; Rabideau, P. W. J. Am. Chem. Soc. 1998, 120, 835. (f) Balch, A. L.; Olmstead, M. M. Chem. Rev. 1998, 98, 2123.

45. (a) Wilson, L. J.; Cagle, D. W.; Thrash, T. P.; Kennel, S. J.; Mirzadeh, S.; Alford, J. M.; Enrhardt, G. J. Coord. Chem. Rev. 1999, 190-192, 199-207. (b) Valli, L.; Guldi, D. M. Dev. Fullerene Sci. 2002, 327-285. (c) Sitharaman, B.; Bolskar, R. D.; Rusakova, I.; Wilson, L. J.; Nano Lett. 2004, 4, 2373-2378.

46. Murray, R.; Scuseria, G. Science 1994, 263, 791-793

47. Cagle, D.; Thrash, T.; Alford, M.; Chibante, L.; Erhardt, G.; Wilson, L. J. Am. Chem. Soc. 1996, 118, 8043-8047.

48. Bradley, D. Science 1996, 272, 648.

49. (a) Marcinow, Z.; Sygula, R.; Rabideau, P. W. Org. Lett. 2001, 3, 3527-3529. (b) Sygula, A.; Karlen, S. D.; Sygula, R.; Rabideau, P. W. Org. Lett. 2002, 4, 3135-3137.

50. (a) Sygula, A.; Rabideau, P. W. J. Am. Chem. Soc. 2000, 122, 6323-6324.(b) Marcinow, Z.; 
Grove, D. I.; Rabideau. P. W. J. Org. Chem 2002, 67, 3537-3539.

51. Grasa, G. A.; Vieiu, M. S.; Huang, J.; Zhang, C.; Trudell, M. L.; Nolan, S. P. Organomettalics 2002, 21, 2866.

52. Higashibayashi, S.; Sakurai, H. J. Am. Chem. Soc. 2008, ASAP.

53. (a) Faust, R.; Vollhardt, K. P. C. J. Chem. Sco., Chem. Commun. 1993, 1471. (b) Sygula, A.; Rabideau, P. W. J. Chem. Sco., Chem. Commun. 1994, 2271. (c) Frash, M. V.; Hopkinson, A. C.; Böhme, D. K. J. Am. Chem. Soc. 2001, 123, 6687. (d) Nunzi, F.; Sgamellotti, A.; Re, N. Organomettalics 2002, 21, 2219. (e) Seiders, T. J.; Baldridge, K. K.; O’Connor, J. M.; Siegel, J. S. Chem. Commun., 2004, 950.

54. Zhu, B.; Ellern, A.; Sygula, A.; Sygula, R.; Angelici, R. Organometallics 2007, 26, 1721-1728.

55. Seiders, T. J.; Baldridge, K. K.; O’Connor, J. M.; Siegel, J. S. J. Am. Chem. Soc. 1997, 119, $4781-4782$.

56. (a) Vecchi, P. A.; Alvarez, C. M.; Ellern, A.; Angelici, R. J.; Sygula, A.; Sygula, R.; Rabideau, P. W. Angew. Chem., Int. Ed. 2004, 43, 4497-4500. (b) Vecchi, P. A.; Alvarez, C. M.; Ellern, A.; Angelici, R. J.; Sygula, A.; Sygula, R.; Rabideau, P. W. Organometallics 2007, 24, 4543 .

57. Alvarez, C. M.; Angelici, R. J.; Sygula, A.; Sygula, R.; Rabideau, P. Organometallics 2003, 22, 624-626.

58. (a) Petrukhina, M. A.; Andreini, K. W.; Mack, J.; Scott, L. T Angew. Chem., Int. Ed. 2003, 42, 3375. (b) Petrukhina, M. A.; Sevryugina, Y.; Rogachev, A. Y.; Jackson, E. A; Mack, J.; Scott, L. T Organometallics 2006, 25, 5492.

59. Lee, H. B.; Sharp, P. R. Organometallics 2005, 24, 4857.

60. (a) Chin, R. M.; Jarosh, M. S.; Russell, J. D. Organometallics 2002, 21, 2027-2029. (b) 
Schmid, M. A.; Alt, H. G.; Milius, W. J. Organomet. Chem. 1995, 501, 101-106. (c) Schmid, M. A.; Alt, H. G.; Milius, W. J. Organomet. Chem. 1996, 525, 15-22. (d) Alt, H. G.; Köppl, A. Chem. Rev. 2000, 100, 1205-1221. (e) Schertl, P.; Alt, H. G. J. Organomet. Chem. 1999, $582,328$.

61. For the recent reviews see: (a) Kla“rner, F.-G.; Kahlert, B. Acc. Chem. Res. 2003, 36, 919-932. (b) Harmata, M. Acc. Chem. Res. 2004, 37, 862-873.

62. (a) Wu, T.-Y.; Siegel, J. S. Chem. Rev. 2006, 106, 4843-4867. (b) Tsefrikas, V. M.; Scott, L. T. Chem. Rev. 2006, 106, 4868-4884. (c) Sygula, A.; Rabideau, P. W. In Carbon Rich Compounds; Haley, M. M., Tykwinski, R. R., Eds.; Willey-VCH: Weinheim, Germany, 2006; p 529-565.

63. Sygula, A.; Fronczek, F. R.; Sygula, R.; Rabideau, P. W.; Olmstead, M. M. J. Am. Chem. Soc. 2007, 129, 3842-3843.

64. (a) Atwood, J. L.; Steed, J. W. Encyclopedia of Supramolecular Chemistry, Marcel Dekker: New York, 2004, Vols. 1-2. (b) Kawase, T.; Kurata, H. Chem. Rev. 2006, 106, 5250-5273.

65. Yang, H. Ph. D. Dissertation, West Virginia University, Morgantown, WV, 2006.

66. White, D. M. J. Org. Chem. 1974, 39, 1951-1952.

67. (a) Jung, M. E.; Lyster, M. A. J. Org. Chem. 1977, 42, 3761-3764. (b) Leksandrov, A. M.; Kashyap, R. P.; Pehk, T. J.; Petrenko,A. E.; Watson, W. H. J. Org. Chem. 1993, 58, 1831-1834. (c) Keinan, E.; Sahai, M. J. Org. Chem. 1990, 55, 3922-3926. (c) Narayana, C.; Padmanabhan, S.; Kabalka, G. W. Tetrahedron Lett 1990, 31, 6977-6978. (d) Alvarez, E.; Zurita, D.; Ruiz-Perez, C.; Rodriguez, M. L.; Martin, J. D. Tetrahedron Lett 1989, 30, 3729-3732. (e) Liu, H. J.; Shewchuk, L. M.; Llinas-Brunet, M. Heterocycles 1986, 24, 3043-3046. (f) Lo, H. C.; Han, H.; D'Souza, L. J.; Sinha, S. C.; Keinan, E. J. Am. Chem. Soc. 2007, 129, 1246-1253. 
68. (a) Curran, D. P.; Totleben, M. J. J. Am. Chem. Soc. 1992, 114, 6050-6058. (b) Girard, P.; Namy, J. L.; Kagan, H. B. J. Am. Chem. Soc. 1980, 102, 2693-2698. (c) Krief, A.; Laval, A.-M. Chem. Rev. 1999, 99, 745-777. (d) Molander, G. A.; Harris, C. R. J. Am. Chem. Soc. 1995, 117, 3705-3716. (e) Molander, G. A.; Harris, C. R. J. Am. Chem. Soc. 1996, 118, 4059-4071. (f) Markó, I. E.; Ates, A. Synlett 1990, 7, 1033-1036. (g) Blomberg, C.; Hartog, F. A. Synthesis, 1977, 18-30. (h) Molander, G. A. Chem. Rev. 1992, 92, 29-68. (i) Molle, G.; Bauer, P. J. Am. Chem. Soc. 1982, 104, 3481-3487. (j) Molander, G. A.; Huérou, Y. L.; Brown, G. A. J. Org. Chem. 2001, 66, 4511-4516.

69. (a) Pearce, P. J.; Richard, D. H.; Scilly, N. F. J. Chem. Soc., Perkin Trans. 1996, 1, 1655. (b) Luche, J. L.; Damiano, J. C. J. Am. Chem. Soc. 1980, 102, 7926-7927. (c) Bailey, W. F.; Gagnier, R. P.; Patricia, J. J. J. Org. Chem. 1984, 49, 2098-2107. (d) Freeman, P. K.; Hutchinson, L. L. J. Org. Chem. 1983, 48, 4705-4713.

70. Keinan, E.; Perez, D. J. Org. Chem. 1987, 52, 4846-4851.

71. Berresheim, A. J.; Müller, M. and Müllen, K. Chem. Rev. 1999, 99, 1747-1785.

72. Müller, M.; Mauermann-Düll, H.; Wagner, M.; Enkelmann, V.; Müllen, K. Angew. Chem., Int. Ed. 1995, 34, 1583-1586. 
Appendix 


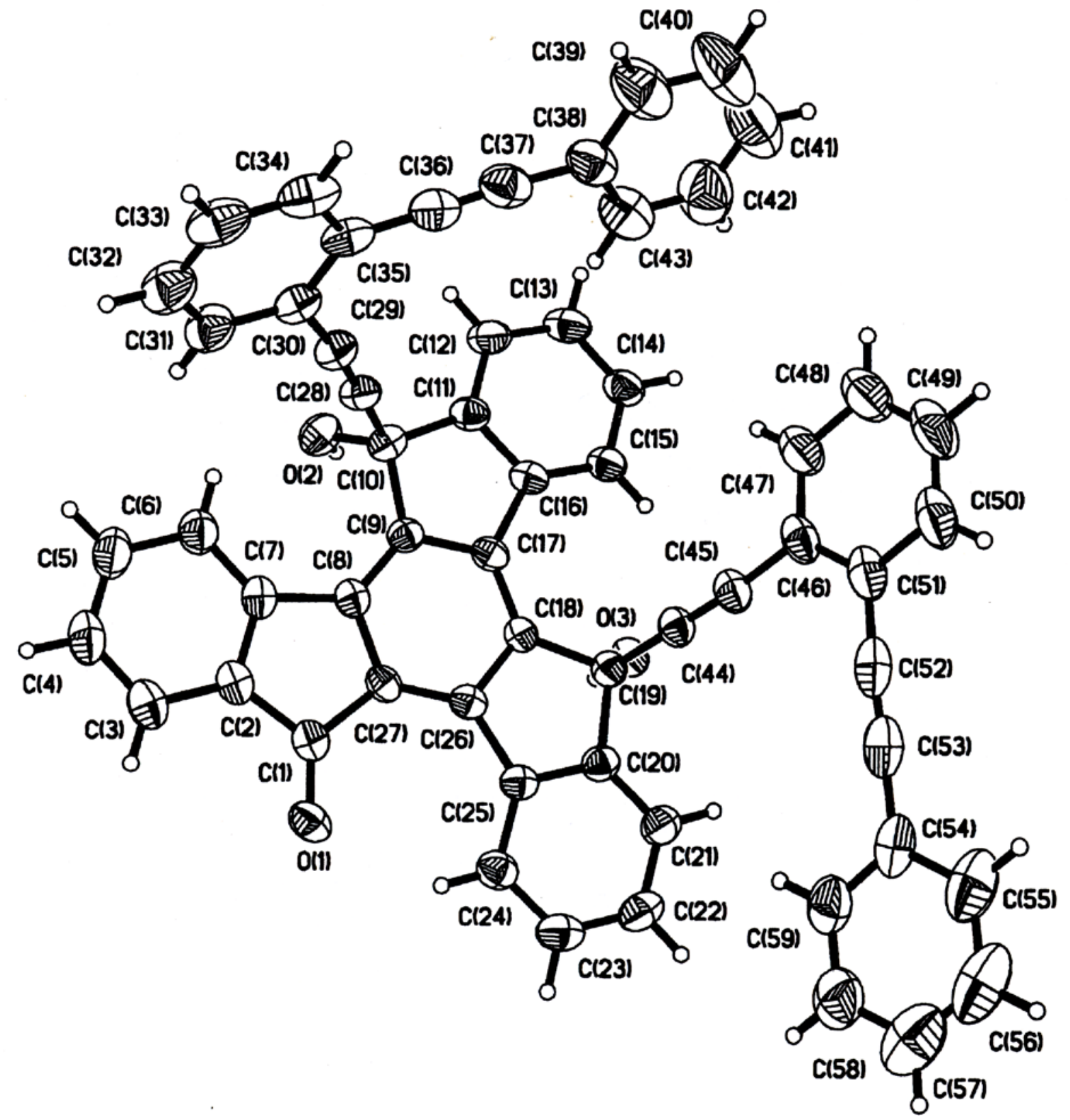

Figure 26. ORTEP drawing of the crystal structure of benzannulated enediynyl cis-diol $\mathbf{3 0}$. 

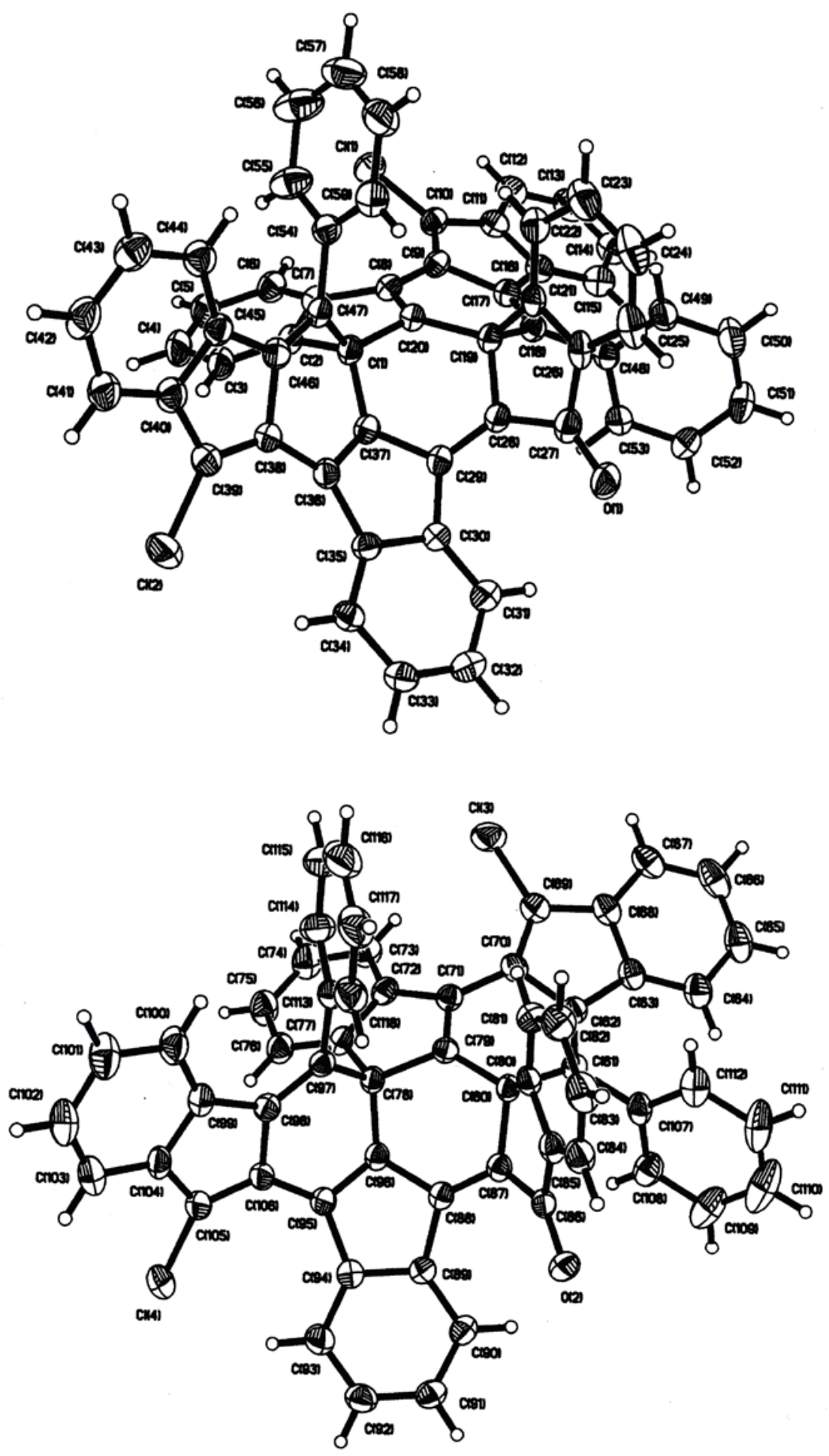

Figure 27. ORTEP drawing of the crystal structure of ketone $\mathbf{3 1}$ with two independent molecules per unit cell. 


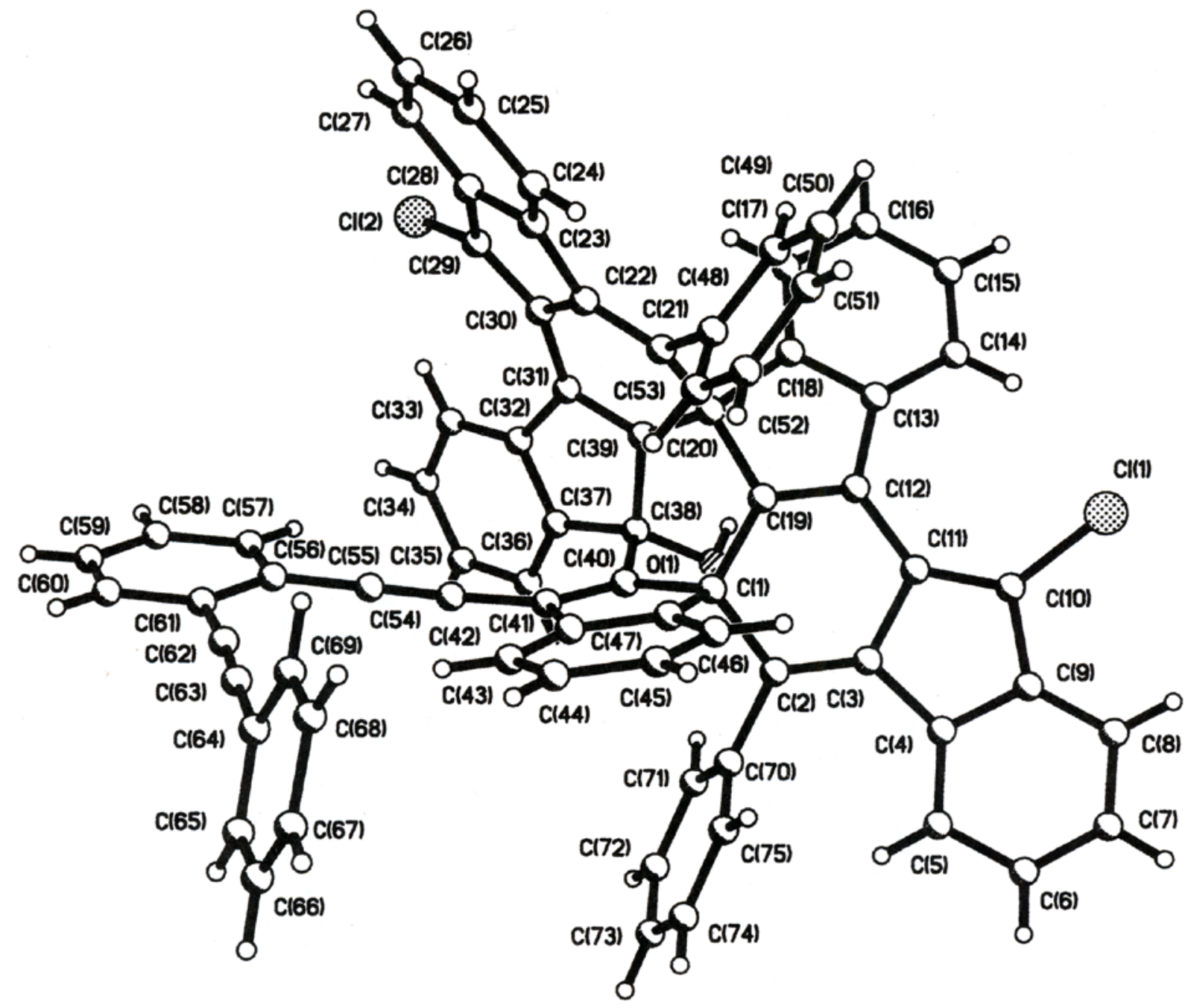

Figure 28. Perspective view of molecular structure of alcohol 34 with the atom labeling scheme. 


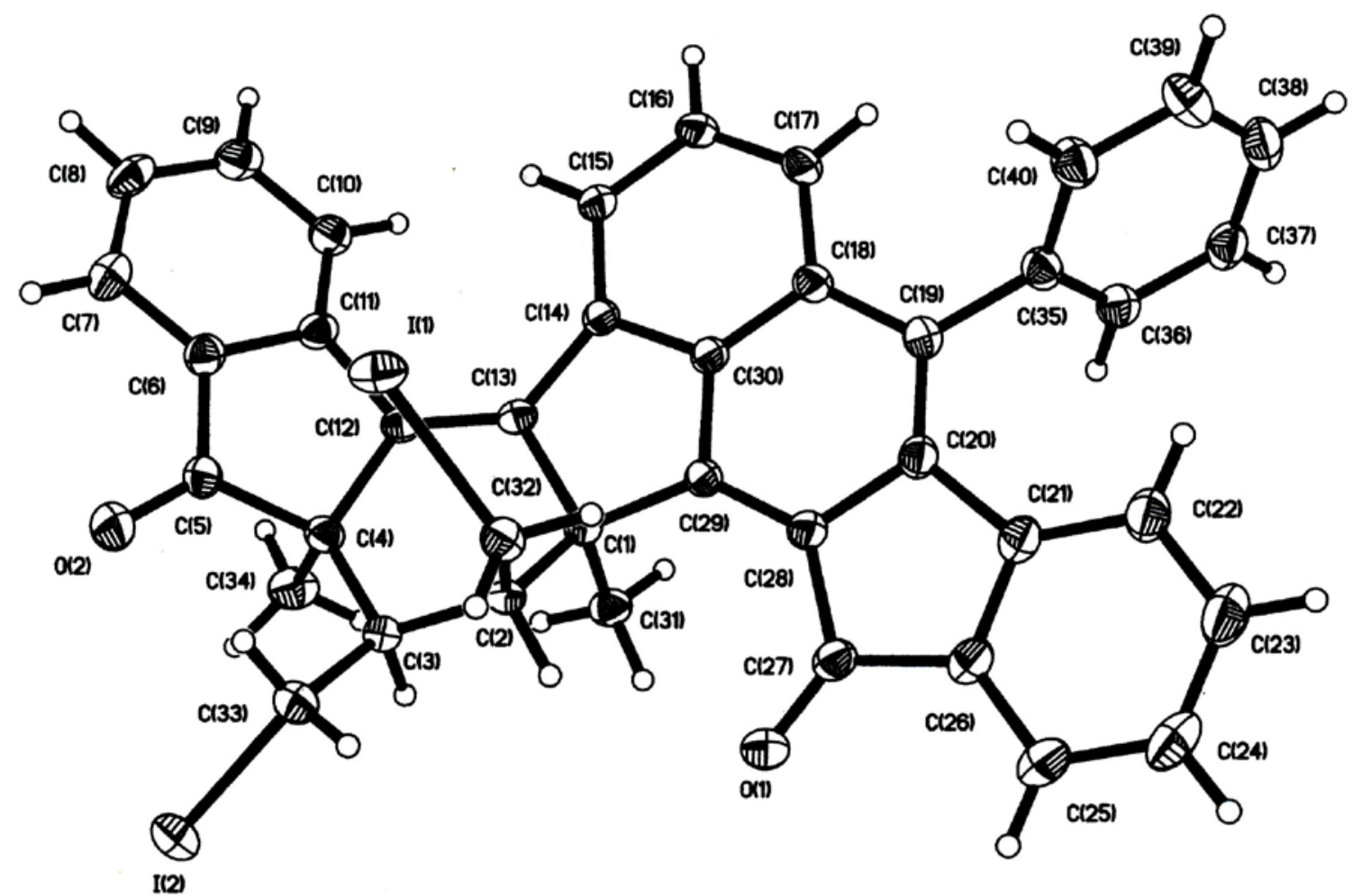

Figure 29. Perspective view of molecular structure of $\mathrm{C}_{40} \mathrm{H}_{28} \mathrm{O}_{2} \mathrm{I}_{2}$ (159). The thermal ellipsoids are scaled to enclose $30 \%$ probability. 


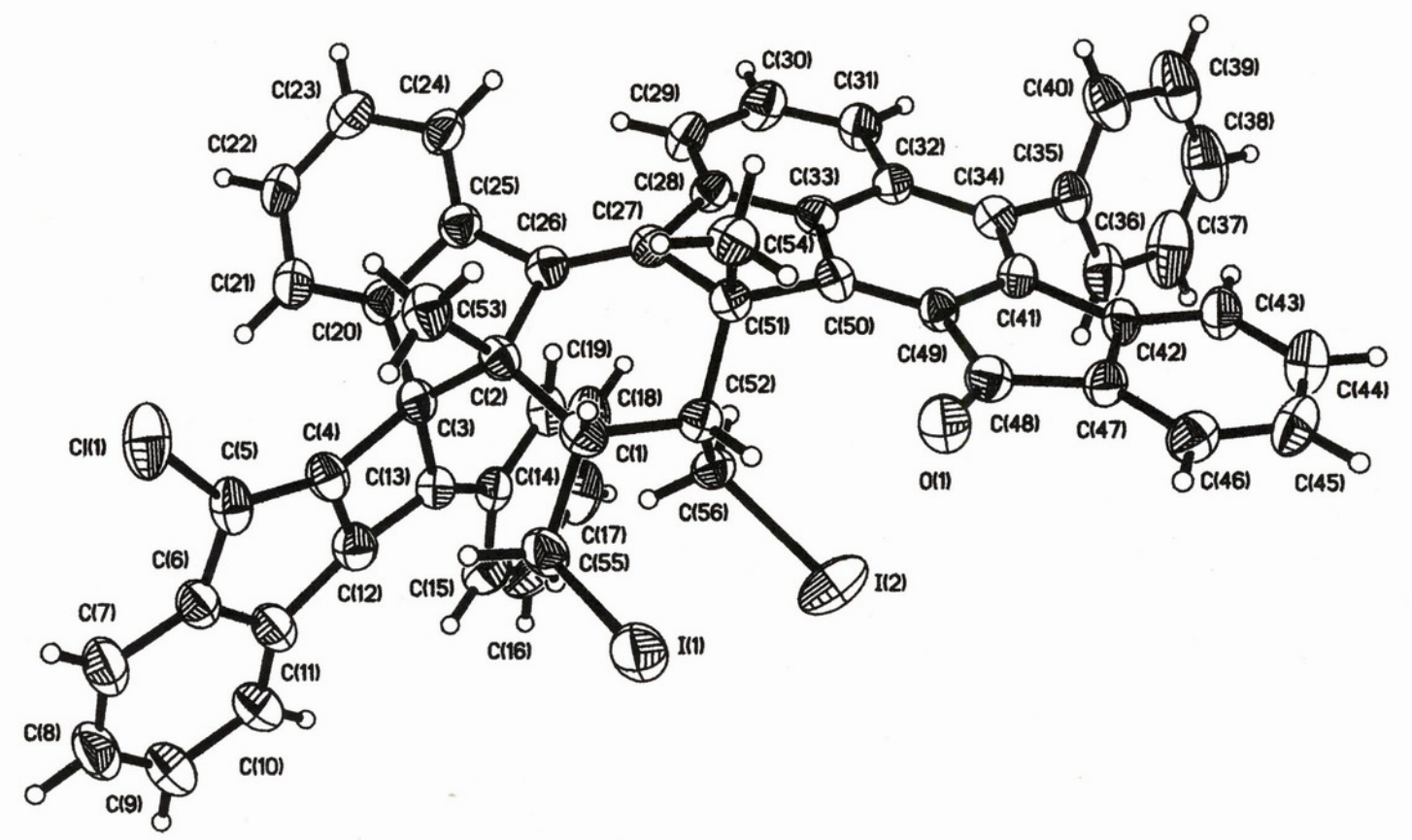

Figure 30. Perspective view of molecular structure of molecule 1 of $\mathbf{1 6 2}$ with the atom labeling scheme. The thermal ellipsoids are scaled to enclose $30 \%$ probability.

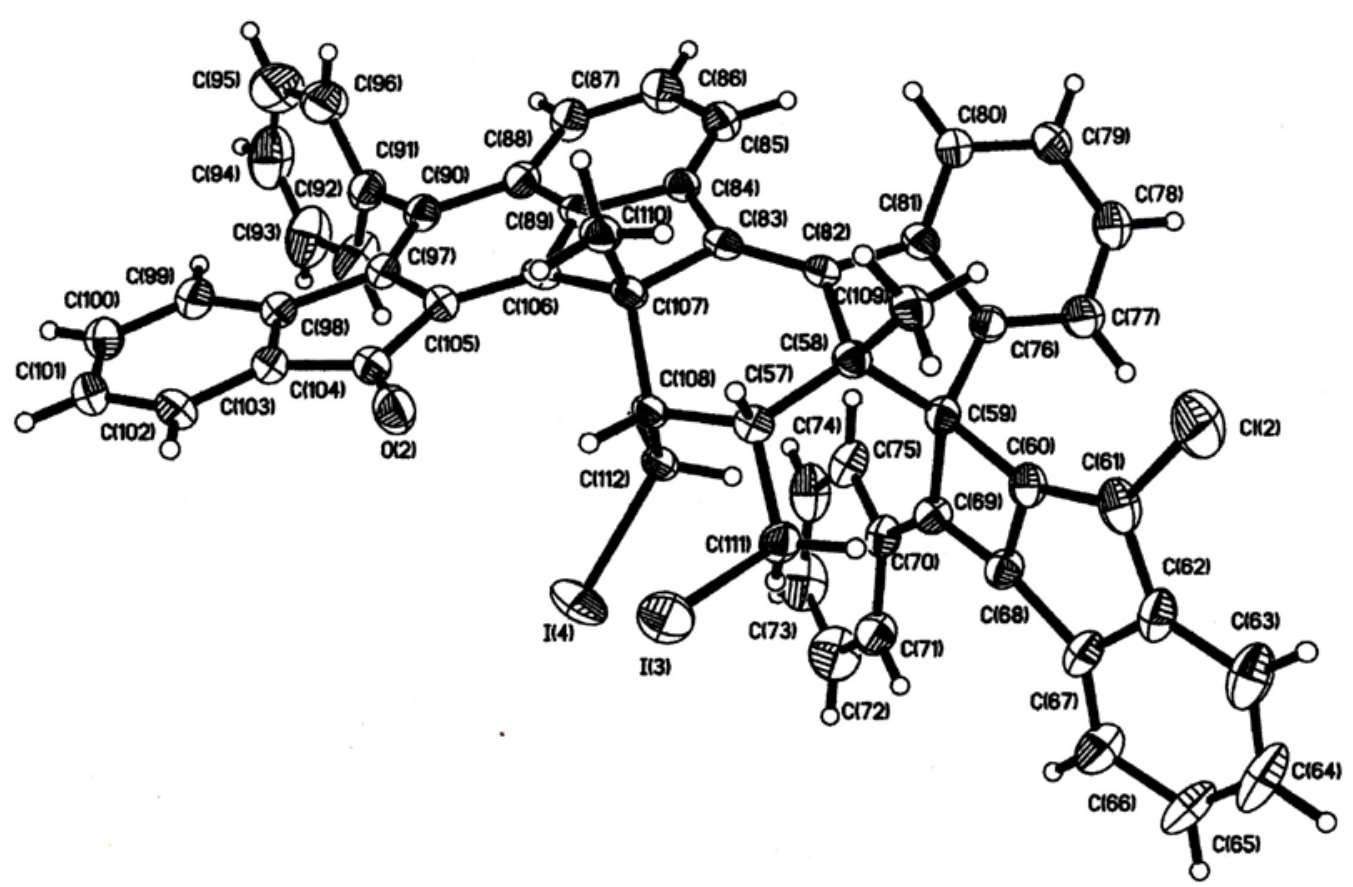

Figure 31. Perspective view of molecular structure of molecule 2 of $\mathbf{1 6 2}$ with the atom labeling scheme. The thermal ellipsoids are scaled to enclose $30 \%$ probability. 


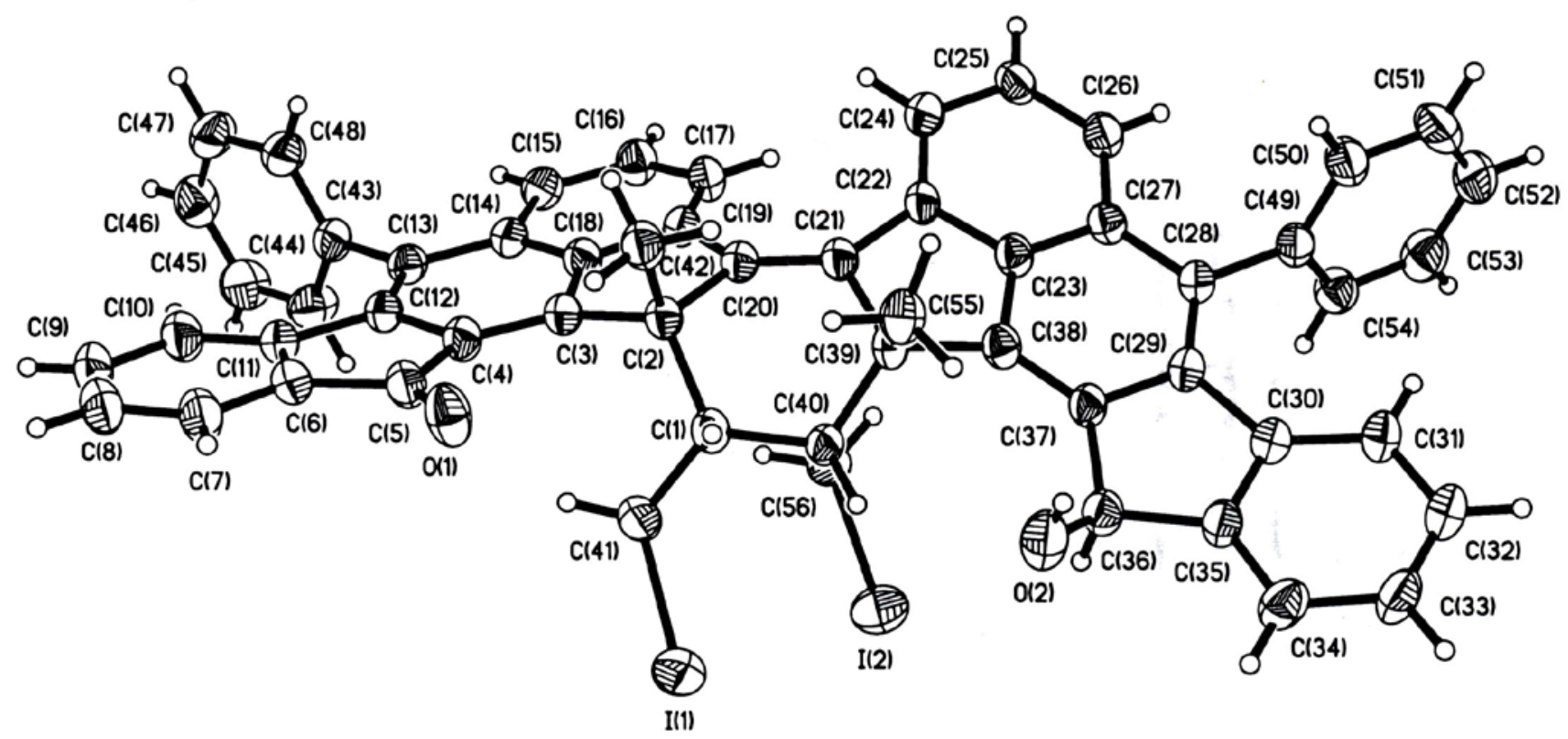

Figure 32. Perspective view of molecular structure of alcohol 163 with the atom labeling scheme. 


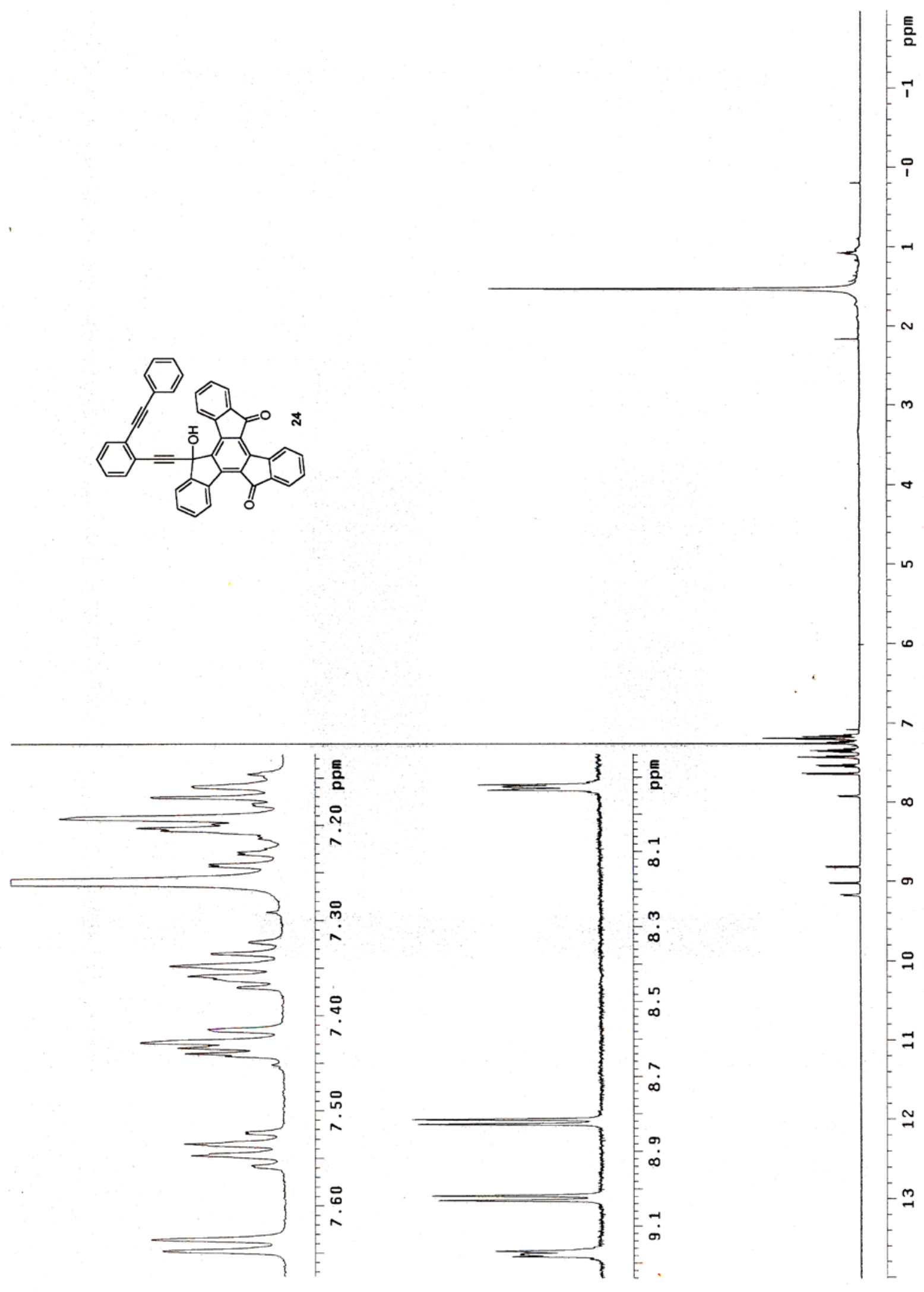




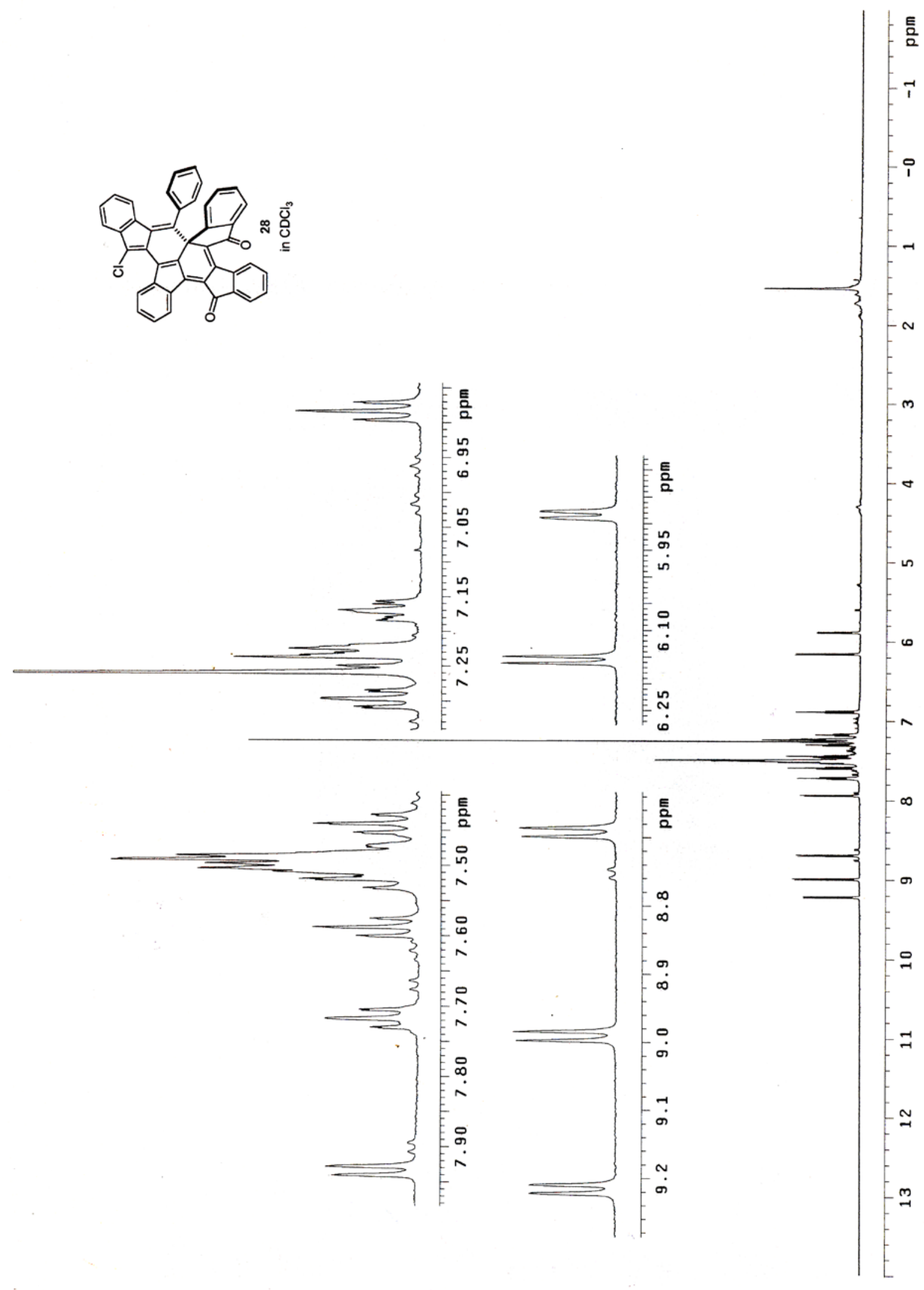




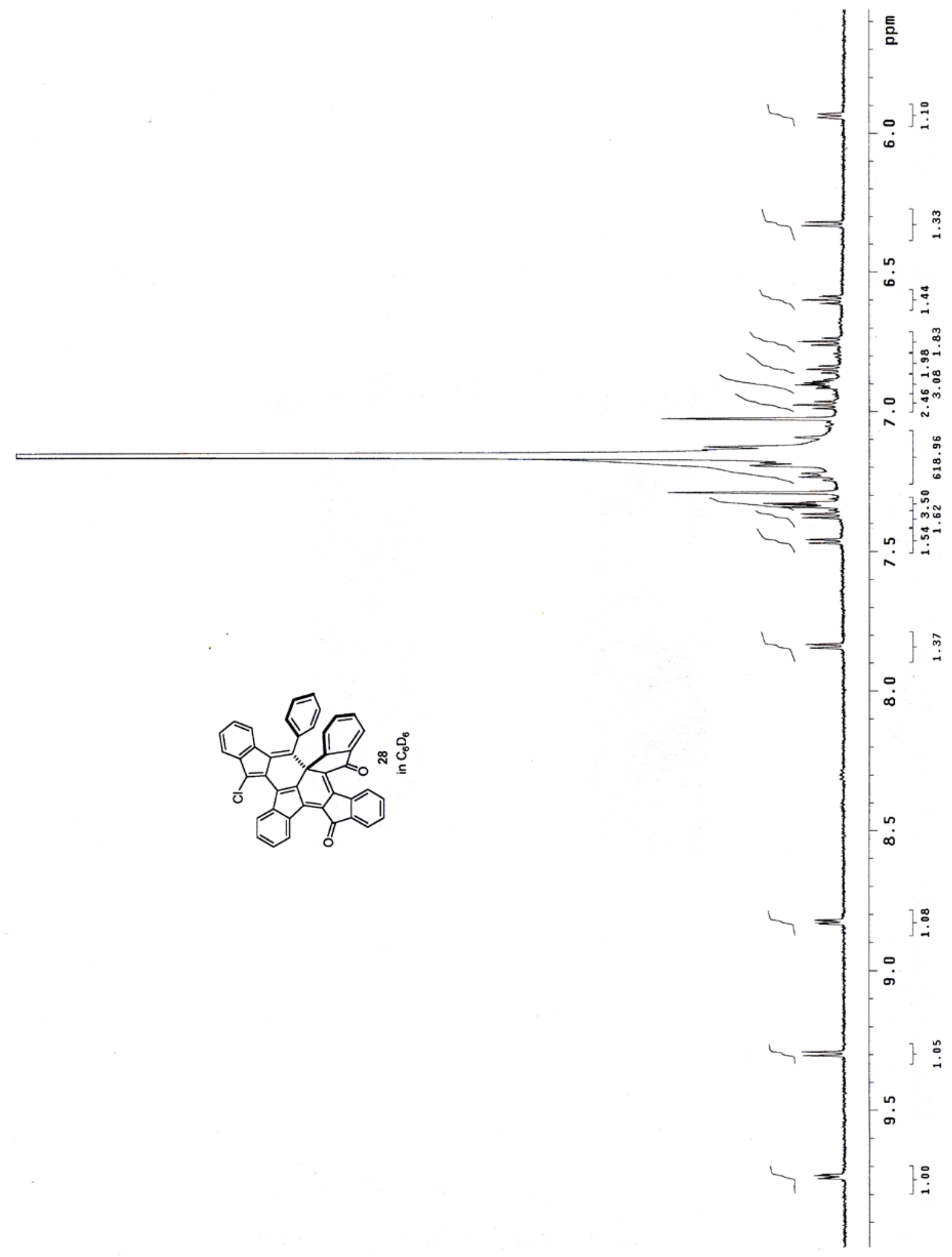




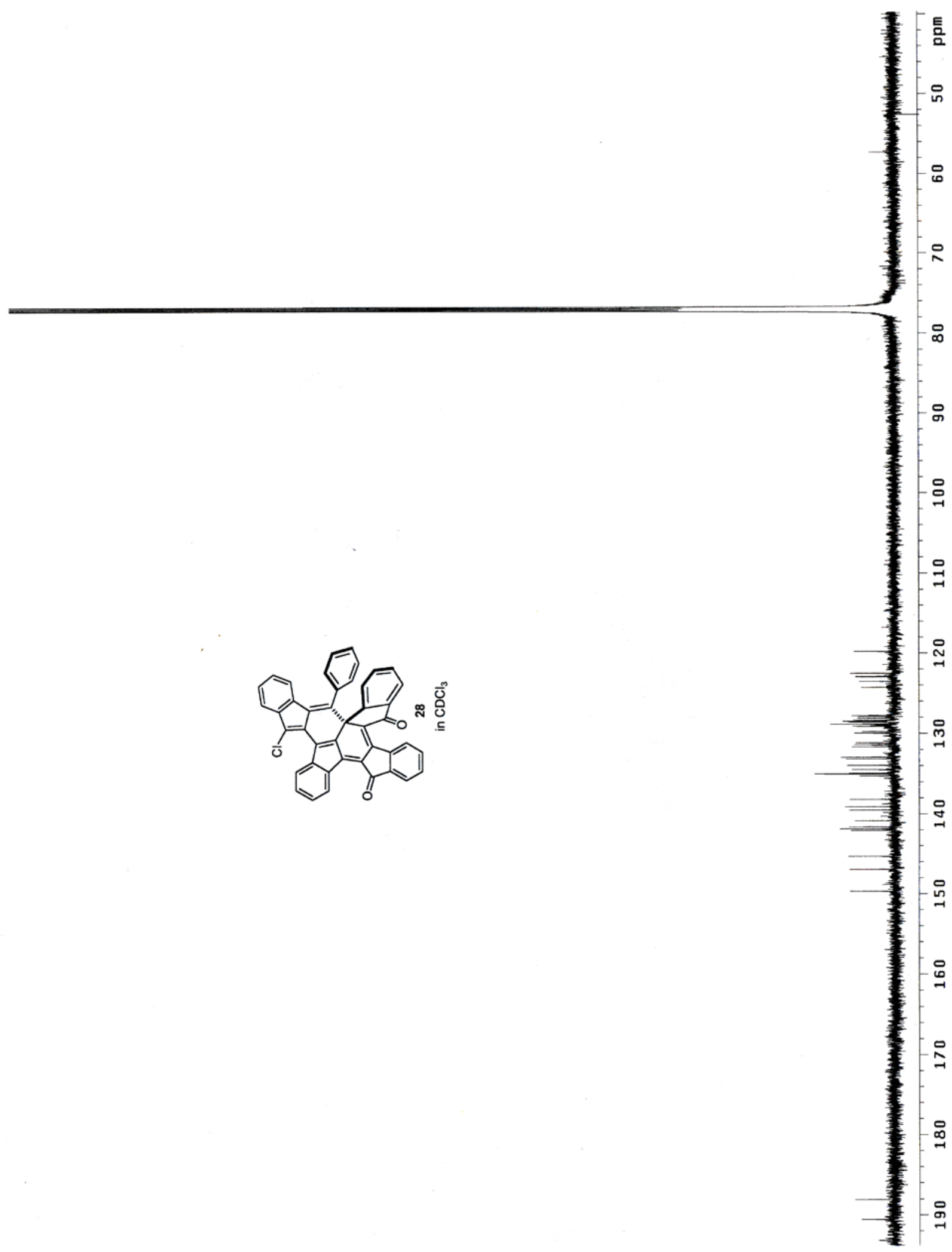



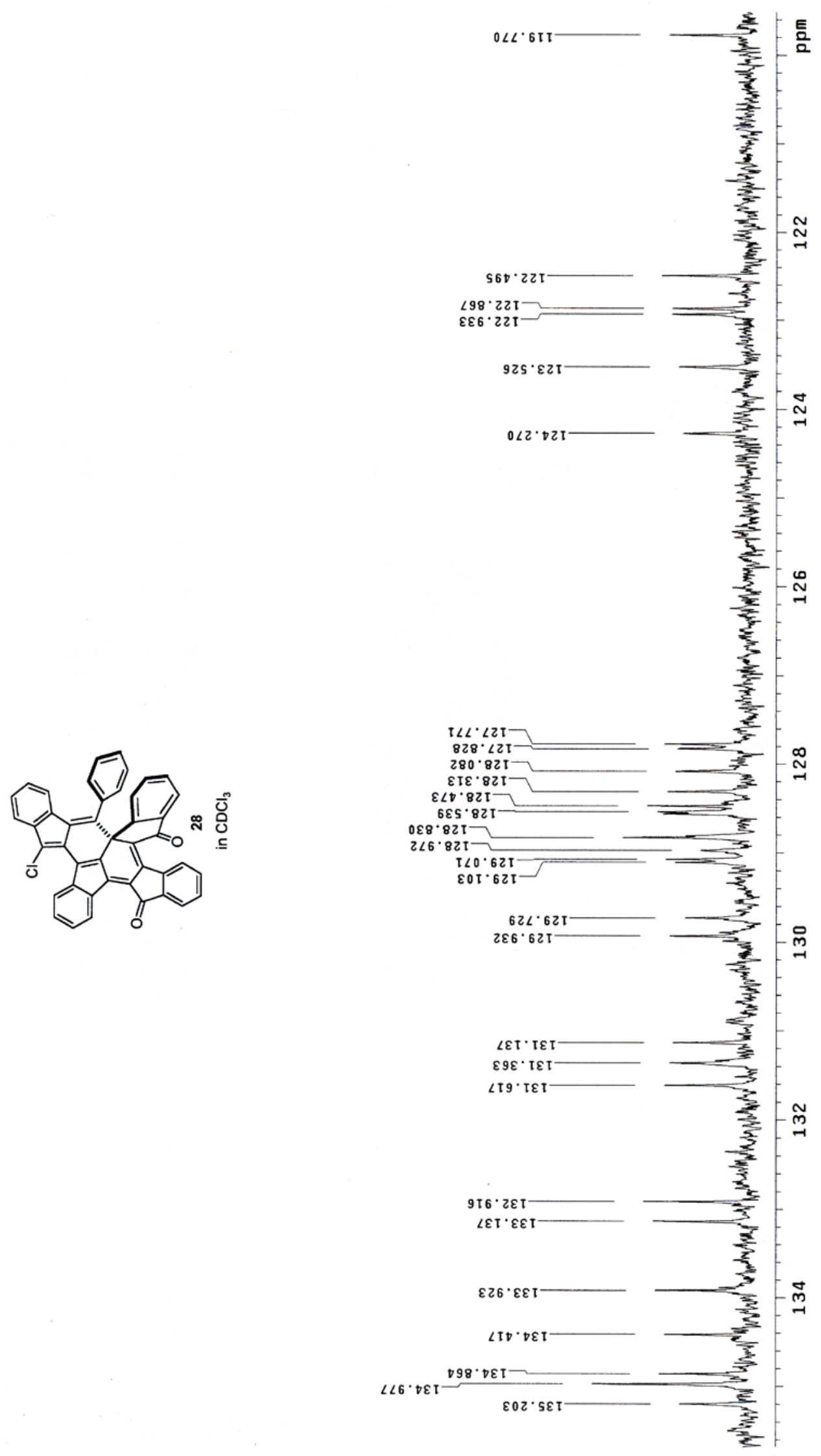


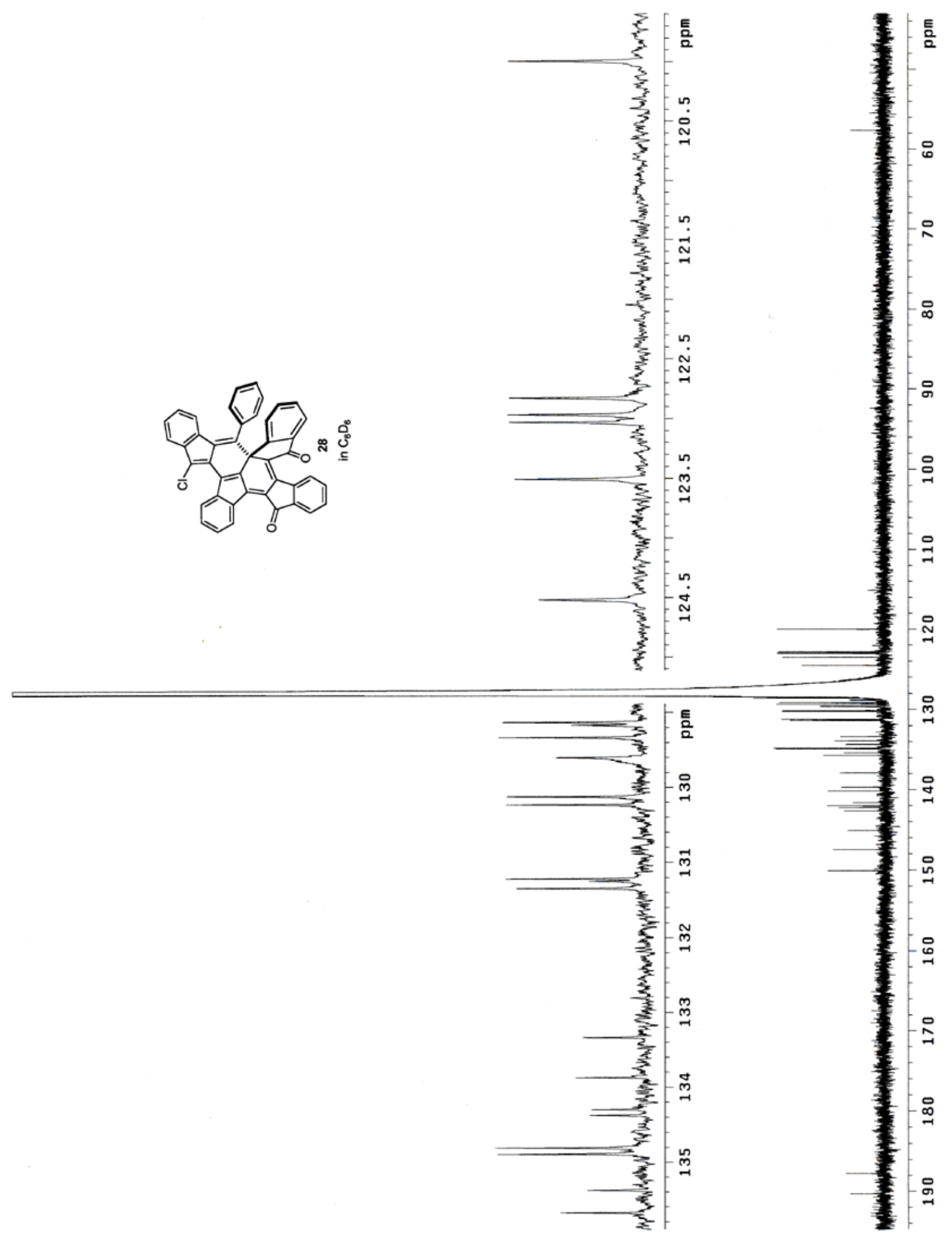




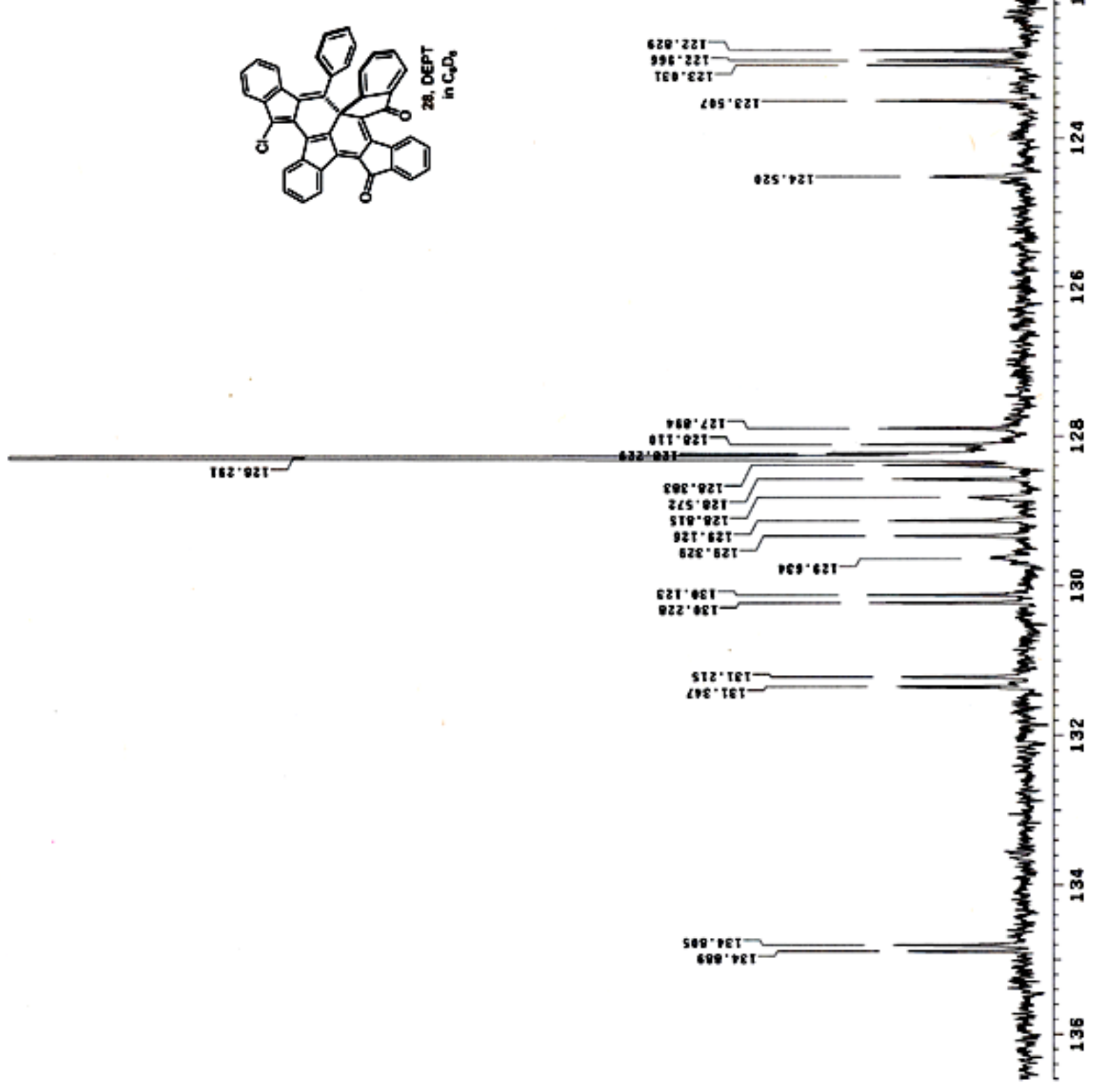


Chemical Shifts $(\delta / \mathrm{ppm})$ and Coupling Constants $(\mathrm{J} / \mathrm{Hz})^{a} \quad$ in 28.

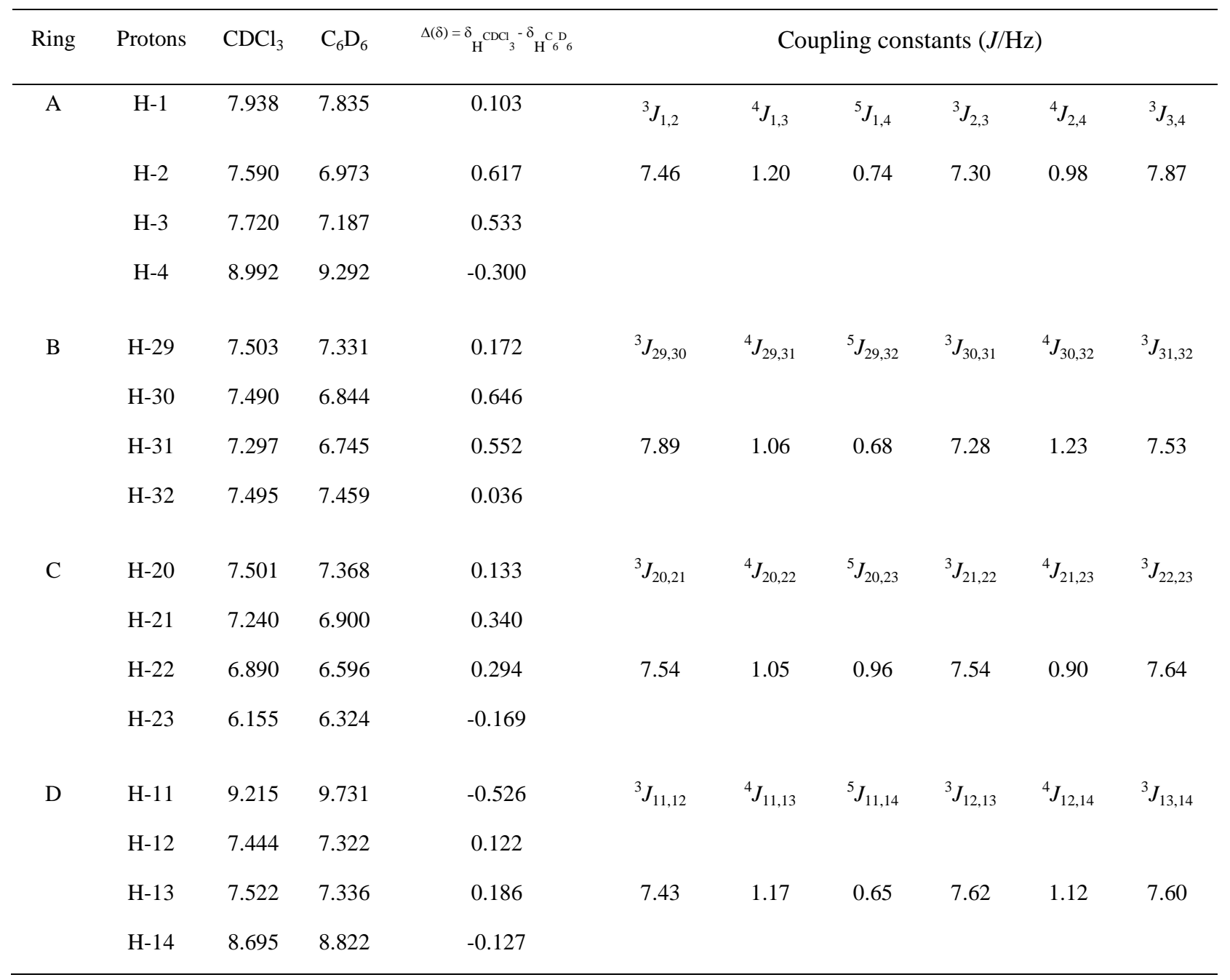

${ }^{a}$ The precise values of the long-range coupling constants in $\mathrm{C}_{6} \mathrm{D}_{6}$ solution were deduced from the simulated spectra using gNMR software.

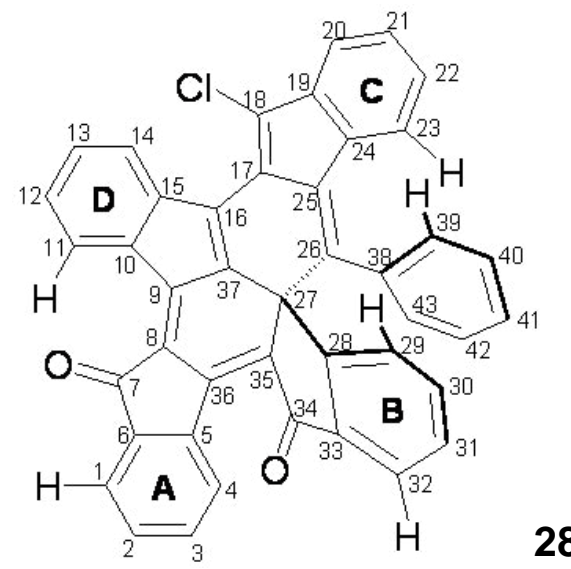


gNMR-Simulated ${ }^{1} \mathrm{H}$ NMR Spectra of 28 in $\mathrm{C}_{6} \mathrm{D}_{6}$ (top - experimental, bottom - calculated)

H-4

H-1

H-2

H-3
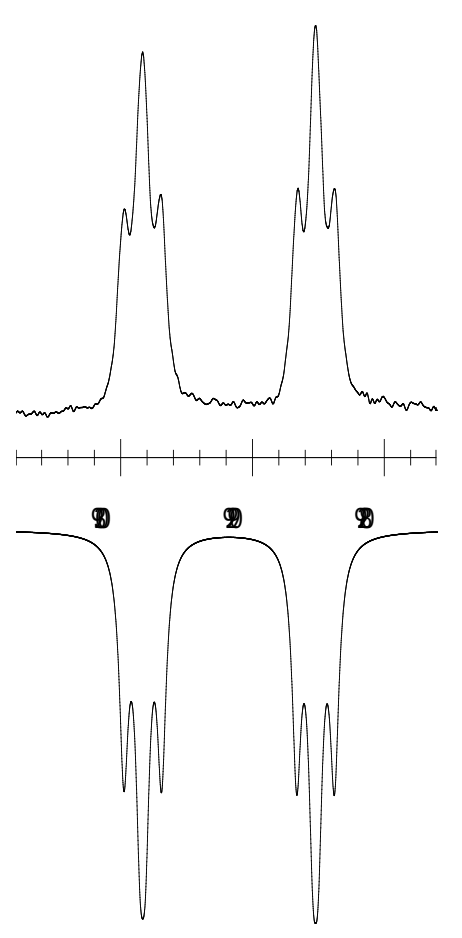

H-11
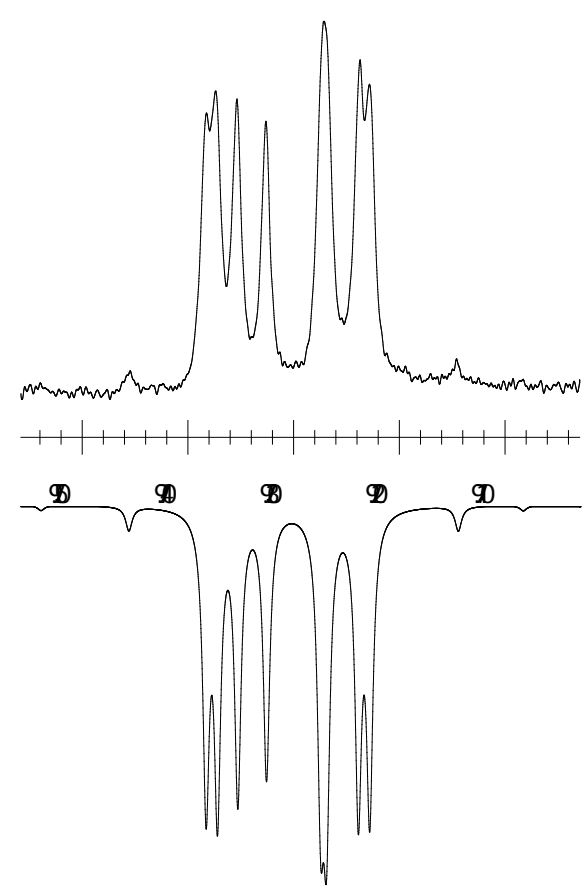
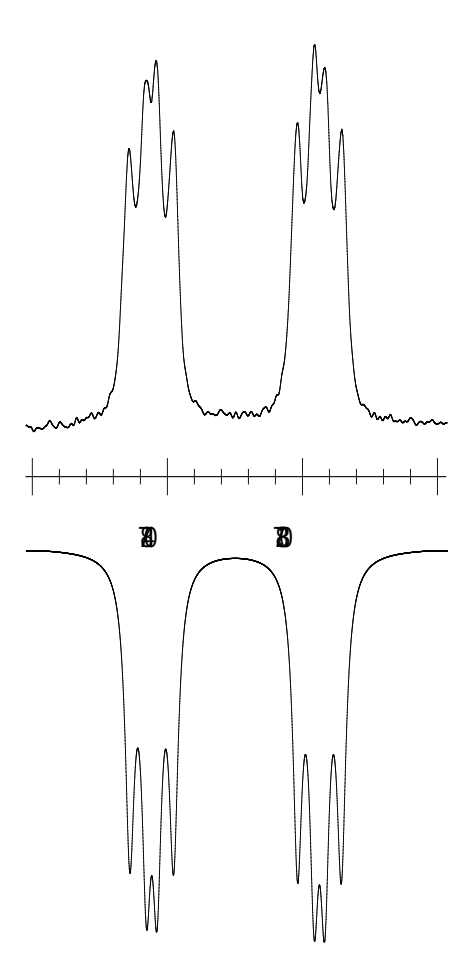

H-14
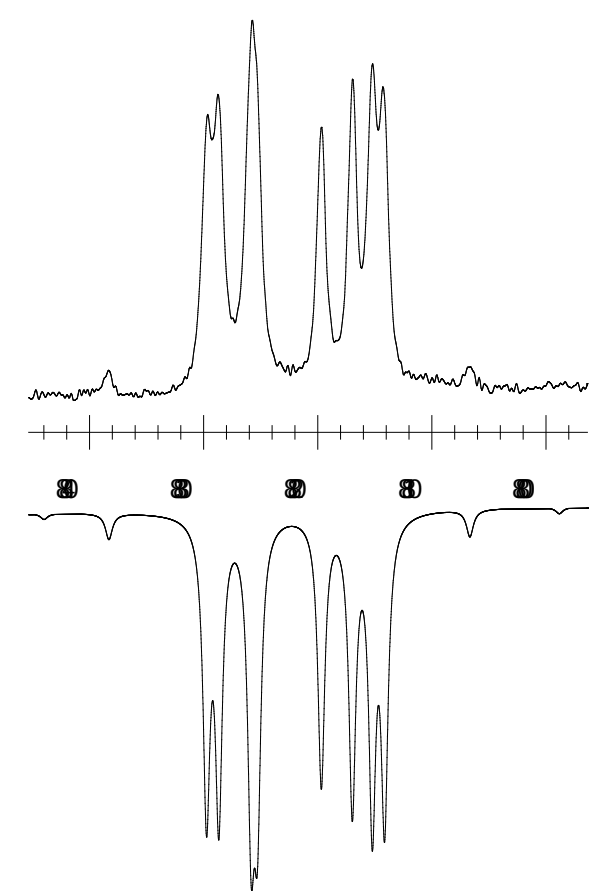
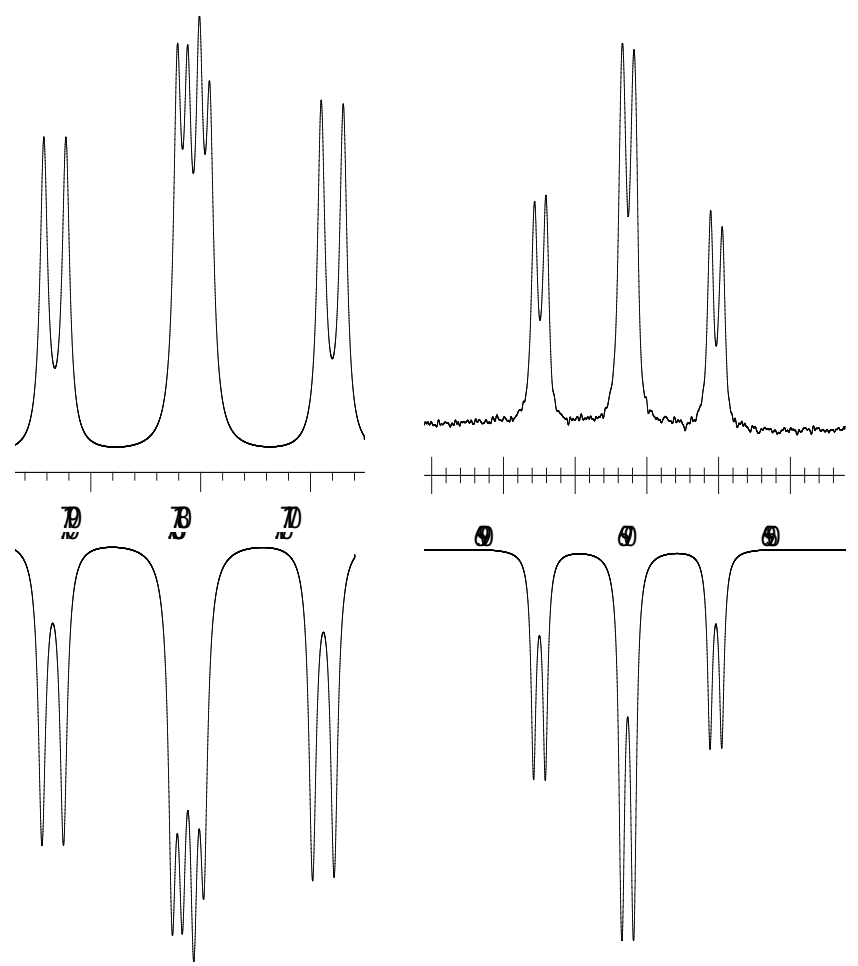

H-29

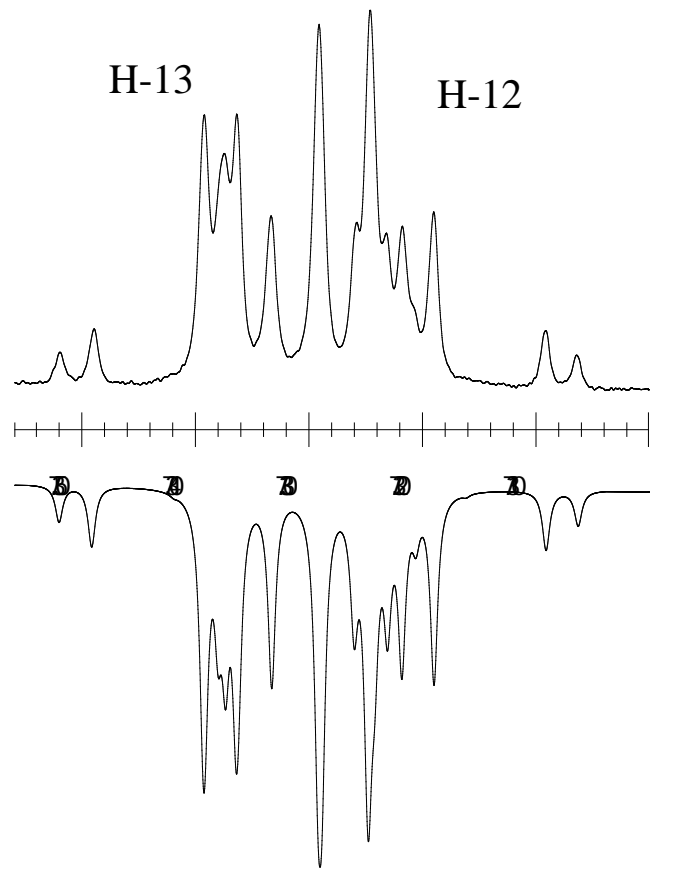


H-20

H-21

H-22

H-23

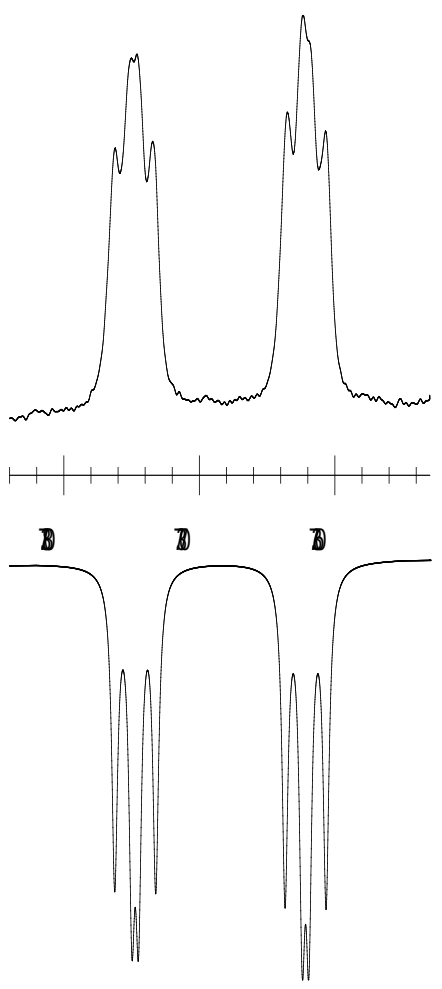

H-32
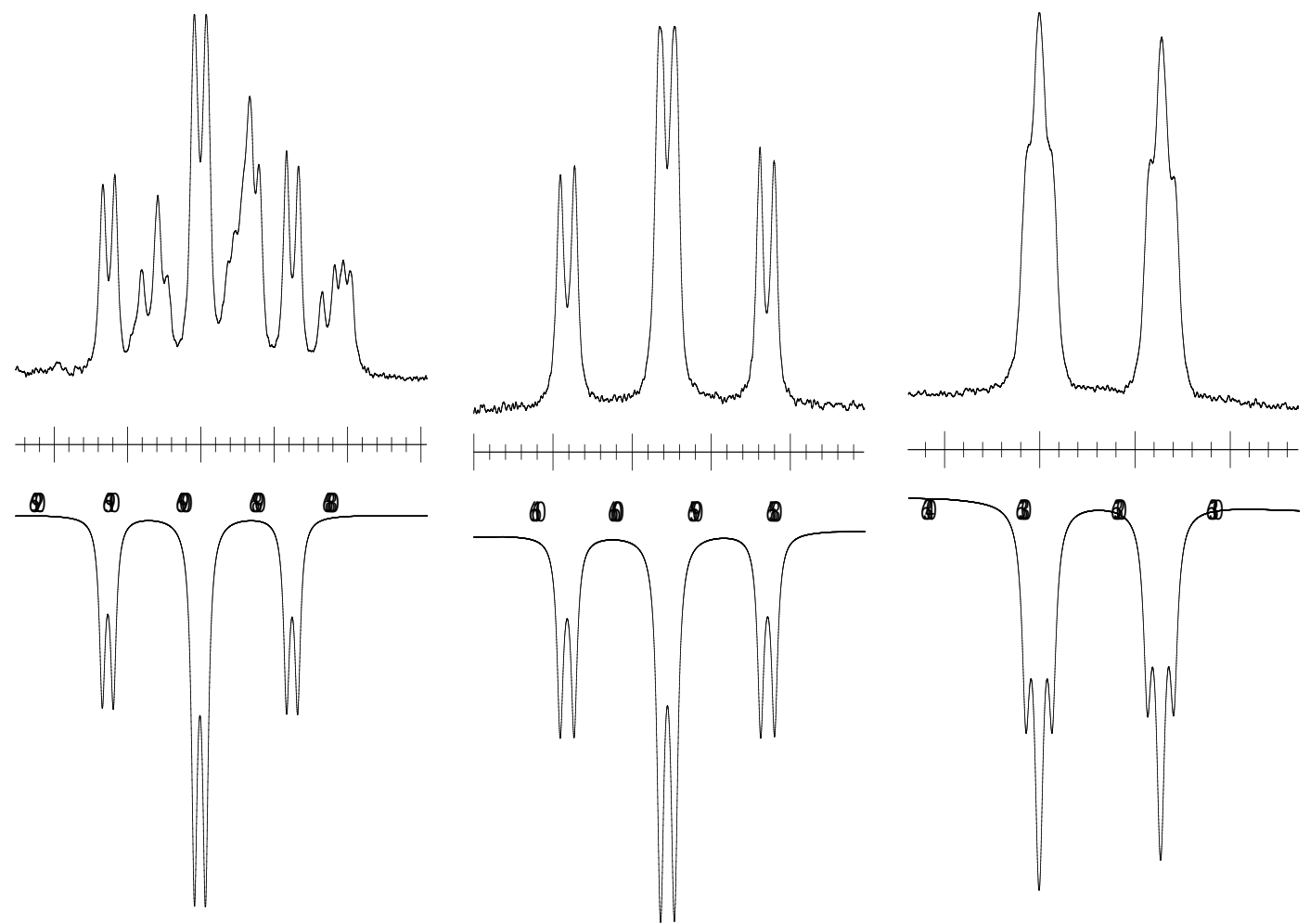

H-29

H-30

H-31
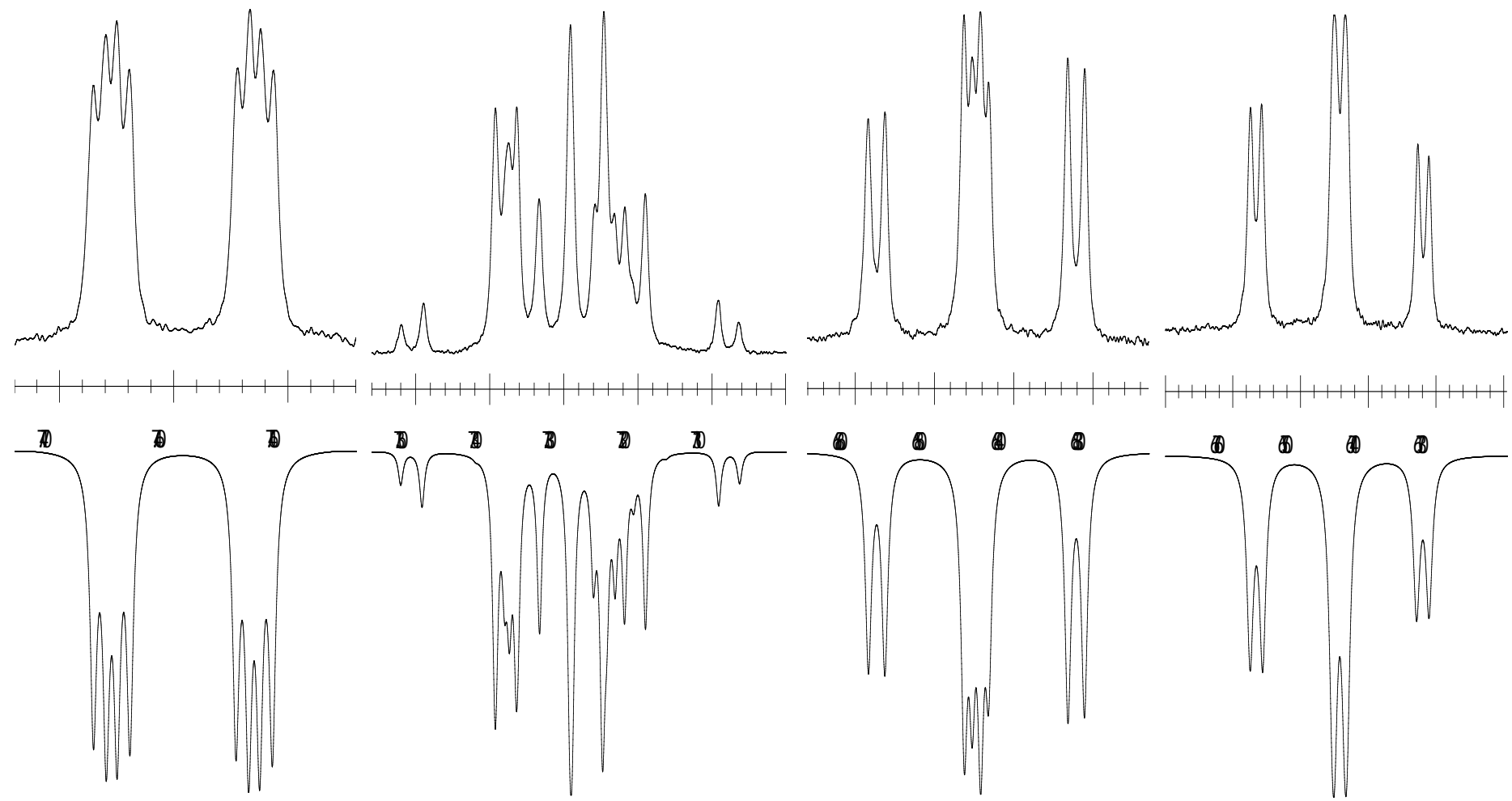
${ }^{1} \mathrm{H}$ and ${ }^{13} \mathrm{C}$ NMR Chemical Shifts of 28 in $\mathrm{C}_{6} \mathrm{D}_{6}$

\begin{tabular}{|c|c|c|}
\hline Carbon and Proton & $\begin{array}{l}{ }^{13} \mathrm{C} \text { NMR chemical } \\
\text { shift (ppm) }\end{array}$ & $\begin{array}{l}{ }^{1} \mathrm{H} \text { NMR chemical } \\
\text { shift (ppm) }\end{array}$ \\
\hline C1-H1 & \begin{tabular}{|l}
123.49 \\
\end{tabular} & 7.84 \\
\hline $\mathrm{C} 2-\mathrm{H} 2$ & 131.33 & 6.97 \\
\hline C3-H3 & \begin{tabular}{|l|}
134.88 \\
\end{tabular} & 7.19 \\
\hline C4-H4 & \begin{tabular}{|l|}
128.79 \\
\end{tabular} & 9.29 \\
\hline C5 & \begin{tabular}{|l|}
142.22 \\
\end{tabular} & \\
\hline C6 & 139.66 & \\
\hline C7 & \begin{tabular}{|l|}
190.30 \\
\end{tabular} & \\
\hline C8 & \begin{tabular}{|l|}
129.15 \\
\end{tabular} & \\
\hline C9 & 145.06 & \\
\hline C10 & \begin{tabular}{|l|}
133.86 \\
\end{tabular} & \\
\hline C11-H11 & 129.63 & 9.73 \\
\hline C12-H12 & \begin{tabular}{|l|}
127.91 \\
\end{tabular} & 7.32 \\
\hline C13-H13 & 131.20 & 7.34 \\
\hline C14-H14 & \begin{tabular}{|l|}
124.51 \\
\end{tabular} & 8.82 \\
\hline C15 & \begin{tabular}{|l|}
142.61 \\
\end{tabular} & \\
\hline C16 & \begin{tabular}{|l|}
137.87 \\
\end{tabular} & \\
\hline C17 & \begin{tabular}{|l|}
134.36 \\
\end{tabular} & \\
\hline C18 & \begin{tabular}{|l|}
131.24 \\
\end{tabular} & \\
\hline C19 & \begin{tabular}{|l|}
142.00 \\
\end{tabular} & \\
\hline C20-H20 & \begin{tabular}{|l|}
119.98 \\
\end{tabular} & 7.37 \\
\hline C21-H21 & \begin{tabular}{|l|}
128.56 \\
\end{tabular} & 6.90 \\
\hline C22-H22 & \begin{tabular}{|l|}
127.83 \\
\end{tabular} & 6.60 \\
\hline C23-H23 & \begin{tabular}{|l|}
122.82 \\
\end{tabular} & 6.32 \\
\hline $\mathrm{C} 24$ & \begin{tabular}{|l|}
133.32 \\
\end{tabular} & \\
\hline $\mathrm{C} 25$ & \begin{tabular}{|l|}
134.28 \\
\end{tabular} & \\
\hline C26 & \begin{tabular}{|l|}
147.45 \\
\end{tabular} & \\
\hline C27 & 57.63 & \\
\hline $\mathrm{C} 28$ & 150.04 & \\
\hline C9-H29 & 123.02 & 7.33 \\
\hline C-30-H30 & 134.79 & 6.84 \\
\hline C31-H31 & \begin{tabular}{|l|}
128.37 \\
\end{tabular} & 6.75 \\
\hline C32-H32 & 122.96 & 7.46 \\
\hline C33 & \begin{tabular}{|l|}
140.12 \\
\end{tabular} & \\
\hline C34 & \begin{tabular}{|l|}
187.73 \\
\end{tabular} & \\
\hline C35 & \begin{tabular}{|l|}
129.59 \\
\end{tabular} & \\
\hline C36 & \begin{tabular}{|l|}
135.37 \\
\end{tabular} & \\
\hline C37 & 141.62 & \\
\hline C38 & \begin{tabular}{|l|}
135.67 \\
\end{tabular} & \\
\hline C39-H399 ortho & 130.11 & 5.94 \\
\hline $\mathrm{C} 40-\mathrm{H}-40^{\text {meta }}$ & \begin{tabular}{|l|}
128.15 \\
\end{tabular} & 6.89 \\
\hline C41-H41 ${ }^{\text {para }}$ & 129.11 & 7.17 \\
\hline $\mathrm{C} 42-\mathrm{H} 42^{\text {meta }}$ & \begin{tabular}{|l|}
129.32 \\
\end{tabular} & 7.24 \\
\hline C43-H43 ${ }^{\text {ortho }}$ & 130.22 & 7.15 \\
\hline
\end{tabular}


gCOSY spectrum of 28 in $\mathrm{C}_{6} \mathrm{D}_{6}$
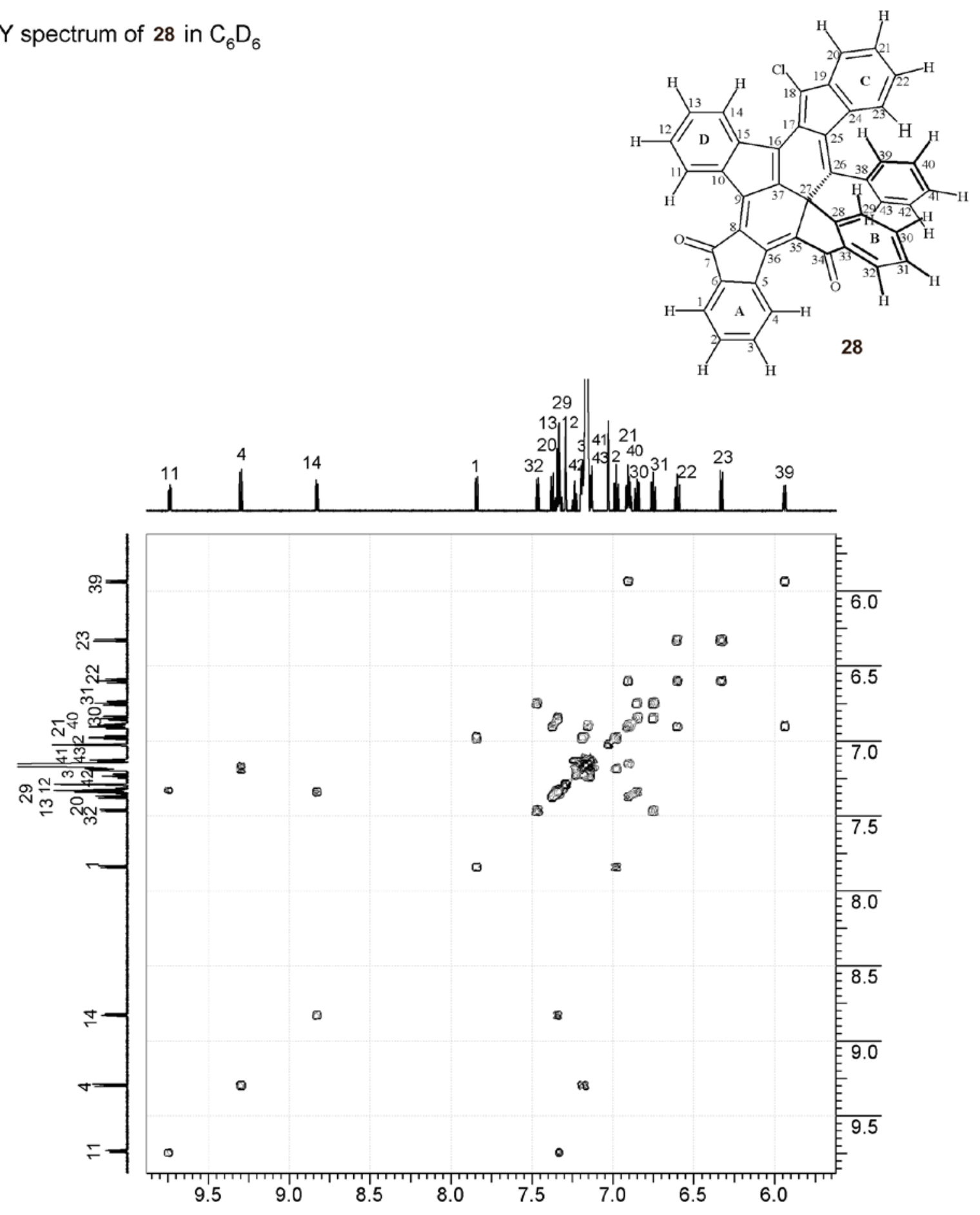


\section{D TOCSY spectra of 28 in $C_{6} D_{6}$}

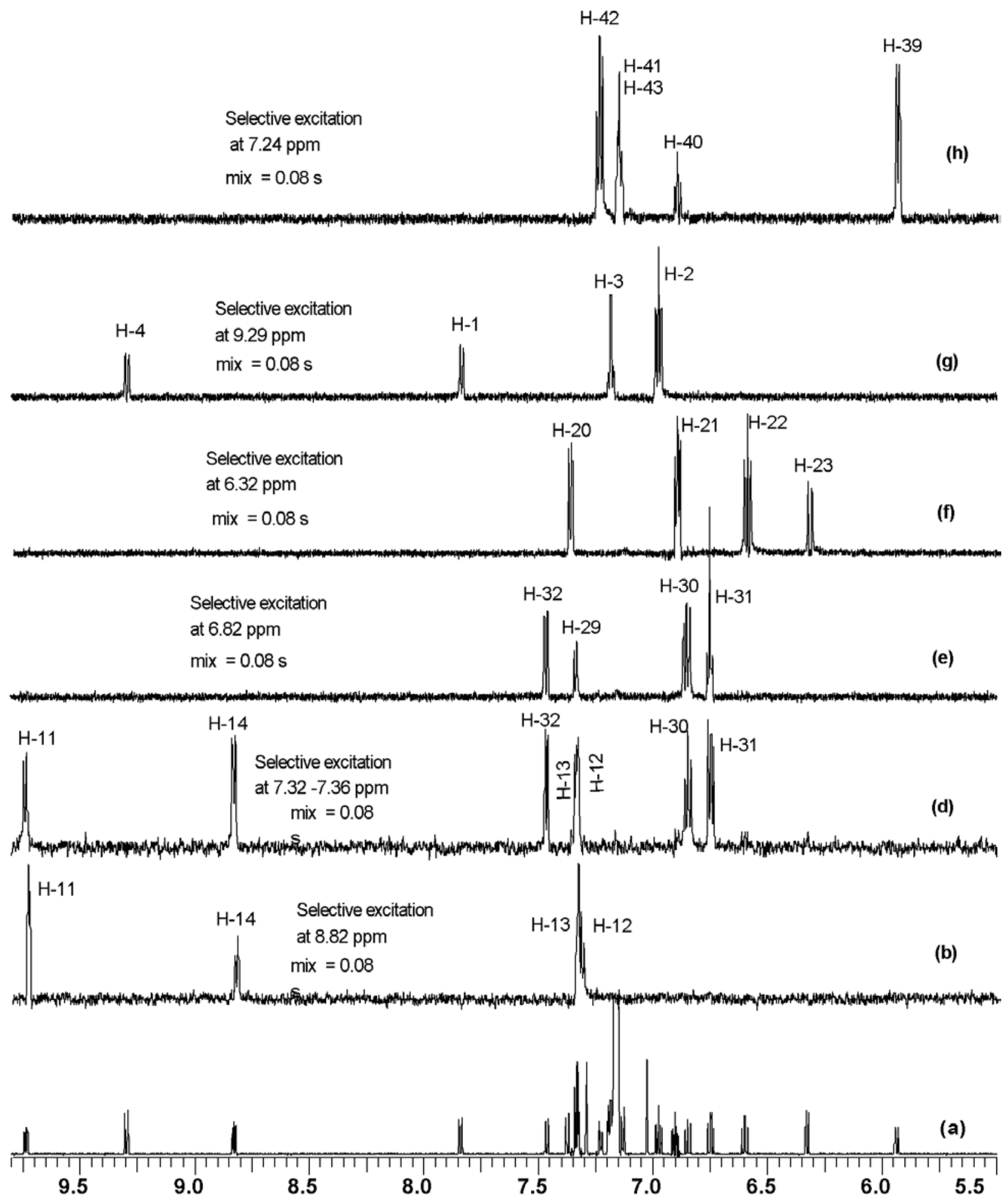




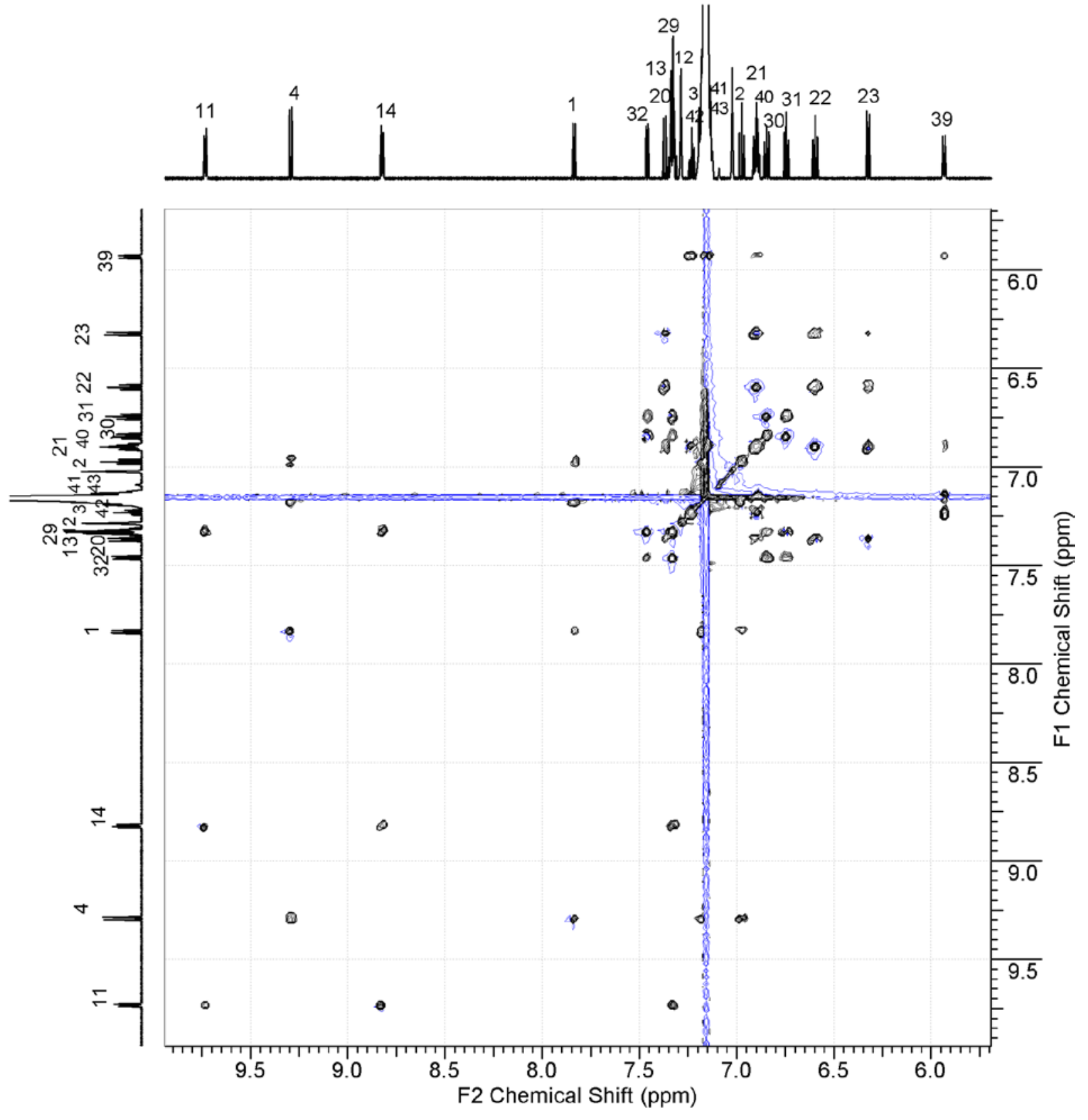


gHSQC spectrum of 28 in $\mathrm{C}_{6} \mathrm{D}_{6}$

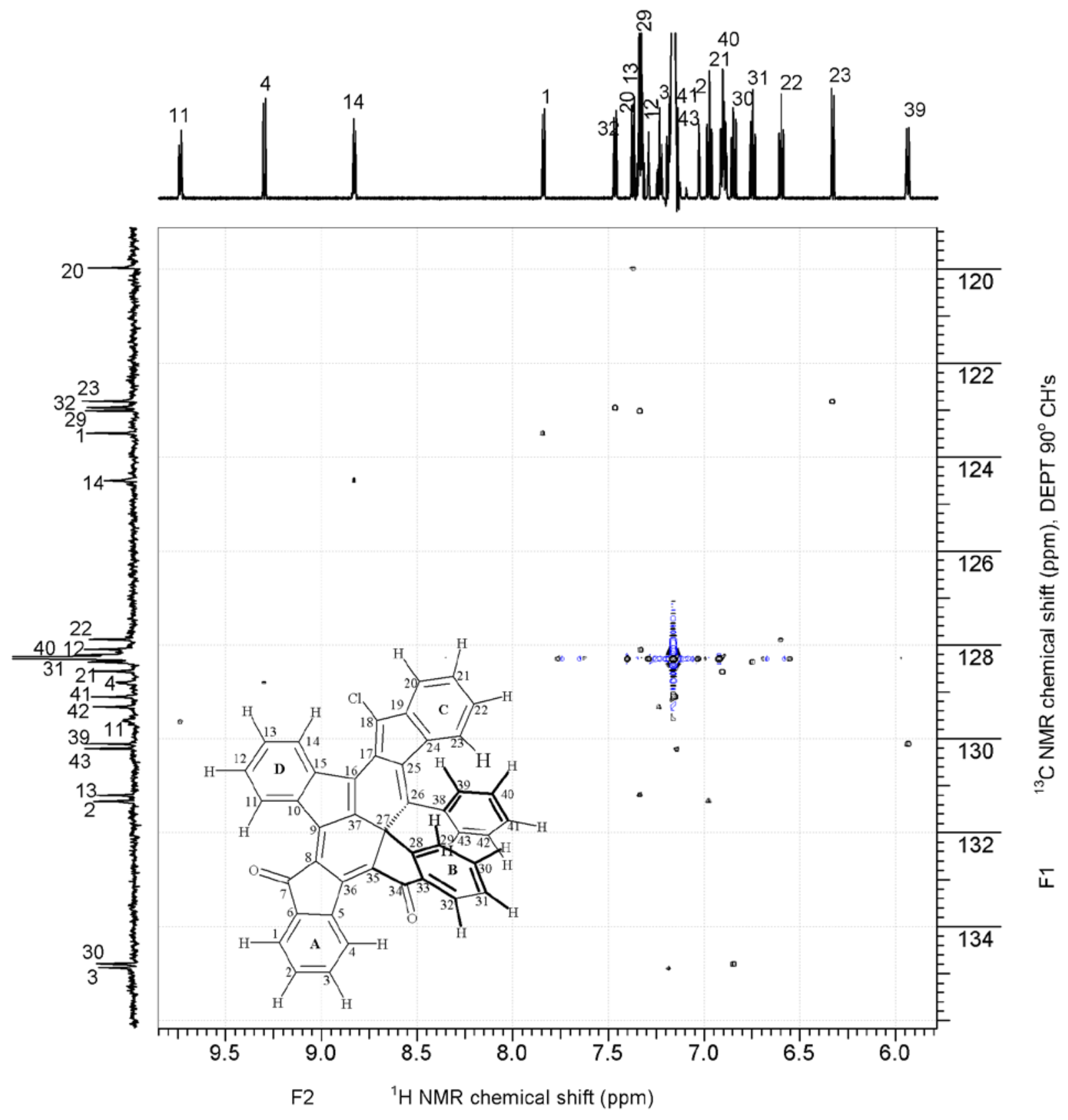


gHMBC spectrum of 28 in $\mathrm{C}_{6} \mathrm{D}_{6}$

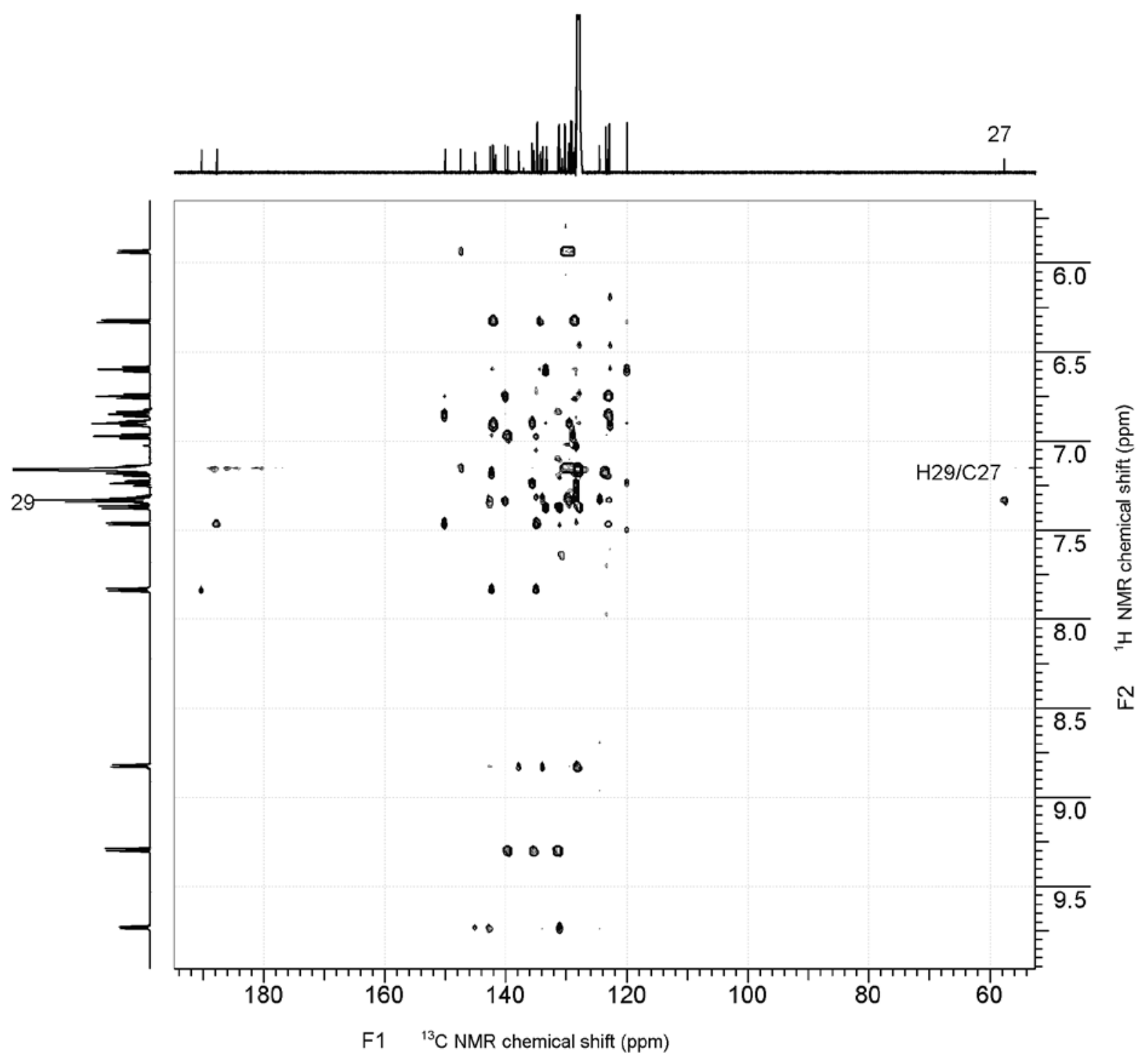


gHSQC-TOCSY spectrum of 28 in $\mathrm{C}_{6} \mathrm{D}_{6}$

(mix $=80 \mathrm{~ms}$ )

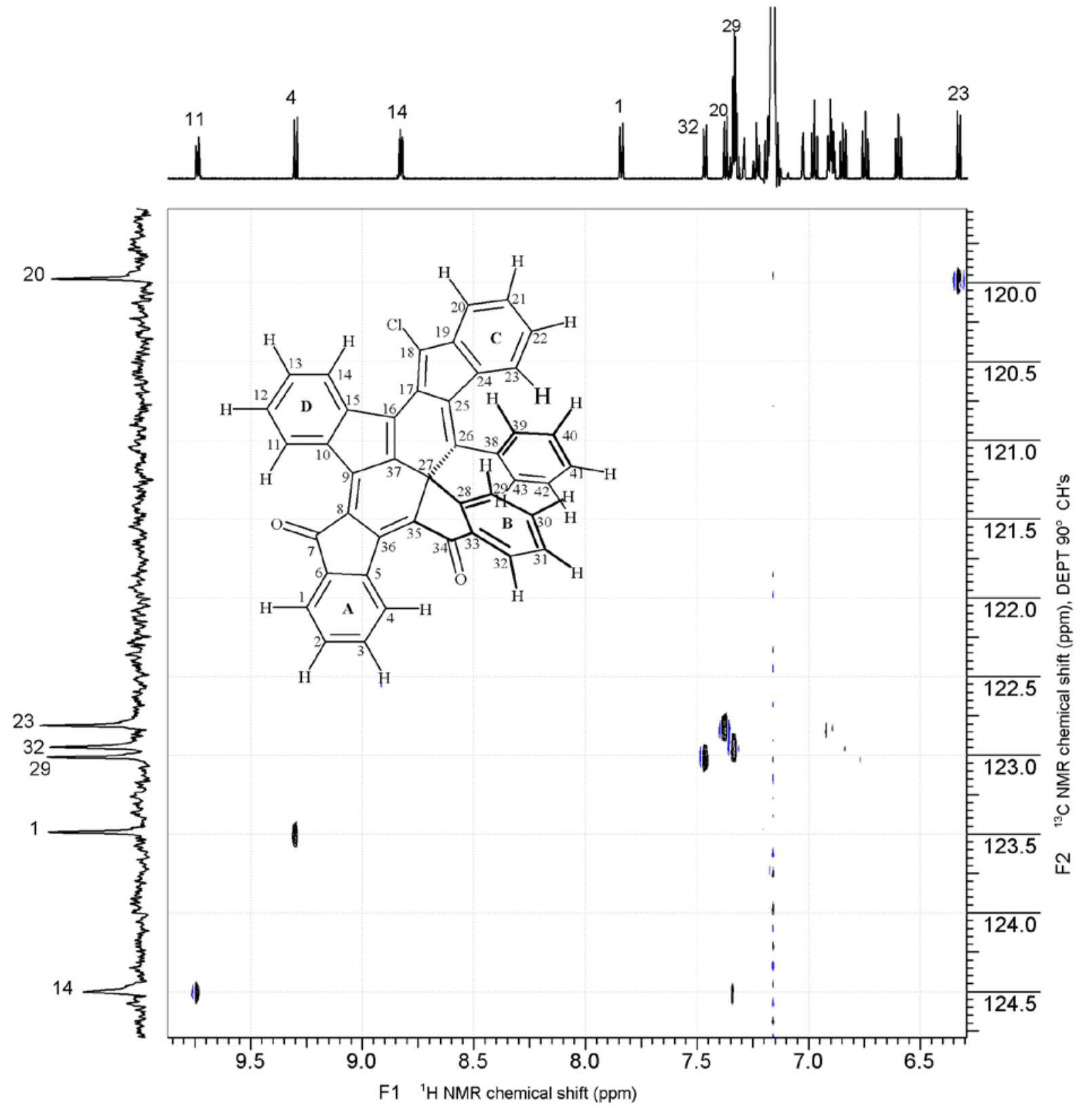




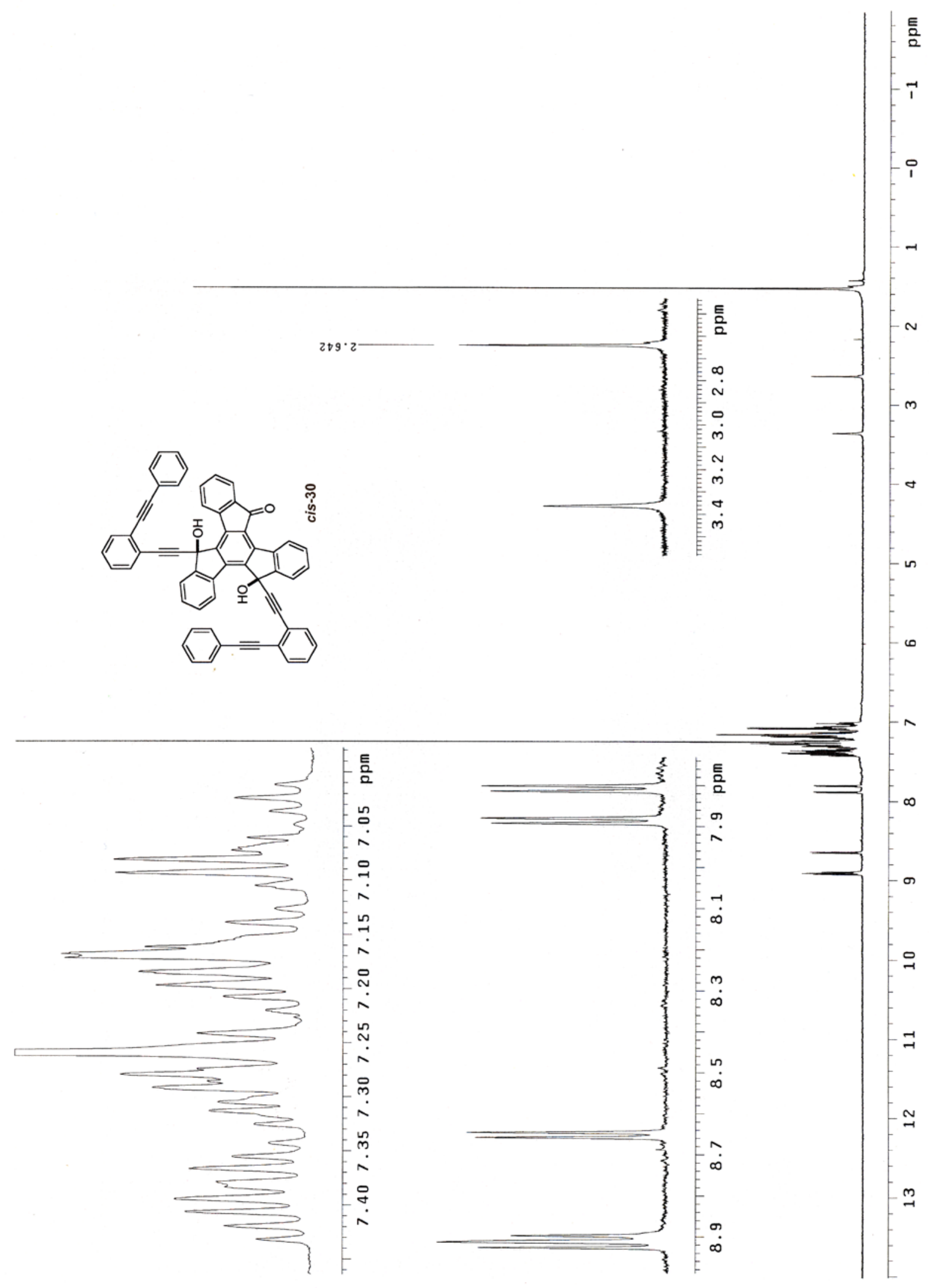




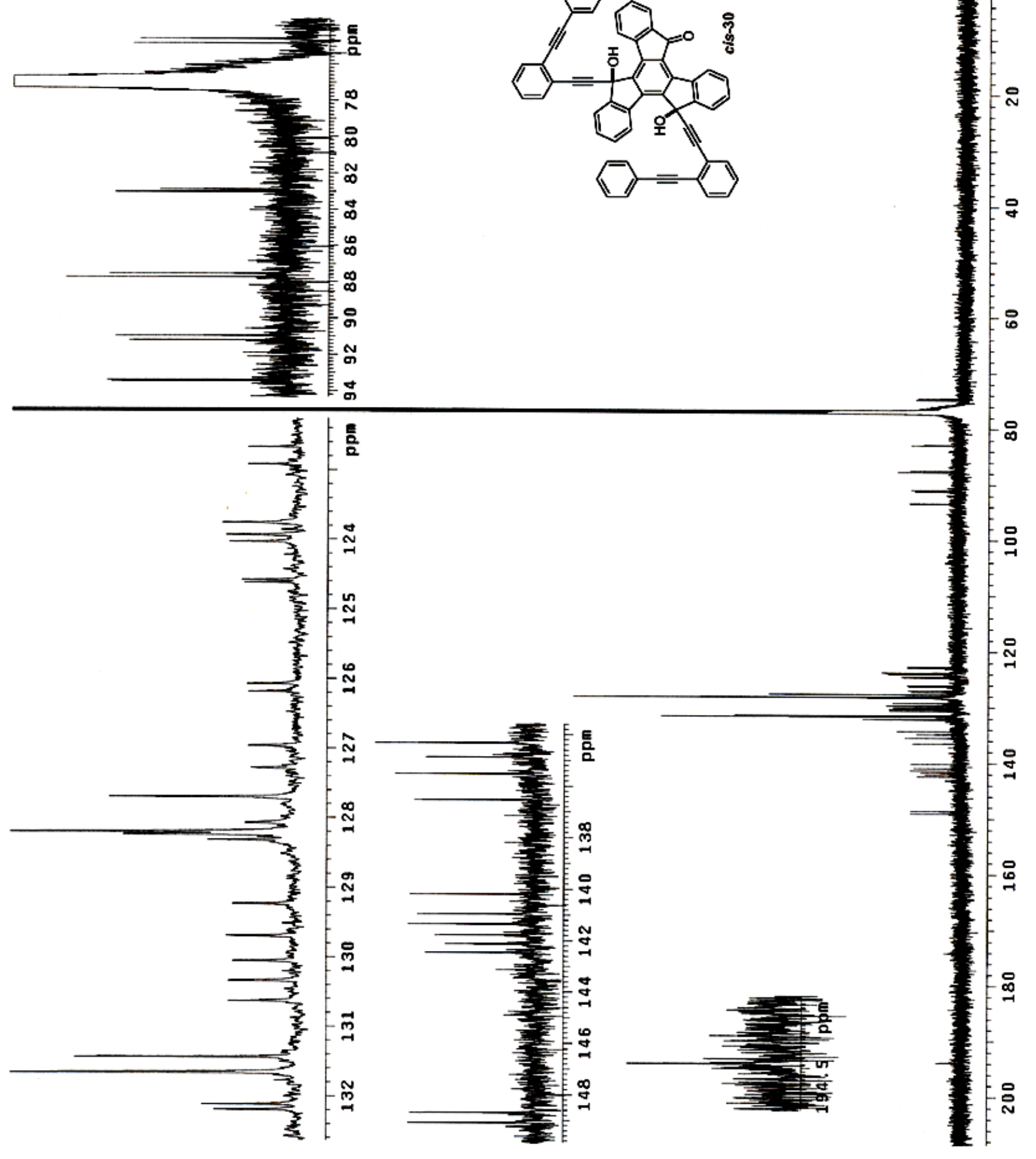




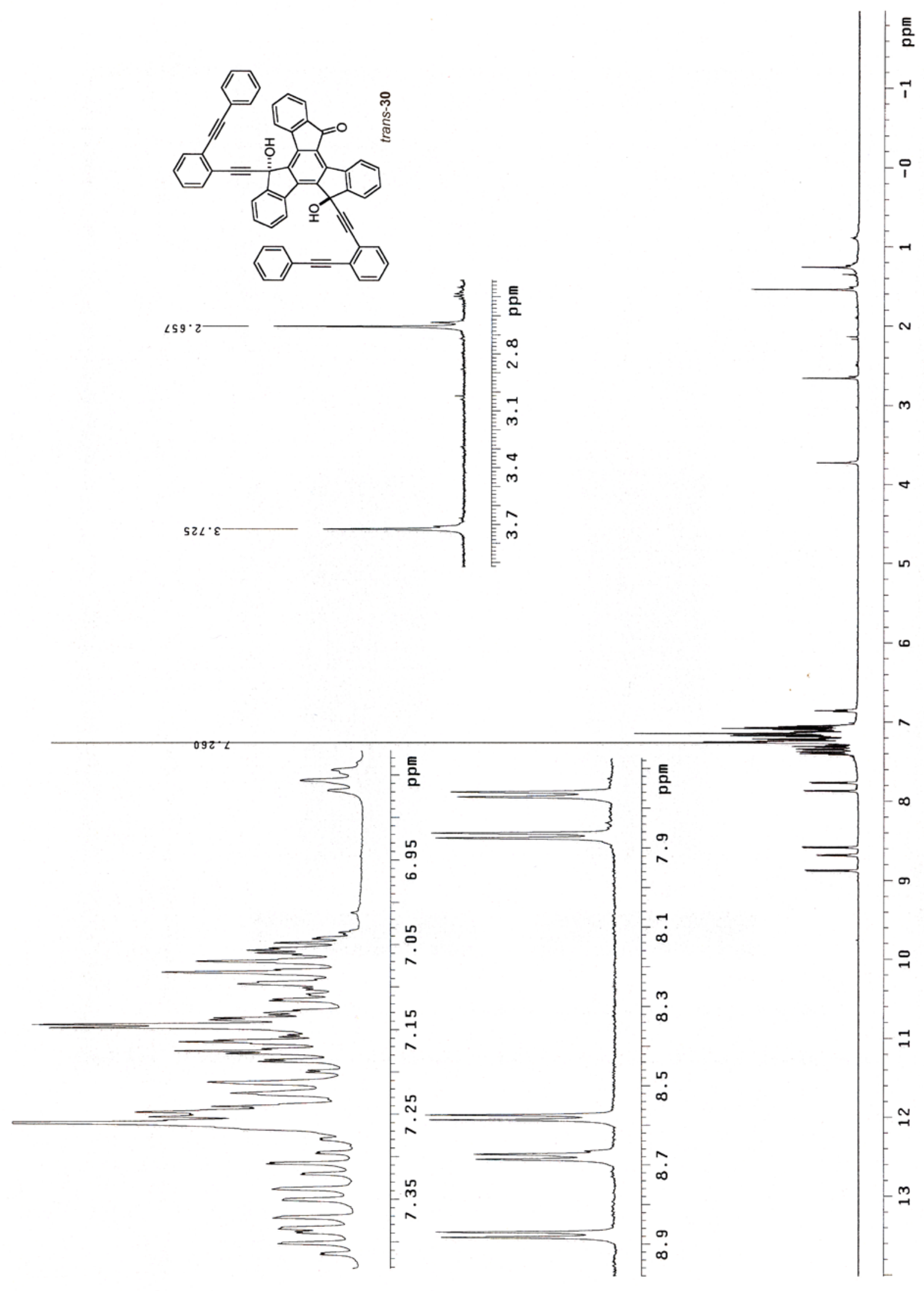




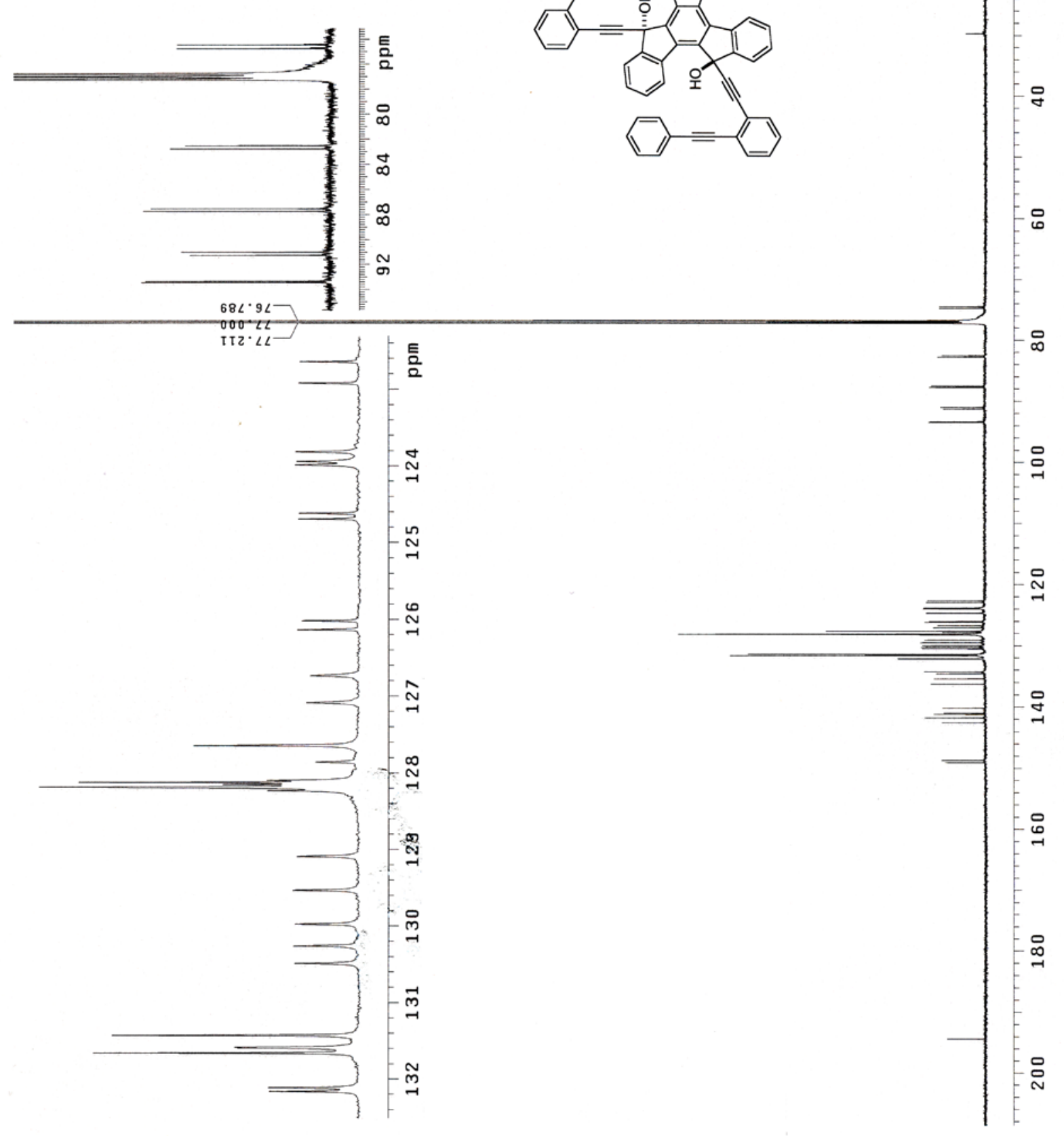




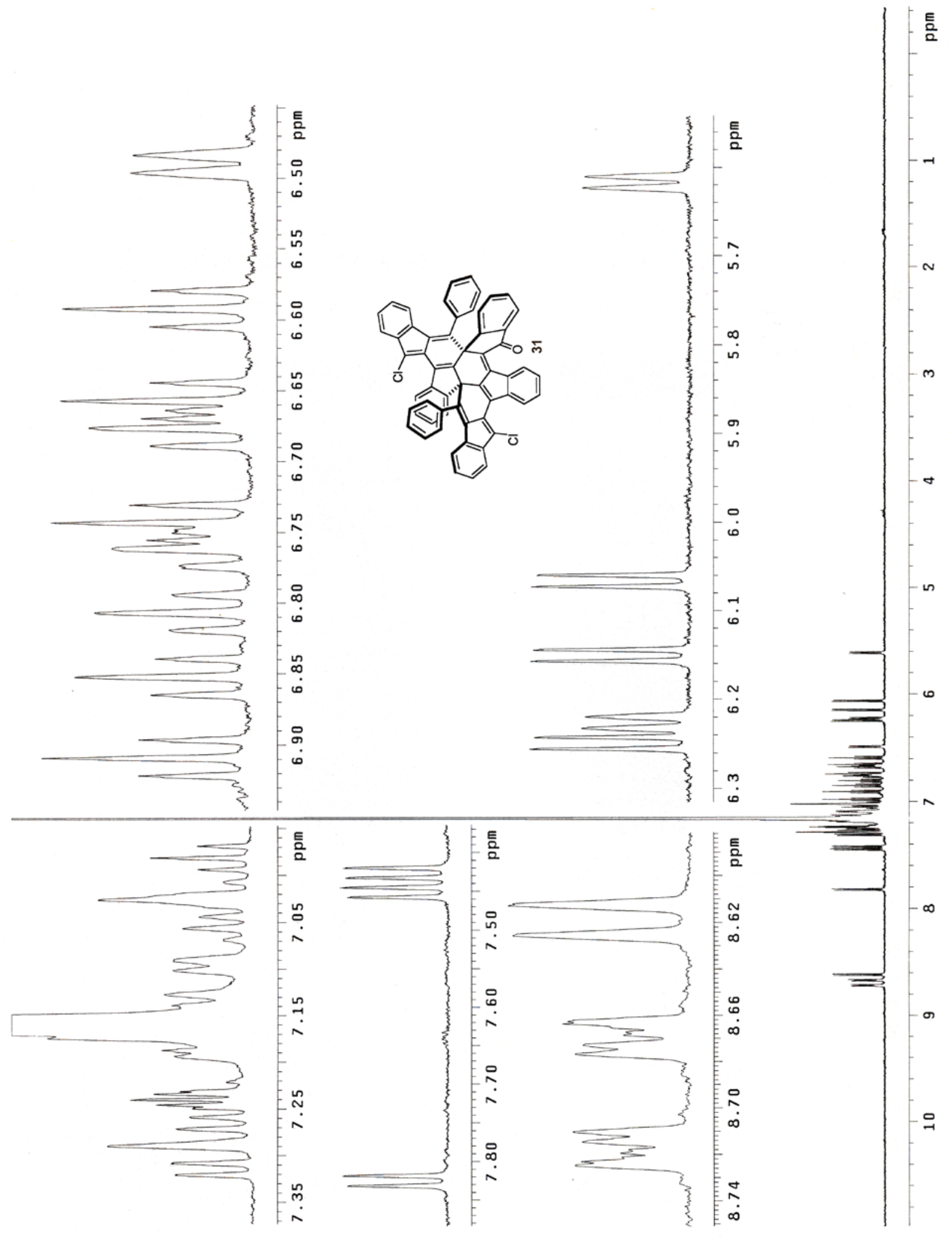




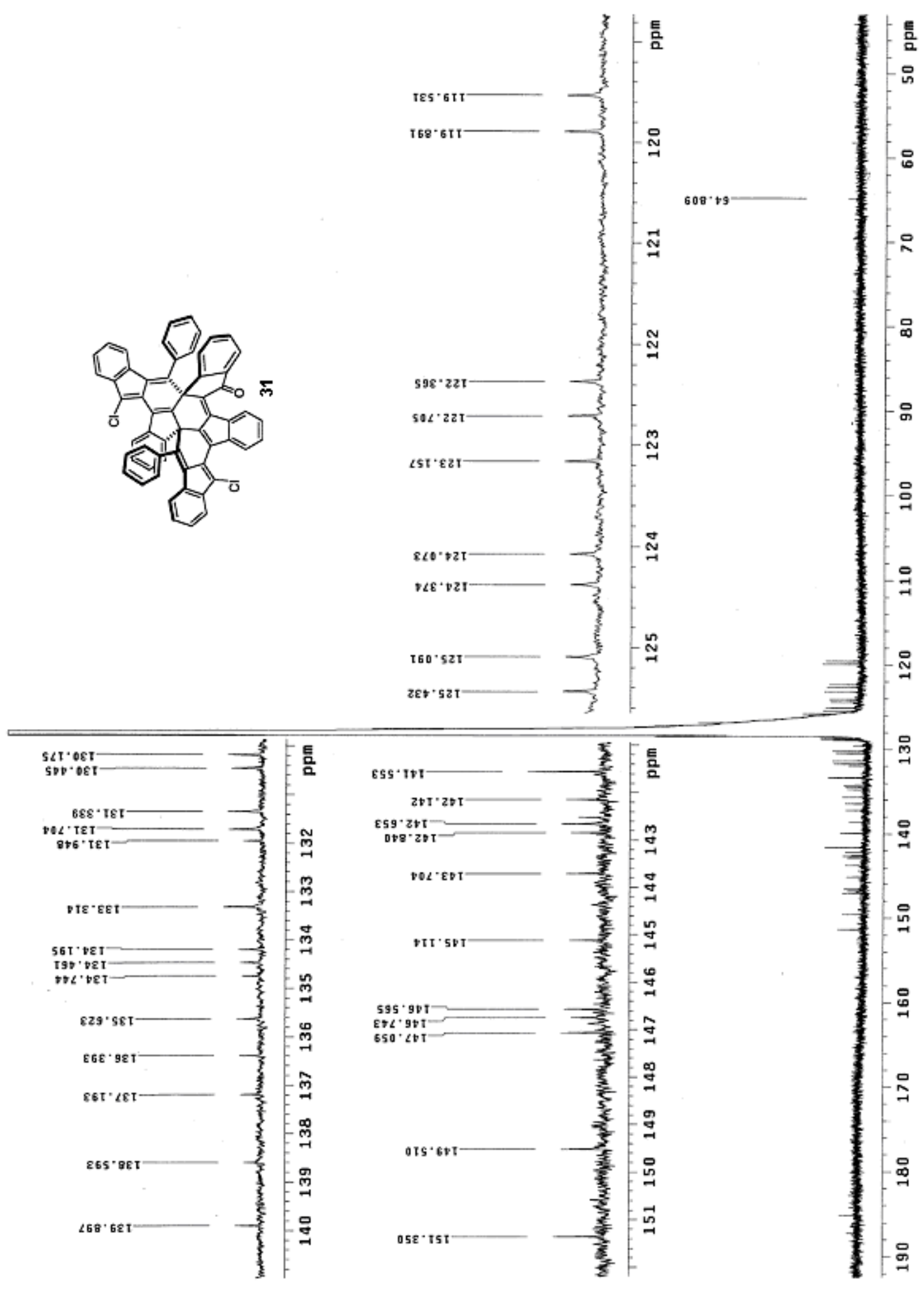




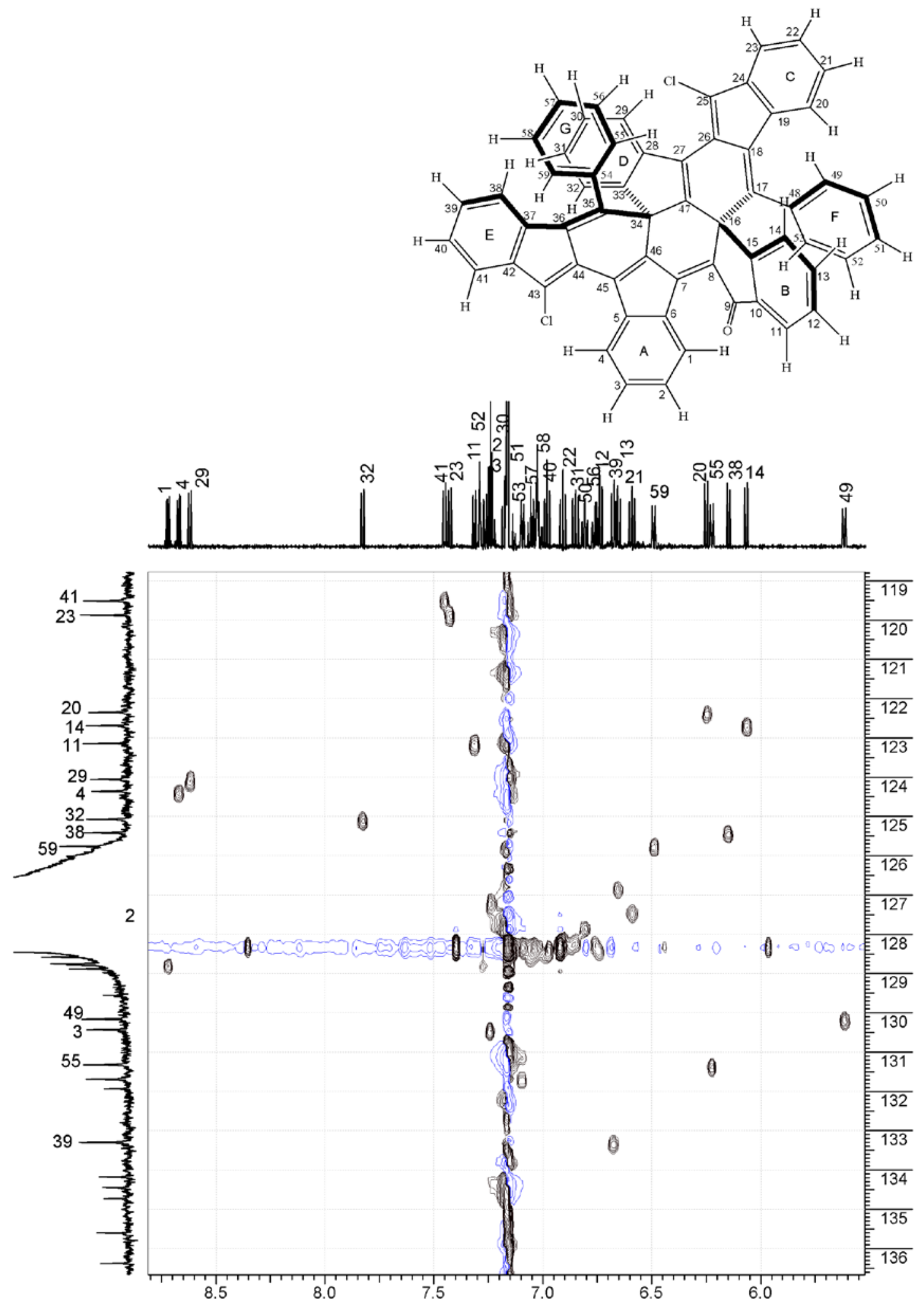


gHSQC spectrum of 31 in $C_{6} D_{6}$ (expansion)
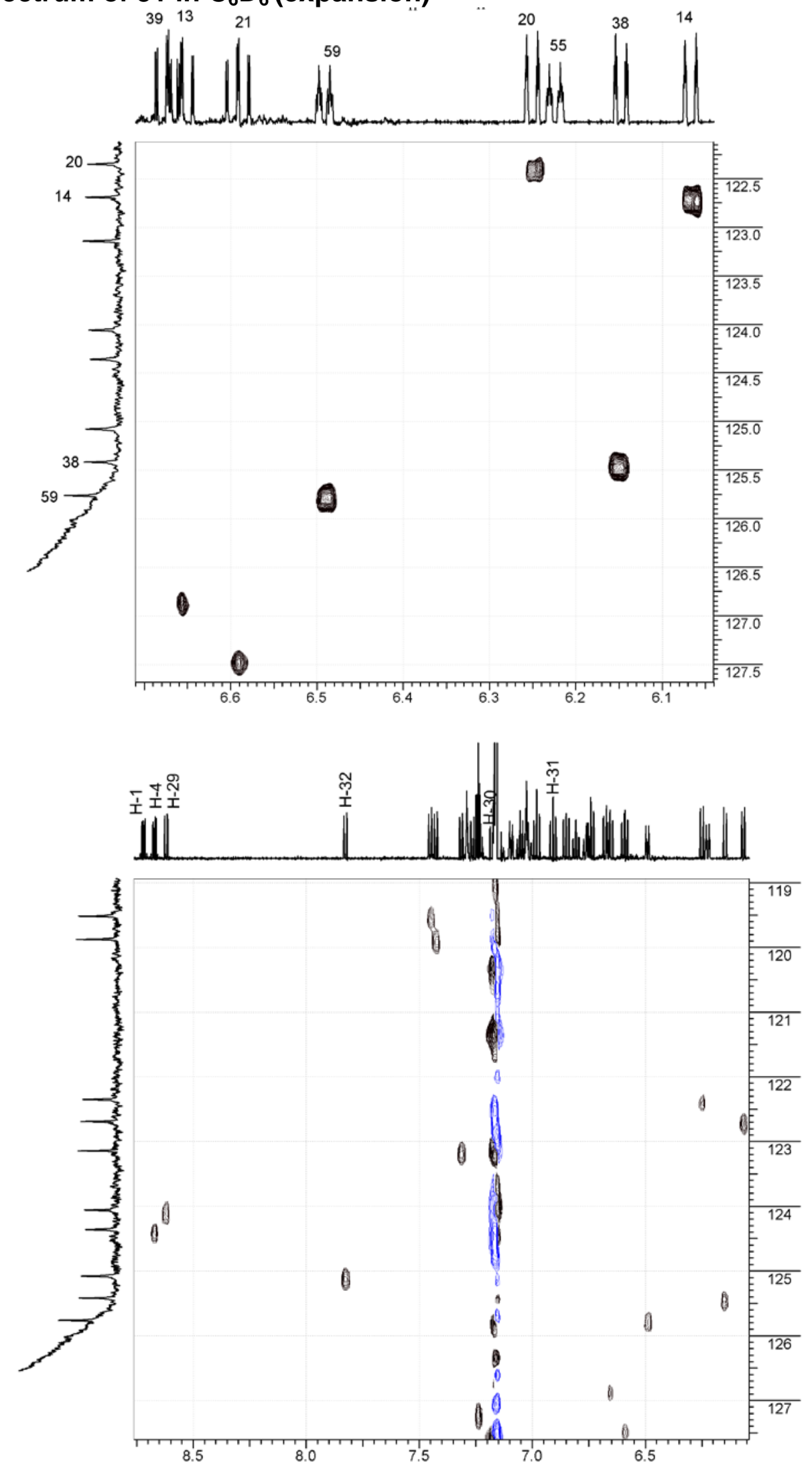


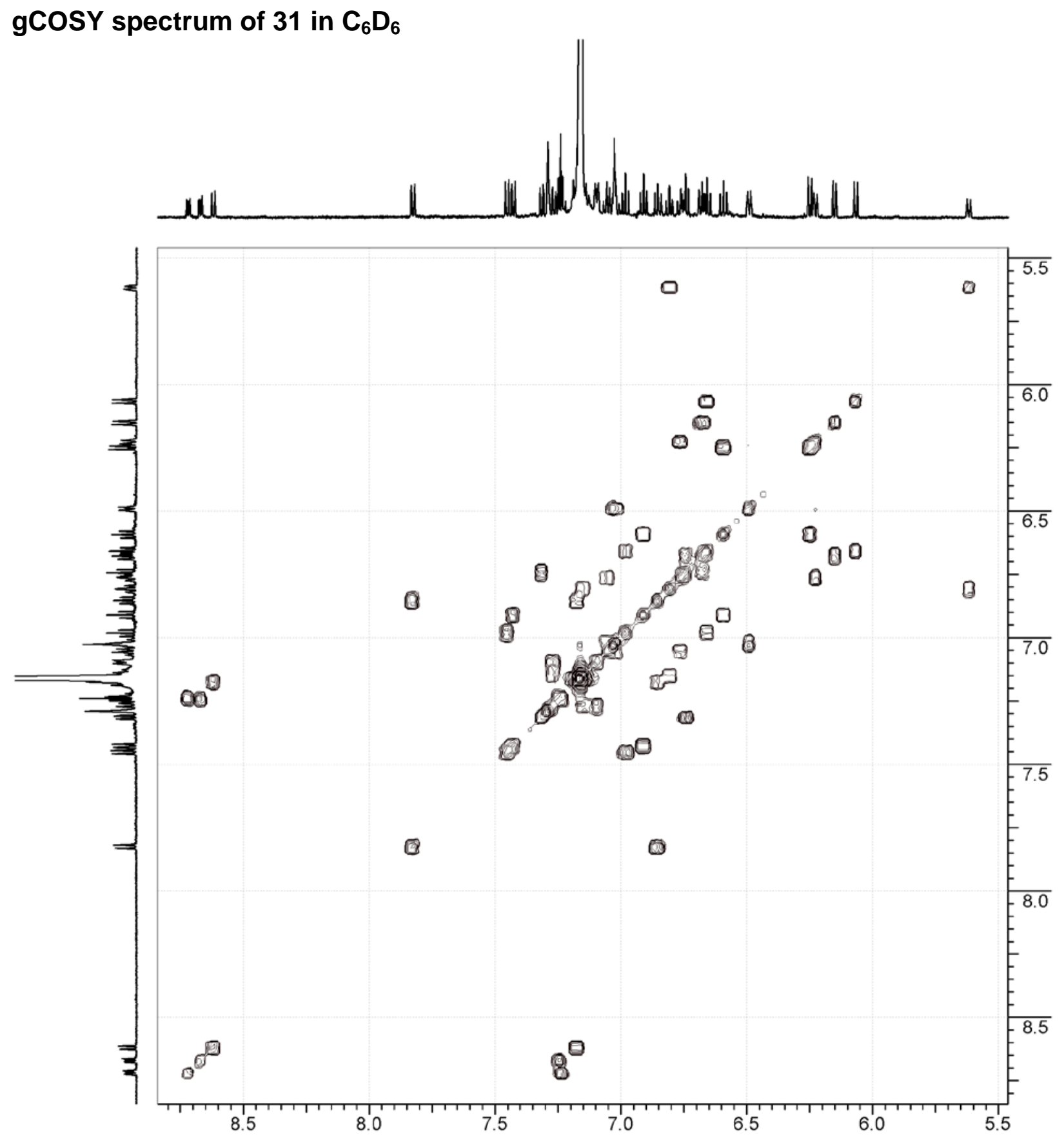




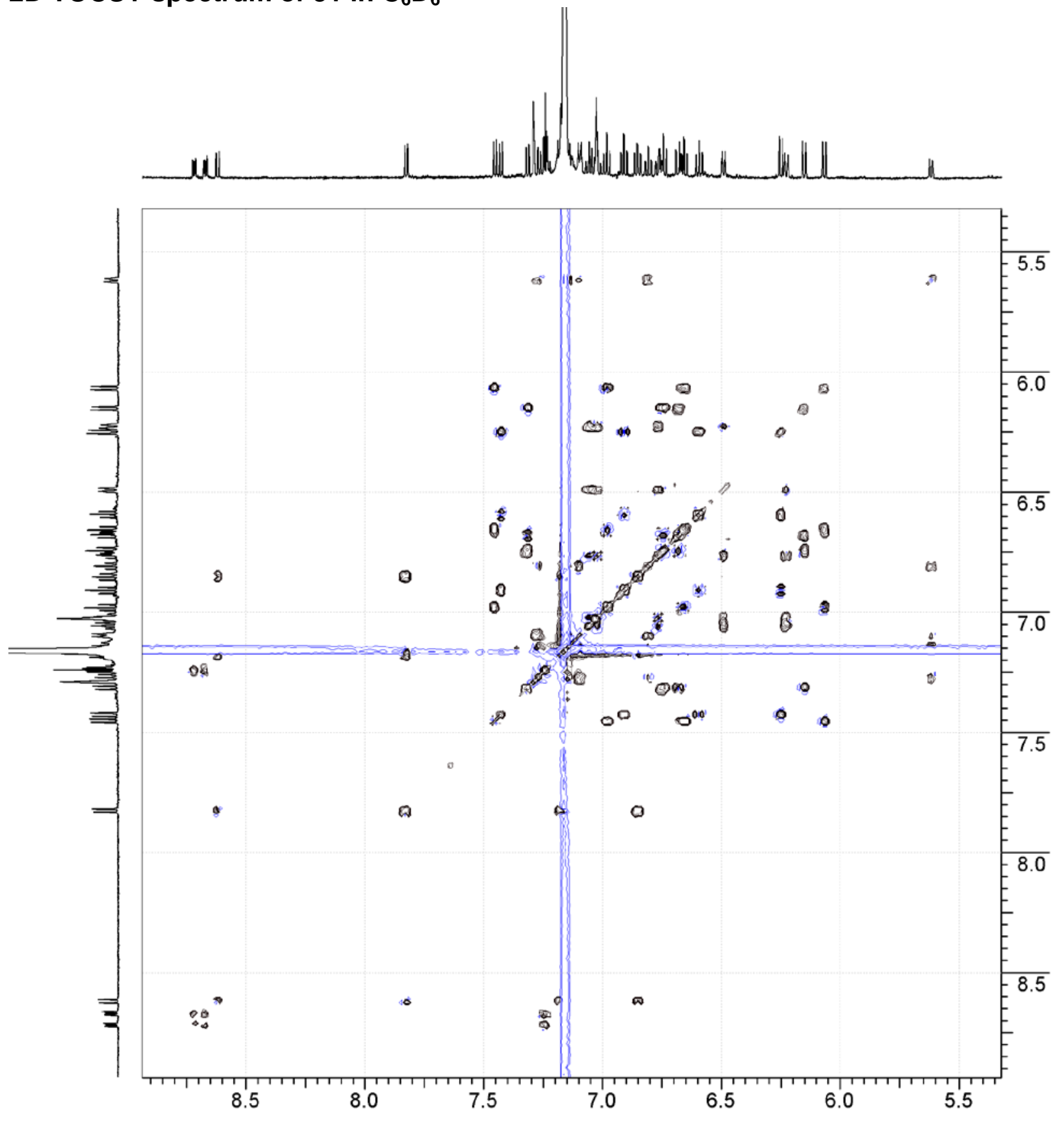


1D TOCSY spectra of 31 in $C_{6} D_{6}(\mathrm{mix}=80 \mathrm{~ms})$

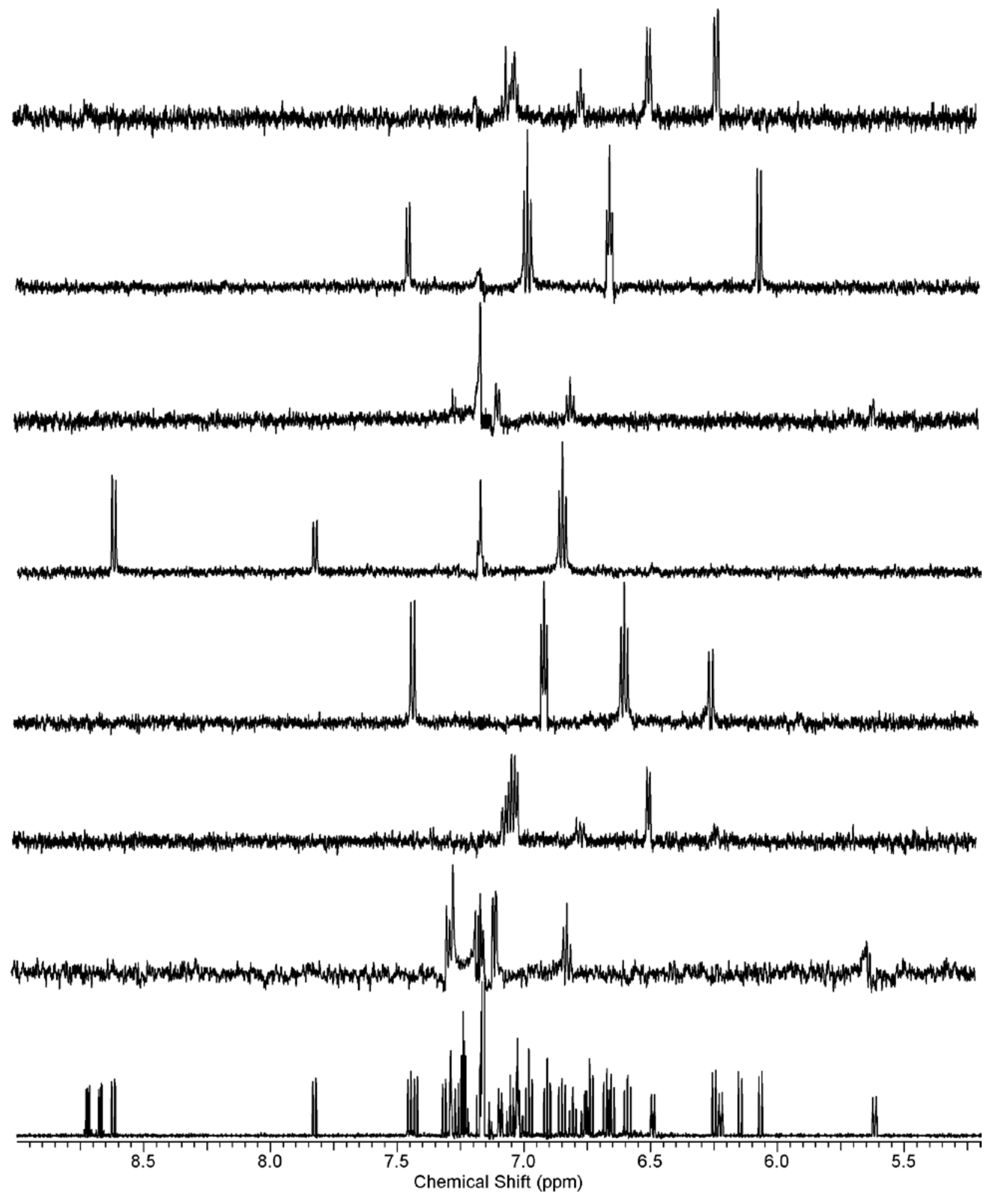




\section{gHMBC spectrum of 31 in $C_{6} D_{6}$ (expansion)}
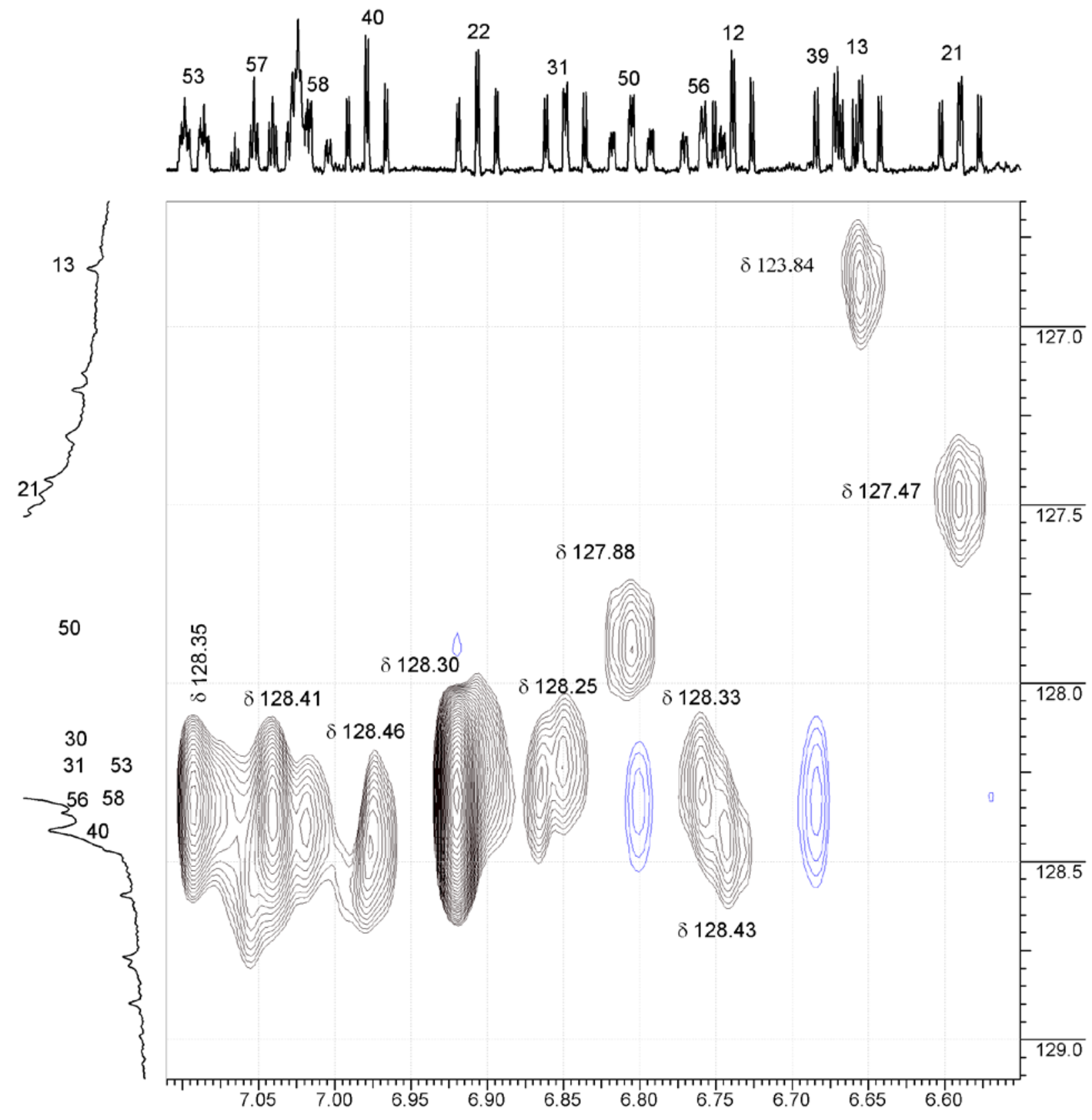


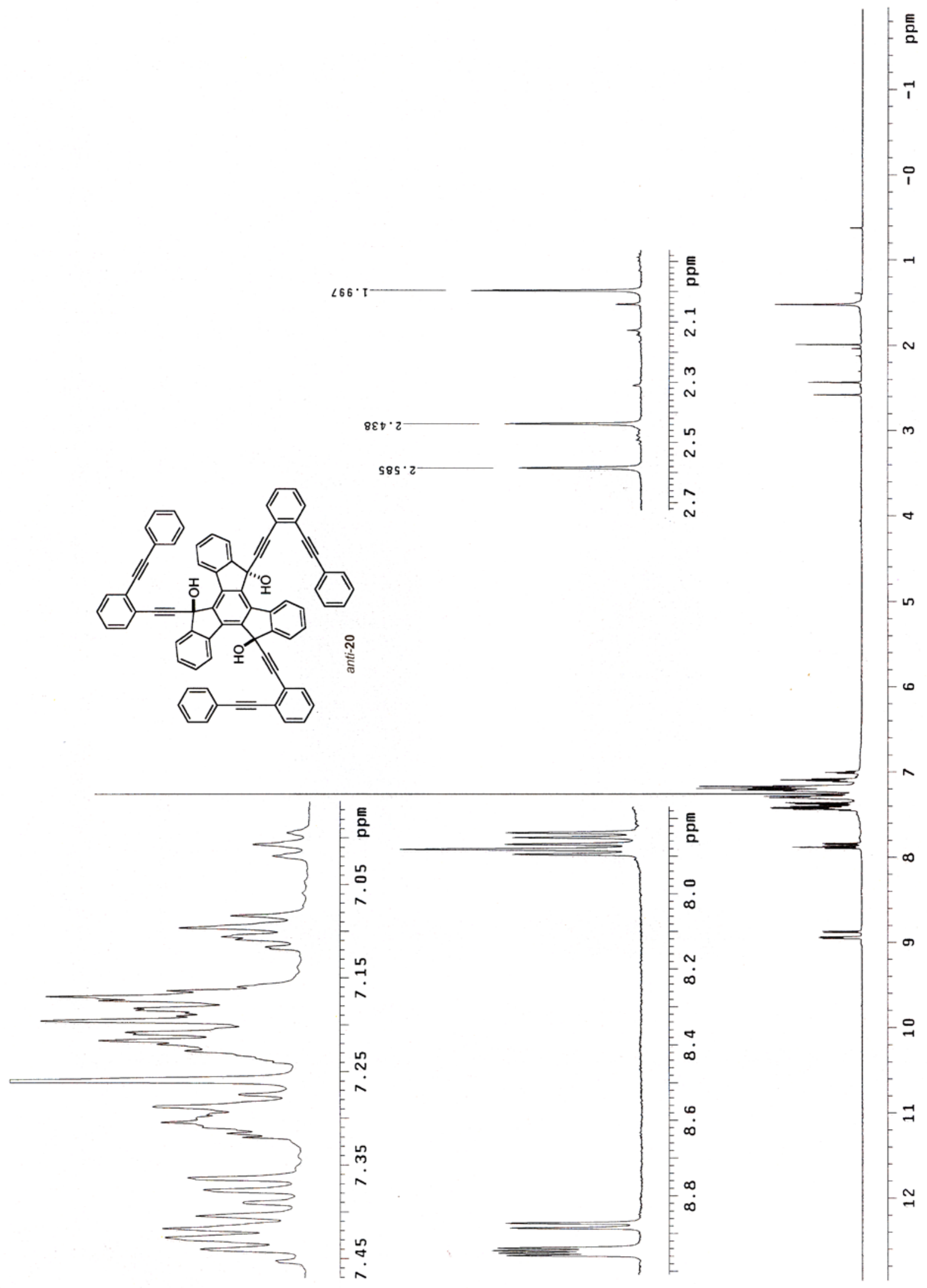




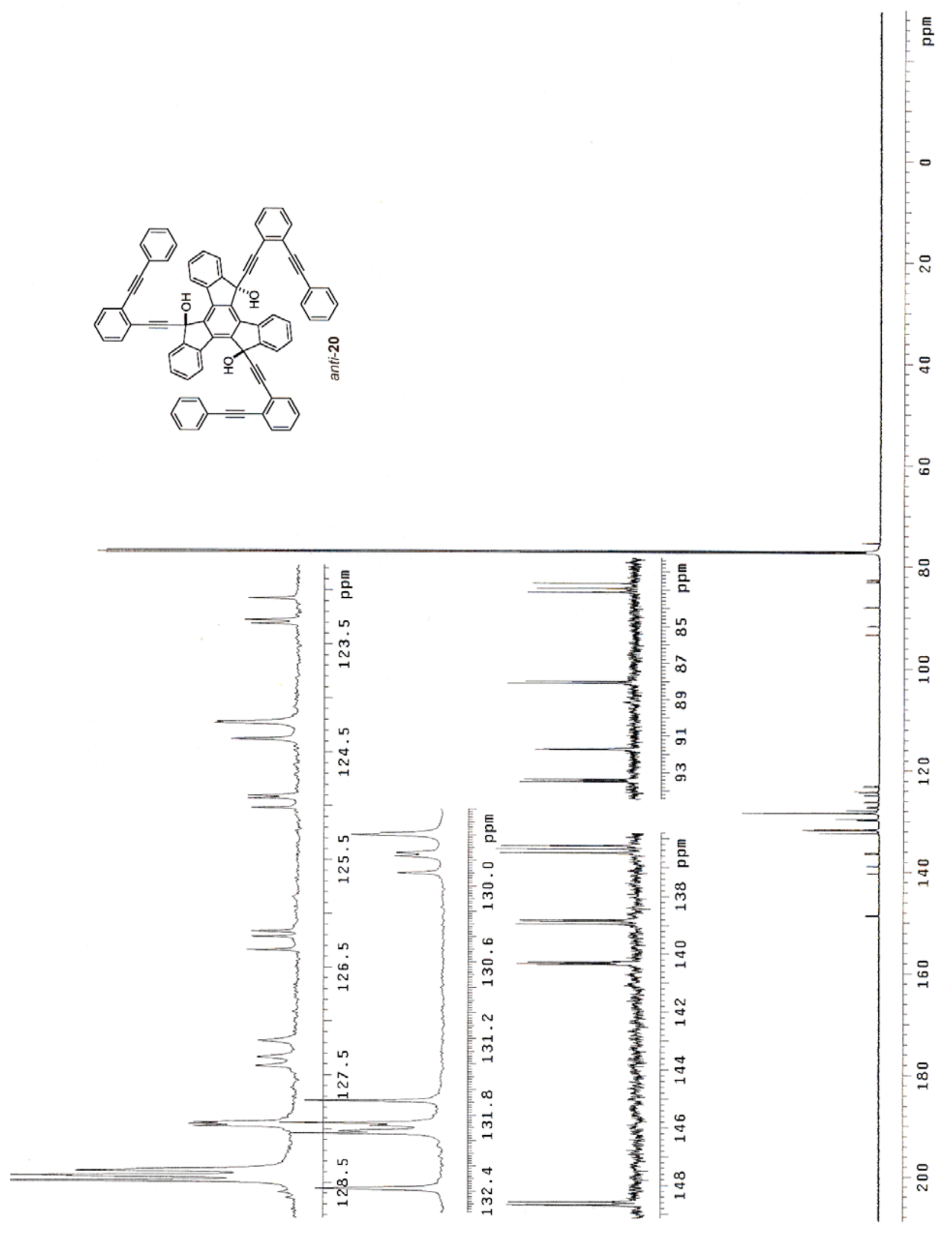




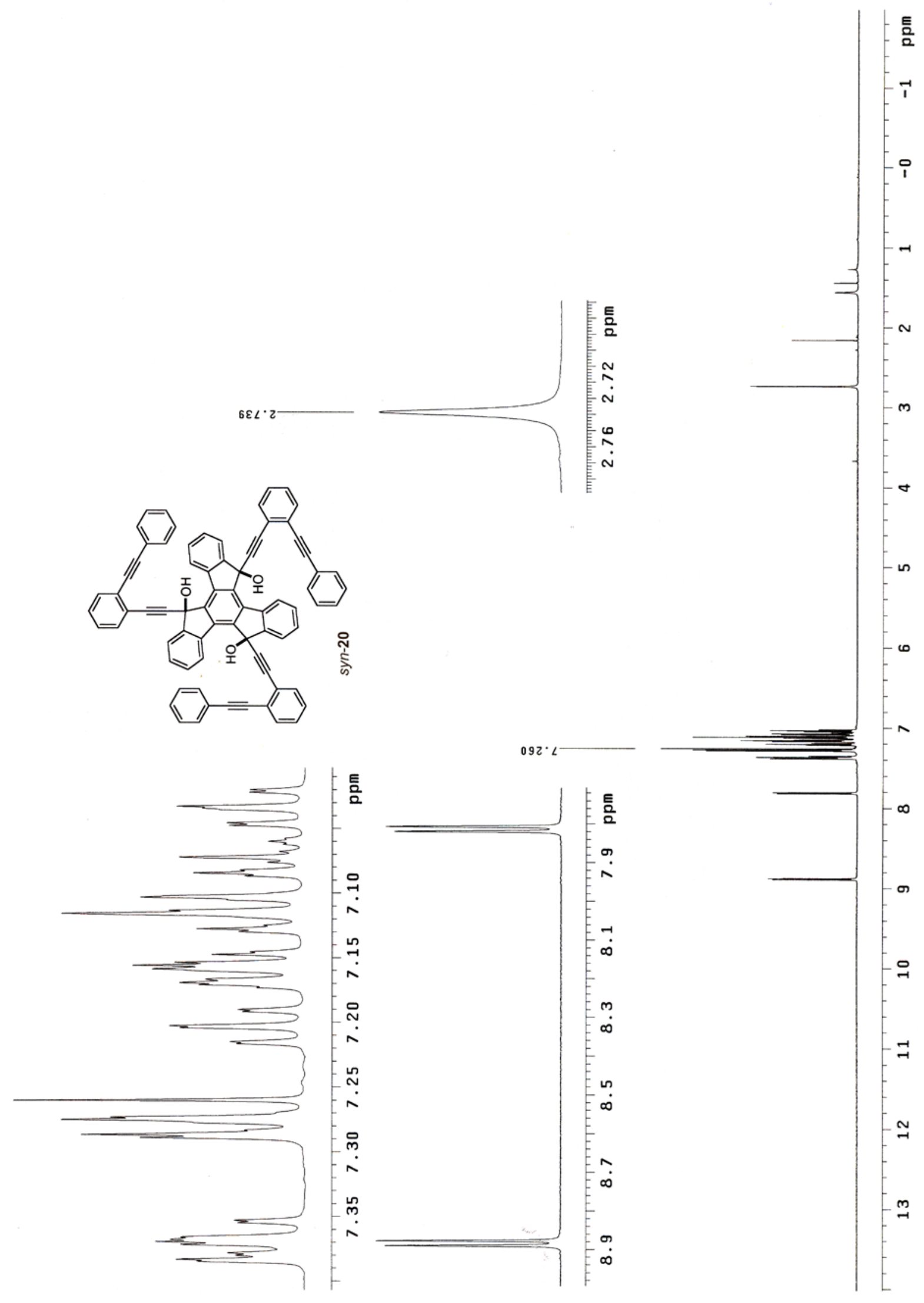




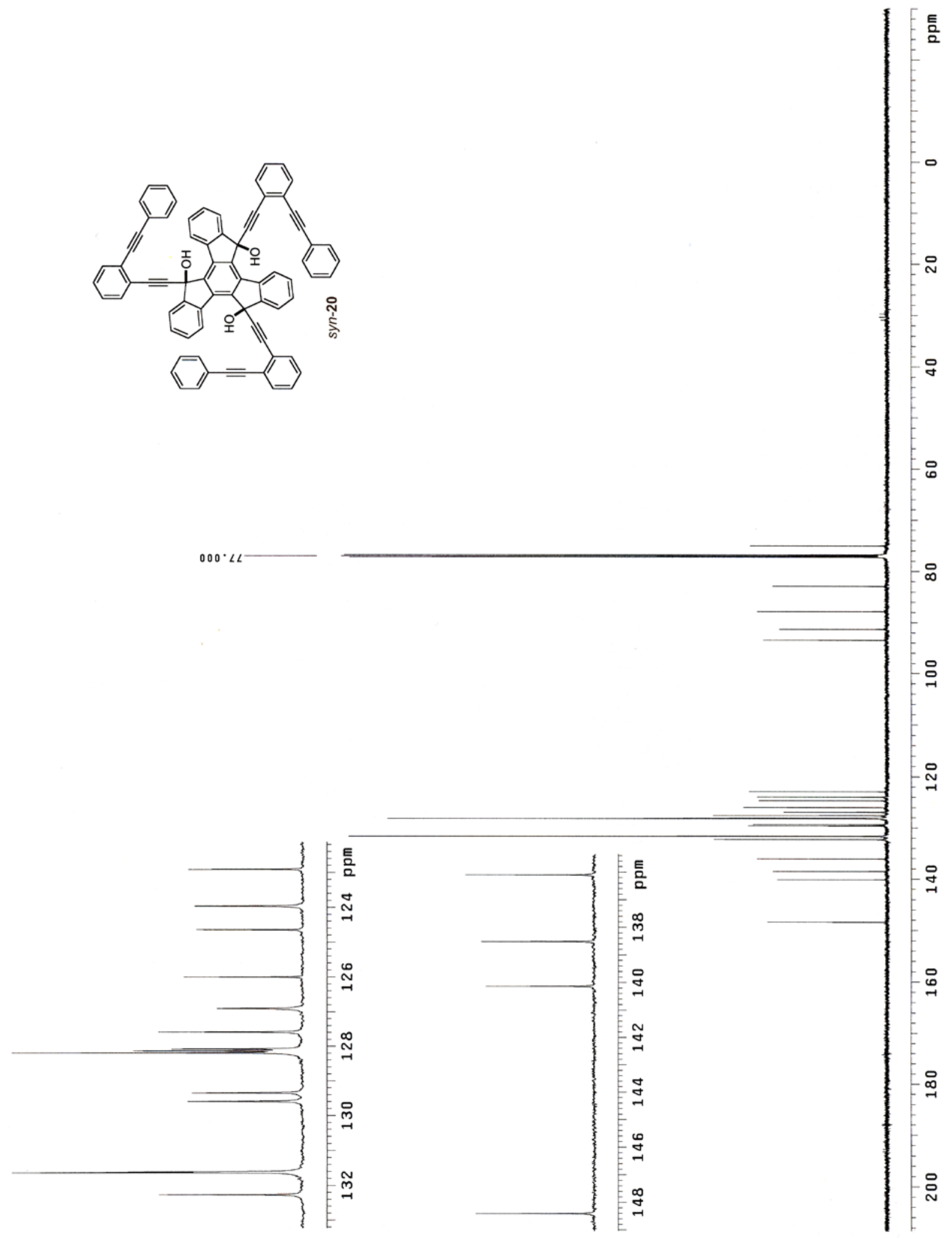




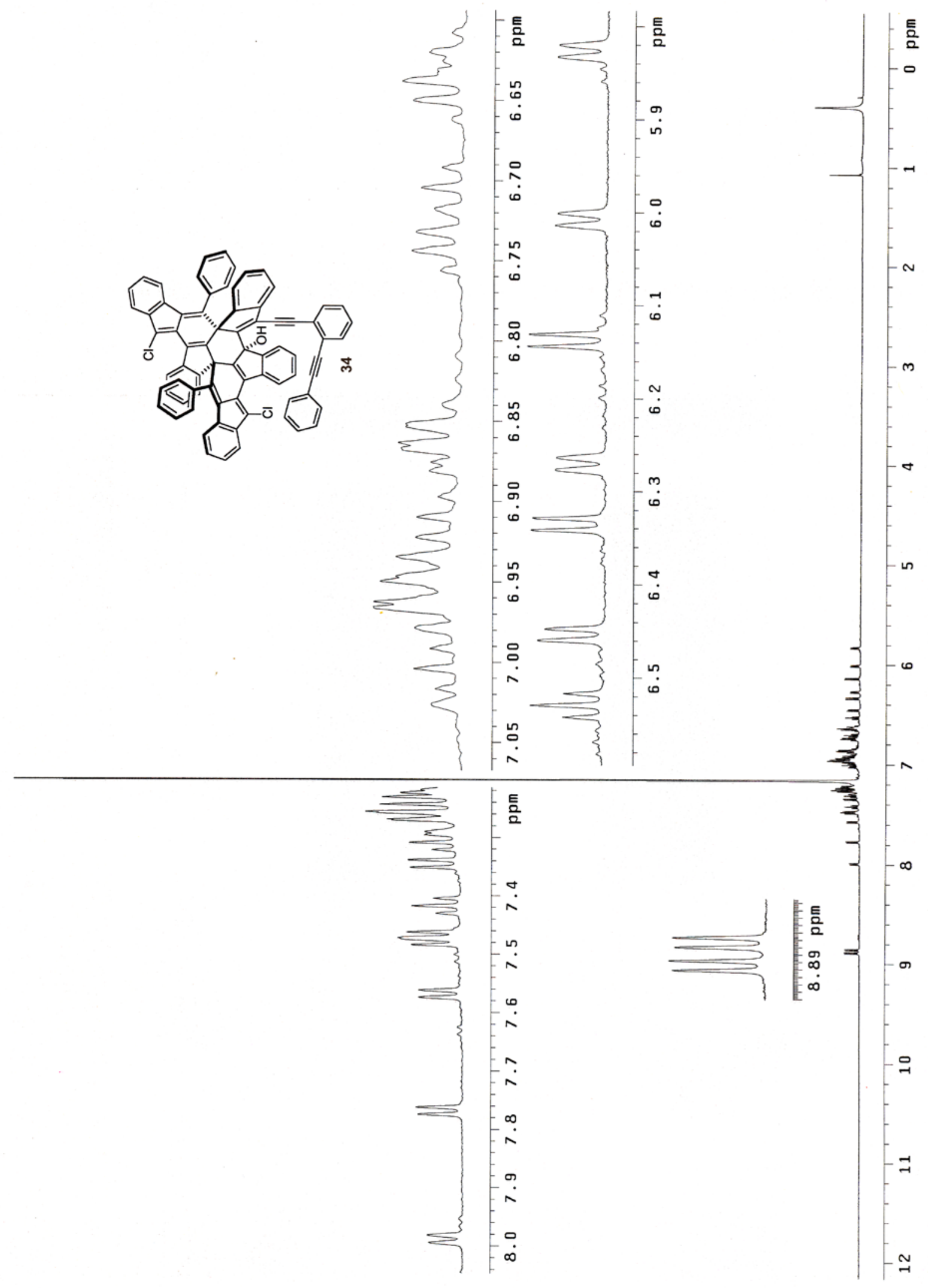




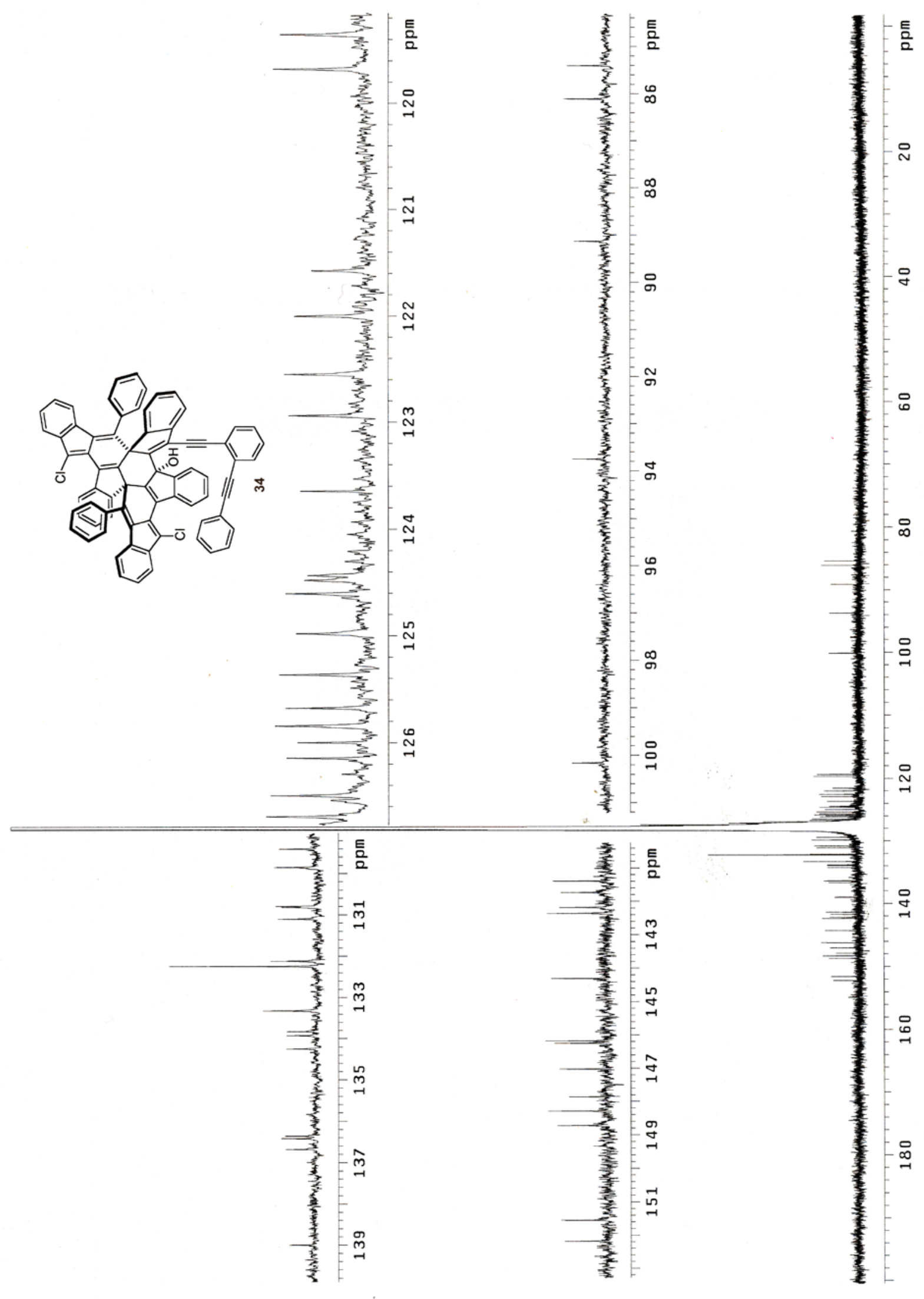




\section{D TOCSY Spectrum of 34 in $\mathrm{C}_{6} \mathrm{D}_{6}$}
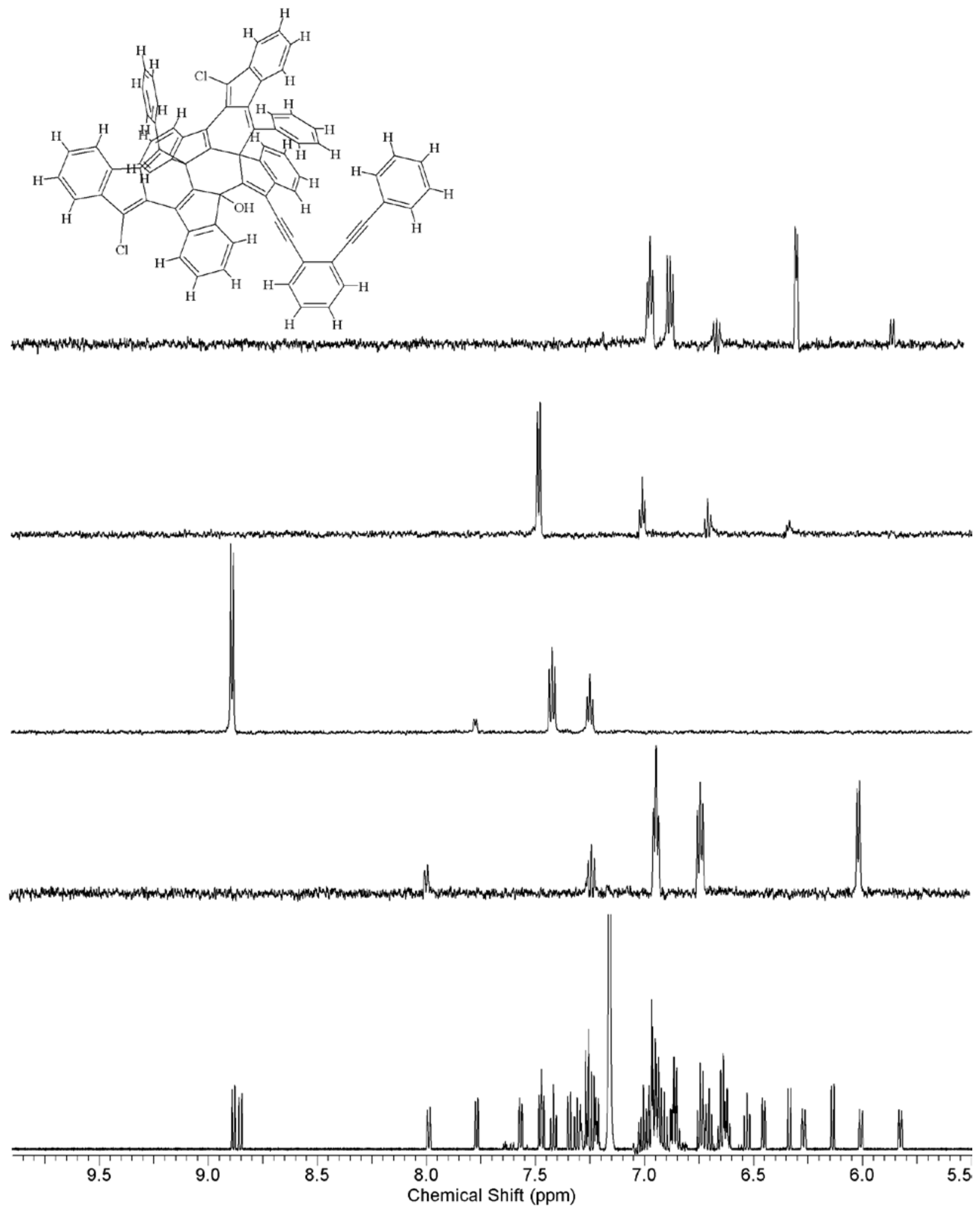


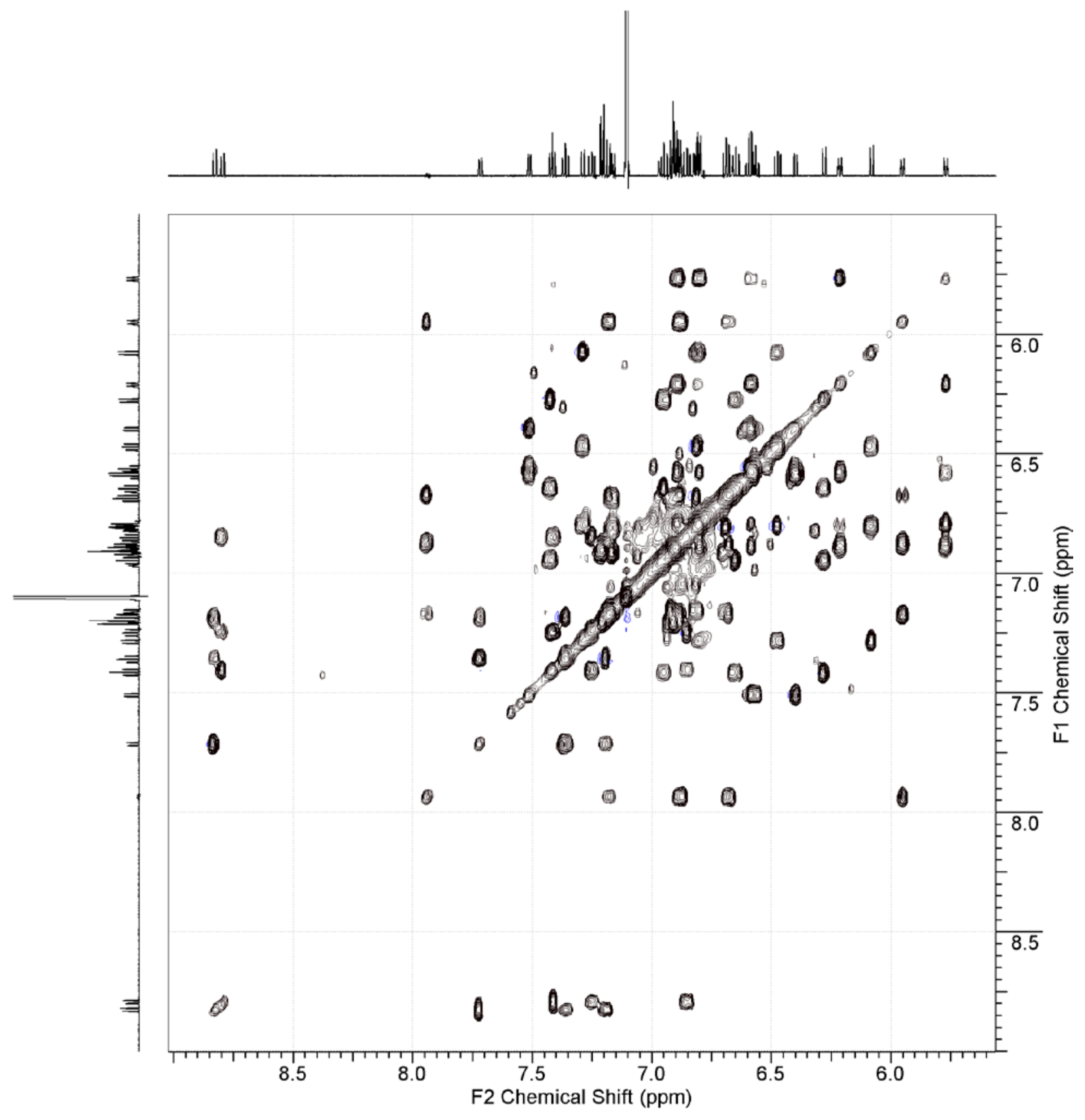




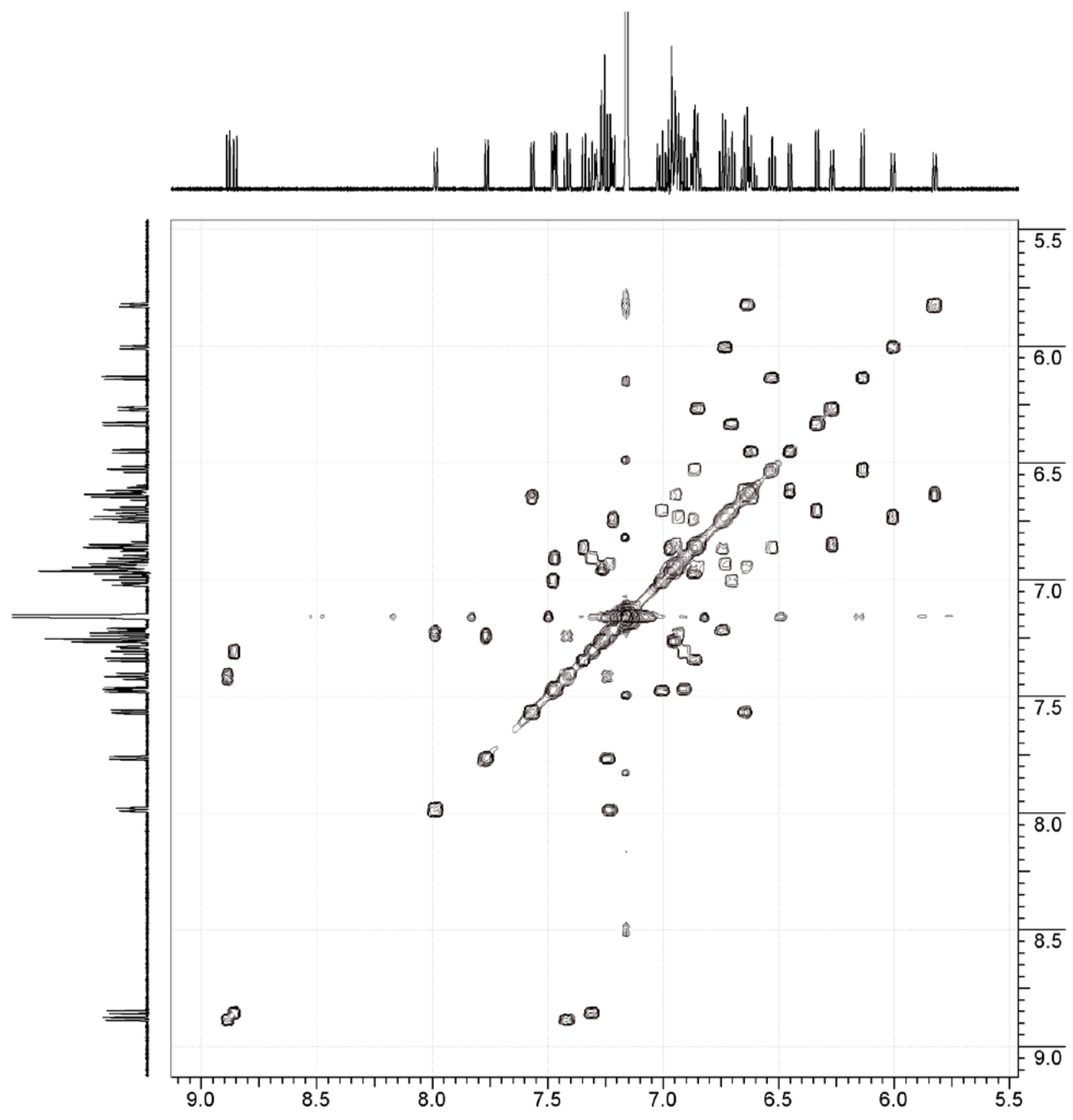


gCosY Spectrum of 34 in $C_{6} D_{6}$ (expansion)
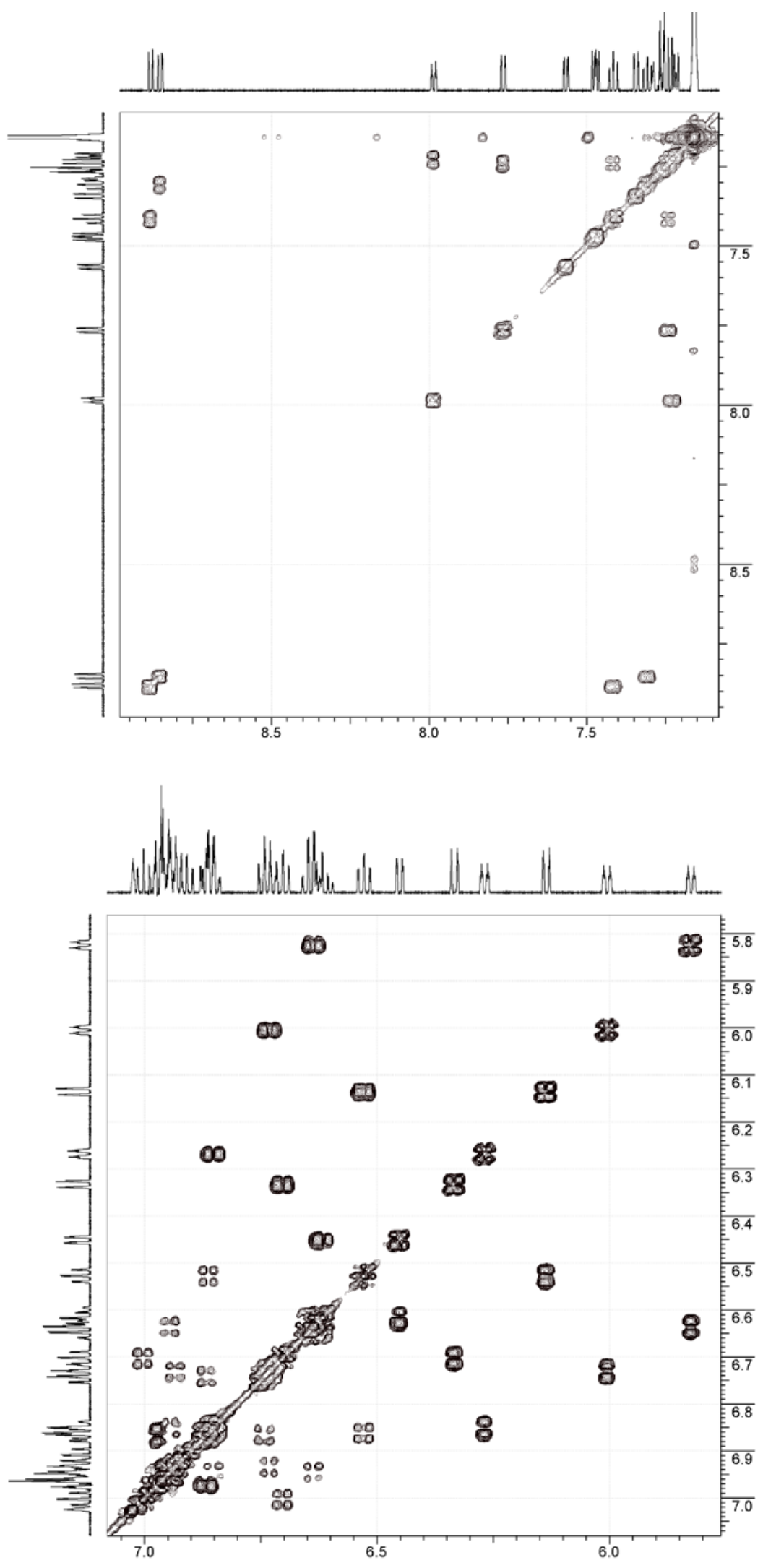


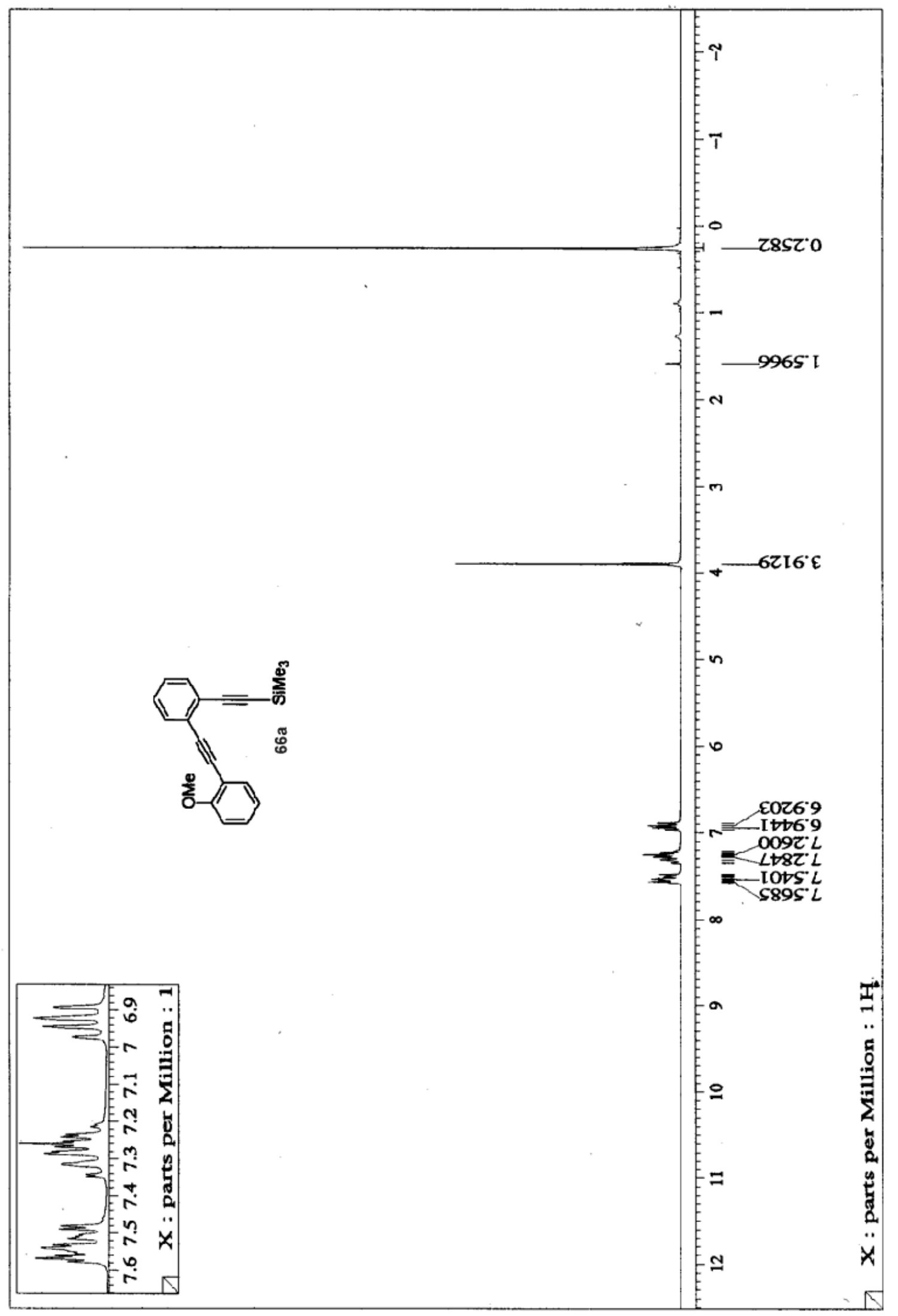




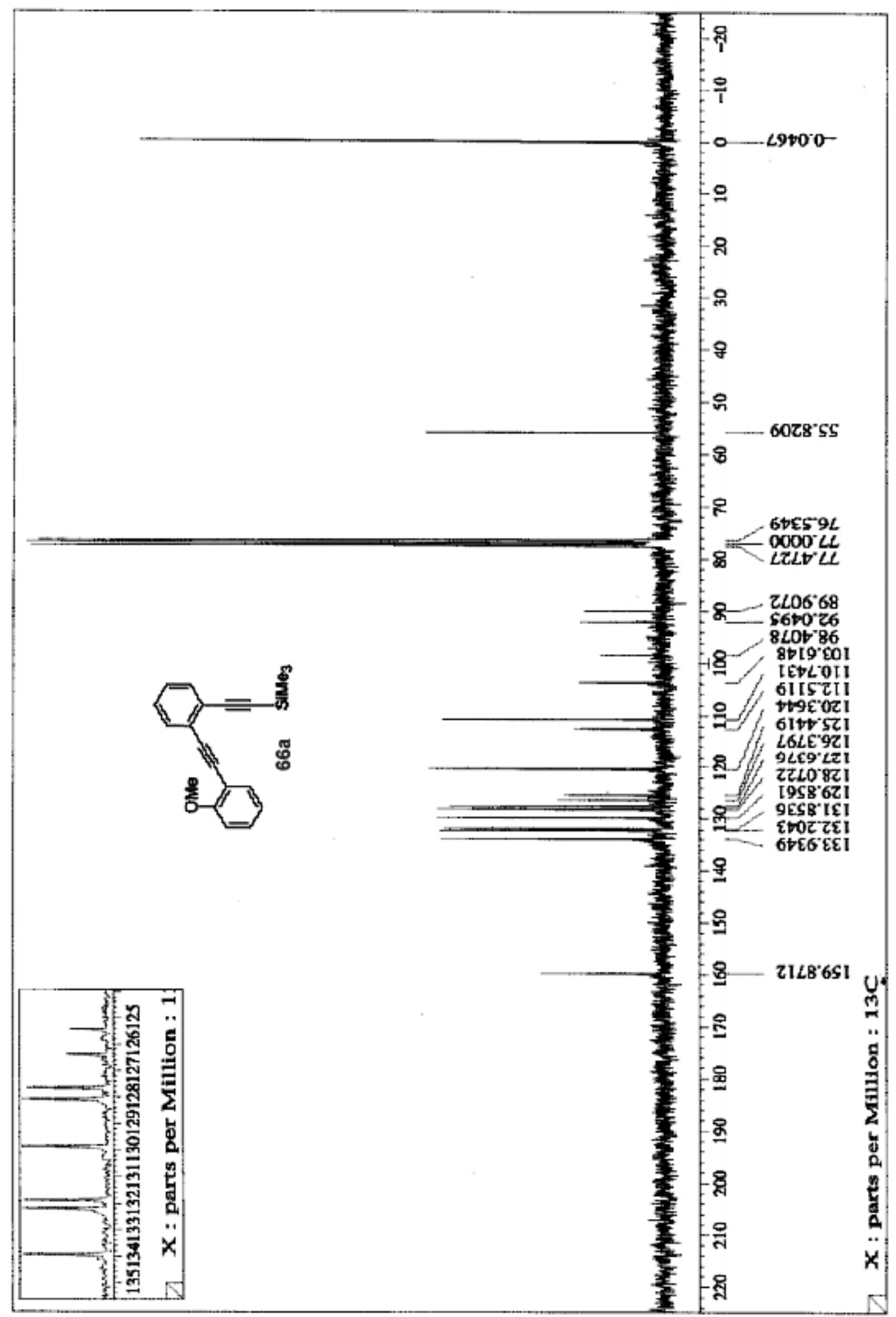




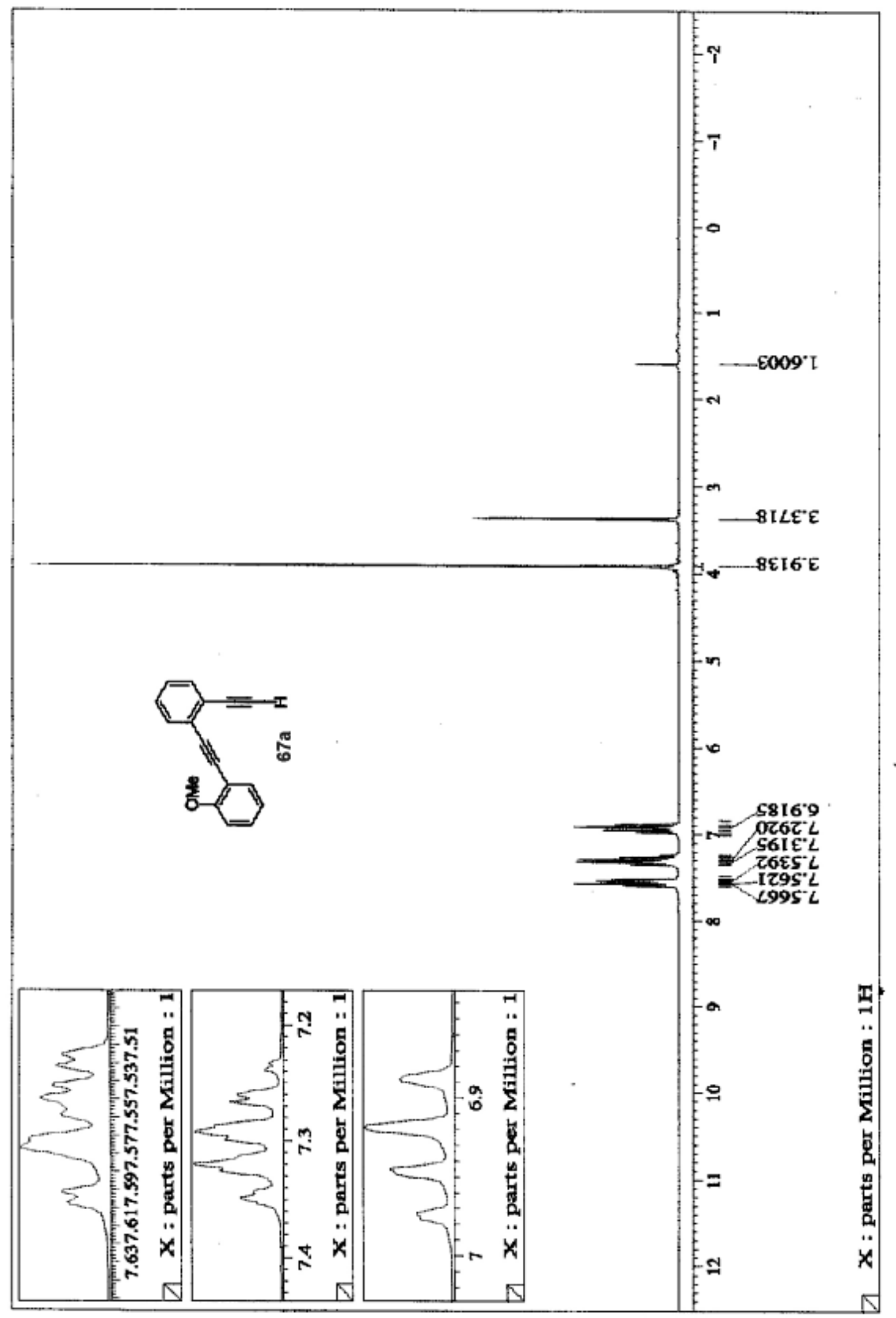




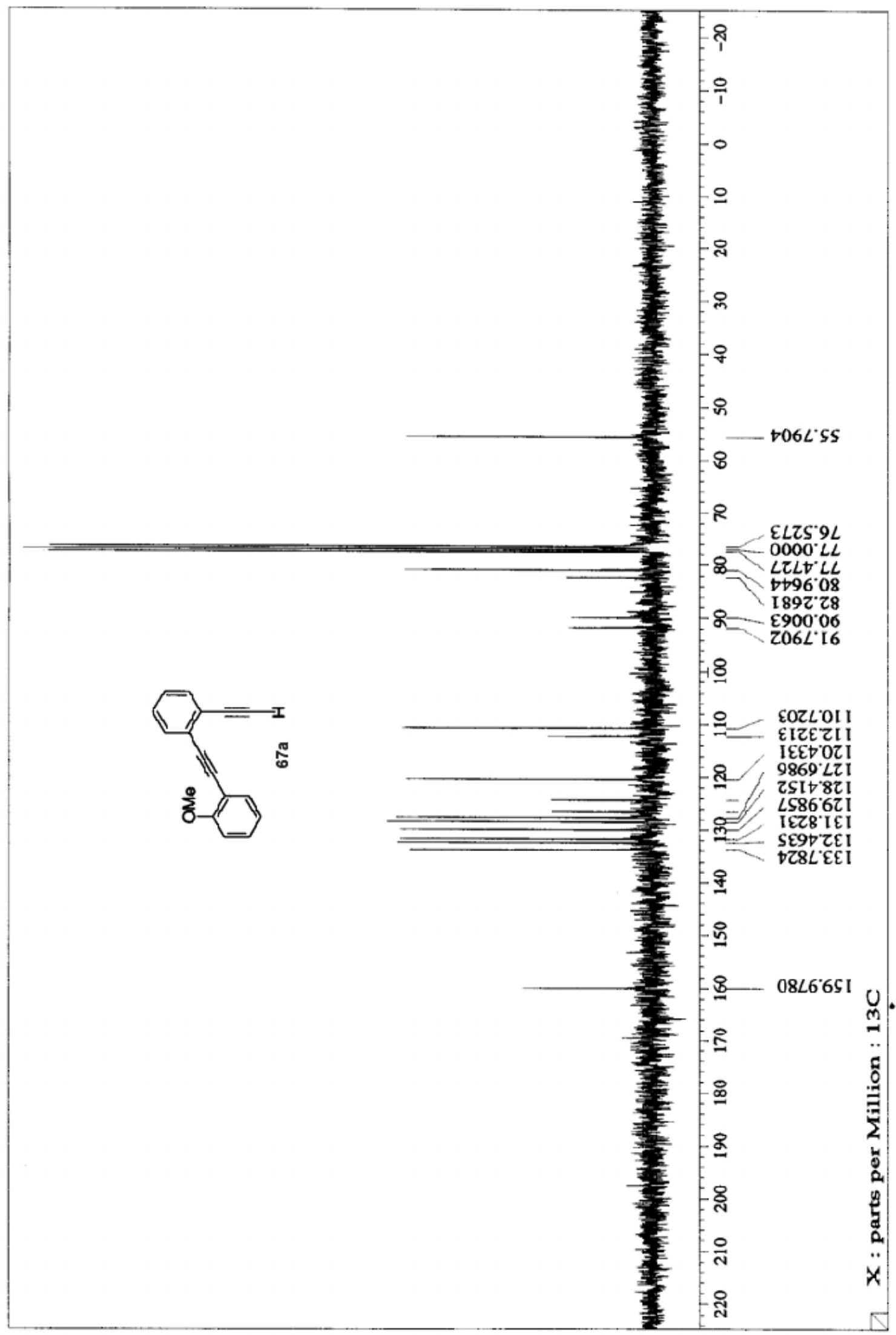




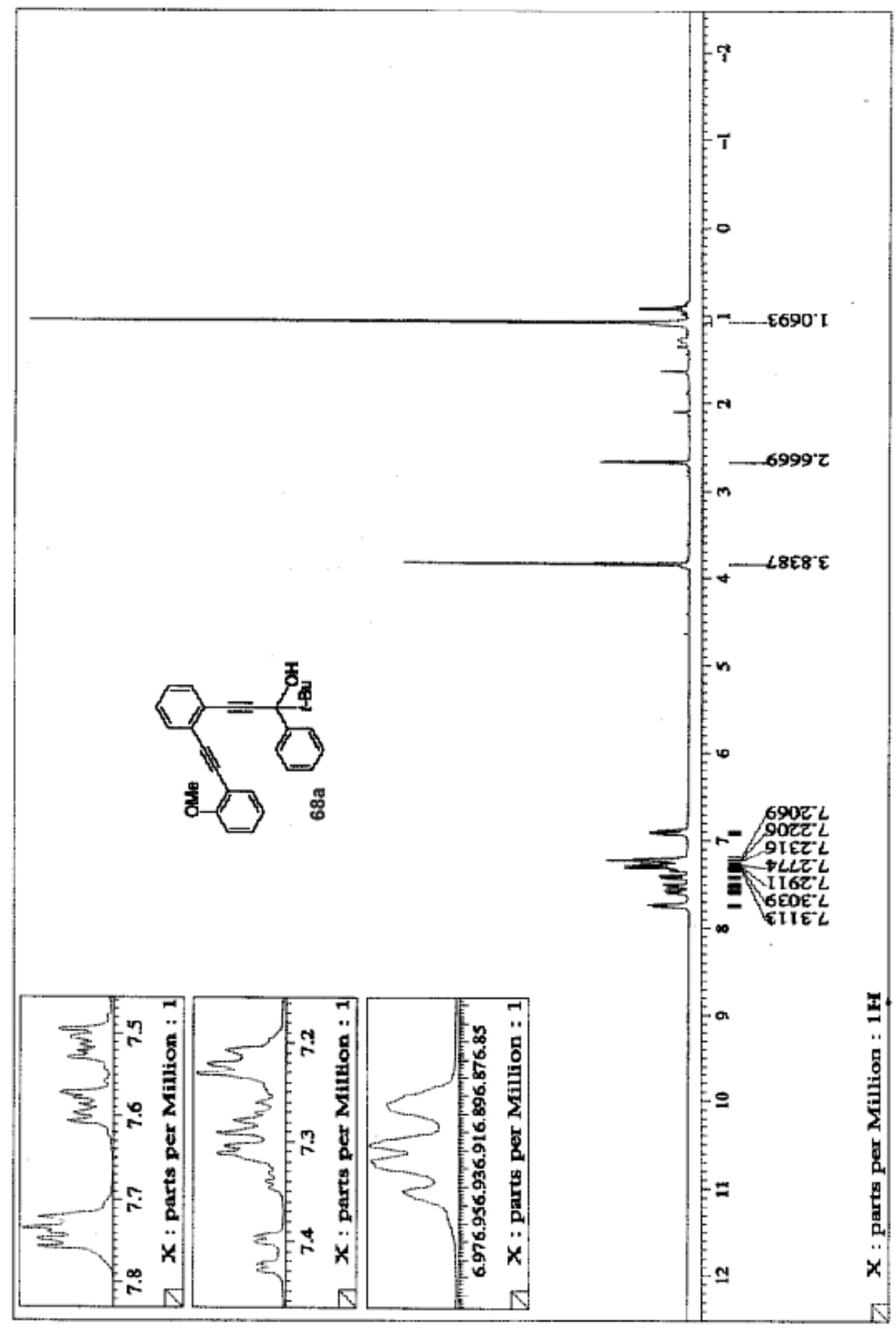




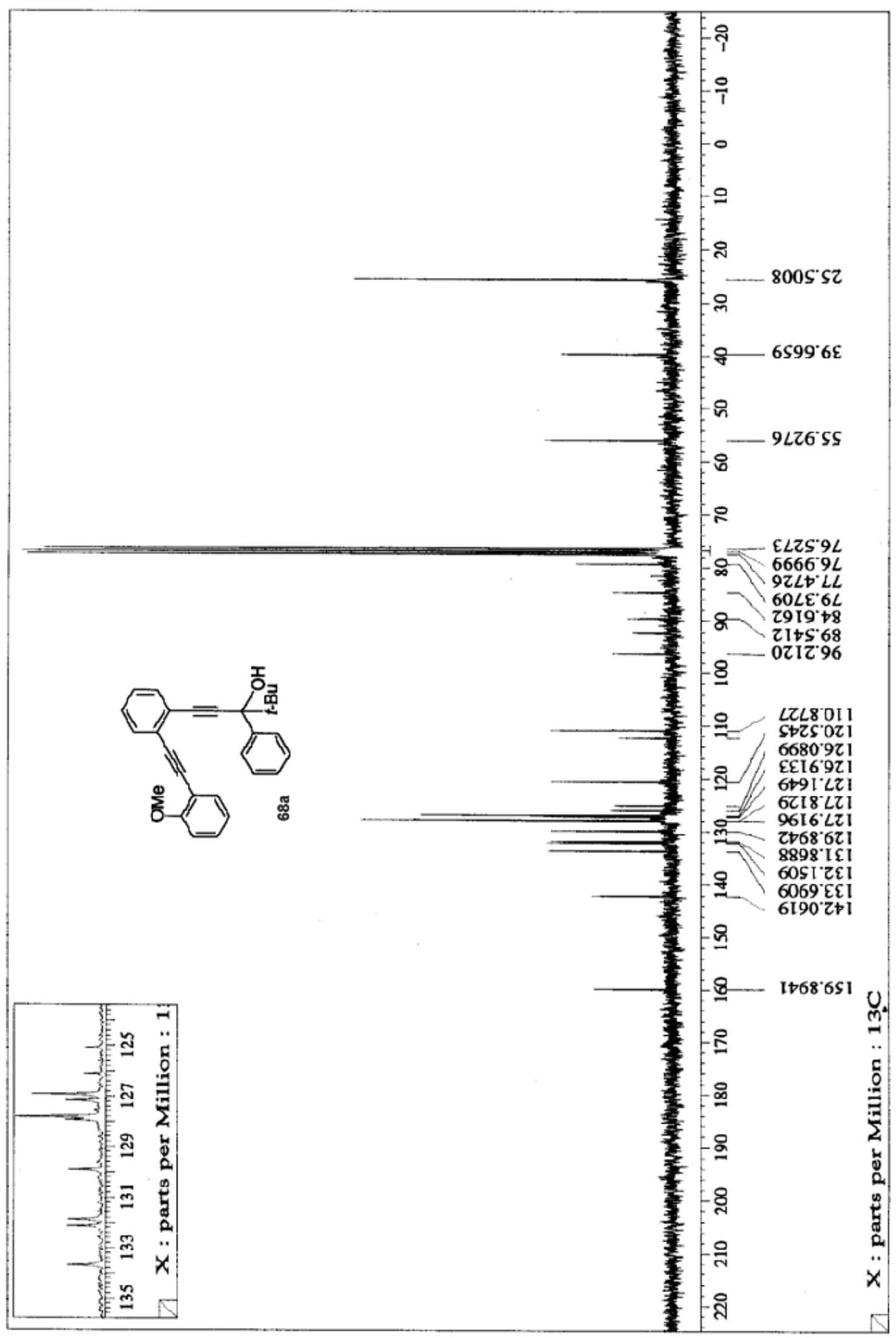




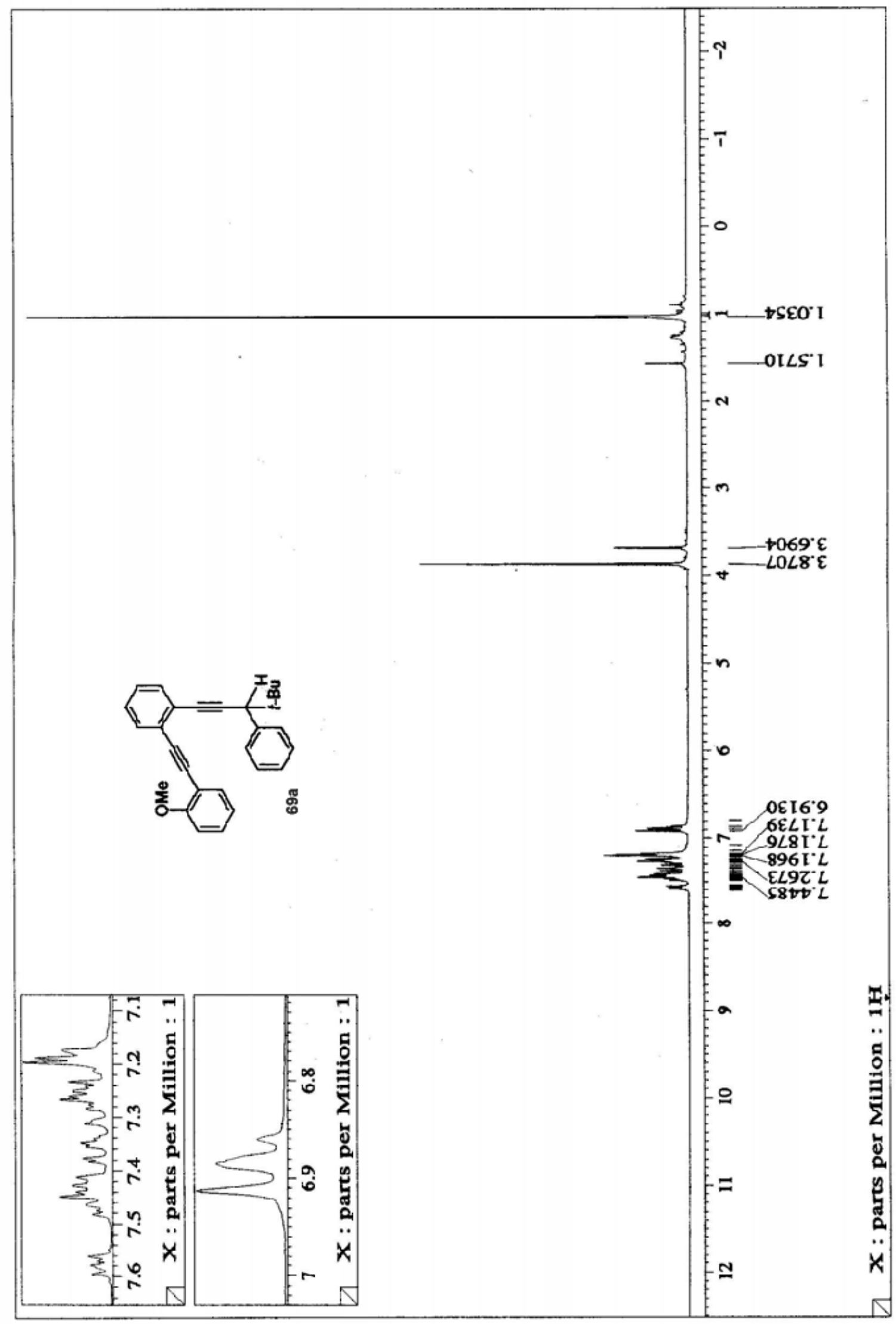




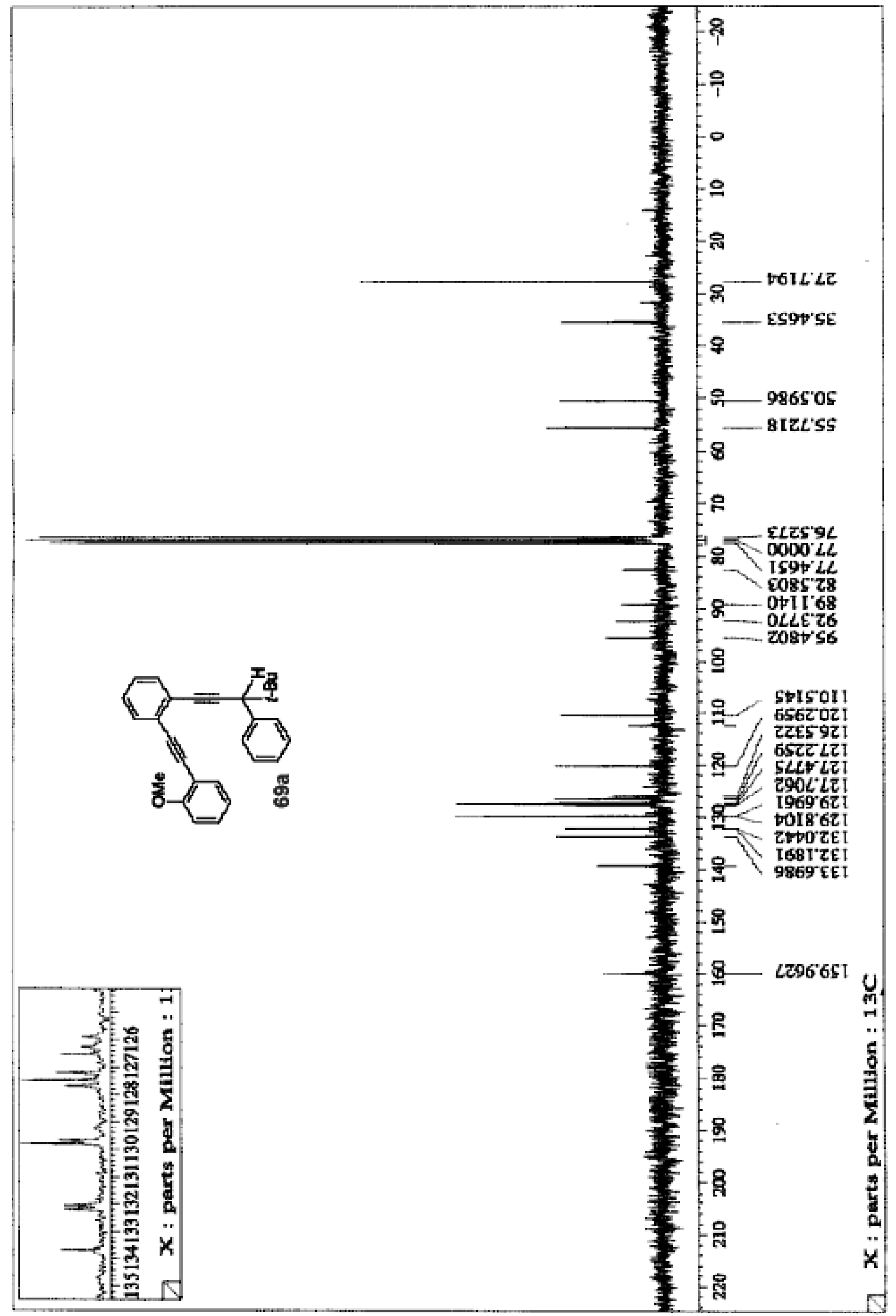




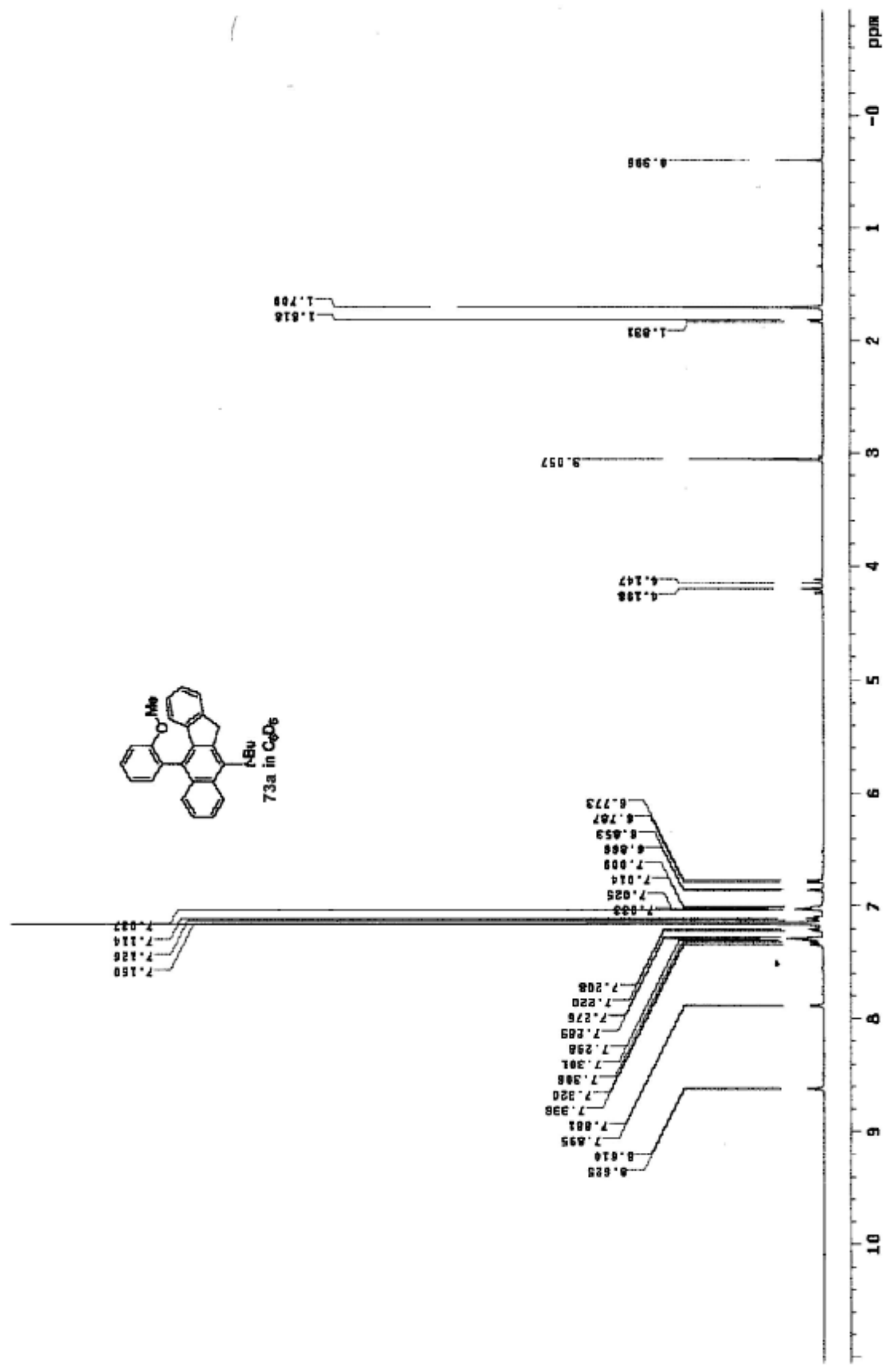




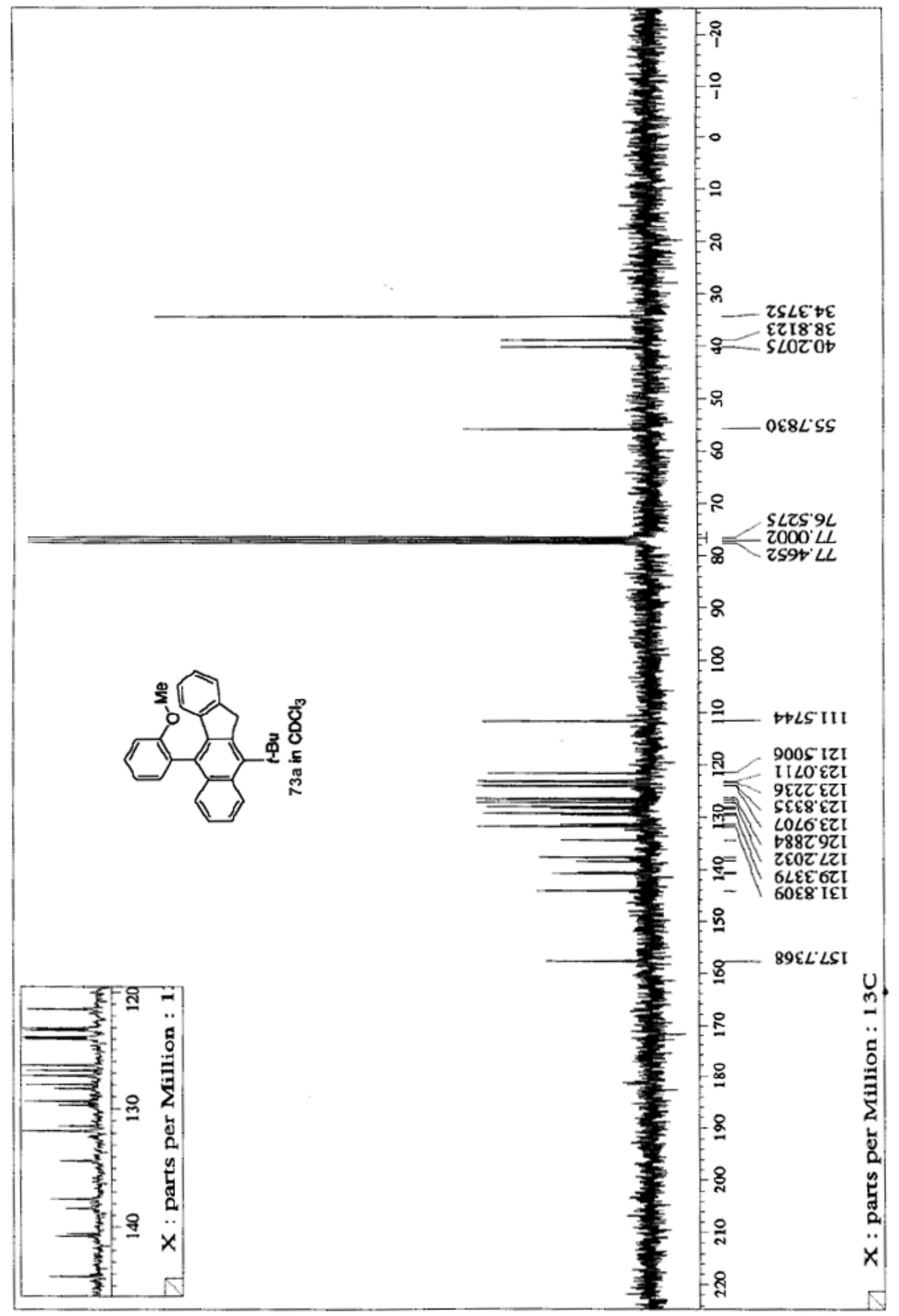




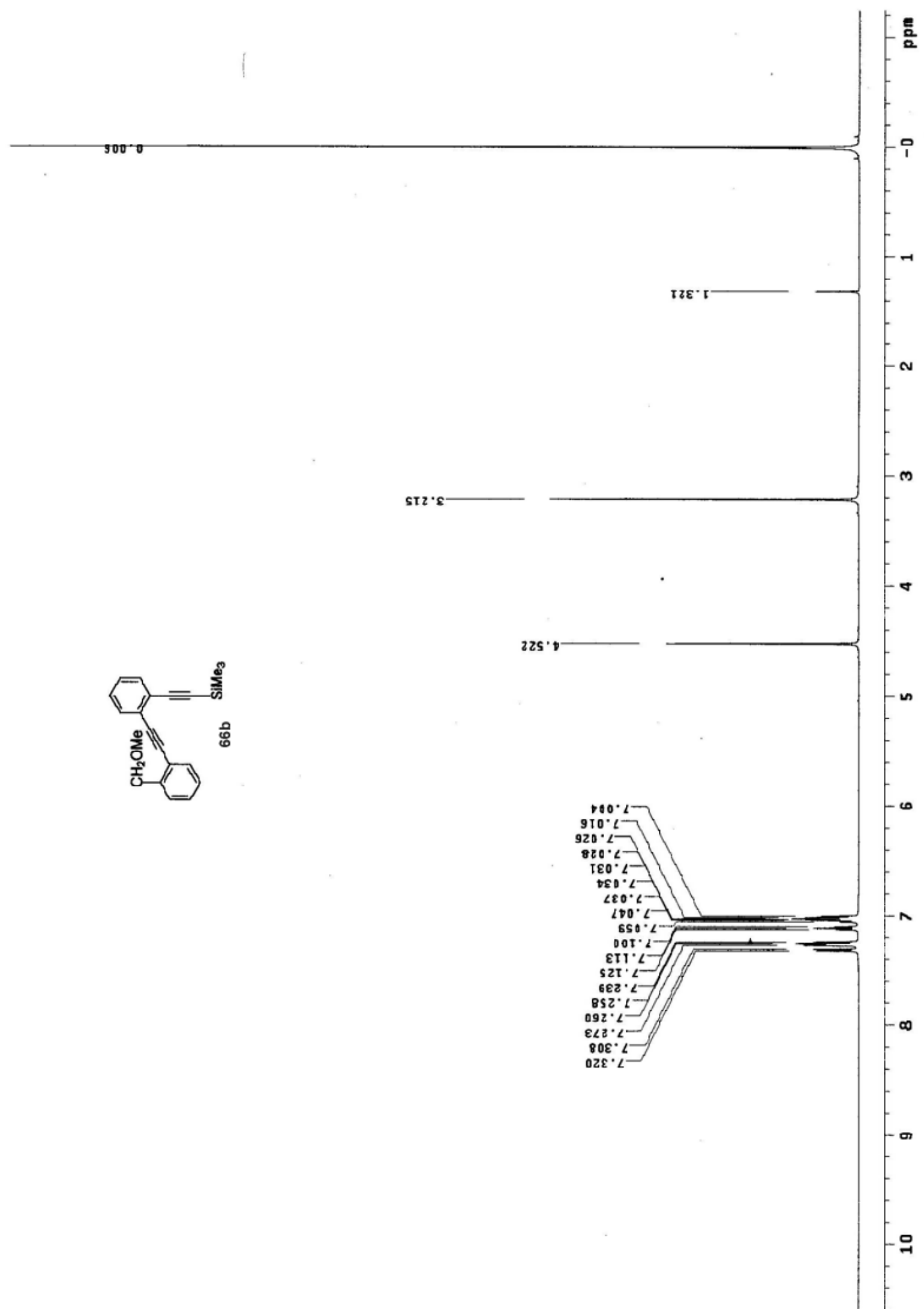




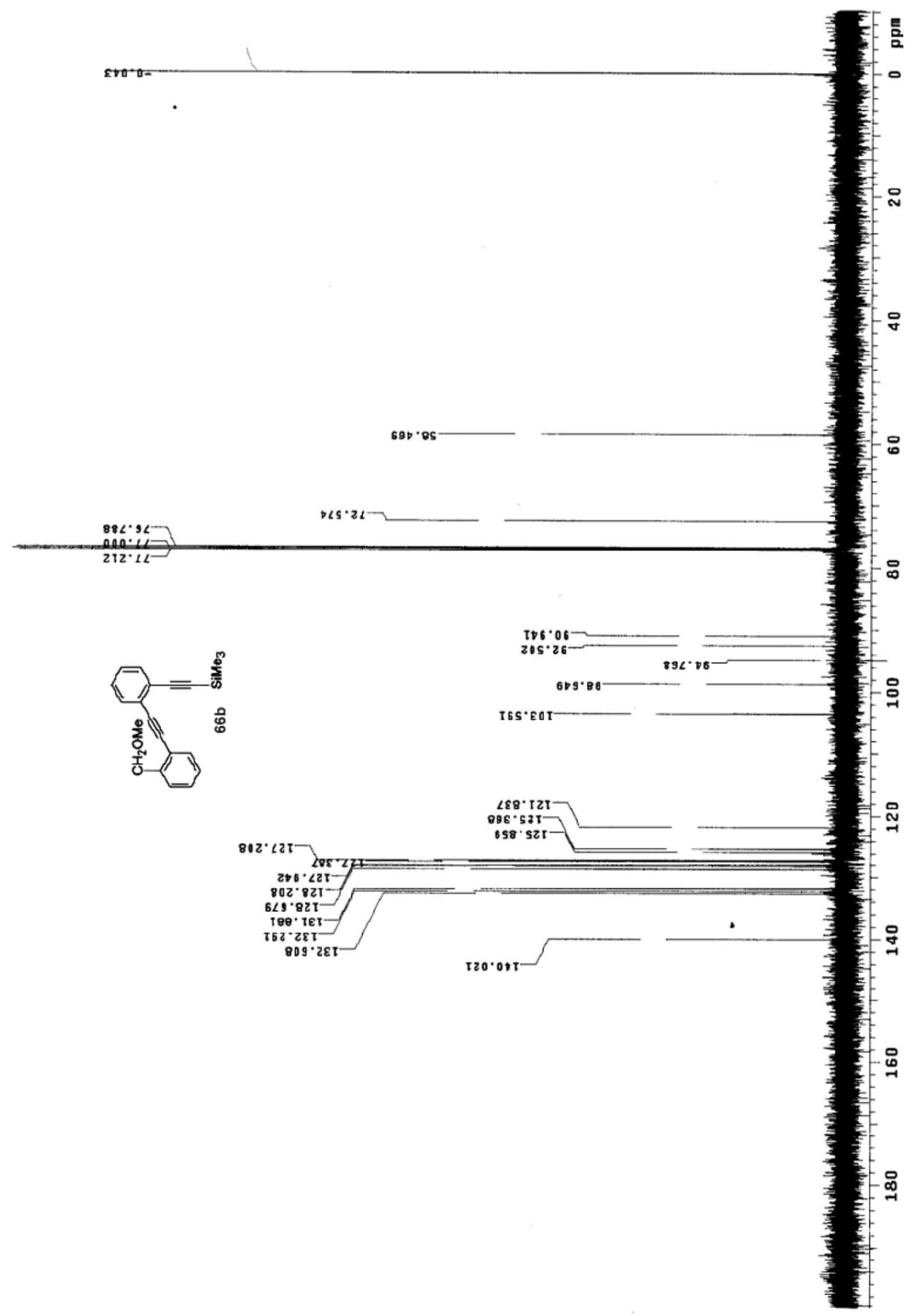




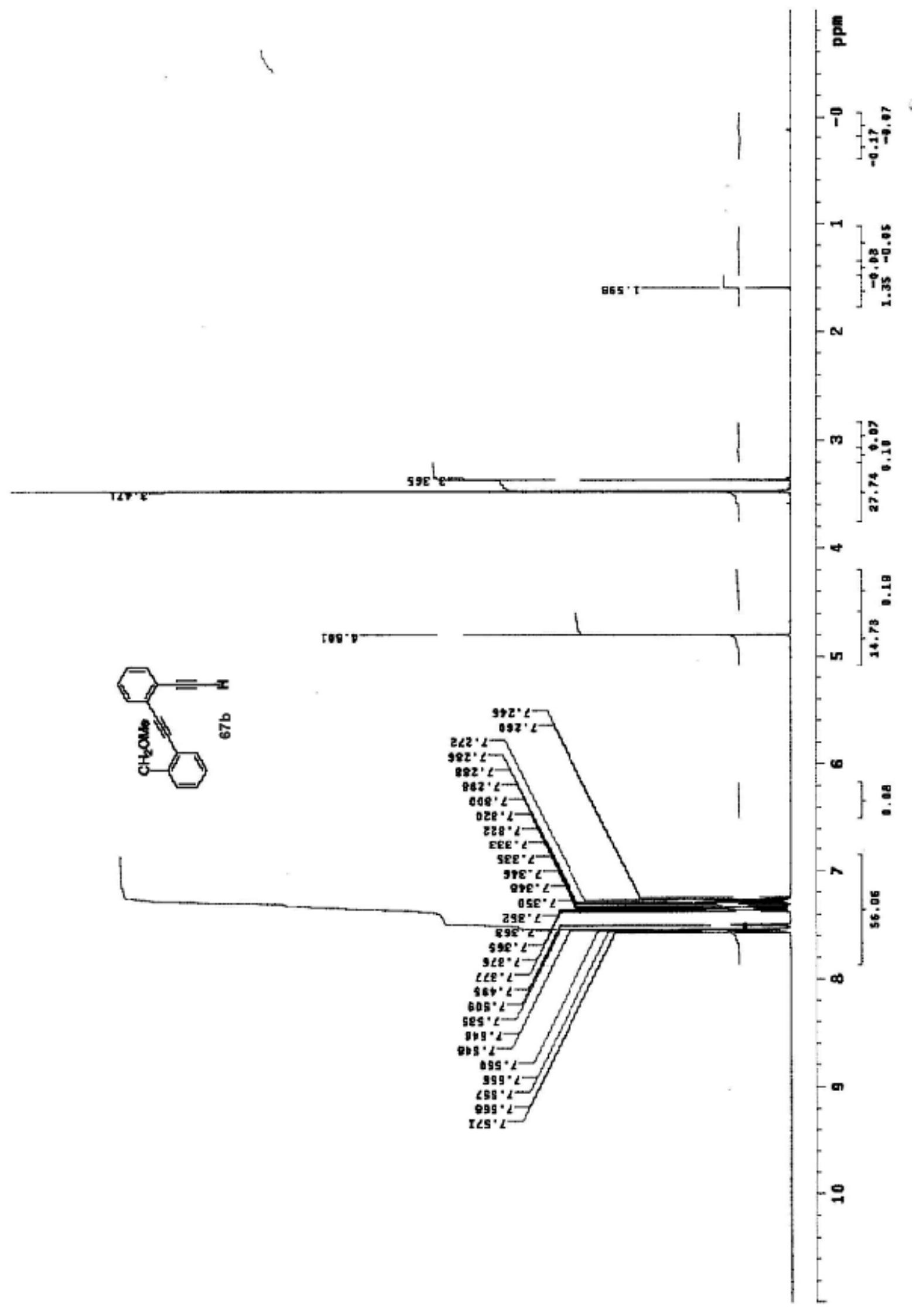




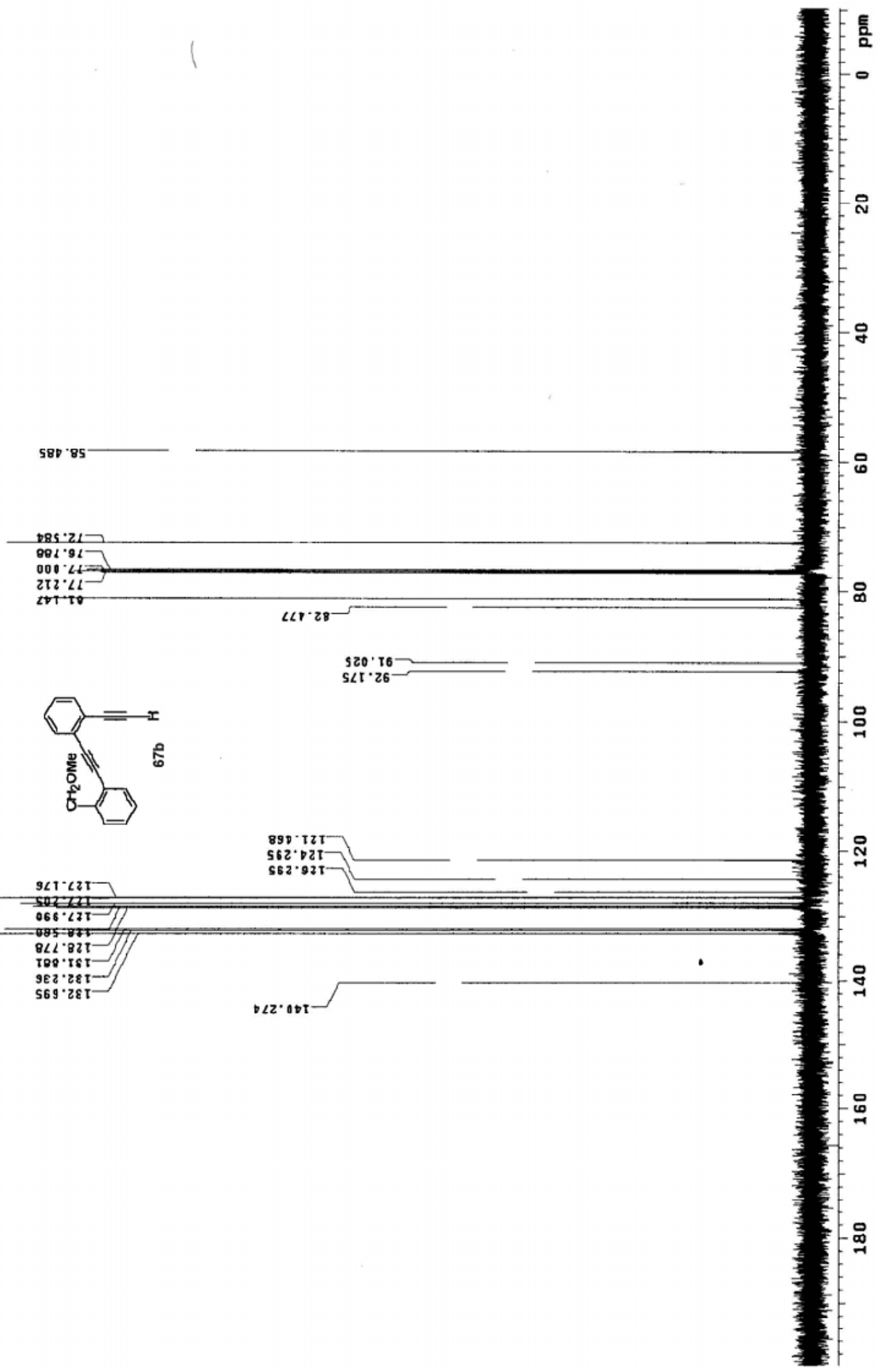




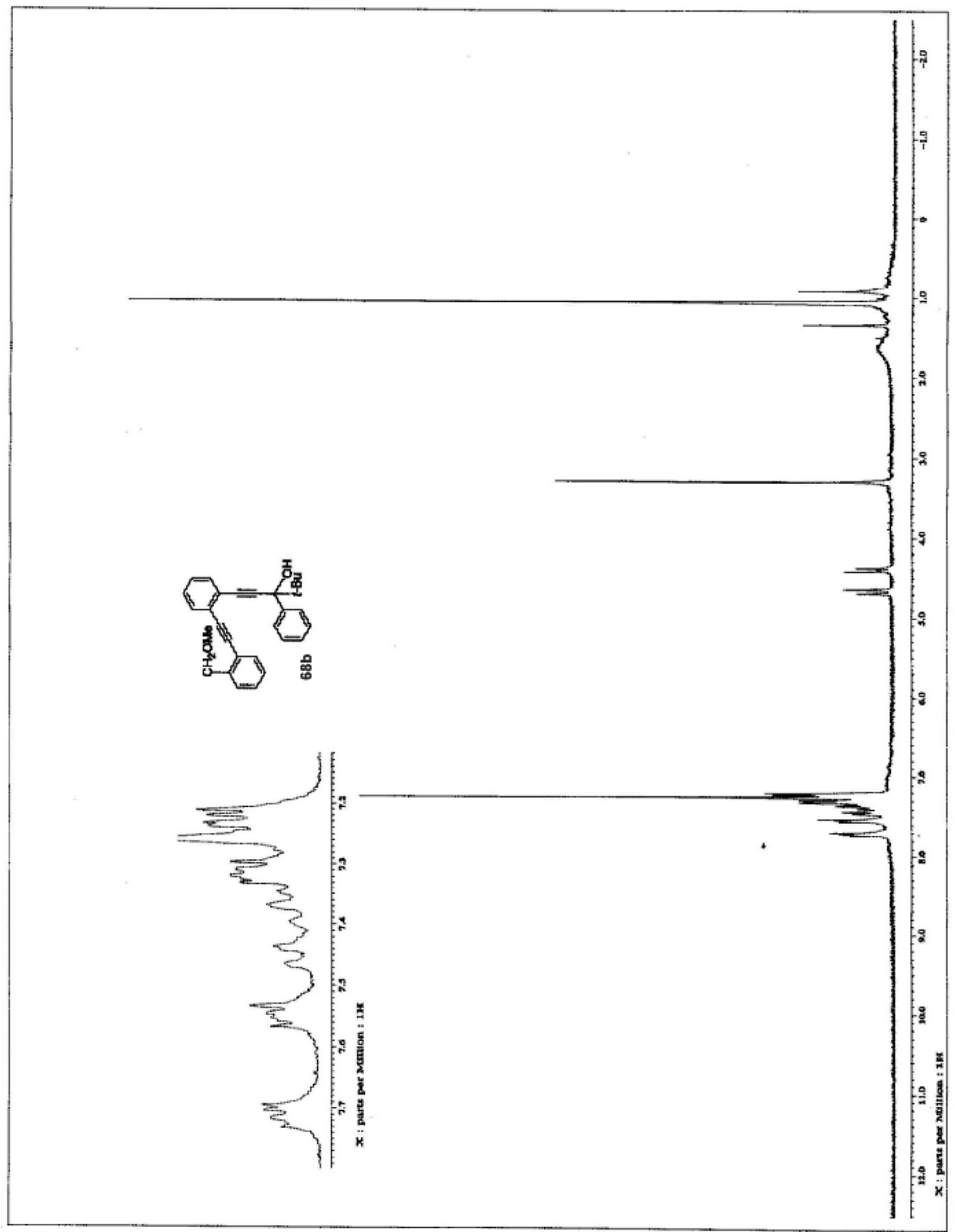




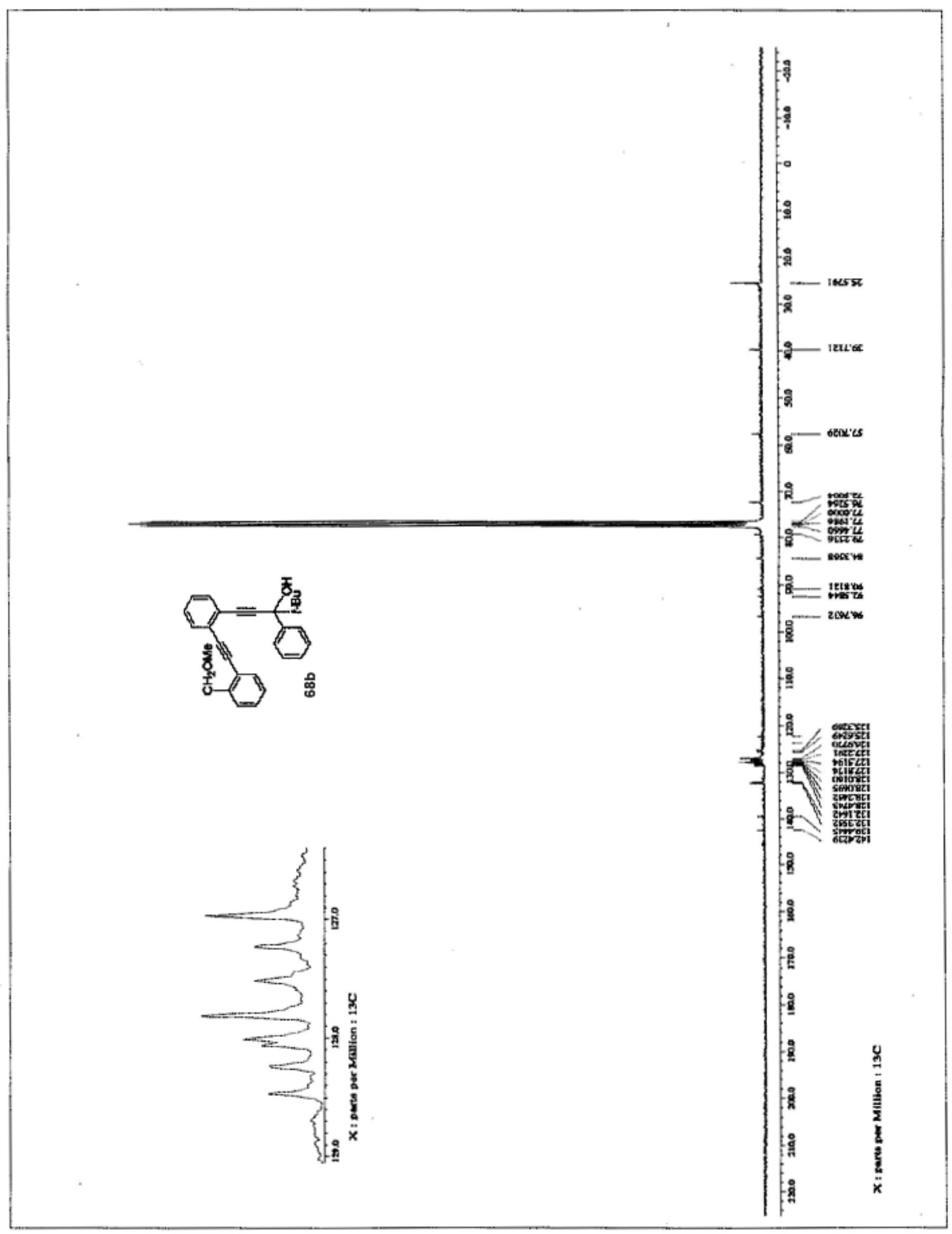




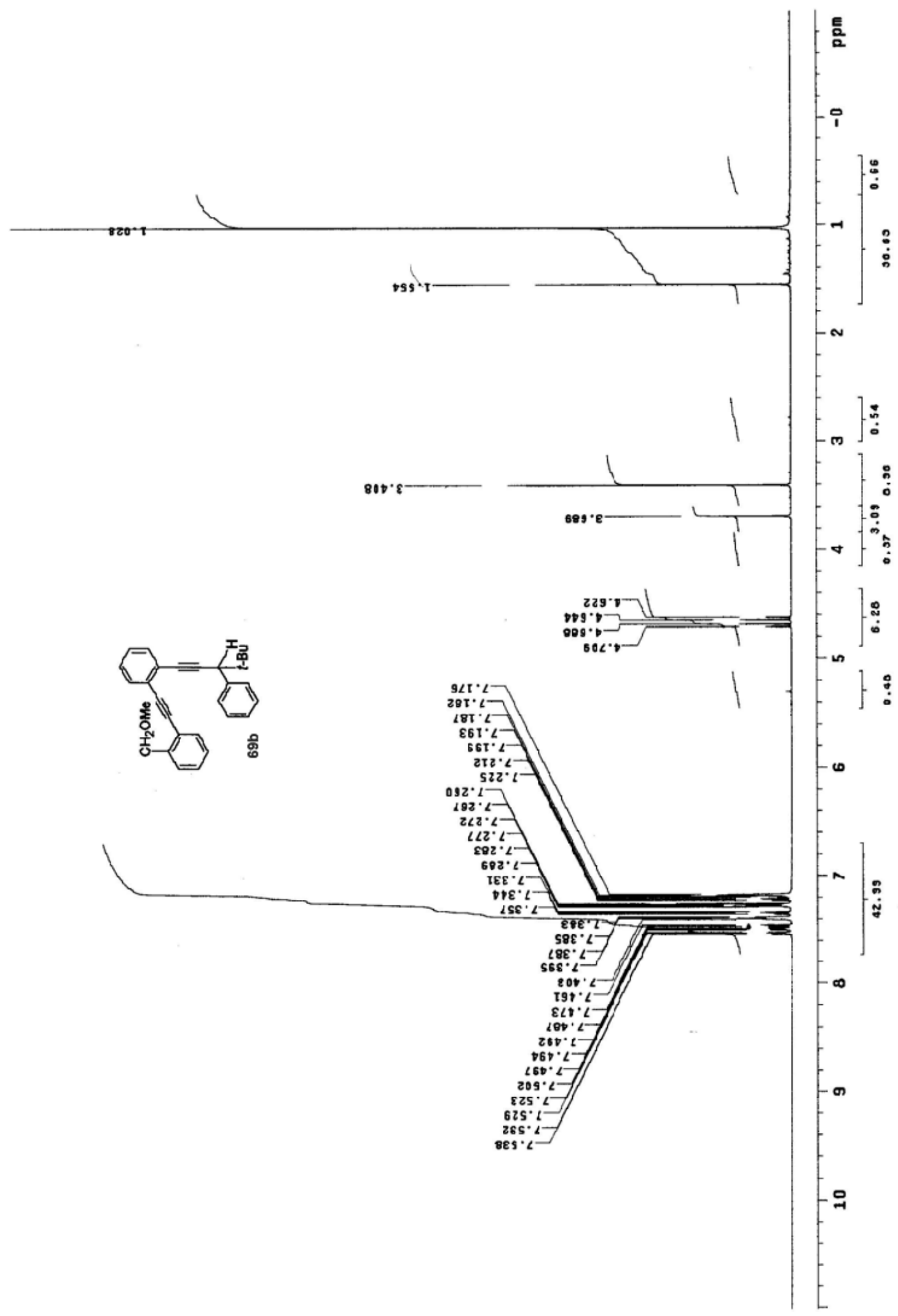




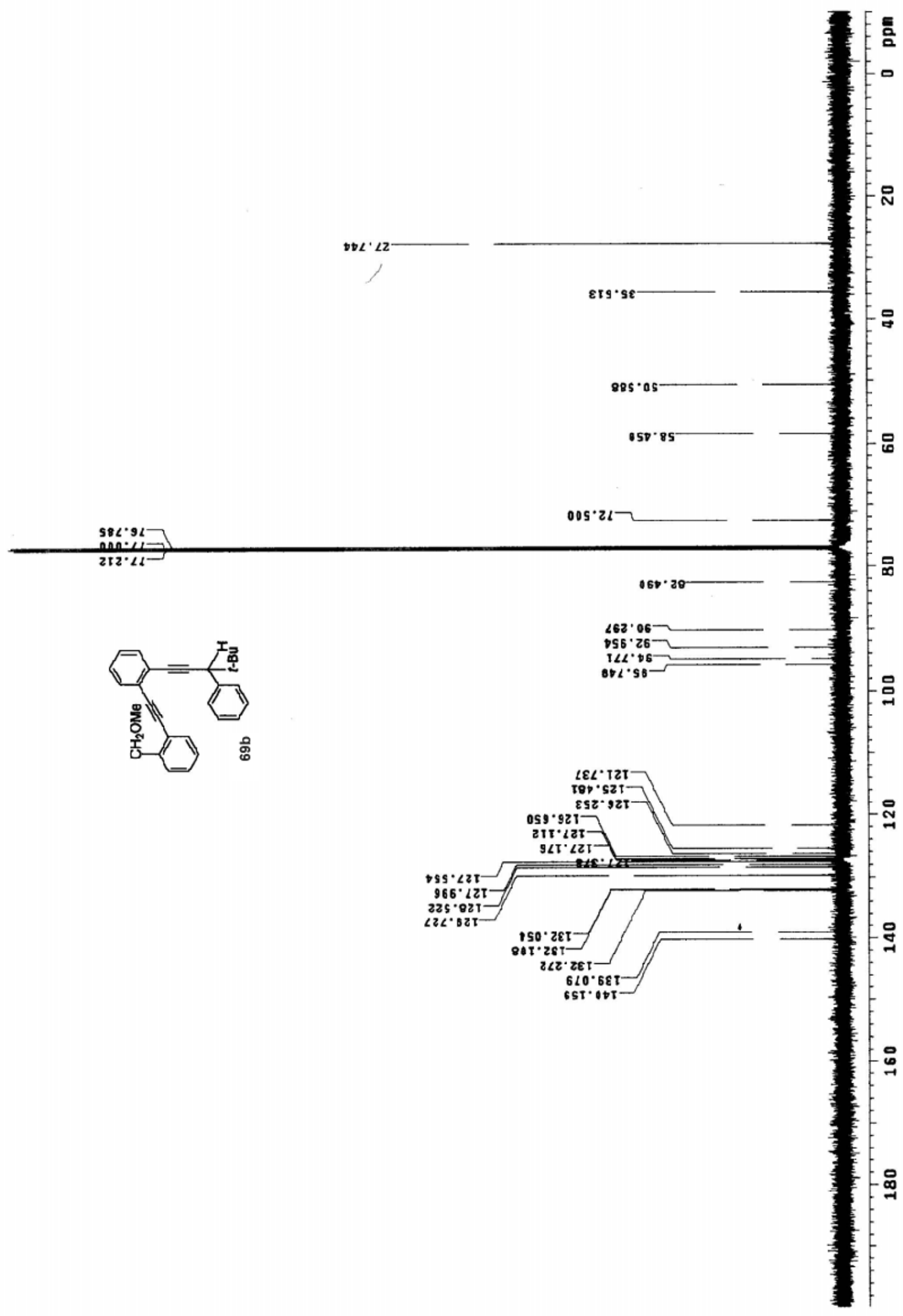




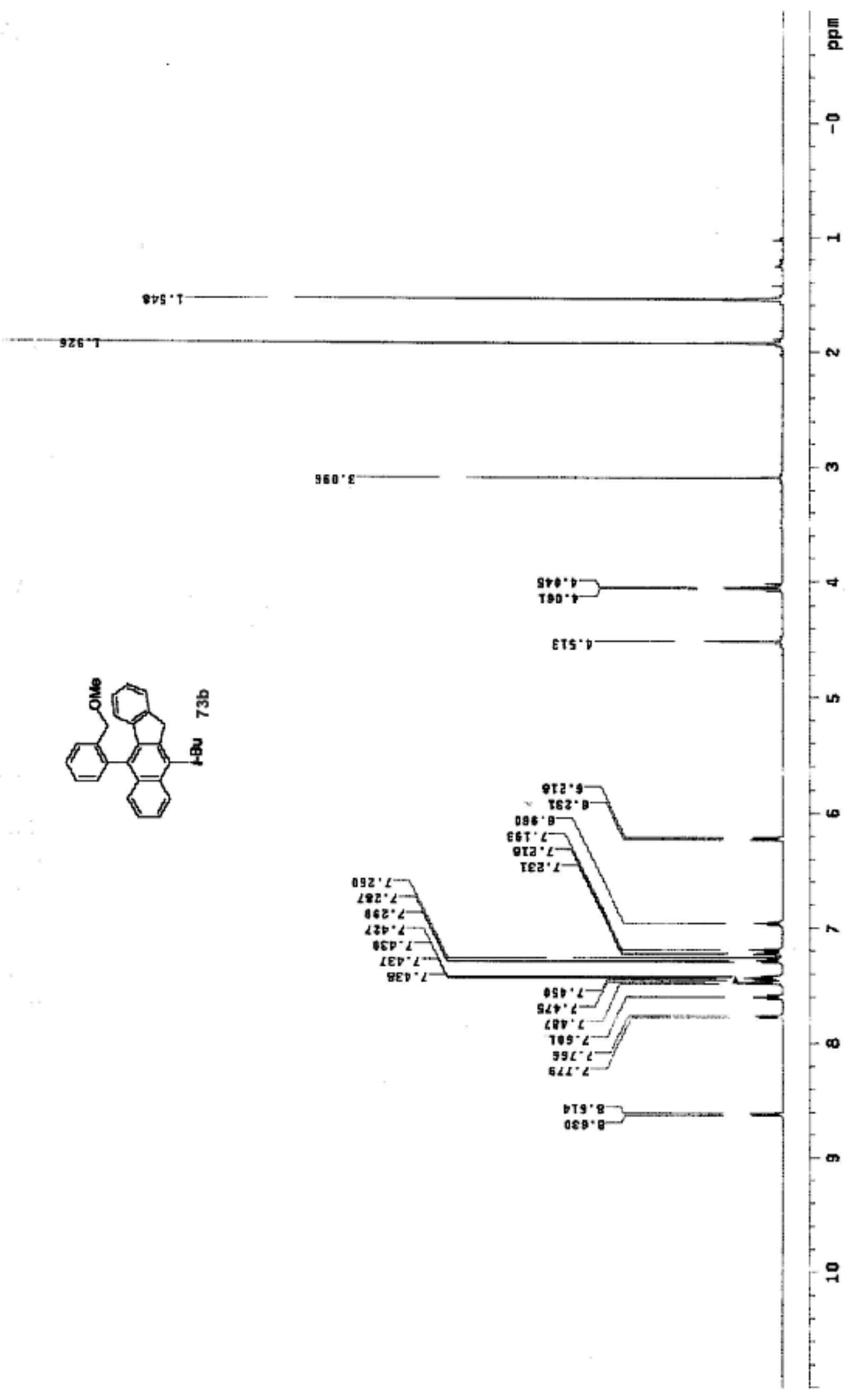




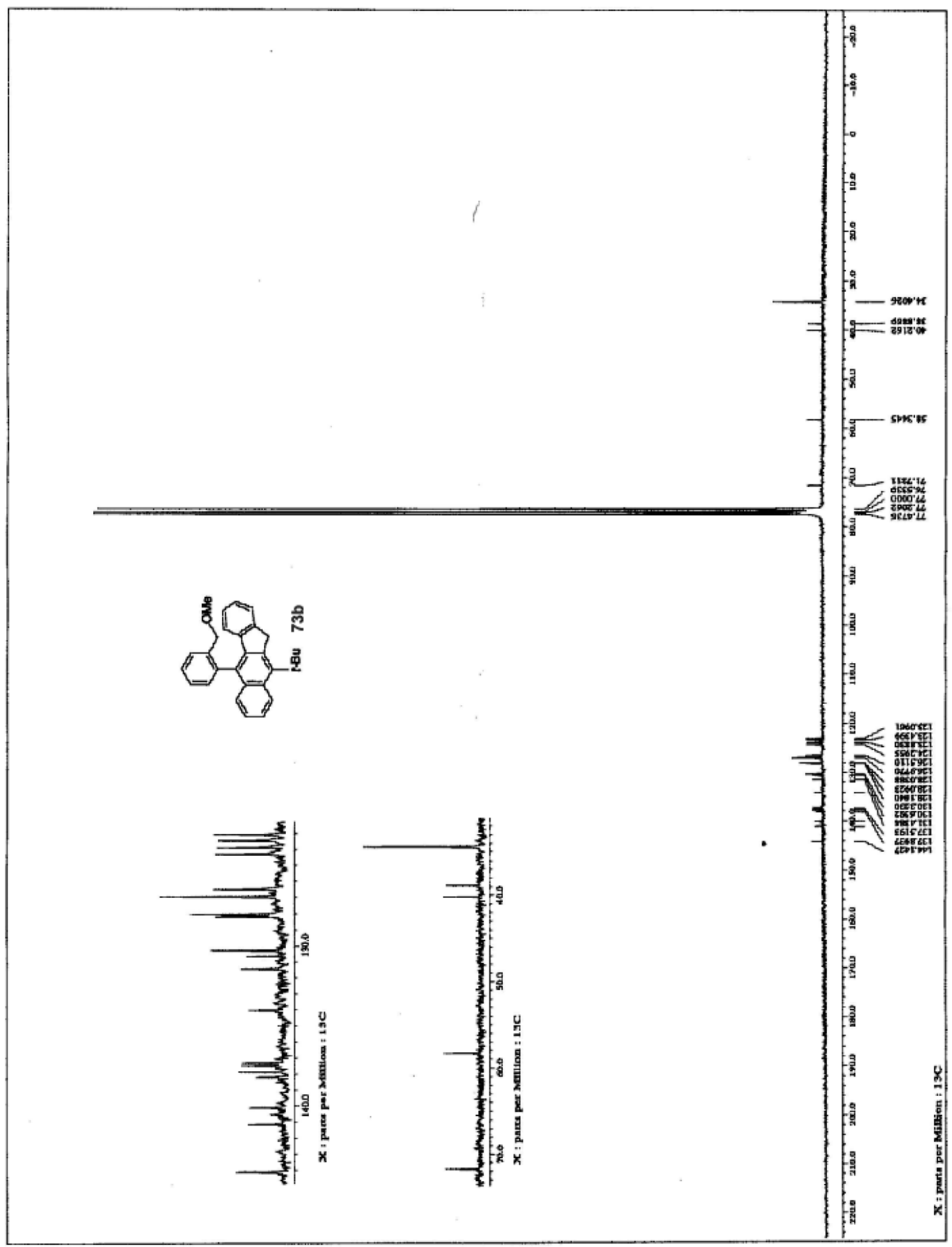




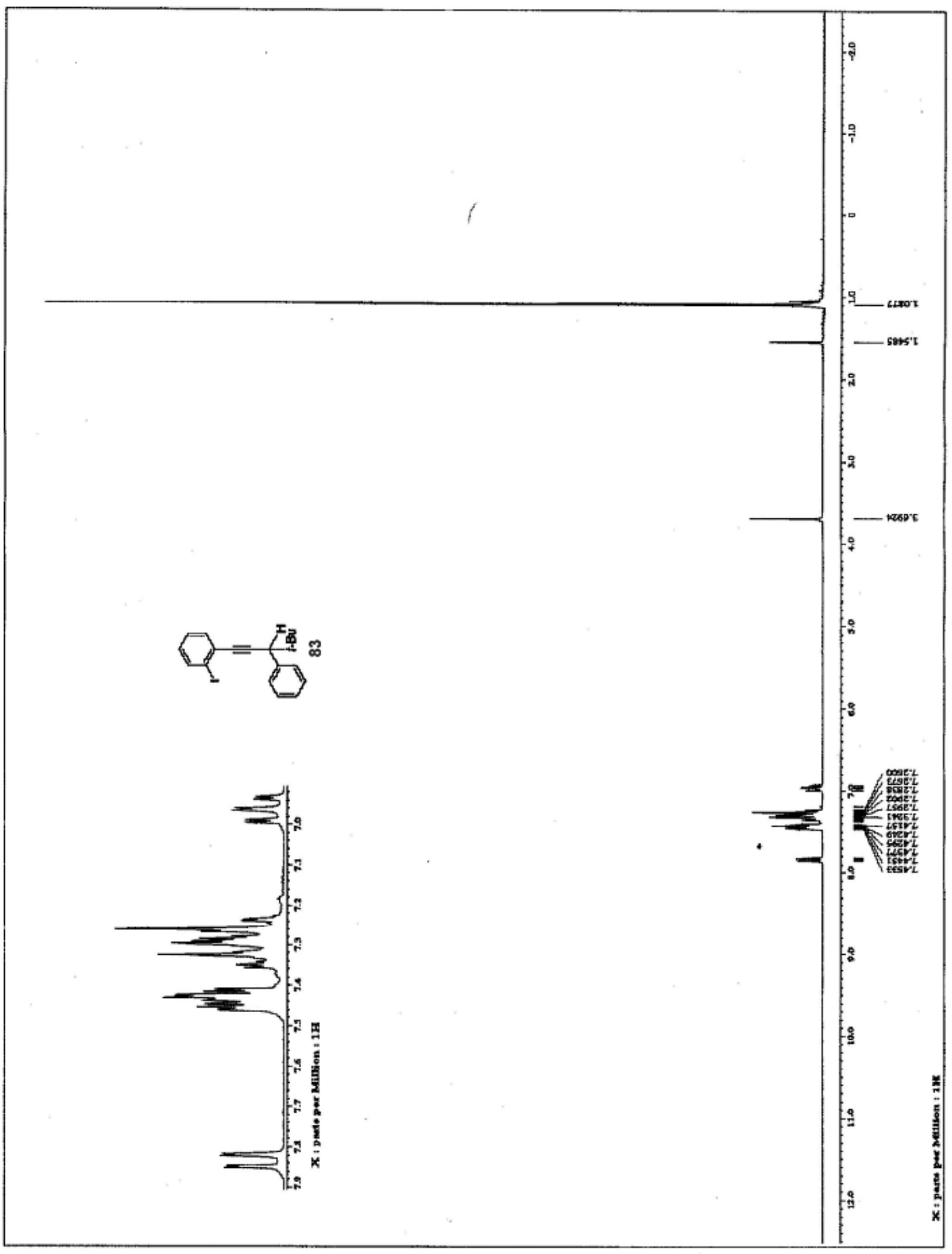




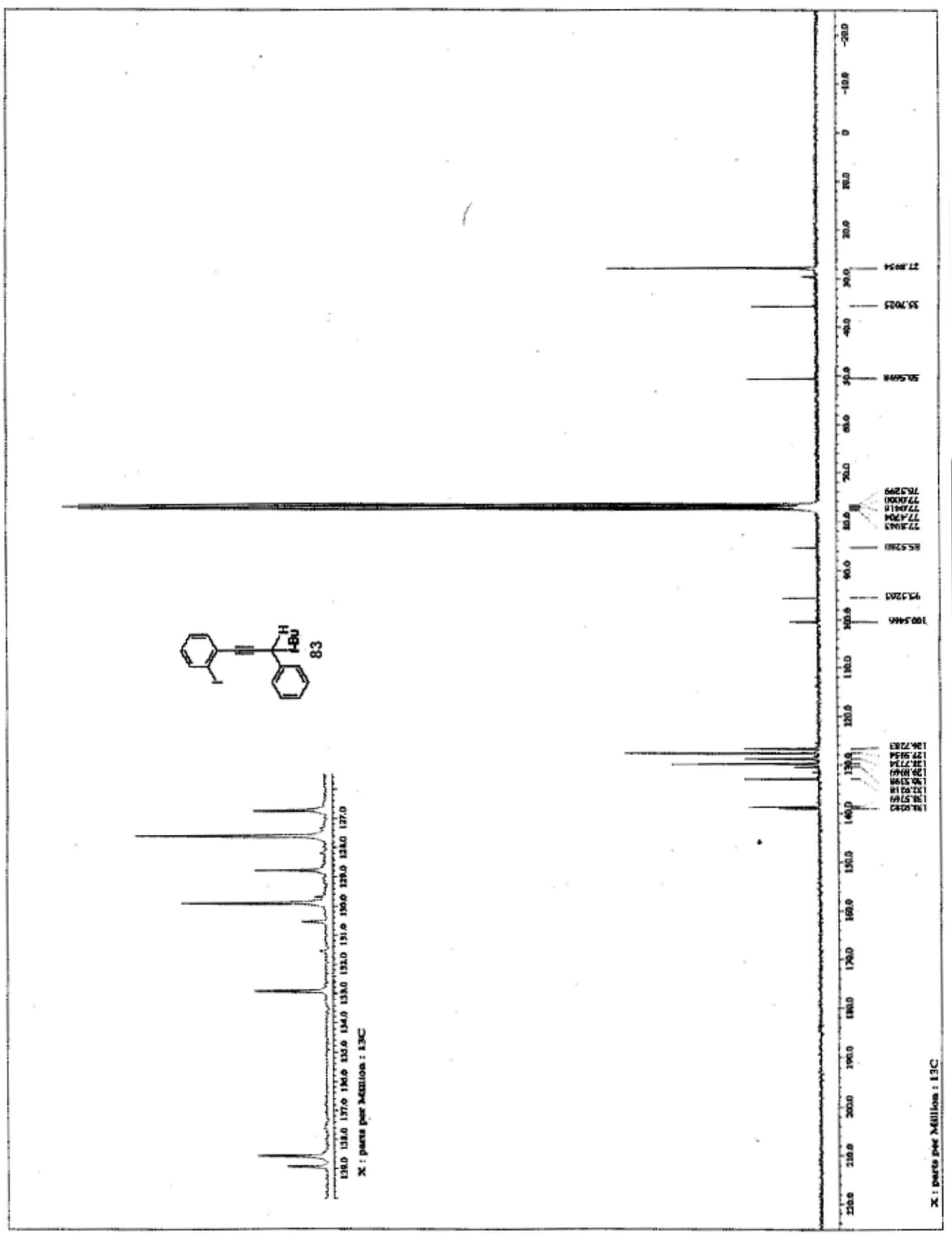




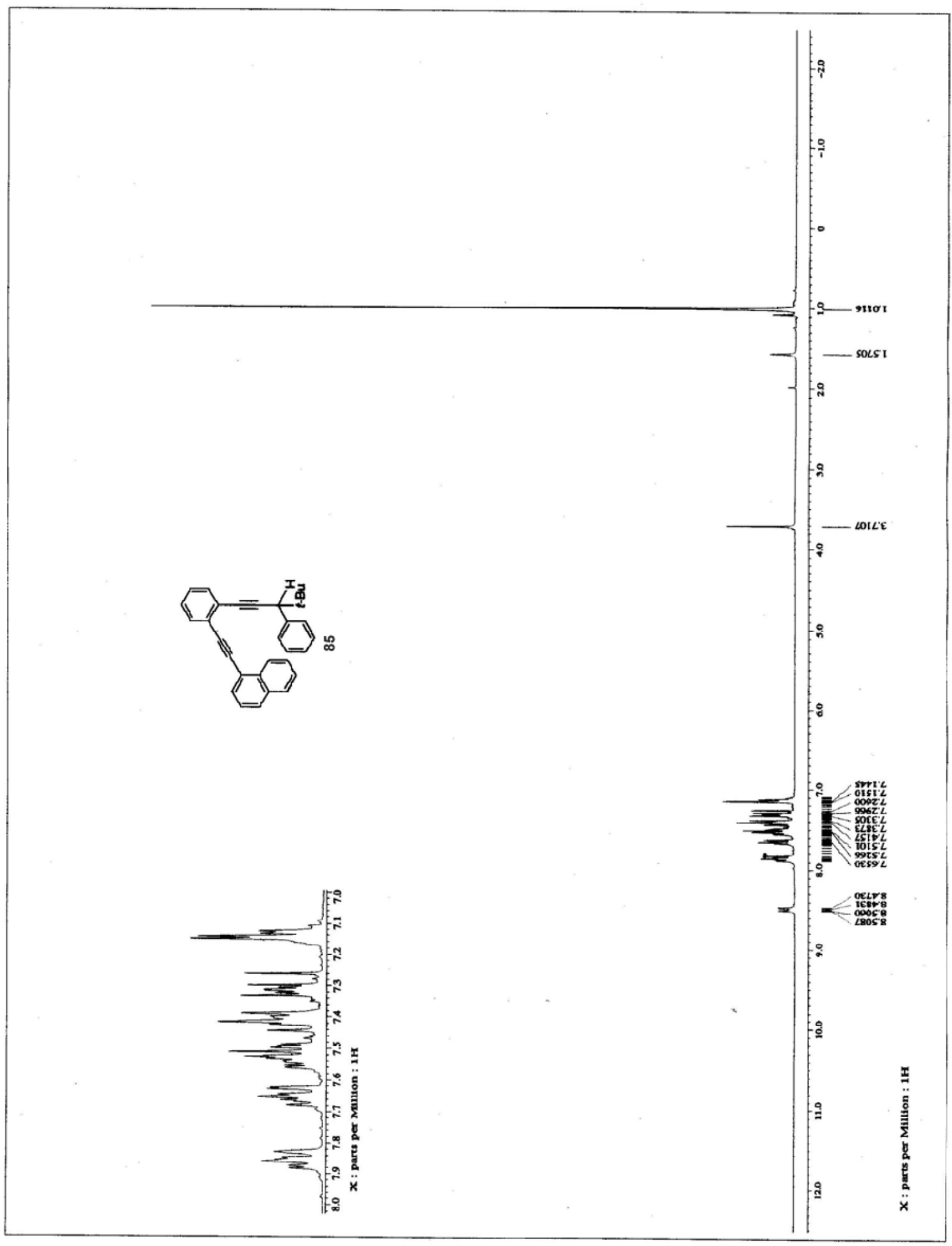




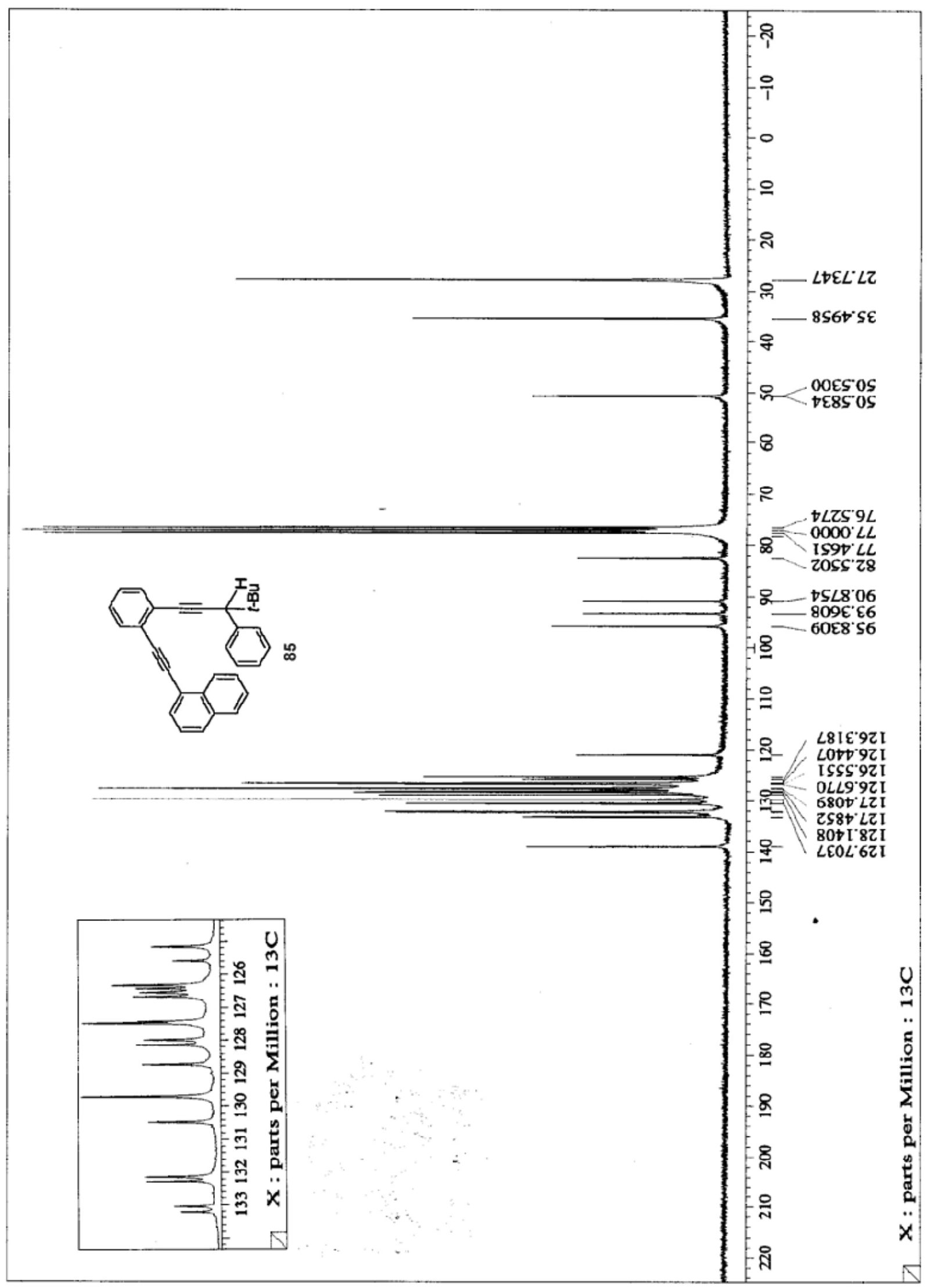




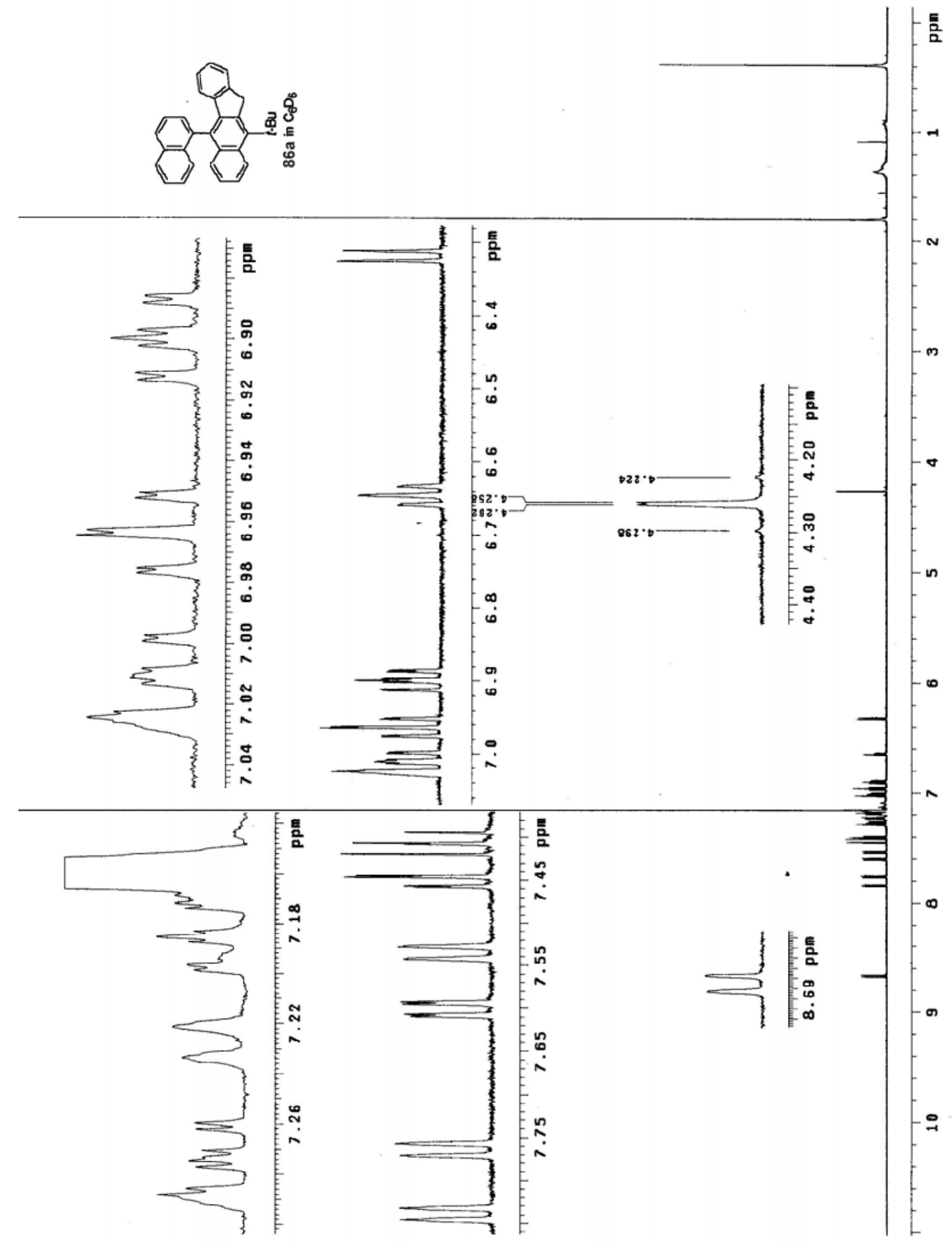




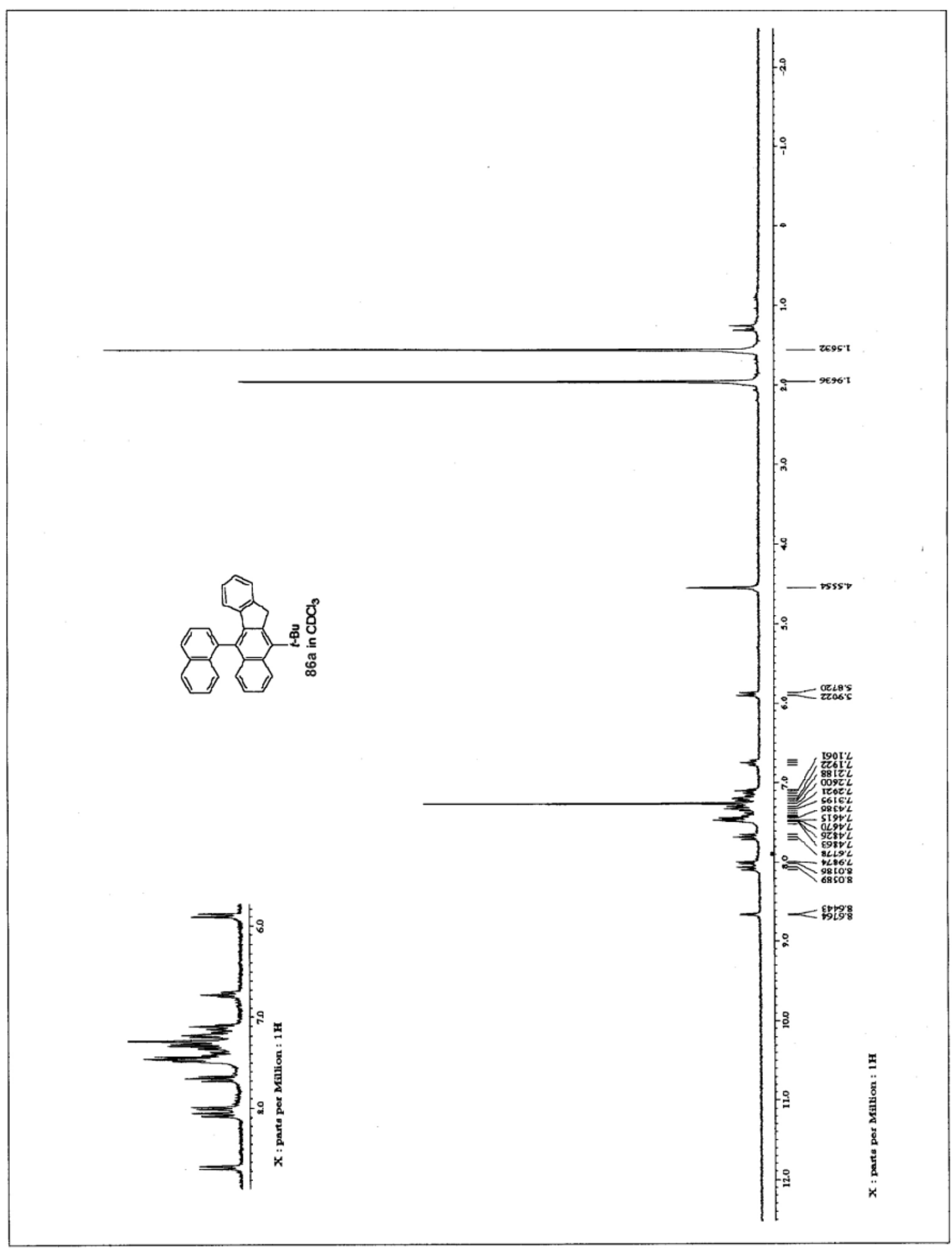




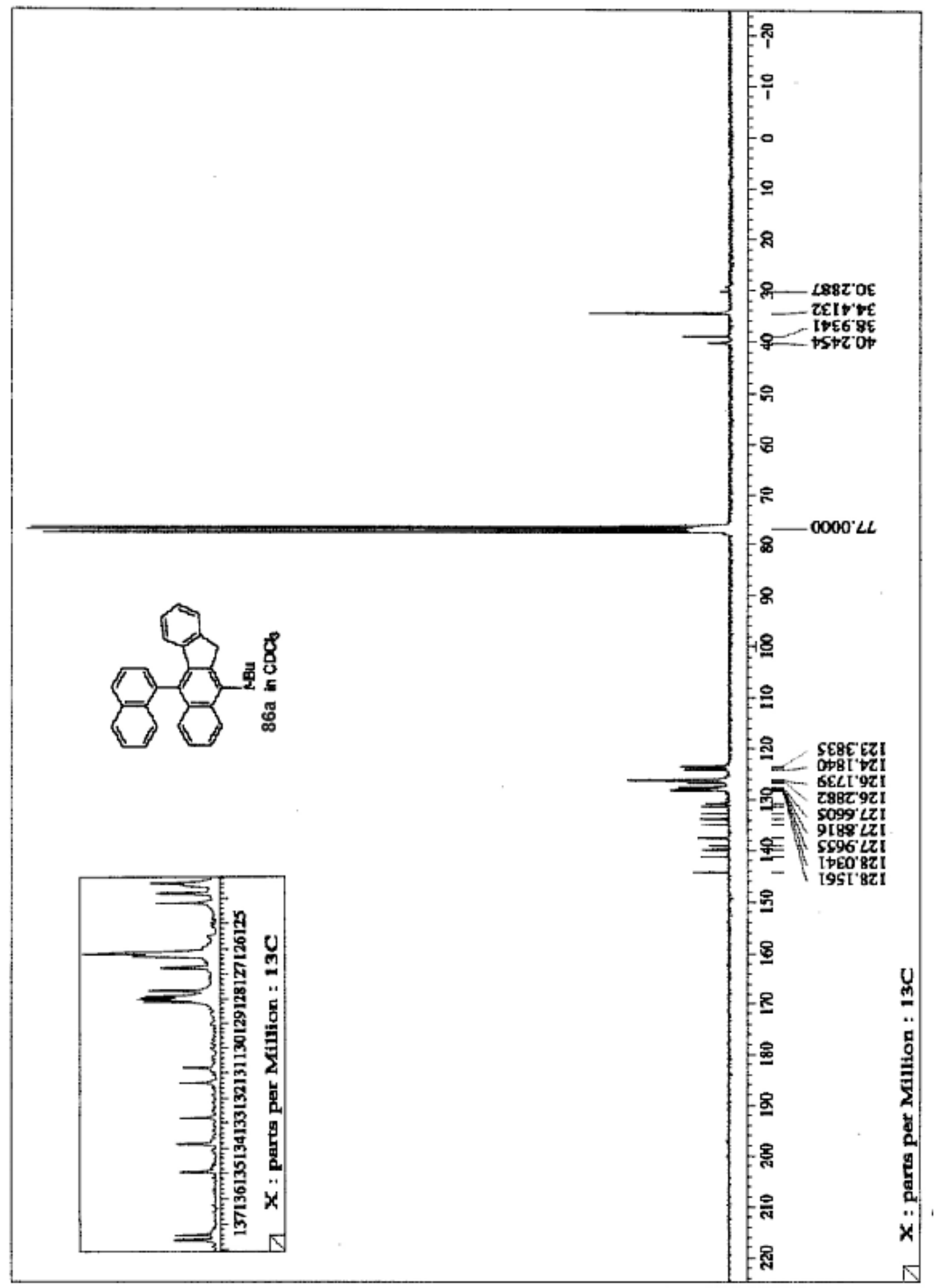




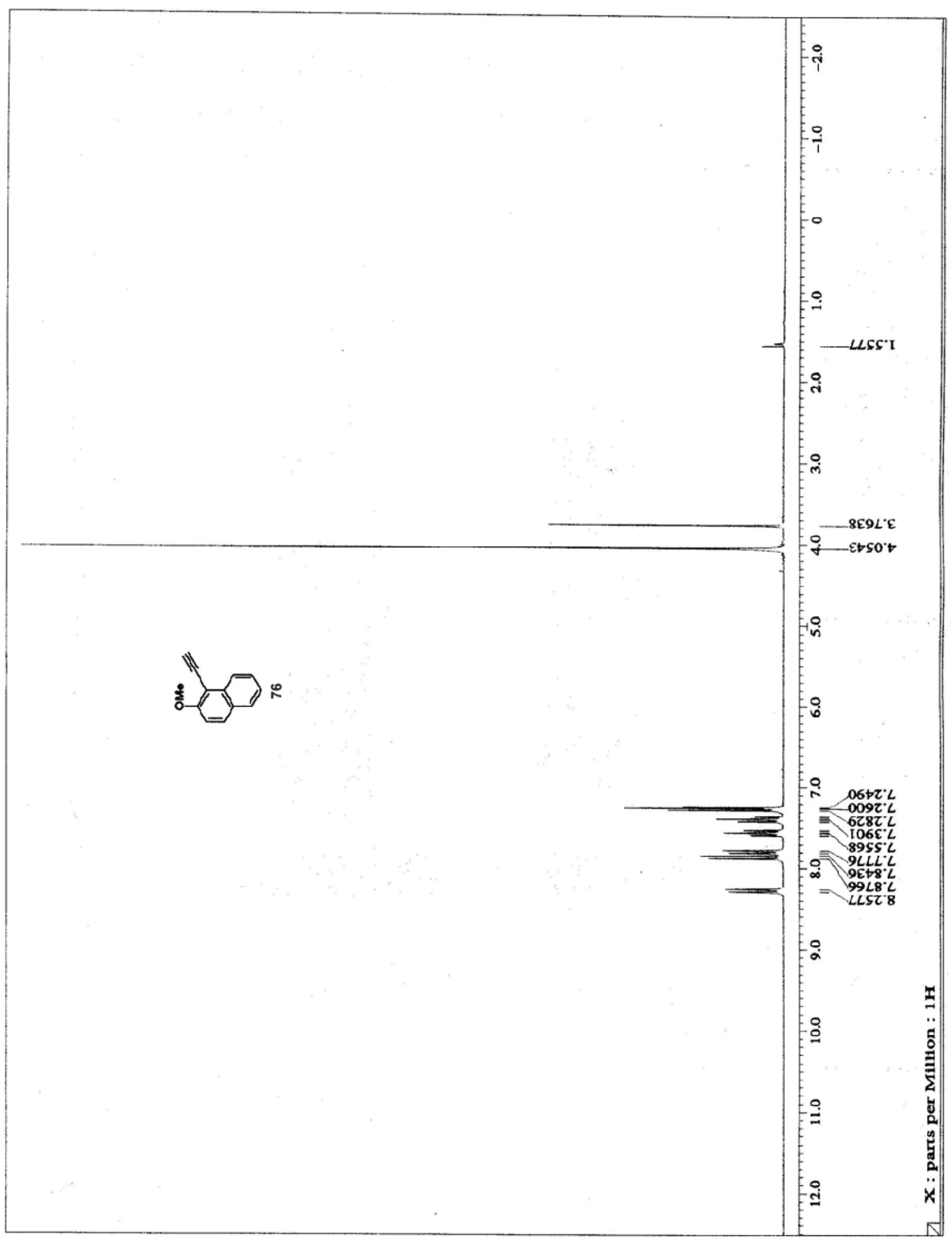




$$
1
$$




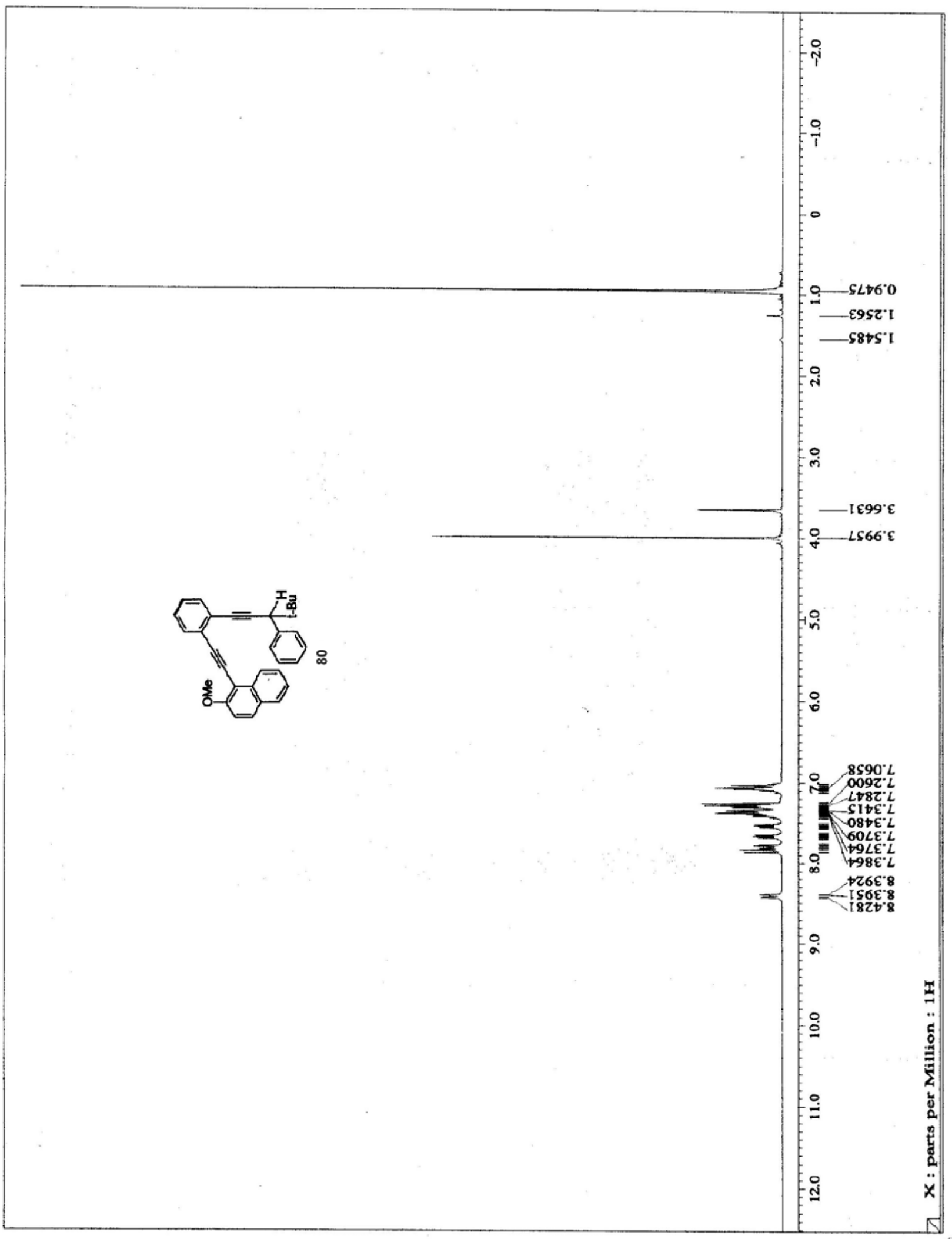




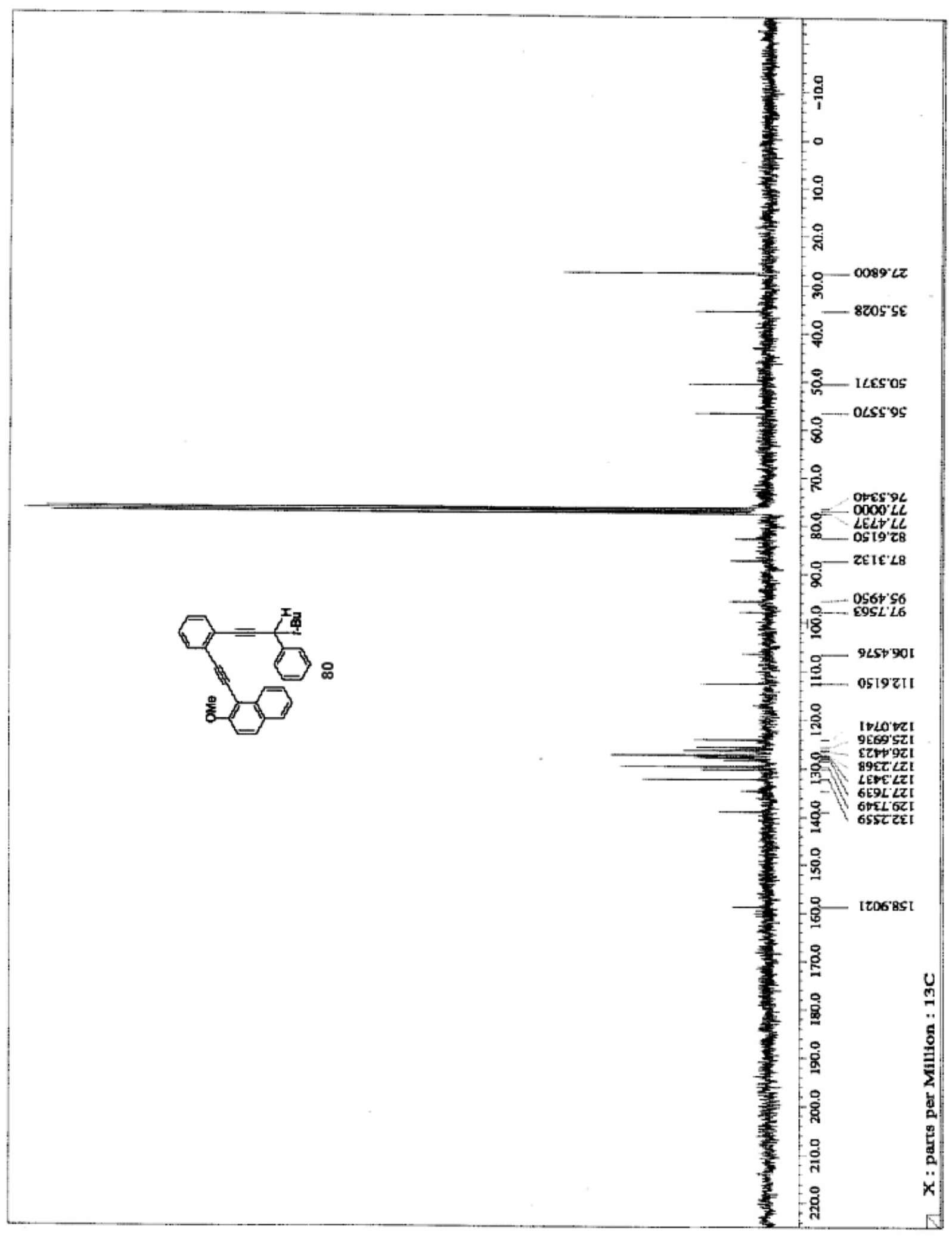




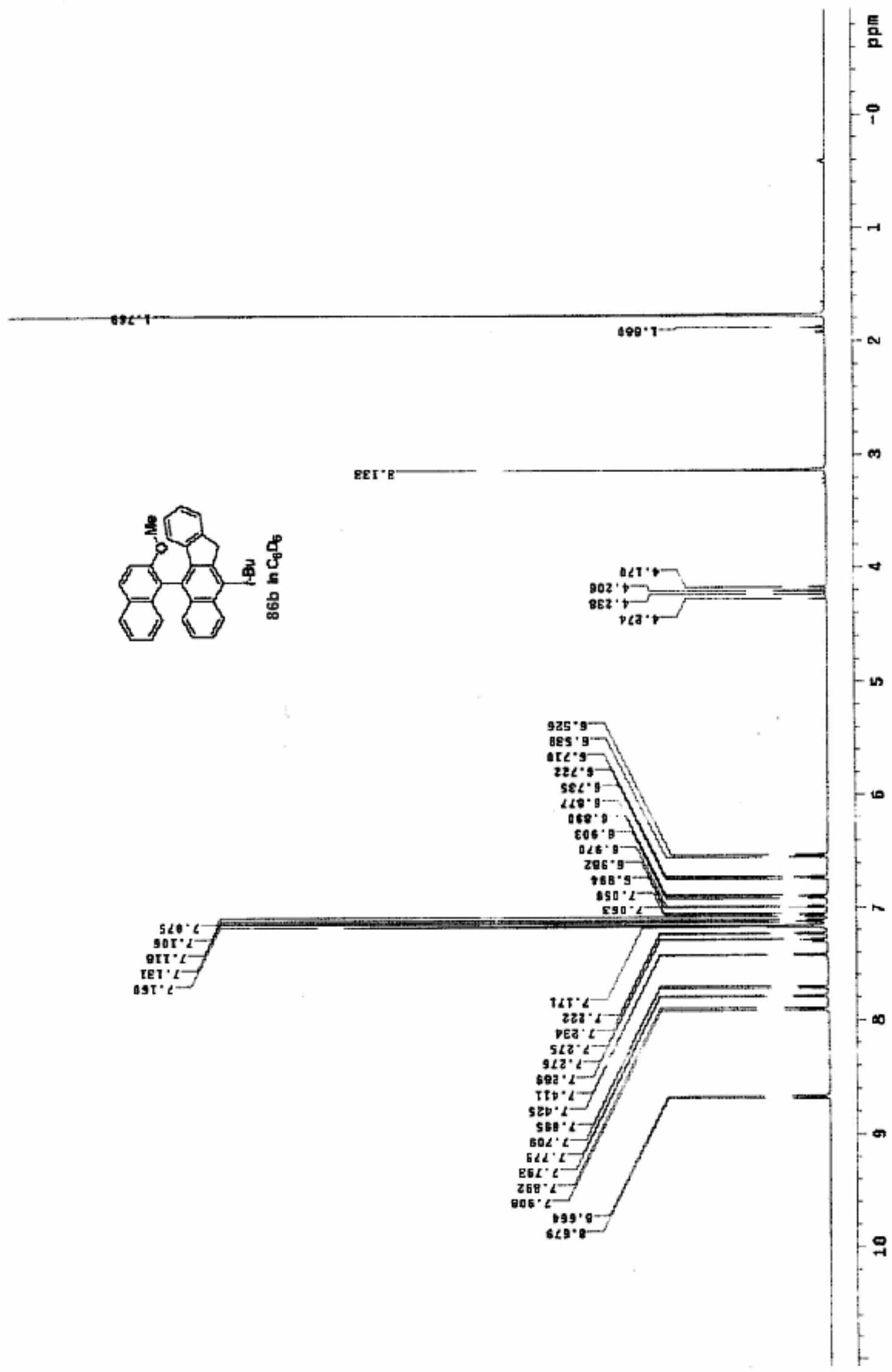




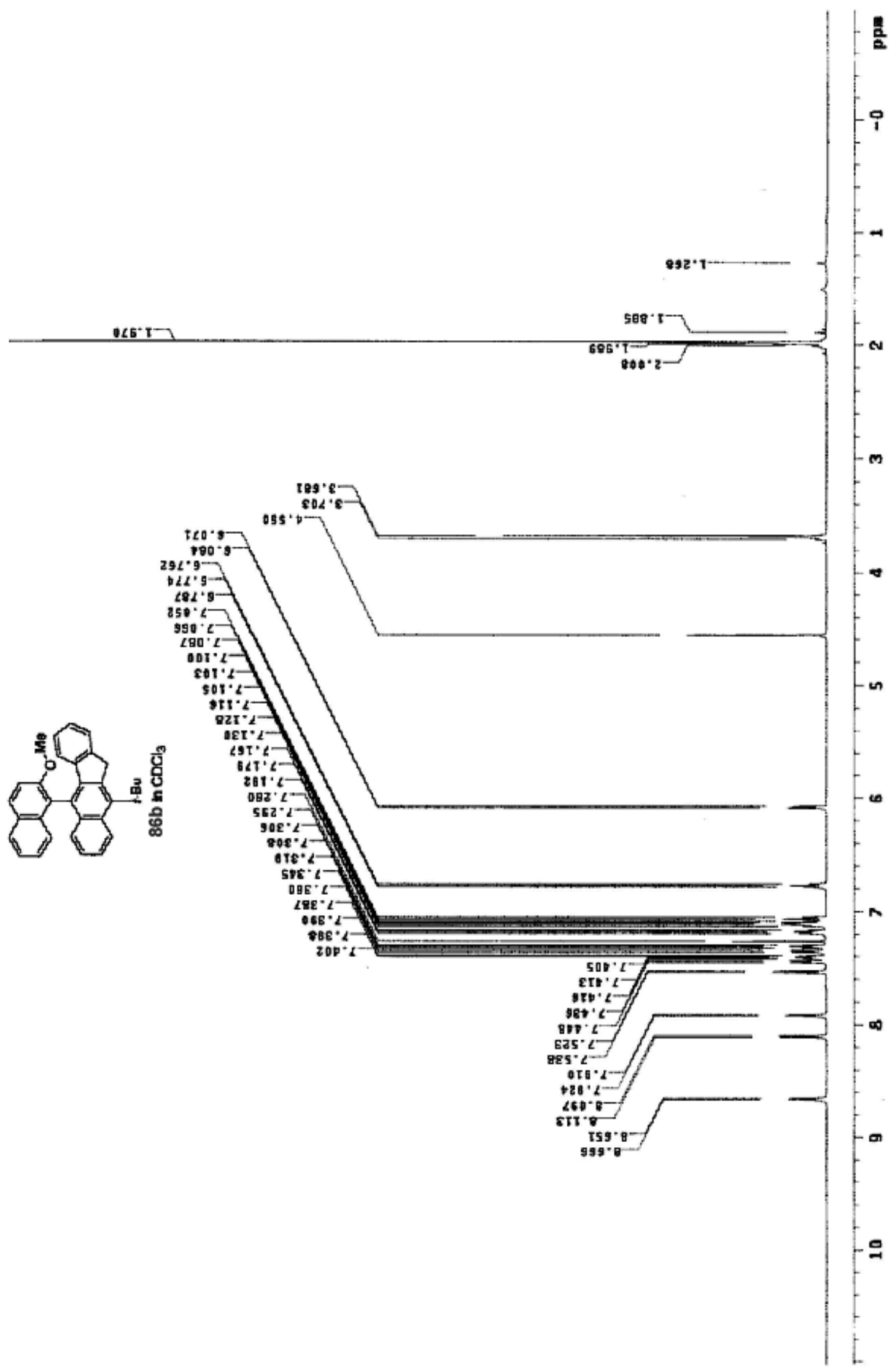




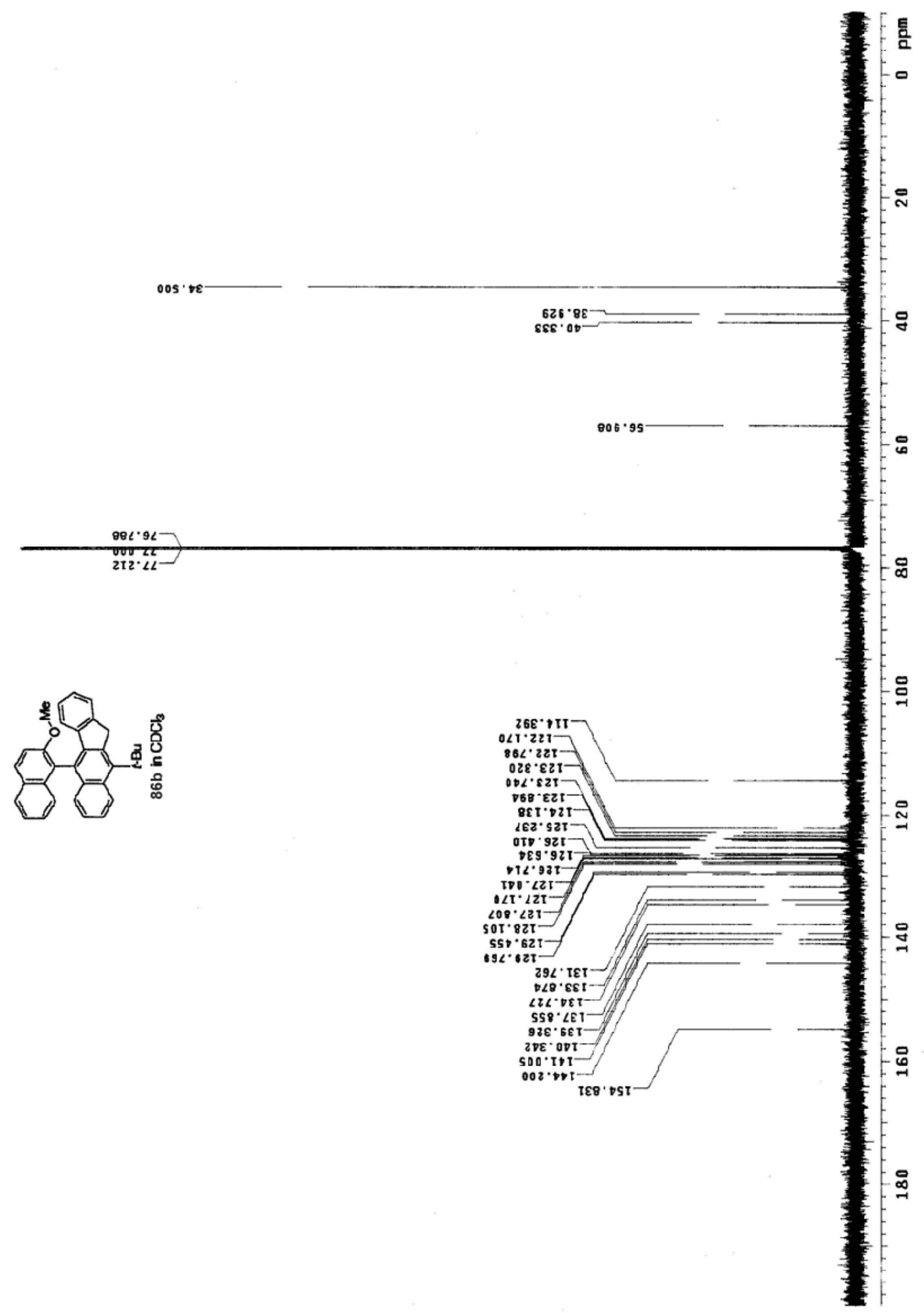




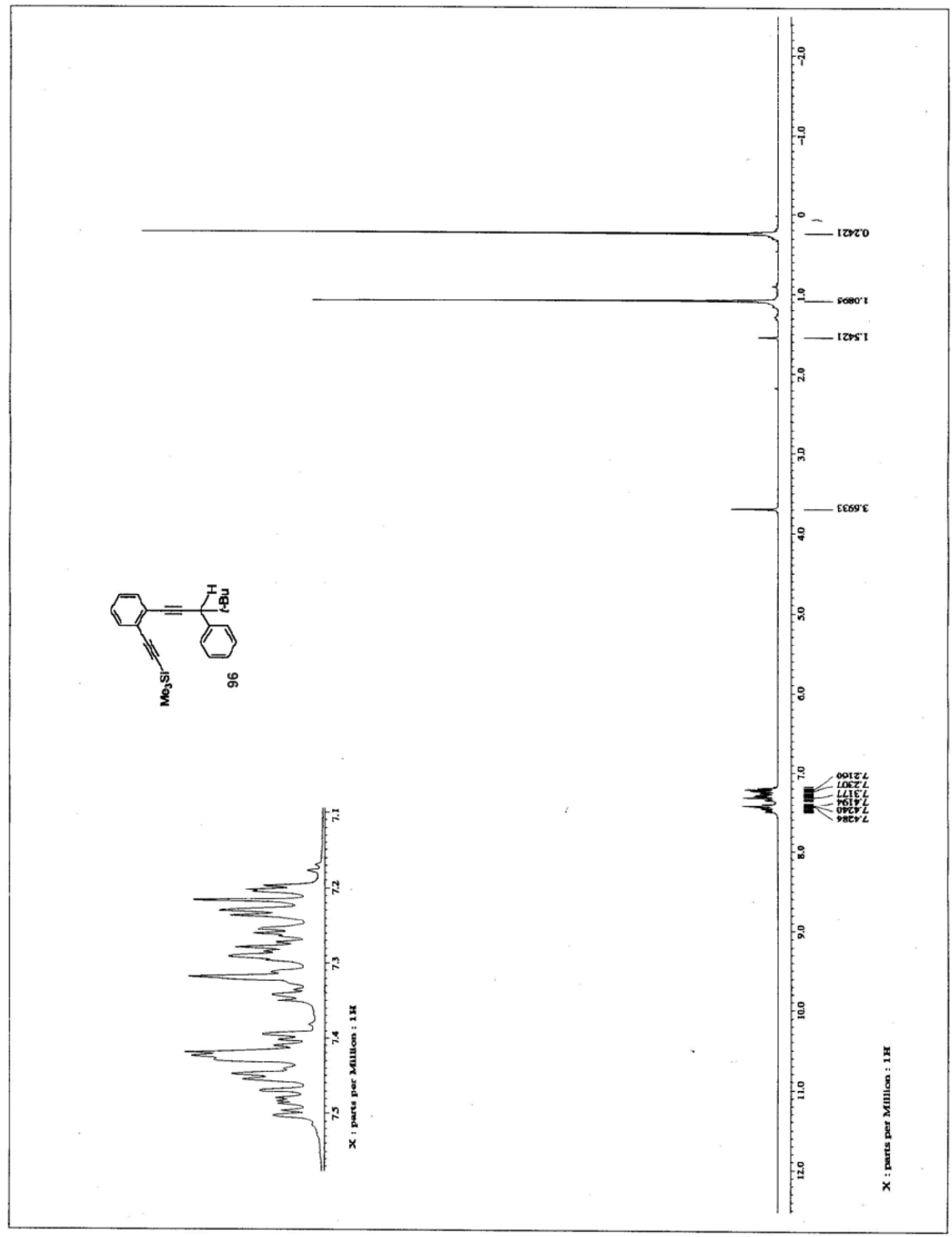




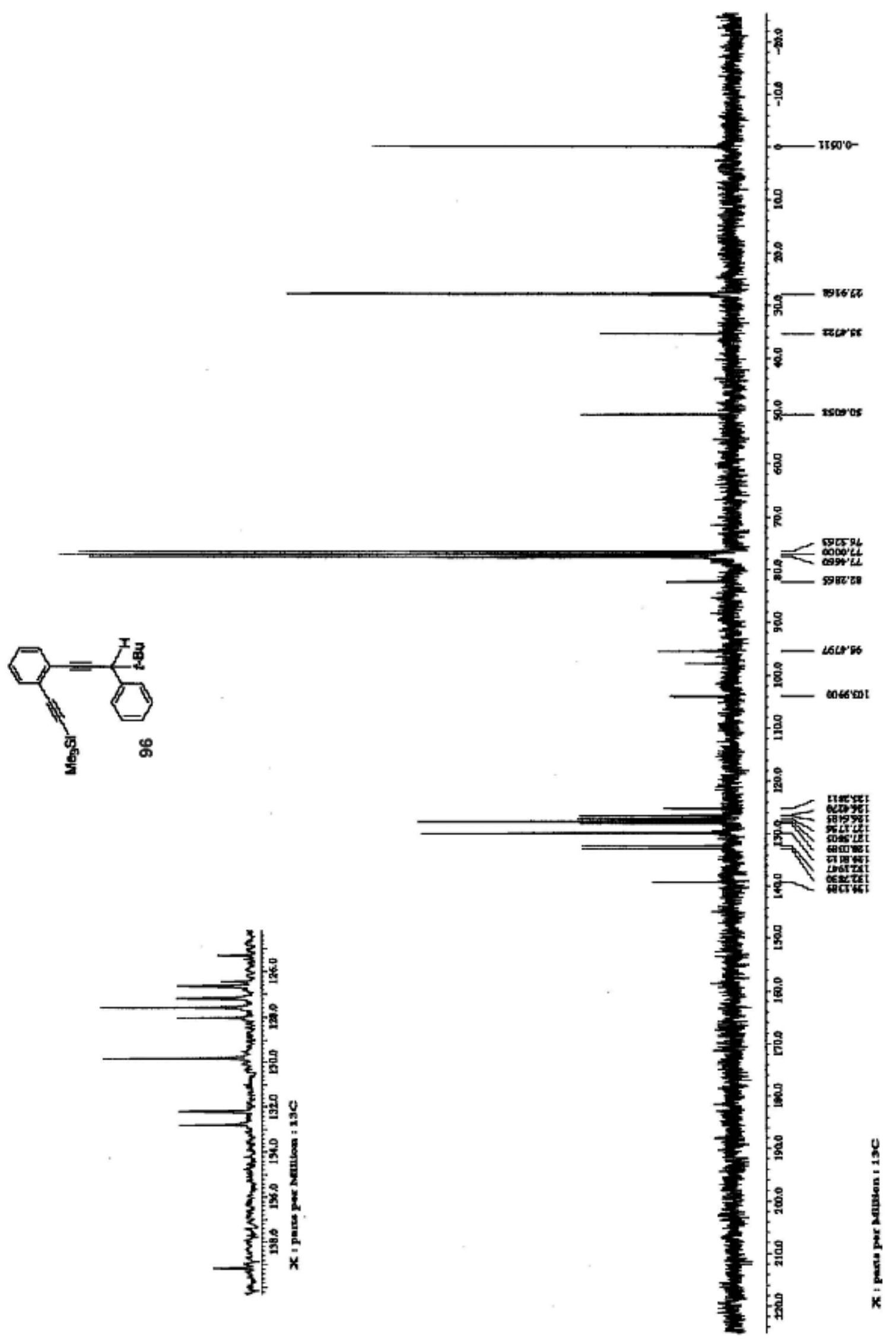




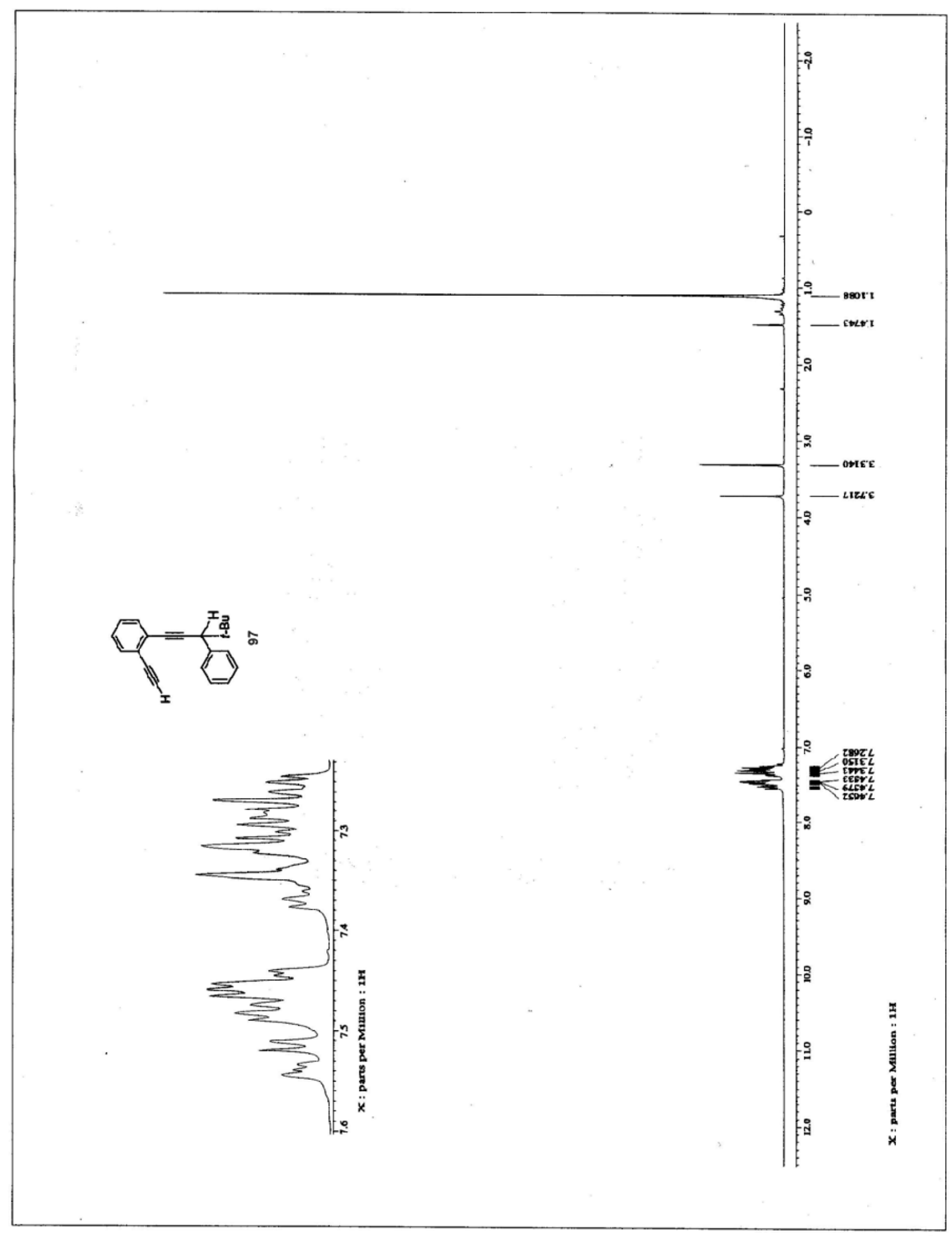




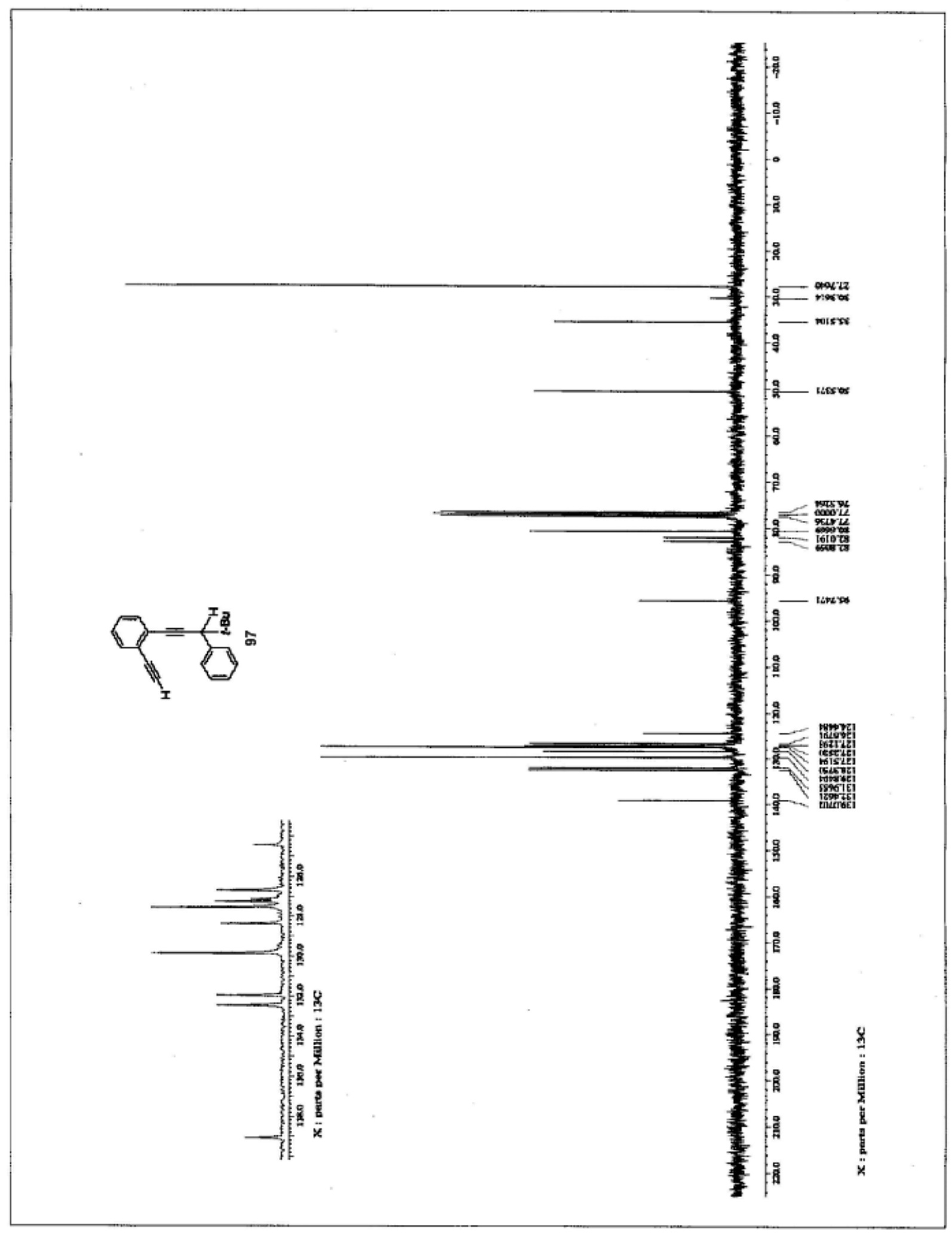




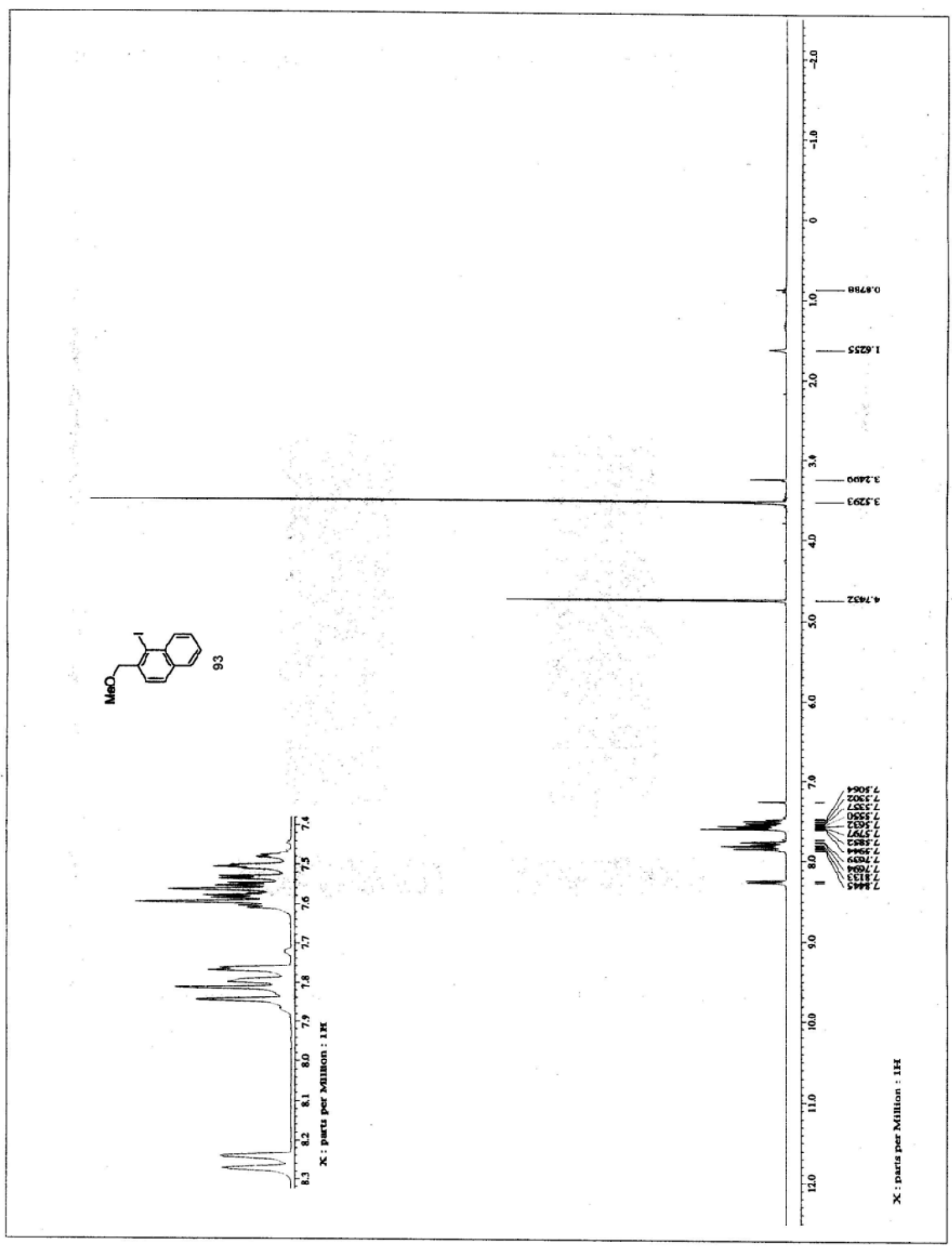




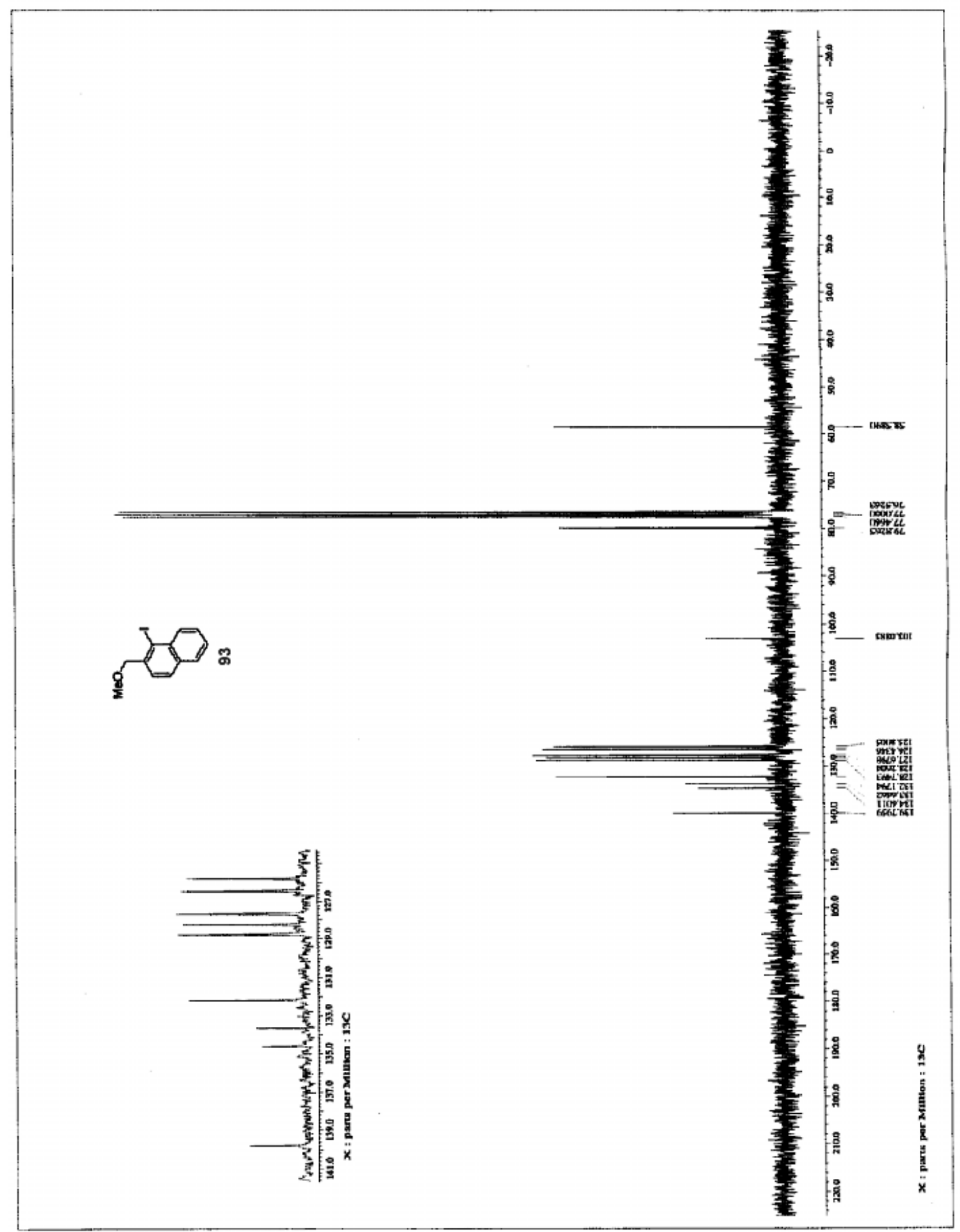




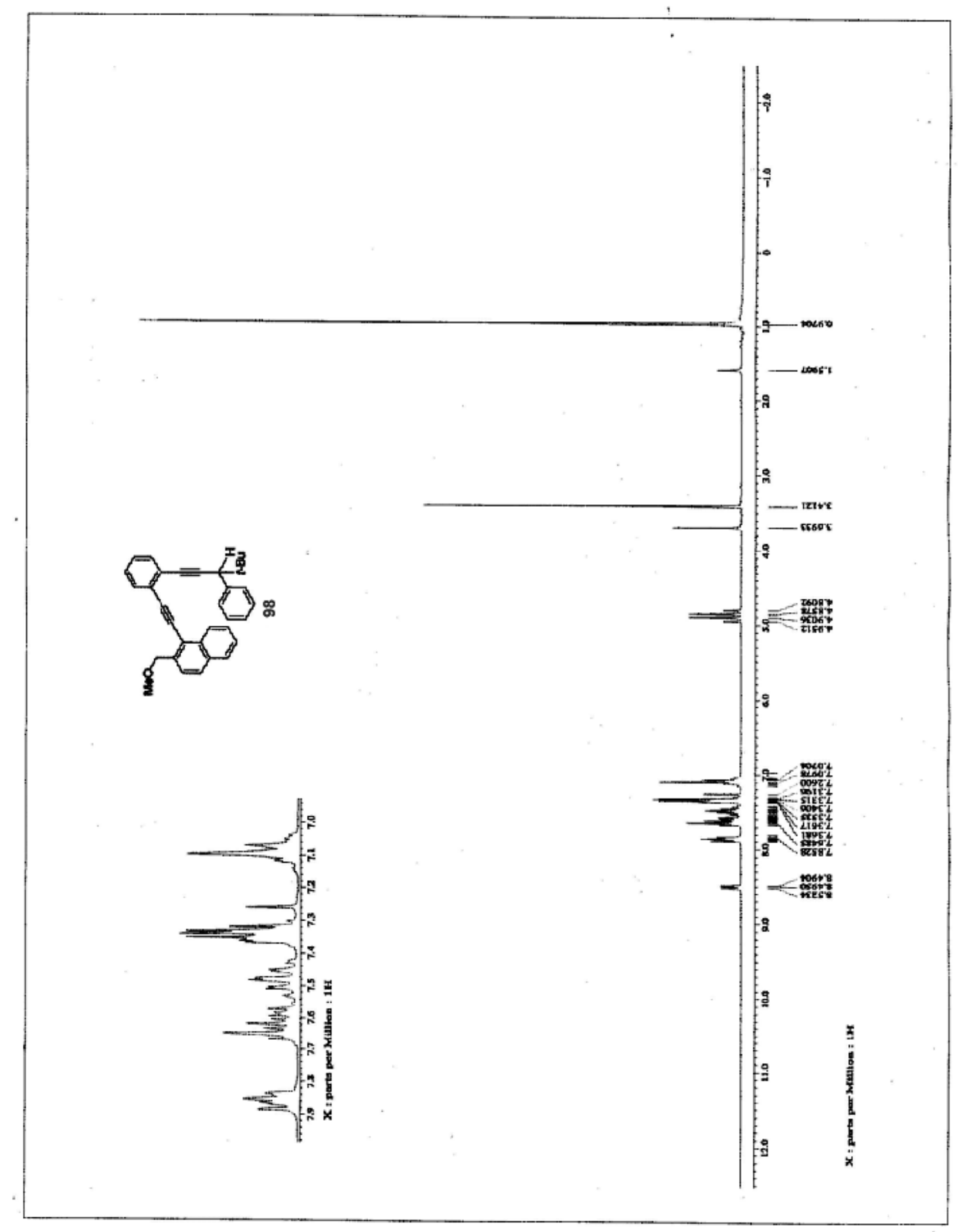




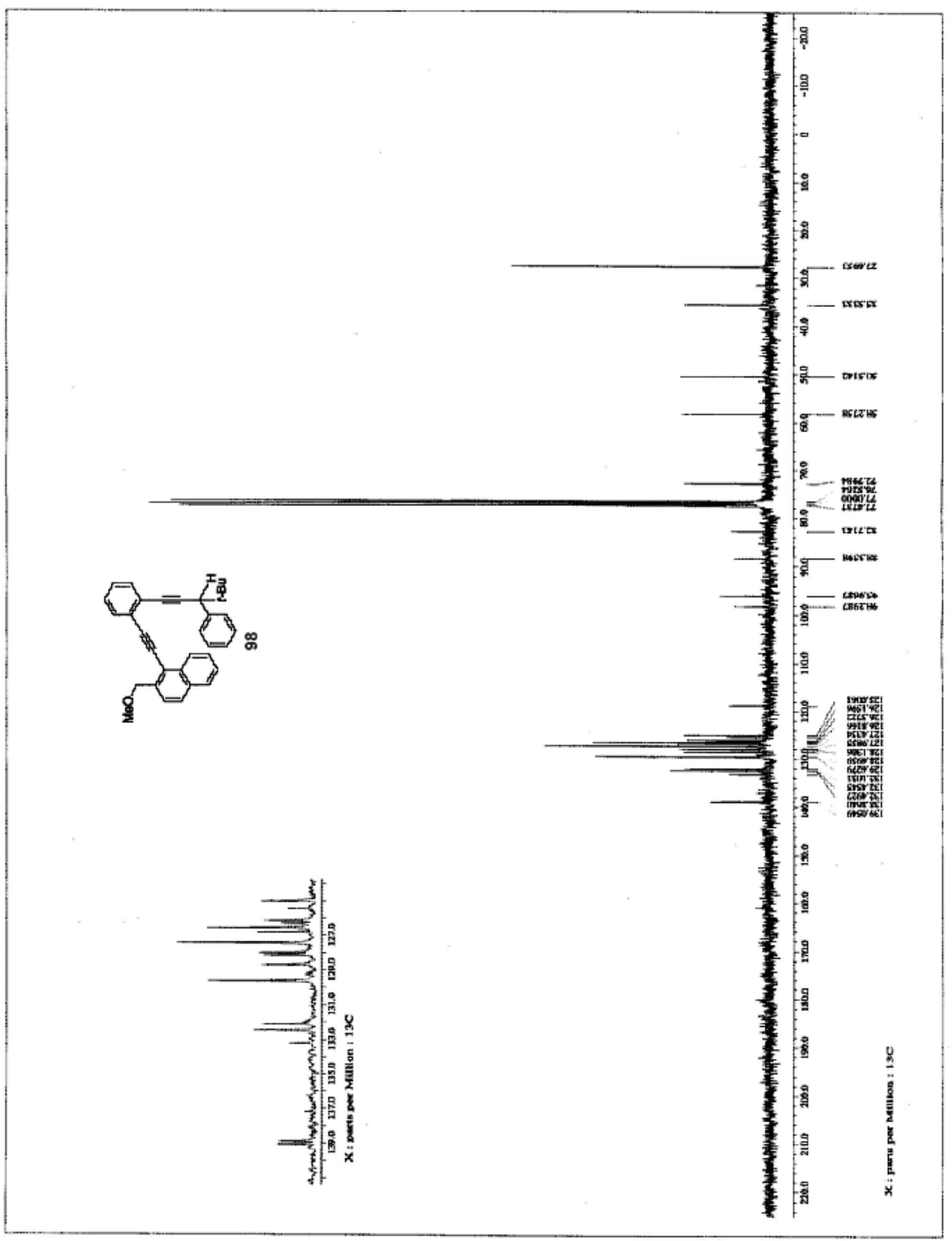




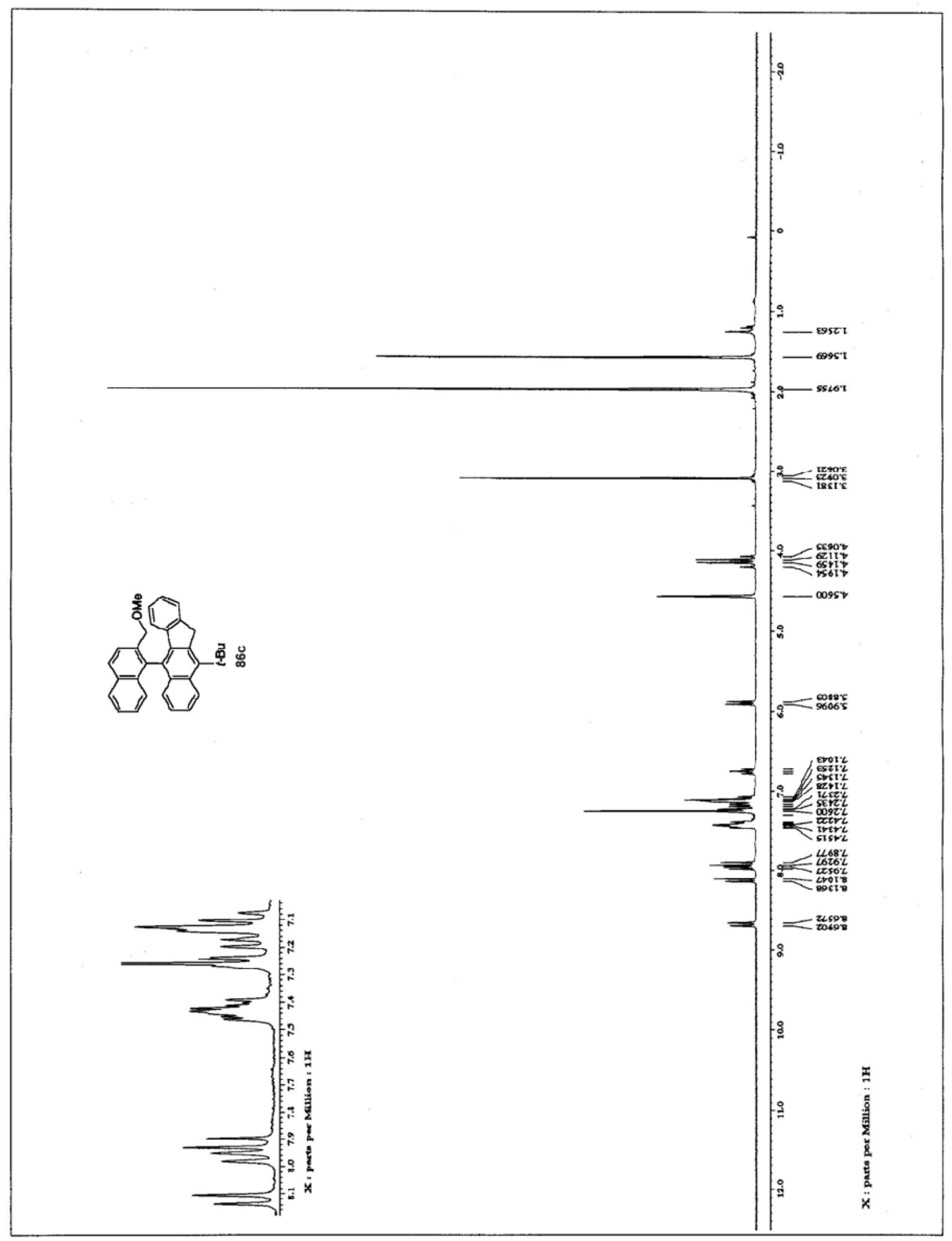




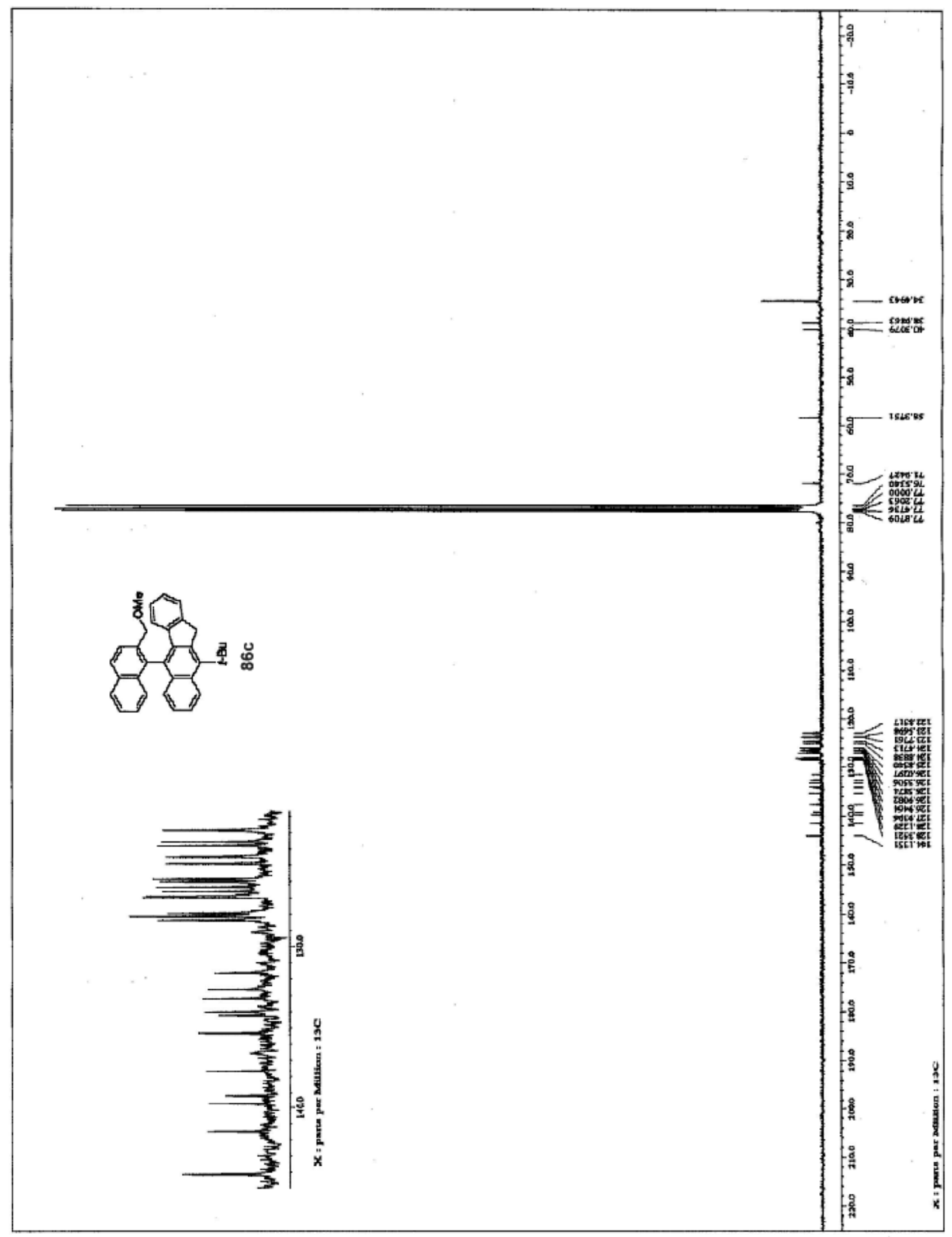




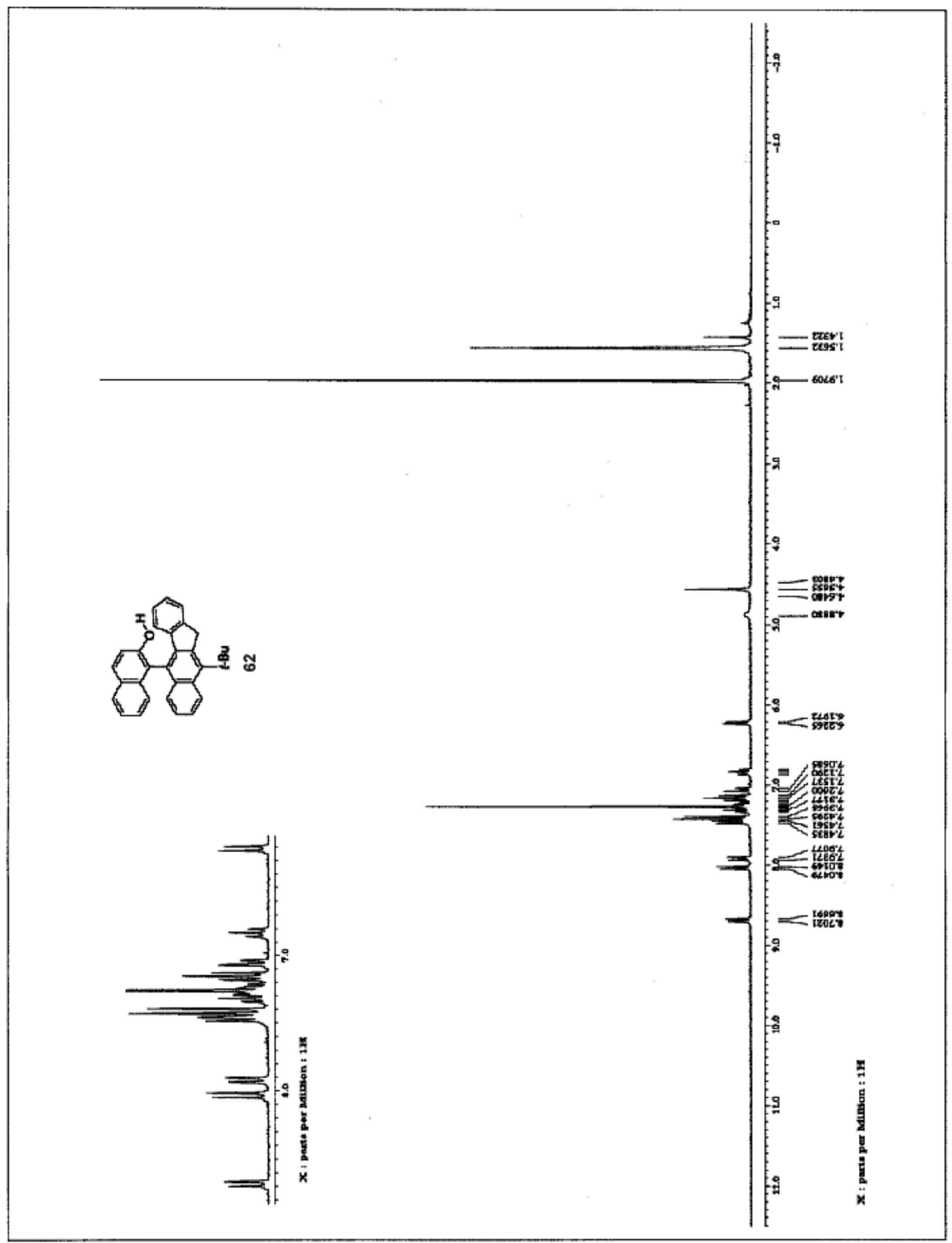




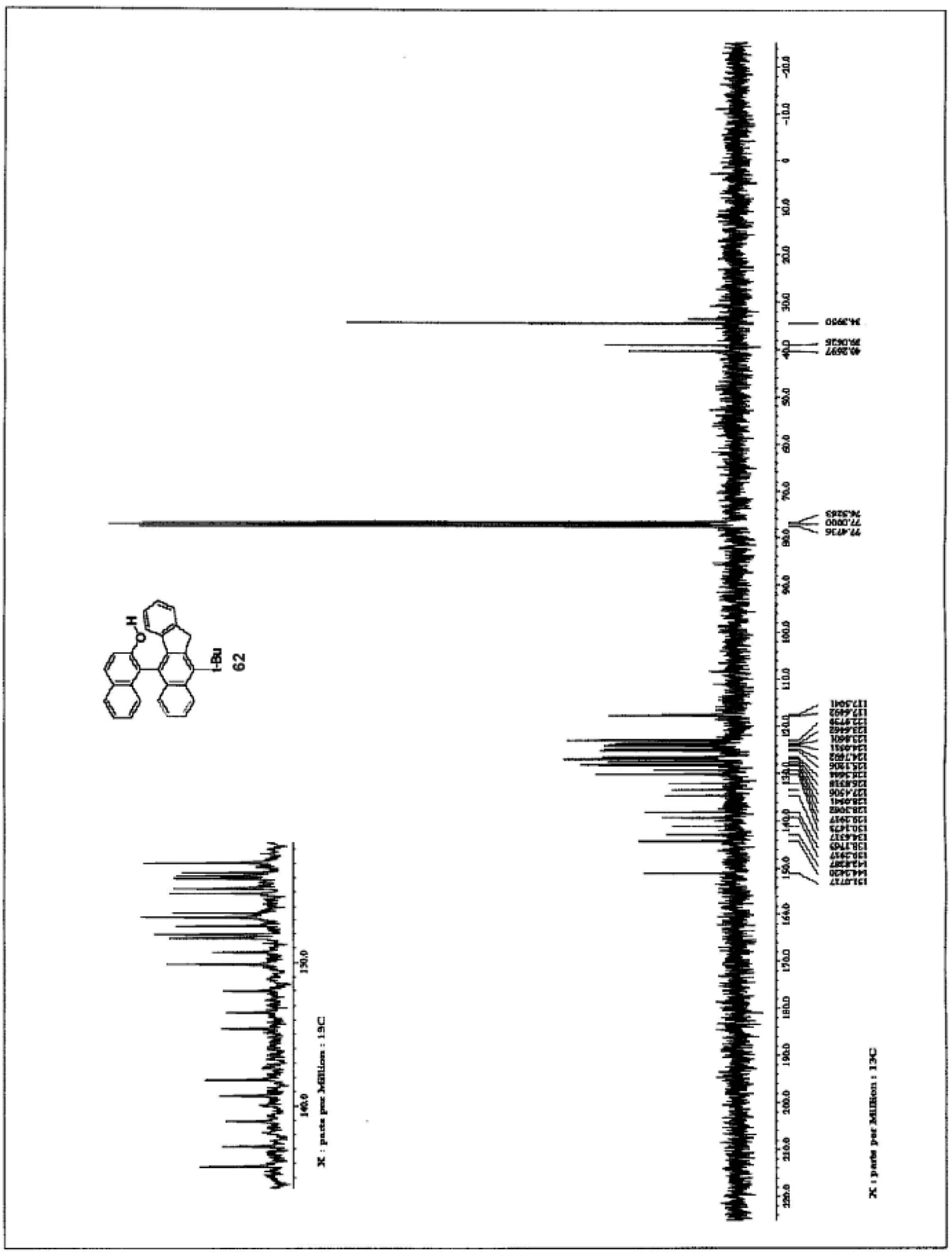




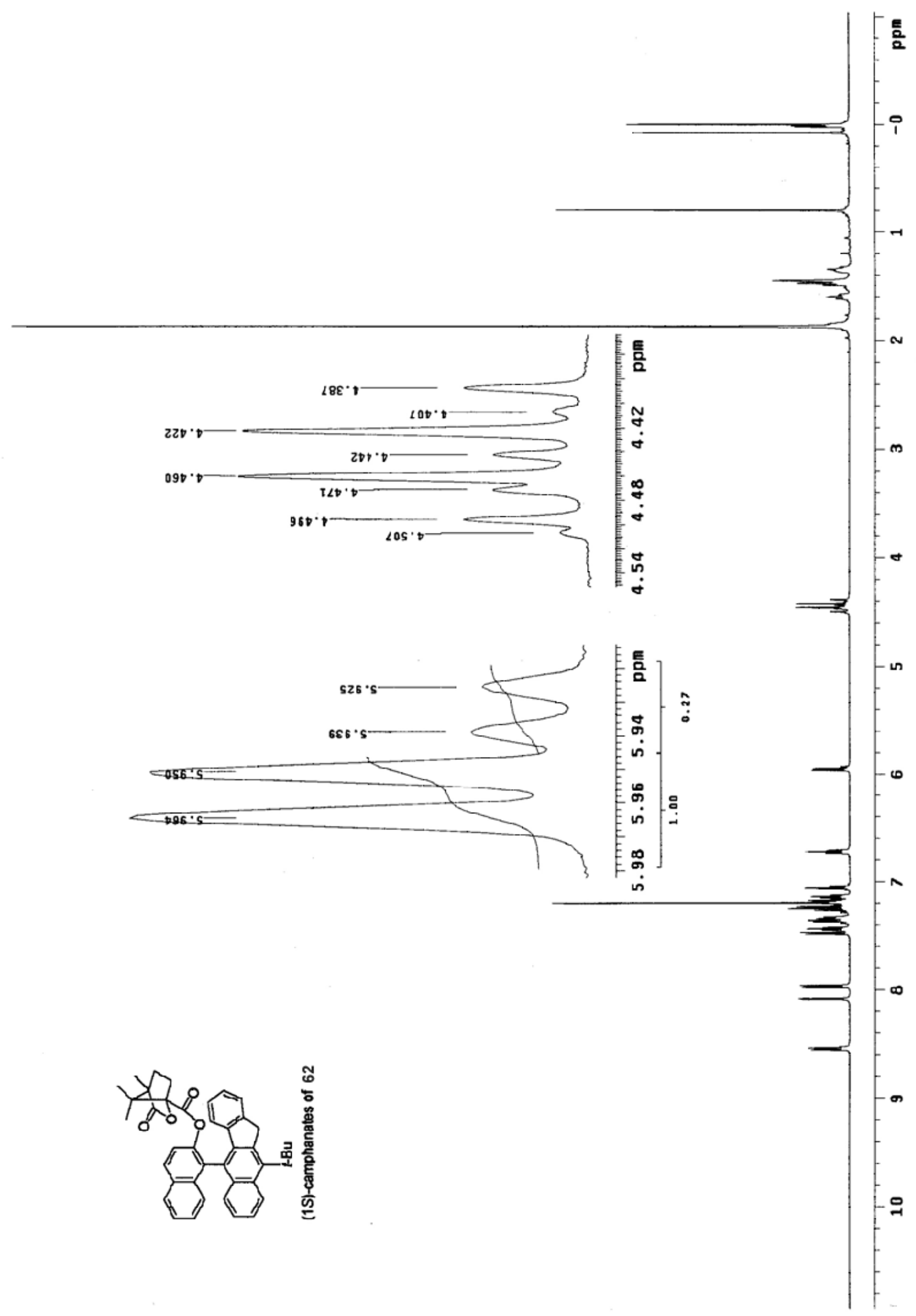




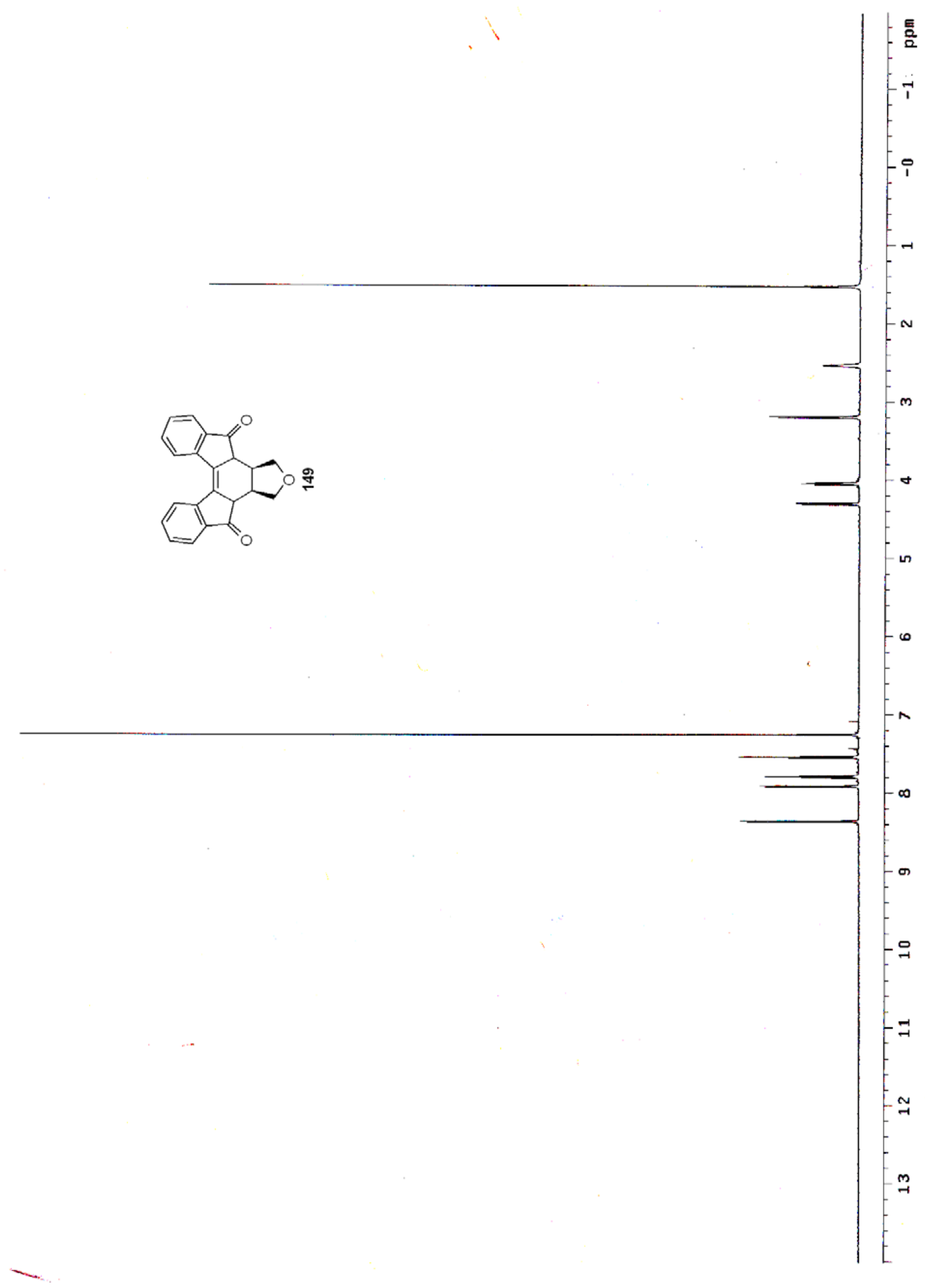




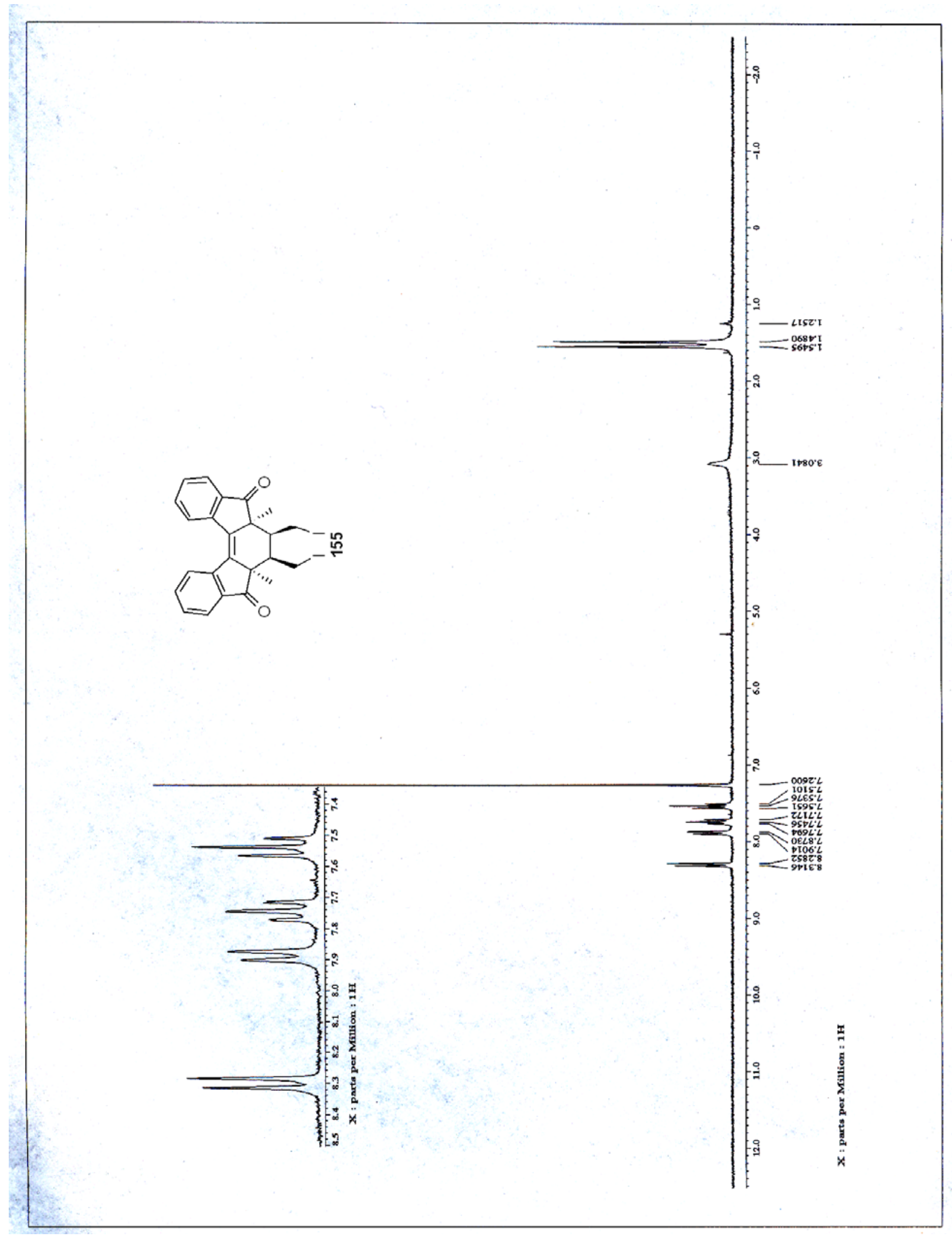




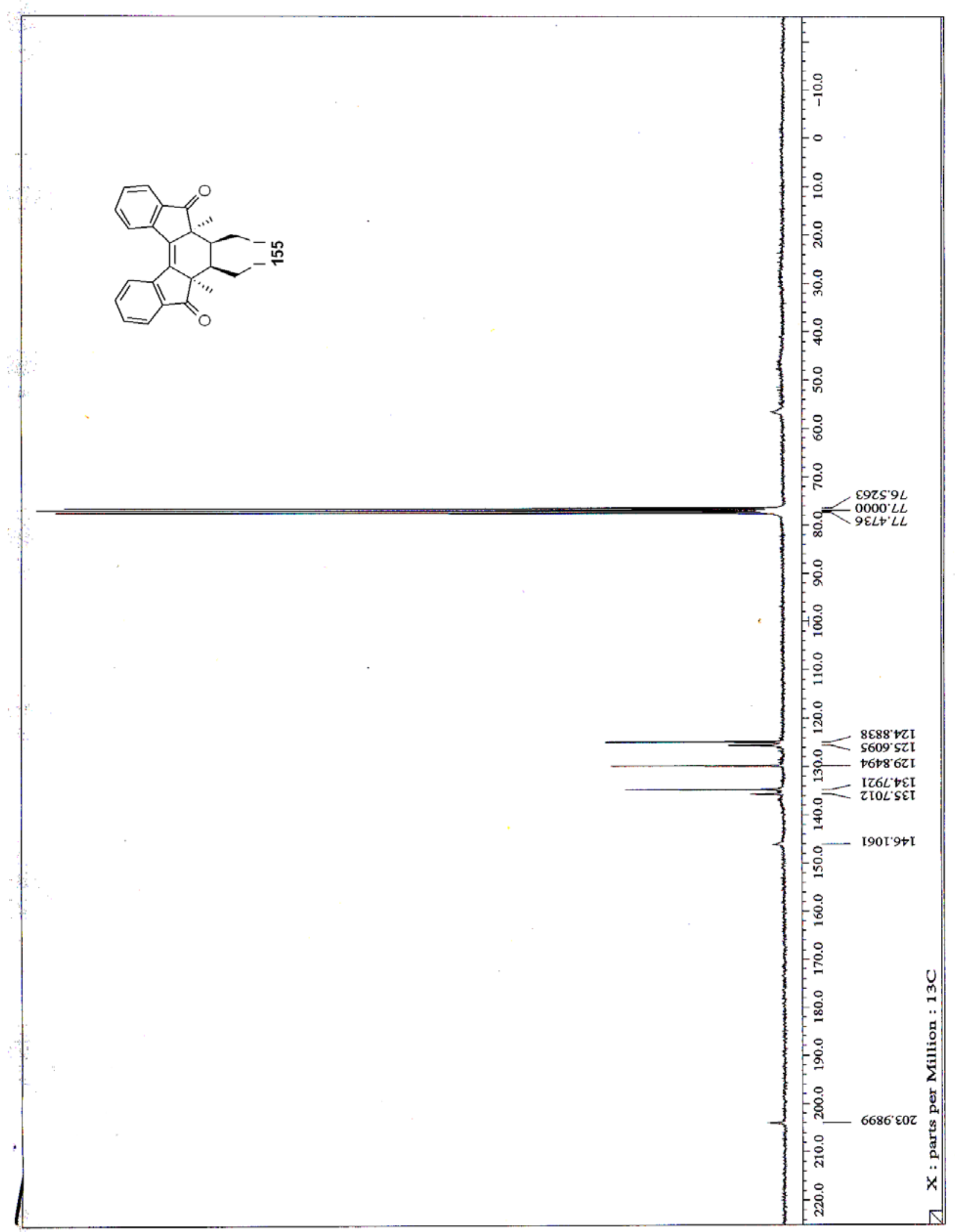




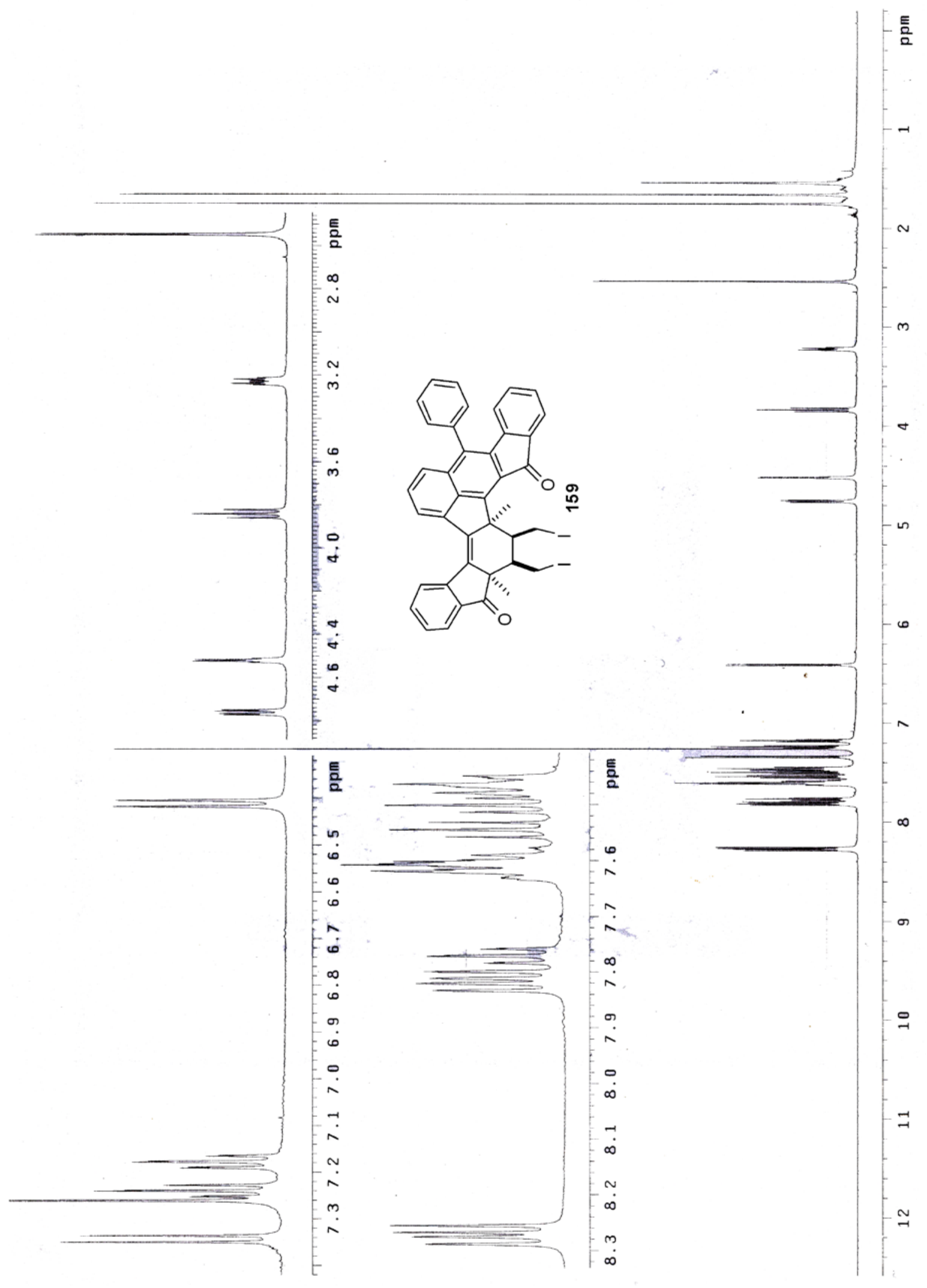



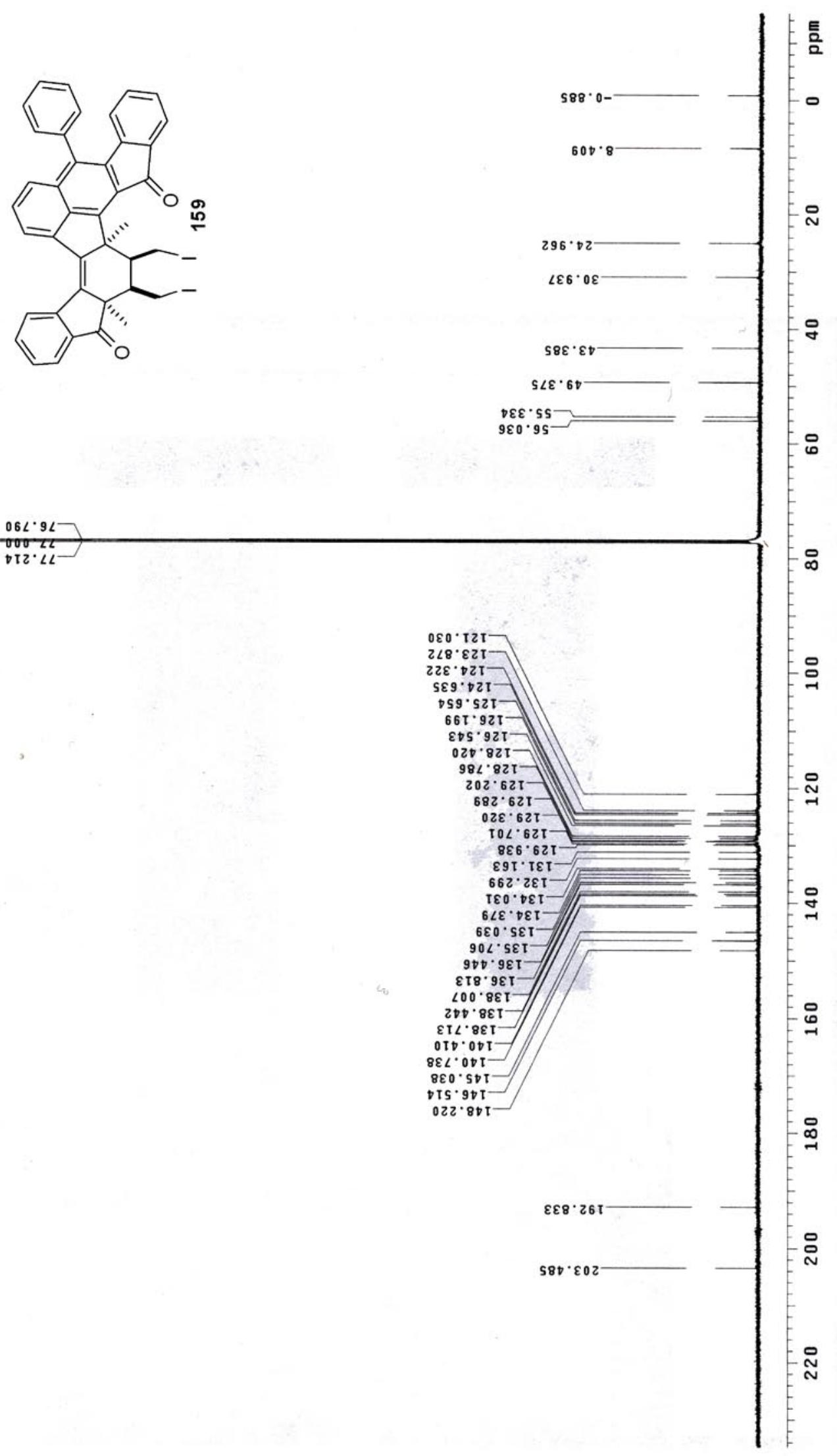


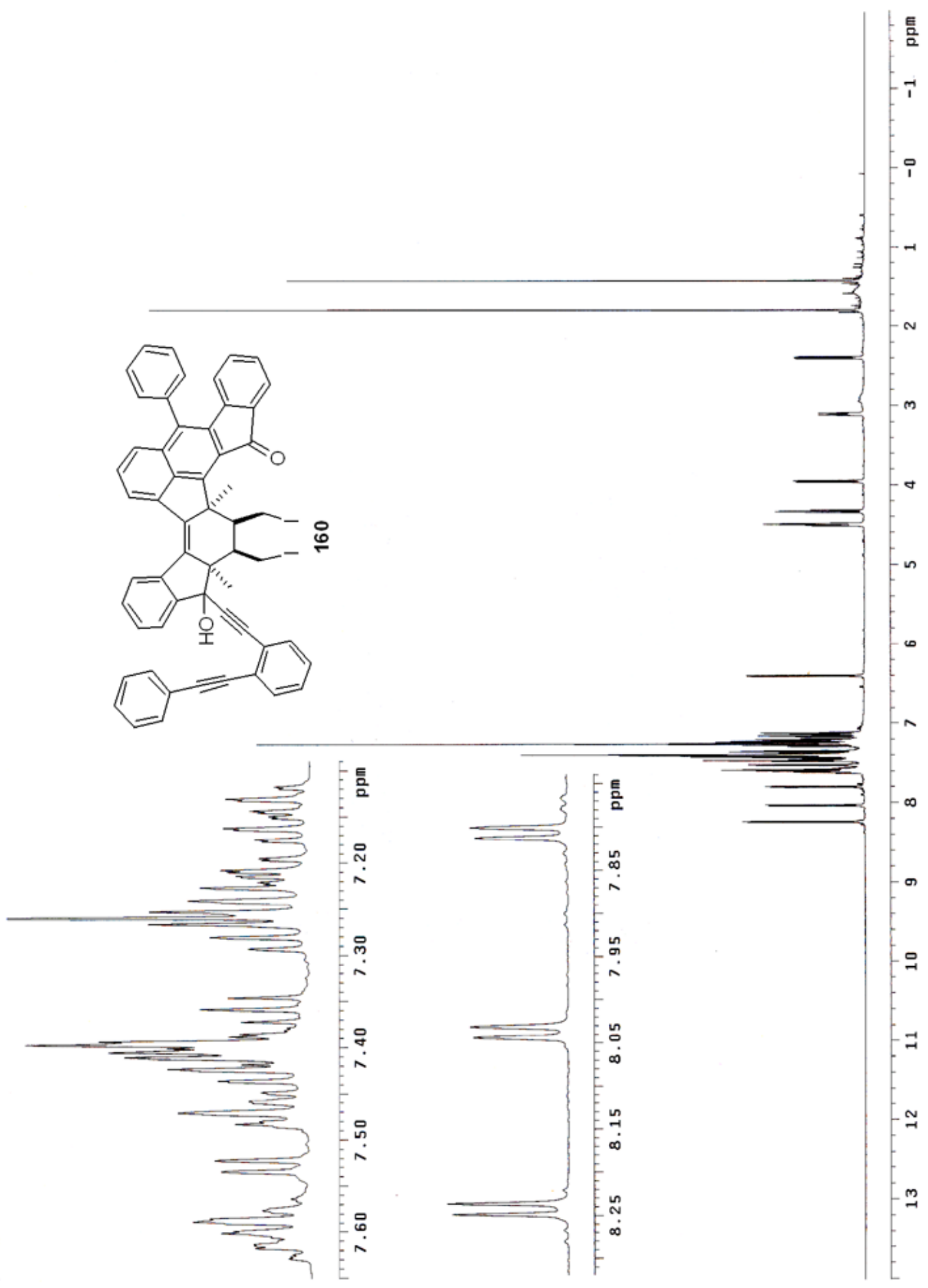




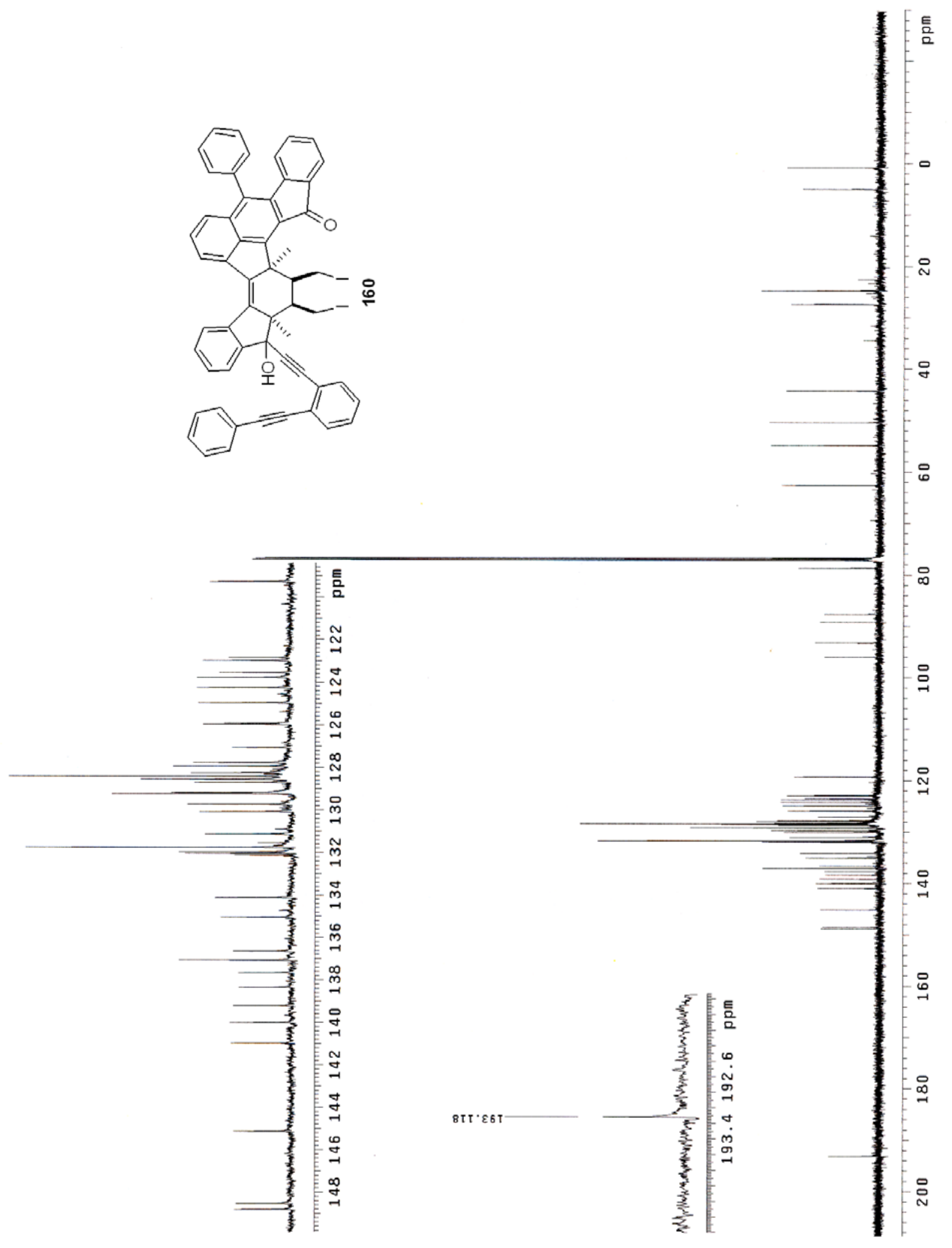




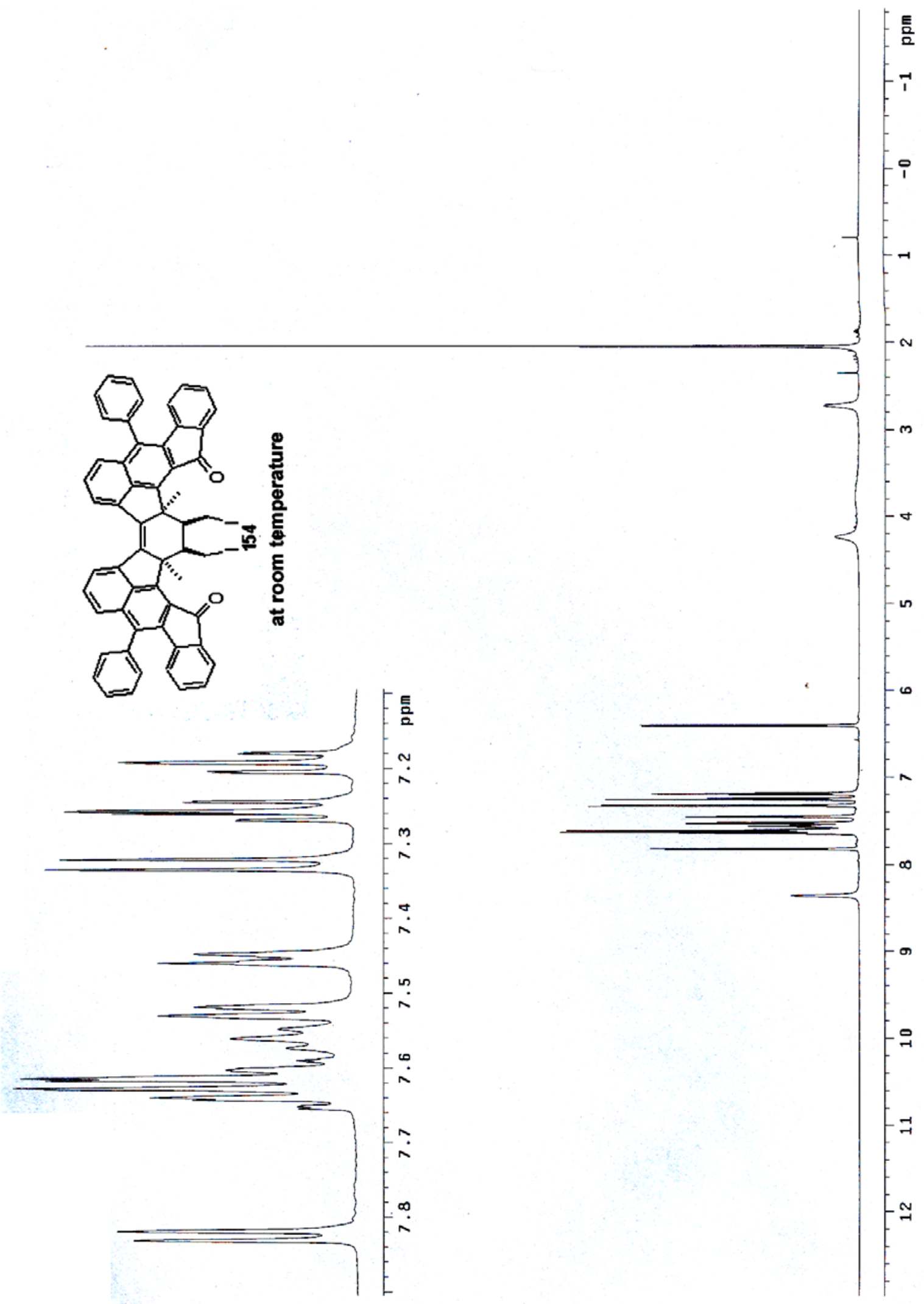




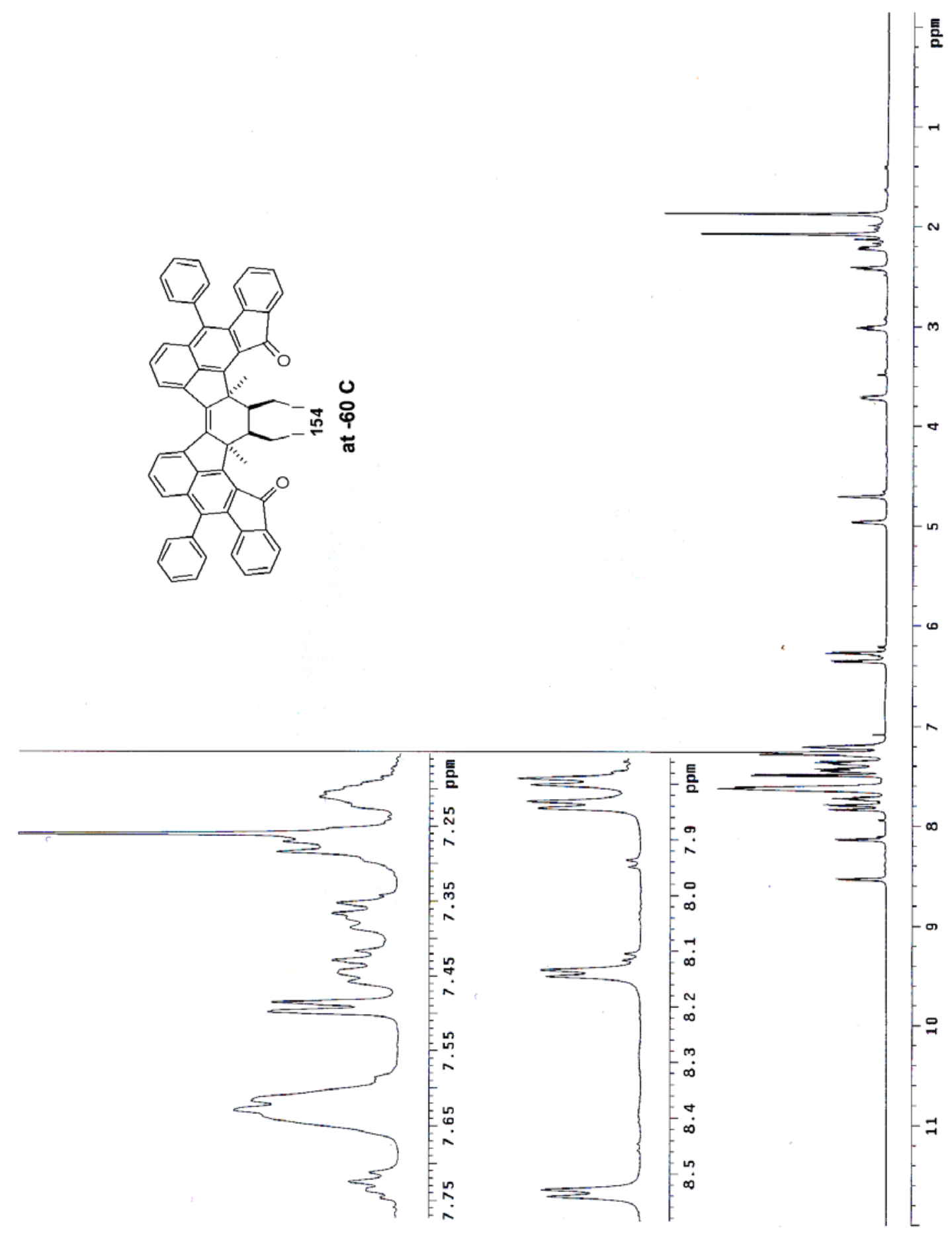




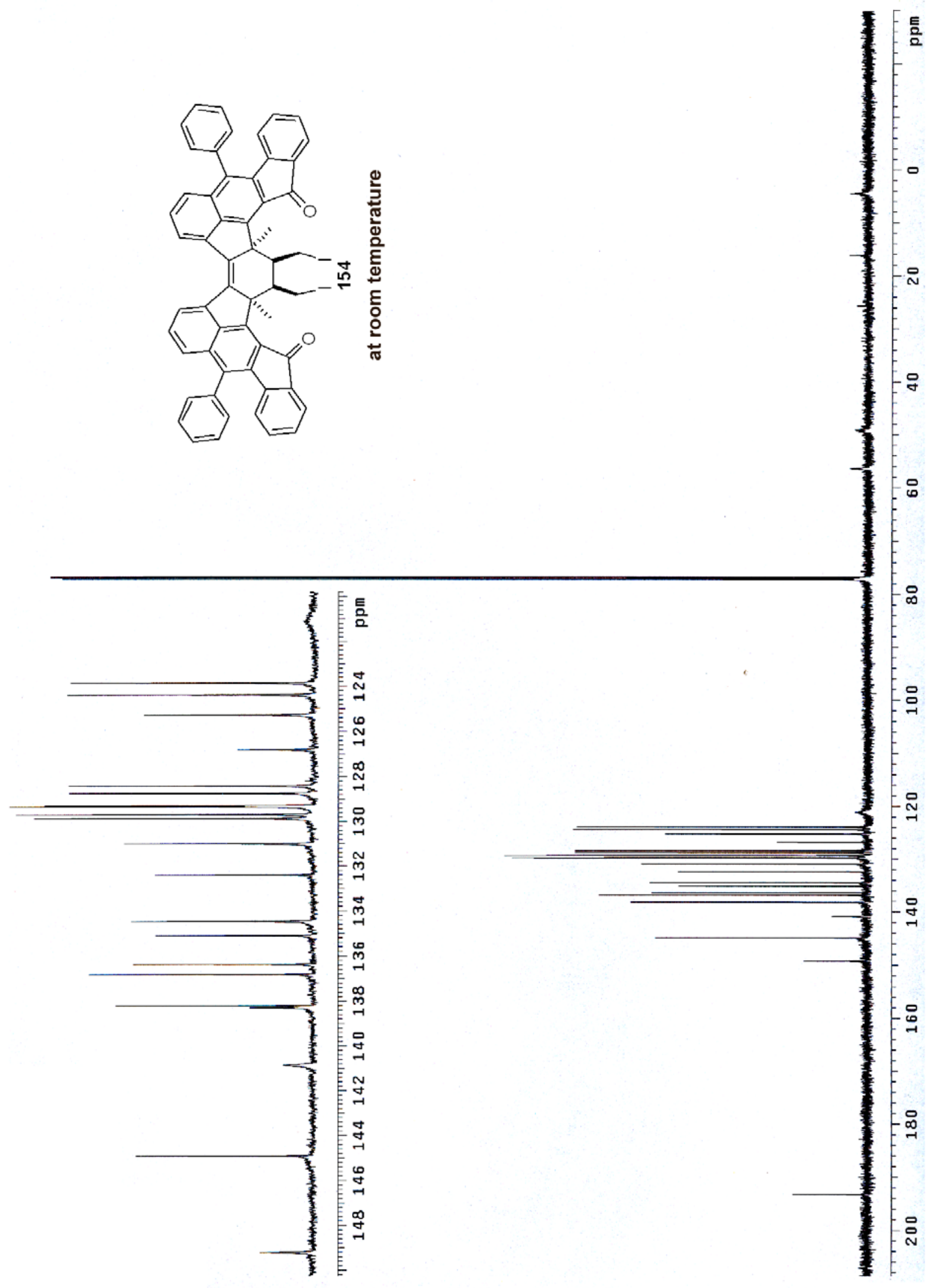


Selective decoupled ${ }^{1} \mathrm{H}$ NMR spectra of 154 in $\mathrm{CDCl}_{3}$

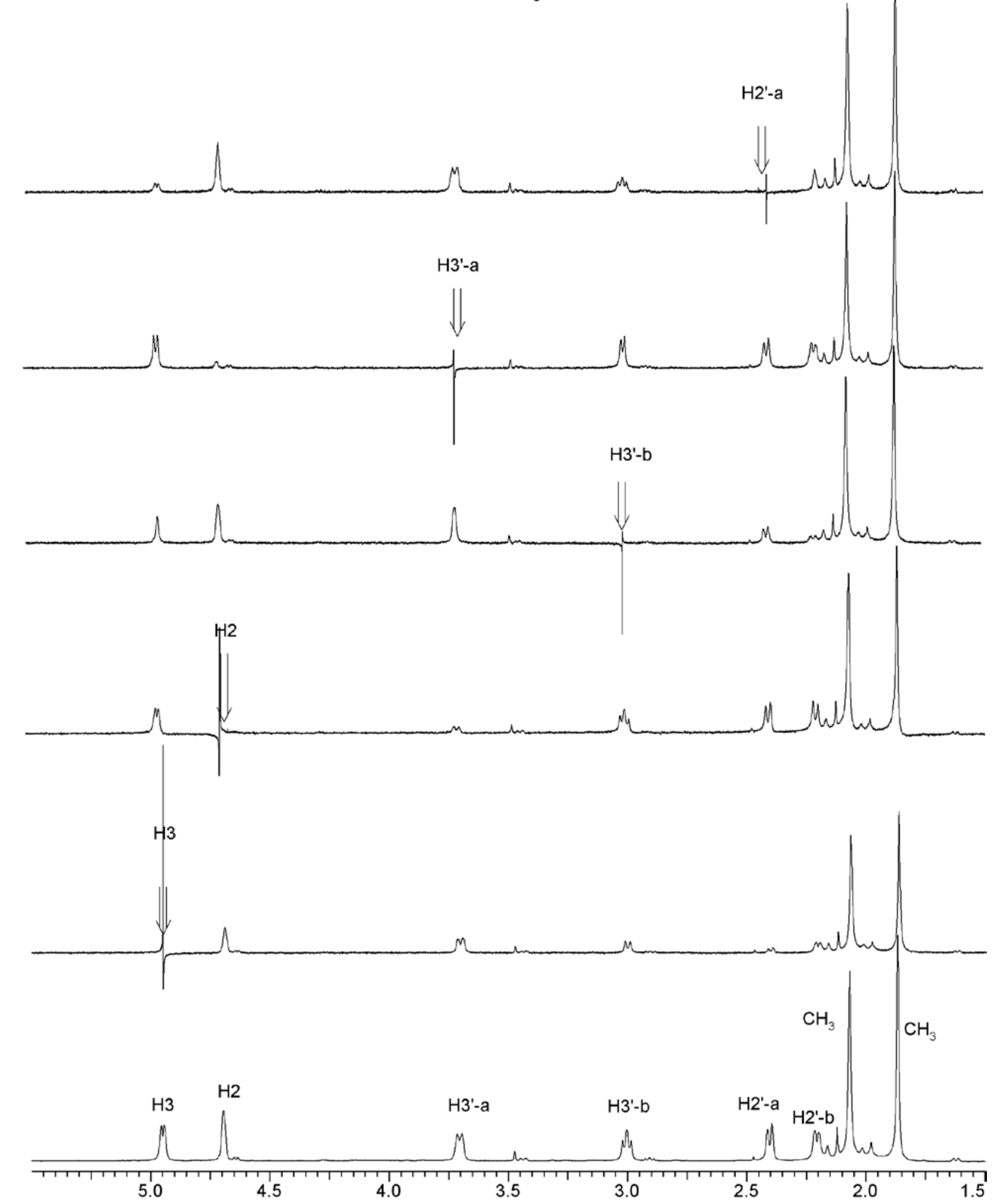


1D TOCSY spectrum of 154 in $\mathrm{CDCl}_{3}$

$$
\mathrm{mix}=30 \mathrm{~ms}
$$

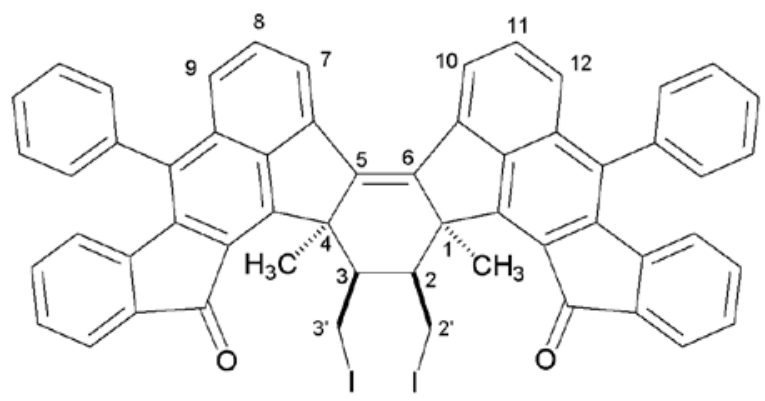

$\mathrm{H} 3$

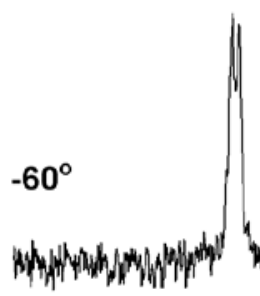

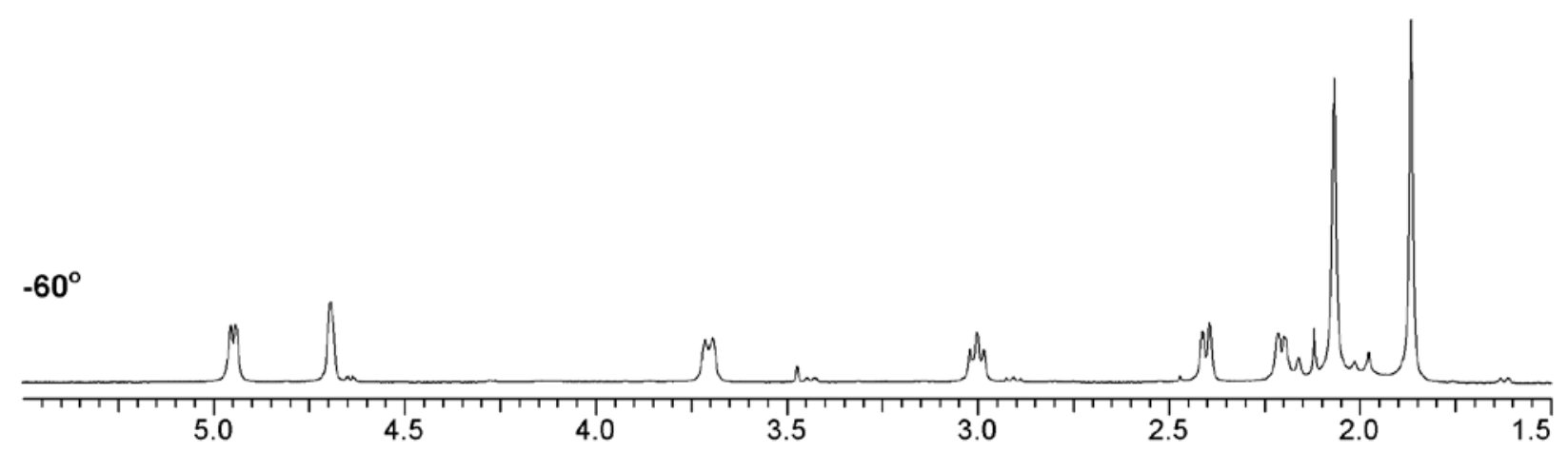




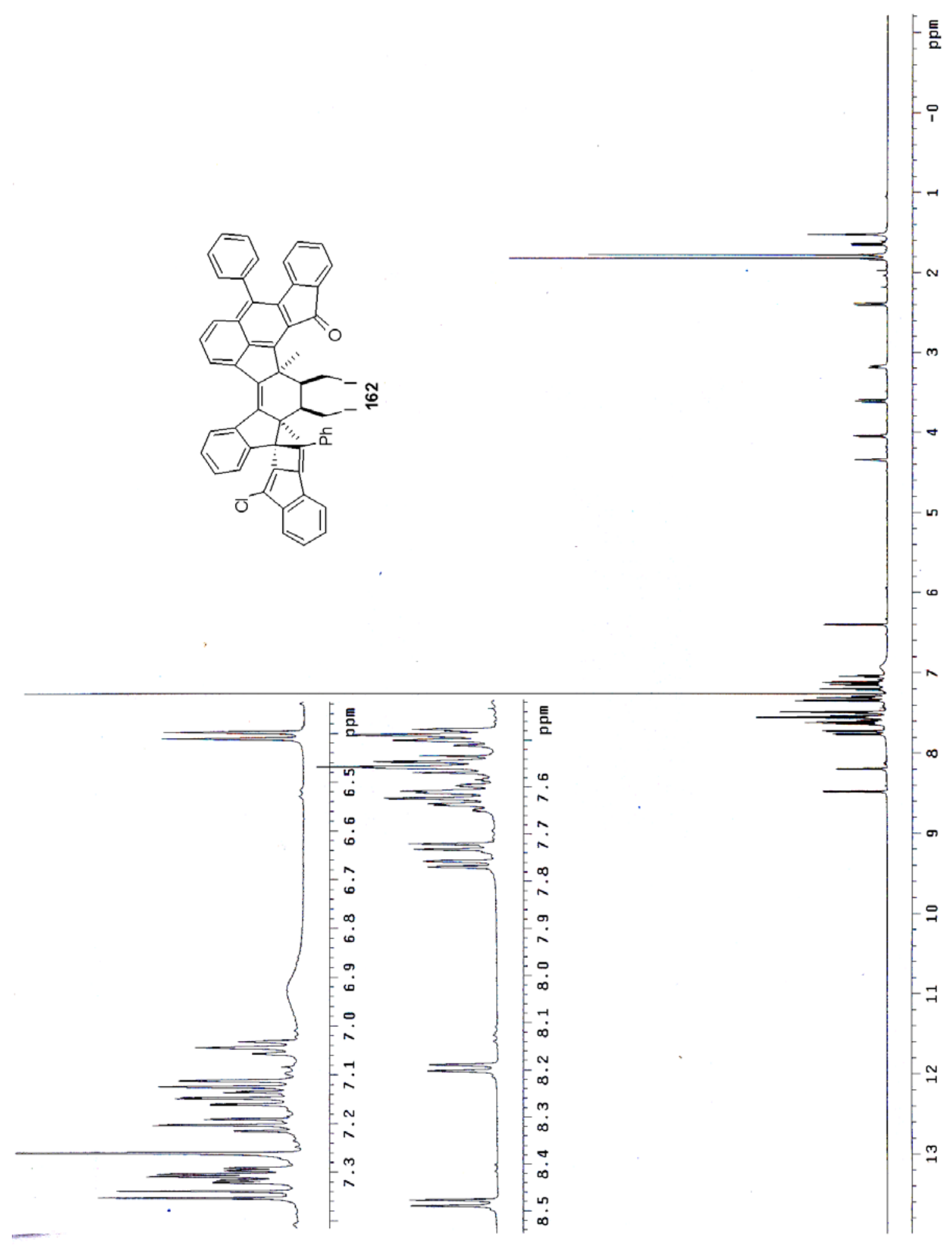



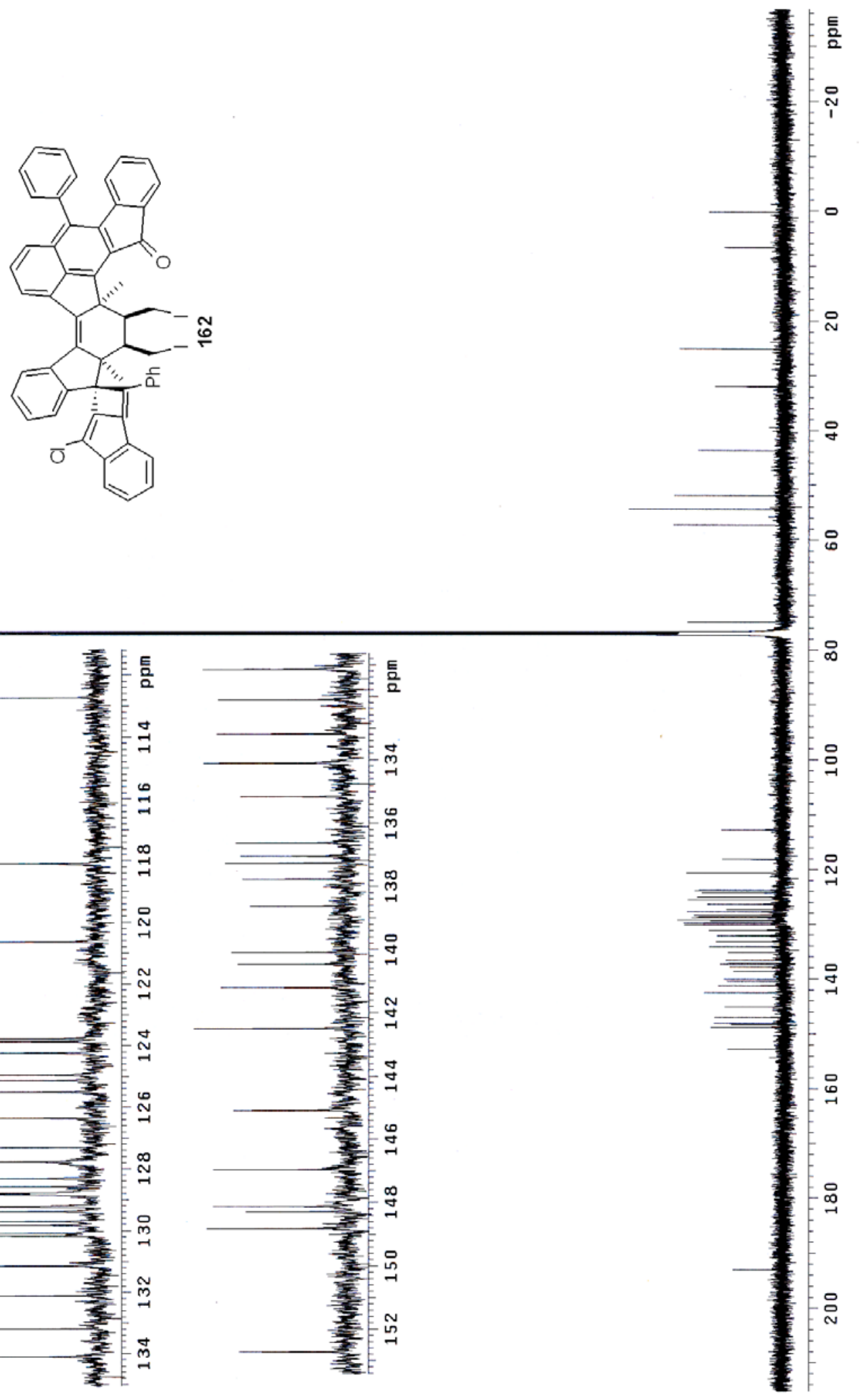
COSY spectrum of 162 in $\mathrm{CDCl}_{3}$

(aromatic region)

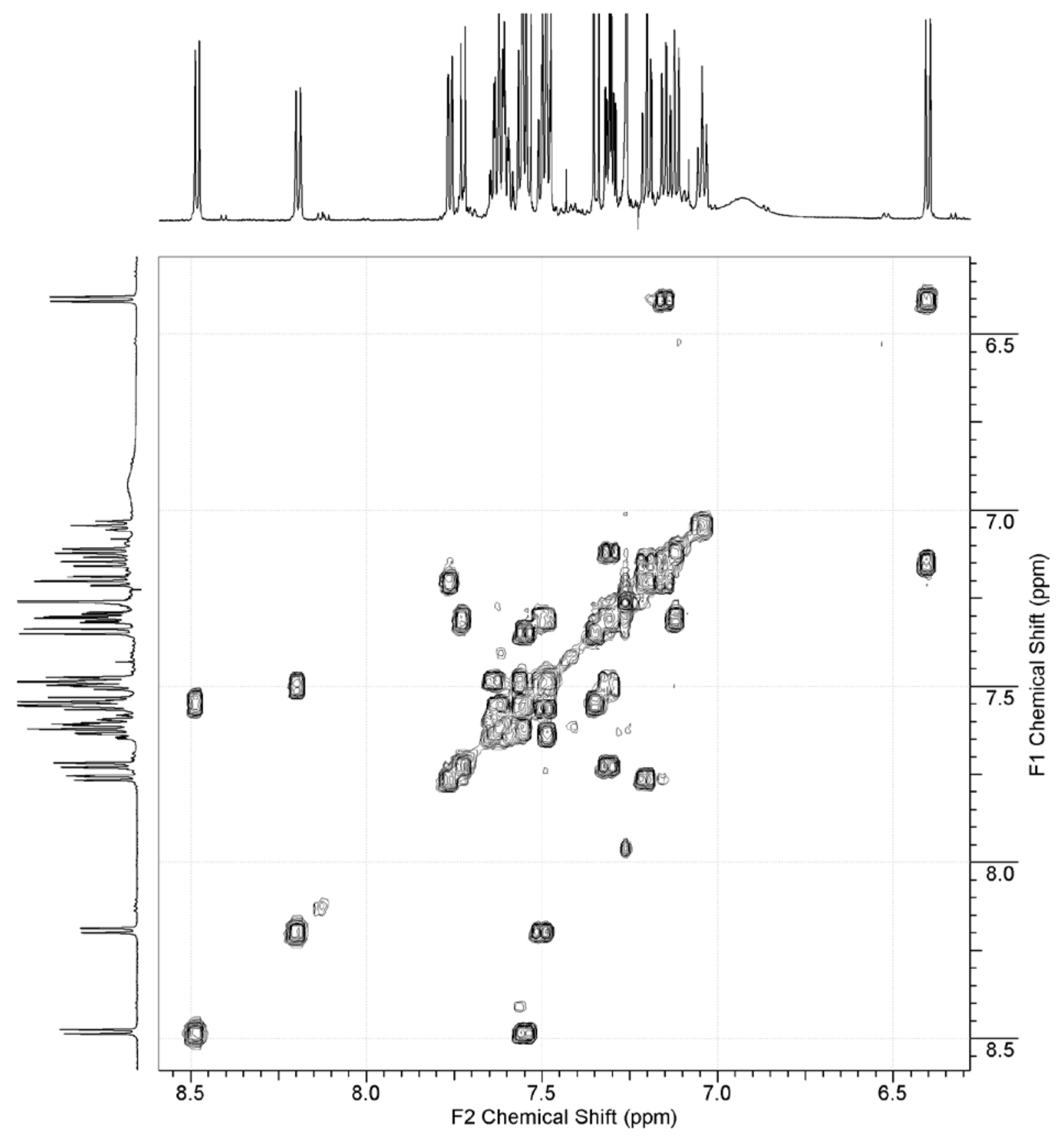


COSY spectrum of 162 in $\mathrm{CDCl}_{3}$

(aromatic region)

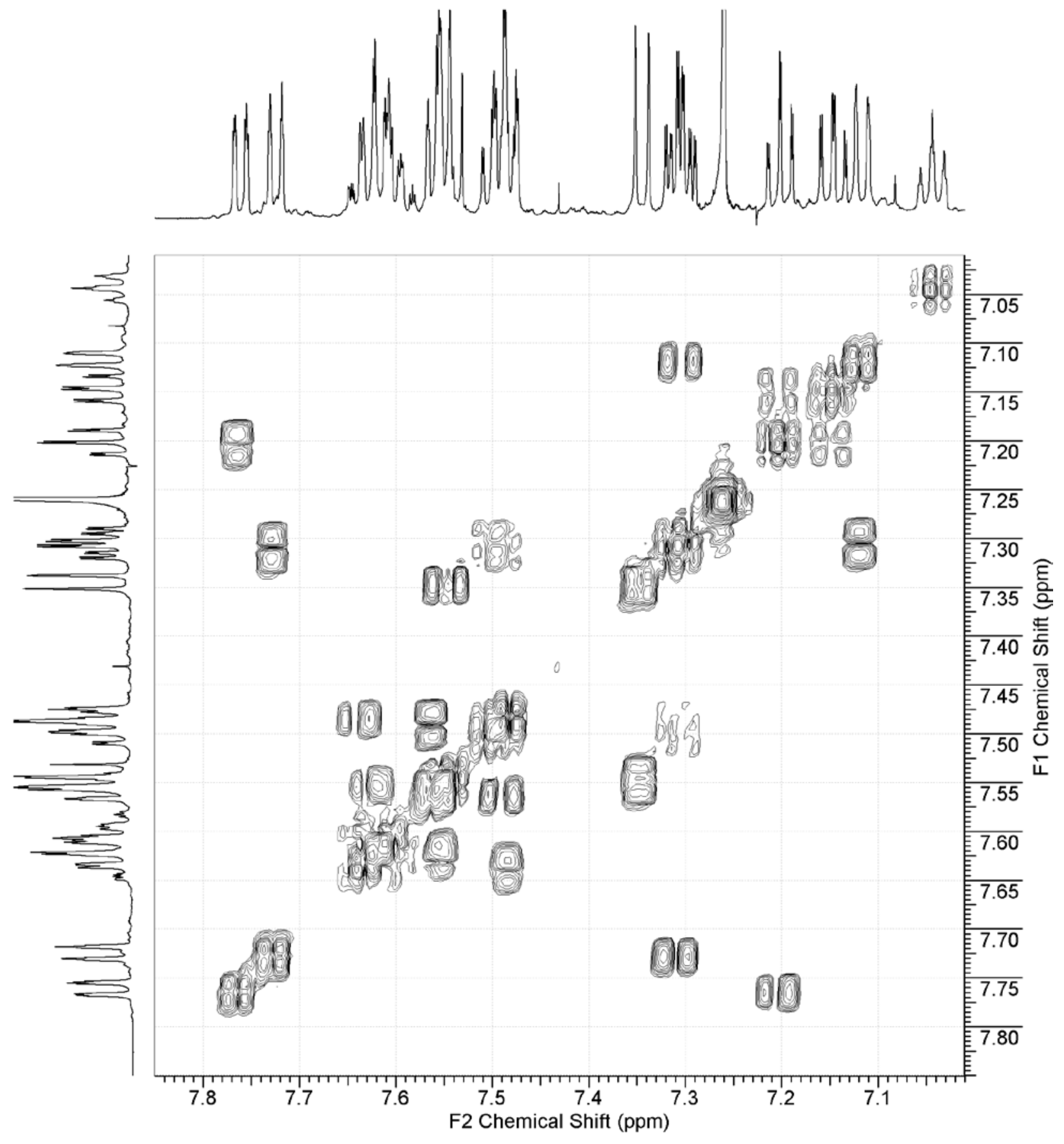


COSY spectrum of 162 in $\mathrm{CDCl}_{3}$ (aliphatic region)

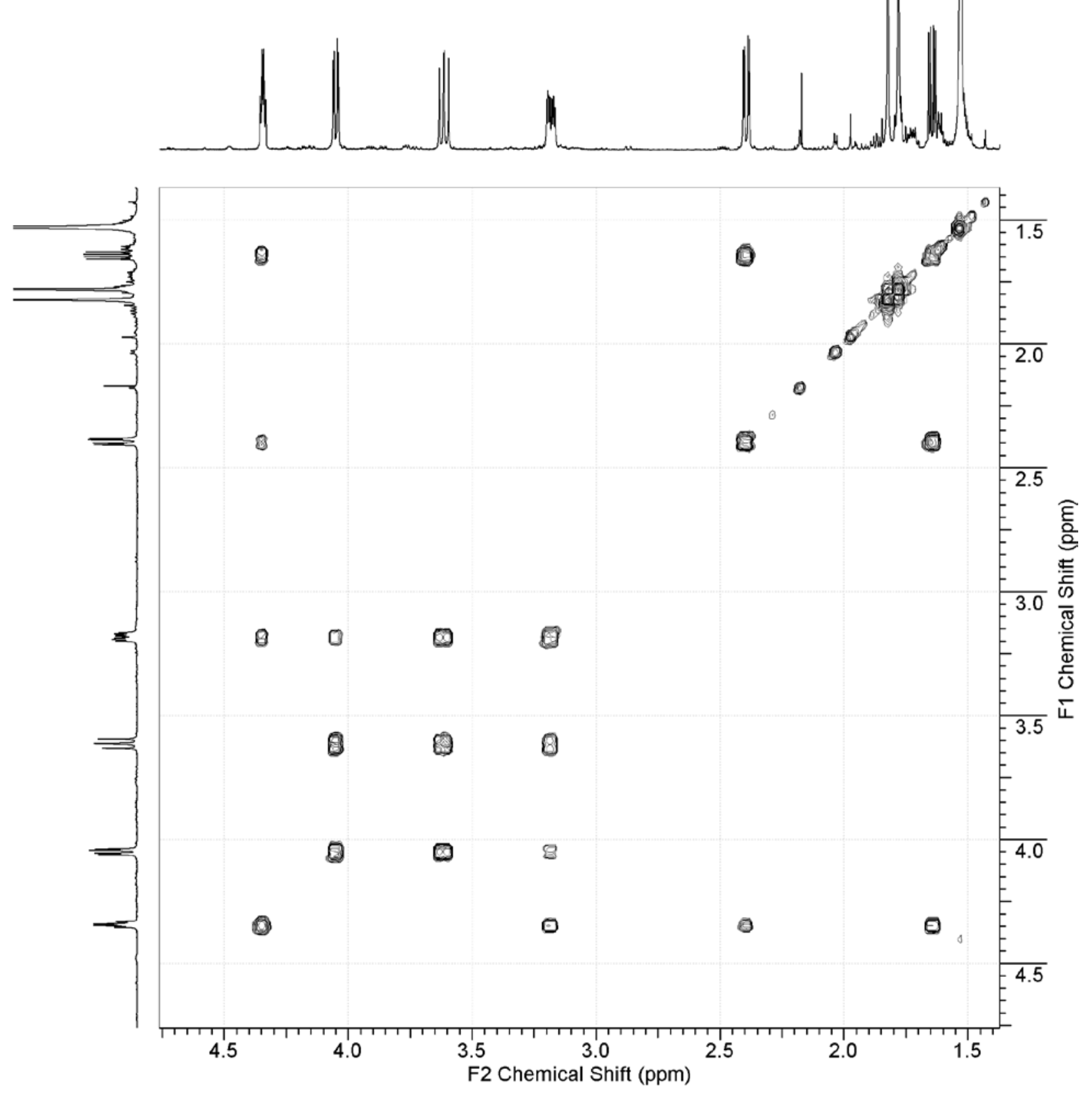


HETCOR spectrum of 162 in $\mathrm{CDCl}_{3}$ (aromatic region)

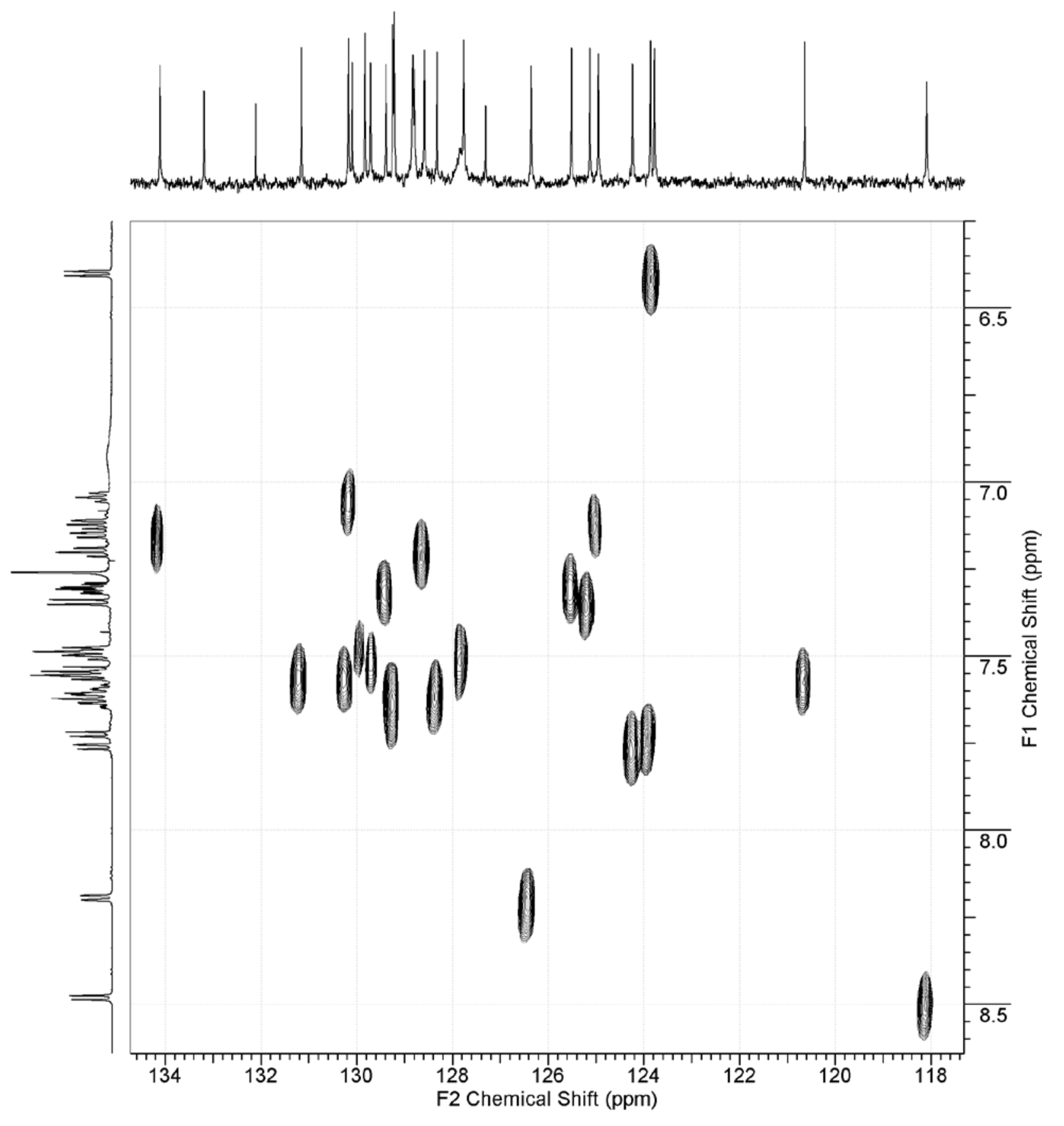


HETCOR spectrum of $\mathbf{1 6 2}$ in $\mathrm{CDCl}_{3}$ (aliphatic region)

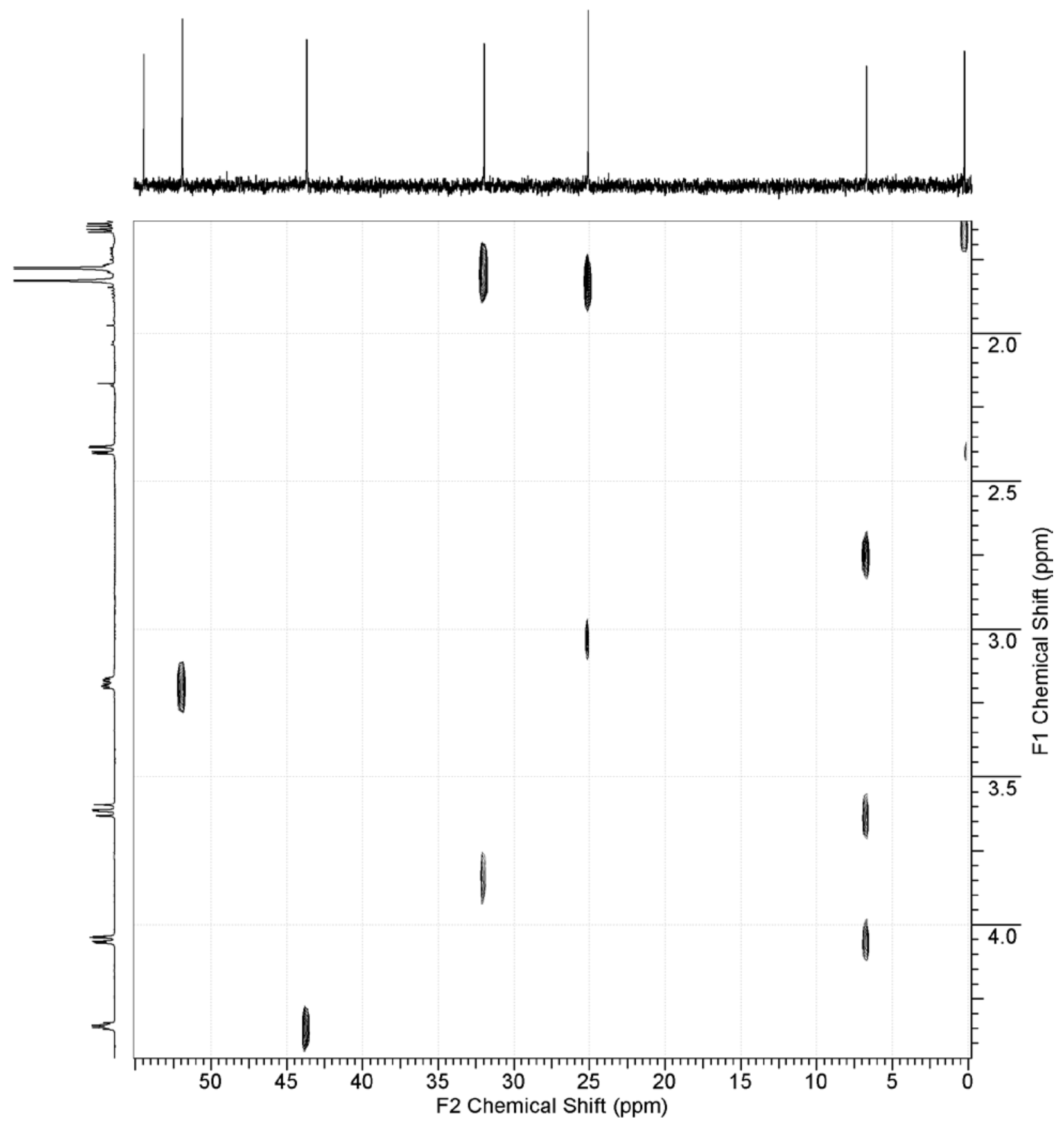




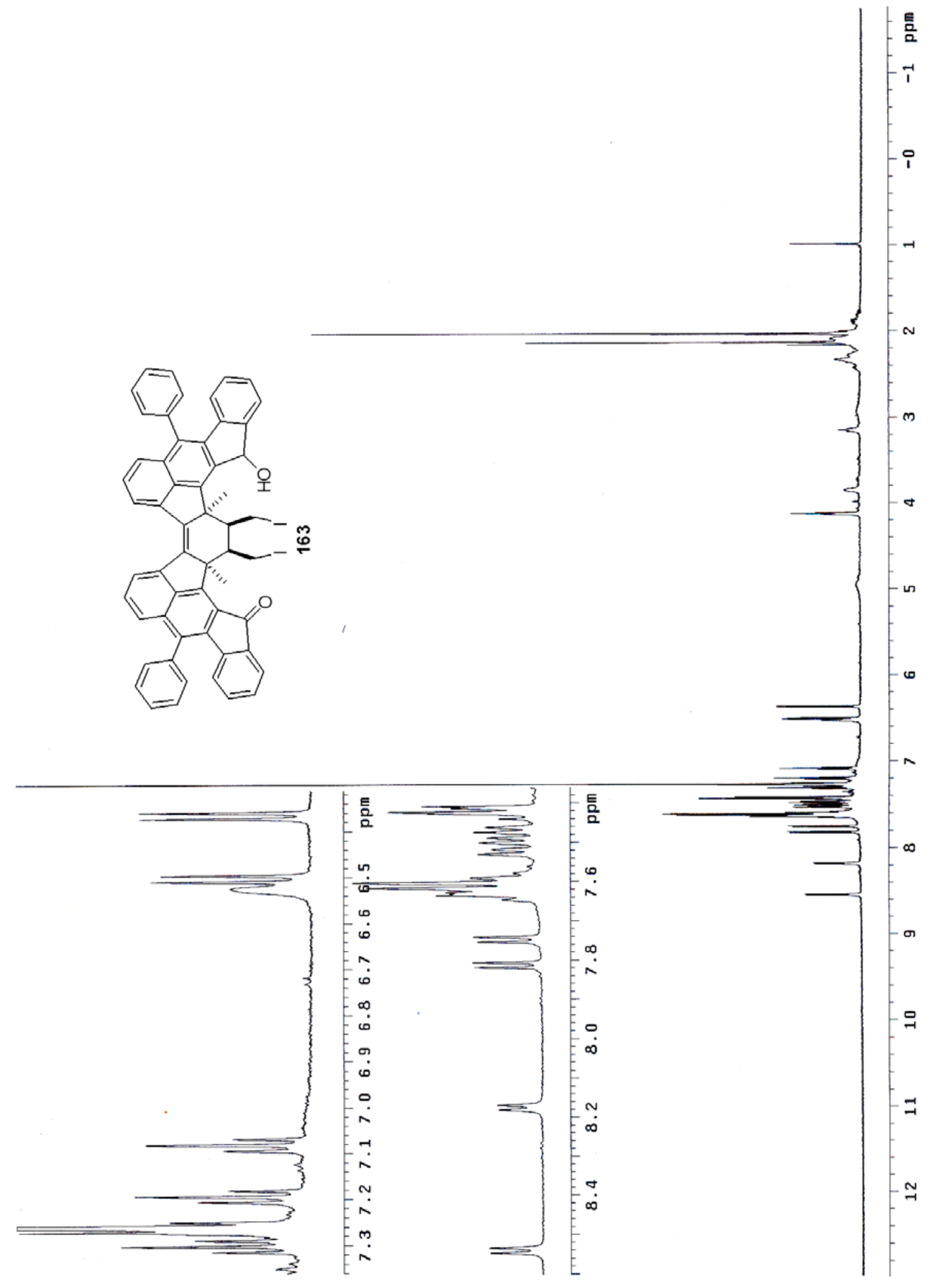



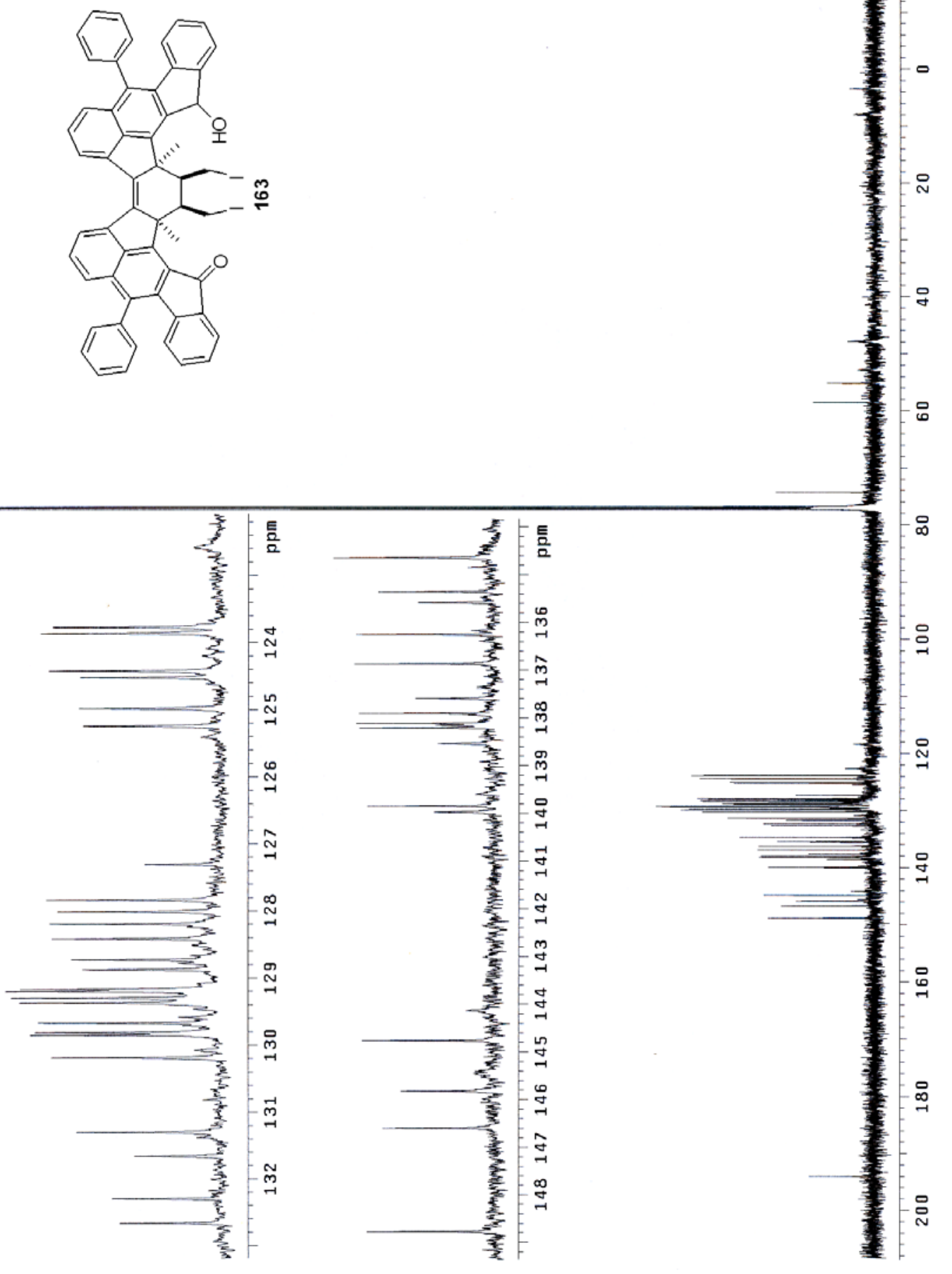


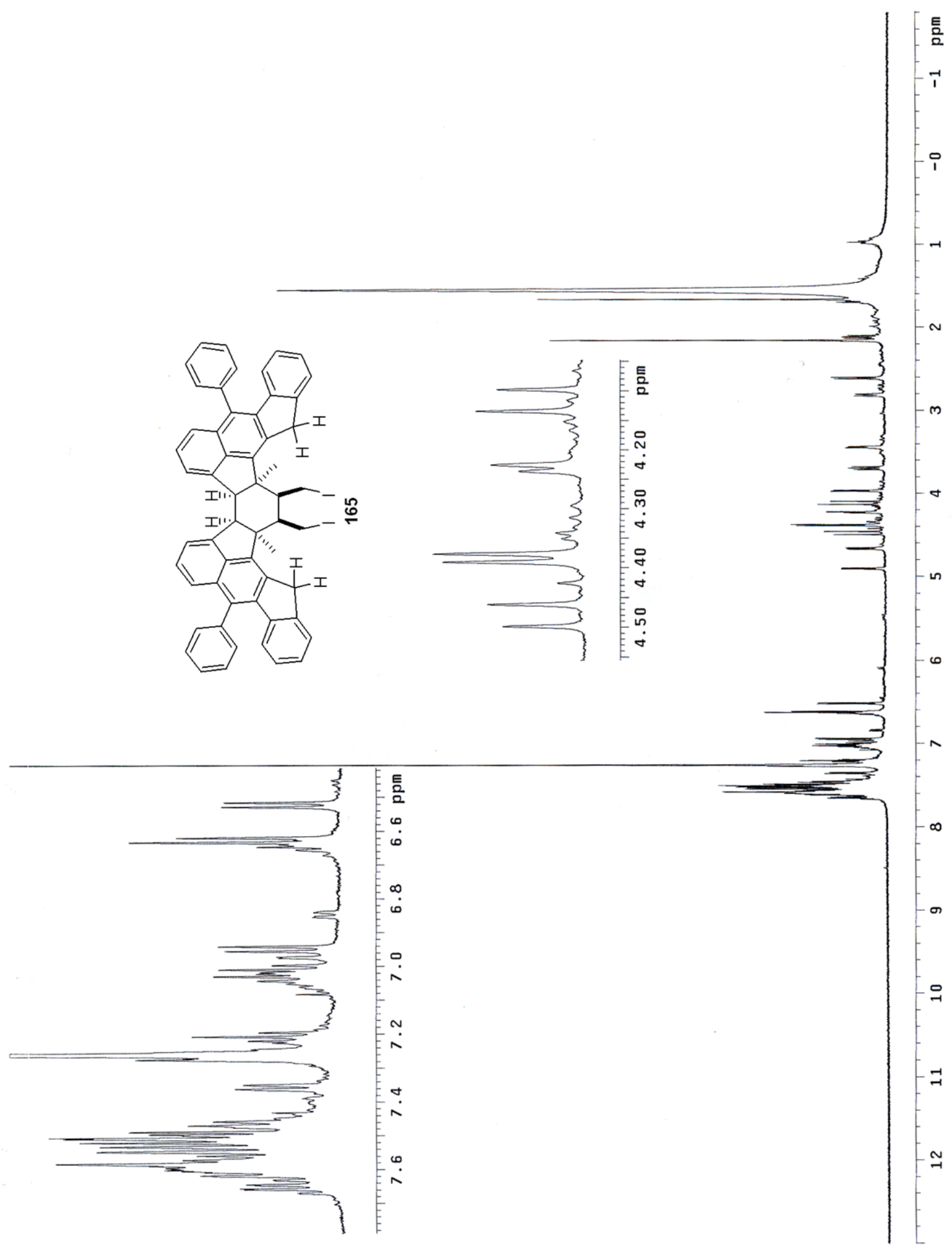




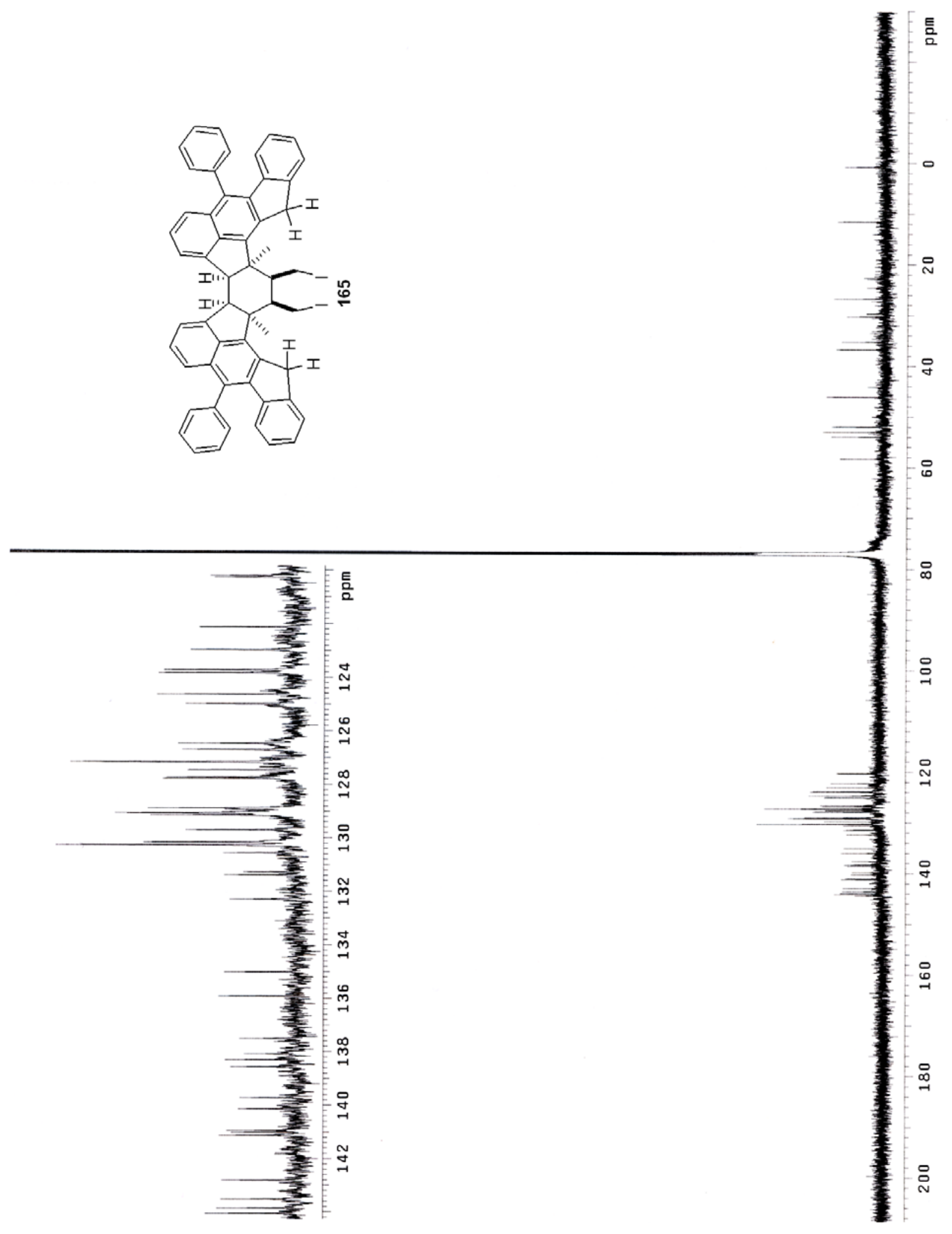




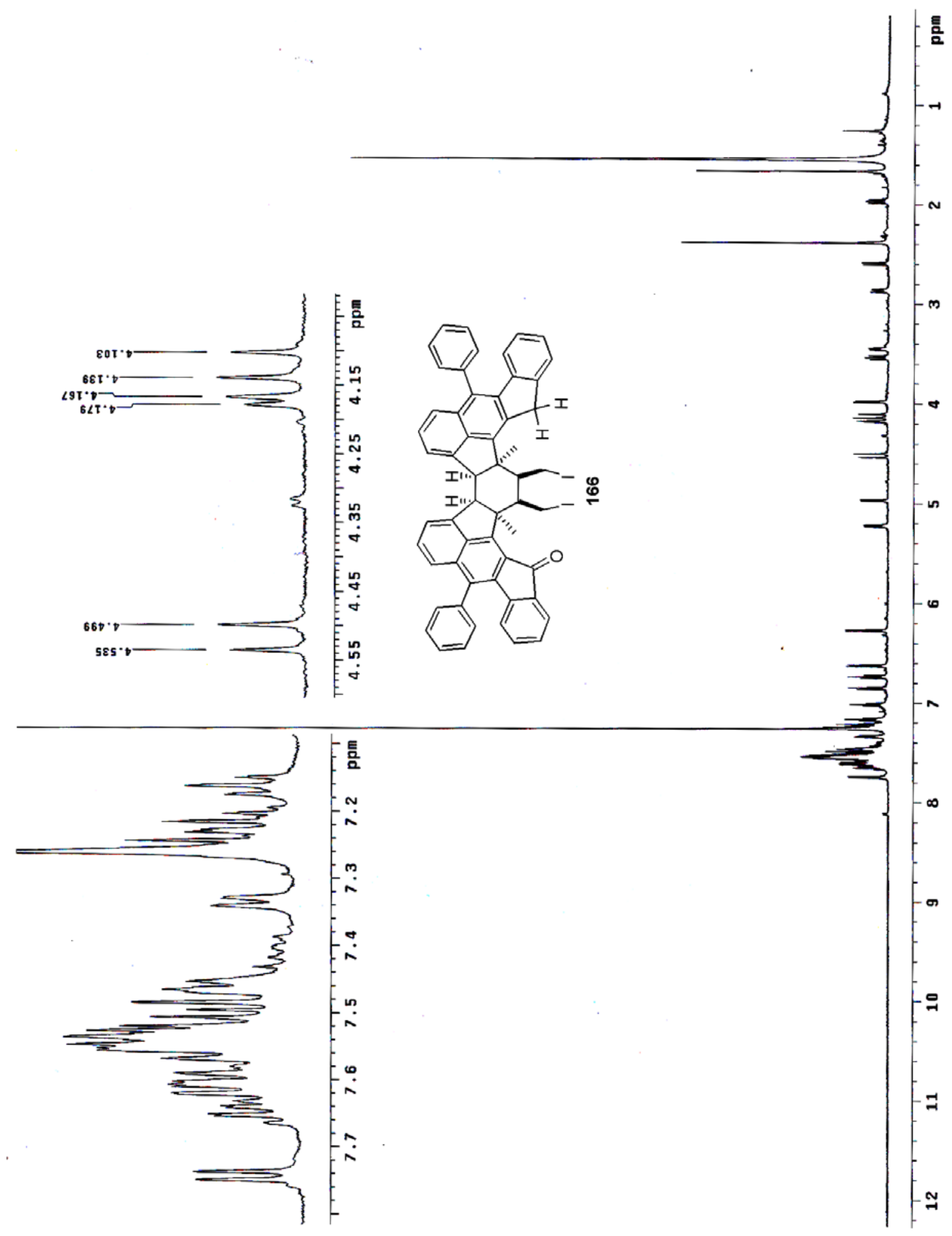




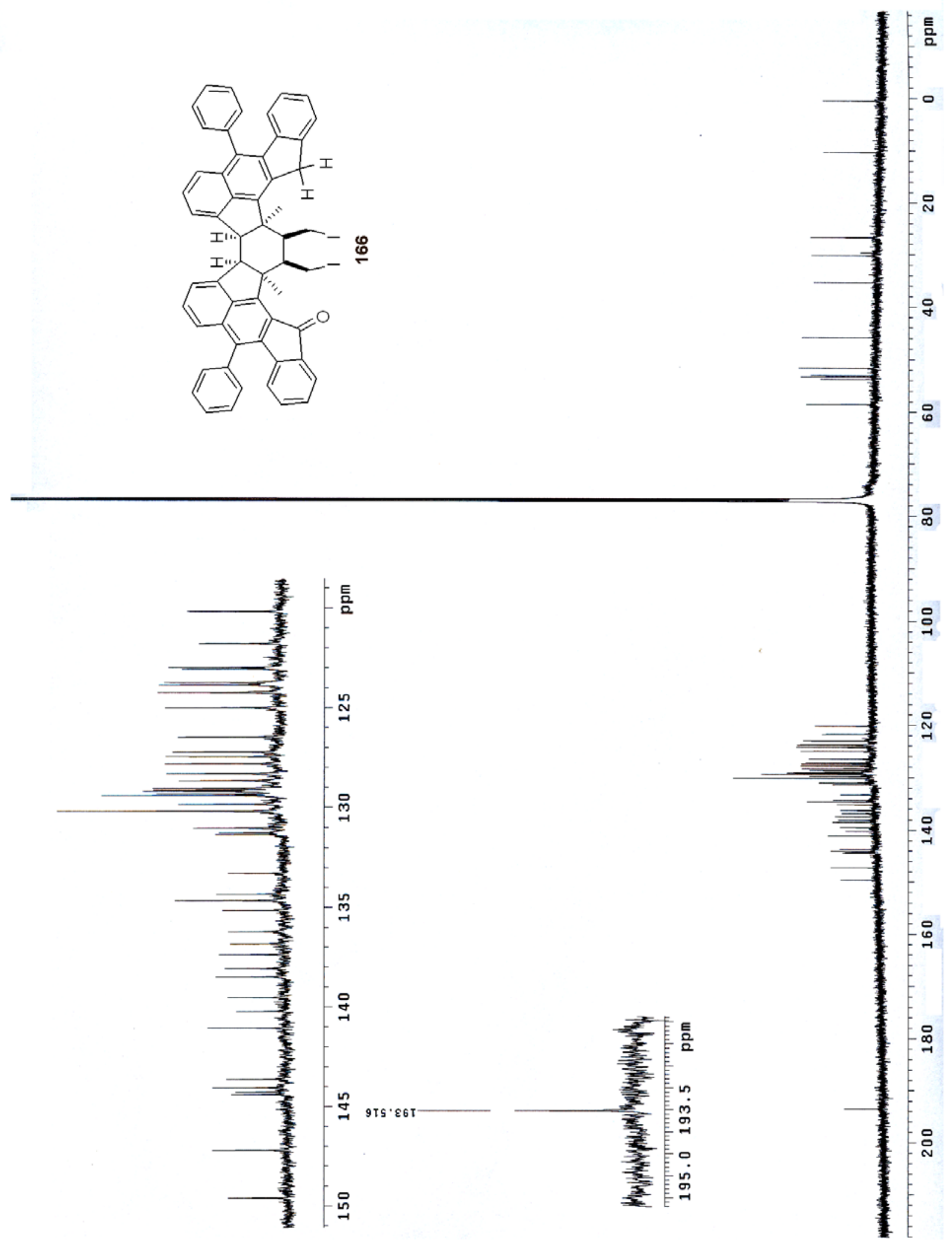


1D TOCSY spectra of 166 in $\mathrm{CDCl}_{3}$

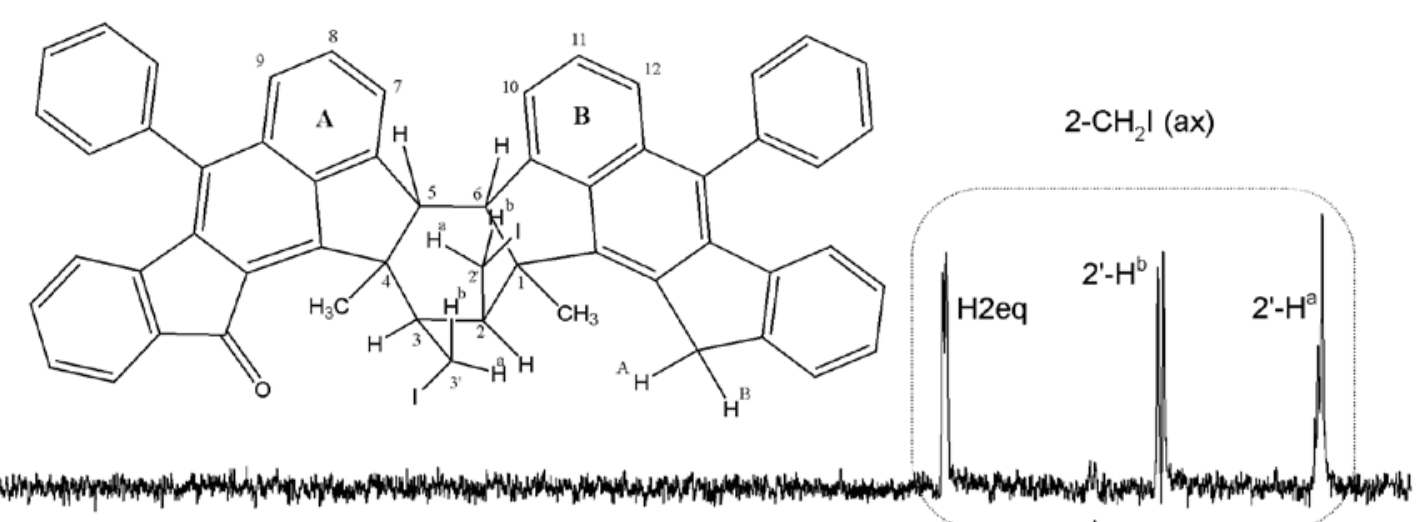

$\operatorname{mix}=80 \mathrm{~ms}$

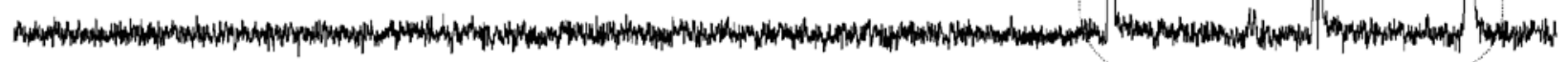
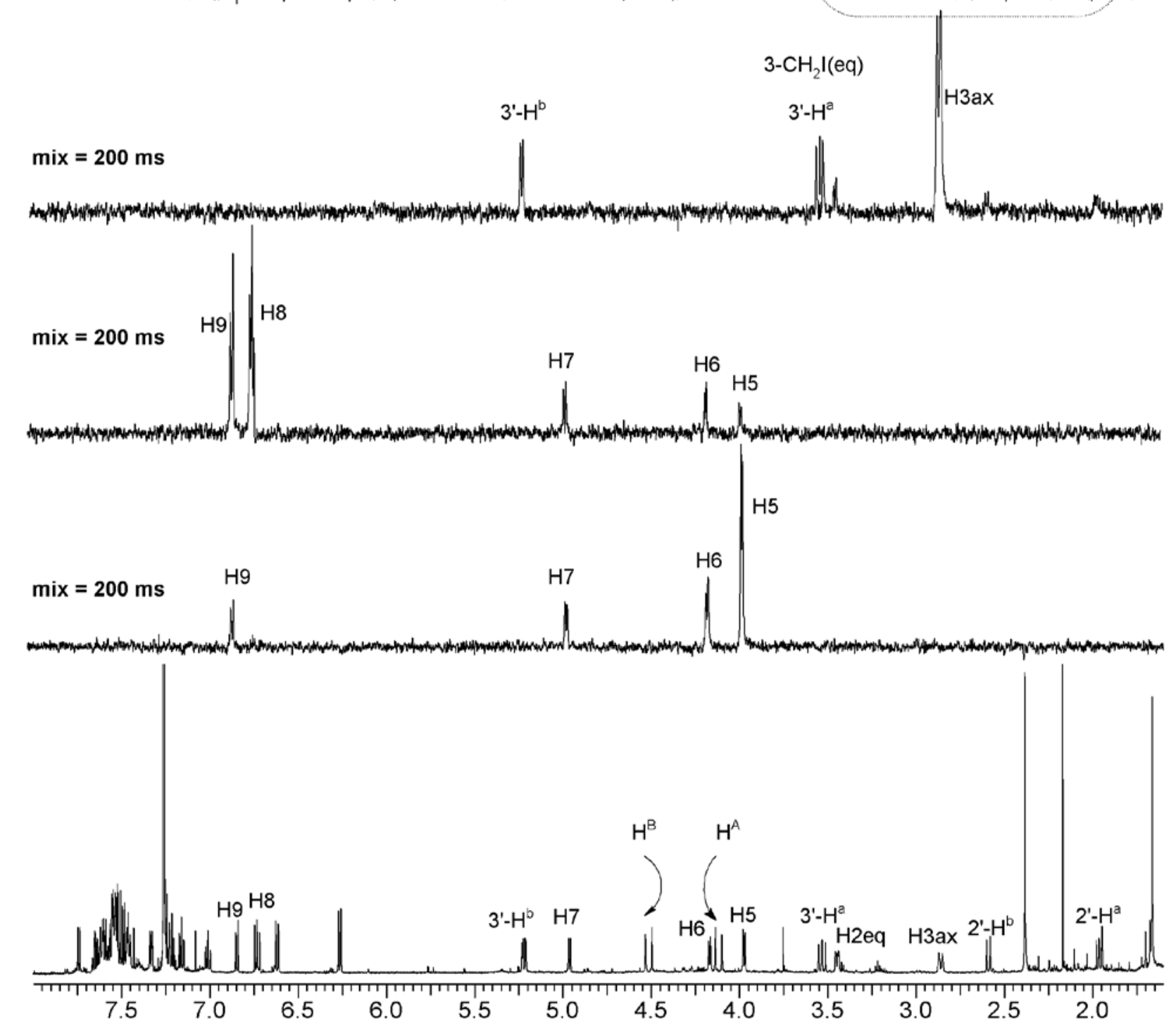
Selective Decoupling Spectra of 166 in $\mathrm{CDCl}_{3}$

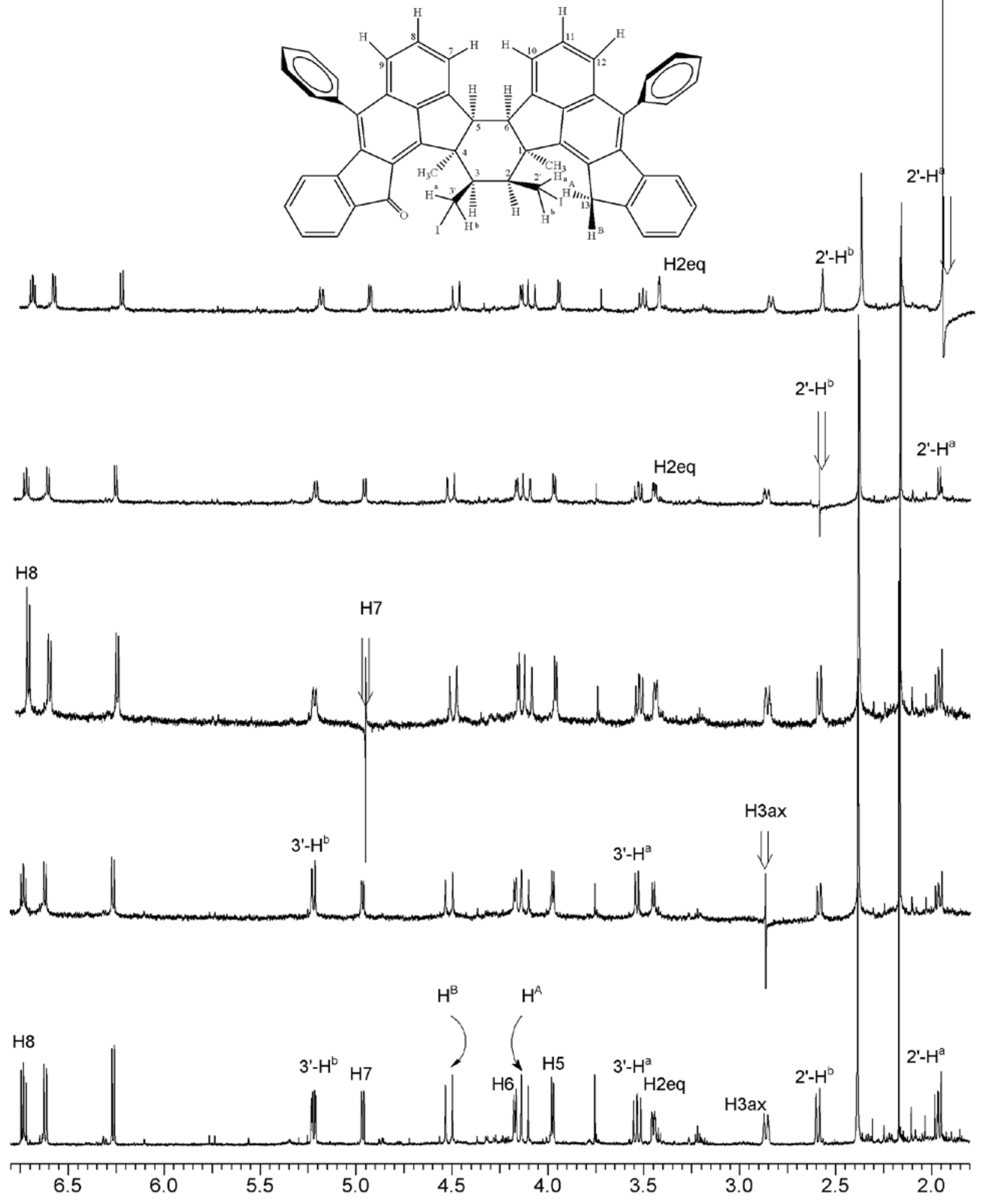


COSY spectrum of 166 in $\mathrm{CDCl}_{3}$
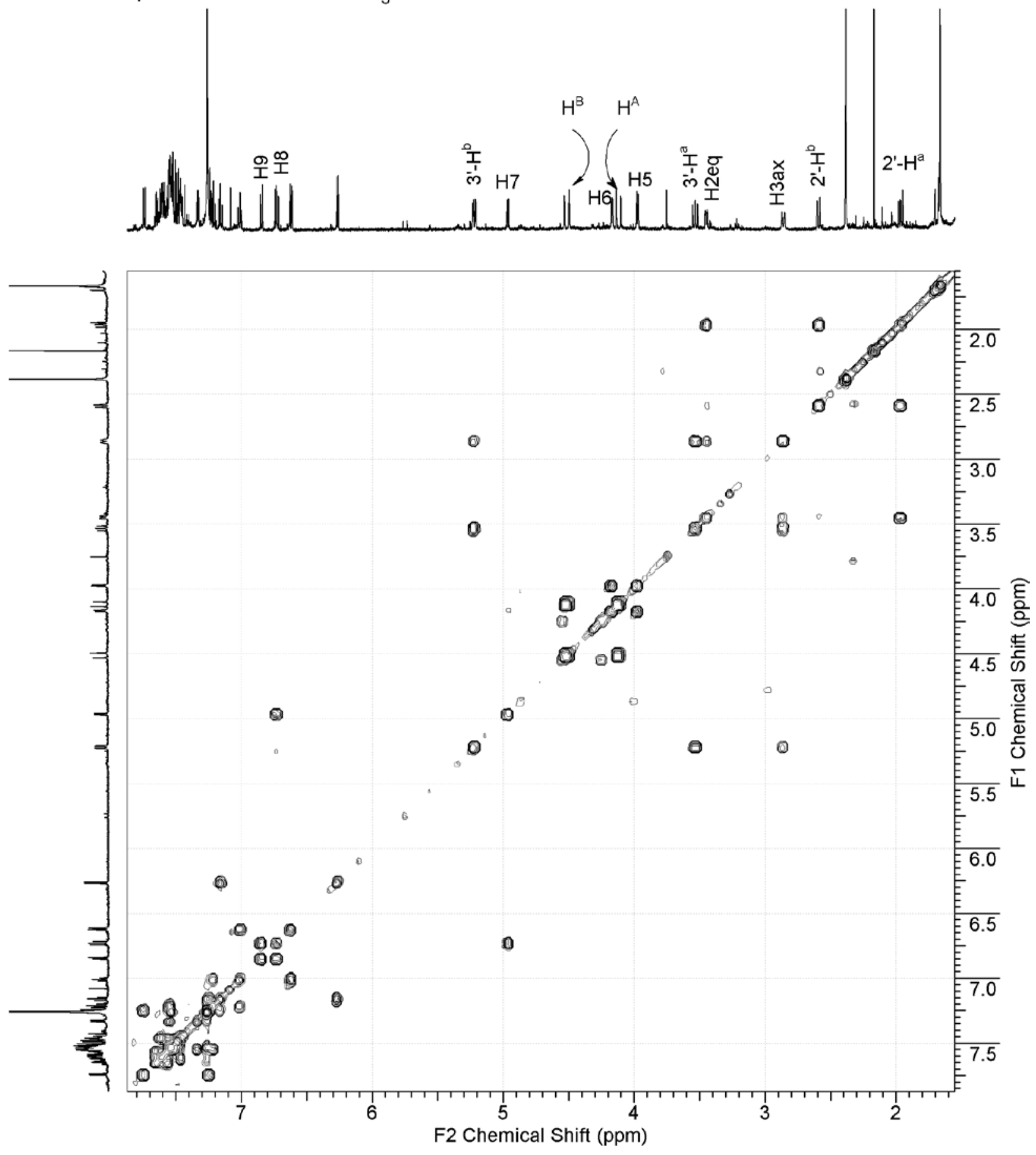
NOESY spectrum of 166 in $\mathrm{CDCl}_{3}$
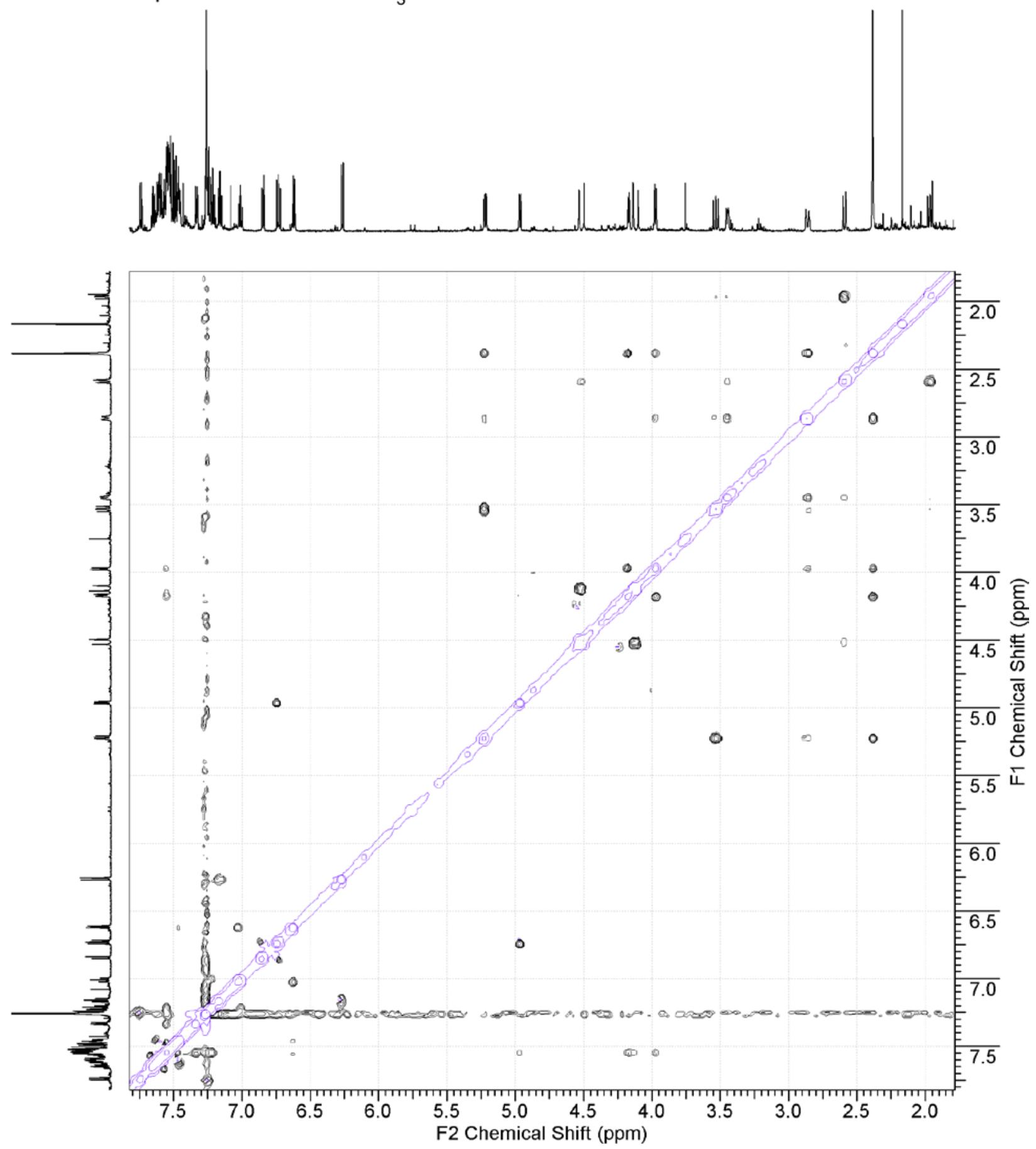
DPFGSENOE spectra of 166 in $\mathrm{CDCl}_{3}$

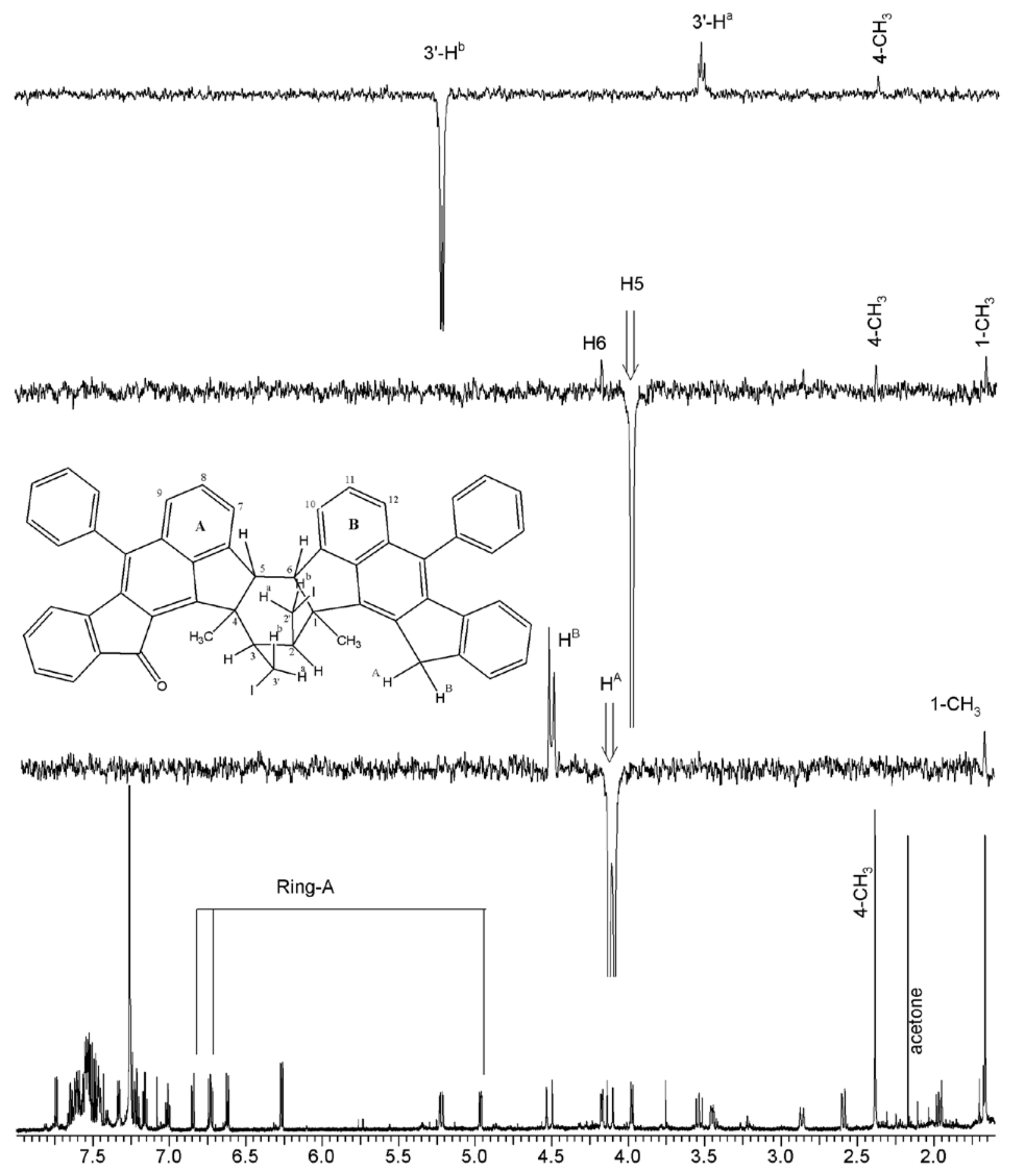


DPFGSENOE spectra of 166 in $\mathrm{CDCl}_{3}$

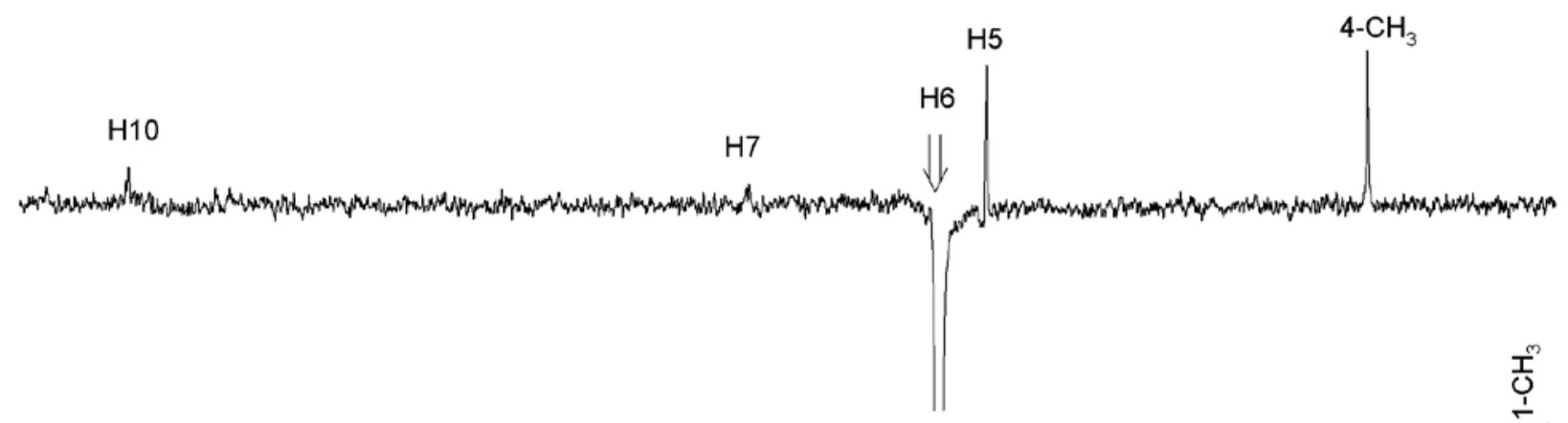

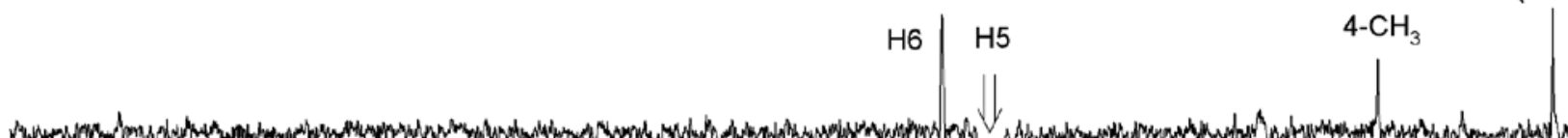

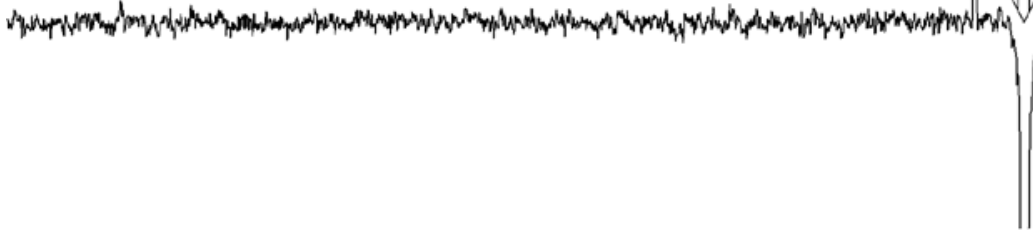

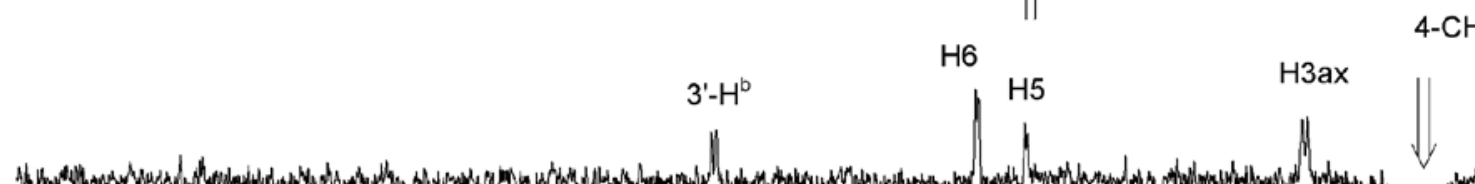

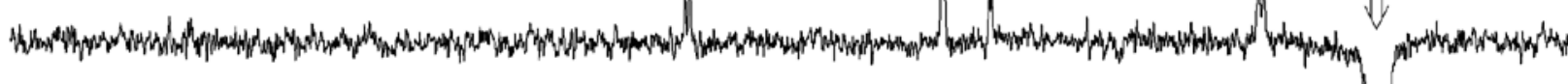

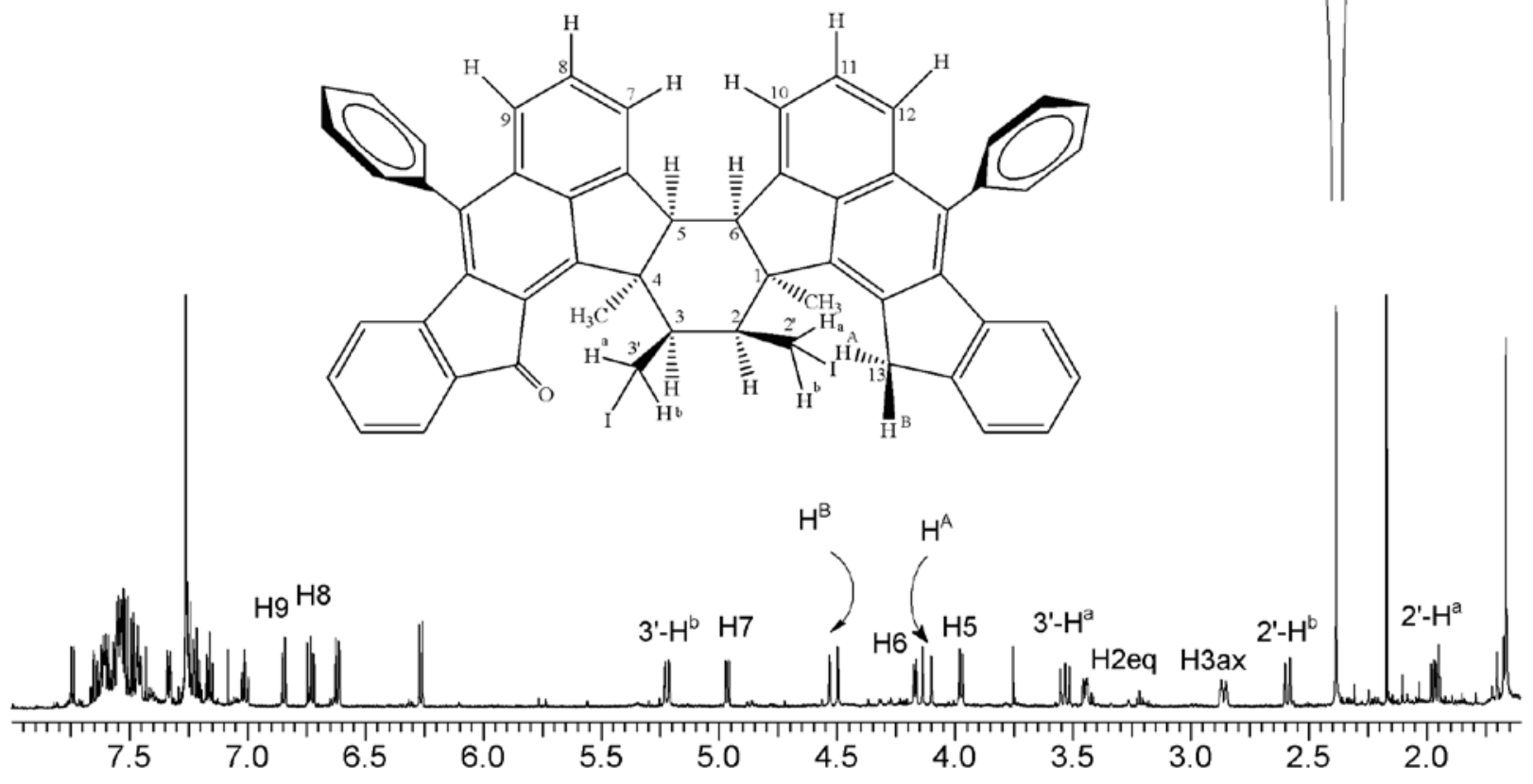


Chemical Shifts $(\delta / \mathrm{ppm})$ and Coupling Constants $(\mathrm{J} / \mathrm{Hz})$ in 167.

\begin{tabular}{|c|c|c|c|}
\hline Protons & $\mathrm{CDCl}_{3}{ }^{b}$ & $\mathrm{C}_{6} \mathrm{D}_{6}$ & Coupling constant (in $\mathrm{Hz})^{a}$ \\
\hline H1 & 4.16 & 4.17 & $\begin{array}{c}J_{1,2 \alpha}=5.4 \\
J_{1,2 \beta}=12.14\end{array}$ \\
\hline $\mathrm{H} 2 \alpha$ & 1.68 & 1.56 & $\begin{array}{c}J_{2 \alpha, 2 \beta}=14.68 \\
J_{2 \alpha, 3}=0.01\end{array}$ \\
\hline $\mathrm{H} 2 \beta$ & 3.37 & 3.04 & $J_{2 \beta, 3}=8.41$ \\
\hline H3 & 3.02 & 2.78 & $J_{3,4}=5.42$ \\
\hline H4 & 1.82 & 1.63 & $\begin{array}{c}J_{4,5 \alpha}=13.23 \\
J_{4,5 \beta}=4.53\end{array}$ \\
\hline $\mathrm{H} 5 \alpha$ & -3.4 & -3.15 & $\begin{array}{c}J_{5 \alpha, 5 \beta}=12.68 \\
J_{5 \alpha, 6}=11.17\end{array}$ \\
\hline $\mathrm{H} 5 \beta$ & 0.28 & 0.20 & $J_{5 \beta, 6}=4.36$ \\
\hline H6 & 2.91 & 2.80 & - \\
\hline H8 & 4.11 & 4.02 & $J_{8,9}=8.00$ \\
\hline H9 & 4.07 & 3.94 & - \\
\hline 7- $\mathrm{CH}_{3}$ & 1.50 & 1.42 & - \\
\hline $10-\mathrm{CH}_{3}$ & 1.70 & 1.55 & - \\
\hline H11 & 3.89 & - & - \\
\hline H12 & 6.25 & - & - \\
\hline H13 & 6.40 & - & - \\
\hline
\end{tabular}

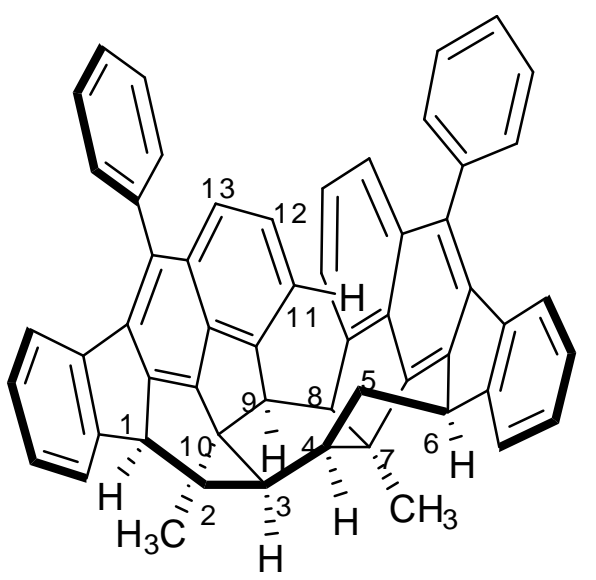

167

${ }^{a}$ in $\mathrm{CDCl}_{3}$

${ }^{b}$ data were recorded as the reference set to TMS $\left({ }^{1} \mathrm{H} \delta 0.00\right)$ 
gNMR-Simulated ${ }^{1} \mathrm{H}$ NMR Spectra of $\mathbf{1 6 7}$ in $\mathrm{CDCl}_{3}$ (top - experimental, bottom - calculated)
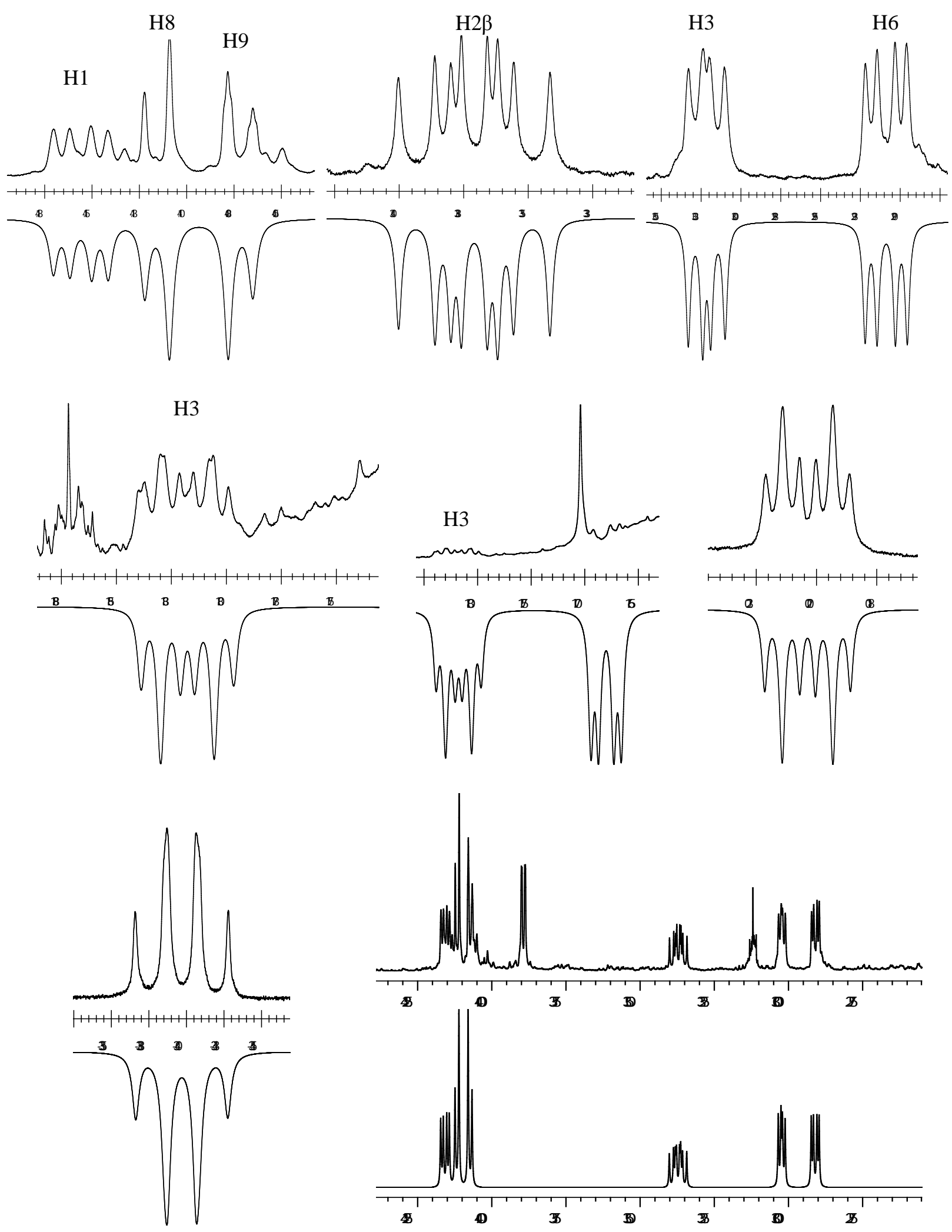


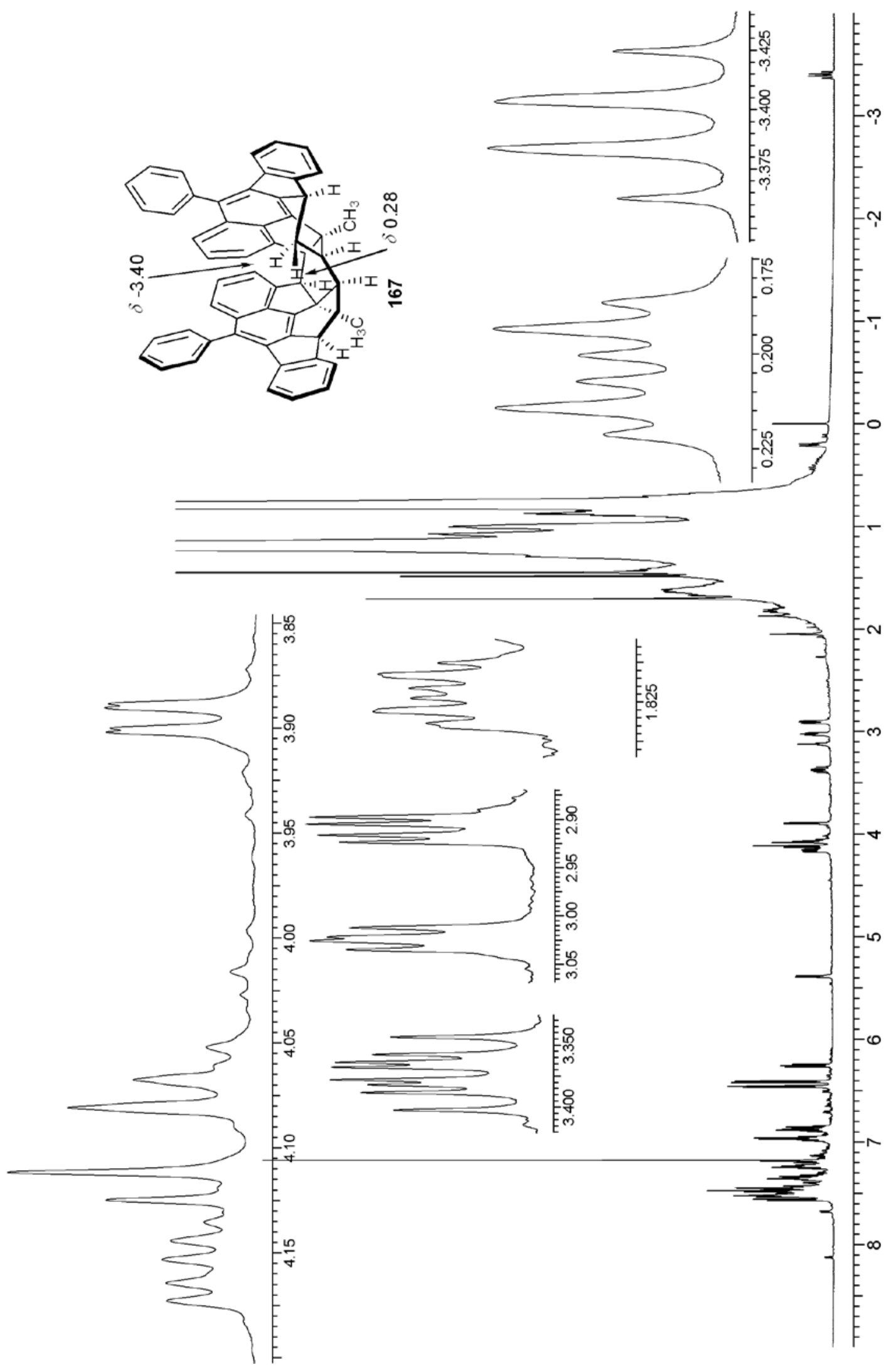




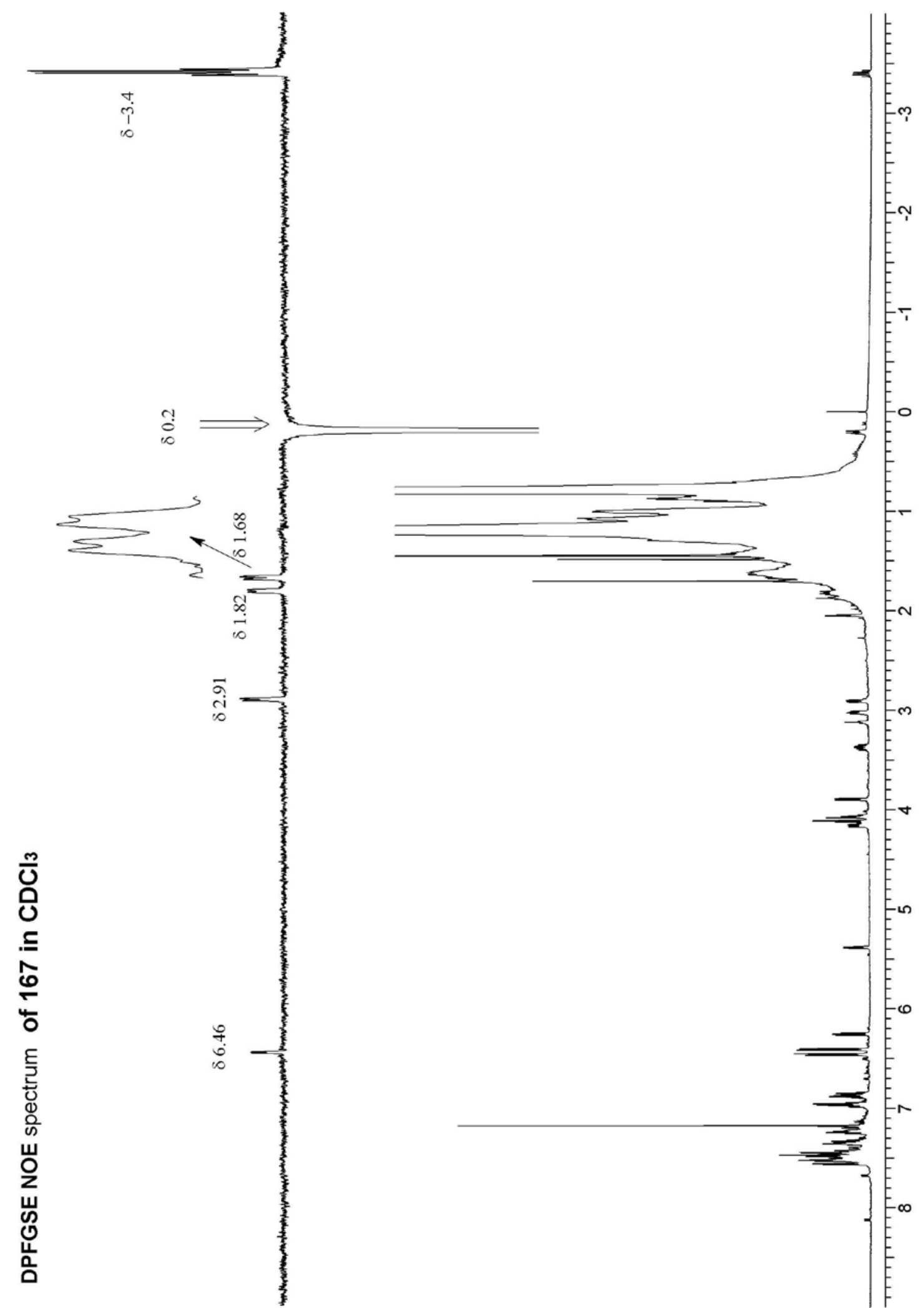




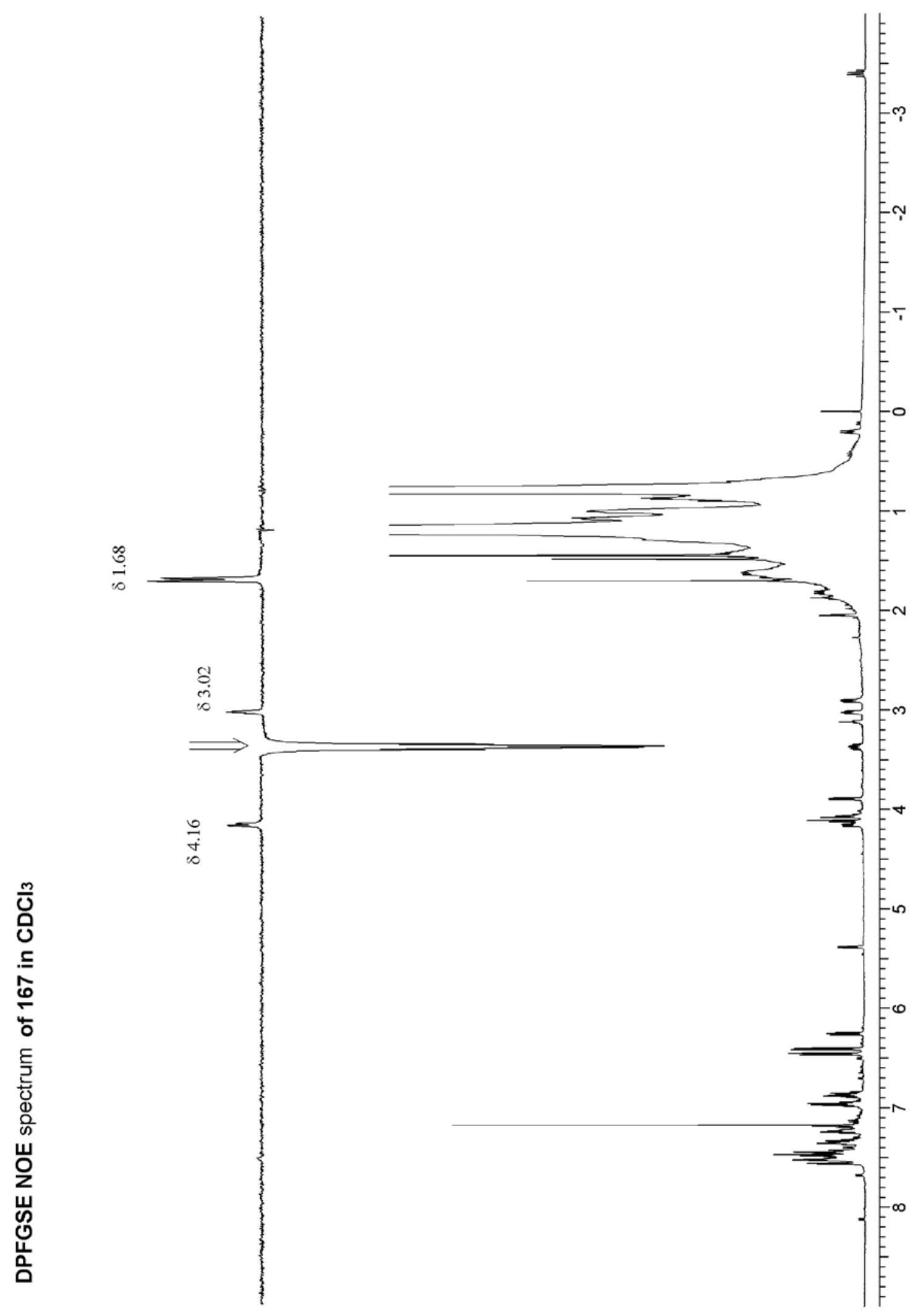


1D TOCSY Spectra of 167 in $\mathrm{CDCl} 3$
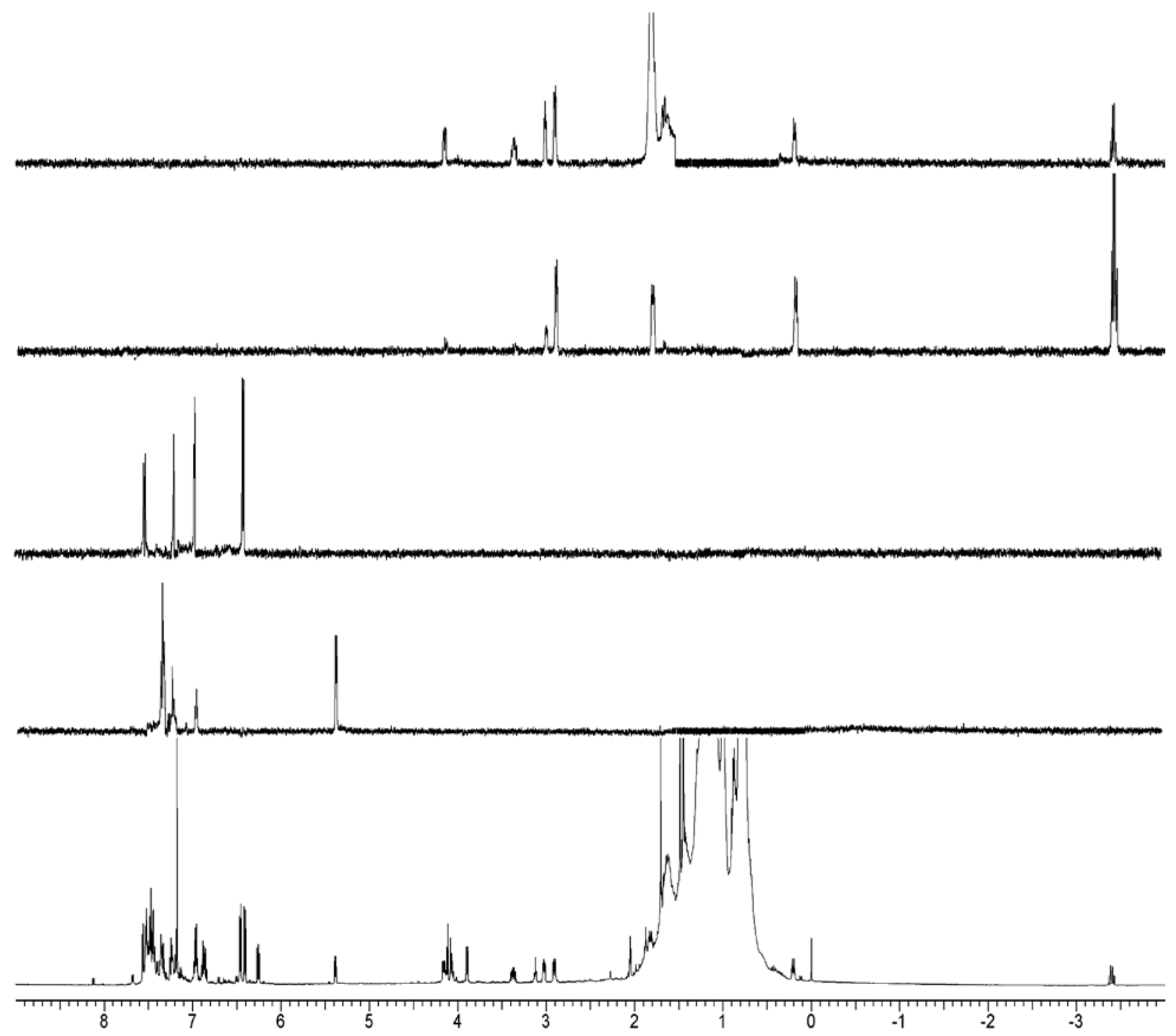
COSY Spectrum of 167 in $\mathrm{CDCl}_{3}$

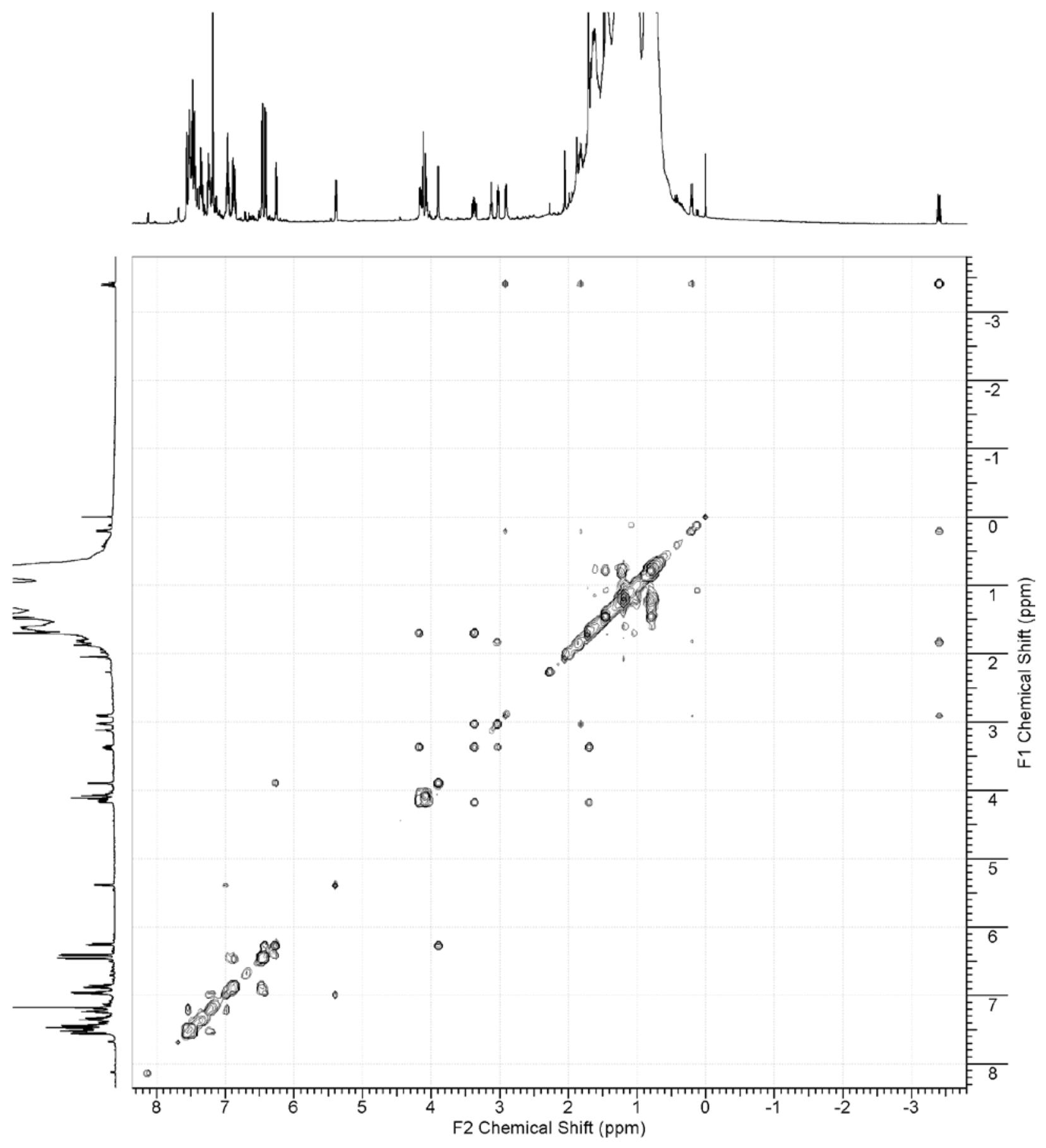


COSY Spectrum of 167 in $\mathrm{CDCl}_{3}$ (Aromatic Region)

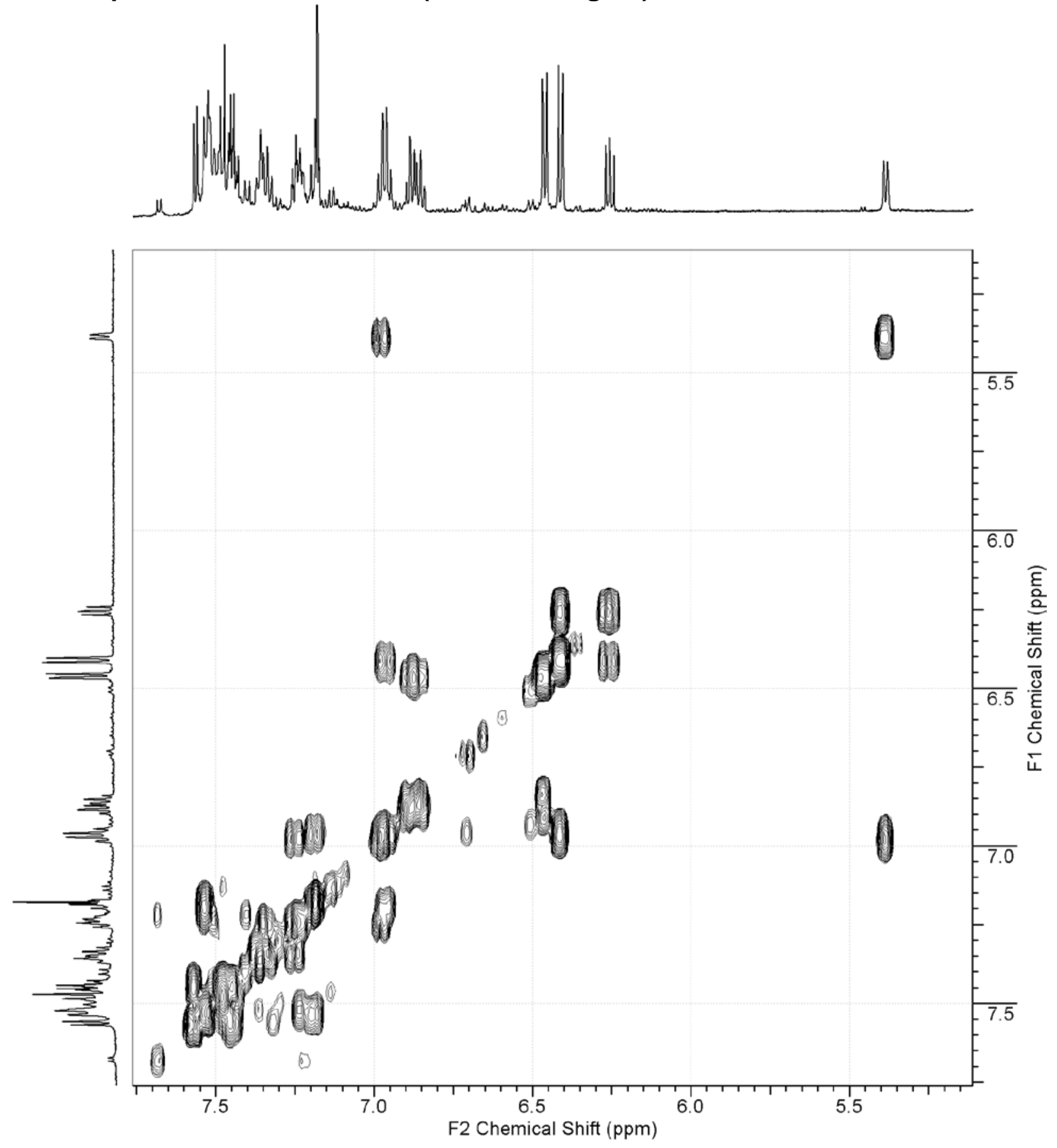


COSY Spectrum of 167 in $\mathrm{CDCl}_{3}$ (Aliphatic Region)

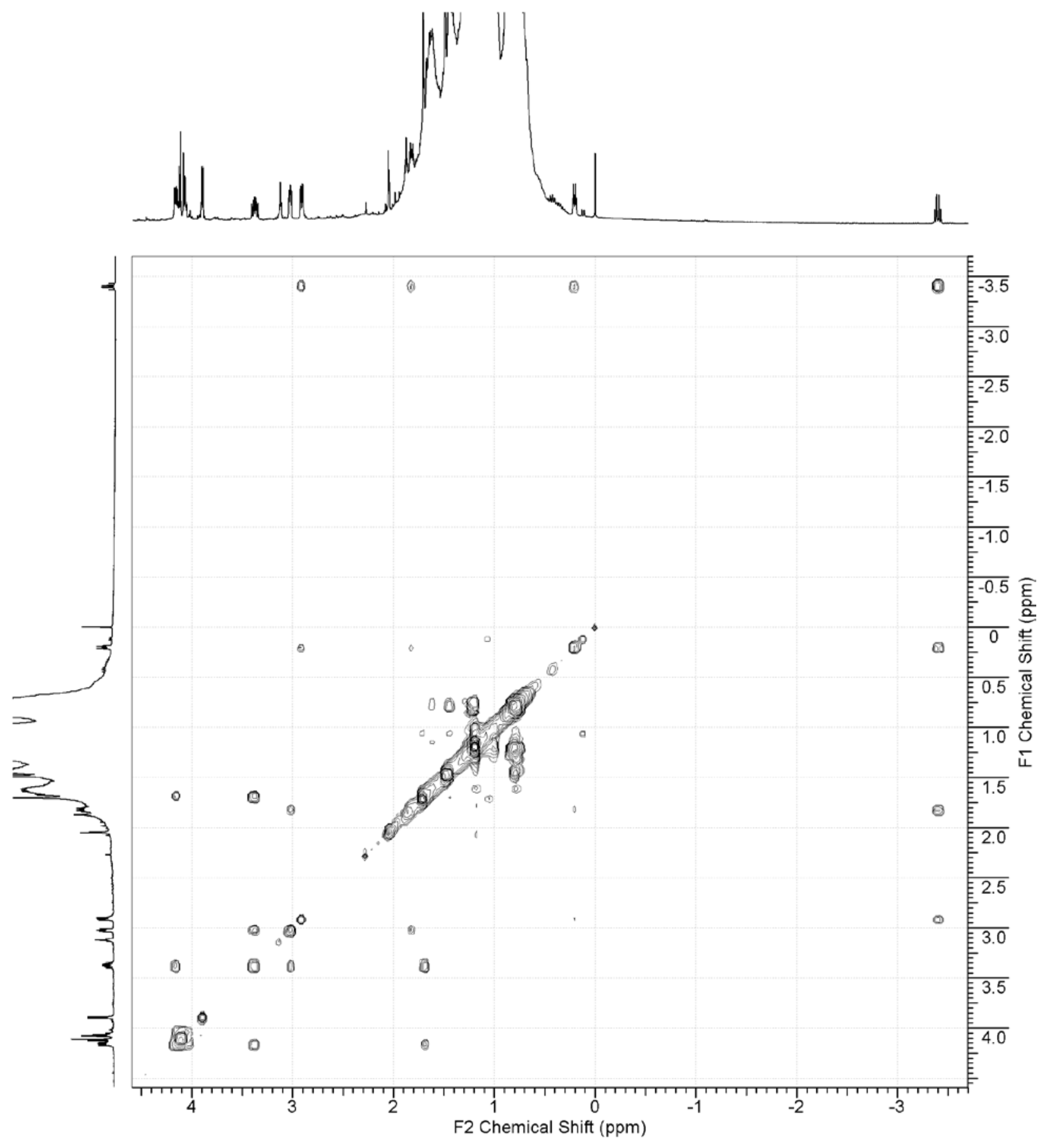


NOESY Spectrum of 167 in $\mathrm{CDCl}_{3}$

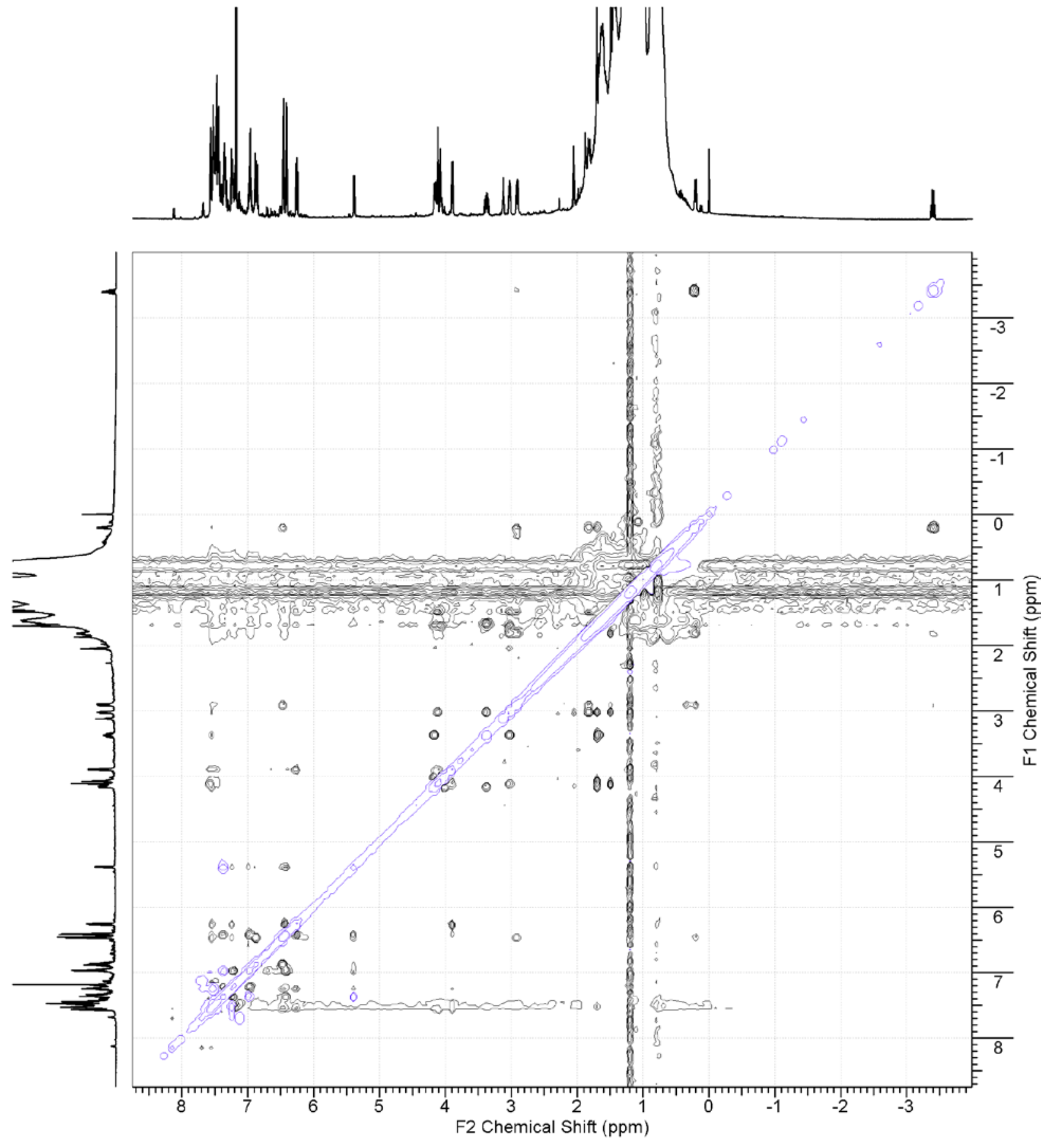


NOESY Spectrum of 167 in $\mathrm{CDCl}_{3}$ (expansion 1)

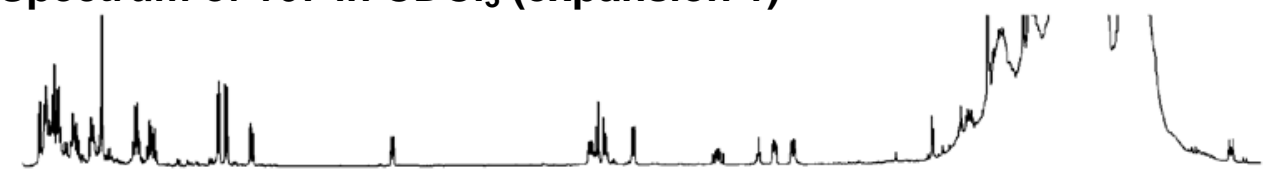
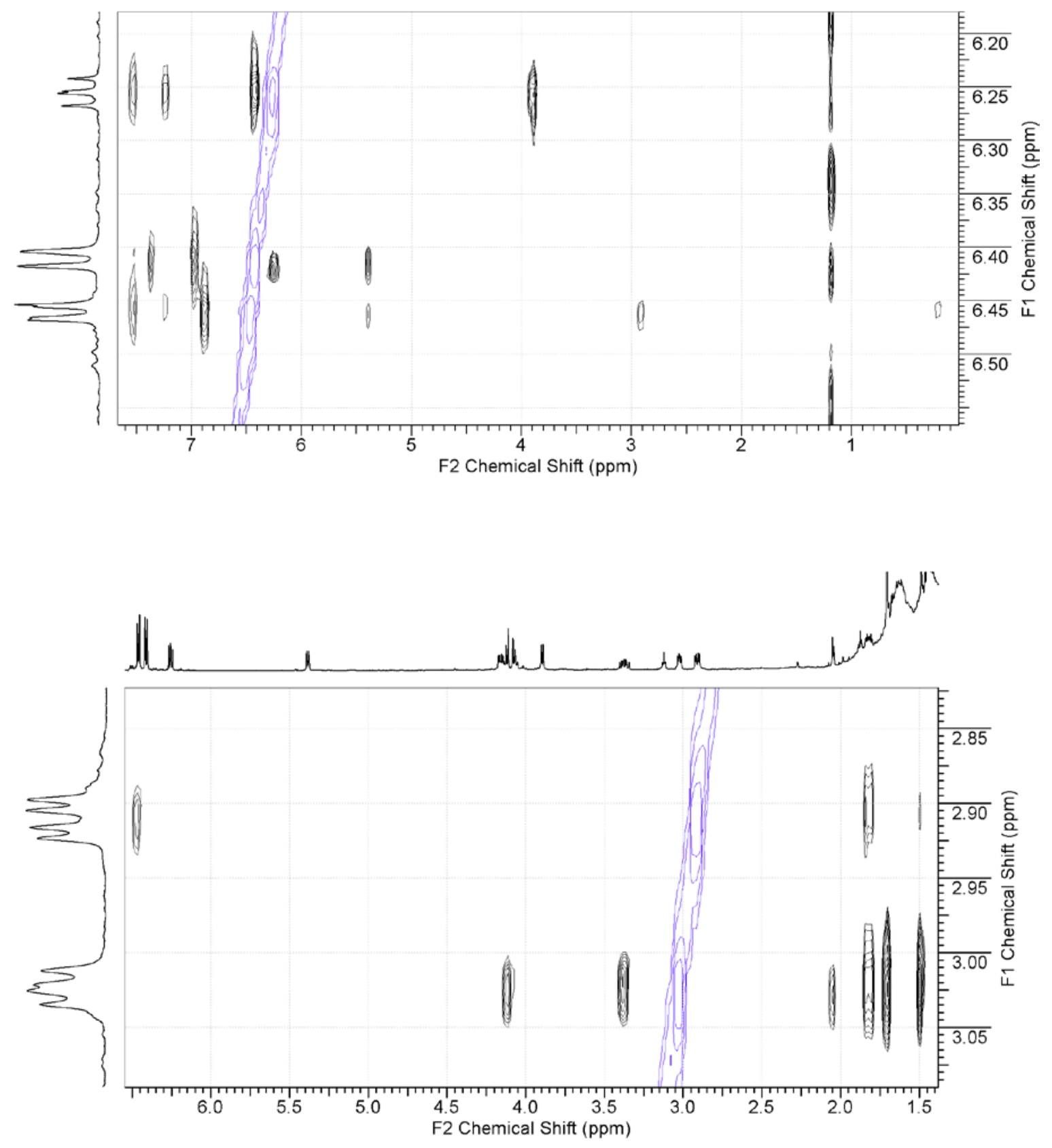
NOESY Spectrum of 167 in $\mathrm{CDCl}_{3}$ (expansion 2)
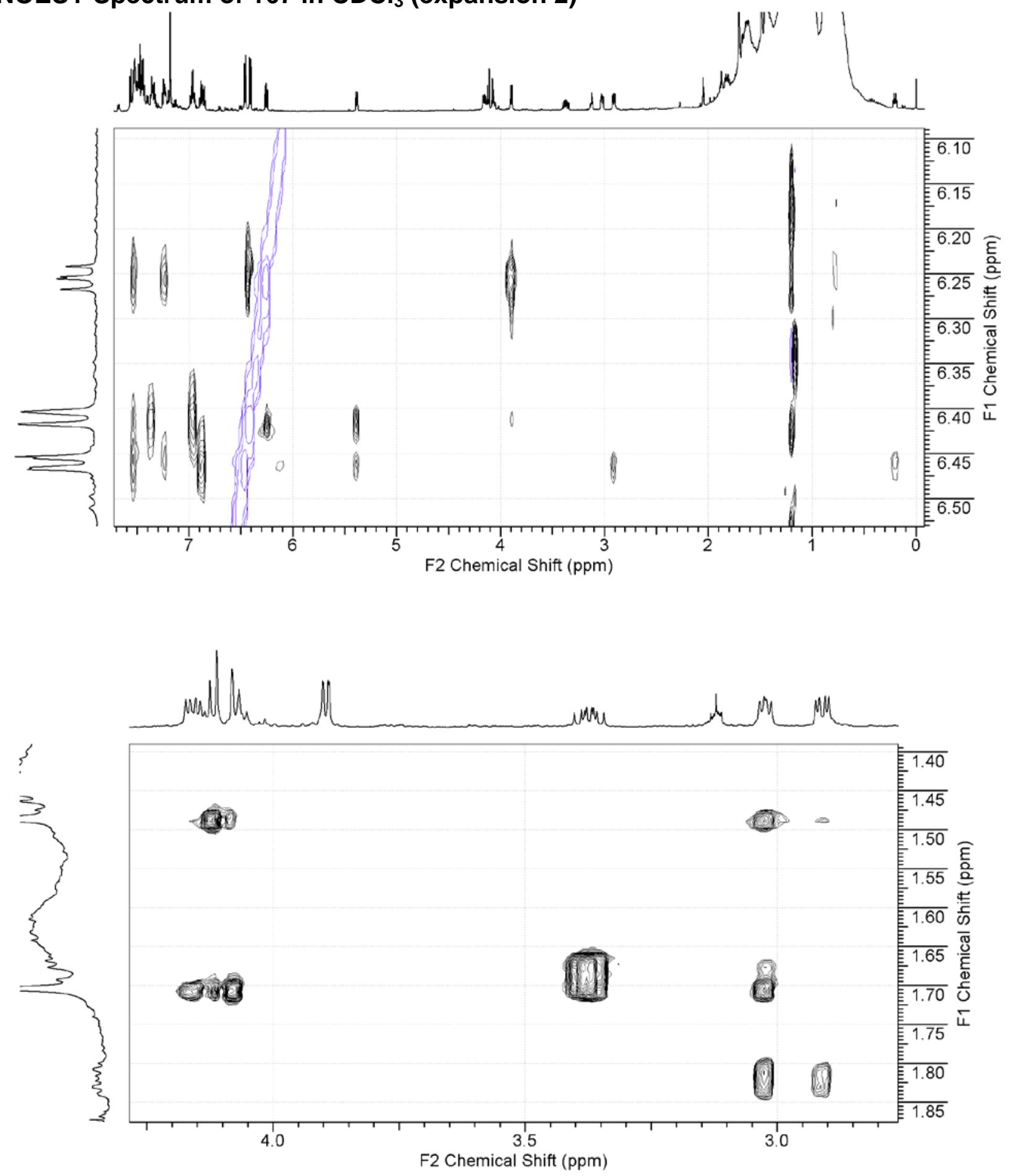